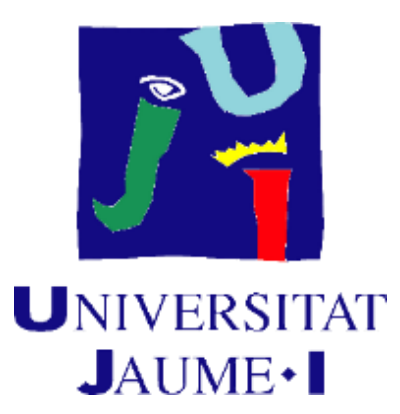

Programa de Doctorat en Estudis Interdisciplinaris de Gènere /

Programa de Doctorado en Estudios Interdisciplinares de Género

TESIS DOCTORAL

Educación para la equidad de género en Guatemala:

implementación del eje curricular en las aulas de Quetzaltenango y

Totonicapán

Doctoranda: Raquel García Sedano

Directora de la tesis: Dra. María Consol Victoria Aguilar Ródenas

Noviembre de 2019 


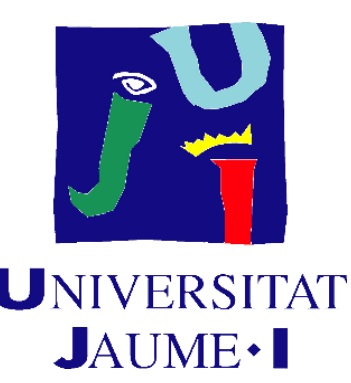

Programa de Doctorat en Estudis Interdisciplinaris de Gènere /

Programa de Doctorado en Estudios Interdisciplinares de Género

Escola de Doctorat de la Universitat Jaume I /

Escuela de Doctorado de la Universitat Jaume I

Títol de la tesi / Título de la tesis

\section{Educación para la equidad de género en Guatemala: implementación del eje curricular en las aulas de Quetzaltenango y Totonicapán}

\footnotetext{
Memòria presentada per Raquel García Sedano per a optar al grau de doctor/a per la Universitat Jaume I/

Memoria presentada por Raquel García Sedano para optar al grado de doctora por la Universitat Jaume I
}

Doctoranda:

Raquel García Sedano
Directora de la tesi:

Dra. María Consol Victoria Aguilar Ródenas 
Dedicado a Nik, Noa, Leire

y a todas las niñas guatemaltecas.

\title{
Agradecimientos
}

\author{
A las maestras, maestros y madres participantes, \\ por el aprendizaje compartido.
}

A las representantes de las siguientes instituciones, por su colaboración y apoyo:

IUMUSAC, especialmente a Miriam Maldonado QPD; Programa de Género de FLACSO, Unidad de Género del MINEDUC; Facultad de Humanidades de la Universidad Rafael Landívar, campus Quetzaltenango, Carrera de Pedagogía y Educación Intercultural de la Universidad de San Carlos de Guatemala, Centro Universitario de Totonicapán; Fe y Alegría Guatemala; PRODESSA; IGER; CPDL; AMLUDI y a todas las personas e instituciones guatemaltecas que han abierto puertas y con su trabajo han inspirado esta investigación.

A mi directora de tesis, Consol Aguilar, por los caminos de aprendizaje que me ha mostrado y, sobre todo, por su apuesta por lo dialógico. 


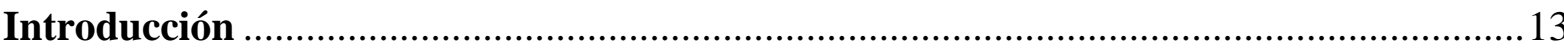

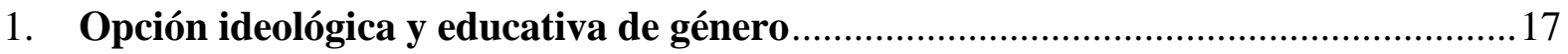

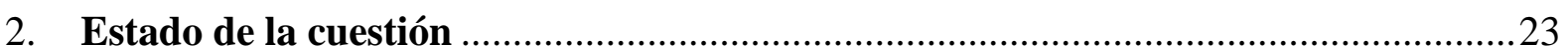

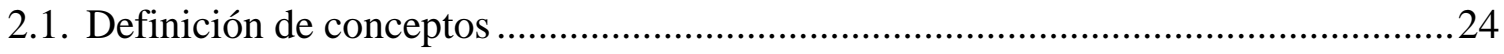

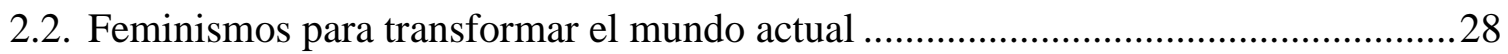

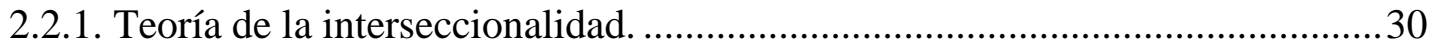

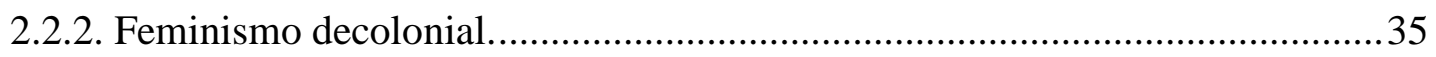

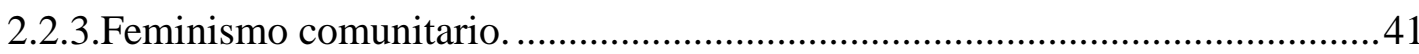

2.2.3.1.Dualidad y complementariedad en la cosmovisión maya. .............................49

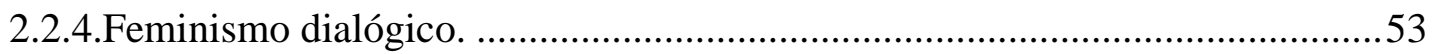

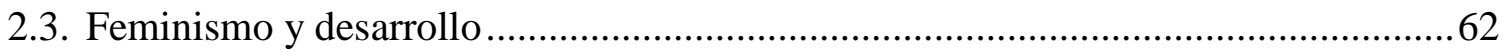

2.3.1. Breve revisión de modelos de desarrollo en América Latina..........................62

2.3.2. ¿Dónde están las mujeres en los modelos de desarrollo? ...............................67

2.3.3. Construcción dialógica del desarrollo. .......................................................69

2.4. Una aproximación al patriarcado en Guatemala ..................................................... 72

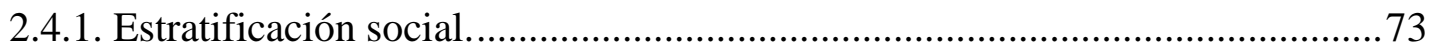

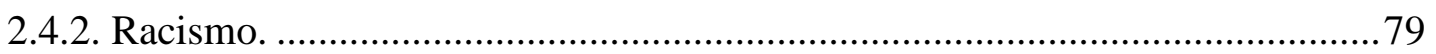

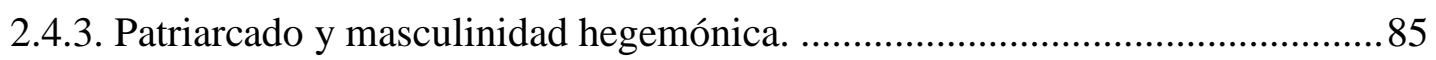

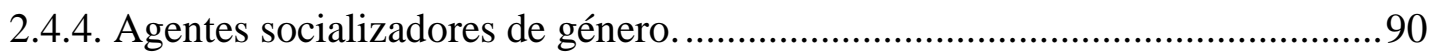

2.4.5. Reproducción de las violencias contra las mujeres: el triángulo de Galtung. .97

2.4.5.1. Triángulo interseccional de violencias contra las mujeres en el patriarcado.

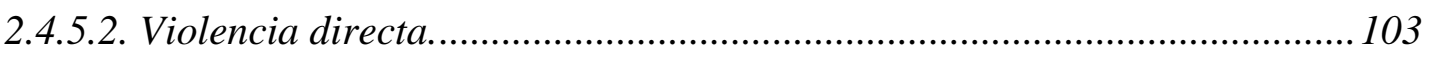


2.5. Pedagogía feminista, coeducación y transformación de la violencia cultural patriarcal

2.5.1.Formación del profesorado.

2.6. Acercamiento a la historia de la educación en Guatemala.....

2.7. Marco jurídico e institucional para la educación para la equidad en Guatemala .... 129

2.7.1. Marco jurídico internacional 130

2.7.2. Marco jurídico nacional.

2.7.3. Instituciones. 136

2.8. Herramientas para la educación crítica: Reforma Educativa, Curriculum Nacional Base y eje transversal de educación para la equidad de género, de etnia y social 137

2.9. El sistema educativo guatemalteco 145

2.9.1. Análisis de la formación docente. 152

2.9.2. La urgencia de un cambio coeducativo en la educación guatemalteca. 158

2.9.3.¿En qué se concreta un proyecto coeducativo desde el enfoque interseccional? . 168

2.9.4. Experiencias significativas en educación para la equidad de género en Guatemala. 170

2.9.4.1. Avance de la Reforma Educativa: PRODESSA....................................... 172

2.9.4.2. Fe y Alegría, apuesta institucional por la equidad de género. .................. 174

2.9.4.3. Equidad de género en educación a distancia: IGER ................................ 175

3. Metodología 179

3.1. Metodología Comunicativa Crítica 179

3.2. Interrogantes de la investigación. 185

3.2.1. Objetivo general. 185 
3.2.3. Preguntas de investigación.

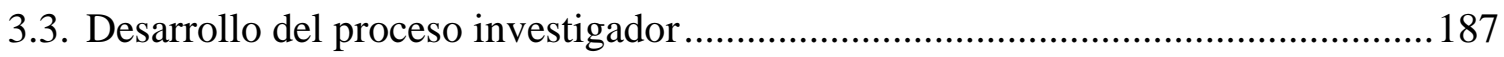

3.4. Participantes y herramientas de investigación utilizadas ...................................... 193

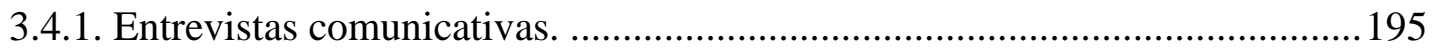

3.4.2. Grupos de discusión comunicativos. ........................................................ 197

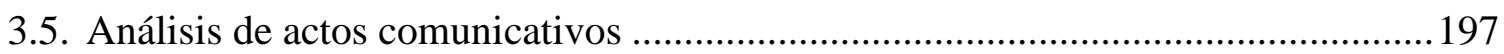

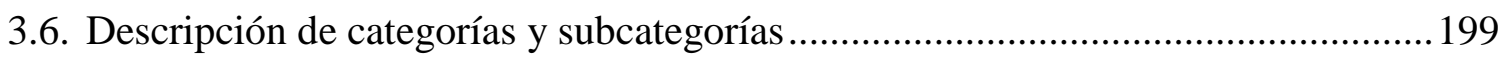

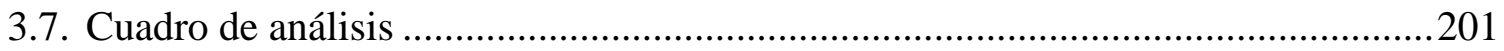

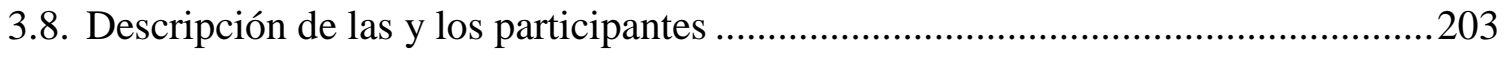

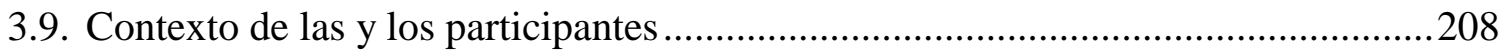

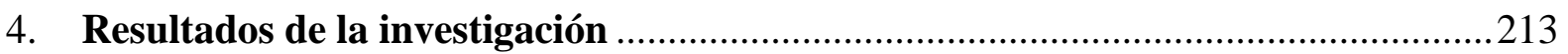

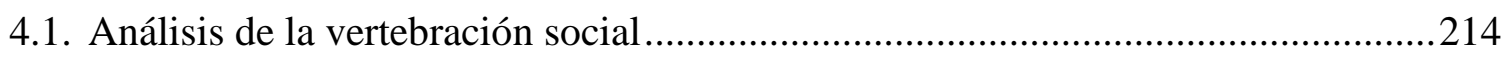

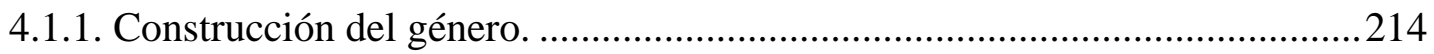

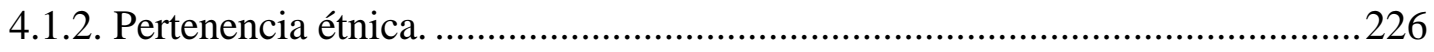

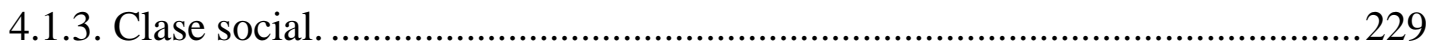

4.1.4. Concepción de género en la cultura maya.....................................................223

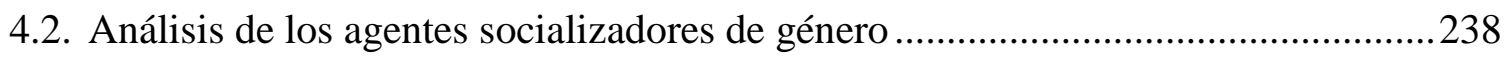

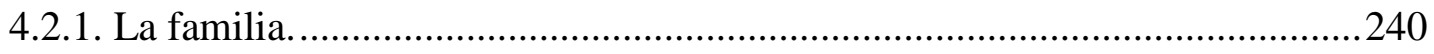

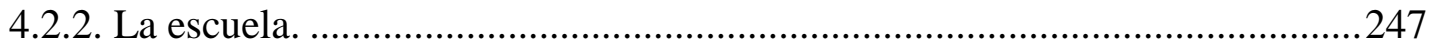

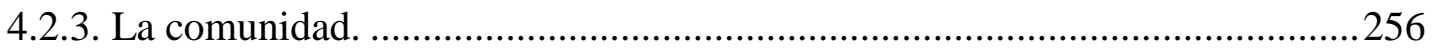

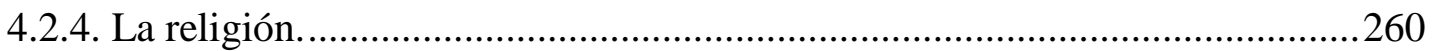

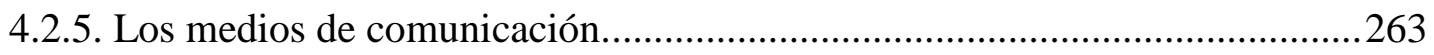

4.3. Análisis de la educación para la equidad de género, de etnia y social en la escuela .... 
4.3.1. Eje de equidad de género, de etnia y social del Curriculum Nacional Base. 267

4.3.2. Formación inicial y permanente de maestras y maestros. .274

4.3.3. Gerencia del sistema educativo. 279

4.3.4. Actividades concretas relacionadas con la educación para la equidad. 287

4.3.5. Las familias y la comunidad. 293

5. Conclusiones .301

6. Referencias bibliográficas 309

7. Anexos 325

Anexo 1: Protocolos de entrevistas comunicativas y grupos de discusión comunicativos .. 325

Anexo 2: Transcripciones de entrevistas comunicativas y grupos de discusión comunicativos 331

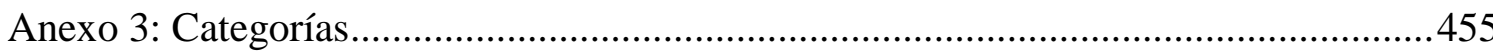

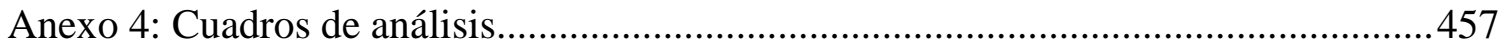

Anexo 5: Recolección de información previa y complementaria.................................515

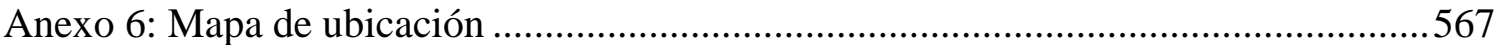

Notas 569 


\section{Índice de tablas}

Tabla 1. Porcentaje de impunidad en casos de femicidio entre 2005 y 2015 104

Tabla 2. Población con ingresos propios en Guatemala 108

Tabla 3. Horas diarias dedicadas al trabajo remunerado y no remunerado por sexo. 109

Tabla 4. Porcentaje de mujeres postuladas y electas en elecciones generales de Guatemala, 2019

Tabla 5. Estudiantes, docentes y centros educativos públicos y privados en Guatemala, 2018

Tabla 6. Entrevistas comunicativas y grupos de discusión comunicativos con maestras y maestros 194

Tabla 7. Entrevistas comunicativas con madres de alumnado 194

Tabla 8. Participantes en técnicas de recogida de información complementaria 195

Tabla 9. Tasa bruta de cobertura por nivel educativo en Quetzaltenango y Totonicapán, 2018

Tabla 10. Los elegidos y los no elegidos .260

\section{Índice de figuras}

Figura 1. Hacia una tipología de modelos sociopolíticos ante la diversidad cultural .82

Figura 2. Triángulo de la violencia de Galtung .98

Figura 3. Triángulo interseccional de violencias patriarcales 101

Figura 4. Sub eje de equidad educativa de la PNPDIM. 136

Figura 5. Eje de equidad de género, de etnia y social del CNB 142

Figura 6. Estructura del sistema educativo guatemalteco 146

Figura 7. Cobertura educativa en Guatemala en 2015 148 
Figura 8. Percepción de equidad de género y etnia en aulas universitarias guatemaltecas ...152

Figura 9. Comparación de formación de docentes en Centro América

Figura 10. Formación mínima para ejercer docencia en Guatemala 154

Figura 11. Niveles de políticas y dimensiones de intervención para transformar un sistema educativo hacia la coeducación 163

Figura 12. Estructura del cuadro de análisis 203

Figura 13. Clasificación de participantes en entrevistas comunicativas dirigidas a maestras y maestros 206

Figura 14. Clasificación de participantes en entrevistas comunicativas dirigidas a madres de alumnado .207

Figura 15. Clasificación de participantes en grupos de discusión comunicativos dirigidos a maestras y maestros .207 


\section{Introducción}

Mi trabajo como educadora social en Guatemala siempre ha estado vinculado a la educación formal y no formal y a las organizaciones sociales. Desde ese contexto de trabajo y de vida, he tenido la oportunidad de aprender de muchas personas, especialmente muchas mujeres que, a menudo desde las peores condiciones de exclusión, luchan por transformar su realidad. A partir de reflexiones y experiencias compartidas me surgieron las inquietudes que dieron origen a esta investigación: ¿qué significa la equidad de género para las mujeres indígenas? ¿Qué características tiene el patriarcado en Guatemala? ¿Cómo se articulan las diversas violencias que enfrentan las mujeres guatemaltecas, algunas comunes y otras específicas según su etnia, clase, ruralidad o urbanidad, nivel académico y otros factores? ¿De qué forma puede contribuir la educación a transformar el patriarcado?

Con esas inquietudes como motor, en el marco de la elaboración del Trabajo de Fin de Máster -TFM- del Máster en Igualdad y Género en el Ámbito Público y Privado en la Universitat Jaume I, comencé a dar forma al proceso investigador del que da cuenta el presente documento. Durante más de cuatro años, las reflexiones se han ido enriqueciendo con la participación de muchas personas, especialmente maestras y maestros, en su mayoría indígenas, y madres de alumnado que han aportado sus experiencias y sus reflexiones para construir conocimiento conjunto sobre la educación para la equidad de género, de etnia y social en los departamentos de Quetzaltenango y Totonicapán, en Guatemala.

He realizado la investigación desde un enfoque cualitativo y crítico, optando por la Metodología Comunicativa Crítica (MCC) como metodología de investigación. La MCC permite dar voz a las personas más excluidas de los sistemas y generar alternativas de transformación de la realidad desde el diálogo horizontal entre todas y todos los participantes. Considero que ambas características de la MCC son un gran aporte a las ciencias sociales y también al feminismo. En la actualidad, la complejidad de los fenómenos sociales y la 
pluralidad de voces y posicionamientos nos exigen trabajar con metodologías dialógicas, que permitan comprender la realidad en profundidad y construir alternativas incluyentes.

El contenido del presente informe de investigación está estructurado en cinco grandes apartados. El primero es la opción ideológica y educativa de género. Presenta las principales premisas ideológicas que orientan los posicionamientos que se defienden en la investigación.

El segundo apartado es el estado de la cuestión, en el que comenzaremos enmarcando la diversidad de corrientes de pensamiento sobre el género y el feminismo que existe en Guatemala y que nos reafirman en la convicción de que es necesario apostar por el pensamiento situado y posicionarnos desde la teoría del feminismo dialógico, incluyendo a las mujeres más excluidas. A continuación, haremos un esbozo de las características del patriarcado en Guatemala y determinaremos la necesidad de una pedagogía crítica y feminista para transformar la violencia cultural patriarcal y con ello movilizar positivamente todo el engranaje de las violencias. Seguidamente, abordaremos el análisis del sistema educativo guatemalteco desde la perspectiva de su potencial para educar en la equidad de género, de etnia y social.

El tercer apartado expone la metodología seguida para realizar la investigación, detallando las técnicas aplicadas y las personas participantes: maestras y maestros mayoritariamente indígenas que desempeñan su trabajo en escuelas de Quetzaltenango y Totonicapán y madres de alumnado de una de esas escuelas. En este apartado también explicaremos cuál ha sido la metodología seguida para analizar las aportaciones de las y los participantes.

En el cuarto apartado desarrollamos los resultados de la investigación, basados en las aportaciones de las y los participantes, y ordenados según las categorías y subcategorías utilizadas para realizar el análisis. 
El quinto y último apartado contiene las conclusiones de la investigación y algunas propuestas de acciones transformadoras para avanzar en la educación para la equidad de género, de etnia y social en Guatemala. 


\section{Opción ideológica y educativa de género}

La presente investigación parte de una serie de premisas sobre el feminismo, el género, el Estado y la pedagogía crítica que conforman la base ideológica sobre la que se asienta el análisis. A continuación, abordamos estas premisas.

El posicionamiento ideológico respecto al feminismo se ubica en el feminismo dialógico y el feminismo decolonial. La realidad sociocultural de Guatemala, en la que se desarrolla la investigación, es precisamente una de esas otras realidades para el feminismo tradicional. Las mujeres indígenas guatemaltecas son esas otras mujeres históricamente invisibilizadas por los discursos hegemónicos por pertenecer a un país del sur y, más aún, por ser indígenas. Es fundamental subrayar que en Guatemala la exclusión desde lo occidental hacia lo indígena también se reproduce fuertemente a lo interno, con el silenciamiento de las voces de las mujeres indígenas desde los discursos del feminismo hegemónico en el país, liderado por mujeres ladinas ${ }^{\mathrm{i}}$. El feminismo dialógico (Lidia Puigvert, 2001), con su premisa de radicalización de los procesos democráticos, posibilita incluir las voces silenciadas desde lo externo y lo interno de Guatemala, no solo en el sentido de tomarlas en cuenta, sino haciendo que estas voces sean las que construyan colectivamente el significado de la equidad de género, de etnia y social y de la educación a esa equidad.

Siguiendo a Pilar Colás (2006:36), "existe una cultura de género transcultural” y a la vez “cada grupo cultural hace una reinterpretación específica, generando su propio modelo cultural de género". En el contexto multicultural de Guatemala, en el que conviven 4 grandes pueblos con 25 etnias diferentes, las formas de entender, vivir y reivindicar el género de las mujeres y hombres indígenas son diferentes a las planteadas por los discursos tradicionales y frecuentemente son deslegitimadas desde los patrones occidentales de pensamiento. El análisis de género en cada contexto particular da lugar a "diversidad cultural y división de grupos en dos planos o niveles; a nivel transversal dividiendo todas las culturas en dos 
grupos (masculino y femenino) y a nivel horizontal estableciendo dos grupos de género en cada cultura" (Colas, 2006:37).

La cosmovisión maya tiene valores que pueden ser promotores de la equidad de género y que están siendo objeto de debate, resignificación y negociación por parte de mujeres y hombres mayas. Estas formas diversas de entender el género son parte-aunque silenciada- de la lucha global por la equidad. Partimos del convencimiento de que un feminismo global solo puede ser construido con los aportes de todas las mujeres, de todas las cosmovisiones, y que esta construcción se hace mediante el diálogo. Nos basamos en uno de los principios fundamentales del feminismo dialógico: "la confianza en la acción de todas las mujeres para cambiar el curso de la historia" (Puigvert, 2006b:100). El feminismo dialógico en Guatemala puede ser una herramienta clave para la construcción de una ecología de saberes feministas (Rosalva Hernández, 2018, Boaventura Santos, 2010) a partir de los feminismos decoloniales, entre los que se encuentra el feminismo comunitario surgido desde mujeres indígenas (Lorena Cabnal, 2010; Julieta Paredes, 2017), el feminismo occidental y otros saberes.

El análisis sobre el Estado de Guatemala en el que se basa esta investigación parte del enfoque de Derechos Humanos, en el cual el Estado es garante de los derechos de la población y, por lo tanto, titular de la obligación de generar estructuras políticas, económicas, sociales y culturales basadas en la democracia y la equidad, evitando brechas de desigualdad y exclusión. En este enfoque, la ciudadanía es titular de derechos y a la vez tiene la responsabilidad de contribuir con el perfeccionamiento de la democracia y la equidad. Esto solo es posible desde una ciudadanía crítica y comprometida con la historia, el presente y el futuro del país y de la región latinoamericana. La estructura actual del Estado de Guatemala dista mucho de esta concepción. La sociedad guatemalteca, multicultural y de mayoría 
indígena, se caracteriza por profundas desigualdades que la convierten en una sociedad estratificada. Según el PNUD (2011),

la región de América Latina es la más desigual en cuanto al bienestar de sus ciudadanos, en comparación con el resto de regiones del mundo. A su vez, Guatemala presenta indicadores de desigualdad más altos que muchos países de la región. (p.7).

Para analizar el Estado de Guatemala, nos basamos en el análisis de la estratificación social de Edelberto Torres-Rivas (2008) y la caracterización del Estado desde el feminismo comunitario de la guatemalteca Lorena Cabnal (2010). Desde estos posicionamientos comprendemos que la actual orientación del Estado guatemalteco es incompatible con la justicia social y la justicia de género. Por lo tanto, defendemos que el Estado de Guatemala debe ser completamente transformado.

La realidad de América Latina y de Guatemala exige que el patriarcado y la equidad sean analizados con enfoque interseccional, advirtiendo que el género se encuentra indisolublemente unido a la etnia y la clase social, además de otras categorías de diferencia como la identidad sexual, las capacidades y otras. El planteamiento sobre la equidad en esta investigación se realiza desde un enfoque interseccional, con la tríada género, etnia y clase social.

En el ámbito educativo, nos basamos en la pedagogía crítica para entender la educación como un proceso cuya "finalidad es trabajar por las transformaciones sociales que ayuden a acabar con las desigualdades de todo tipo, trabajar a favor de un mundo más justo y solidario" (Consol Aguilar, 2009:1). Apostamos por una educación que, como afirma Aguilar (2009:2), basada en Giroux (1999), extienda "los principios de igualdad, justicia y libertad al mayor número posible de relaciones institucionales y vitales”. Giroux (1999), referenciado por Aguilar (2013:178), añade que "la educación produce, además de conocimiento, sujetos políticos", es decir, produce a las personas que organizan la sociedad y sus instituciones y 
sostienen relaciones sociales e interpersonales que pueden ser de poder y dominación o de horizontalidad y diálogo. Con el convencimiento de que la sociedad guatemalteca precisa eliminar las desigualdades, es urgente que el profesorado enseñe a "analizar, cuestionar y transformar las desigualdades sociales. Y debe hacerlo desde un discurso que incorpore la diferencia para comprender cómo se construyen las identidades y subjetividades del estudiantado desde múltiples y contradictorias maneras" (Aguilar, 2013:178).

El protagonismo del profesorado en la tarea de transformación de la sociedad se basa en la idea de que la identidad de género, de etnia y social comienza a construirse a temprana edad. Con Pilar Colás (2006:32), definimos la identidad como "la ubicación propia y de otros sujetos en referencia a una cultura, la catalogación de una persona en un grupo o categoría que asume determinados rasgos o conductas". La identidad de género, de etnia y social se adquiere a través de la socialización temprana y continúa formándose a lo largo de la vida, en un proceso dialéctico de adaptación y transgresión.

Emilia Moreno, Teresa Padilla, Isabel López y Mercedes Martín (2001), siguiendo a Romero y González-Anleo (1974), explican que la socialización es

un proceso por el que el individuo se hace persona social incorporando a su individualidad las formas de vida (pautas sociales, símbolos, expectativas culturales, sentimientos, etc.) bien de un grupo social determinado bien de toda la sociedad global, incorporación que le permitirá proceder y actuar de manera conveniente y ajustada a las exigencias de dicho grupo o dicha sociedad. (p.146)

Puesto que el proceso de socialización es, por definición, un proceso educativo amplio en el que tienen cabida múltiples agentes -familia, escuela, comunidad, religión, medios de comunicación y otros-, reafirmamos la capacidad transformadora de la escuela para educar en la equidad de género, de etnia y social. No podemos perder de vista que "la escuela, como institución socializadora que es, genera, produce y reproduce todas las desigualdades 
sociales" (Amparo Tomé, 2011:2). Pensar que la escuela educa de forma neutra sería una ingenuidad. Educadoras y educadores y toda la estructura escolar transmiten de forma permanente, en cada uno de sus actos, sus palabras y sus omisiones, sus planificaciones, la disposición del espacio físico, etc. una visión particular de lo que se espera de cada persona en función de su sexo y de otras variables -como la etnia y la posición social-. En palabras de Tomé (2011:5), “educamos en valores tanto si queremos como si no lo deseamos, aunque no seamos conscientes de ello". Por lo tanto, la educación para la equidad de género, de etnia y social solo puede abordarse desde la pedagogía crítica, cuestionadora de la realidad y de los sistemas.

Para que la escuela, a través del profesorado, pueda poner en práctica una pedagogía crítica orientada a la equidad de género, de etnia y social, el primer paso es desechar cualquier determinismo biológico sobre el género y la etnia, que anularía per se el potencial transformador de la educación. La concepción radical del género como construcción cultural, que puede parecer obvia, no lo es tanto y por ello se hace imprescindible retomarla. En las primeras fases de esta investigación se realizaron encuestas a docentes a modo de acercamiento a su concepción sobre los conceptos en los que se profundizaría en el estudio (anexo 5). Ante la pregunta de ¿Las niñas y los niños nacen con caracteres, gustos, habilidades y capacidades diferentes?, de 48 maestras y maestros en activo encuestados, un abrumador $87.5 \%$ contestó que sí, frente a 6 personas que contestaron que no. Como señala José María Toro (2011:5), considerar que la naturaleza determina los gustos, capacidades y aptitudes de niñas y niños es un planteamiento anclado en el siglo XIX, pero de hecho en "la ideología androcéntrica subyacen todavía los determinismos biológicos, que justifican las acciones humanas por el organismo biológico, hasta el punto de afirmar que somos lo que somos gracias a los genes”. Para Toro (2011) estas justificaciones que confunden lo natural y lo cultural son difíciles de romper porque 
se fundamentan en una pseudo-racionalidad ideológica, es decir, una falsa racionalidad justificada por un conjunto, más o menos estructurado de ideas, imágenes y valoraciones condicionadas culturalmente, admitido, sin más, como verdadero, sin examen crítico alguno, tan solo autorizado por el peso de la tradición. (p.6)

Todo lo anterior demuestra que cualquier proceso de educación para la equidad debe considerar la formación docente como uno de sus elementos clave.

En la coeducación encontramos una alternativa educativa orientada a la transformación de la desigualdad desde la educación y enmarcada en la pedagogía crítica. Según la Federación de Trabajadores de la Enseñanza -FETE- (2013), la coeducación

implica: reconocer -y valorar- la diversidad de los chicos y de las chicas y hacer de ello una ventaja, un enriquecimiento cultural y una aportación de valores y prácticas tradicionalmente asociados a las mujeres. Rehúye, por lo tanto, en el fondo y en la forma, de los modelos tradicionalmente patriarcales -entiéndase importantes porque masculinos- y neutralizadores por asimiladores, para convertirse en un espacio compartido en el que los estereotipos, las desigualdades sociales o la jerarquía cultural desaparecen. (p.6)

En Guatemala, la coeducación necesariamente debe ampliar su óptica hacia un enfoque interseccional, abordando la eliminación de la discriminación de género, de etnia y social, al menos. La coeducación, por lo tanto, tiene un componente político que parte de la transformación de cada individuo, en coherencia con la premisa feminista que certeramente señala que "todo lo personal es político". Concluimos que la coeducación en Guatemala es una estrategia clave para acelerar el cambio cultural necesario para trasformar el patriarcado racista, clasista y neoliberal. Por eso, ponemos el acento en este enfoque educativo en la presente investigación. 


\section{Estado de la cuestión}

La educación para la equidad de género, de etnia y social, equivalente al enfoque coeducativo, se concreta en Guatemala en la existencia de un eje transversal de igual nombre que forma parte del Curriculum Nacional Base (CNB) y que es de obligada aplicación en todos los niveles educativos, exceptuando el universitario. El eje de educación para la equidad de género, de etnia y social forma parte de las innovaciones introducidas en el sistema educativo guatemalteco en el marco de la Reforma Educativa, todavía hoy inconclusa, fruto de los compromisos adquiridos por el Estado de Guatemala con la firma de los Acuerdos de Paz de 1996, que pusieron fin a un conflicto armado interno de 36 años de duración.

El abordaje de la educación para la equidad de género, de etnia y social desde un punto de vista teórico feminista requiere analizar en profundidad diferentes conceptos y utilizar perspectivas teóricas que permitan explicar las relaciones de género y el potencial de transformación hacia la igualdad en la complejidad de la sociedad guatemalteca, multicultural, profundamente desigual y ubicada en el sur empobrecido.

En las siguientes páginas se desarrollará el estado de la cuestión relacionado con la educación para la equidad de género, de etnia y social en dos departamentos de Guatemala: Quetzaltenango y Totonicapán. Se trata de departamentos eminentemente indígenas. Comenzaremos definiendo algunos conceptos clave que nos ayudarán a situarnos en la discusión teórica posterior. Después, se abordarán dos perspectivas del feminismo que permiten avanzar en la superación de las desigualdades entre los feminismos en el mundo plural actual: el feminismo comunitario y el feminismo dialógico. A continuación, se analizará la construcción de las relaciones sociales y de género en Guatemala desde el enfoque interseccional para encontrar en la coeducación una de las herramientas fundamentales en la tarea ineludible de transformar el país hacia la igualdad. Nos 
acercaremos posteriormente a la historia de la educación guatemalteca desde la perspectiva de la educación para la equidad y al Curriculum Nacional Base como herramienta actual para su implementación, analizándolo desde la óptica de las posibilidades que ofrece en materia de educación para la equidad de género, de etnia y social. Todo lo anterior nos llevará a describir la urgencia de implementar en enfoque coeducativo en Guatemala, con acciones reales, llevadas a las aulas, que se encuentran respaldadas por el marco jurídico internacional y nacional existente. Para finalizar, se exponen algunos avances en la implementación del eje de equidad de género, de etnia y social en las aulas, con la presentación de algunas experiencias significativas identificadas a lo largo de la investigación.

\subsection{Definición de conceptos}

La definición del concepto de equidad resulta relevante para esta investigación. Con este término nos referimos al hecho de no favorecer a una persona o grupo en detrimento de otro, en virtud de sus características sociales, biológicas o culturales. En el contexto guatemalteco, marcado por profundas brechas de exclusión que tienen que ver con el género, con la pertenencia étnica y la clase social, entre otras, es frecuente priorizar la utilización del término equidad frente a igualdad al entender que es preciso superar la exclusión con medidas de equidad, que serán diferentes según las necesidades de cada persona y grupo social para brindarle las oportunidades que le han sido negadas. El Curriculum Nacional Base de Guatemala define el principio de equidad como "garantizar el respeto a las diferencias individuales, sociales, culturales y étnicas y promover la igualdad de oportunidades para todos y todas" (Ministerio de Educación -MINEDUC-, 2008:20). En este sentido, la equidad enfatiza el respeto a las diferencias y la equiparación de oportunidades. Esta última característica también sitúa la equidad como un paso previo a la igualdad, entendiendo ésta como igualdad en la diferencia, no como una categoría homogeneizante. El eje curricular que 
nos ocupa en la presente investigación se denomina "eje de equidad de género, de etnia y social”. El Curriculum Nacional Base de Guatemala diseñado por el MINEDUC (2008) lo define de la siguiente forma:

[la equidad de género, de etnia y social] se refiere, fundamentalmente, a la relación de justicia entre hombres y mujeres de los diferentes Pueblos que conforman el país. Requiere, por lo tanto, del reconocimiento, aceptación y valoración justa y ponderada de todos y todas en sus interacciones sociales y culturales. Orienta el currículo hacia la atención de niños y niñas de acuerdo con sus particulares características y necesidades favoreciendo, especialmente, a quienes han estado al margen de los beneficios de la educación y de los beneficios sociales en general. (p.28)

Como se ha explicado en el apartado de la opción ideológica de género, la investigación se fundamenta en la premisa de la igualdad de género, de etnia y social, desde un enfoque de igualdad en la diferencia, apostando por una verdadera transformación social. Sin embargo, se utiliza el término equidad, respetando la denominación formal en Guatemala en el marco del CNB.

El concepto de etnia se utiliza en referencia a la pertenencia étnica que expresa cada persona y que determina en gran medida su posición dentro de la estructura social de Guatemala. El país se caracteriza por su multiculturalidad, con cuatro pueblos principales: maya -conformado por 22 comunidades lingüísticas o etnias diferentes-, xinca, garífuna y ladino. Los tres primeros pueblos son considerados indígenas porque habitaban territorios americanos antes de la conquista española. El pueblo ladino es el surgido a partir del mestizaje que conllevó la época colonial. A pesar de que la población indígena es mayoritaria en Guatemala, el poder y los recursos se concentran en una élite ladina que se mantiene desde la Colonia. Esto configura una estructura social de exclusión/poder configurada por el 
racismo y sustentada y reproducida por la violencia cultural hacia lo indígena. En palabras de Marta Elena Casaús (2011):

las bases y los espacios sobre las que se construyó y reprodujo el racismo en Guatemala, desde la Colonia hasta nuestros días, permanecen incólumes y no parece que haya habido ningún indicio de que los estereotipos y prejuicios que lo sustentan se hayan desactivado, todo lo contrario. (p.67)

En la presente investigación se aborda la pertenencia étnica desde la libre adhesión de cada sujeto, es decir, como un aspecto de su identidad elegida, no determinado por rasgos físicos, apellidos, preferencias en el vestir, residencia en áreas rurales o urbanas o incluso por el uso de determinados idiomas. La pertenencia étnica como libre adhesión postula que cada persona se autodenomina perteneciente a uno $\mathrm{u}$ otro pueblo al identificarse con y sentirse parte de un grupo cultural determinado, que puede ser el de alguno de sus padres o familiares, el grupo en el que ha crecido o el grupo con el que se identifica en la edad adulta tras valorar su historia personal, entre otros supuestos. La pertenencia étnica como libre adhesión no supera el racismo y discriminación estructural hacia lo indígena en Guatemala, pero eleva la autoestima de las personas y los pueblos y contribuye a romper estereotipos y prejuicios que etiquetan a los sujetos. Este enfoque basado en la libertad individual y en la diversidad de la sociedad guatemalteca confronta las posturas deterministas y biologicistas que se utilizan para justificar la desigualdad basada en el racismo en Guatemala.

Abordamos ahora el concepto de clase social. La definición marxista - leninista de este concepto nos permite una primera aproximación. Guillermo Díaz (2011) retoma la definición de clases sociales de Lenin (1961):

grandes grupos de hombres que se diferencian [...] por las relaciones en que se encuentran con respecto a los medios de producción, por el papel que desempeñan en la 
organización social del trabajo y, consiguientemente, por el modo y la proporción en que perciben la parte de riqueza social de que disponen. (p.208)

Sin embargo, para comprender la dinámica de las clases sociales en Guatemala es necesario ir más allá de la relación de los sujetos y grupos con los medios de producción y la organización del trabajo, para abarcar también el estatus y el poder. Siguiendo a Díaz (2011), encontramos que la teoría weberiana aporta elementos que complejizan el concepto de clase social al introducir una estratificación social según criterios no solo económicos, sino también de prestigio social y de poder. Así, esta definición de clase social de Max Weber permite visibilizar que la configuración de las clases sociales en Guatemala se da a partir de: a) el nivel de ingresos económicos, que puede relacionarse o no con la tenencia y control de medios de producción, b) la pertenencia a grupos sociales prestigiosos, asociados a lo blanco y lo urbano, y c) todo lo anterior confiere el acceso al poder político a los sujetos ricos, blancos, urbanos y, por supuesto, hombres, al estar el sistema de clases sujeto a un sistema de poder superior que es el patriarcado.

El término coeducación es escasamente conocido por docentes y personas vinculadas al mundo educativo en Guatemala. De hecho, en las indagaciones realizadas, hemos encontrado una única universidad -privada- que incluye una asignatura llamada "Coeducación" en el pensum de estudios de la carrera de Educación Inicial y Pre-Primaria. Los textos, materiales y propuestas educativas utilizadas por la docente que facilita esta asignatura, entrevistada en el marco de la investigación, son provenientes de otros países, ya que no se encuentra producción guatemalteca al respecto. En la educación guatemalteca se habla de equidad de género, de etnia y social, que constituye un eje transversal del Curriculum Nacional Base que orienta la acción educativa en los niveles Inicial, Primaria, Básico - donde concluye la educación obligatoria- y Diversificado, que incluye Bachilleratos con diversas orientaciones y las llamadas carreras medias que cualifican para el ejercicio profesional. La 
transversalización de este eje en todas las asignaturas de cada nivel significaría aplicar un enfoque coeducativo o al menos, poner en práctica proyectos coeducativos que permitirían superar el sesgo androcéntrico, racista y clasista de la educación, que hace de la escuela un espacio de reproducción de la discriminación hacia las mujeres, la población indígena y las personas provenientes de contextos sociales empobrecidos. Así, en la presente investigación no hablaremos tanto de coeducación como de implementación del eje de equidad de género, de etnia y social o coeducación con enfoque interseccional.

Por último, explicar que utilizaremos el término escuela en dos acepciones: la primera, como sustantivo que engloba el proceso educativo formal en su conjunto, desde el nivel Inicial hasta el Diversificado, alejándonos del lenguaje popular de Guatemala que utiliza el término escuela para referirse a un centro educativo público, frente a colegio, que identifica a un centro educativo privado; en la segunda acepción, escuela será el nombre genérico del agente socializador de género que constituye el proceso educativo formal para niñas, niños y jóvenes.

\subsection{Feminismos para transformar el mundo actual}

El feminismo, como teoría crítica y práctica política, busca la transformación de las sociedades hacia la justicia. Es artífice de las mayores revoluciones pacíficas de la historia, contribuyendo decisivamente a la construcción de cultura de paz. Como señalan Beverly Castillo y Mayela Vílchez (2013:268), el feminismo no puede abordarse "aislándolo de la paz y la cultura de paz, como si no fuesen éstos los escenarios en donde tiene cabida la interpretación y actuación de lo que es el feminismo en toda su extensión".

El mundo actual presenta retos mayúsculos para la justicia social. Se precisa una verdadera revolución social para transformar las estructuras de dominación y crear nuevos contratos sociales basados en la igualdad en las diferencias. En este sentido, la teoría de la 
interseccionalidad es un aporte fundamental del feminismo a las ciencias sociales que permite analizar críticamente dichas estructuras de dominación y, desde ese conocimiento situado, abordar transformaciones reales desde la acción política.

Las teorías feministas, con un papel fundamental no solo en las ciencias sociales sino también en el activismo transformador, están llamadas a desarrollar sus potenciales más estratégicos para aportar decisivamente a la revolución imprescindible. Para ello, son necesarias propuestas situadas y a la vez globales que pueden encontrarse en dos corrientes: 1) el feminismo comunitario, enmarcado en el feminismo decolonial, en el que feministas indígenas latinoamericanas cuestionan su posición tanto en la sociedad multicultural como dentro de sus propios pueblos y comunidades. Desde ahí, generan alternativas de transformación que tocan las bases del sistema patriarcal, racista y clasista de los estados latinoamericanos. El feminismo comunitario constituye una propuesta situada en la realidad latinoamericana, que permite generar respuestas desde lo local. Será necesaria su puesta en diálogo con el feminismo occidental y con otras propuestas feministas situadas desde las realidades de otras mujeres del mundo que también están excluidas de los discursos del feminismo hegemónico. 2) El feminismo dialógico como herramienta para superar las distancias entre las diversas corrientes feministas y, especialmente, para incluir los saberes y prácticas feministas de las mujeres más excluidas, que en todas las culturas son las mujeres no académicas. Sin duda, el diálogo es la metodología por excelencia para responder a los retos del mundo actual. Siguiendo a Carmen Elboj y Ainhoa Flecha (2002:160) "nos encontramos ante sociedades que se vuelven dialógicas puesto que las tradiciones, maneras de hacer y demás componentes del horizonte de nuestro mundo de la vida se ven continuamente cuestionados y nos confrontan a la necesidad de consensuar y dialogar". En este contexto, el feminismo dialógico permitirá construir un proyecto feminista plural, que abarque las diferencias situadas de cada feminismo local -incluyendo el feminismo 
hegemónico que desde esta óptica se convertiría en el feminismo situado de las mujeres estadounidenses y europeas, con todas sus diferencias internas-, y que supere las diferencias en pro del objetivo superior del bienestar de todas las mujeres en nuevos sistemas sociales y de relaciones internacionales regidos por la justicia social. Lidia Puigvert, precursora del feminismo dialógico, señala que uno de los retos más grandes de esta teoría es que el proyecto feminista global pueda "recoger y teorizar las dinámicas y propuestas que se están formulando desde movimientos de mujeres populares y minorías culturales" (Puigvert, 2006b:98).

En los párrafos siguientes se desarrollan estas ideas, comenzando por la teoría de la interseccionalidad. Después, se aborda el feminismo decolonial como corriente en la que se enmarcan los feminismos latinoamericanos, entre ellos el feminismo comunitario. Se profundizará en él porque constituye una propuesta especialmente relevante para el contexto guatemalteco y el contexto de las maestras, maestros y madres de alumnado, mayoritariamente indígenas, protagonistas de la presente investigación. Para finalizar, abordaremos el feminismo dialógico, que puede ser una teoría clave para la generación de grandes consensos feministas basados en el diálogo horizontal entre todas las mujeres desde toda la diversidad de sus experiencias de vida, entre corrientes epistemológicas diversas y prácticas diferentes, aportando a políticas globales desde la valoración de la diversidad.

\subsubsection{Teoría de la interseccionalidad.}

El feminismo de las mujeres estadounidenses y europeas, blancas, de clase media o alta, académicas, heterosexuales y de formación cristiana revolucionó las ciencias sociales al acuñar el género como concepto que permite visibilizar las diferentes posiciones y realidades de las mujeres y los hombres en todas las esferas de la vida. Se creó así un potente instrumento de denuncia y transformación de las opresiones históricas hacia las mujeres. Sin 
embargo, el análisis de género por sí mismo es ciego a las diferencias que existen en la vivencia de opresiones/privilegios por parte de las mujeres según el conjunto de rasgos que configura su identidad: clase social, etnia, identidad sexual, nacionalidad, capacidades y otros rasgos diferenciales que puedan ser relevantes en cada contexto. En 1989, la feminista afroamericana Kimberlé Crenshaw, advirtiendo la limitación del concepto de género para explicar la realidad de las mujeres afrodescendientes, formuló el concepto de interseccionalidad aplicado al ámbito jurídico. Este concepto tenía sus antecedentes en el Manifiesto del Combahee River Collective de Boston (1977). Había sido elaborado por el grupo de feministas lesbianas negras del mismo nombre que denunciaba la opresión entrelazada que vivían las mujeres negras por lo racial, sexual, heterosexual y de clase, así como el racismo en el feminismo blanco y la necesidad de eliminar el capitalismo, el imperialismo y el patriarcado, entre otras premisas. En la genealogía de la interseccionalidad también se encuentra la literatura chicana y post colonial, en la que feministas mexicanas en Estados Unidos y otras en toda América Latina denunciaban que sus experiencias vitales como mujeres quedaban invisibilizadas en el discurso feminista. María Caterina La Barbera (2016) explica cómo la interseccionalidad evidencia que al considerar como estándares las experiencias de las mujeres blancas heterosexuales y los modelos familiares de la clase media, el feminismo no consiguió entender cómo la raza, la clase y la identidad sexual pluralizan y particularizan el significado de ser mujer. (p.108)

Desde la interseccionalidad, siguiendo a La Barbera (2016), se constata que las feministas blancas, que criticaban el uso de la norma masculina como parámetro universal, cometieron el mismo error de universalizar la experiencia de las mujeres a partir del parámetro de las mujeres blancas, heterosexuales, de clase media, académicas y de formación cristiana. Norma Alarcón (1990), referenciada por La Barbera (2016), explica que 
una "se convierte en mujer" de maneras que son mucho más complejas que en simple oposición a los hombres. En culturas donde las relaciones asimétricas tanto raciales como de clase son un principio organizador central de la sociedad, una también "se convierte en mujer" en oposición a otras mujeres. (p.109)

Se puede afirmar, sin duda, que la interseccionalidad es uno de los mayores aportes del feminismo en los últimos años. Itziar Gandarias (2017), apoyada en Platero (2012), aporta la siguiente definición:

el concepto de interseccionalidad permite analizar la relación en que distintos ejes de categorización y diferenciación como el género, la etnicidad, la sexualidad, la clase, la posición de ciudadanía, la diversidad funcional, la edad o el nivel de formación entre otros están imbricados de manera compleja en los procesos de dominación. Es un enfoque que subraya cómo las categorías sociales, lejos de ser "naturales" o "biológicas" son construidas y están interrelacionadas entre sí y supone un cuestionamiento de las relaciones de poder y de cómo se articula el privilegio. (p.74)

La interseccionalidad no entiende las desigualdades como producto de la suma o adición de las mismas, sino que ahonda en la posición particular de discriminación o privilegio que se produce en una persona al confluir en ella y en la configuración de su identidad un conjunto único de características. La Barbera (2016) retoma los tres niveles de interseccionalidad que identificó Crenshaw: el nivel estructural, el político y el simbólico. El nivel estructural hace referencia a las estructuras sociales y la posición de las personas en ellas. Este nivel explicita la discriminación que sufre una persona al encontrarse en la intersección de dos o más sistemas de subordinación y cómo estos sistemas se amplifican entre sí. Así, siguiendo a La Barbera (2016), basada en Matsuda (1991), para abordar la situación de las mujeres afroamericanas, por ejemplo, es necesario considerar cómo el racismo amplifica el sexismo y la homofobia amplifica el racismo. En el nivel político, la interseccionalidad permite 
identificar el sexismo, racismo, homofobia, explotación de clase y otras categorías en la formulación, ejecución y evaluación de políticas públicas. El nivel simbólico -o representacional- muestra cómo se produce la construcción cultural de los sujetos subordinados a través de creencias estereotipadas, mensajes políticos, medios de comunicación y otros agentes socializadores. Los tres niveles de la interseccionalidad identificados por Crenshaw se relacionan con los tres vértices del triángulo de la violencia que establece Johan Galtung. Estos se abordarán más adelante para explicar de forma sistémica los mecanismos de reproducción de las violencias contra las mujeres en el patriarcado y el potencial de la coeducación como herramienta que puede cambiar el sustrato cultural en el que éstas se enraízan, impulsando la transformación de todo el sistema.

En los estudios sociales que utilizan el enfoque interseccional se identifican dos tipos fundamentales de acercamiento, según la perspectiva desde la que se analicen las diferentes categorías de exclusión/privilegio: el acercamiento inter categorial y el intra categorial. Nira Yuval-Davis (2012), basada en Leslie McCall (2005), explica que el acercamiento inter categorial pone el énfasis en cómo las categorías de género, raza, clase, identidad sexual, etc. afectan al comportamiento social y a la distribución de los recursos entre los individuos. El acercamiento intra categorial, en cambio, centra la discusión en los límites de definición de las propias categorías. Desde un análisis social comprometido con la transformación hacia la justicia, es evidente que el acercamiento intra categorial despoja a la interseccionalidad de la propia orientación política y revolucionaria con la que surgió.

En la década de los noventa, el concepto de interseccionalidad se extendió rápidamente en el ámbito académico y político de Estados Unidos y el norte de Europa, convirtiéndose tanto en una teoría feminista para la investigación como en una herramienta para el diseño de políticas públicas sensibles a la complejidad de las experiencias de exclusión que viven las personas. Según Mara Viveros (2016:7), "la amplia aceptación de este enfoque ha sido 
facilitada por las críticas posmodernas al positivismo y su búsqueda de explicaciones más complejas de la desigualdad social”. En el sur de Europa y en contextos francófonos y latinoamericanos el concepto de interseccionalidad comenzó a divulgarse en la década de dos mil. Respecto a su expansión en América Latina, Viveros (2016) apoyada en Marta Zapata (2011), considera que el concepto de interseccionalidad no ha calado al no aportar nada nuevo para muchas feministas, ya que en esta región las mujeres históricamente se han enfrentado a diversas formas interconectadas de opresión y les han hecho frente desde los movimientos sociales, principalmente. En el caso de Guatemala, Ana Silvia Monzón (2008) sitúa el inicio de análisis sobre género, etnia y clase social en los años noventa, pero explica que para finales de la década de dos mil no se había realizado un debate sistemático y faltaba mucho por profundizar en la discusión sobre la construcción estereotipada de identidades y relaciones que permita consolidar un bagaje conceptual al respecto. Actualmente, finalizando una década más, esta afirmación continúa vigente.

La aplicación de la interseccionalidad en el diseño de políticas públicas es un aporte muy interesante que complejiza la concepción de los Estados sobre su función social y redistributiva y que puede dar lugar a una mejora sustancial de las condiciones de vida de colectivos marginados. Sin embargo, no hay que perder de vista que el origen de la interseccionalidad está indisolublemente unido a la crítica al sistema capitalista, imperialista y al patriarcado, es decir, a un feminismo revolucionario y no a uno reformista. Las feministas lesbianas negras de Combahee River Collective visibilizaron las exclusiones de raza, de clase y de identidad sexual en el marco de complejos sistemas de poder que era necesario eliminar. Posteriormente, en el neoliberalismo, la interseccionalidad corre el riesgo de perder su carácter revolucionario para convertirse en una herramienta reformista al servicio del sistema, desde un enfoque funcionalista en el que los sujetos excluidos deben ser 
integrados para mejor funcionamiento, menor riesgo de desestabilización y más rendimiento de dividendos del propio sistema.

Para concluir, es importante recordar que la interseccionalidad es un aporte realizado desde el black feminism y especialmente desde feministas negras lesbianas, con antecedentes en la literatura chicana y post colonial. Como resalta Mara Viveros (2016:14), "el origen social de quienes crearon las teorizaciones llamadas hoy interseccionales es fundamental para entender su génesis y desarrollo, y el lugar que ocupan la raza y el racismo como modalidades particulares de la dominación". Además, es imprescindible visibilizar que "el origen de la interseccionalidad está fuertemente insertado en el desarrollo del pensamiento y praxis feministas no-hegemónicos" (La Barbera, 2016:110). Todo ello pone de manifiesto el potencial de transformación que existe en los colectivos marginados y enriquece el debate actual sobre la necesidad de que el feminismo esté constituido por voces diversas desde realidades diversas, en igualdad de posición, para integrar los análisis situados de todas las mujeres dentro de un discurso feminista global construido desde el diálogo igualitario.

En esta línea de pensamiento, ponemos ahora el foco de atención en la realidad latinoamericana, profundizando en los aportes del feminismo decolonial y, dentro de él, del feminismo comunitario propuesto por mujeres indígenas para, posteriormente, abordar el feminismo dialógico.

\subsubsection{Feminismo decolonial.}

Un análisis crítico del devenir histórico de feminismo pone de manifiesto la existencia de un pensamiento feminista hegemónico configurado a partir de mujeres occidentales. Según Nathalia Jaramillo (2014:5) los feminismos occidentales están "basados -tanto filosófica como sociológicamente- en corrientes de pensamiento liberales progresistas". Este pensamiento está situado en la realidad de mujeres estadounidenses y europeas. Fue 
elaborado por mujeres que responden a un patrón privilegiado -blancas, académicas, de clase social acomodada, heterosexuales, de tradición cristiana- y fue producido desde los centros de poder del mundo donde ellas estaban situadas, aunque no ostentaran poder. De esta forma, el feminismo occidental se extendió imbuido del poder de la posición de sus portavoces, colonizando otros pensamientos y creando el constructo cultural de las otras mujeres para referirse a todas las que no encarnan el patrón privilegiado, como si las feministas occidentales no fueran las otras para las otras. Junto a relaciones internacionales basadas en la exclusión centros-periferias y en modelos de desarrollo liberales, el feminismo occidental fue exportado por las mujeres del norte enriquecido hacia las mujeres del sur empobrecido, como parte de políticas neocolonialistas que mantienen subordinados a los países del sur. El feminismo occidental se convirtió así en un feminismo hegemónico.

Tal y como señalaron feministas indígenas en el Foro Internacional de las Mujeres Indígenas en el Foro de AWID (Bangkok, 2005), recogido por Morna Macleod (2011), históricamente se han reproducido las exclusiones racistas y discriminatorias del feminismo tradicional que

ha establecido esquemas en los que existe un centro y una periferia, y las mujeres indígenas, negras, pobres, somos siempre las feministas de la periferia que tenemos que aceptar las ideas y conceptualización de la lucha feminista que presenta un sesgo homogeneizante y discriminatorio en su análisis que establece relaciones encubiertas de poder y autoridad dentro del movimiento feminista, que dejan fuera de estos esquemas a las mujeres indígenas. (p.121)

En el caso de Guatemala, esta asimetría de poder centro-periferia se ha dado no solo desde el feminismo hegemónico de tradición norteamericana y europea hacia los feminismos surgidos en el país, sino también a lo interno, con una clara preponderancia de las ideas y 
prácticas de mujeres ladinas, académicas, de clase media o alta sobre las ideas y prácticas de las mujeres indígenas.

Como denunció la feminista india Chandra Mohanty, existe una colonización discursiva del feminismo occidental sobre otros feminismos, que son minusvalorados, invisibilizados o analizados desde el paternalismo de una visión lineal y unívoca de la historia y del desarrollo, que consideraría que las luchas de las mujeres indígenas, afrodescendientes y mestizas pertenecen a estadios primarios de un proceso ya superado por las mujeres occidentales, quienes serían las protagonistas de las verdaderas luchas emancipadoras, libradas desde enfoques auténticamente feministas. Para Rosalva Hernández (2006), la visibilización del colonialismo dentro del feminismo

ponía en la mesa del debate la "violencia epistémica" que se ejercía cuando una forma de ver el mundo, de entender la justicia y la emancipación, era reivindicada como la única forma de "liberarse" de la dominación. No se trataba sólo de que los problemas de las mujeres indígenas y campesinas no se incluyeran en las agendas feministas, sino que el proceso de borramiento de su existencia era más profundo. (p.21)

Los feminismos latinoamericanos surgen de la diversidad de movimientos de mujeres que luchan por transformar una realidad personal, social y política fuertemente marcada por opresiones de género, de raza y de clase social en sociedades caracterizadas por la multiculturalidad y por la desigualdad estructural creada por el liberalismo en la región. Muchos feminismos latinoamericanos se enmarcan en una corriente crítica y postestructuralista del feminismo: el feminismo decolonial. Éste cuestiona el discurso feminista hegemónico poniendo en tela de juicio, en primer lugar, al liberalismo. Julieta Paredes (2017:116) explica que el feminismo decolonial "recoge en los fundamentos de su ideario este concepto estratificador del liberalismo, $[\ldots]$ en el liberalismo no hay iguales, hay ciudadanos de primera, de segunda, tercera, de cuarta, de quinta clase, etcétera". El 
feminismo decolonial avanza hacia un pensamiento y prácticas feministas propias, surgidas desde los contextos particulares de las mujeres latinoamericanas que se caracterizan por las enormes brechas de desigualdad creadas por la estratificación social racializada herencia del período colonial y por las medidas de ajuste estructural del liberalismo. En el feminismo decolonial, el enfoque interseccional ha estado siempre implícito en los análisis y prácticas, yendo más allá de las opresiones de género para desenmascarar las opresiones racistas y clasistas del sistema patriarcal.

Los feminismos decoloniales se construyen desde las otras mujeres, desde la diferencia, dando voz a las históricamente excluidas del discurso feminista hegemónico: las mujeres pobres, racializadas, con bajo nivel académico. Como explican Castillo y Vílchez (2013), basadas en Alba Carosio (2011),

el pensamiento feminista desde las mujeres ha llamado la atención sobre la diferencia, cuestionando lo que se constituye como diferencia y cómo lo diferente se equipara como lo periférico, lo deficiente -frente a lo universal y lo central, conformándose así relaciones asimétricas de poder. Frente a la idea de un sujeto político moderno las feministas latinoamericanas van descolonizando identidades y produciendo reflexiones desde las sujetas oprimidas e invisibles. Así tienen lugar los feminismos afrodescendientes, indígenas, populares, comunitarios, entre otros. (p.270)

Para Jaramillo (2014), el feminismo decolonial es una forma de entender la manera en que la opresión sexualizada y de género está enlazada en la sociedad de hoy en día, como un artefacto del legado duradero de la colonización, un subproducto del capital neoliberal, una manifestación de un sistema mundial diferenciado por una jerarquía racializada, y un sistema de creencias profundamente arraigado en nuestro inconsciente colectivo. (p.5) 
Un análisis profundo de las particularidades de las agendas feministas nos lleva a constatar diferencias importantes entre los proyectos políticos que emanan del feminismo occidental y del feminismo decolonial. El feminismo occidental, tradicionalmente, ha privilegiado la "dominación patriarcal como la fuente de la opresión de la mujer" (Jaramillo, 2014:5), obviando otros sistemas de poder -racismo, clasismo, heteronormatividad y otros- que configuran su posición en la sociedad y en el mundo y que solo son visibles a través de un análisis interseccional. Esto ha dado lugar a una respuesta "reformista en vez de revolucionaria, se ha luchado por políticas y se ha dejado la estructura social y política preponderante de la sociedad relativamente intacta" (Jaramillo, 2014:5). El feminismo decolonial, sin embargo, desde una conciencia clara de la indisolubilidad del género, la raza y la clase social, busca una transformación profunda de la estructura de las sociedades, con agendas más revolucionarias que reformistas.

El feminismo decolonial no puede pensarse como la corriente a la que se adscriben todos los feminismos latinoamericanos. Es importante visibilizar la existencia de múltiples corrientes feministas en América Latina, algunas de ellas adscritas al feminismo hegemónico occidental. En este sentido, resulta fundamental retomar la crítica que realiza la feminista dominicana Yuderkis Espinosa acerca de la colonización y la colonialidad de los discursos de las feministas hegemónicas del sur, que no solo habrían importado modelos feministas anglosajones con propuestas de cambio social y cultural no válidas para el contexto latinoamericano, sino que también estarían construyendo discursos feministas reproductores del orden social colonial, basados en la exclusión de raza y clase social. Para Yuderkys Espinosa (2009),

esta acogida de la ideología y los proyectos de emancipación occidental si bien han servido a los proyectos feministas latinoamericanos también ha tenido consecuencias nefastas en la instalación de una mirada y unos objetivos políticos productivos 
exclusivamente a las mujeres de determinadas clases, orígenes y sexualidad del continente. (p.44)

En la misma línea de discusión, Adriana Guzmán (2015) sitúa el origen de la desarticulación de los feminismos en América Latina y el Caribe precisamente en el hecho de basarse en ideas feministas colonizadas y colonizantes:

creemos que sería injusto hablar de un movimiento feminista en América Latina y el Caribe, sí podemos hablar de colectivos y organizaciones, también de académicas y “estudiosas" que, en conjunto, no han logrado articularse pues siguen construyendo desde un feminismo colonizado y colonizante, sobre categorías insuficientes y fragmentadas, haciendo luchas temáticas, por los derechos, por la diversidad, por la inclusión, alejándose de la lucha contra el sistema. Hablamos de un feminismo que, al dejar de nombrar y de ver al patriarcado, o al reducirlo a la relación de los hombres hacia las mujeres, ha perdido la perspectiva revolucionaria y se ha vuelto funcional a éste. (p.1)

Los feminismos en Guatemala son diversos, al igual que en toda la región latinoamericana. Esta diversidad surge sin duda de la diversidad de las mujeres guatemaltecas, con experiencias vitales muy dispares dentro de la complejidad de una estructura social profundamente marcada por el post conflicto y el genocidio, por la desigualdad intrínseca al neoliberalismo en un país de la periferia y por la perpetuación del poder sobre la base del racismo, el clasismo y el machismo. En este contexto, los discursos y prácticas feministas hegemónicas en Guatemala provienen de mujeres mayoritariamente ladinas, urbanas, de nivel académico alto, con posiciones vitales y reivindicaciones más afines a las de las feministas occidentales. Por otro lado, se encuentran los feminismos indígenas, frecuentemente no reconocidos e incluso auto reconocidos como tal, que generalmente parten de prácticas transformadoras y de luchas políticas de mujeres indígenas. Los espacios en los que 
confluyen estos feminismos diversos no están exentos de controversia y de relaciones de poder que hacen evidente la reproducción del sistema racista y clasista en los movimientos de mujeres, permeados a su vez por el enfrentamiento en el que el sistema patriarcal socializa a las mujeres, para conveniencia de la perpetuación del poder en manos de los hombres.

Entre los feminismos indígenas en Guatemala toma fuerza el feminismo comunitario, que constituye un aporte fundamental al feminismo decolonial. El feminismo comunitario construye análisis y propuestas de acción desde la realidad de las mujeres y de los pueblos indígenas con una mirada política universal de la que el mundo está urgido: el Buen Vivir. La feminista comunitaria xinca guatemalteca Lorena Cabnal (s/f:1) explica que el Buen Vivir es "un aporte a la humanidad para el establecimiento de un nuevo orden simbólico para la vida".

\subsubsection{Feminismo comunitario.}

El feminismo comunitario es una propuesta crítica desarrollada por mujeres indígenas de Abya Yalai que busca generar pensamiento situado desde la realidad de las mujeres indígenas. Para Cabnal (2010:11), el feminismo comunitario es "una recreación y creación de pensamiento político ideológico feminista y cosmogónico, que ha surgido para reinterpretar las realidades de la vida histórica y cotidiana de las mujeres indígenas, dentro del mundo indígena". El emerger de las mujeres indígenas como sujetos epistémicos en el debate feminista mundial supone la incorporación de voces históricamente silenciadas y de experiencias vitales invisibilizadas por un feminismo hegemónico que ha tendido a representar a las mujeres indígenas, pero sin contar con ellas. De esta forma, desde una crítica decolonial, las mujeres indígenas se habrían convertido no solo en la otra respecto a las feministas occidentales, sino en la otra de la otra, al verse subordinadas respecto a las feministas hegemónicas del sur. En palabras de Espinosa (2009), 
la violencia epistémica es tal que la «mujer del tercer mundo» queda atrapada doblemente por la colonización discursiva del feminismo de Occidente que construye a la «Otra» monolítica de América Latina, y por la práctica discursiva de las feministas del Sur, quienes, estableciendo una distancia con ella y, al mismo tiempo, manteniendo una continuidad con la matriz de privilegio colonial, la constituye en la otra de la Otra. (p.48)

El surgimiento del feminismo comunitario como propuesta propia de las mujeres indígenas latinoamericanas tiene su explicación al analizar el contexto histórico, político y socioeconómico particular de la región. Paredes (2017) explica que

el pesado peso de las reformas económicas neoliberales cayó fuertemente sobre las mujeres de clases bajas e indígenas empobrecidas, en el llamado tercer mundo [...] En este panorama, no es raro entonces que los intereses y las búsquedas de las mujeres hayan sido muy diferentes, dependiendo de la clase social y de la cultura a la que pertenecían. (p.116)

El feminismo comunitario es crítico con la invisibilización de las diversas opresiones que se cruzan en los cuerpos de las mujeres indígenas y, desde un enfoque interseccional, pone de manifiesto que esta invisibilización se ha dado tanto desde el feminismo occidental como desde los feminismos hegemónicos del sur, así como desde los esencialismos culturales indígenas. El feminismo comunitario realiza esta crítica abierta, pero a la vez muestra un gran potencial de diálogo y de contribución a la transformación política al entenderse a sí mismo como parte de las resistencias globales de las mujeres a lo largo de la historia. En este sentido, Cabnal (2010) expresa que como feminista comunitaria busca aportar a la pluralidad de feminismos construidos en diferentes partes del mundo, con el fin de ser parte del continuum de resistencia, transgresión y epistemología de las 
mujeres en espacios y temporalidades, para la abolición del patriarcado originario ancestral y occidental. (p.12)

La propuesta epistemológica y política del feminismo comunitario parte de una definición de la identidad de las mujeres indígenas $-\mathrm{y}$ de los pueblos indígenas- estrechamente relacionada con la comunidad, que es territorio y es vida sobre el territorio. En la Declaración de Lima "Mujeres indígenas hacia la visibilidad y la inclusión" (2013), las mujeres indígenas reunidas, de diversas nacionalidades, recordaban que

para los Pueblos Indígenas, nuestros territorios abarcan no sólo la distribución geográfica y áreas físicas de nuestras tierras, aguas, océanos, glaciares, montañas y bosques, sino también las profundas relaciones culturales, sociales y espirituales, así como los valores y responsabilidades, que nos conectan con nuestros territorios ancestrales.

La feminista comunitaria boliviana Julieta Paredes (2017:125), explica que con el término comunidad "queremos abarcar en su comprensión a todas las comunidades, no solo estamos hablando de las comunidades rurales o comunidades indígenas. Es otra manera de entender y organizar la sociedad y vivir la vida". Desde el feminismo comunitario, se afirma la igualdad política de las mujeres y hombres dentro de la comunidad, criticando la heteronormatividad y la supremacía de los hombres. Paredes (2017) explica que

la comunidad está constituida por mujeres y hombres como dos mitades imprescindibles, complementarias, no jerárquicas, recíprocas y autónomas una de la otra. Lo cual no necesariamente significa una heterosexualidad obligatoria, porque no estamos hablando de pareja, sino de par de representación política, no estamos hablando de familia, sino de comunidad. (p.126)

El feminismo comunitario analiza la relación existente entre la expropiación del cuerpo sexuado de las mujeres y la explotación y expropiación de la tierra y el territorio dentro del 
sistema patriarcal histórico, al que se suma el neoliberalismo actual. Siguiendo a Paredes (2017), la expropiación del cuerpo de las mujeres se relaciona con la escisión cristiana y colonial entre cuerpo y alma, que no es propia de la integralidad del ser en la cosmovisión indígena. Por otro lado, la expropiación del cuerpo tiene que ver con el ser-para-otros que devela Marcela Lagarde (2011) como elemento determinante de la posición de las mujeres dentro del sistema patriarcal:

la mujer se concibe a sí misma primero como hija de, que como mujer; primero como esposa, madre, viuda, ayudante de, que como mujer. Su conciencia femenina se estructura a partir de su ser para otros, de sus relaciones conyugales y maternales o por su dependencia en relación con los hombres y el poder, que como mujer con características de su particular situación. (p.344)

Lagarde (2014) retoma la idea de Franca Basaglia de que las sociedades patriarcales hacen de las mujeres seres-para-los-hombres y, en cualquier caso, seres-para-otros, todo ello mediante una expropiación de sus cuerpos que tiene como consecuencia el sometimiento de su subjetividad en función de la condición de género sometida. Así, para Lagarde (2014) la expropiación del cuerpo de las mujeres es la base y el origen de la expropiación en todo su orden vital:

las sociedades patriarcales expropian a las mujeres su sexualidad, sus hijas e hijos y los productos de su trabajo y su creatividad. Los mecanismos son: la dependencia sexual y afectiva, la subalteridad, la pobreza de género, a las que se suman otras formas de dependencia, las leyes patriarcales y en particular la ley del padre, la simbolización y el lenguaje, la invisibilización y la anulación de la autoría de las mujeres. (p.187) 
En cuanto a la expropiación y explotación de la tierra, desde el feminismo comunitario se constata que se trata de un proceso histórico potenciado por el liberalismo y maximizado actualmente por el neoliberalismo. Cabnal (2010) indica que

a este proceso histórico de opresión contra la naturaleza y sus bienes, se une todo el actual sistema extractivista neoliberal que, en su visión de desarrollo occidental pretende "mejorar la vida de los pueblos", con estrategias de participación e involucramiento de las comunidades en el trabajo extractivista para mejorar su condición de pobreza.

Surge así la noción de territorio cuerpo-tierra, cuya emancipación es necesariamente conjunta y se convierte en una premisa base del feminismo comunitario. Esta noción enlaza profundamente con el postulado feminista de "lo personal es político", aportando una perspectiva histórica y política a la expropiación de los cuerpos de las mujeres. Cabnal (s/f) habla de su propia experiencia como feminista comunitaria:

reconocer cómo mi primer territorio cuerpo ha sido expropiado y pactado histórica y estructuralmente para beneficio y sostenimiento de estos sistemas (colonial, liberal, neoliberal), es importante porque me remite también a pensar como nuestro territoriotierra ha sido expropiado y pactado, por lo tanto construido sobre él, formas de organización que se concretan en repúblicas, países, fronteras y estados, donde la vida de los pueblos originarios y de las mujeres indígenas en particular está siendo dominada por el poder de un estado nación- colonial. (p.5)

La concepción conjunta e inseparable de la lucha por la defensa de la tierra y el territorio y la lucha por la recuperación del territorio cuerpo-tierra pone de manifiesto una incoherencia fundamental común en las luchas sociales: defender la tierra frente a la violación de sus derechos y no luchar de la misma forma para erradicar la violación de derechos infligida a las personas, especialmente a las mujeres. Cabnal (s/f) denuncia que 
pareciera que no nos indigna la violencia sexual contra las niñas, el incesto, el feminicidio, no nos pronunciamos contra eso, pero sí nos indigna la violencia que penetra con maquinaria la tierra y extrae los bienes naturales. [...] Las feministas comunitarias por eso es que planteamos la recuperación y defensa de nuestro territorio cuerpo-tierra, $[\ldots]$, es incoherente que la tierra este en paz, mientras el cuerpo esta con dolor. (p.13)

El feminismo comunitario busca construir una visión feminista del Buen Vivir (Cabnal, s/f) trabajando por la transformación de las comunidades como base de la transformación de toda la convivencia humana y de su relación con la naturaleza para avanzar hacia modelos de solidaridad y armonía entre todo lo que existe. La labor de transformación de las comunidades parte de la reivindicación de las mujeres indígenas "como sujetas epistémicas, [...] porque tenemos solvencia y autoridad para cuestionar, criticar y proponer aboliciones y deconstrucciones de las opresiones históricas que vivimos" (Cabnal, 2010:12). Así, el feminismo comunitario deconstruye los postulados básicos de la cosmovisión indígena desde un enfoque de género e interseccional, proponiendo nuevas categorías de análisis que son fundamentales para una acción política verdaderamente transformadora de las opresiones de género, raza, clase y heteronormatividad que viven las mujeres indígenas de América Latina.

El primer concepto que propone el feminismo comunitario es el patriarcado originario ancestral. Se demuestra la existencia de un patriarcado precolonial que se entroncó con el patriarcado occidental durante la época colonial, refuncionalizándose para servir al nuevo orden social y económico (Cabnal, 2010, Paredes, 2017). El concepto de patriarcado ancestral originario produce una ruptura epistémica con los postulados indigenistas más esencialistas que defienden la existencia de un orden de armonía, igualdad y complementariedad entre mujeres y hombres en las sociedades precolombinas, expresado en el chacha -warmi (hombre-mujer) de la cosmovisión del pueblo aymara boliviano o en los valores de la 
dualidad y complementariedad de la cosmovisión de los pueblos mayas guatemaltecos. Desde perspectivas esencialistas, el orden de armonía habría sido transgredido con la imposición del machismo por parte de los conquistadores españoles y su régimen, de manera que la Conquista sería el origen del patriarcado y de todo un conjunto de perversiones que quedaron incrustadas en las culturas indígenas. El feminismo comunitario rompe con esta idealización: "el concepto de memoria larga que es usado en el indigenismo, nos remite acríticamente a la época precolonial, como algo idílico, un mundo casi perfecto para las mujeres" (Paredes, 2017: 137). En su lugar, el feminismo comunitario visibiliza la existencia de un sistema precolonial, milenario de hecho, basado en la opresión de las mujeres indígenas. Esto queda patente en las guerras documentadas entre pueblos originarios, entre otras realidades históricas. Se alerta sobre la mencionada memoria larga: Paredes (2017) explica que ésta es interesada y selectiva al

no reconocer patriarcalismos, opresiones, autoritarismos e injusticias heredadas y que, por supuesto, estaban presentes en las sociedades precoloniales, también. Hay que despatriarcalizar la memoria y reconocer que hubo un patriarcado precolonial y que la situación de las mujeres no es solo a partir de la colonia. (p.137)

A la luz de estas reflexiones críticas, se construye el concepto de patriarcado originario ancestral, que Cabnal (2010) define de la siguiente forma:

es un sistema milenario estructural de opresión contra las mujeres originarias o indígenas. Este sistema establece su base de opresión desde su filosofía que norma la heterorealidad cosmogónica como mandato, tanto para la vida de las mujeres y hombres y de éstos en su relación con el cosmos. (p.14)

Como puede observarse, el feminismo comunitario desmonta la mitificada igualdad de las cosmovisiones indígenas evidenciando no solo la misoginia de una dualidad opresora para las mujeres, que quedan relegadas a roles carentes de poder en la comunidad, sino también 
alertando de la heteronormatividad que se esconde en los conceptos de dualidad y complementariedad: contienen un mandato heterosexual que vincula a la mujer con la fecundidad, la tierra y la vida y al hombre con el poder y la fecundación, negando la existencia de otras identidades sexuales y reduciendo la esfera relacional humana al ámbito de la pareja heterosexual y la reproducción. Desde el feminismo comunitario se hace un llamado a cuestionar los fundamentalismos étnicos para construir un pensamiento verdaderamente decolonial y emancipador: "no veo posibilidades para la liberación de la vida de las mujeres, para la armonización total cósmica, si continuamos refuncionalizando fundamentalismos étnicos" (Cabnal, 2010:19).

Siguiendo la línea de crítica interna a las culturas indígenas, las feministas comunitarias proponen los conceptos de victimización histórica situada y de racismo internalizado (Cabnal, 2010) que pueden convertirse en potentes propulsores de una auténtica transformación decolonial en los pueblos indígenas latinoamericanos. La victimización histórica situada tiene que ver con esa postura esencialista, acrítica y desmovilizadora que achacaría todos los males de los pueblos indígenas al hecho histórico de la Conquista. "Para quienes se asumen desde este planteamiento, ese hecho histórico [la Conquista], marca la raíz o nacimiento de todas nuestras opresiones históricas y actuales" (Cabnal, 2010:19). El racismo internalizado, por su parte, constituye una crítica decolonial al propio pensamiento indígena al mostrar que actualmente el racismo, junto con la victimización histórica situada, forman parte del imaginario de los pueblos indígenas $\mathrm{y}$, por lo tanto, de su propia construcción cultural, como un efecto de la colonización. Para Cabnal (2010),

este efecto colonizador ha seguido siendo parte de nuestras vidas y radica en nuestros cuerpos y mentes, por lo cual es importante para mí cuestionar nuestra victimización histórica situada, para poder trascender el racismo internalizado y posibilitarnos verlo 
en nuestra construcción cultural, pues si no, la mayoría de lo que estamos haciendo para su erradicación será un trabajo parcial, pues lo miramos a lo externo. (p.20)

La propuesta política del feminismo comunitario se basa en actuar en cinco campos de acción desde las comunidades: cuerpo, espacio, tiempo, movimientos sociales y memoria. Se trata de despatriarcalizar estos campos de acción, recuperándolos para una vida comunitaria plena y feliz, en igualdad. Paredes (2017) invita

a todas las mujeres y hombres feministas a la desobediencia. Desobedecer las órdenes patriarcales que han limitado y reprimido nuestros cuerpos, nuestros espacios y nuestros tiempos, y han contaminado de machismo nuestros movimientos y organizaciones sociales, borrando de nuestra memoria que nacimos diferentes pero iguales para vivir en comunidad. (p.138)

\subsubsection{Dualidad y complementariedad en la cosmovisión maya.}

Como se ha expuesto, los conceptos de dualidad y complementariedad de la cosmovisión maya son criticados por el feminismo comunitario como parte del esencialismo étnico indigenista que oculta la supremacía milenaria y actual de los hombres indígenas sobre las mujeres. Sin embargo, la dualidad y la complementariedad son, a su vez, dos principios filosóficos cuyo contenido permite a la cosmovisión maya fundamentar la necesidad de eliminar todos los mecanismos de subordinación y avanzar hacia la igualdad. En este sentido, es relevante profundizar en el análisis de estos conceptos y su significación en la cultura maya guatemalteca actual, ya que se encuentran presentes en el imaginario de las personas protagonistas de la presente investigación y pueden ser de gran ayuda en la búsqueda de alternativas para la transformación del machismo.

El concepto de equidad de género, de concepción occidental, produce controversia en diversos sectores de Guatemala por ser considerado como una imposición neocolonial alejada 
de la cultura maya, por un lado, y como un mero requerimiento de las agencias de cooperación internacional para la aprobación de proyectos, por otro. Para otros sectores, el concepto de equidad de género va en consonancia con valores propios de la cultura maya. Es el caso de una maestra maya-k'iche' participante en este proceso de investigación, que afirma que:

para otras personas la equidad de género entraría más en lo occidental, podríamos decir, pero viéndolo desde el punto de vista de los mayas también lo tenemos, solo que tal vez de otro nombre, pero llega a lo mismo, sí es un mismo concepto. $(\mathrm{E} 05 / \mathrm{B} / \mathrm{M})$

Desde la cosmovisión maya, los conceptos de complementariedad y dualidad expresan el equilibrio y la armonía como aspiración máxima del ser humano, que es parte de la comunidad, de la naturaleza y del cosmos, en equilibrio con el Creador y Formador. Morna Macleod (2011) transcribe las palabras de la ajq’ij -guía espiritual maya- Virginia Ajxup sobre la dualidad

todos los seres o fenómenos de la naturaleza interactúan y se organizan dualística y complementariamente. [...] Dualidad es la integración de dos elementos para la conservación y continuación de la vida, que puede comprenderse como lo que completa y armoniza al ser, no es contrapuesta, sino es el otro yo. Ese yo totalmente diferente. [...] No son contraposiciones excluyentes sino necesarias, se manifiestan a todo nivel y en todos los ámbitos de la vida natural y social. (p.124)

La complementariedad, continúa explicando Virgina Ajxup, transcrita por Macleod (2011) es el proceso y comprensión de integración para llegar a la totalidad o plenitud. Ningún ente y ninguna acción existe "monádicamente” [en sentido de uno solo], sino siempre en coexistencia con su complemento específico, que hace completo el 
elemento correspondiente. La Complementariedad es la experiencia total de la realidad. (p.124)

La misma maestra maya-k'iche' afirma que dualidad y complementariedad son dos valores importantes, en donde los mayas decimos que todo lo que existe a nuestro alrededor tiene importancia y tanto hombre y mujer se complementan, es una dualidad, son dos para ser uno. (E05/B/M)

La complementariedad y dualidad hacen referencia a la interconexión entre todos los elementos del universo, siendo las mujeres y los hombres una parte más de él que precisa convivir en armonía para mantener el equilibrio global. De esta forma, cualquier daño infligido a uno de los elementos, daña a los demás: dañar a la madre naturaleza daña al ser humano, obrar injustamente daña a la comunidad, provocar daño en la relación entre mujer y hombre genera daño mutuo, daño comunitario y desequilibrio general. Por lo tanto, de una manera directa podría entenderse que la cosmovisión maya invita a establecer relaciones de género basadas en el respeto, la horizontalidad y la cooperación mutuas, partiendo de la concepción de la mujer y el hombre como dos partes del mismo todo, una dualidad perfecta que se complementa y que a su vez es tan solo un aspecto del gran todo universal. Esta interpretación es confirmada por algunas mujeres mayas, como Estela Jocón en la entrevista recogida por Macleod (2011), quien argumenta que la complementariedad se da en la relación entre mujer y hombre, al igual que entre los seres humanos y todos los elementos de la naturaleza, no siendo posible reducir la complementariedad a las relaciones de género.

Dualidad y complementariedad son conceptos muy complejos que "resultan difíciles de entender y aprehender por la falta de referentes en el pensamiento occidental" (Macleod, 2011:123). Así mismo, algunas mujeres mayas consideran que estos conceptos han sido utilizados por intelectuales indígenas para justificar el machismo desde la defensa acérrima de la conservación de la cultura y la idealización romántica de sus preceptos. Esta es la 
postura de la académica maya k'iche' Irma Alicia Velásquez, en entrevista recogida por Macleod (2011), que afirma que

esto [la complementariedad mujer-hombre] es un concepto discursivo, simplemente queda en el discurso, en la práctica no es así. Los hombres mayas en sus conferencias, no tanto ahora como años atrás, lo utilizaban como una de sus banderas políticas. Hablaban de que las relaciones entre los hombres y las mujeres en las comunidades mayas son de complementariedad, son de noche-día y te ponían una serie de ejemplos; pero en el fondo no era nada así, en el fondo esa complementariedad significaba opresión, implicaba que solo el hombre podía salir, participar políticamente, hablar públicamente, en otras palabras ocupar los espacios públicos, mientras las mujeres se quedaban en los espacios privados y también en algunos espacios económicos, pero fuera de eso no. (p.134)

Nos encontramos ante un debate profundo que en el que hay que entender que el avance hacia la equidad va abriéndose paso en el discurso y en la práctica dentro de la construcción permanente de la cultura, "terreno en el que se negocian constantemente los significados de los símbolos, principios y normas" (Macleod, 2011:136). La brecha entre preceptos culturales y práctica de vida, entre discurso y acción, se da en todas las culturas del mundo. Acusar a los pueblos indígenas de incoherencia por las brechas existentes entre su cosmovisión y su actuar es una forma más de violencia cultural hacia los pueblos indígenas ejercida desde la cultura hegemónica, que busca argumentar su inferioridad moral para justificar la violencia estructural y directa contra ellos.

La aproximación teórica a las luchas de las mujeres indígenas por una vida libre de violencia y con equidad de oportunidades desde los conceptos de la complementariedad, la dualidad y el equilibrio es, siguiendo a Macleod (2011:150), "una estrategia de descolonización -con semejanzas al womanism afroamericano- que busca construir una vía 
desde el pensamiento propio, que se fundamenta en la valoración, la educación, el deber-ser, la no confrontación”. Recordamos aquí el valor que tiene la deconstrucción de la dualidad y la complementariedad que realiza el feminismo comunitario, con una crítica cultural desde dentro. Resignificar estos principios cosmogónicos partiendo de la deconstrucción que hace de ellos el feminismo comunitario, permitiría a las mujeres y a los pueblos indígenas recuperar la dualidad y complementariedad para la lucha feminista.

\subsubsection{Feminismo dialógico.}

Miren Camisón (s/f:1) advierte que "el feminismo, como corriente reivindicativa y progresista, necesita un cambio de paradigma acorde a los problemas acuciantes que se deben resolver en el siglo XXI". Esta afirmación enlaza con el debate anterior sobre la diversidad de los feminismos y la corriente decolonial que muestra las brechas interpretativas de las mujeres sobre la realidad, según sus experiencias políticas, culturales y de posición en cada sociedad.

Carmen Elboj y Ainhoa Flecha (2002:160), basadas en Lidia Puigvert (2001), explican que la sociedad del siglo XXI, marcada por la era de la información, se caracteriza por un giro dialógico que consiste en que "las tradiciones, maneras de hacer y demás componentes del horizonte de nuestro mundo de la vida se ven continuamente cuestionados y nos confrontan a la necesidad de consensuar y dialogar”. Este giro dialógico se está produciendo en todas las instituciones sociales, desde la familia, que actualmente se configura de formas diversas, hasta los Estados, instados al diálogo sobre sus contratos sociales a partir de las reivindicaciones de colectivos sociales, grupos culturales y otros agentes.

El paso a la sociedad de la información es una realidad en el contexto latinoamericano, a pesar de los ritmos heterogéneos con los que se producen los cambios en sociedades marcadas por profundas brechas de desigualdad. En cualquier caso, el giro dialógico en la 
sociedad guatemalteca actual es constatable en la transición desde modelos familiares basados en el autoritarismo a modelos con más orientación democrática, entre otros hechos. En la Guatemala actual se confirma con Puigvert (2006b) que todas las personas asumen y exigen cada vez más ser sujetos activos que influyen en la transformación social de las estructuras sociales. Sujetos capaces de acción que cuestionan y modifican la realidad preestablecida e impuesta, sujetos que estamos consiguiendo conquistas sociales y que vamos modificando la realidad y adaptándola a nuestras necesidades. (p.89)

En coherencia con lo anterior, el diálogo horizontal como herramienta para superar desigualdades también es, sin duda, una necesidad del feminismo actual. Prueba de ello son los siguientes aportes. En primer lugar, Castillo y Vílchez (2013), apoyadas en Sheyla Benhabid, alertan sobre la polarización que afecta al discurso feminista contemporáneo: por un lado, la preocupación liberal por la igualdad y los derechos de las mujeres en sociedades multiculturales, acusada de eurocentrista y, por otro lado, los defensores de la pluralidad de tradiciones que son señalados de relativismo cultural que obvia los derechos de las mujeres.

Rosalva Hernández (2014:22), por su parte, también se inclina por el diálogo para superar la colonialidad en el feminismo, señalando que "descolonizar nuestros feminismos requiere de la construcción de diálogos interculturales que rompan con las lógicas de borramiento de otros saberes y desnaturalicen las jerarquías de género, clase y raza".

En este mismo sentido, el feminismo comunitario resalta la importancia del diálogo para generar análisis globales que lleven a propuestas políticas globales. Cabnal (2010) manifiesta que

[el feminismo comunitario] me ha llevado a ver la importancia de tejer pensamientos con otras mujeres, sean indígenas de los diversos pueblos originarios, o sean "occidentales", porque creo que nos conviene a todas propiciar espacios y encuentros 
para reflexionarnos, para atrevernos a hacer desmontajes y para construir en colectividad transgresiones y propuestas para una nueva vida. (p.25)

La posición de superioridad en la que tradicionalmente se han colocado las mujeres académicas sobre las no académicas, que da lugar a la exclusión del discurso feminista de las mujeres no académicas, explicaría, añadiendo causas históricas y geopolíticas, la colonización ejercida por del feminismo occidental hegemónico sobre otros feminismos. Para Elboj y Flecha (2002),

la exclusión de las Otras mujeres se ha producido por la priorización dada a los saberes académicos propios de la cultura dominante. La gran mayoría de feministas y mujeres académicas construyen barreras a la participación de aquellas Otras mujeres que no poseen un título universitario. (p.162)

En este sentido, se da la paradoja que explica Puigvert (2006b): actualmente hay mujeres feministas de países y culturas anteriormente invisibilizados que ya están participando en los discursos feministas globales; sin embargo, las mujeres no académicas siguen excluidas dentro de sus propios países o contextos. La incorporación a los discursos globales de movimientos de mujeres minorizados se produjo, según Puigvert (2006b), en la segunda fase de la nueva sociedad caracterizada por el giro dialógico. La primera fase de la sociedad dialógica estuvo marcada por el darwinismo social que surgió a causa de las exclusiones que la sociedad de la información impuso a los países y sujetos con menos recursos, a quienes no alcanzó la revolución de la información. En la segunda fase de la sociedad dialógica, los movimientos sociales tomaron protagonismo para exigir la superación de las desigualdades. En este contexto, según Puigvert (2006b:88), "los movimientos de mujeres [...] toman significatividad. No es que no existieran antes, sino que ahora pueden convertirse también en protagonistas del feminismo, incorporando sus luchas y reivindicaciones en un movimiento radicalmente más democrático". 
Sin embargo, a pesar de la incorporación de movimientos de mujeres diversos al feminismo global, la inclusión de las mujeres no académicas a los discursos feministas que se producen en cada contexto todavía no es una realidad. Esto ocurre en Guatemala, donde es palpable la exclusión hacia las mujeres no académicas e indígenas en la producción del discurso feminista dominante. Sin embargo, como nos muestra el feminismo decolonial y, dentro de él, los feminismos latinoamericanos, precisamente son las otras mujeres las que están planteando "modificar los criterios y las pautas desde los cuales hemos acabado decidiendo el rumbo de las luchas feministas" (Puigvert, 2006 b:99).

El feminismo dialógico es una teoría que recoge la necesidad de incorporar al feminismo todas las voces de todas las mujeres, desde la diversidad de posiciones sociales y situaciones personales en las que se encuentren y tomando especialmente en cuenta a las mujeres más excluidas. "Pretende unir los esfuerzos de todas las mujeres (distintos niveles de estudios, posiciones sociales o etnias) para superar las desigualdades que sufrimos" (Puigvert, 2006b:99). Siguiendo a la misma autora, basada en Beck-Gernsheim, Butler y Puigvert (2001), el planteamiento del feminismo dialógico consiste en

defender una radicalización de los procesos democráticos para elaborar entre todas una teoría que permita una sola definición de la feminidad, no entendida como homogeneizadora, sino que sea inclusiva, dinámica e igualadora de todas las voces. Es decir, que tenga presentes las diferencias de género en lugar de fomentar su desaparición y que sea sensible al contexto en lugar de indiferente a las situaciones. $(\mathrm{p} .134)$

Para el feminismo dialógico, es fundamental detenerse en la exclusión de las otras mujeres dentro de cada país o contexto: mujeres adultas, no académicas y pertenecientes a minorías. O como en el caso de Guatemala, mujeres pertenecientes a las mayorías -indígenas, rurales, de nivel educativo bajo- que han sido históricamente excluidas por el sistema racista 
y elitista. Estas mujeres excluidas de los centros privilegiados donde se produce el pensamiento están desarrollando luchas cotidianas que son el origen mismo del feminismo y que, por lo tanto, constituyen experiencias esenciales para construir un proyecto feminista global, mucho más radical (Puigvert, 2006b), que responda a las necesidades actuales. Es imperativo desmotar el prejuicio de que la creación de conocimiento feminista es exclusiva de las mujeres académicas y revalorizar las prácticas transformadoras como base de todo movimiento social y de la generación de teoría. Puigvert (2001) resalta que es necesario comprender que

hay quienes desde las universidades y los contextos académicos resuelven con éxito situaciones de desigualad, pero no saben enfrentarse a las mismas desigualdades que viven en su vida personal, en tanto otras modifican sus acciones sin saber que, con ello, elaboran nuevas teorías feministas y apoyan los estudios sociales más influyentes de la actualidad. (p.55)

Desde el feminismo dialógico, podemos afirmar que es urgente abrir un dialogo horizontal entre todas las mujeres y todos los feminismos, desde sus diferentes perspectivas basadas en las experiencias particulares de ser mujer, que permita superar las jerarquías y exclusiones y crear alternativas epistemológicas y políticas para un feminismo global que revolucione el patriarcado. Como explica Camisón (s/f: 1) “el feminismo dialógico es una herramienta que hay que comenzar a desarrollar, para que la lucha y reivindicaciones de las mujeres en el mundo sea global, superando las múltiples barreras culturales, de clase, educativas, laborales y sociales". Siguiendo a Boaventura de Sousa Santos (2010:46), encontramos un aporte importante al debate sobre la necesidad del diálogo entre mujeres diversas en el feminismo, para construir conocimiento conjunto desde la justicia e igualdad entre todos los saberes, que sostenga la lucha global de las mujeres: "la resistencia política de este modo necesita ser 
presupuesta sobre la resistencia epistemológica. [...] no es posible una justicia social global sin una justicia cognitiva global”.

Para Puigvert (2006b), la construcción de luchas globales en el feminismo demanda rescatar la centralidad de la solidaridad. Puigvert (2006b), retoma el concepto de solidaridad de Touraine $(1997,2005)$ según el cual todas las personas tenemos el deber de la solidaridad en virtud de defender el universalismo del sujeto, es decir, hacer valer el derecho de todos los seres humanos a dar sentido a nuestra existencia. Desde esta premisa, Puigvert defiende la solidaridad como una condición para que existan acciones coordinadas entre las mujeres a favor del bien de todas ellas: "mientras exista una acción coordinada entre todas las mujeres, podemos luchar para mejorar unas condiciones de vida comunes, pero en el momento que estas acciones son cuestionadas, las posibilidades de luchar para mejoras comunes y globales disminuye, sino desaparece" (Puigvert, 2006b:91).

El feminismo dialógico se construye alrededor de dos ejes fundamentales: a) la radicalización de los principios de la Modernidad y b) la confianza en la acción de todas las mujeres para cambiar el curso de la historia (Puigvert, 2006b). La primera característica surge de la constatación de que, mientras el feminismo potencia las posibilidades de conquistas democráticas, la postmodernidad las socava. Por eso, se hace imprescindible "defender la radicalización de los procesos democráticos que favorezcan la elaboración, entre todas, de una teoría que se aleje de intentos homogeneizadores y, por el contrario, promueva que sea inclusiva, dinámica e igualadora de todas las voces" (Puigvert, 2006b:99). La segunda característica se vincula con uno de los principios del feminismo dialógico que se desarrollará más adelante: la igualdad de las diferencias. Confiar en que todas las mujeres podemos cambiar el curso de la historia es hacerlo respetando y valorando las características y condiciones particulares de cada mujer, alejándonos de pretensiones aculturadoras. Por otro lado, esta característica es coherente con los planteamientos de las ciencias sociales que 
indican que "hay que cuestionar la monopolización del conocimiento experto, que en el movimiento feminista se traduce como la apertura hacia todos los colectivos de mujeres" (Puigvert, 2006b:101). En este punto, introducir el concepto de pensamiento abismal de Santos (2010) enriquece la reflexión sobre la monopolización del conocimiento experto en el feminismo, al tener en cuenta el colonialismo que caracteriza al monopolio de las ideas feministas occidentales. Esto nos permite enlazar el feminismo dialógico con los planteamientos del feminismo decolonial y, especialmente, con la invisibilización del pensamiento de las mujeres indígenas en el feminismo, tanto por parte de las feministas occidentales como por parte de las feministas hegemónicas del sur. Santos (2010) explica la existencia de un pensamiento abismal que

opera por la definición unilateral de líneas radicales que dividen las experiencias, los actores y los saberes sociales entre los que son visibles, inteligibles o útiles (los que quedan de este lado de la línea) y los que son invisibles, ininteligibles, olvidados o peligrosos (los que quedan del otro lado de la línea). (p.8)

El feminismo dialógico, sin duda, contribuye a superar el pensamiento abismal dentro de los feminismos, confiriéndoles más fuerza y capacidad transformadora.

El feminismo dialógico se basa en los siete principios del aprendizaje dialógico. El primero, es el diálogo igualitario que, según Elboj y Flecha (2002), basadas en Flecha (1997), prioriza la validez de los argumentos, en lugar de las posiciones de poder de quienes los emiten. Además, el diálogo que promueve el feminismo dialógico "conlleva una ética basada en la escucha" (Camisón, s/f:4). El segundo principio es la inteligencia cultural, noción elaborada por el CREA ${ }^{\mathrm{iii}}$ y que hace referencia a la inteligencia que todas las personas poseemos, formada por "las inteligencias académica y práctica y todas las capacidades de lenguaje y acción de los seres humanos que hacen posible llegar a acuerdos en los diferentes ámbitos sociales" (Elboj y Flecha, 2002:165). La inteligencia cultural permite superar las 
teorías basadas en los déficits que son utilizadas para justificar la exclusión en la construcción de conocimiento de personas no académicas y otras personas que no encarnan el patrón hegemónico. El tercer principio es la transformación a la que está orientada el feminismo dialógico: con Elboj y Flecha (2002), constatamos que el diálogo horizontal entre mujeres diversas da lugar a un feminismo más radical, y por lo tanto más transformador, que el feminismo monopolizado por mujeres universitarias. El cuarto principio es la dimensión instrumental, que explica que el aprendizaje dialógico no está enfrentado con el aprendizaje instrumental de conocimientos y habilidades; al contrario, lo abarca y permite experiencias integrales de aprendizaje en todos los ámbitos de la vida, público y privado. Desde el feminismo dialógico, es fundamental promover un diálogo horizontal entre las mujeres diversas para generar aprendizajes conjuntos que traspasen las fronteras del ámbito público y privado de las vidas de las mujeres. El quinto principio es la creación de sentido: "a través del diálogo igualitario, las mujeres se enriquecen de las contribuciones de sus compañeras y buscan su propio sentido" (Elboj y Flecha, 2002:167). El sexto principio es la solidaridad, que es una de las claves para la transformación de las desigualdades. Sin duda, un nuevo feminismo solo será posible desde la solidaridad entre mujeres, incluyendo todas las voces y todas las estrategias surgidas desde las diversas posiciones sociales en las que se encuentran las mujeres. El séptimo y último principio, y quizá el que marca de manera decisiva el carácter integrador y superador de las desigualdades del feminismo dialógico, es el principio de igualdad de diferencias. Este principio parte de que una igualdad verdadera contempla el derecho de toda persona a ser diferente, y mantener sus diferencias, y busca "sentar las bases para crear una condiciones más libres e igualitarias para el diálogo y el consenso entre todas [las mujeres]" (Elboj y Flecha, 2002:168). En palabras de Lidia Puigvert (2006a), la igualdad de diferencias 
se trata del igual derecho que tiene toda mujer a vivir de forma diferente: igualdad por cuanto las "otras mujeres" luchan por sus derechos como iguales ante los hombres pero también ante el resto de mujeres, aunque no se persigue una igualdad homogeneizadora. Lo que se persigue es una igualdad que respete las diferencias entre todas las mujeres independientemente de su clase social, cultura, clase social o edad, sin que ello suponga la discriminación de ninguna persona. También se habla de inclusión de esa pluralidad de voces femeninas en el movimiento feminista para liberarlo del elitismo por el que ha estado guiado. (p.134)

El feminismo dialógico representa un gran reto para todas las mujeres, académicas y no académicas, de contextos enriquecidos y empobrecidos, de culturas, etnias y orientaciones sexuales diversas: desaprender la superioridad o inferioridad internalizadas y desarrollar una capacidad de verdadera escucha, sobre la base de una inquebrantable voluntad de entendimiento mutuo y construcción conjunta. Hernández (2018:95), apoyada en Santos (2008), propone la ecología de saberes feministas desde la perspectiva de valorar los "aportes de las intelectuales indígenas que desde la academia o el activismo político están desarrollando sus propias teorizaciones en torno a los derechos colectivos de sus pueblos y a los derechos de las mujeres". La ecología de saberes feministas, como apertura y no rechazo mutuo per se a los aportes de mujeres diferentes, es un planteamiento que se enlaza con el principio de diálogo igualitario propuesto por el feminismo dialógico.

Para Puigvert (2006b), el feminismo en la actualidad ya comienza a comprender la validez de las experiencias de transformación que llevan a cabo todas las mujeres y la necesidad de incorporarlas al discurso. Aunque queda mucho camino por recorrer, el feminismo ya se va sumando al giro dialógico de la sociedad y de las ciencias sociales. Como afirma Puigvert (2006b): 
las teorías feministas, aunque todavía muy influidas por corrientes posmodernas que han colonizado el debate intelectual durante la última década del siglo XX, empiezan también a plantearse este debate vinculado a la solidaridad y a entender que sus postulados deberán ser complementados y enriquecidos por los de aquellas otras mujeres que -siendo de niveles académicos, etnias, religiones... muy diferentes- son necesarias para asegurar el éxito de sus objetivos y, por tanto, la superación ante situaciones de injusticia y abuso de poder. (p.92)

\subsection{Feminismo y desarrollo}

\subsubsection{Breve revisión de modelos de desarrollo en América Latina.}

Los modelos de desarrollo son formas de organización social, política y económica planificados sobre la base de una ideología y preceptos culturales determinados, ejecutados a través de políticas y orientados hacia un fin.

El significado práctico del concepto de desarrollo es ampliamente debatido. Concentra la paradoja de ser un concepto subjetivo y variable para las diversas personas y pueblos y, a la vez, una aspiración universal de todo grupo humano. Carlos Iturralde (2019), siguiendo a Martínez Echevarría y Crespo (2011), vincula la noción de desarrollo con las reflexiones del ser humano sobre cómo mejorar la vida y alcanzar la felicidad. En términos muy generales, los modelos de desarrollo se pueden clasificar según el objeto que cada uno coloca como central: economicistas, antropocentristas y holísticos o alternativos.

El devenir histórico, político y socioeconómico de los pueblos tiene como resultado diversas perspectivas o modelos de desarrollo. Igual que ocurrió con las ideas feministas, los enfoques de desarrollo planteados desde los países del norte colonizador y enriquecido, 
centrados en la dialéctica entre desarrollo y subdesarrollo, han sido exportados e impuestos al sur empobrecido, con consecuencias nefastas en términos de despojo.

En América Latina, los paradigmas de desarrollo implementados desde la Colonia a la actualidad son de corte economicista, con la excepción de las relevantes experiencias de Bolivia y Ecuador vinculadas al Buen Vivir. A partir de la Segunda Guerra Mundial, la teoría de la modernización fue utilizada para analizar y planificar el desarrollo en la región, con decisiva influencia de los intereses de las potencias de la época. Iturralde (2019) explica que esta teoría sostiene que

para alcanzar el desarrollo hay que superar varias etapas de un camino que ya fue recorrido por las grandes potencias cuyos pasos debían ser imitados por los países subdesarrollados, requiriendo que los valores occidentales reemplacen a los tradicionales, pues erróneamente los asumieron incompatibles. (p.9)

Desde la teoría de la modernización, los estados de América Latina debían modernizarse con infraestructura e importaciones, haciendo crecer a la industria y la tecnología para alcanzar al fin al nivel más alto de desarrollo, que sería el consumo de masas. El planteamiento de la modernización lleva implícito la aculturación de los pueblos indígenas, cuyas culturas milenarias y valores opuestos a la centralidad de lo económico serían un lastre para el desarrollo e incluso, la causa del subdesarrollo. Así mismo, se trata de un planteamiento desarrollista que no tiene en cuenta la naturaleza finita de los recursos naturales sobre cuya explotación se asienta el propio modelo.

Los aportes críticos del estructuralismo desde el pensamiento de la CEPAL en la década de los cuarenta desmintieron la concepción del desarrollo como lineal y por etapas, denunciando el reparto inequitativo de las ganancias del comercio en un sistema de centroperiferia: para América Latina, como región periférica respecto a Estados Unidos principalmente, la exportación de materia prima e importación de bienes de alto valor 
agregado solo suponía empobrecimiento. A pesar de ello, en términos generales las políticas de desarrollo de la región desde entonces hasta hoy han continuado siendo de corte economicista y después neoliberal. La dependencia de los países latinoamericanos respecto a los centros de poder mundiales no ha hecho sino aumentar.

En la década de los noventa, las Naciones Unidas adoptaron el concepto de desarrollo humano surgido de la mano del economista indio Amartya Sen y comenzaron a realizar mediciones del índice de desarrollo humano de los diferentes países. El desarrollo humano va más allá de la concepción economicista, incorporando la dimensión social. Se trata de un enfoque antropocéntrico que coloca el desarrollo económico en función del bienestar de las personas y no al contrario. Carmen de la Cruz (2007:22), basada en el pensamiento de Amartya Sen, explica que el desarrollo humano consiste en la ampliación de los “funcionamientos y las capacidades de la gente para vivir en libertad y dignidad". Según la misma autora, se entienden estos funcionamientos como los logros que alcanza la persona en su vida, mientras que las capacidades tienen que ver con la libertad para elegir entre diferentes opciones que nos confieren los logros alcanzados y el contexto social y cultural. Martha Nussbaum, por su parte, amplía que es necesario determinar en qué consiste un buen funcionamiento humano y para ello establece una serie de capacidades humanas, adaptables a cualquier cultura, que deben poder ejercerse para hablar de desarrollo humano. Es importante destacar que la autora da relevancia a capacidades éticas y morales. De la Cruz (2007) retoma las capacidades humanas descritas por Nussbaum (2007):

1. Vida. Poder vivir hasta el final una vida humana completa, tanto como sea posible.

2. Salud corporal. Poder tener buena salud; estar suficientemente alimentado; tener alojamiento suficiente; tener oportunidades de satisfacción sexual; poder desplazarse de un lugar a otro. 
3. Integridad corporal. Poder evitar el dolor innecesario y perjudicial, así como tener experiencias placenteras.

4. Sentidos, imaginación y pensamientos. Poder usar los cinco sentidos, imaginar, pensar y razonar.

5. Emociones. Poder relacionarse con personas y cosas fuera de nosotros mismos; amar a quienes nos aman y se preocupan por nosotros; sentir pena por su ausencia; en general, amar, padecer, sentir anhelos y gratitud.

6. Razón práctica. Poder formarse una concepción del bien y comprometerse en una reflexión crítica acerca de la planificación de la propia vida.

7. Afiliación. Poder vivir con y para otros, reconocer y mostrar preocupación por otros seres humanos, comprometerse en varias formas de interacción social familiar y social.

8. Otras especies. Poder vivir preocupado por animales, plantas y el mundo de la naturaleza, y en relación con ellos.

9. Juego. Poder reír, jugar, disfrutar de actividades recreativas.

10. Control del propio entorno: a) Político: participar eficazmente en las decisiones políticas con protección de la libertad de expresión y de asociación; b) Material: poseer propiedades no sólo de manera formal, sino con oportunidad real. (p.28).

El planteamiento del desarrollo como ampliación de capacidades permite superar la limitación de los enfoques anteriores que giraban en torno a la satisfacción de necesidades básicas. La satisfacción de necesidades básicas contribuía a visiones “de mínimos” respecto al desarrollo, en lugar de abrir el horizonte hacia la ampliación máxima de las posibilidades de las personas en el marco integral que ofrecen los Derechos Humanos de primera, segunda, tercera y cuarta generación. 
Posteriormente, el concepto de desarrollo humano fue ampliado con la incorporación de la dimensión medioambiental: era imperativo establecer parámetros que consideraran la finitud de los recursos naturales ante la devastación medioambiental y las alarmas sobre el cambio climático. Surge así el concepto de desarrollo humano sostenible. Para Iturralde (2019), con el desarrollo humano sostenible

a las dimensiones «económica» $\mathrm{y}$ «social» se sumó la «dimensión ambiental», al añadir de manera explícita la relevancia del medio ambiente para el desarrollo, incorporando el derecho de las futuras generaciones a satisfacer sus necesidades, asegurando la conservación y extensión de la vida humana, y consolidando la perspectiva multidimensional que requiere del apoyo de ciencias sociales y naturales, superando definitivamente la visión economicista. (p.20)

El desarrollo humano sostenible fue adoptado por las Naciones Unidas como paradigma a promover en sus políticas internas y en sus programas de cooperación con países empobrecidos. Sin embargo, en América Latina, y concretamente en Guatemala, esto no ha dado lugar a un cambio en las políticas de Estado, que continúan plegadas a los intereses estadounidenses, aplicando un neoliberalismo feroz basado en la reducción de lo público y la privatización, en el extractivismo, en la exportación de materia prima y productos no procesados y en la exportación textil desde el modelo de maquilas.

Ante el colapso de las promesas neoliberalistas de generar desarrollo humano, a finales del siglo XX surge el Sumak Kawsay o Buen Vivir desde los pueblos indígenas de América Latina. Se trata de un paradigma de desarrollo alternativo u holístico basado en la cosmovisión de los pueblos indígenas. La antropóloga maya-kaqchikel Aura Cumes, en un documento colectivo de organizaciones feministas y mayas de Guatemala agrupadas en la Confluencia Nuevo B'aqtun, expresa que "el Buen Vivir, es un proyecto político de vida; es 
el proceso de satisfacción y bienestar colectivo para potenciar la vida en equilibrio de la madre naturaleza y el cosmos para lograr la armonía”(Confluencia Nuevo B’aqtun, 2014:7).

El Buen Vivir forma parte de la corriente decolonial del pensamiento y su importancia fundamental es que proviene de los pueblos indígenas. Sofía Zaragocín (2017) explica que el Buen Vivir, al ser parte de una colectividad con una plataforma amplia y plural, es parte de las epistemologías del Sur. Es fundamental señalar que son autores indígenas y cosmovisiones indígenas las que en parte han tejido el Buen Vivir, lo cual no ha ocurrido con otras epistemologías del Sur. (p.22)

Hasta el momento, el Buen Vivir como modelo que haya producido cambios a nivel del Estado solo se ha materializado en Bolivia y Ecuador, que incorporaron este paradigma de desarrollo en sus Constituciones en la primera década del siglo XXI. Desde entonces, ambos países han puesto en marcha planes de desarrollo y políticas con mayor o menor apego al paradigma que las inspira.

\subsection{2. ¿Dónde están las mujeres en los modelos de desarrollo?}

Desde que tomó auge el discurso del desarrollo en los años 50, se han sucedido diversos debates que han dado lugar a perspectivas diferentes sobre las mujeres y el desarrollo. En grandes líneas, los dos principales enfoques han sido el enfoque de Mujeres en el Desarrollo -MED- y el del Género en el Desarrollo -GED.

El enfoque MED, en palabras de Alba Carosio (2009), estaba basado en políticas "antipobreza", que adolecía de una falta de crítica a la división sexual del trabajo y de los roles entre hombres y mujeres, y, posteriormente, el enfoque de eficiencia, que reconocía el potencial carácter de microempresarias de las mujeres o su papel como mano de obra industrial o agrícola, pero que sin embargo se olvidaba por completo de las necesidades de cambio social. Solamente se pretendía 
integrar a las mujeres de una manera funcional a la producción, sin cuestionar ni el modelo de desarrollo ni la división sexual y social del trabajo. (p.244)

El enfoque GED, surgido en la década de los 80, tiene como objetivo transversalizar la igualdad de género en las estrategias de desarrollo. Su finalidad es el desarrollo humano sostenible y equitativo y, por lo tanto, no solo considera la intervención con las mujeres, sino con los hombres y las mujeres como parte del todo de las relaciones de poder. De la mano de este enfoque surgió el concepto de empoderamiento, que se convirtió en un enfoque útil para planificar acciones y políticas. Carosio (2009) define el enfoque GED como equivalente al enfoque de empoderamiento:

el enfoque del empoderamiento (empowerment) surge a finales de los ochenta como respuesta a las insuficiencias de los anteriores y puede resumirse en aumentar el reparto y el acceso de las mujeres al poder, con especial énfasis en la mejora de su posición social y aumento de la autoestima como persona. Mediante el mismo se pretende fomentar una mayor autonomía física (sexual/fertilidad), económica (acceso y control de los medios de producción), política (autodeterminación y participación en el poder) y sociocultural (identidad propia y autorespeto) de las mujeres. (p.245)

El enfoque GED permite la distinción entre la condición y la posición de las mujeres en la estructura social y entre sus necesidades prácticas, ligadas a la mejora de su condición, y sus necesidades estratégicas, vinculadas a mejorar la posición de las mujeres, con mayor acceso y control de los recursos y más ejercicio de poder.

Siguiendo a Adela García (2009), podemos resumir que el enfoque GED sitúa el problema en las relaciones desiguales de poder entre hombres y mujeres que frenan un desarrollo igualitario y la plena participación de las mujeres. Su objetivo es el desarrollo igualitario y sostenible y sus estrategias consisten en identificar y señalar las necesidades prácticas y 
estratégicas de mujeres y hombres para mejorar sus condiciones de vida y la posición de las mujeres.

En América Latina, las intervenciones dirigidas a incorporar el enfoque GED no han logrado transformar los modelos de desarrollo, que están insertos en el sistema patriarcal. Desde una mirada crítica, podemos advertir rápidamente que ninguno de los modelos de desarrollo analizados incorpora una visión feminista. El desarrollo humano sostenible plantea la equidad como uno de sus pilares. Sin embargo, esa aspiración de equidad es contradictoria con el propio capitalismo neoliberal sobre el que aspira a aplicarse el desarrollo humano sostenible y nunca explicita cuál es la posición de las mujeres. El Buen Vivir, por su parte, postula la dualidad y complementariedad entre los géneros -utilizando los conceptos del pueblo maya-, pero las críticas desde el feminismo comunitario develan que estos conceptos en sí mismos no implican una trasformación del patriarcado.

\subsubsection{Construcción dialógica del desarrollo.}

Los modelos de desarrollo holístico o alternativo buscan transformar los sistemas económicos, políticos y sociales, históricamente marcados por el economicismo, el ecocidio y el despojo hacia los países del sur, creando paradigmas en los que prevalezcan la justicia social y la sostenibilidad ambiental. El objetivo del feminismo como teoría política, por su parte, es desmontar la injusticia del sistema de supremacía masculina, blanca, heterosexual que constituye el patriarcado y construir un nuevo orden social basado en la igualdad. Así, feminismo y modelos de desarrollo alternativo no pueden desvincularse. El punto de encuentro de ambos es su carácter revolucionario del sistema y su orientación hacia la justicia social.

El feminismo ha realizado aportes fundamentales a la construcción de modelos de desarrollo holístico y alternativo, aunque este aporte sea escasamente reconocido. Por 
ejemplo, la relación entre los planteamientos feministas y los del Buen vivir es muy clara, aunque esto no implique que el Buen Vivir en sí mismo sea un modelo de desarrollo feminista.

El Buen Vivir recoge el legado de la economía feminista que, según Silvia Vega (2017:47) "es pues reorganizar el funcionamiento de la sociedad y de la economía en torno a la sostenibilidad de la vida, dando prioridad al trabajo de reproducción y cuidado y subordinando a éste las demás actividades humanas". Esto, según la misma autora, responde a la economía feminista de la ruptura, que se distingue de la economía feminista de la conciliación por buscar un cambio radical en la organización del sistema de reproducciónproducción poniendo lo reproductivo como centro, en vez de diseñar formas de conciliar el trabajo productivo con el reproductivo manteniendo la hegemonía de lo productivo como norte del desarrollo.

Sin embargo, existe una diferencia fundamental en el planteamiento de la continuidad de la vida en el Buen vivir y en el feminismo. Según Vega (2017),

en la propuesta del Sumak Kawsay, el énfasis se coloca en la relación armónica de la comunidad con la naturaleza, en el respeto y conexión con sus ciclos, pues de ella depende la continuidad de la vida económica y comunitaria. En la propuesta feminista, el énfasis radica en el trabajo de cuidado que se realiza para atender las necesidades humanas y que ha sido asignado culturalmente, principalmente a las mujeres. (p.44)

Colocar el énfasis en el cuidado y no en la armonía permite visibilizar los conocimientos ancestrales de las mujeres, transmitidos de forma matrilineal, además de denunciar la posición de subordinación que viven las mujeres como producto de la infravaloración del trabajo de cuidados, incrustada en el imaginario colectivo heredado del capitalismo. 
La realidad actual está caracterizada por la interconexión global y esto impone la necesidad de construir modelos dialógicos de desarrollo enmarcados en el paradigma holístico. Sin duda, dar respuestas a los retos del mundo actual exige un diálogo horizontal entre saberes y entre pueblos, entre mujeres, entre hombres, entre mujeres y hombres, desde la academia y, principalmente, desde fuera de ella. Se trata de un diálogo profundo desde la ecología de saberes que propone de Sousa (2010). En América Latina, un modelo de desarrollo que aúne los aportes del feminismo y del Buen Vivir tendría un enorme potencial transformador. Vega (2017), expresa este desafío en términos de esfuerzo teórico-político: el desafío conjunto es pues encontrar significados comunes entre economía feminista, ecologismo, Sumak Kawsay u otras utopías que hoy, pese a las apariencias, no están dados. Estas convergencias no surgirán espontáneamente ni serán dadas de antemano, sino implicarán un esfuerzo teórico-político deliberado. (p.51)

El feminismo dialógico nos permite concretar que el diálogo es la estrategia para este esfuerzo teórico político que menciona Vega (2017). El feminismo comunitario y el Buen Vivir, como epistemologías del sur, desde el marco del feminismo dialógico, podrían revolucionar el pensamiento actual sobre el desarrollo, transformar el sistema de producción - reproducción, superar el ordenamiento basado en el Estado-nación y descentrar las relaciones internacionales.

Un interesante acercamiento al diálogo entre el feminismo y el Buen Vivir lo encontramos en el documento producido por la Confluencia Nuevo B'aqtun en Guatemala (2014). Organizaciones feministas y organizaciones indígenas definen el concepto de Buen Vivir incorporando la diversidad de sexual y de género, la igualdad en la diferencia y la atención a todas las voces.

El Buen Vivir es un proyecto político de vida; es el proceso de satisfacción y bienestar colectivo para potenciar la vida en equilibrio de la madre naturaleza y el cosmos para 
lograr la armonía. El Buen Vivir es integral, promueve la cosmoconvivencia y la complementariedad, la libertad y derechos de la naturaleza, la libre determinación de las personas y los Pueblos, de las identidades, cuerpos, sexualidades y territorios; es colectivo y promueve el cuidado de la vida y el placer, loq'b'al k'u'xaj (k'iche')natwaajo' (tz'utujil) -ajo'wabel (kaqchikel)- amores, la alegría y las distintas maneras de expresarlo, así como el cosmocimiento sentipensante.

Es un proyecto político que promueve la recuperación de todos los principios y su práctica conlleva al ejercicio de la descolonización y despatriarcalización así como la emancipación de las distintas opresiones. Recupera, reconstruye, reconstituye, recrea y asume los conocimientos y prácticas de Utzilaj K'aslemal / Raxnaqil / K'aslemal, ral ch'och.

El Buen Vivir reconoce la vida como todo lo que existe en el cosmos, y todo lo que tiene vida es fundamental y parte activa en la construcción del buen vivir. Para su impulso construimos pactos, acuerdos y alianzas sin jerarquización. Se reconoce en todas las personas la calidad de pactantes desde la niñez hasta la vejez. (p.19)

\subsection{Una aproximación al patriarcado en Guatemala}

En la complejidad de las sociedades latinoamericanas, caracterizadas por la multiculturalidad y la desigualdad, un análisis social comprometido que pretenda determinar las diferentes posiciones de los sujetos en el sistema para generar alternativas de transformación, no puede realizarse al margen de la interseccionalidad -nótese de nuevo cómo el feminismo ha hecho avanzar a las ciencias sociales-. Así, en los siguientes párrafos analizaremos tres dimensiones principales que permiten aproximarse a la realidad guatemalteca actual: la estratificación social, el racismo y el patriarcado. 


\subsubsection{Estratificación social.}

Celia Duek y Graciela Inda (2006) retoman la definición weberiana de estratificación social explicado que ésta hace referencia a la distribución del poder dentro de una comunidad, considerando una concepción tridimensional del poder: económico, social y político. De esta forma, el concepto de estratificación social es más abarcador que el concepto marxista de clase social, que clasifica a los grupos de personas desde criterios económicos, según su relación con la propiedad y los medios de producción. Camilo Sémbler (2006), explica que

desde la óptica marxiana, como es sabido, la delimitación y diferenciación de grupos (clases) sociales se vincula directamente con la forma en que se organiza el proceso de trabajo en un determinado momento histórico (división social del trabajo), o en términos más amplios, con la articulación de un modo de producción y su consiguiente estructuración de determinadas relaciones sociales. (p.12)

Según el último informe de desarrollo humano de Guatemala publicado por el PNUD (2016), para 2015 el país presentaba un coeficiente Gini de 0.531. Diversos estudios posteriores presumen que la desigualdad ha aumentado para 2019. Para la interpretación del coeficiente Gini, 0 es la expresión de máxima igualdad mientras 1 es la expresión de máxima desigualdad. El índice Gini en Guatemala se refiere a la desigualdad en el ingreso familiar per capita y muestra una desigualdad alta. Esto nos aproxima a la existencia de fuertes brechas de desigualdad entre clases sociales, pero no permite ver más allá.

Un análisis de la estructura social de Guatemala basado en la categoría marxista de clases sociales resulta muy limitado para interpretar su complejidad social, ya que las dimensiones que configuran las diferentes posiciones en la estructura social del país no son únicamente económicas. Edelberto Torres-Rivas (2008:3) explica que en la sociedad guatemalteca "la mayor fuente de diferencias se aprecia cuando se le examina como una sociedad estratificada 
no solo por el ingreso material sino por la magnitud de las enormes desigualdades que se han producido en su interior". Así, el concepto weberiano de estratificación social resulta más útil para el análisis social en Guatemala, al añadir a la dimensión económica las dimensiones social y política como configuradoras del poder individual y colectivo. Estas dimensiones deben ser operativizadas definiendo los elementos que forman parte de cada una de ellas. Por ejemplo, ¿qué factores tienen peso en el acceso de un sujeto al poder social en Guatemala? ¿Y al poder político?

En la estratificación social de Guatemala tiene fuerte peso la ruralidad/urbanidad como categoría que trasciende las características del medio en el que se desarrolla cada comunidad, para dar forma a todo un universo estereotipado de caracterización de las personas y las realidades. Este universo se basa en, y a la vez alimenta, la exclusión de lo rural de las débiles políticas de desarrollo del país. Además, el género, la etnia, la clase social, la identidad sexual y otros componentes definen el lugar de cada persona y colectivo en la estructura social del país. Como explica Edelberto Torres-Rivas (2008), en Guatemala hay notables contrastes entre el mundo rural y urbano, especialmente si la comparamos con aquel se hace a partir de la zona metropolitana de la ciudad capital. También hay fuertes discrepancias de género, visibles en la condición subalterna de las mujeres, aún atrapadas en la cultura machista, patriarcal y violenta. La hendidura étnico -cultural es más visible y decisiva en el funcionamiento del conjunto social porque las relaciones ínter étnicas se alimentan del veneno del racismo y la discriminación, de desconfianzas y rencores históricos. (p.2)

Torres-Rivas (2008) ilustra la estratificación social de Guatemala a través del símil de un edificio de cinco niveles:

una manera metafórica de aproximarse a la realidad de una sociedad muy heterogénea se hace "mirando" cómo vive en el interior de ese edificio de cinco pisos la población 
nacional. Ella está dividida en cinco estratos sociales, de tamaños y calidades significativamente distintos. (p.3)

En el símil de Torres-Rivas (2008), el edificio de la estructura social de Guatemala tiene forma piramidal y permite realizar tres constataciones fundamentales: a) las importantes distancias sociales, económicas y culturales de Guatemala, especialmente para la población indígena; b) el hecho de que la gran mayoría de la población de Guatemala es pobre y c) la enorme distancia entre las masas de población pobre y la élite del país.

Siguiendo a Torres-Rivas (2008), en la base del edificio está el sótano 2, constituido por el estrato bajo extremo de la sociedad, formado por campesinado sin tierra y población marginal urbana, que puede alcanzar al $20 \%$ de la población. Este estrato tiene rostro infantil por el alto índice de natalidad.

En el sótano 1 se encuentra el estrato bajo de la sociedad, que aglomera casi a la mitad de la población guatemalteca. "Este es un universo mestizo, de un fuerte sincretismo cultural, que podría representar en su conjunto una referencia fundamental de cómo es la sociedad guatemalteca" (Torres-Rivas, 2008:4). El estrato bajo se caracteriza por una difícil supervivencia. De ambos estratos, bajo extremo y bajo, surgen masas de juventud marginalizada, desempleada y sin oportunidades que se convierten en presa fácil de la delincuencia y el crimen organizado.

El primer piso está formando por el estrato medio bajo, con alrededor del $20 \%$ de la población. En este estrato hay poca población indígena, la mayoría es mestiza. Como en los otros estratos, hay un comportamiento negativo hacia los más pobres y los clasificados como indígenas. Los años de escolaridad son sensiblemente más amplios que los de los estratos anteriores, pero su nivel de vida y acceso a oportunidades el limitado y permanentemente inseguro, a merced de las crisis económicas. 
En el segundo piso se ubica el estrato medio "cuyos rasgos típicos coinciden con la heterogeneidad abigarrada de las clases medias del subdesarrollo" (Torres-Rivas, 2008:5). Su volumen no alcanza el $10 \%$ de la población nacional. La población indígena y rural es totalmente minoritaria en este estrato. En este estrato, muchas personas poseen educación superior -a la que solo accede un $2.24 \%$ de la población guatemalteca, según encuesta realizada por el periódico más vendido en el país ${ }^{\mathrm{iv}}$-. A él pertenecen intelectuales, artistas y los sectores progresistas y de izquierda. De este estrato salen en buena medida quienes dirigen el Estado, el ejército, las iglesias, las universidades y otras instituciones públicas y privadas. Torres-Rivas (2008:5) continúa explicando que a pesar de que "en algunos países se dice que las clases medias son el pilar de la democracia y de los programas sociales, en Guatemala no existe información que permita afirmarlo".

En el tercer nivel, por último, vive el estrato alto que representa menos del $2 \%$ de la población. Es un estrato eminentemente urbano y prácticamente sin población indígena. “Es una élite criolla y/o blanca europea y solo excepcionalmente es mestiza; practican la endogamia y el racismo y formas abiertas de discriminación en sus relaciones sociales" (Torres-Rivas, 2008:7). Vive principalmente de ganancias de capital invertido y otros productos financieros. La población de este estrato frecuentemente tiene una estrecha relación con Estados Unidos, con viajes, inversiones y acceso a servicios privados de salud en ese país que suplen las carencias que presenta Guatemala para satisfacer las demandas de consumo y servicios de esta élite.

La pirámide estratificada de la estructura social de Guatemala tiene la característica de no contar con mecanismos de movilidad social (Torres-Rivas, 2008; Díaz, 2011). "En este edificio no hay ascensores sino varias escaleras. La movilidad social, cuando ocurre, no es estructural sino estrictamente individual" (Torres-Rivas, 2008:6). Esto está estrechamente vinculado al carácter neoliberal de las políticas del Estado de Guatemala, reducido a su 
mínima expresión hasta el punto de ser incapaz de cumplir con sus mandatos constitucionales. Partiendo de la premisa de que la movilidad educativa puede ser un mecanismo importante para el ascenso en la estructura social, podemos concluir que la bajísima inversión de presupuesto en educación pública que realiza Guatemala es una estrategia para mantener la inmovilidad de los estratos sociales y, con ella, el estatus quo. En 2017, según la web “datos macro” el país invirtió el 2.8\% del PIB en educación”, tan solo 1 punto porcentual más que en 1970, cuando la población total del país representaba un tercio de la actual. La inversión, la más baja de América Latina, se aleja mucho de la recomendación que la UNESCO realiza a Guatemala de invertir el 7\% del PIB en educación.

La estratificación social de Guatemala que presenta Torres-Rivas (2008) permite identificar que la estructura social del país se basa en la supremacía blanca, urbana y de clase media-alta. Analizando el ejercicio del poder desde la teoría weberiana de la estratificación social, encontramos que: a) el poder económico en Guatemala se concentra en los estratos medio y alto, de población eminentemente mestiza, criolla o de ascendencia extranjera, que es la que maneja los recursos económicos fruto de su ocupación laboral, de su patrimonio e inversiones y/o de la tenencia de los medios de producción; b) el análisis del poder social, sin embargo, se torna más complejo: en la pirámide como conjunto, el poder social está profundamente marcado por lo racial y por la urbanidad como constructos asociados a la identidad, siendo lo indígena y rural categorías socialmente despreciadas que menoscaban el poder de los sujetos que las encarnan; c) el poder político, a pesar de ser ejercido por sujetos que principalmente salen de la clase media, es movido en realidad por y para la clase alta. Las élites sociales y económicas del país dirigen el diseño y ejecución de políticas a través de la cooptación de las instituciones y poderes del Estado, siempre en su propio beneficio e incluso en detrimento del desarrollo de los demás estratos. 
El estudio de la estratificación social de Guatemala de Torres-Rivas (2008) no contiene un análisis de género. El de Guillermo Díaz (2011), por su parte, sí incluye el género como variable en el análisis de la movilidad educativa, evidenciando una brecha sensible entre mujeres y hombres: las mujeres gozan de menos movilidad educativa que los hombres en general y las mujeres indígenas, todavía menos.

Se evidencia la necesidad de profundizar el estudio de la estratificación social de Guatemala con enfoque de género, de manera que se pueda identificar cuál es la posición de las mujeres en cada uno de los estratos sociales. De forma preliminar, podemos afirmar que las mujeres ocupan las posiciones más bajas en cada estrato, con menos acceso a las pocas o muchas oportunidades de las que gozan los hombres de ese mismo estrato. Así mismo, el ejercicio del poder de las mujeres también es mucho más limitado que el de los hombres en todos los ámbitos de la vida en cada uno de los estratos. Como explicaremos más adelante, el patriarcado constituye el sistema general por el que se rige la estratificación social de Guatemala. El sistema patriarcal es causa y consecuencia de la merma de las autonomías de las mujeres en todo estrato social, dando lugar a su subordinación y al mantenimiento de la supremacía masculina.

Por otra parte, los dos estudios mencionados no abordan la estratificación social dentro de las comunidades indígenas, siendo este un campo muy relevante de investigación que puede aportar a la construcción de nuevos paradigmas de organización social y desarrollo.

Las comunidades indígenas de Guatemala se ubican, en su conjunto, en los estratos bajo y medio bajo de la pirámide social. Esto nos lleva a retomar la afirmación de Torres-Rivas (2008) sobre la movilidad social en Guatemala: nunca es estructural, sino individual. Así, las comunidades indígenas como colectivo, ancladas en la intersección de clase y raza, aquejan la falta de medidas estructurales para la movilidad social por parte de un Estado racista y elitista. La movilidad social que se produce en las comunidades indígenas es de sujetos 
individuales, principalmente hombres. En cuando al ejercicio del poder social y político, muchas comunidades indígenas poseen un sistema interno de organización que funciona con valores muy diferentes a los occidentales y que giran en torno a la responsabilidad colectiva, el cuidado del medioambiente, la mediación de conflictos, entre otros. Para un acercamiento preliminar a este tema, es útil el enfoque funcionalista de la estratificación social que, siguiendo a Sémbler (2006), basado en Parsons (1967), consiste en el orden de superioridad o inferioridad que guardan los individuos sobre ciertos aspectos socialmente relevantes, regido por la evaluación moral. Así, una parte del poder social en las comunidades indígenas está determinado por la valoración del papel que desempeña cada persona dentro de ella comadrona, huesero, guía espiritual, etc.-. En cuanto al poder político, es ejercido por personas electas por la comunidad bajo sistemas de turnos, que desempeñan cargos variados ad honorem, denominados servicio comunitario. La valoración moral que se desprende del ejercicio de este tipo de poder político se traslada a una valoración social que trasciende la duración del cargo y convierte a las personas, mayoritariamente hombres, en consejeros de la comunidad, llamadas principales o ancianos. Es importante reparar en que el poder económico, social y político dentro de las comunidades indígenas de Guatemala está articulado bajo las reglas del sistema patriarcal, tal como evidencia el feminismo comunitario. Así, a pesar de que las mujeres puedan tener poder social siendo comadronas, hueseras o, en menos casos, guías espirituales, no tienen el mismo reconocimiento que los hombres y se encuentran excluidas del poder político y económico.

\subsubsection{Racismo.}

Guatemala está formada actualmente por cuatro pueblos: tres pueblos indígenas -maya, xinca y garífuna- y el pueblo ladino. Dentro del pueblo maya existen veintidós etnias diferentes, haciendo un total de veinticinco culturas y veinticinco idiomas en el territorio 
nacional. Santiago Bastos (2010) explica que la diversidad cultural de Guatemala históricamente había sido negada y no fue hasta 1996, con el acuerdo de Identidad y Derechos de los Pueblos Indígenas, parte de los Acuerdos de Paz, que se "reconoció la existencia en Guatemala de diversos colectivos histórica y culturalmente diferenciados que habían sido sistemáticamente negados por el Estado" (Bastos, 2010:28). Para entender la realidad multicultural de Guatemala y América Latina hay que analizar las categorías de diferencia y desigualdad (Bastos, 2010). La diferencia se refiere al hecho de la existencia de grupos histórica y culturalmente diferenciados, mientras que la desigualdad indica la estructura jerárquica racializada que caracteriza a estas sociedades.

Diversos estudios han demostrado que la diferencia social basada en el origen surgió en Guatemala y América Latina con el sistema colonial. Se estableció entonces un régimen de grupos estamentales basados en la sangre y la raza. Cuando desapareció el régimen colonial, el sistema nacional creó un sistema de ciudadanía a partir de diferencias culturales, excluyendo a la población indígena (Bastos, 2010).

En la actualidad, en Guatemala persiste la categoría de raza como elemento de estratificación social. "La actual jerarquía étnica se basa en la suma de un pasado colonial y un presente nacional. Esta combinación produce un doble efecto sobre la existencia de los indígenas, que se mantiene entre la asimilación y la segregación" (Bastos, 2010:33). Marta Elena Casaús (2010) demuestra que el Estado de Guatemala transitó desde un Estado racial a un Estado racista:

el tránsito de un Estado racial a un Estado racista basado en la jerarquización de las razas y en un modelo de Estado monoétnico y monocultural, se produce cuando los aparatos represivos e ideológicos del Estado, obedecen a una lógica de discriminación racial, de exclusión social y política e incluso de exterminio físico o cultural hacia otros grupos étnicos o pueblos con el fin de mantener un dominio de clase, etnia o 
género, pero fundamentado especialmente en la justificación de la superioridad racial de un grupo frente a los otros. (p.20)

Durante el conflicto armado interno, especialmente en los primeros años de la década de los ochenta, el Estado racista de Guatemala aplicó hacia los pueblos indígenas lo que Carlos Giménez (2003) conceptualiza como la forma más extrema de exclusión, que es la eliminación del otro: el genocidio. Actualmente, nos encontramos ante un Estado guatemalteco que practica una inclusión aparente, respaldado en una Constitución que afirma la igualdad de todas las personas. Sin embargo, sus prácticas son homogeneizadoras, colocando a los pueblos indígenas, como indicaba Bastos (2010), en la disyuntiva de la asimilación o la segregación. La clasificación de los modelos sociopolíticos ante la diversidad cultural que realiza Carlos Giménez (2003) resulta de gran ayuda para situar estos conceptos.

\begin{tabular}{|c|c|c|c|}
\hline \multirow{5}{*}{$\begin{array}{l}\text { EXCLUSIÓN } \\
\text { Racismo, Xenofobia, } \\
\text { Antisemitismo, Apartheid, } \\
\text { Holocausto, etc. }\end{array}$} & \multirow{2}{*}{$\begin{array}{l}\text { Discriminación del } \\
\text { Otro } \\
\text { (trato desigual) }\end{array}$} & Legal & Leyes discriminatorias \\
\hline & & Social & $\begin{array}{l}\text { Prácticas } \\
\text { discriminatorias }\end{array}$ \\
\hline & \multirow[t]{2}{*}{$\begin{array}{l}\text { Segregación del } \\
\text { Otro }\end{array}$} & Espacial & $\begin{array}{l}\text { Guetos residenciales } \\
\text { Delimitación de } \\
\text { espacios públicos }\end{array}$ \\
\hline & & Institucional & $\begin{array}{l}\text { Guetización escolar } \\
\text { Guetización sanitaria }\end{array}$ \\
\hline & $\begin{array}{l}\text { Eliminación del } \\
\text { Otro }\end{array}$ & Cultural & $\begin{array}{l}\text { Etnocidio } \\
\text { Fundamentalismo } \\
\text { cultural }\end{array}$ \\
\hline
\end{tabular}




\begin{tabular}{|c|c|c|c|c|}
\hline & & & Física & $\begin{array}{l}\text { Genocidio } \\
\text { Limpieza étnica }\end{array}$ \\
\hline \multirow[t]{4}{*}{ INCLUSIÓN } & \multirow[t]{2}{*}{ Aparente } & \multirow[t]{2}{*}{ Homogeneización } & Asimilación & $\begin{array}{l}\text { Anglicización } \\
\text { Arabización } \\
\text { Ladinización }\end{array}$ \\
\hline & & & Fusión cultural & Melting Pot \\
\hline & \multirow[t]{2}{*}{ Real } & \multirow{2}{*}{$\begin{array}{l}\text { Aceptación de la } \\
\text { diversidad cultural } \\
\text { como positiva }\end{array}$} & \multirow[t]{2}{*}{$\begin{array}{l}\text { Pluralismo } \\
\text { cultural }\end{array}$} & Multiculturalismo \\
\hline & & & & Interculturalismo \\
\hline
\end{tabular}

Figura 1. Hacia una tipología de modelos sociopolíticos ante la diversidad cultural. Giménez (2003:9)

Los modelos sociopolíticos ante la diversidad cultural que propone Giménez (2003) no permiten visibilizar la particular posición de las mujeres en las sociedades multiculturales, en la intersección entre cultura, género y otras categorías. Se ha escrito mucho sobre el genocidio y el conflicto armado interno de Guatemala, pero muy poco todavía sobre el feminicidio y la violencia de género institucionalizadas en ese período. Como explica Ana Isabel González (2014), durante el conflicto armado interno

las violaciones sexuales con carácter selectivo se cometieron principalmente en el medio urbano o semiurbano contra mujeres que participaban en organizaciones sociales, sindicales, periodistas, políticas, de derechos humanos; que integraran cualquiera de las organizaciones guerrilleras, o tan sólo porque eventualmente fueran 
consideradas disidentes, o ejercieran algún tipo de liderazgo o tuvieran familiares acusados o sospechados de insurgentes. (p.8)

La violencia sexual contra las mujeres ladinas e indígenas fue sistemáticamente utilizada como estrategia de guerra. Sin embargo, las mujeres indígenas sufrieron formas de violencia específica solo explicable desde la intersección del género y la raza. Siguiendo a González (2014),

en el caso de las mujeres mayas la violencia de género cobró características particulares relacionadas con la discriminación étnica y el medio rural, alejado de medios de comunicación. Las violaciones masivas y públicas, en el contexto de las masacres indiscriminadas de la tierra arrasada, la ejecución de los niños y la destrucción de los fetos extraídos de los vientres de las embarazadas, sucedieron casi con exclusividad cuando se trató de población maya y rural. (p.9)

En 2016, un teniente coronel y un ex comisionado militar fueron condenados por esclavitud sexual y doméstica de mujeres maya-q'eqchi' en el destacamento militar de Sepur Zarco durante el conflicto armado interno. Irma Alicia Velásquez Nimatuj (2019), en las conclusiones del peritaje cultural realizado para el caso, denuncia que

la violencia sexual, física y de servidumbre a la que fueron sometidas en el reciente conflicto armado no fue una práctica nueva por parte del Estado y sus instituciones, sino que formó parte de una violencia contra ellas constante en la historia de las mujeres indígenas. (p.102)

La violencia exacerbada contra las mujeres indígenas en el contexto de guerra muestra que racismo y patriarcado son parte de un mismo sistema que somete los cuerpos y las vidas de las mujeres indígenas. En Guatemala en la actualidad, es necesario profundizar la investigación sobre cómo operan, cómo se reproducen y cómo pueden ser eliminadas las 
violencias específicas a las que están sometidas las mujeres en general y las mujeres indígenas en particular.

En la reproducción del racismo, es fundamental poner de manifiesto el papel no solo del Estado, sino también de toda la sociedad, reproductora de una violencia cultural que legitima la violencia estructural y directa contra los pueblos indígenas. En este sentido, Casaús (2010) explica que

en términos funcionales, el Estado racista opera en la mente de los ciudadanos y se naturaliza en la vida cotidiana, de modo que se manifiesta en las actitudes y comportamientos del conjunto de la población por medio de burlas, chistes o de expresiones despectivas en el entorno social y en los medios de comunicación. (p.21)

Por lo anterior, una verdadera transformación del racismo en Guatemala que permita transitar del Estado racista y monocultural a un Estado plural pasa por que todos los actores sociales asuman su parte de responsabilidad. "Pareciera que se produce una exculpación de los actores sociales y una denuncia de que el Estado es el responsable del racismo y el único que debe velar porque este problema desaparezca" (Casaús, 2010:16).

Actualmente, el debate sobre el Estado racista y monocultural en Guatemala está abierto, con una amplia presencia de movimientos indígenas que cuestionan, reivindican y buscan un cambio hacia modelos de nación y Estado más plurales. Casaús (2010) explica que

el reclamo hacia el Estado va acompañado de movimientos étnicos que demandan el cumplimiento de los derechos humanos como elemento básico y aglutinador que les confiere una identidad, pero también un reconocimiento de sus identidades étnicas y de sus símbolos nacionales, en el marco de proyectos y agendas políticas que incluyan al conjunto de la población, pero que partan de un nuevo pacto fundacional de los estados nacionales. (p.23) 
Sin embargo, encontramos que las demandas de las mujeres no están insertas en las agendas políticas de los pueblos indígenas. Velásquez (2019) manifiesta que en las luchas actuales en Guatemala encontramos, por un lado,

las demandas de los movimientos de mujeres que luchas por la equidad de género en diferentes instancias y, por otro, las demandas de los pueblos indígenas que buscan alcanzar la igualdad étnica plena [...], pero que opacan o invisibilizan las demandas específicas de la diversidad de mujeres indígenas, mestizas o ladinas. (p.31)

Se evidencia la necesidad de que las feministas indígenas, autoidentificadas o no como tal, desde un posicionamiento dialógico hacia dentro y hacia fuera, disputen su espacio dentro de los movimientos indígenas para generar agendas interseccionales que apunten a una verdadera transformación del sistema. Por supuesto, la disputa de espacio en los movimientos indígenas no es una lucha unidireccional de las mujeres, sino que exige un ejercicio de apertura, diálogo y flexibilización de posiciones hacia la igualdad de género por parte de los movimientos indígenas, actualmente encabezados por hombres.

\subsubsection{Patriarcado y masculinidad hegemónica.}

El patriarcado es una forma de organización social y poder, extendida en la mayoría de las sociedades conocidas, que se basa en la supremacía de los hombres sobre las mujeres. Feministas y otros científicos sociales han hecho del patriarcado una teoría de análisis multidisciplinario que arroja luz sobre la subordinación/privilegio que caracteriza a las relaciones entre los géneros, siendo las mujeres las históricamente subordinadas (Lagarde, 2014).

Como hemos ido identificando en páginas anteriores, las categorías de género, clase y raza, entre otras, se entrelazan indisolublemente en la configuración de la posición de cada persona en las sociedades, especialmente en sociedades tan heterogéneas como las 
latinoamericanas. La forma de operar de esas categorías está definida por el sistema patriarcal y da lugar a exclusión y privilegios. Esta conceptualización del patriarcado nos permite colocarlo en su verdadera dimensión: como sistema de poder transversal en las relaciones de género, de clase, de raza, caracterizado por la dominación y la exclusión. Así, el patriarcado no puede disociarse de otras dominaciones como el racismo, el clasismo y la heteronormatividad, sino que estas dominaciones son parte del propio patriarcado. En este orden de ideas, Lagarde (2011:117), refiriéndose al contexto mexicano, explica que "el poder patriarcal se expande en cualquier relación opresiva, por eso se articula también con las opresiones de clase, nacional, étnica, religiosa, política, lingüística y racial, por solo mencionar las que constituyen la rama dominante de la opresión en México".

De la misma forma que el racismo o el clasismo, el patriarcado se reproduce y perpetúa no solo a través de las políticas del Estado sino también a través del imaginario estereotipado de la ciudadanía. La cultura machista es una de las características del patriarcado identificada por Lagarde (2011), junto con el antagonismo entre géneros y la escisión del género femenino. En la cultura machista somos socializados tanto los hombres como las mujeres, de manera que ambos tenemos el potencial de reproducirla o transformarla. Lagarde (2011) entiende el machismo como

el fenómeno cultural basado tanto en el poder masculino patriarcal como en la inferiorización y en la discriminación de las mujeres producto de su opresión, y en la exaltación de la virilidad opresora y de la feminidad opresiva, construidos en deberes e identidades compulsivos e ineludibles para hombres y mujeres. (p.117)

La virilidad opresora y la feminidad opresiva son rasgos comunes a todas las sociedades patriarcales. Tienen que ver con la construcción del género que realizan hombres y mujeres, es decir, con los procesos por los cuales cada sociedad asigna a los sujetos unas 
características, unos roles y unas normas que determinarán su experiencia vital en su cuerpo, pensamiento, relaciones sociales, acceso a recursos y en el ejercicio del poder.

Raewyn Connell (1995) explica que el género es una forma de ordenar las prácticas sociales que abarca, al menos, tres dimensiones: el poder, la producción y la cathexis. Siguiendo a la misma autora, la dimensión del poder sería el eje principal del sistema de género. Se trata un poder asimétrico, siendo los hombres quienes lo ostentan y las mujeres quienes quedan deslegitimadas. La dimensión de las relaciones de producción que propone Connell tiene que ver con la división sexual del trabajo: "una economía capitalista que trabaja mediante una división por género del trabajo, es, necesariamente, un proceso de acumulación de género" (Connell, 1995:9). Esto explicaría la acumulación de la riqueza en los hombres y el consiguiente empobrecimiento de las mujeres. La dimensión de la cathexis, por último, está vinculada a la construcción cultural del deseo sexual, que es parte de la construcción del género.

El estudio de la masculinidad y la feminidad es fundamental para comprender el patriarcado. Nicolás Schongut (2012), basado en Connell, (1995), Ramírez (2005) y Connell y Messerschimdt (2005), elabora la siguiente definición de masculinidad:

la masculinidad más que un producto es un proceso, un conjunto de prácticas que se inscribe en un sistema sexo/género culturalmente específico para la regulación de las relaciones de poder, de los roles sociales y de los cuerpos de los individuos. (p.41)

Las masculinidades son múltiples, tanto en los diversos contextos históricos como en un mismo contexto, teniendo en cuenta los efectos de la raza, la clase, la identidad sexual y otros. Por eso, Connell (1995) alerta de la necesidad de no solo reconocer que existe más de un tipo de masculinidad, sino también de examinar las relaciones de género que operan entre los hombres. De esta forma, nos acercamos al concepto de masculinidad hegemónica. Schongut (2012), basado en Connell (1987), explica que las diferentes masculinidades no se 
encuentran en la misma posición de poder, sino que existe en cada sociedad un modelo de masculinidad hegemónica que subordina a las demás masculinidades y también subordina a las mujeres. De esta forma, en la sociedad guatemalteca, por ejemplo, hombres indígenas, afrodescendientes, homosexuales, ancianos, pobres, de áreas rurales, no académicos, con discapacidad, etc. están subordinados bajo la masculinidad hegemónica ostentada por los hombres blancos, jóvenes, heterosexuales, urbanos, académicos, de alto poder adquisitivo. Esto no implica homogeneidad dentro del país. El modelo de masculinidad hegemónica es diverso en los contextos locales. Así, por ejemplo, lo heterosexual ostenta hegemonía sobre lo homosexual entre hombres indígenas, igualmente subordinados respecto a la masculinidad hegemónica.

El carácter histórico y cultural y, por lo tanto, cambiante, de las masculinidades hegemónicas queda demostrado por Connell (1995):

enfatizo que la masculinidad hegemónica encarna una estrategia corrientemente aceptada. Cuando cambien las condiciones de resistencia del patriarcado, estarán corroídas las bases para el dominio de una masculinidad particular. Grupos nuevos pueden cuestionar las viejas soluciones y construir una nueva hegemonía. La dominación de cualquier grupo de hombres puede ser desafiada por las mujeres. Entonces, la hegemonía es una relación históricamente móvil. (p.12)

La masculinidad hegemónica, y el sistema patriarcal del que forma parte, están indisolublemente unidos a la violencia. Connell (1995) ofrece una reveladora explicación para esto: partiendo del concepto de dividendo patriarcal, observamos que los hombres obtienen grandes beneficios en términos materiales, de honor, prestigio y poder gracias al patriarcado. Estos beneficios son obtenidos tanto por los hombres que encarnan el modelo hegemónico de masculinidad, que podríamos situarlos en la primera línea del patriarcado, como los hombres con masculinidades más inclusivas hacia las mujeres y hacia otros 
hombres. Así, queda patente que el patriarcado es un sistema de despojo y "una estructura de desigualdad a esta escala (el patriarcado), que involucra un despojo masivo de recursos sociales, es difícil imaginaria sin violencia" (Connell, 1995:17). La lucha contra el patriarcado se convierte en una cuestión de justicia social.

La violencia del patriarcado y de la masculinidad hegemónica, según Connell (1995), se produce principalmente a dos niveles: a) violencia de los hombres contra las mujeres, para sostener su dominación y b) violencia de los hombres contra otros hombres, para afirmar la masculinidad hegemónica y hacer exclusiones. Walda Barrios y Ana Lucía Ramazzini (2016), basadas en Michael Kaufmann (1989), añaden otro nivel de violencia en la masculinidad hegemónica:

Violencia contra sí mismo: tercer elemento de la tríada y el más profundo de ellos, ya que implica al ser en sí mismo. Manifestado en suicidios, alcoholismo, consumo de sustancias y adicciones, enfermedades psicosomáticas y descuido del cuerpo, por carencia de auto cuidado. (p.32)

La investigación de Barrios y Ramazzini (2016) sobre la masculinidad hegemónica en Guatemala demuestra que ésta se construye alrededor de la violencia, con tres presupuestos que tienen un impacto enorme en la vida de las mujeres y las niñas y contribuyen a la perpetuación de los embarazos, uniones y matrimonios en la adolescencia.

- Naturalización de la violencia y discriminación contra las mujeres, niñas y adolescentes.

- Consideración de los cuerpos y las vidas de las mujeres, niñas y adolescentes como propiedad y posesión. Los cuerpos como territorios para que otros se los apropien. 
- Control de la sexualidad de las mujeres, niñas y adolescentes para procurar y limitar los comportamientos que se salen de la norma y favorecen la autonomía. (p.32)

Teniendo en cuenta lo anterior, interesa identificar dos aspectos fundamentales: el primero, cuáles son los espacios en los que nos socializamos en el género y cómo lo hacemos, es decir, dónde y bajo qué reglas aprendemos lo que se espera de nosotros al ser mujeres u hombres de determinada etnia, clase social, identidad sexual, etc. El segundo aspecto de interés es cómo opera y se reproduce la violencia dentro del sistema patriarcal. Esto es una cuestión fundamental porque, como hemos visto con Connell (1995), es posible erosionar las bases de la masculinidad hegemónica y permitir el surgimiento de otros modelos. Un cambio en la masculinidad opresora y en la feminidad opresiva hacia modelos de masculinidad y feminidad dialógicos, democráticos, pacíficos, corresponsables y paritarios en el acceso a los recursos y el ejercicio del poder significaría la eliminación del patriarcado.

\subsubsection{Agentes socializadores de género.}

Los agentes socializadores son los espacios sociales de transmisión cultural en los que, desde el nacimiento y durante toda la vida, recibimos mensajes acerca de qué es lo "deseable" y "socialmente aceptado". Los agentes socializadores son la familia, la escuela, la comunidad, las iglesias, los medios de comunidad, la institucionalidad pública, entre otros. Sobre la complejidad del funcionamiento de los agentes socializadores, Marina Pibernat (2017) indica que

[los agentes socializadores] son variados y diversos, y han ido incrementándose y modificándose con el tiempo. Es necesaria una visión diacrónica para hacerse una idea del solapamiento e interacciones entre ellos durante el proceso de socialización de niños, niñas y adolescentes en nuestro tiempo. (p.531) 
Uno de los parámetros culturales transmitidos por los agentes socializadores es el género. Pibernat (2017:530) explica que "el sexo/género - así como la clase social o la etnia- de los individuos, determina desde el principio y en gran parte los contenidos específicos del proceso de socialización o transmisión cultural según la costumbre de la sociedad en cuestión". Esto implica que desde la familia, la escuela, los medios de comunicación, etc. se va configurando el género en cada persona, profundamente vinculado a otras categorías. El género, según Barrios y Ramazzini (2016), abarca tres niveles de la construcción social:

el relacionado con la formación de la identidad, en el que la sexualidad tiene un papel fundamental. La construcción del campo social que tiene que ver con la asignación de roles masculinos y femeninos y la asignación de valores, que nos conduce al tercer nivel, el género como sistema normativo. (p.19)

El proceso de socialización de género es permanente y dialéctico. A partir de la adolescencia, los mensajes recibidos desde los agentes socializadores serán aceptados o entrarán en conflicto con la propia racionalidad crítica del individuo, que tiene la oportunidad de transitar de una identidad de género asignada a una elegida. Probablemente, se producirán en los individuos escisiones de género, que son las incoherencias entre el discurso socialmente aceptado y la práctica (Lagarde, 2014). Para el caso de las mujeres, Lagarde (2014), afirma que todas pasamos por procesos complejos de sincretismo y escisión de género:

el sincretismo de género de todas las mujeres contemporáneas sintetiza contradicciones que provienen de la configuración premoderna y moderna de la condición de género de cada una. El grado de conflicto que suscita se concreta en la escisión de género: herida identitaria resultante del choque entre la ética de la entrega derivada del ser-para-otros y la ética de la mismidad concordante con el ser-para-sí y con la libertad. (p.306) 
Profundizaremos ahora sobre la familia, la escuela y los medios de comunicación como agentes socializadores de género en Guatemala. La familia, en cualquier contexto cultural e histórico y en sus diversas manifestaciones -nuclear, extensa, biparental, monoparental, etc.-, es para Pibernat (2017)

el agente de socialización primario más relevante en las primeras etapas de la vida. Es dentro de la misma donde es posible nuestra existencia física, y donde aprendemos nuestra lengua materna y preceptos culturales básicos. Es en esta etapa cuando empezamos a comprender lo que significa el rol de madre, el de padre o cómo se conforma la división sexual del trabajo. (p.531)

Sobre la socialización de género en la familia en Guatemala, encontramos que es marcadamente sexista. Orienta a las mujeres al espacio privado y a la vivencia del rol reproductivo, con actitudes y expectativas vinculadas a la sumisión y a ser mantenida por un hombre, en pareja heterosexual como norma. Por el contrario, dirige a los hombres al espacio público, al trabajo remunerado y la participación política, con actitudes relacionadas con el mando, el liderazgo y el rol proveedor. Actualmente, existe gran variedad de modelos de familia en Guatemala. Es de destacar el fenómeno de las migraciones, que repercute decisivamente en la ausencia de la figura paterna en muchas familias $\mathrm{y}$, en menor medida en la ausencia de la figura materna. En estos últimos casos, es común que niñas y niños queden al cuidado de abuelos o tíos. Sin embargo, independientemente de la configuración de la familia, la socialización de género tiende a producirse desde patrones sexistas y machistas.

Respecto a la escuela, nos referimos a ella como categoría que comprende el conjunto de contenidos, formas de relación, normas, valores, etc. que son parte tanto del currículo explícito del sistema educativo de un país, como del currículo oculto de cada una de las instituciones educativas. En la categoría escuela podemos incluir, incluso, la formación profesional y universitaria. 
La escuela es un potente agente socializador. Como afirman Emilia Moreno, Teresa Padilla, Isabel López y Mercedes Martín (2001:154), en ella “tiene lugar el trasvase de las normas, valores, roles, etc. de la vida privada a la vida pública”. FLACSO (2015), siguiendo a Granados (2003), explica que la escuela puede tener dos funciones: las manifiestas y las latentes. Las funciones manifiestas se reflejan en el currículo explícito y están relacionadas con los aprendizajes intencionados. Las funciones latentes se vinculan al currículo oculto, al que pertenecen las normas, creencias y valores que estructuran la vida en la escuela y que son transmitidos inconscientemente, influyendo en la socialización de las niñas, niños y jóvenes más que el propio currículo explícito. La transmisión de modelos de feminidad y masculinidad se sitúa principalmente en las funciones latentes de la escuela. Enrique Díez (2019) resalta que las constantes de la masculinidad hegemónica se ven reforzadas por un contexto escolar que sigue menospreciando la cultura y el saber de las mujeres en los contenidos escolares, en el uso del lenguaje y en su concepción de los espacios y los estilos de relación y convivencia. (p.1).

A pesar de lo anterior, la escuela es el espacio con más posibilidades para educar en la igualdad. Esta afirmación no está exenta de controversia, especialmente en el contexto guatemalteco, en el que la cantidad, profundidad y compleja interrelación de problemas sociales tiende a ocultar las oportunidades de transformación. Una de las resistencias de orden determinista que prevalece entre docentes guatemaltecos para reconocer la capacidad transformadora de la escuela $-\mathrm{y}$ por lo tanto su propio protagonismo y responsabilidad como agentes de cambio- coincide con lo señalado por Marina Subirats (1994:74): “niñas y niños llegan a la escuela con una socialización primaria, obtenida básicamente a través de la familia, en la cual permanecen muchos elementos de desigualdad por razón de sexo que ya han configurado muchos trazos de su personalidad". Ante esta postura, es necesario 
identificar las obligaciones y ventajas que presenta la escuela para convertirse en motor de la educación para la igualdad de género:

- Como parte del Estado, la escuela es titular de obligaciones desde el enfoque de Derechos Humanos. La igualdad es intrínseca a la realización de los Derechos Humanos, de manera que la escuela tiene el deber de cumplir con una socialización de género para la igualdad.

- Tiene amplia cobertura y alcance, incluso en contextos con bajos índices de escolaridad como el guatemalteco: por la escuela pasa más población que por cualquier otra institución del Estado y se mantiene en ella durante años.

- Su carácter institucionalizado facilita la estandarización de herramientas y procesos: introducción de nuevos contenidos y eliminación de otros, uso de determinados materiales educativos, formación a equipos docentes, etc.

- Maestras y maestros tienen un ascendente de autoridad moral sobre el alumnado que definitivamente moldea su percepción del mundo.

Los medios de comunicación - televisión, redes sociales e internet, radio, prensa- son un agente socializador de género de creciente importancia en la sociedad actual. Median la construcción de consensos acerca de la estructura simbólica y los pactos sociales en sociedades cada vez más globales. Según Olga Villalta (2017:21) "su intervención en el proceso comunicativo puede ayudar a mantener ideas o transformarlas". El papel de los medios como productores de cultura les confiere una importancia crucial en la socialización de género. Un somero análisis del contenido de los medios de comunicación en Guatemala, desde los tradicionales como la televisión, radio y prensa hasta los más actuales como las redes sociales, evidencia una constante reproducción de la violencia cultural contra las mujeres, desde un patriarcado racista, clasista, imperialista y homófobo. Los medios transmiten un ideal de blanquitud, ejerciendo fuerte violencia cultural en una sociedad indígena y mestiza. Las mujeres, además, son objetivadas como un cuerpo, su subyugación es 
normalizada y todo lo femenino es desvalorizado (Villalta, 2017). En las redes sociales, también prevalece esta realidad. Sin embargo, es necesario observar que en este caso las y los usuarios se convierten en "programadores" de contenidos, al producir, buscar y compartir elementos que reflejan su propia concepción del mundo. Más allá de la influencia modeladora de la cultura que tienen los algoritmos de algunas redes sociales y buscadores de internet, la era de internet ha creado millones de productores y consumidores de contenidos. Son los prosumidores que nombra Pibernat (2017). La autora explica así este fenómeno:

Los contenidos audiovisuales son de acceso fácil y gratuito o a muy bajo coste a través de la red, lo cual ha hecho que el catálogo se incrementara notablemente. Además, combinadas con la tecnología de consumo, las nuevas redes sociales virtuales ofrecen público y la posibilidad de producir y difundir contenidos audiovisuales. Esto ha dado lugar a la llamada juventud prosumidora. (p. 541)

En Guatemala, la brecha digital marca profundamente el acceso diferenciado a internet de la población rural y urbana. Teniendo en cuenta que la mayoría de la población indígena se encuentra en las áreas rurales, la brecha digital también está afectada, sin duda, por la categoría de raza. Se calcula que en algunos departamentos del país la brecha digital entre áreas rurales y urbanas alcanza el 79.2\%, según noticia de prensa ${ }^{\mathrm{vi}}$. Teniendo esto en cuenta, el fenómeno del consumo de información a través de internet no es tan masivo como en otros países. Sin embargo, no puede obviarse el peso decisivo y creciente que tienen los contenidos de internet en la socialización de género.

Las regulaciones respecto a los estereotipos de género y contenidos explícitamente machistas que son transmitidos en medios de comunicación son inexistentes en Guatemala. Las organizaciones feministas son los únicos actores que periódicamente ponen en la mira anuncios o mensajes especialmente oprobiosos para la igualdad de género. Así, en Guatemala resulta imperativo que el análisis crítico de los contenidos de los medios sea un contenido de 
formación en la escuela y en las formaciones formales y no formales que reciben las y los periodistas y gestores de medios, contribuyendo a la formación de una ciudadanía crítica y comprometida con la igualdad.

Sobre la socialización de género vinculada a la religión, en Guatemala existe un vacío de análisis que permita identificar la influencia de las religiones en la configuración de la masculinidad y la feminidad en la actualidad. Se trata de objeto de estudio muy relevante teniendo en cuenta que en el país, según datos de una encuesta realizada por el principal periódico, el 89\% de la población se manifiesta creyente en alguna religión: 45\% católica, $42 \%$ protestante de diferentes denominaciones y $2 \%$ otras religiones, entre la que se incluye la espiritualidad maya ${ }^{\text {vii }}$. Aunque no haya evidencias para valorar la influencia de las religiones en la socialización de género, identificamos con Emelina Galarza, Rosa Cobo y Mar Esquembre (2016) que

toda sociedad tiene un centro simbólico en el que se asientan los valores dominantes de la sociedad. Este centro simbólico está vinculado a las diferentes instancias de socialización. Abarca el mundo de las definiciones sociales, desde los prejuicios hasta las grandes construcciones científicas y religiosas. (p.821)

Así, las religiones en Guatemala atesoran gran parte del centro simbólico relacionado con la supremacía masculina, con múltiples dichos populares, saberes no científicos y normas que se respaldan en el núcleo irracional de lo sacralizado y, por lo tanto, incuestionable.

De igual forma, no se cuenta con estudios acerca de la socialización de género vinculada a la comunidad y la institucionalidad. Hay que destacar la complejidad que entrañan los estudios de esta naturaleza en Guatemala, por la diversidad de contextos, sistemas comunitarios de regulación y culturas existentes. 


\subsubsection{Reproducción de las violencias contra las mujeres: el triángulo de Galtung.}

Johan Galtung ofrece una definición amplia de la violencia que permite trascender los evidentes actos de agresión directa para entrar en el terreno crucial de la violencia intangible: “entiendo la violencia como afrentas evitables a las necesidades humanas básicas [...] que rebajan el nivel real de la satisfacción de las necesidades por debajo de los que es potencialmente posible" (Galtung, 2003b:9). La realidad de las mujeres en cuanto a la satisfacción de sus necesidades básicas nos interpela: ¿cuántas mujeres en Guatemala -y en el mundo- no satisfacen sus necesidades de alimentación, educación, afecto, salud, participación, libertad, muy por debajo de lo que desearían?

Galtung (2003a) explica que la violencia de todo tipo opera y se reproduce a través del triángulo vicioso que forman la violencia directa, la violencia estructural y la violencia cultural. En palabras del autor, "la violencia directa es un acontecimiento, la violencia estructural es un proceso con sus altos y bajos, y la violencia cultural es una constante, una permanencia" (Galtung, 2003a:12). Calderón (2009), basado en Galtung (2003), define los conceptos de violencia directa y estructural de la siguiente forma:

la violencia directa es la violencia manifiesta, es el aspecto más evidente de esta. $\mathrm{Su}$ manifestación puede ser por lo general física, verbal o psicológica. La violencia estructural se trata de la violencia intrínseca a los sistemas sociales, políticos y económicos mismos que gobiernan las sociedades, los estados y el mundo. (p.17)

La violencia cultural, por su parte, es el conjunto simbólico que inferioriza las características, capacidades y roles asignados a unos sujetos respecto a los asignados a otros. 


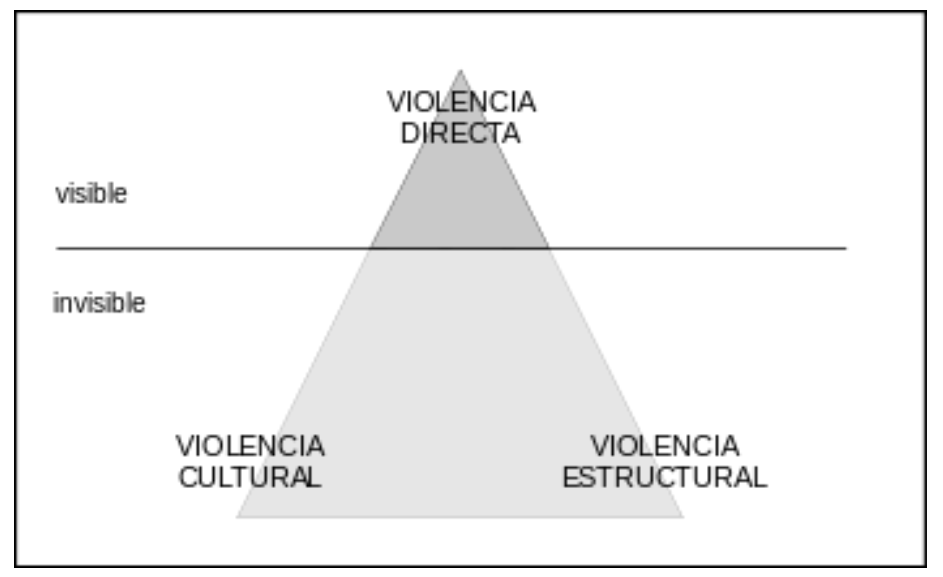

Figura 2. Triángulo de la violencia de Galtung. Fuente:www.wikipedia.org

El triángulo de la violencia de Galtung es una herramienta muy útil para desentrañar el funcionamiento de las violencias contra las mujeres en el sistema patriarcal. Encontramos así que: a) la violencia directa son todas las expresiones de violencia psicológica -insultos, amenazas, burlas, humillaciones- de violencia física -golpes, malos tratos y asesinatos infligidos dentro o fuera de la familia-, violencia sexual y patrimonial; b) la violencia estructural son todas las formas de discriminación y exclusión hacia las mujeres perpetradas por las diversas estructuras sociales, desde la familia, las comunidades, las iglesias, etc. hasta las instituciones del Estado, llegando a convertirse incluso en leyes y políticas; c) la violencia cultural está conformada por el conjunto de estereotipos y prejuicios que minusvaloran a las mujeres en el imaginario colectivo y que constituyen la cultura del machismo. Los estereotipos de género son asumidos y transmitidos de forma eficaz por los diversos agentes socializadores: "las mujeres son para casarse y no para estudiar", "las mujeres no tienen nada que decir en decisiones comunitarias, políticas o sociales", "las mujeres deben vivir bajo las orientaciones de sus esposos, padres o hermanos", "no merece la pena invertir en la educación de las niñas, finalmente se casarán y se irán de la casa", "las mujeres no pueden administrar los bienes familiares, por eso no hay que dejárselos en herencia”, etc.

Las violencias cultural y estructural tienen límites difusos, en una retroalimentación continua. Por ejemplo: en Guatemala, en algunas familias se pueden dar fuertes agravios 
comparativos entre hijas e hijos, beneficiando a los niños a costa del perjuicio a las niñas. Esto son manifestaciones de violencia estructural contra las niñas y mujeres -dividendos del patriarcado para los niños y hombres- que se ejercen sobre la base de creencias y perjuicios. Los agravios pueden ser celebrar más el nacimiento de un niño que el de una niña, dar prioridad a los hijos en el acceso o permanencia en el sistema educativo impidiendo que las hijas estudien, no asignar recursos para el cuidado de la salud de niñas y mujeres de la familia, alimentar mejor a los niños y hombres sirviéndoles más abundante comida y las mejores piezas de carne, privilegiar a los hijos en detrimento de las hijas en las herencias y gestión de bienes, limitar la participación comunitaria y ciudadana de las jóvenes y mujeres, entre otros.

La figura del triángulo de la violencia que hemos observado muestra cómo la violencia directa contra las mujeres se asienta sobre las violencias cultural y estructural, que conforman el sustrato que legitima las agresiones directas contra las mujeres. Sin embargo, el triángulo vicioso de la violencia puede colocarse sobre cualquiera de sus bases, arrojando diferentes interpretaciones. Girando este triángulo hacia la derecha, la violencia cultural queda en la cúspide y las violencias estructural y directa en las bases. En esta posición, "la imagen que suscita es la de la violencia cultural como legitimadora de ambas -violencia directa y estructural-" (Galtung, 2003a:12).

\subsubsection{Triángulo interseccional de violencias contra las mujeres en el patriarcado.}

La teoría de la interseccionalidad demuestra que interpretar las violencias que sufren las mujeres en el sistema patriarcal solo desde la perspectiva del género es una simplificación que nos aleja de la realidad, especialmente en sociedades multiculturales y profundamente desiguales como la guatemalteca. Kimberlé Crenshaw identificó tres niveles de interseccionalidad: estructural, político y simbólico (La Barbera, 2016). Estos niveles 
también podrían organizarse en forma de triángulo, dando lugar a un sistema de ámbitos interconectados que configuran la experiencia de exclusión/privilegio en las personas dentro del patriarcado. Si superponemos el triángulo de la violencia de Galtung y el triángulo de los ámbitos de la interseccionalidad, obtenemos una poderosa herramienta de análisis de las violencias que sufren las mujeres y otros sujetos oprimidos por el patriarcado, con la profundidad que aporta la interseccionalidad. Así, proponemos un triángulo interseccional de violencias patriarcales, en el que hay una correspondencia entre los niveles de la interseccionalidad de Crenshaw y las violencias de Galtung:

a) el nivel estructural que propone Crenshaw se corresponde con la violencia estructural de Galtung. Por ejemplo, en Guatemala una mujer indígena y lesbiana está sometida a una violencia estructural más compleja que una mujer ladina heterosexual. Lo mismo le ocurre a cualquier hombre homosexual respecto a los hombres heterosexuales.

b) el nivel político de la interseccionalidad se corresponde con la violencia directa de Galtung: este es el nivel de las políticas racistas, homófobas, clasistas, etc. que tienen un efecto directo sobre los cuerpos y las vidas de las mujeres y de otros sujetos oprimidos y que les afectan de forma diferencial según las características que se intersecten en cada persona. Por ejemplo, en Guatemala las mujeres indígenas no tienen acceso a un sistema público de salud con pertinencia cultural, lo que deriva en altos índices de muerte materna, entre otros. De la misma forma, hombres indígenas y rurales frecuentemente se ven abocados al trabajo en fincas y maquilas, con poco o nulo acceso a otro tipo de experiencia laboral.

c) el nivel simbólico de la interseccionalidad es la violencia cultural de Galtung, constituido por todo el imaginario cultural que sitúa como sujetos subordinados a las mujeres y a todos los hombres que no encarnan el patrón hegemónico de masculinidad. Se reproduce 
a través de los agentes socializadores: familia, escuela, medios de comunicación, iglesias, instituciones, etc.

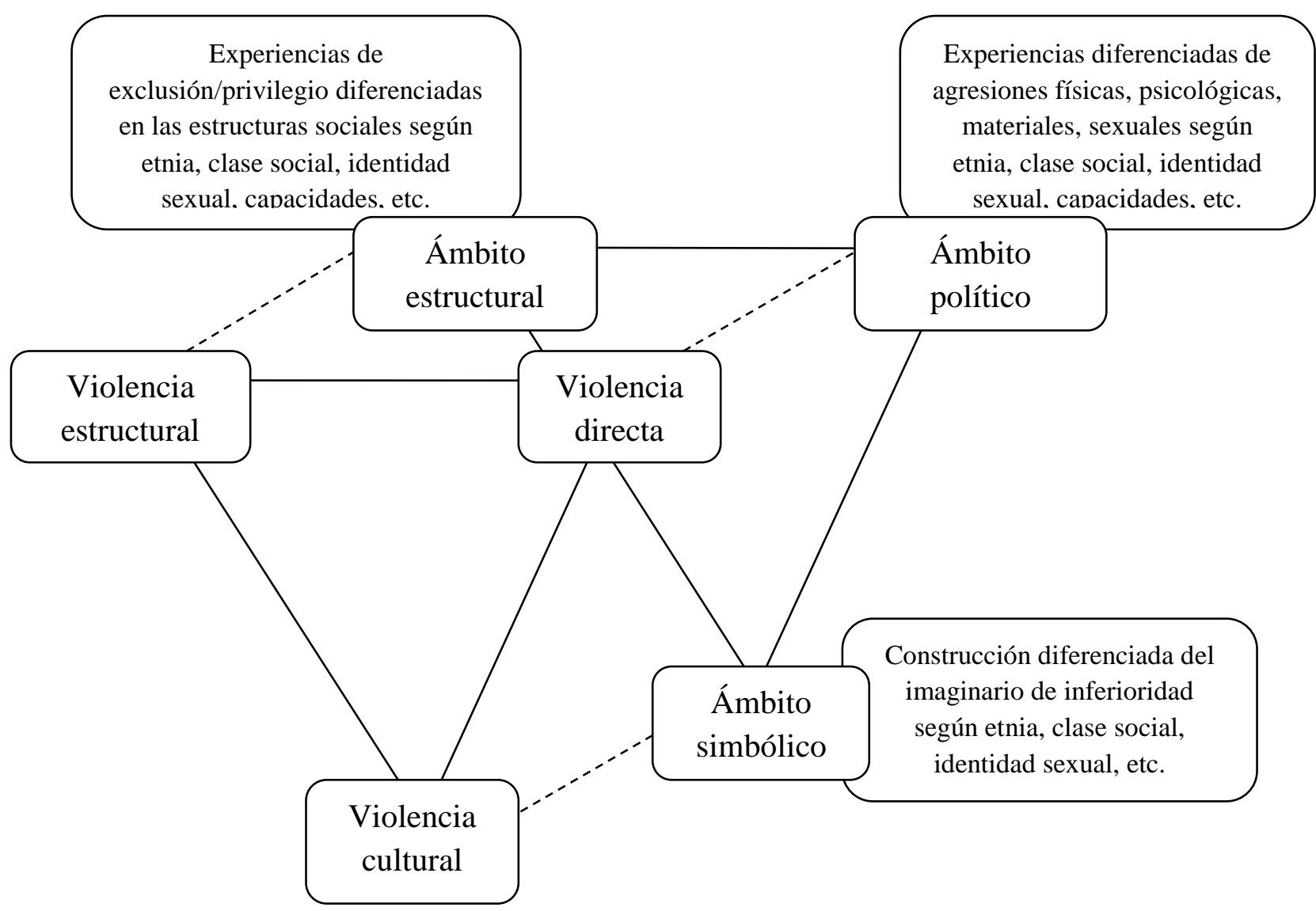

Figura 3. Triángulo interseccional de violencias patriarcales. Fuente: elaboración propia.

Los triángulos de la figura se han dibujado invertidos, con la violencia cultural y el ámbito simbólico abajo, para representar que éstas constituyen las raíces, el sustrato, de las violencias estructural y directa en el patriarcado. La representación sistémica de las violencias contra las mujeres y otros sujetos subordinados que permite este triángulo tiene el potencial de mostrar las oportunidades de transformación: puesto que todos los elementos del sistema se refuerzan mutuamente, actuar en la transformación de uno de ellos moviliza cambios en todo el sistema. Así, por ejemplo, la aprobación y aplicación de leyes que tipifican y sancionan la violencia contra las mujeres, tiene un efecto educativo en la sociedad, contribuyendo a modificar el imaginario de la violencia cultural. 
A pesar de que es imposible establecer un orden de jerarquía entre las violencias estructural, cultural y directa para determinar cuál constituye el origen, es evidente que las intervenciones en las violencias estructural y directa en sí mismas no consolidan cambios. Muestra de ello es que la modificación del Código Civil que realizó Guatemala en 2015 para elevar la edad de matrimonio de mujeres y hombres a los 18 años no consigue erradicar las uniones tempranas, o que las leyes de conciliación familiar en España no cambian el hecho de que sean las mujeres quienes mayoritariamente reducen su jornada laboral, cotización y salario para desarrollar tareas de cuidados. Esto nos lleva a colocar la violencia cultural como raíz y sustrato, con un peso muy significativo en la reproducción y legitimación de todo el sistema de violencias. Galtung (2003a:13) explica que "se puede establecer un flujo causal de la violencia cultural a la violencia directa, pasando por la estructural”.

Teniendo en cuenta lo anterior, la intervención sobre la violencia cultural se convierte en una estrategia decisiva para la transformación del patriarcado. La propia naturaleza cultural de esta violencia determina que la intervención debe darse necesariamente desde lo educativo, entendido desde una perspectiva amplia: escuelas, familias y comunidades, medios de comunicación, etc. Sin duda, la educación formal promovida desde ministerios de educación o entes gubernamentales similares es la política educativa de mayor cobertura y alcance en muchos países. Esto convierte a las escuelas en agentes clave para cambiar o reproducir el machismo, el racismo, la homofobia y otras expresiones de la exclusión.

La relevancia del tema de estudio de esta investigación emana de este mismo debate. Se busca comprender los avances que se están produciendo en Quetzaltenango y Totonicapán, Guatemala, en la transformación de la violencia cultural contra las mujeres desde una perspectiva interseccional, a través de la intervención educativa que supone la aplicación del eje transversal de equidad de género, de etnia y social en las escuelas públicas. 
A continuación se presentan algunos datos que permiten obtener una fotografía de la magnitud de las violencias directa, cultural y estructural contra las mujeres en Guatemala. Es necesario resaltar que el vacío de registro estadístico en general, y desagregado por sexo, etnia, clase social y otras variables en particular, es un problema de base en el país. Por este motivo, no es posible contar con la profundidad de análisis deseable desde una perspectiva interseccional.

\subsubsection{Violencia directa.}

La violencia directa contra las mujeres, como producto de un engranaje sistémico de violencias estructurales y culturales, es un problema global que afecta a todas las sociedades del mundo, conformadas con base en el poder patriarcal. La división sexual del trabajo asigna a las mujeres el trabajo reproductivo, no remunerado, mientras que coloca a los hombres en el ámbito productivo, remunerado, y esto contribuye a fortalecer su poder sobre las mujeres. El poco acceso de las mujeres a actividades remuneradas que les permitan disponer de recursos propios es una estrategia del sistema patriarcal para mantener a las mujeres (su cuerpo, su sexualidad, sus capacidades, su libertad) bajo el dominio y al servicio de los hombres, al tiempo que hace que los hombres sean receptores de los dividendos patriarcales.

Guatemala cerró el año 2018 con un promedio de 13.46 homicidios diarios ${ }^{\text {viii }}$, con múltiples causas como el crimen organizado en forma de maras y grupos extorsionistas, la muy extendida tenencia irregular de armas, conflictos comunitarios por colindancias y territorios, entre otros. Cabe destacar que el número de homicidios viene descendiendo en los últimos años. Sin embargo, entre enero y octubre de 2018, 628 de los homicidios se registraron como femicidios ${ }^{\text {ix }}$, con un promedio de 2 muertes violentas de mujeres al día. El $45 \%$ de los femicidios son contra mujeres jóvenes, entre 18 y 34 años de edad. En estos crímenes, destaca el ensañamiento, siendo frecuentes los desmembramientos, mutilaciones, 
ahogamientos y otras formas de asesinato atroz que provocan sufrimiento extremo en la víctima antes de morir. La tasa de femicidios no solo no desciende, sino que ha aumentado en los últimos años, mostrando que sus causas son mucho más profundas que la violencia común y hunden sus raíces en el patriarcado. El índice de impunidad en delitos de femicidio es alarmante.

\section{Tabla 1}

Porcentaje de impunidad en casos de femicidio entre 2005 y 2015

2005-2015

Casos de femicidio $\quad 6,370$ mujeres

Sentencias

606

condenatorias

$\%$ impunidad

$88.89 \%$

Fuente: Policía Nacional Civil.

Además, en Guatemala se registran 22 violaciones sexuales al día ${ }^{\mathrm{x}}$, principalmente contra mujeres y niñas. El delito de violación, del que son sobrevivientes las niñas entre 5 y 16 años, principalmente, es el menos denunciado por la connotación cultural y de rechazo que implica para las mujeres a lo largo de sus vidas y porque se comete principalmente dentro del ámbito familiar. Según el Observatorio de Salud Sexual y Reproductiva -OSAR- en 2018 se reportaron 116.773 embarazos en niñas y adolescentes de 10 a 19 años ${ }^{x i}$. La Encuesta Nacional de Salud Materno Infantil (ENSMI), realizada en 2008, presentó una cifra reveladora: el $30 \%$ de las mujeres encuestadas a nivel nacional que tuvieron relaciones sexuales antes de los 13 años, las habían tenido con un familiar. El Código Penal de 
Guatemala tipifica como delito de violación toda relación sexual con una niña menor de 14 años y, por lo tanto, estos casos deberían corresponderse con otros tantos procesos legales abiertos en aquel período. Sin embargo, esto no ocurrió. La impunidad en los delitos contra la libertad sexual se calculaba en el $99.52 \%$ en 2016, de acuerdo a datos del Ministerio Público y la Comisión Internacional Contra la Impunidad en Guatemala -CICIG- reportados en noticia de prensa ${ }^{\mathrm{xii}}$.

La violencia sexual determina en gran medida los embarazos en la adolescencia e incide decisivamente en las uniones y matrimonios tempranos, a pesar de que en 2015 se introdujo una modificación en el Código Civil guatemalteco que elevo la edad de matrimonio a 18 años tanto para hombres como para mujeres.

El registro de casos de violencia de género comenzó en Guatemala en 2008, con la aprobación de la Ley contra el Femicidio y otras formas de violencia contra la mujer, decreto 22-2008. Hasta ese momento, la violencia contra las mujeres se manejaba como violencia intrafamiliar. La Ley contra el Femicidio contempla cuatro tipos de violencia directa basada en el género: física, psicológica, sexual y patrimonial. En 2008, se contabilizaron 12.431 demandas por violencia contra las mujeres, mientras que en 2013 se registraron 51.525. En 2015, sin embargo, el número de denuncias por violencia contra las mujeres registradas por el Ministerio Público bajó a 49.680. La falta de denuncia de casos de violencia contra las mujeres da lugar a cifras que no reflejan la realidad. Tomando como referencia datos de la ONU en 2013, la incidencia de la violencia de género alcanza un 35\% de la población mundial de mujeres. Así, de los más de 8 millones de mujeres guatemaltecas, al menos 2 millones y medio habrían sufrido algún tipo de violencia basada en el género. Estas cifras están muy lejos de las denuncias interpuestas.

La baja tasa de denuncia por delitos de violencia contra las mujeres tiene que ver con: 
- Falta de información: desconocimiento por parte de las mujeres -especialmente mujeres rurales e indígenas- de los derechos, instituciones de apoyo e instrumentos legales que les asisten.

- Centralización, burocratización e inoperancia de las instituciones de seguridad y justicia: las mujeres rurales deben realizar largos y costosos desplazamientos para acceder a las instituciones, con procesos legales de duración indeterminada.

- Privatización de los servicios de defensa penal: el enlentecimiento de los procesos legales y la escasez de servicios públicos de defensa hace que el seguimiento de un proceso legal sin la contratación particular de un/a profesional del derecho sea prácticamente imposible. Los honorarios de este tipo de profesionales generalmente están fuera del alcance de las mujeres víctimas de violencia, especialmente, de las mujeres indígenas y rurales.

- Inequidad en el tratamiento de la violencia contra las mujeres por parte de instituciones de seguridad y justicia (PNC, Juzgado de Paz, etc.): las mujeres frecuentemente enfrentan la revictimización por parte de operadores de seguridad y justicia. En el caso de las mujeres indígenas, a esto se suma la discriminación cultural y lingüística del sistema, que utiliza el español como idioma único, no cumpliendo con su obligación de atender en el idioma de cada persona.

- Condicionantes de género: dependencia económica, patrimonial y emocional de las mujeres respecto a esposos, parejas y hombres de la familia, que representan el mayor porcentaje de victimarios. Además, la cultura tendente a la normalización de la violencia de género carga a las sobrevivientes y personas denunciantes con el estigma de la culpabilidad y el temor a las represalias y desalienta las denuncias por parte del personal de instituciones públicas que tiene la obligación de hacerlo. 
Como se puede observar, entre las razones que inciden en la baja tasa de denuncia de delitos de violencia contra las mujeres se encuentran aspectos estructurales y culturales. A continuación, profundizaremos en estos dos tipos de violencia.

\subsubsection{Violencia estructural.}

La violencia estructural contra las mujeres presenta muchas aristas: desde las formas de organización y gestión de recursos en las familias, hasta el ámbito laboral, institucional y de las leyes. A continuación, analizaremos los aspectos del patrimonio familiar, el trabajo, las políticas públicas de prevención, atención y sanción de la violencia contra las mujeres y la participación política de las mujeres.

El legado y titularidad patrilineal de los bienes es un pacto patriarcal decisivo para mantener en manos masculinas los recursos obtenidos de la acumulación de los dividendos patriarcales señalada por Connell (1995). Tradicionalmente, las mujeres al casarse dejan el hogar de sus padres para vivir en el hogar de sus suegros, donde se integran en las labores domésticas y de servicio familiar. Aunque no se cuenta con datos estadísticos, es común que las mujeres no reciban herencia, o reciban menor cantidad que sus hermanos hombres, lo que las hace dependientes del patrimonio de sus esposos, quienes heredan la propiedad de su padre, siendo dueños de la vivienda conyugal y decidiendo sobre la gestión y uso del patrimonio.

En cuanto a la actividad laboral de las mujeres, encontramos dos situaciones predominantes: a) mujeres que solo realizan trabajo no remunerado y por lo tanto no cuentan con ingresos propios y b) mujeres que realizan trabajo remunerado y no remunerado, con ingresos propios que suelen ser muy bajos y dedicados íntegramente al sostenimiento familiar, con pocas oportunidades de dedicar recursos a su desarrollo personal.

La proporción de mujeres sin ningún ingreso propio es mucho más elevada que la de hombres, tanto en áreas rurales como urbanas. 


\section{Tabla 2}

Población con ingresos propios en Guatemala

\section{Mujeres Hombres}

$\begin{array}{lll}\text { Población urbana sin ingresos propios } \quad 31.2 \% & 7.4 \%\end{array}$

Población rural sin ingresos propios $\quad 52 \% \quad 10.4 \%$

Fuente: CEPAL (2012)

La falta de ingresos propios de las mujeres, o que éstos sean muy escasos, es una condicionante básica para la dependencia de los hombres de su familia - padre, esposo o hermanos mayores, generalmente- que en muchos casos lleva a soportar situaciones de violencia física, psicológica y sexual y legitima el ejercicio de la violencia contra ellas al considerarlas personas dependientes, necesitadas de sostenimiento y sin poder de decisión.

Respecto a las mujeres que realizan trabajo remunerado y no remunerado, la mayoría de ellas se inserta en la economía informal, que abarca a un alarmante porcentaje general de la población ocupada de Guatemala: se calcula que casi el $70 \%$ de la población ocupada en Guatemala, mujeres y hombres, lo está en el sector informal, según noticia de prensa digital $^{\text {xiii }}$. Esto tiene consecuencias determinantes en la recaudación físcal del país, así como en la desprotección de la población respecto al sistema de seguridad social, que solo ofrece servicios médicos y un posible subsidio por jubilación a las y los trabajadores afiliados al sistema.

Muchas mujeres obtienen ingresos a través del tejido y venta de güipiles y fajas que forman parte del traje típico de las mujeres indígenas, venta de hortalizas, venta de comida de elaboración casera, lavado de ropa a mano, servicio doméstico, etc. Según la CEPAL (2012), en Guatemala, la mayoría de mujeres realiza trabajos remunerados con una diferencia de 
dedicación de poco más de 1 hora diaria respecto a los hombres. Sin embargo, existe una diferencia de más de 3 horas en el tiempo diario que dedican mujeres y hombres al trabajo no remunerado. Esto implica, por un lado, que las mujeres están aportando decisivamente a la economía familiar, generalmente desde trabajos en la economía informal, invisibilizados, muy mal remunerados y con muy poco reconocimiento al respecto por parte de los demás miembros de la familia. Por otro lado, las extensas jornadas de trabajo desarrolladas por las mujeres, junto a la insuficiente alimentación y escasa asignación de recursos para la prevención de enfermedades y atención médica en un sistema de salud privatizado, repercuten fatalmente en el deterioro de su salud física y mental.

\section{Tabla 3}

Horas diarias dedicadas al trabajo remunerado y no remunerado por sexo

\begin{tabular}{llll}
\hline & $\begin{array}{l}\text { Tiempo total } \\
\text { de trabajo }\end{array}$ & $\begin{array}{l}\text { Trabajo } \\
\text { doméstico no } \\
\text { remunerado }\end{array}$ & $\begin{array}{l}\text { Trabajo } \\
\text { remunerado }\end{array}$ \\
\hline Hombres: horas al día & $10.8 \mathrm{~h}$ & $2.6 \mathrm{~h}$ & $8.2 \mathrm{~h}$ \\
Mujeres: horas al día & $12.9 \mathrm{~h}$ & $6 \mathrm{~h}$ & $6.9 \mathrm{~h}$ \\
\hline
\end{tabular}

Fuente: CEPAL (2012)

Los datos anteriormente expuestos no son sensibles a la estratificación social del país ni a la variable étnica. Corresponden a un promedio nacional que queda caracterizado por la realidad de una mayoría de población conformada por los estratos bajo extremo, bajo y medio bajo, siguiendo el modelo de estratificación de Torres-Rivas (2008). Por lo tanto, se trata de datos que ocultan la realidad interseccional de la diversidad de mujeres guatemaltecas.

En el ámbito de las políticas públicas, encontramos un Estado no dirigido a satisfacer las necesidades de la población ni a protegerla. En 2019, el Grupo Guatemalteco de Mujeres - 
GGM- y la Red de la No Violencia contra las Mujeres -REDNOVI-, integrada por organizaciones feministas, en el marco de los 25 años del mandato de la Relatora Especial sobre Violencia contra las Mujeres sus causas y consecuencias de Naciones Unidas, emitió una serie de aportes que denuncian aspectos relacionados con la dejación de responsabilidades por parte del Estado de Guatemala respecto a la prevención, atención y sanción de la violencia contra las mujeres. GGM y REDNOVI (2019) denuncian, entre otros aspectos, que:

- [... la Coordinadora Nacional para la Prevención de la Violencia contra las Mujeres-CONAPREVI, a pesar de contar con un mandato, leyes específicas que la nombran, a la fecha no cuenta con recursos para funcionar, y no cumple con su mandato, desde el año 2012 ha sido debilitada sin que a la fecha el Estado de una respuesta contundente hacia la verdadera reactivación de dicho mecanismo. (p.2)

- Existe centralismo en la implementación de las leyes y políticas públicas, por lo que el acceso a la justicia para las mujeres que viven en los territorios lejanos sigue siendo un desafío, principalmente para mujeres indígenas, afro descendientes y rurales. (p.3)

- En el año 2004, se impulsó en Guatemala el Plan Nacional de Prevención y Erradicación de la Violencia Intrafamiliar y contra las Mujeres-PLANOVI 20042014, sin embargo, a la fecha no se cuenta con el nuevo Plan, para el próximo periodo, el cual debería retomar los avances mundiales y nacionales específicos en violencia contra las mujeres en su formulación, además se deben priorizar los recursos específicos para su implementación. (p.3)

- Aunque existe un marco normativo nacional que tipifica la violencia contra las mujeres como un delito, persiste la tendencia por parte de las y los operadores de justicia de utilizar leyes de violencia intrafamiliar, medidas sustitutivas, 
alternativas de resolución de conflictos o medidas desjudicializadoras para aplicar las menores penas. (p.4)

Por otro lado, merece la pena analizar la participación política de las mujeres, que es fiel reflejo de la organización del sistema y la reproducción de sus valores patriarcales. En las elecciones generales de 2019, el 54\% del padrón electoral estuvo constituido por mujeres, según noticia de prensa ${ }^{x i v}$. Sin embargo, el porcentaje de mujeres que se postulan para cargos de representación y que son finalmente electas es extremadamente bajo.

\section{Tabla 4}

Porcentaje de mujeres postuladas y electas en elecciones generales de Guatemala 2019

\begin{tabular}{lccc}
\hline & Total país & $\begin{array}{c}\text { \% de mujeres } \\
\text { postuladas }\end{array}$ & $\begin{array}{c}\text { \% de mujeres } \\
\text { electas }\end{array}$ \\
\hline Alcaldías & 340 & 6 & 3.23 \\
$\begin{array}{l}\text { Diputaciones en el } \\
\text { Congreso }\end{array}$ & 160 & 27.7 & 19.37 \\
Presidencia & 1 & 2 & 0 \\
\hline
\end{tabular}

Fuente: Nómada (2019)https://nomada.gt/pais/entender-la-politica/la-politica-de-loshombres/

En 2016, el Congreso de la República no aprobó una propuesta de ley de paridad que buscaba establecer un sistema de cuotas para garantizar la paridad de género en el Congreso. Los debates sociales se produjeron en medio de un discurso sexista y racista que pretendía contraponer las cuotas a la meritocracia.

La sub representación de las mujeres en el ámbito político es un efecto de la exclusión a la que están sometidas, por un lado, y retroalimenta la violencia cultural y directa a la vez: sin 
mujeres en política, es mucho más improbable que se legisle y se ejecuten políticas públicas a favor de las necesidades y demandas de las mujeres.

\subsubsection{Violencia cultural.}

La violencia cultural contra las mujeres se manifiesta en múltiples ámbitos de la sociedad. Desde el enfoque interseccional, reparamos en que la violencia cultural del patriarcado va más allá de las mujeres, subordinando a todos los hombres que no encarnan el patrón de masculinidad hegemónica. Además, desde la interseccionalidad, la violencia cultural contra las mujeres adquiere mucha más profundidad y complejidad al tomar en cuenta las categorías de raza, clase, identidad sexual, capacidades y otras. Llamaremos violencia cultural patriarcal a la violencia cultural complejizada al colocar el lente de la interseccionalidad sobre el patriarcado.

Galtung (2003a) identifica cinco ámbitos de manifestación de la violencia cultural que, observados desde la perspectiva de la violencia contra las mujeres, nos permiten analizar lo siguiente: a) la religión, en la cual Dios habría elegido al hombre para liderar la humanidad, siendo la "elegibilidad" una "forma perversa de violencia cultural" (Galtung, 2003a:16) que puede observarse en la base atrocidades cometidas bajo discursos de raza aria o caudillo por la gracia de Dios, por mencionar solo algunos ejemplos; b) la ideología, con el machismo como ideología del patriarcado; c) la lengua, en la que las mujeres son invisibilizadas a través del uso del lenguaje, además de difamadas extendiendo el uso de adjetivos y expresiones machistas; d) el arte, ámbito en el que se hipersexualiza el cuerpo de las mujeres, se reproduce la violencia sexual y se invisibiliza el aporte de las mujeres y e) las ciencias, en las

que igualmente se invisibiliza el aporte de las mujeres, además de constituir un ámbito tradicionalmente regido por patrones masculinos de análisis e investigación. 
Además de estos ámbitos de manifestación y reproducción de la violencia cultural señalados por Galtung, ésta también se reproduce en todos los agentes socializadores del patriarcado que se desarrollaron más arriba: la familia, la escuela, los medios de comunicación, las iglesias, la comunidad y la institucionalidad, principalmente.

\subsection{Pedagogía feminista, coeducación y transformación de la violencia cultural patriarcal}

A la luz del triángulo de la violencia de Galtung, constatamos el potencial de la educación como campo de transformación de la violencia cultural patriarcal. Una educación crítica y orientada a superar las desigualdades de género, de etnia, de clase, de identidad sexual y de todo tipo incide sobre el vértice de la violencia cultural o simbólica y contribuye decisivamente a movilizar el triángulo vicioso hacia una dinámica de igualdad de las diferencias. No se pretende aquí defender un planteamiento ingenuo que dibuje la educación crítica como la respuesta integral al patriarcado, lo cual además de ser falso podría restar relevancia a la intervención estructural. Al contrario, se busca poner de manifiesto el carácter político de la educación y la necesidad de no perder de vista el ámbito de la educación formal como objetivo de la lucha feminista para transformar el patriarcado. De acuerdo con Irene Martínez (2016:131), "la educación, como la cultura o la socialización, no son elementos neutrales ya que, o bien pueden ser responsables de normalizar y reproducir sociedades desiguales, o bien pueden servir como herramientas de transformación para ciudadanías en igualdad".

Se trata, por lo tanto, de intencionar un cambio cultural desde la intervención educativa. Para abordar las profundas implicaciones que tiene hablar de un cambio cultural y la relación de éste con el proceso educativo formal, es de gran ayuda retomar la definición de cultura. El sociólogo Anthony Giddens (1991) explica que 
cultura se refiere a los valores que comparten los miembros de un grupo dado, a las normas que pactan y a los bienes materiales que producen. Los valores son ideales abstractos, mientras que las normas son principios definidos o reglas que las personas deben cumplir. (p.65)

Por lo tanto, el cambio cultural que se busca tiene que ver con transformar los valores y el imaginario patriarcal y cambiar el ejercicio político, eliminando las normas de organización, de relación social y de gestión de la reproducción/producción que subordinan a las mujeres y a otros sujetos.

La pedagogía feminista se enmarca en la corriente crítica de la pedagogía. La finalidad de la pedagogía crítica, siguiendo a Consol Aguilar (2009:122), "es trabajar por las transformaciones sociales que ayuden a acabar con las desigualdades de todo tipo, trabajar a favor de un mundo más justo y solidario". La pedagogía feminista, según Luz María Maceira (2006),

puede entenderse como un conjunto de prácticas y discursos en torno a dos ideas centrales: un posicionamiento crítico ante el poder y dominación masculinos, y una orientación que emancipa a las mujeres y que busca fortalecerlas para construir de manera colectiva una sociedad más libre y democrática. (p.31)

A lo anterior hay que agregar que, desde un análisis interseccional del patriarcado, la pedagogía feminista irá más allá del posicionamiento crítico acerca del poder masculino y la búsqueda de la emancipación de las mujeres, cuestionando también el complejo poder patriarcal y sus mecanismos de subordinación de los hombres a través de la masculinidad hegemónica. En esta misma dirección, Martínez (2016), desde una visión decolonial, enfatiza la diversidad como valor intrínseco a la pedagogía feminista:

es necesario romper las barreras y narraciones androcéntricas y coloniales, donde se prima una única manera (blanca y masculina) de conocer y donde se legitima una 
única forma de conocimiento valioso. Por el contrario, reconocer la existencia de una diversidad de saberes que incluyan lo subalterno implica tener en cuenta la existencia de múltiples sujetos experienciales, sean mujeres u hombres, blancos o negros... sin jerarquizar ni dicotomizar sus conocimientos. (p.141)

La pedagogía feminista no busca únicamente al empoderamiento de las mujeres. Busca una transformación de estereotipos y roles de género que atañen a ambos sexos y, especialmente, se orienta a deconstruir la masculinidad hegemónica. "La pedagogía feminista reconoce la necesidad de hacer una «revolución» de los hombres -y no solo de las mujerespromoviendo la construcción de nuevas masculinidades" (Martínez, 2016:141).

Actualmente, la pedagogía feminista es una disciplina en construcción que necesita fortalecer su corpus teórico y metodológico. Respecto a los aportes de los que actualmente se nutre, Maceira (2006) identifica

el feminismo, la democracia genérica y la educación popular. Constituyen referentes que aportan, en los dos primeros casos, contenidos y sentidos a la educación, así como una red de conceptos y un lenguaje para el desarrollo del proceso educativo. En el caso de la educación popular, ésta ofrece además elementos metodológicos para la práctica educativa e implica a su vez un foco para el análisis de la dimensión de clase. (p.33)

Martínez (2016) realiza una interesante revisión de perspectivas con la que establece los siguientes rasgos de una pedagogía feminista postcolonial y crítica:

- [...] Impartir enseñanzas sobre una ciudadanía activa en las luchas por la justicia social. Estas propuestas permiten a Mohanty (2008) abordar [...] procesos de investigación y acción sobre experiencias de justicia, cultura, poder y equidad desde unas posturas inter y trans-culturales. 
- Responder al reto de: ¿Cómo hacer educación desde la experiencia y los saberes de las mujeres? Fennell y Arnot (2009), siguiendo a Mohanty, proponen: 1) Deconstruir los conceptos dominantes de la teoría universal del género (lenguaje, ideas, teorías modelos...); 2) Hacer crítica sobre las simplificaciones y generalizaciones de las narrativas dominantes acerca del significado de ser mujer en los territorios del «Sur»; 3) Descolonizar la diversidad de experiencias de las mujeres, sus luchas, negociaciones, resistencias, formas de opresión...; 4) Incluir puntos de vista locales, comprendiendo aspectos como la maternidad o las relaciones familiares desde el entendimiento multidimensional de los roles de género; y 5) Enfatizar el poder de las mujeres desde sus culturas y experiencias propias.

- Educar en la capacidad crítica, entendiendo que el mundo puede ser transformado y comprendido desde su diversidad, pero sin caer en posturas «neo-colonizadoras», de asimilación o de relativismo cultural.

- Reconocer y de-construir las relaciones entre poder y educación. [...]

- Orientar los procesos de enseñanza y aprendizaje feministas hacia un desarrollo de la ciudadanía local, a la vez que global, como forma de promoción humana que contemple la cultura de cada contexto concreto, sus posibilidades y limitaciones.

- Releer la realidad, nuestras prácticas, a partir del saber popular y de los contenidos culturales haciendo posible la apropiación crítica de los mismos; [...]

- Promover una dimensión dialógica que se fundamente en la importancia de la diversidad de narrativas, en las historias de vida, en las reflexiones compartidas y en la construcción colectiva de conocimiento. (p.144)

La coeducación es un enfoque educativo que puede resultar muy útil para concretar los objetivos de la pedagogía feminista en el quehacer de la escuela y las aulas. En palabras de Juan Lillo (2014:31), la coeducación no es otra cosa que "la didáctica de la igualdad de 
género. Es decir, todas aquellas estrategias educativas que tienen por objeto la promoción del valor de la igualdad entre varones y mujeres en la escuela y desde la escuela". Marina Subirats (1994:62) define un objetivo más abarcador para la coeducación: "la desaparición de los mecanismos discriminatorios, no sólo en la estructura formal de la escuela, sino también en la ideología y en la práctica educativa”. En esta definición de Subirats, observamos que la coeducación también abarca la eliminación de la discriminación por etnia, clase, identidad sexual, capacidades y otras. Desde esta perspectiva, es necesario tener en cuenta que la aplicación de la coeducación en contextos multiculturales exige una mirada interseccional. De esta forma, la coeducación con enfoque interseccional, desde un pensamiento decolonial y crítico, es un paradigma educativo muy apropiado para intervenir sobre la violencia cultural patriarcal en Guatemala, respondiendo a la diversidad de género, de etnia y social del país.

La coeducación es cuestionada desde la tensión entre reformismo/transformación de los sistemas educativos. Maceira (2006), tras analizar el devenir de la coeducación en España, concluye que este enfoque ha permitido articular género y educación, pero no abordar las transformaciones integrales que busca la pedagogía feminista.

las propuestas coeducativas han consistido en reflexiones, propuestas y estudios, para articular el género y la educación en el sistema educativo (modificando el diseño curricular, los objetivos y metodologías educativos); es decir, han buscado incidir en las formas de organización y actuación del sistema escolar, pero no necesariamente en su concepción misma ni en los supuestos y principios de los que parte, no se han propuesto una verdadera revolución pedagógica ni constituir un movimiento educativo, tareas a las que, sin embargo, la coeducación puede aportar mucho, ya que todo lo que ha generado es un pilar para la construcción de una o de varias pedagogías feministas. (p.29) 
Siendo acertada la crítica anterior, también es necesario visibilizar las ventajas de la coeducación: ya cuenta trayectoria y experiencias que pueden compararse y retroalimentarse en diferentes contextos, tiene estrategias y herramientas definidas y ofrece claridad en cuanto a los niveles y aspectos del sistema educativo en los que es necesario intervenir. La coeducación puede ser aplicada desde el nivel macro, abordando la transformación de todo un sistema educativo, hasta los niveles más micro, constituidos por un proyecto coeducativo de centro escolar o incluso de un aula. En cualquier caso, la aplicación del enfoque de coeducación debería tocar la estructura de poder y decisión, los contenidos y las normas de relación.

La desaparición de los mecanismos discriminatorios de la ideología educativa que busca la coeducación (Subirats, 1994) supone una revisión crítica de la propia epistemología de la educación.

En primer lugar, surge el cuestionamiento sobre cuál es el tipo de ciudadanía que se busca construir desde cada sistema educativo: ¿una ciudadanía crítica y global que pueda fortalecer las democracias y los estados de derecho? ¿O una ciudadanía al servicio de sistemas políticos y económicos excluyentes? Los sistemas educativos actuales frecuentemente están enfocados a la creación de consumidores en lugar de ciudadanas y ciudadanos, es decir, sujetos útiles para los intereses económicos de las élites, que ponen la educación al servicio del capital y perpetuán así las exclusiones. En el caso de Guatemala, el sistema educativo se enfoca en la creación de consumidores acríticos y de mano de obra poco cualificada gracias al raquitismo deliberado de los recursos asignados a educación, engrasando el funcionamiento del sistema neoliberal. Se produce sin duda una mercantilización del conocimiento que es, además, "un proceso de mercantilización de la propia persona, para un proceso de individualización y de competencia en lugar de solidaridad" (Aguilar, 2015a:44). Esto es contrario a los principios de la pedagogía crítica y la coeducación, que apuestan por la educación en y para la 
ciudadanía crítica y la democracia. Emilio Lucio-Villegas, Marina Aparicio y Pep Aparicio (2008:12), citados por Aguilar (2015a:44) señalan que

la educación tiene la función de enriquecer la vida y disfrutarla en su máxima plenitud, por lo que es necesario un sistema educativo que capacite críticamente a los ciudadanos y las ciudadanas desde el punto de vista humano y profesional y que facilite el acceso a una formación permanente al largo de la vida. (p.44)

En segundo lugar, aparece el cuestionamiento sobre la concepción de género en la que se basa la educación. Tradicionalmente, se trata de una concepción de género que reproduce la dicotomía entre la esfera pública y privada, que es funcional para los modelos mercantilistas que se basan en el ensalzamiento de la esfera pública vinculada al trabajo productivo y a lo masculino, desvalorizando e invisibilizando la esfera privada vinculada a lo reproductivo y lo femenino. Aguilar (2015a), siguiendo a Madeleine Arnot (2009), señala la necesidad de romper la dicotomía de la esfera privada ligada a la crianza y la pública ligada a lo político. Según Aguilar (2015a:49) es necesario "el reconocimiento de la esfera privada como una esfera válida para la actividad política, incluyendo la voz de las mujeres en la reconstrucción de la práctica democrática, de la esfera pública, desde el reconocimiento de las funciones de crianza”. Arnot (2009) continúa analizando la construcción de ciudadanía desde el género, yendo más allá de la dicotomía de esferas. Aguilar (2015a:60-62) expone las tres conceptualizaciones que Arnot (2009) identifica como prioritarias para investigar las problemáticas de la democracia liberal desde la teoría política feminista: a) el contrato sexual que implica la separación de la esfera privada femenina y la esfera pública masculina; b) la generización del estatus de nación y los estados nacionales, que incluye los mecanismos con los que los sistemas políticos continúan marginando a las mujeres y c) la "mujer" como categoría política que permite analizar cómo se representan en los sistemas de gobierno las prácticas sociales marcadas por el género. Sin duda, la ideología de la educación es una clave 
explicativa de las dinámicas sociales de cada país en cada una de las tres categorías, ya que la educación contribuye a reproducir o transformar el contrato sexual, el sistema político y la posición de las mujeres en el mismo. La coeducación con enfoque interseccional es muy pertinente para construir verdaderas democracias con igualdad de género y superado todas las desigualdades.

Por último, encontramos otro aspecto de la ideología de la educación que es necesario revisar críticamente: la concepción sobre naturaleza/cultura que subyace en los sistemas educativos y que ha servido para justificar la dicotomía de esferas analizada en el párrafo anterior. Actualmente, el determinismo biológico está en auge, marcando la tendencia a justificar diferencias en los procesos de aprendizaje, preferencias, conductas y otros aspectos de las niñas y niños desde argumentos biologicistas sustentados en investigaciones realizadas desde la neurobiología, la lingüística y la psicología (Aguilar, 2015a). Estas investigaciones, según Aguilar (2015a), basada en Natasha Walter (2010), en muchos casos no tienen rigor científico e incluso existen otras investigaciones que prueban su invalidez. Sin embargo, las creencias en torno al determinismo biológico "se han introducido y reforzado constantemente en la cultura que rodea a los niños y niñas y, además, el sistema educativo las reproduce, sin cuestionamiento, sin reflexión crítica" (Aguilar, 2015a:51). Desde la coeducación deben revisarse las concepciones sobre el aprendizaje y sobre el ser humano que subyacen en el sistema educativo, desterrando los determinismos que liberan de responsabilidad a los sistemas, para abrir paso a ejercicios educativos críticos y comprometidos con la formación integral orientada a la igualdad y la democracia.

Todo lo anterior evidencia que la coeducación debe tocar los ámbitos más estratégicos de la educación, como son su orientación política y su concepción de género. Sin embargo, también debe abordar los aspectos más prácticos. Elena Simón (2010) identifica los siguientes: 
a) Relaciones entre chicas y chicos, profesoras y profesores, madres y padres, personal no docente o adscrito y todas las interacciones cruzadas que se producen.

b) Saberes formales, incluyendo la obra humana de las mujeres, la educación sexual y para la autonomía personal y el cuidado. Materiales didácticos y metodologías de aprendizaje.

c) Comunicación: lenguajes para la igualdad.

d) Cargos e instancias de responsabilidad, poder y decisión.

e) Formación para la igualdad y fomento de una nueva cultura escolar, que pueda ir desterrando el machismo, la misoginia, la homofobia, el sexismo y el androcentrismo, identificándolos previamente. (p.140)

El profundo replanteamiento ideológico que precisa la educación para estar al servicio de la construcción de ciudadanía crítica necesariamente intervendrá en el curriculum, que es un “instrumento de configuración de estructuras sociales, de construcción de nuestro colectivo simbólico y de nuestra identidad de género" (Aguilar, 2015a:49). Siguiendo a Simón (2010) el enfoque coeducativo debe aplicarse a los tres tipos de currículos presentes en la educación formal:

Currículo formal o explícito: contenidos, materiales, metodologías, evaluación. Todo aquello que se debe enseñar y aprender, aunque no se enseñe ni se aprenda. Es el preceptivo «deber ser» escolar, lo que se evalúa numéricamente.

Currículo oculto o implícito: relaciones, lenguajes, uso de espacios, instancias de poder y representación, roles, estereotipos, funciones, programas extraescolares o complementarios, etc. Aquello que aunque no se enseñe se aprende.

Currículo omitido: lo que se considera socialmente conveniente o necesario que se aprenda, aunque no se haga en el seno de la institución escolar sistemáticamente. Lo 
que se debe enseñar y aprender en estos tiempos, pero no se enseña ni se aprende. (p.141)

En el nivel macro de la transformación de los sistemas educativos, Subirats (1998) explica que es necesaria la intervención en las siguientes dimensiones:

1. Legislación. Se refiere a los cambios legislativos necesarios para borrar todas las barreras legales que puedan impedir el acceso de las mujeres a la educación en condiciones igualitarias.

2. Acceso de alumnas. Se refiere al proceso de entrada de las mujeres en el sistema educativo, hasta lograr la paridad en todos los niveles y tipos de estudios.

3. Estructura de los centros educativos. Se refiere al carácter segregado o unitario de los centros educativos, así como al uso de los espacios dentro de ellos.

4. Estructura curricular. Se refiere a las prescripciones existentes en relación a los currícula, a todos los niveles de la educación, así como al conjunto de conocimientos y valores que se inscriben en los currícula.

5. Libros de texto. Se refiere a la presencia o ausencia de las mujeres y de los temas relativos al ámbito privado que figuran en los libros de texto.

6. Curriculum oculto. Se refiere al conjunto de prácticas habituales en el sistema educativo que no están explicitadas en forma patente, pero que forman parte de los hábitos de la docencia, tanto en términos de atención al alumnado como de observaciones, valoraciones, etc. que el profesorado realiza.

7. Lenguaje. Se refiere al carácter sexista o no sexista del lenguaje utilizado en el sistema educativo, tanto en los textos como en la práctica educativa.

8. Actividades deportivas. Hace referencia a todas las actividades deportivas y lúdicas, escolares o extraescolares, que se realizan en relación al sistema educativo. 
9. Capacitación y formación profesional. Se refiere al tratamiento a dar a la capacitación y formación profesional, en todos sus niveles.

10. Paridad del profesorado. Hace referencia a la composición por sexos del profesorado, tanto en términos de presencia o ausencia como de posiciones ocupadas y tareas desempeñadas. (p.15)

Nos detendremos especialmente en el ámbito de la capacitación y formación profesional desde la convicción de que para la aplicación de la coeducación y el desarrollo teórico y metodológico de la pedagogía feminista, la formación del profesorado constituye una de las claves.

\subsubsection{Formación del profesorado.}

El profesorado es una pieza fundamental de todo sistema educativo, quizá la más importante junto con las y los estudiantes. Por eso, no nos equivocamos al afirmar que la formación del profesorado es la intervención más importante que se debe realizar si se busca transformar un sistema educativo.

Dichos populares advierten que uno no enseña lo que sabe, sino lo que es. Teniendo en cuenta que profesoras y profesores han sido socializados en la cultura a la que pertenecen léase cultura patriarcal-, la tendencia natural es que sean portadores y reproductores de la misma en el ejercicio de su profesión. Por lo tanto, promover un cambio cultural sobre la base de sujetos portadores de la cultura que se quiere cambiar, necesariamente implica un proceso previo de desaprendizaje y adquisición de nuevos valores, prácticas y aspiraciones. Aguilar (2015b:78) siguiendo a Bejarano y Mateos (2014), advierte de que la falta de formación docente en género menoscaba la perspectiva educativa centrada en el respeto de los derechos humanos y alimenta concepciones confusas sobre la igualdad educativa. 
La escasa formación en género en el profesorado es una debilidad recurrente en diferentes países, como se refleja en la investigación de Martínez (2016) sobre el contexto latinoamericano y las investigaciones de Aguilar (2013 y 2015b) sobre el contexto español.

Teniendo en cuenta lo anterior, hay mucho por hacer en esta materia. Una primera tarea es definir enfoques, contenidos y estrategias para esta formación. Martínez (2016) identifica una serie de estrategias para una formación de género poscolonial y crítica dirigida al profesorado y enmarcada en la pedagogía feminista:

1. Sistematización crítica de buenas prácticas y experiencias positivas de lucha contra la desigualdad;

2. Reconstrucción con enfoque de género de las diversas dimensiones formativas del profesorado, como por ejemplo el desarrollo de proyectos, materiales, sistemas de evaluación, relaciones con el entorno, innovaciones...

3. Generación de redes comunitarias con potencialidades para ampliar los recursos, espacios y tiempos de la educación adaptándose y respondiendo a las diversas realidades sociales.

4. Investigación para la acción sobre aspectos específicos de la desigualdad de género y sus causas.

5. Evaluación y seguimiento del impacto de la nueva formación con el fin de trasladar los resultados y actuar en consecuencia.

6. Consideración del género como una asignatura fundamental de la formación del profesorado pero también como aspecto transversal, en este sentido los contenidos de la formación deben favorecer: a) Cuestionamiento de los mandatos de género; b) Concienciación sobre las posiciones de poder desiguales; c) Inclusión de temas de género desde la diversidad y no solo «temas de mujeres»; d) Problematización de los asuntos relacionados con la masculinidad hegemónica; e) Reconocimiento 
del legado e historia de las mujeres (construcción de una genealogía de las mujeres); f) De-construcción de los estereotipos asumidos por hombres y mujeres y que tienen su reflejo en la labor docente; g) Generalización del lenguaje no neutro como vehículo de transformación... y, en definitiva, un cuerpo de contenidos que responda a la necesidad de re-educarnos y re-socializarnos en cuestiones de género incardinadas en nuestros contextos. (p. 146)

Las estrategias expuestas están centradas en la formación en género. Sin embargo, y especialmente en Guatemala, es necesario ampliar la mirada hacia una formación crítica y decolonial sobre la raza, la clase social, la identidad sexual y las relaciones sociales derivadas de estas categorías, abordando así todo el imaginario social asociado con la violencia cultural patriarcal desde un enfoque interseccional.

\subsection{Acercamiento a la historia de la educación en Guatemala}

La historia de la educación en Guatemala está marcada por diversas etapas, desde el segregacionismo por etnia y sexo, hasta llegar a la escuela pública, mixta y con avances curriculares en materia de formación para la equidad de género, de etnia y social con la que se cuenta hoy en día, a pesar de las deficiencias que persisten en el sistema público en cuanto a cobertura y calidad. A continuación, realizaremos un recorrido por la historia de la educación en Guatemala desde el punto de vista de la integración de las mujeres y el género en la educación.

Luis Antonio Menéndez (2006) expone que en la sociedad maya de la época precolombina, que abarca desde el origen de la civilización maya hasta la llegada de los conquistadores en 1524 al territorio que hoy se llama Guatemala, la educación era "de tipo familiar, con impregnaciones religiosas y aplicación a la agricultura, particularmente al cultivo del maíz [...]. La educación femenina tenía un espíritu doméstico” (Menéndez, 
2006:38). Siguiendo al mismo autor, encontramos que durante el gobierno colonial español, vigente de 1524 hasta la independencia de Guatemala en 1821, la Iglesia Católica se encargó de la educación, dirigida solo a hijos de españoles y mestizos, excluyendo a mujeres y hombres indígenas. Según Ana Silvia Monzón (2001:6), “de esta época la historia oficial apenas registra nombres de mujeres ilustradas que, especialmente por su pertenencia de clase y etnia, apenas tenían acceso a actividades que no fueran propias de su sexo". Monzón (2001:6), apoyada en Carlos González (1980), explica que "el pensamiento feudal [...] no sentía ninguna urgencia de que la mujer elevara sus conocimientos, como no fuera en las bellas artes o en las actividades del hogar"; así, "en la segunda mitad del siglo XVI había solamente una escuela para niñas blancas, una escuela para niñas indias y un asilo para doncellas pobres”. Según Ana Patricia Borrayo (2005) durante la Colonia, la educación de las mujeres se realizaba en beaterios, con clases de religión, cocina, bordado y música y se les preparaba para el matrimonio o para la vida religiosa.

En los primeros años de la Independencia, se gestaron las ideas de que "la educación debe ser una preocupación del Estado y solo a través de ella es posible la estructuración de la patria" (Menéndez, 2006:37). En 1866 existían en Guatemala 45 escuelas para niñas con un total de 1.944 alumnas matriculadas; para 1874, el total de escuelas para niñas del país era de 183, con 6.312 alumnas, ninguna de ellas indígena (PNUD, 2000).

Tras un período conservador de 30 años, en 1871 comenzó la época liberal que habría de durar hasta la revolución de 1944. Desde el punto de vista de los avances educativos, en este período destaca el gobierno del presidente Justo Rufino Barrios (1873-1885), conocido como “el Reformador", en cuyo mandato se creó el Ministerio de Educación. Como indica el PNUD (2000:26), ya en 1871 se produjo “una reforma educativa que le quitó el control a la Iglesia y convirtió la educación estatal en laica, gratuita y obligatoria”. A pesar de que la falta de recursos impidió llevarla a término en toda su profundidad, en esta época se fundó el 
Colegio para la Civilización de los Indígenas y varios institutos para indígenas, siguiendo una política claramente segregacionista que brindaba una oportunidad educativa a esta población anteriormente excluida del sistema educativo. Borrayo (2005), siguiendo a González (1986), explica que

en 1875 se estableció el Colegio Nacional de Niñas, con carácter de Instituto de secundaria; en 1879 se estableció una sección normal en el referido Colegio y se creó la Primera Normal de Señoritas, con una sección para la enseñanza del magisterio, en tanto se establecía el Instituto de Señoritas “Belén” en 1888. (p.37)

El PNUD (2000) subraya que, en esta época, el dictador militar Rafael Carrera estableció que

en las escuelas de niñas, que siempre estarán a cargo de señoras de respeto, además de enseñarse y practicarse [moral y urbanidad, doctrina cristiana, escritura y las cuatro reglas de la aritmética] se les instruirá en coser, bordar, economía doméstica y otras materias propias de su sexo. (p.26)

En la década de 1890 también se crearon las primeras escuelas secundarias femeninas (Escuelas Normales de Señoritas) en Guatemala, Quetzaltenango y Chiquimula y la escuela de artes y oficios femeniles (1891). Estas escuelas no preparaban a las mujeres para su inserción en el mercado laboral ni para su participación política, sino para "perfeccionar conocimientos domésticos tales como economía doméstica, arreglo y limpieza del hogar, higiene personal, lavado, planchado y cocina" (PNUD, 2000:26). De esta cuenta, la incursión de las mujeres en las aulas universitarias fue muy lenta. Sin embargo, había mujeres que a expresaban sus ideas políticas como Adelaida Cheves y Vicenta Laparra de la Cerda que, junto a Isabel de Castellano, Carmen de Silva y otras fundaron el periódico "El Ideal” (1887) con el lema "por los intereses de las mujeres". 
El mismo informe del PNUD (2000) señala que en los últimos años del siglo XIX las mujeres fueron incorporándose al trabajo como maestras, a pesar de ser considerado indecente que trabajaran fuera de casa. De hecho, al contraer matrimonio, las maestras eran destituidas de su cargo. Según Borrayo (2005), en 1919, Olimpia Altuve, oriunda de Quetzaltenango, se convirtió en la primera mujer graduada universitaria en Centroamérica, con el título de farmacéutico (cabe destacar que los títulos se eran otorgados en masculino). Sin embargo, a esta mujer pionera se le negó el derecho a la toga y al ejercicio de su profesión, al no gozar las mujeres de derechos civiles. Solo en 1967, con el impulso de la Asociación Guatemalteca de Mujeres Universitarias, Olimpia Altuve recibió el título de Química Bióloga, invistiéndola con la toga. En 1927, Luz Castillo Díaz Ordaz se graduó de Abogado y Notario en la Escuela de Derecho de Occidente, en Quetzaltenango, sufriendo el cierre de las puertas de su bufete por parte de las autoridades. Otras mujeres pioneras en las aulas universitarias guatemaltecas fueron Francisca Fernández Hall, María Isabel Escobar Quintana, Graciela Quan Valenzuela, Elena Ruiz de Barrios Klée, entre otras.

Entre 1926 y 1930, bajo en gobierno del general Lázaro Chacón se creó la Escuela Normal para Maestras de Párvulos, profesionalizando este ejercicio magisterial que solía ser empírico, en espacios anexos a las escuelas primarias. Tras la oscuridad de los años del gobierno del general Ubico (1931-1944), que clausuró centros educativos y dictaminó retrocesos generales en educación, el período revolucionario de 1944 a 1954 permitió un avance sin precedentes en materia educativa del país, con la creación de centros educativos de todos los niveles, la atención a la educación especial y el impulso de la investigación, entre otros aspectos.

La intervención militar de Estados Unidos para deponer el gobierno de Jacobo Arbenz en 1954 puso fin a este período de "primavera", comenzando en 1960 las primeras acciones del conflicto armado interno que sufrió Guatemala durante los 36 años posteriores. Los Acuerdos 
de Paz de 1996 firmados entre el gobierno y la Unidad Revolucionaria Nacional Guatemalteca-URNG- pusieron fin a una guerra cruel en la que se cometió uno de los peores genocidios de América Latina, además de terribles violaciones de Derechos Humanos que se ensañaron especialmente en las mujeres indígenas. El Acuerdo sobre Identidad y Derechos de los Pueblos Indígenas, como parte del conjunto de los 12 Acuerdos de Paz, incluye la Reforma Educativa que propone una educación intercultural para garantizar la inclusión de la población maya y de los demás pueblos del país. La Reforma Educativa se plantea como "un proceso político, cultural, técnico y científico que se desarrolla de manera integral, gradual y permanente e implica transformaciones profundas del sector y sistema educativos, de la sociedad y del Estado" (COPARE, 1998:59). Consta decuatro grandes ejes sobre los que debe girar la educación guatemalteca: unidad en la diversidad, vida en democracia y cultura de paz, desarrollo integral sostenible y ciencia y tecnología.

En la actualidad, la Reforma Educativa se encuentra todavía en proceso de implementación, perfeccionamiento y adaptación a las nuevas necesidades sociales. Constituye el marco referencial para múltiples leyes de aprobación posterior como la Ley de Educación Nacional 12-1991 y la Ley Educativa contra la Discriminación 81-2002.

\subsection{Marco jurídico e institucional para la educación para la equidad en Guatemala}

El marco jurídico de la educación en Guatemala aborda la equidad de género con poca profundidad. La Reforma Educativa, iniciada tras los Acuerdos de Paz de 1996 e inconclusa en la actualidad, y la Ley de Educación Nacional, decreto 12-91, no refieren directamente la educación en y para la equidad de género. La Ley de Promoción Educativa contra la Discriminación, decreto 81-2002, sí menciona la necesidad de difundir desde los Ministerios de Educación y Cultura "programas tendientes hacia la eliminación de la discriminación étnica o racial, de género y toda forma de discriminación" (art.1). De esta cuenta, el 
Curriculum Nacional Base, a partir de 2004, incluyó el eje transversal de equidad de género, de etnia y social y algunos contenidos relativos a la desigualdad.

Realizando un análisis del marco jurídico de la educación para la equidad en Guatemala desde el nivel internacional hasta la concreción de instrumentos nacionales, encontramos lo siguiente.

\subsubsection{Marco jurídico internacional.}

Guatemala es firmante de diversas convenciones y acuerdos internacionales que ratifican el compromiso del país con la equidad de género en la educación. Entre ellos destaca la Convención Sobre la Eliminación de Todas las Formas de Discriminación contra la Mujeres y su Protocolo Facultativo -CEDAW- por su interpelación directa no solo a la paridad en el acceso a la educación para niñas y niños, sino también a las características que debe tener el proceso educativo para educar en equidad.

La CEDAW, de 1979, fue adoptada por Guatemala en 1982 como Convención y en 2002 en su Protocolo, siendo Guatemala uno de los 186 países que la ha ratificado hasta la fecha. Las disposiciones que atañen a la educación para la equidad son:

- Artículo 5, literal a.: Los Estados Partes tomarán todas las medidas apropiadas para modificar los patrones socioculturales de conducta de hombres y mujeres, con miras a alcanzar la eliminación de los prejuicios y las prácticas consuetudinarias y de cualquier otra índole que estén basados en la idea de inferioridad o superioridad de cualquiera de los sexos o en funciones estereotipadas de hombres y mujeres.

- Artículo 10, literal c.: Los Estados Partes adoptarán todas las medidas apropiadas para la eliminación de todo concepto estereotipado de los papeles masculino y femenino en todos los niveles y en todas las formas de enseñanza, mediante el estímulo de la educación mixta y de otros tipos de educación que contribuyan a lograr este objetivo 
y, en particular, mediante la modificación de los libros y programas escolares y la adaptación de los métodos en enseñanza.

El informe alternativo publicado en 2018 por organizaciones sociales de Guatemala sobre el cumplimento de los compromisos adquiridos por el Estado de Guatemala en el marco de la CEDAW revela fuertes vacíos. A pesar de algunos avances, son preocupantes las deficiencias en atención integral a la violencia contra las mujeres y los intentos de aprobación de legislación regresiva en materia de educación integral en sexualidad, de derechos del colectivo LGTBI u orientada a mayor restricción del aborto. Así mismo, los avances en educación no se acercan a lo deseable, con un sistema educativo que no garantiza la cobertura para todos los niveles de educación obligatoria. Los contenidos educativos más relacionados con la transformación de las relaciones de género son los de Educación Integral en Sexualidad que, aunque fueron aprobados e incluidos en el Curriculum Nacional Base, no se están aplicando por falta de voluntad política y bloqueo manifiesto por parte de sectores conservadores. Humanistas Guatemala, Incide Joven y REDLAC (2018), en el informe alternativo mencionado, manifiestan que:

El Estado de Guatemala ha reportado en su respuesta a la lista de cuestiones del Comité en julio de 2017 una campaña de comunicación "menos victimización, más empoderamiento" para brindar información a las mujeres sobre participación, prevención, derechos de la mujer, eliminar actitudes de victimización, fortalecer actitudes de empoderamiento y socializar guías de acompañamiento para las mujeres. Sin embargo, es importante hacer énfasis en que realizar una campaña en el período de 9años después de las recomendaciones del Comité CEDAW no es suficiente y se evidencia que el Estado tiene poca voluntad política para generar cambios profundos y significativos para la sociedad en cuanto a disminuir los estereotipos y prácticas culturales, incluidas las perspectivas que tienen las autoridades institucionales del gobierno sobre las mujeres, 
especialmente si las mujeres, niñas, adolescentes y jóvenes son víctimas de algún tipo de violencia, la respuesta a su atención no es para protegerlas sino para re victimizarlas y verlas como inservibles. (p.8)

\subsubsection{Marco jurídico nacional.}

La educación en Guatemala es un derecho inherente a todas las personas, una obligación ciudadana dentro de los márgenes de edad señalados y es obligación del Estado proveerla de forma gratuita. Así lo establecen la Constitución Política de la República en sus artículos 74 y 75 y la Ley de Educación Nacional 12-91, cuyo reglamento específico no se ha concretado hasta el momento. José Miguel Rosales (2006:36) explica que actualmente "se sigue aplicando el reglamento del Acuerdo Gubernativo 13-77 que se elaboró para la Ley Educación Nacional Decreto 73-76 del Congreso de la República”.

Además, el marco jurídico nacional que respalda la educación para la equidad incluye la Política Nacional de Educación, la Ley de Promoción Educativa contra la Discriminación, decreto 81-2002, los Acuerdos de Paz y la Reforma Educativa.

Existe también una política pública para el desarrollo de las mujeres vigente en la actualidad que realiza aportes fundamentales al trabajo educativo para superar las exclusiones desde la perspectiva de género, de etnia y de clase: la Política Nacional de Promoción y Desarrollo Integral de las Mujeres -PNPDIM- y el Plan de Equidad de Oportunidades 20082023 -PEO.

La PNPDIM y el PEO fueron aprobados el 11 de noviembre de 2009, a través del acuerdo gubernativo 302-2009. Nacieron del consenso entre organizaciones de mujeres de la sociedad civil y los mecanismos institucionales para el avance de la mujer en Guatemala, formados por la Secretaría Presidencial de la Mujer-SEPREM- como ente máximo, la Defensoría de la Mujer Indígena -DEMI-, el Foro Nacional de la Mujer - FNM- y la Coordinadora Nacional 
para la Prevención de la Violencia contra la Mujer - CONAPREVI-. Actualmente, la PNPDIM es la única política pública nacional para el desarrollo de las mujeres vigente. Su objetivo general es "promover el desarrollo integral de las mujeres mayas, garífunas, xinkas y mestizas en todas las esferas de la vida económica, social, política y cultural.” (SEPREM, 2009:27). La PNPDIM y el PEO contemplan 12 ejes de trabajo para lograr sus objetivos:

1. Eje de Desarrollo Económico y Productivo con Equidad,

2. Eje de Recursos Naturales, Tierra y Vivienda,

3. Eje de Equidad Educativa con Pertinencia Cultural,

4. Eje de Equidad en el Desarrollo de la Salud Integral con Pertinencia Cultural,

5. Eje de Erradicación de la Violencia contra las Mujeres,

6. Eje de Equidad Jurídica,

7. Eje de Racismo y Discriminación contra las Mujeres,

8. Eje de Equidad e Identidad en el Desarrollo Cultural,

9. Eje de Equidad Laboral,

10. Eje de Mecanismos Institucionales,

11. Eje de Participación Sociopolítica y

12. Eje de Identidad Cultural de las Mujeres Mayas, Garífunas y Xinkas

El eje número 3 está relacionado con la equidad educativa, siendo el Ministerio de Educación -MINEDUC- y el Consejo Nacional de Educación ${ }^{\mathrm{xv}}$ los entes responsables de su implementación. Este eje número 3 de la PNPDIM podría concretarse en la aplicación del enfoque coeducativo interseccional en Guatemala. Contiene 7 sub-ejes (SEPREM, 2009):

1. Garantizar la integración y aplicación del principio de equidad entre mujeres y hombres, mayas, garífunas, xinkas y mestizos en los fundamentos de la filosofía, principios, valores y prácticas de la educación. 
2. Garantizar el ingreso, permanencia y cobertura educativa de las niñas, adolescentes, jóvenes y mujeres mayas, garífunas, xinkas y mestizas en todos los niveles del sistema de educación nacional, priorizando a mujeres sobrevivientes del conflicto armado interno.

3. Garantizar la eliminación del analfabetismo de las niñas, adolecentes, jóvenes y mujeres mayas, garífunas, xinkas y mestizas.

4. Garantizar el acceso de las mujeres mayas, garífunas, xinkas y mestizas a programas de formación, profesional, científica y tecnológica.

5. Asegurar la participación equitativa de mujeres en los distintos niveles de la dirección y administración del sistema educativo comunitario, municipal, departamental y nacional.

6. Garantizar la integración y aplicación del principio de equidad entre mujeres de diversas identidades étnicas culturales y económicas, en el sistema educativo.

7. Garantizar la educación sexual en todos los niveles del sistema educativo con pertinencia cultural, científica y humanística. (p.32)

Cada sub - eje describe una serie de programas, sub-programas, proyectos y actividades a llevar a cabo. La implementación del eje curricular de equidad de género, de etnia y social en las aulas se concreta en los programas previstos para el sub - eje número 1, "Garantizar la integración y aplicación del principio de equidad entre mujeres y hombres, mayas, garífunas, xinkas y mestizos en los fundamentos de la filosofía, principios, valores y prácticas de la educación" (SEPREM, 2009:65). 


\section{Programas, sub-programas, proyectos y actividades del sub-eje 1}

\section{del eje de equidad educativa con pertinencia cultural}

\section{de la PNPDIM}

a. Crear e implementar el curso de derechos humanos de las mujeres en su diversidad étnico cultural en la CNB de todos los niveles del sistema de educación nacional del Ministerio de Educación.

b. Integrar en los contenidos de las guías, textos y materiales escolares de todas las disciplinas y en todos los niveles del sistema de educación, valores, principios y prácticas que reconozcan los aportes y papel de las mujeres mayas, garífunas, xinkas y mestizas en la política, historia, ciencias, artes, literatura, cultura, deportes y otras disciplinas.

c. Integrar a las CNB de educación nacional, materias y prácticas que potencien el desarrollo integral de las mujeres mayas, garífunas, xinkas y mestizas al egresar de los diferentes niveles del sistema educativo nacional.

d. Integrar a las CNB los componentes y prácticas que permitan el desarrollo de conocimientos, competencias y habilidades científico-tecnológicas en las niñas y adolescentes mayas, garífunas, xinkas y mestizas.

e. Adecuar las CNB para que respondan a las características y necesidades de niñas, adolescentes y mujeres mayas, garífunas, xinkas y mestizas.

f. Gestionar ante el Consejo de Universidades del sistema de educación superior que se incorpore y reconozca en la curricula, guías, textos y materiales de todas las disciplinas científicas, derechos humanos, aportes y papel de las mujeres mayas, 
garífunas, xinkas y mestizas en las mismas.

g. Revisar el marco legal y administrativo nacional del sistema educativo, a efecto que se incorporen medidas que sancionen la violación de los derechos de las niñas, adolescentes y jóvenes mayas, garífunas, xinkas y mestizas, en el sistema educativo nacional y local.

h. Promover y aplicar programas de formación para docentes a fin de que promuevan y apliquen prácticas de equidad entre mujeres y hombres

i. Promover la educación bilingüe intercultural para las niñas, adolescentes y jóvenes mayas, garífunas, xinkas y mestizas en los diferentes niveles del sistema educativo nacional.

j. Desarrollar procesos de capacitación en derechos humanos de las mujeres, dirigidos a padres, madres y familias mayas, garífunas, xinkas y mestizas, desde el sistema educativo formal, no formal y otros.

Figura 4. Sub eje de equidad educativa de la PNPDIM. (SEPREM, 2009:65)

Es importante rescatar el énfasis que se hace en la formación de docentes y de madres y padres de familia, lo que ofrece una perspectiva amplia de la educación para la equidad, que debe involucrar a todos los actores del hecho educativo.

\subsubsection{Instituciones.}

El Ministerio de Educación, máximo responsable de las políticas educativas del país, cuenta desde 2011 con la Unidad de Género y Pertinencia Étnica-UNEGEPE- que, según su página web, es "responsable de asesorar, acompañar y apoyar a las Direcciones Generales y Direcciones Departamentales -de Educación- en el diseño e implementación de lo 
establecido en el plan para la institucionalización - dentro del MINEDUC- de la Política Nacional de Promoción y Desarrollo Integral de las Mujeres PNPDIM así como con estrategias específicas para dar cumplimiento a lo establecido en los marcos legales

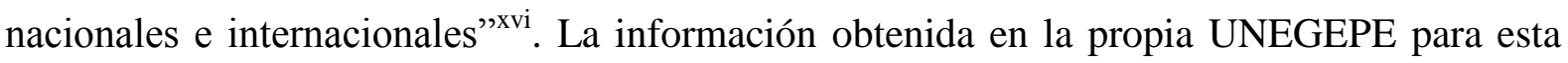
investigación señala que el trabajo de esta Unidad comenzó por la sensibilización sobre equidad para personal que forma parte de la estructura del MINEDUC a nivel de la sede central y de las delegaciones departamentales, siendo difícil llegar a las y los docentes y las aulas. Las temáticas de trabajo que se proponen para las aulas están relacionadas con prevención de la violencia en general y la educación sexual.

La Universidad de San Carlos de Guatemala -USAC- cuenta desde 2004 con el Instituto Universitario de la Mujer de la Mujer -IUMUSAC- cuya misión, según información de su página web, es ser el "ente rector de las políticas a favor de las mujeres y la equidad de

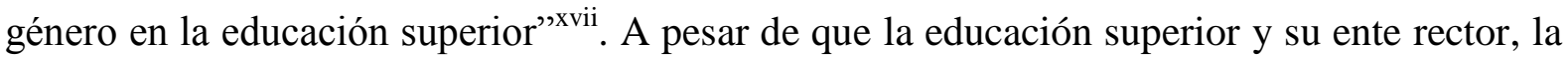
USAC, están fuera del ámbito de influencia del Ministerio de Educación, es muy relevante la existencia del IUMUSAC y su trabajo de investigación, docencia y extensión (actividades más allá de la Universidad) porque favorece el debate, investigación y divulgación de conocimientos y prácticas acerca de la equidad en la educación y la educación para la equidad.

\subsection{Herramientas para la educación crítica: Reforma Educativa, Curriculum} Nacional Base y eje transversal de educación para la equidad de género, de etnia y social

Desde la década de 2000, el Currículum Nacional Base -CNB-, cuya creación, divulgación y adaptación está a cargo de la Dirección General de Currículo -DIGECUR- del Ministerio de Educación, busca una transformación curricular que haga realidad la Reforma 
Educativa, operativizándola en las aulas. Se trata de un nuevo paradigma curricular que coloca al ser humano como el centro del proceso educativo, señalando que "la convivencia humana se realiza en la interdependencia, la cooperación, la competencia y el espíritu de responsabilidad y solidaridad en un marco de respeto a sí mismo y hacia los demás mediante el reconocimiento de los Derechos Humanos" (MINEDUC, 2008:19). Para lograr esto, son necesarios un enfoque, métodos, contenidos y estrategias didácticas renovadas que apunten hacia el "mejoramiento de la calidad de la educación [...] así como la incorporación al proceso de enseñanza-aprendizaje de los aprendizajes teórico-prácticos para la vivencia informada, consciente y sensible, condiciones ineludibles para el perfeccionamiento humano" (MINEDUC, 2008:15). Como modelo conceptual de calidad educativa, el Ministerio de Educación se acoge al marco de la UNESCO que, entre otras premisas, se "basa en los cuatros pilares de Educación para Todos: aprender a conocer, aprender a hacer, aprender a convivir y aprender a ser (Delors, J. et al., 1996)" (MINEDUC, 2008:13).

Jacques Delors (1996) en su famoso informe La educación encierra un tesoro, explica que el objetivo de la educación es que las personas desarrollen cuatro grandes competencias: aprender a ser, aprender a hacer, aprender a conocer $\mathrm{y}$ aprender a convivir. Estas competencias se desarrollan en todos los espacios de la vida, en un ejercicio permanente de adaptación, y están íntimamente ligadas a la cultura de cada sociedad, es decir, a cómo se es persona, cómo se conocen y se hacen las cosas y cómo se debe convivir dentro de los valores y normas establecidos. La escuela es, sin duda, uno de los escenarios fundamentales para el desarrollo de competencias. En el proceso educativo formal, las cuatro competencias se van adquiriendo en el aula a través de contenidos declarativos, procedimentales y actitudinales que se trabajan progresivamente en las diferentes etapas educativas. Esto abarca tanto el curriculum explícito, como al curriculum oculto. 
La Reforma Educativa introdujo cuatro ejes para la educación nacional: 1) unidad en la diversidad; 2) vida en democracia y cultura de paz, 3) desarrollo integral sostenible y 4) ciencia y tecnología. Posteriormente, el CNB ha definido un total de siete ejes transversales que desglosan más los ejes de la Reforma Educativa. Entre los siete ejes del CNB se encuentra el eje transversal de equidad de género, de etnia y social, enmarcado en el eje vida en democracia y cultura de paz de la Reforma Educativa. De esta forma, la coeducación con enfoque interseccional se concretaría en Guatemala en la aplicación del eje transversal de equidad de género, de etnia y social del CNB.

Respecto a las transformaciones relacionadas con la equidad de género que se desprenden de la transformación curricular, el Ministerio de Educación (2008) en el documento del Curriculum Nacional Base especifica las siguientes:

- La Reforma Educativa tiene como propósito superior:

satisfacer la necesidad de un futuro mejor, esto es, lograr una sociedad pluralista, incluyente, solidaria, justa, participativa, intercultural, pluricultural, multiétnica y multilingüe. Una sociedad en la que todas las personas participen consciente y activamente en la construcción del bien común [...] sin discriminación alguna por razones políticas, ideológicas, étnicas, sociales, culturales, lingüísticas y de género. (MINEDUC, 2008:6).

- Entre los propósitos específicos de la transformación curricular está: “el fortalecimiento de la participación de la niña y de la mujer en el sistema educativo en el marco de las relaciones equitativas entre los géneros" (MINEDUC, 2008:15).

- En el CNB, uno de sus principios es la equidad definida como: "garantizar el respeto a las diferencias individuales, sociales, culturales y étnicas y promover la igualdad de oportunidades para todas y todos" (MINEDUC, 2008:20). 
- El CNB se organiza en competencias a desarrollar por el alumnado a lo largo de su proceso educativo, siendo una de las competencias que la o el estudiante: "vivencia y promueve la unidad en la diversidad y la organización social con equidad, como base del desarrollo social” (MINEDUC, 2008:25).

- El eje número 2 del Currículum llamado "Equidad de género, de etnia y social" se desagrega en los componentes de "equidad e igualdad, género y autoestima, educación sexual -VIH-SIDA, equidad laboral, equidad étnica, equidad social, género y clase, género y poder, género y etnicidad” (MINEDUC, 2008:26)

A continuación, podemos observar cómo conceptualiza el CNB los aspectos incluidos en el eje curricular de "equidad de género, etnia y social":

\begin{tabular}{|c|c|c|}
\hline Eje & Componentes & Subcomponentes \\
\hline $\begin{array}{l}\text { Equidad de género, de } \\
\text { etnia y social } \\
\text { Se refiere, } \\
\text { fundamentalmente, a la } \\
\text { relación de justicia } \\
\text { entre hombres y } \\
\text { mujeres de los } \\
\text { diferentes Pueblos que } \\
\text { conforman el país. } \\
\text { Requiere, } \\
\text { por lo tanto, del } \\
\text { reconocimiento, } \\
\text { aceptación y valoración } \\
\text { justa y ponderada de }\end{array}$ & $\begin{array}{l}\text { Equidad e igualdad } \\
\text { Su propósito principal es eliminar } \\
\text { toda forma de discriminación entre } \\
\text { hombres y mujeres y lograr la } \\
\text { igualdad en: derechos, } \\
\text { oportunidades, responsabilidad, } \\
\text { acceso a la educación, participación } \\
\text { social y ciudadanía. }\end{array}$ & \\
\hline
\end{tabular}




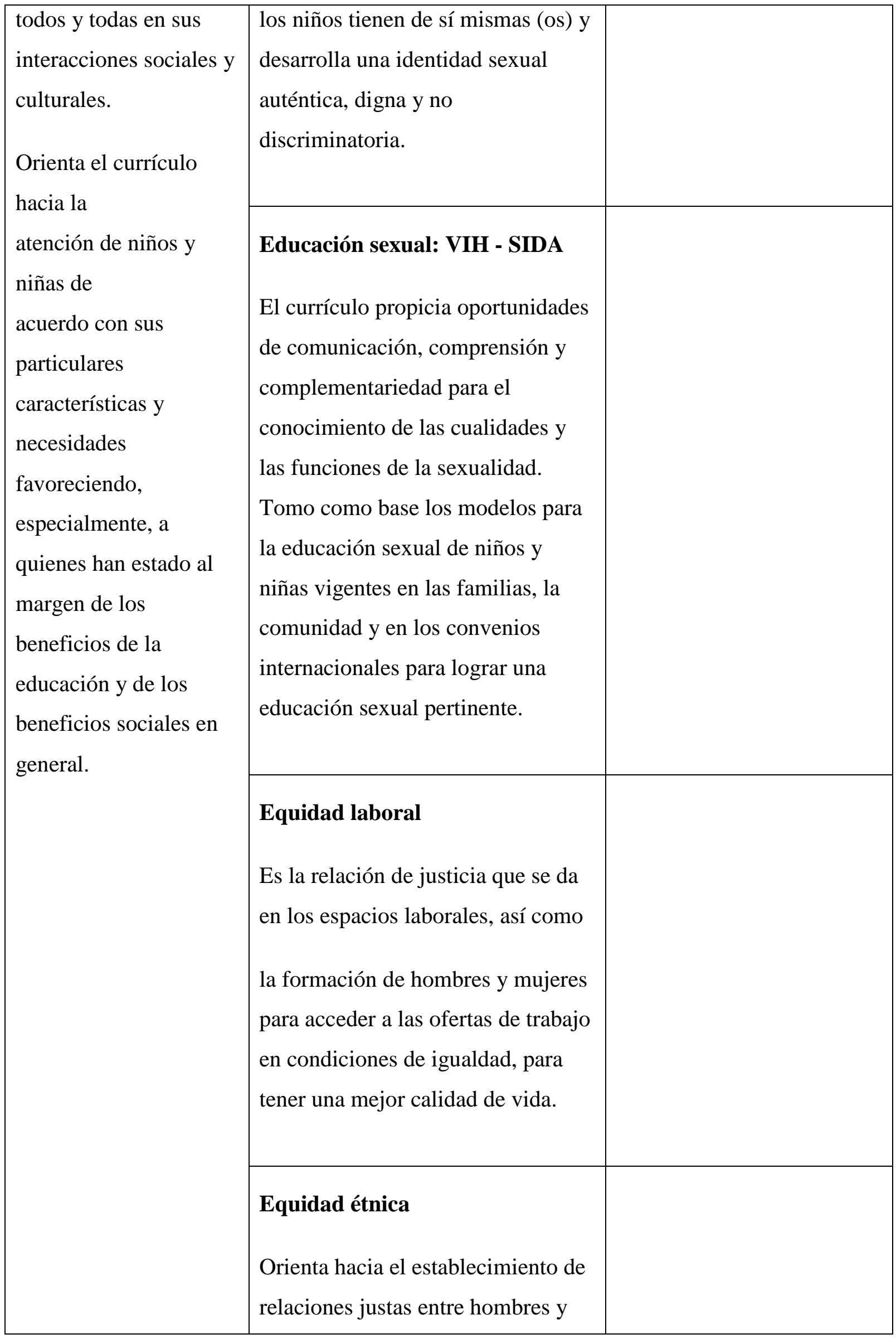




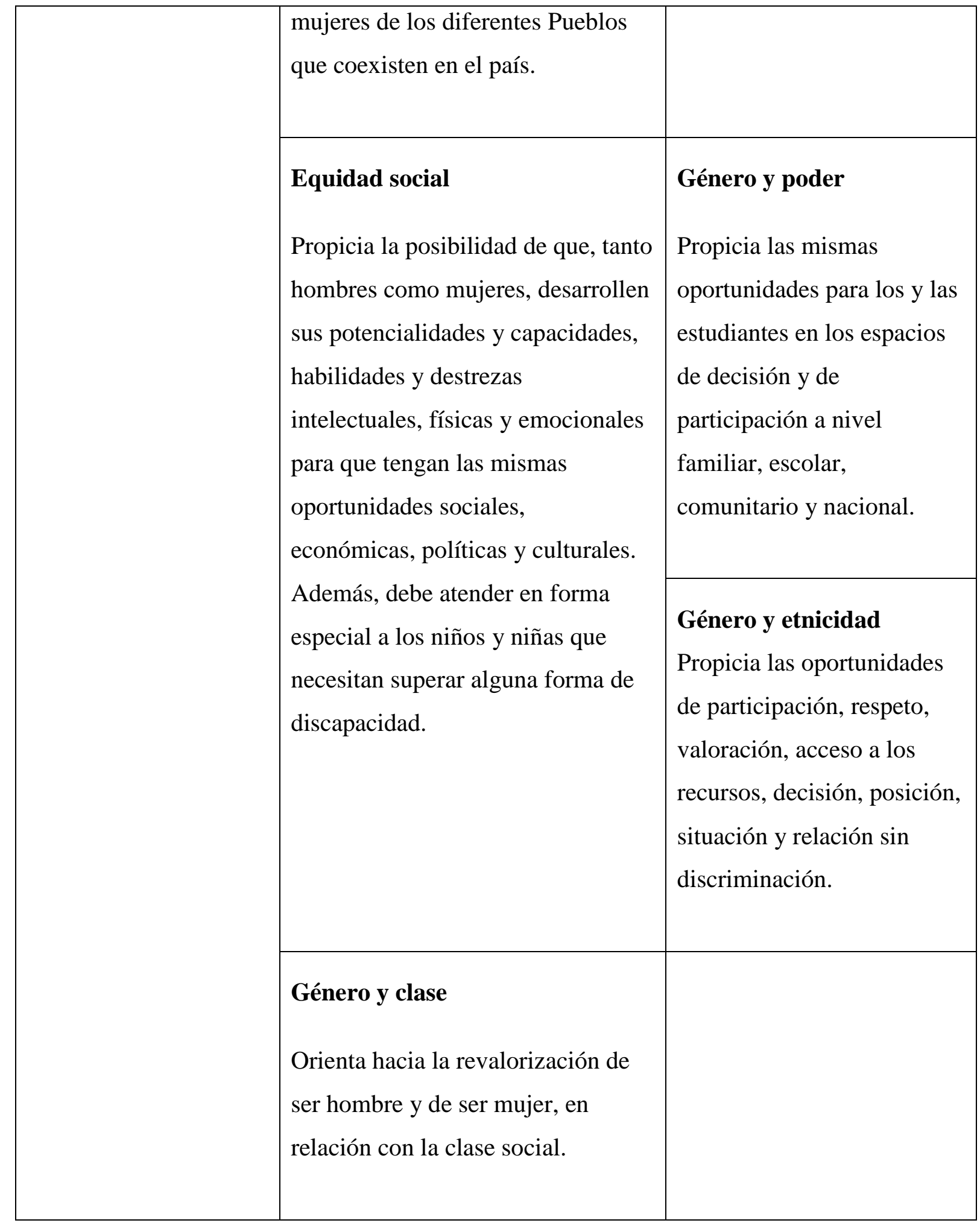

Figura 5. Eje de equidad de género, de etnia y social del CNB. MINEDUC (2008:28)

Siguiendo los conceptos desarrollados por el CNB, el eje transversal de equidad de género, de etnia y social se convierte en una base fundamental del aprender a conocer, aprender a ser, 
aprender a hacer y aprender a convivir de las nuevas generaciones de niñas, niños y jóvenes guatemaltecos. Implementar este eje transversal en las aulas ayudaría a que las nuevas generaciones desarrollen el cambio cultural necesario para avanzar en la transformación del patriarcado.

Desde los presupuestos del CNB, educadoras y educadores tienen la oportunidad de cimentar sólidamente los cuatro pilares de la educación de Delors: que su alumnado conozca la realidad actual desde los aportes tanto de los hombres como de las mujeres de todos las etnias y clases, que tenga una visión de la historia del país justa con las luchas, sufrimientos y logros de todos los sectores, especialmente las mujeres, que se acerque a las diferentes áreas de conocimiento enriqueciéndose con los aportes de investigadoras, literatas, científicas, etc. Las y los docentes, además, pueden enseñar a su alumnado a ser personas sensibles, cariñosas, no violentas, atentas a las necesidades de las demás personas, dispuestas a dar lo mejor de sí mismas por la justicia y la equidad en el país, sea desde la profesión o posición social que sea, con el reto de que esto se logra fundamentalmente a través del modelaje. Estas formas de conocer y de ser irán acompañadas de un saber hacer en consonancia, que genere prácticas sociales incluyentes, de vida armónica entre mujeres y hombres de todas las culturas del país, algo que en definitiva llevará a cambios positivos en cuanto a un convivir más justo y equitativo en Guatemala.

La conceptualización de género que realiza el CNB es amplia y abarca aspectos fundamentales como la equidad laboral, la equidad social o la educación sexual. Destaca la toma en consideración del género y autoestima que permitirá trabajar en identidades de género libres de prejuicios, sobre la base del auto-reconocimiento de cada persona como igual en derechos, oportunidades y responsabilidades. La unión de equidad de género y de etnia, haciendo constante referencia a la equidad entre mujeres y hombres de todos los pueblos que 
conforman Guatemala, refleja sensibilidad hacia la realidad multicultural del país y la necesidad de dar pasos certeros hacia la interculturalidad.

En el CNB, la concreción de la equidad de género, de etnia y social llega hasta el nivel de eje transversal. Las siguientes fases del Curriculum son las competencias de área (asignatura), de grado (nivel) y desglose de contenidos declarativos, procedimentales y actitudinales para alcanzar cada competencia de grado. En ellas no encontramos propuestas específicas para la implementación de éste ni de los demás ejes transversales.

A pesar de esta falta de concreción de lo transversal, el CNB en sí mismo constituye un documento de enfoque abierto, flexible y perfectible por cada institución educativa y por cada docente. Una de sus mayores virtudes, teniendo en cuenta la multiculturalidad de Guatemala, es que permite contextualizar los contenidos en la realidad de cada región del país. Esto aporta al proceso educativo una flexibilidad que puede convertirse en un gran potencial transformador en manos de cada docente. Sin embargo, es claro que las y los docentes se enfrentan a un fuerte reto: concretar los ejes transversales es difícil per se y a ello se suma la deficiente formación con la que cuentan.

Otra de las virtudes del CNB es la posibilidad de establecer nuevos papeles para los sujetos del hecho educativo, entre los que se incluye al alumnado, madres y padres, docentes, consejos de educación, administradores educativos, comunidad y administradores escolares. De cara a los procesos de educación para la equidad de género, de etnia y social y al cambio cultural que se precisa promover, la inclusión de las madres y padres de familia es especialmente importante. Un proyecto coeducativo difícilmente podrá alcanzar resultados sin la participación estrecha de madres y padres de familia, a través de diferentes iniciativas como puede ser una escuela de padres y madres, la inclusión de éstos en actividades escolares o su concientización para apoyar en el reparto mixto de tareas de limpieza o el trabajo mixto en una asignatura de tecnología, por ejemplo. De la misma forma, la apertura de la escuela a 
toda la comunidad en la que está inserta permitirá mejores resultados educativos desde una óptica integral. La implicación de administradores educativos y escolares que marcan pautas curriculares, por último, es un elemento clave para la transformación educativa que se plantea.

\subsection{El sistema educativo guatemalteco}

El sistema educativo guatemalteco está liderado por el Ministerio de Educación MINEDUC, con los siguientes datos generales para 2018, según el anuario estadístico del MINEDUC (2019):

\section{Tabla 5}

Estudiantes, docentes y centros educativos públicos y privados en Guatemala, 2018

Total centros públicos y

\% centros públicos

privados

Número de estudiantes

Número de docentes

Número de centros
4.239 .233

282.405

53.117
$72 \%$

$52.29 \%$

$66.12 \%$

Fuente: Elaboración propia basada en MINEDUC (2019)

http://estadistica.mineduc.gob.gt/Anuario/home.html\#

Según el mismo anuario estadístico, en 2018 en Guatemala estaban escolarizados 6 de cada 10 niñas y niños en edad escolar. Como se puede apreciar en la tabla anterior, la mayoría de estudiantes se concentra en una minoría de centros educativos públicos. Analizando la tabla desde la perspectiva del sector privado de la educación, solo un $28 \%$ de estudiantes goza del $47.71 \%$ de docentes y del $33.88 \%$ de los centros educativos. 
La educación formal en Guatemala consta de varios niveles que se encuentran bajo la dirección de entes distintos. Los niveles Inicial, Pre-Primario, Primario, Básico y Diversificado abarcan la formación reglada desde los 0 años hasta los 18 y se desarrollan bajo las directrices del Ministerio de Educación -MINEDUC-, con centros educativos públicos y multiplicidad de privados extendidos por todo el territorio nacional. El nivel universitario o educación superior cuenta con una sola universidad pública, la Universidad San Carlos de Guatemala, quien a su vez es el ente rector de este nivel educativo, y 13 universidades privadas.

El siguiente cuadro presenta la estructura simplificada del sistema educativo guatemalteco según datos de la Oficina Internacional de Educación de la UNESCO ${ }^{\text {xviii }}$. Cabe destacar que en la actualidad la formación de Magisterio Primaria se ha trasladado al nivel universitario.

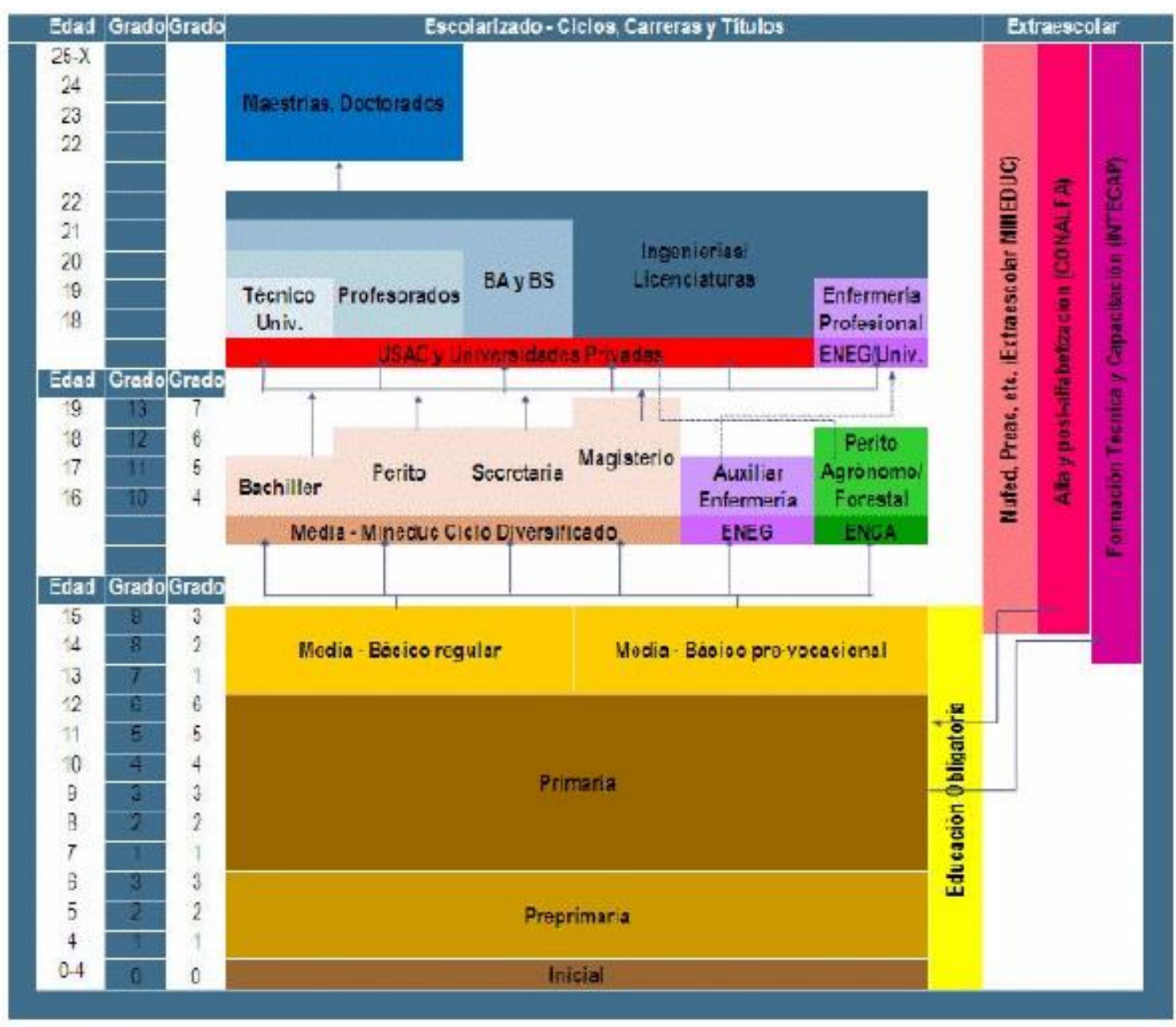

Figura 6. Estructura del sistema educativo guatemalteco. UNESCO. 
El sistema educativo, según la Ley de Educación Nacional, está conformado por el Ministerio de Educación, la Comunidad Educativa y los Centros Educativos. La escolaridad obligatoria, tal y como lo establece el artículo 74 de la Constitución Política de la República de Guatemala, abarca los niveles de Inicial a Básico, accesibles a la población a través de los centros educativos públicos promovidos por el MINEDUC. Las edades implícitas en estos niveles obligatorios abarcan de los 0 a los 15 años aproximadamente. Es necesario destacar que la educación Inicial, e incluso la Pre-Primaria, se encuentran poco desarrolladas y acotadas en edades, de manera que en la práctica la obligatoriedad de asistencia a un centro educativo se sitúa entre los 6 y los 15 años de edad. La oferta formativa para personas adultas o en sobre edad para la matriculación en los grados es escasísima por parte del MINEDUC.

Desde los aportes de una de las expertas entrevistadas en el marco de esta investigación (anexo 5), el enfoque del sistema educativo guatemalteco sería economicista, orientado a la tríada educación-empleo-ingresos, en detrimento de la creación de ciudadanía que demandaría la realidad nacional de exclusión e injusticia. Otra de las expertas alertaba sobre la necesidad de entender los sistemas educativos como espacios de los grandes grupos de poder para reproducir hegemonías. En este sentido, el sistema educativo guatemalteco estaría reproduciendo el perfil de mano de obra no cualificada que resulta útil a las élites económicas y empresariales del país, centradas en la agroexportación y la exportación de textiles desde el modelo de maquilas.

Merece la pena detenernos brevemente en la cobertura de la educación pública guatemalteca. La ampliación de esta cobertura para asegurar el derecho constitucional a la educación es una de las principales preocupaciones de los entes rectores de la educación nacional. Las Políticas Educativas de Guatemala, plasmadas en el acuerdo Ministerial 34092011, establecen la cobertura como principal línea de trabajo, seguida de la calidad y otros aspectos relativos a la mejora de la gestión. La línea de equidad también está presente en 
estas políticas, pero es enfocada únicamente como equidad cultural: "garantizar la educación con calidad que demandan las personas que conforman los cuatro pueblos, especialmente los grupos más vulnerables, reconociendo su contexto y el mundo actual”.

El Plan Estratégico de Educación 2016-2020 (MINEDUC, 2016) establece una línea de base sobre cobertura educativa en 2016 con las siguientes tasas netas de matriculación: nivel Pre-Primario 47.3\%, nivel Primario 82\%, nivel Básico 46\%, nivel Diversificado 24\%. Las metas que establece este plan buscan aumentar la cobertura de primaria, Básico y Diversificado en 4 puntos porcentuales. El mayor esfuerzo se centra en la Pre-Primaria, con una aspiración de aumento de cobertura de 12 puntos porcentuales.

\section{Cobertura nivel Pre-Primario}

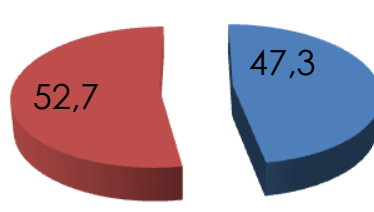

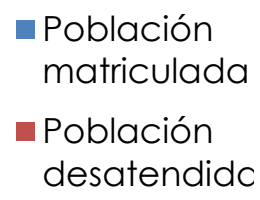

desatendidc

\section{Cobertura nivel Primario}

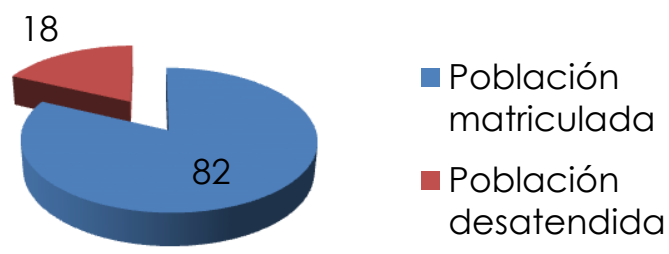

Cobertura nivel Básico
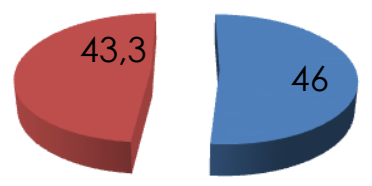

$$
\begin{aligned}
& \text { - Población } \\
& \text { matriculada } \\
& \text { - Población } \\
& \text { desatendida }
\end{aligned}
$$

\section{Cobertura nivel Diversificado}

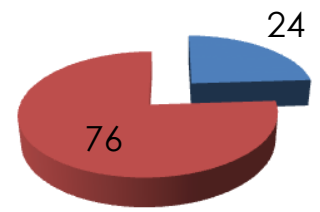

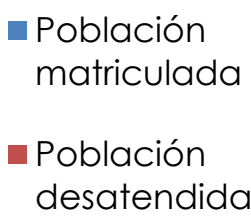

- Población

Población

Figura 7. Cobertura educativa en Guatemala en 2015. Elaboración propia basada en MINEDUC (2016:11)

Como se puede apreciar, el mayor esfuerzo se ha concentrado en la cobertura Primaria que, según el anterior Plan de Implementación Estratégica de la Educación 2012-2016 (MINEDUC, 2012), aumentó en 21.1 puntos porcentuales de 1991 a 2011 en los niveles PrePrimario y Diversificado, especialmente en algunas áreas rurales del país. Persisten serias 
carencias en el nivel Inicial, ausente incluso en las metas expuestas. Algunos estudios indican que la tasa de escolarización en el nivel Inicial se sitúa en torno al 2\%. Es necesario destacar que el Plan Estratégico de Educación 2016-2020 al que estamos haciendo referencia no presenta datos desagregados por sexo y, por lo tanto, tampoco análisis explicativos de la realidad educativa sensibles al género.

Respecto a la calidad educativa, el presente Plan Estratégico de Educación 2016-2020 no presenta ningún tipo de diagnóstico o línea de base. El anterior Plan de Implementación Estratégica de la Educación 2012-2016 ofrecía datos de diagnóstico alarmantes: "los resultados del Sistema Nacional de Evaluación e Investigación Educativa (SINEIE) reflejan que solo cinco de cada diez alumnos de sexto grado -Primaria- comprenden lo que leen" (MINEDUC, 2012:11).

La evaluación educativa de los estudiantes de nivel Diversificado realizada anualmente por el MINEDUC mediante una prueba estandarizada de contenidos mínimos de obligada realización, muestra que en 2018 solo el $11.44 \%$ de estudiantes superó la prueba de matemáticas y el $34.81 \%$, la de lectura. El informe de resultados, disponible en la web del MINEDUC ${ }^{\text {xix }}$, está desagregado por sexo, etnia y ruralidad/urbanidad, indicando mejores resultados para estudiantes ladinos que indígenas, para estudiantes de área urbana que de área rural y para estudiantes de centros educativos privados que públicos. Entre mujeres y hombres, los resultados son iguales en lectura y 5 puntos porcentuales más altos para hombres que para mujeres en matemáticas.

La prueba internacional de educación PISA-D, en la que en 2017 participaron 5.100 estudiantes de Guatemala, muestra que el $90 \%$ no alcanza el nivel esperado en lectura, matemáticas y ciencias ${ }^{\mathrm{xx}}$. Guatemala presenta uno de los resultados más bajos de América Latina, junto con la República Dominicana. 
Hay múltiples factores asociados a esta realidad de la deficiente calidad educativa del país. Entre otros, señalamos:

- Escasa cobertura y calidad de los programas bilingües, que obliga a niñas y niños a alfabetizarse en español aun cuando no sea su idioma materno.

- Falta de cobertura en educación Inicial y Pre-Primaria unida a factores culturales que retardan la edad de entrada a la escuela, dificultando el desarrollo temprano de habilidades cognitivas y motivación para el aprendizaje escolar.

- Falta de infraestructura escolar adecuada y materiales didácticos para cada materia y estudiante.

- Falta de dignificación y reconocimiento social de la profesión docente con salarios que impiden la dedicación laboral exclusiva.

- Nivel "incipiente" de supervisión y de evaluación docente (MINEDUC, 2012), fruto de la debilidad institucional del propio MINEDUC. Esto limita la línea de incidencia desde los despachos de coordinación hasta las aulas, dejando espacios propicios para la dejación de responsabilidades y corrupción en diferentes niveles.

- Y, sobre todo, fuerte rezago en la formación de maestras y maestros, en el que profundizaremos más adelante.

La escasez de cobertura y deficiente calidad de la educación pública en todos los niveles educativos favorecen la proliferación de centros educativos privados de muy diversa índole que, si bien su funcionamiento está amparado por la Ley de Educación Nacional y deben contar con la aprobación del MINEDUC, ofrecen una educación de calidad muy variable: desde los colegios de élite con excelentes resultados académicos ubicados en su mayoría en la ciudad capital y gestionados por congregaciones religiosas o reconocidas figuras del mundo académico, hasta colegios privados fundados por iniciativa particular, funcionando en casas de habitación o infraestructuras no adecuadas, cuyos resultados se ubican por debajo de los 
de los centros públicos. Los centros privados ofrecen educación en todos los niveles, desde Inicial hasta Diversificado y Universitario y cuentan con una aceptación social amplia, muy por encima de los públicos. Los centros públicos socialmente se perciben inferiores, destinados a quien no puede pagar un centro privado, aunque sea de la categoría más baja, con todo un imaginario construido alrededor de estereotipos.

En el país no se cuenta con estudios que aporten datos sobre la socialización de género que se produce en las escuelas desde el nivel Inicial hasta el Diversificado. Sí se cuenta con un estudio referido al nivel universitario, realizado por la investigadora guatemalteca Ana Lucía Ramazzini (2013), que analizó la experiencia educativa de estudiantes universitarias de la escuela de Ciencia Política de la Universidad de San Carlos desde la perspectiva de la coeducación. El estudio señala diferentes aspectos en los que las estudiantes han percibido inequidad.

\begin{tabular}{|c|c|}
\hline $\begin{array}{l}\text { Lenguaje verbal y } \\
\text { gestual }\end{array}$ & $\begin{array}{l}\text { - Transmisión de mensajes sexistas y racistas en expresiones } \\
\text { utilizadas. } \\
\text { - Uso de términos descalificativos y prejuiciosos hacia las mujeres. } \\
\text { - Lenguaje androcéntrico, excluyente y discriminador. }\end{array}$ \\
\hline Contenidos & $\begin{array}{l}\text { Desvalorización de las mujeres a través del material didáctico } \\
\text { utilizado. } \\
\text { - Se ignora a las mujeres y su obra. } \\
\text { - Poca bibliografía sobre autoras en general y sobre autoras indígenas } \\
\text { y afrodescendientes en particular. }\end{array}$ \\
\hline $\begin{array}{l}\text { Agrupaciones y } \\
\text { actividades }\end{array}$ & $\begin{array}{l}\text { - Distribución de funciones y cargos de acuerdo a roles diferenciados } \\
\text { por sexo. } \\
\text { - Asignación de trabajo secretarial a las mujeres. } \\
\text { - Descalificación a las preguntas y/o comentarios de las mujeres. }\end{array}$ \\
\hline
\end{tabular}




\begin{tabular}{|l|l|}
\hline $\begin{array}{l}\text { Relación de } \\
\text { catedrático/a }\end{array}$ & $\begin{array}{l}\text { - } \begin{array}{l}\text { Diferenciación de los niveles de exigencia, según sexo o etnia. } \\
\text { hacia las } \\
\text { estudiantes }\end{array} \\
\text { inferiores que a los hombres. }\end{array}$ \\
& $\begin{array}{l}\text { Demostraciones de abuso de poder hacia las mujeres (amenazas, } \\
\text { autoritarismo, acoso sexual...). }\end{array}$ \\
\hline
\end{tabular}

Figura 8. Percepción de equidad de género y etnia en aulas universitarias guatemaltecas. Ramazzini (2013:38).

\subsubsection{Análisis de la formación docente.}

Continuando con el análisis del sistema educativo guatemalteco, debemos detenernos en un elemento clave: la formación docente. Como evidencian Michael Barbery Mona Mourshed (2008), los sistemas educativos más exitosos del mundo tienen en común dos elementos esenciales: conseguir las personas más aptas para ejercer la docencia y ofrecerles formación y apoyo continuos para que desarrollen prácticas cada vez más eficaces.

En este sentido, la formación de docentes en Guatemala, su nivel de cualificación y calidad, es un reto de enormes dimensiones. Como se aprecia en el siguiente cuadro comparativo, Guatemala es prácticamente el único país de Centroamérica en el que las y los docentes de Pre-Primaria y Primaria pueden ejercer su profesión solo la denominada carrera media de magisterio, correspondiente nivel Diversificado. 
Comparación entre niveles, años de formación e instituciones que forman maestros del nivel preprimario y primario en Centro América

\begin{tabular}{|c|c|c|c|c|}
\hline PAís & NIVEL & $\begin{array}{l}\text { AÑOS DE } \\
\text { FORMACIÓN }\end{array}$ & $\begin{array}{l}\text { INSTITUCIONES QUE } \\
\text { LAS OFRECEN }\end{array}$ & $\begin{array}{l}\text { NÚMERO DE INSTITUCIONES } \\
\text { QUE FORMAN DOCENTES }\end{array}$ \\
\hline Guatemala & Medio & 304 & Escuelas Normales* ${ }^{*}$ & 369 \\
\hline El Salvador & Superior & 3 & Universidades & $\begin{array}{c}1 \text { Instituto docente de nivel superior y } 7 \\
\text { Universidades }\end{array}$ \\
\hline Honduras & $\begin{array}{l}\text { Superior y } \\
\text { Medio* }^{* *}\end{array}$ & $\begin{array}{l}\text { 2: nivel superior } \\
\text { 3: nivel medio }\end{array}$ & $\begin{array}{l}\text { Universidad y Escuelas } \\
\text { Normales }\end{array}$ & 1 Universidad y 8 Normales \\
\hline Nicaragua & $\begin{array}{l}\text { Superior y } \\
\text { Medio*t }\end{array}$ & $\begin{array}{l}\text { 2: nivel superior } \\
\text { 3: nivel medio }\end{array}$ & Escuelas Normales & 2 escuelas normales y 1 Universidad \\
\hline $\begin{array}{l}\text { Costa Rica } \\
\text { Panamá }\end{array}$ & $\begin{array}{l}\text { Superior } \\
\text { Superior }\end{array}$ & $\begin{array}{l}5 \\
4\end{array}$ & $\begin{array}{l}\text { Instituto Normal } \\
\text { Superior }\end{array}$ & $\begin{array}{l}4 \\
1\end{array}$ \\
\hline
\end{tabular}

Censo sobre Escuelas Normales en Guatemala 2004. Universidad Rafael Landivar. Guatemala. 2005.

* El documento fue presentado en 2004, y desde entonces han desaparecido varias entidades formadoras de docentes pero, aparecieron otras.

" En Honduras y Nicaragua se tiene una politica clara de ir desapareciendo las Escuelas Normales del nivel medio para transformar la formación de docentes de Educación Superior.

Figura 9. Comparación de formación de docentes en Centro América. MINEDUC (2012:19)

El siguiente cuadro muestra el nivel educativo mínimo exigido para ejercer docencia en cada etapa:

\section{Nivel en el que se Nivel educativo mínimo exigido ejerce docencia}

Pre-Primaria Diversificado (actualmente también existe la carrera especializada en el nivel universitario)

Primaria

Diversificado (actualmente en transición

hacia nivel universitario)

Básico

Universitario de nivel técnico en la materia que se imparte (llamado PEM, Profesor de Enseñanza media)

Diversificado Universitario de nivel técnico en la materia que se imparte (llamado PEM, Profesor de Enseñanza media) 


$\begin{array}{ll}\text { Universitario } & \text { Licenciatura en rama afín a la materia que se } \\ & \text { imparte (actualmente con tendencia a } \\ & \text { solicitud de título de máster) }\end{array}$

Figura 10. Formación mínima para ejercer docencia en Guatemala. Elaboración propia.

En los últimos años, desde los diferentes gobiernos se han iniciado acciones de cambio tendentes a elevar toda la formación docente al nivel universitario, pero encuentran múltiples resistencias y generan fuertes confrontaciones sociales. Desde 2013, el paso de la carrera de magisterio de Primaria del nivel Diversificado al universitario se puede decir que es un hecho: se ha eliminado la carrera del nivel Diversificado (encontrándose hasta el momento generalizada en la carrera universitaria de Pedagogía ya sea en nivel técnico o profesorado, o en el nivel de licenciatura) y se llevan a cabo programas de actualización docente para las y los profesionales en activo, aunque su realización es optativa.

La formación de docentes se revela como una de las variables fundamentales de esta investigación, ya que ellas y ellos son piezas clave de la intervención educativa para transformar la violencia cultural patriarcal. Para los casos de las y los docentes de PrePrimaria y Primaria, hasta que la eliminación de la carrera del nivel Diversificado sea un hecho, la escasez de años de formación recibida influye no solo en la amplitud de sus habilidades didácticas y conocimientos teóricos y prácticos, sino en la madurez que presentan al comenzar a ejercer su profesión, rondando a penas los 19 años. A continuación, analizaremos aspectos importantes de la formación de docentes relacionándolos con la formación para educar en la equidad: el curriculum de estudios, los materiales con los que se forman y sus resultados en evaluaciones diagnósticas.

El curriculum de estudios establecido para la formación de docentes de Pre-Primaria en el nivel Diversificado, disponible en la web del MINEDUC ${ }^{\mathrm{xxi}}$, no presenta ninguna asignatura específica sobre equidad de género, sobre implementación del eje curricular de "equidad de 
género, de etnia y social" o sobre implementación de ejes transversales en general. Es importante destacar que este curriculum oficial es muy general y susceptible de ser desarrollado y ampliado de diferentes formas por cada centro educativo, de manera que pueden existir centros que sí aborden la formación en género y metodologías educativas relacionadas con la coeducación en el proceso de su estudiantado.

Las entrevistas realizadas para esta investigación revelan que las y los docentes de PrePrimaria en activo no han recibido formación específica en género o implementación del eje curricular de equidad (entrevistas E01/PrPr/M y E02/PrPrH, en anexo 2). Actualmente, las universidades privadas lideran el proceso de elevar la formación de docentes de Pre-Primaria al nivel universitario. En la región de Quetzaltenango y Totonicapán, solo una de estas universidades cuenta en su curriculum de estudios con una asignatura llamada "coeducación". Se ha conocido la experiencia de una docente que imparte esta materia, quien explica que se autoformó en el momento en que le propusieron dar esa clase (entrevista E01/PrPr/M, en anexo 2). Una de las personas expertas en educación, entrevistadas en la fase de recolección de información previa en esta investigación, señalaba el hecho de que en Guatemala la mayoría de docentes son mujeres, pero esto no asegura en absoluto que estén educando en equidad de género porque ellas mismas fueron formadas en la inequidad.

La formación de maestras y maestros de Primaria en la actualidad se encuentra en pleno proceso de cambio con el paso de la carrera del nivel Diversificado al universitario. La mayor parte de docentes que ejerce en la actualidad todavía se formó con la carrera de magisterio de Primaria en nivel Diversificado. La información derivada de las entrevistas realizadas indica que no recibieron formación en equidad de género ni en implementación de ejes transversales (entrevistas E03/Pr/M y E04/Pr/H en anexos 2). Actualmente, parte de estas maestras y maestros que buscan actualizarse, así como las nuevas generaciones de docentes de Primaria, cursan profesorados universitarios (3 años de formación) o licenciaturas (5 años) en 
Pedagogía con orientación en múltiples campos: intercultural, Derechos Humanos, administración educativa y otras. También cursan estas carreras universitarias muchos de los docentes que imparten clases en el nivel Básico y Diversificado. En el curriculum de estudios universitarios, orientado por el ente rector correspondiente, la Universidad de San Carlos de Guatemala, para las carreras vinculadas a Pedagogía ${ }^{x x i i}$ no existen asignaturas específicas sobre género, equidad de género o implementación del eje curricular de equidad de género, de etnia y social. En los profesorados y licenciaturas de Pedagogía Intercultural y Pedagogía y Derechos Humanos, existe la materia de Derechos Humanos. La descripción de esta asignatura presenta temas relacionados con la igualdad de derechos para todas las personas, sin concretar aspectos vinculados con el género. Estudiantes de Pedagogía y Educación Intercultural entrevistados para esta investigación señalaron que durante su carrera universitaria no recibieron formación en género ni en implementación del eje de equidad de género, etnia y social.

Respecto a los materiales para la formación de docentes, en el nivel Diversificado éstos varían de un centro a otro, según la elección de una u otra editorial de textos educativos. En el nivel universitario, cada docente provee a las y los estudiantes los textos que considera más pertinentes haciendo uso de la libertad de cátedra. Especialmente fuera de la capital del país, donde es difícil y caro conseguir libros y revistas especializadas, los materiales formativos suelen consistir en copias de fragmentos de libros o artículos, presentaciones elaboradas por la o el docente y material disponible en internet. Sabiendo de la ausencia de materias específicas relacionadas con la educación para la equidad de género, sería muy esclarecedor realizar un análisis de género de los materiales, ejemplos, imágenes, tipos de actividades y tareas, etc. que se utilizan en todas las asignaturas, especialmente en las relacionadas con planificación curricular. Sin embargo, la diversidad de editoriales educativas en el nivel 
Diversificado y la discrecionalidad de las y los docentes para proveer materiales en el nivel universitario dificultan mucho un análisis de este tipo.

En los últimos años, el MINEDUC ha realizado esfuerzos significativos en el diagnóstico de capacidades del personal docente, valoradas a través de exámenes de comprensión lectora, matemática y habilidades docentes. Los últimos resultados disponibles abiertos al público corresponden a 2007. Según el MINEDUC (2008), en 2007 el 50\% de las y los docentes de Primaria evaluados en matemática no alcanzaron el resultado mínimo de 60 puntos y el 40\% no lo hizo en comprensión lectora. En la prueba de habilidades docentes aplicada en 2008, "las áreas de mayor dificultad evidenciadas fueron planificación, ambientación, dominio del área, desarrollo del proceso de enseñanza-aprendizaje”.

Entre los temas que formaron parte del temario para la evaluación de las capacidades de docentes en 2019, disponibles en la web del MINEDUC ${ }^{\text {xiii }}$, figuran los ejes del CNB, pero no la implementación del eje curricular de equidad de género, de etnia y social ni nada relacionado con el género.

Ante las debilidades que presenta el Ministerio de Educación para elevar el nivel de la formación docente en general, y en materia de equidad de género, de etnia y social en particular, encontramos un aporte determinante de la sociedad civil. En Guatemala existen ONG especializadas en educación que, tanto desde la educación no formal como desde procesos vinculados a Ministerio de Educación, impactan en la formación en género y equidad de maestras y maestros. Esta realidad fue resaltada por una de las personas expertas entrevistadas en la fase de recolección de información previa en esta investigación y se confirmó también al momento de identificar las experiencias significativas de coeducación en Guatemala que se expondrán más adelante, que pertenecen en su mayoría al ámbito de las ONG. 
El análisis realizado acerca de la formación docente en Guatemala nos lleva a la reflexión de que la implementación de ejes transversales como el de equidad de género, de etnia y social queda a merced de la autoformación y la creación de estrategias por cuenta propia por parte de cada profesional. Sin embargo, esto se convierte en una tarea muy compleja dadas las carencias formativas que presentan, las debilidades en la actualización permanente y los vacíos en la supervisión del desempeño desde la perspectiva de la didáctica y la calidad que sufre el sistema educativo. A favor, se cuenta con maestras y maestros participativos e interesados en transformar el sistema. Una de las expertas entrevistadas en el marco de la investigación (anexo 5) subrayaba que la gran fortaleza del sistema educativo guatemalteco son sus maestras y maestros, que están impulsando cambios trabajando en las peores condiciones.

\subsubsection{La urgencia de un cambio coeducativo en la educación guatemalteca.}

El cambio cultural hacia la igualdad de género es urgente en la mayoría de las sociedades del mundo en las que, con diferencias importantes, persiste la exclusión y diversas formas de violencia contra las mujeres. La observación que realiza Subirats (s/f) respecto al contexto español es perfectamente extrapolable a la realidad guatemalteca:

fenómenos [...] como la iniquidad de una violencia de género masculino cada vez más mortífera, la violencia que se manifiesta en los centros educativos, la profunda desorientación y amplio fracaso escolar de los chicos, las dificultades con que las chicas encaran su vida adulta, con exceso de responsabilidades que les resultan agobiantes, nos muestran que cambiar algunos elementos de nuestra cultura no es solo una cuestión de justicia y equidad, es también una cuestión de supervivencia y felicidad. (p.4) 
Sin duda, desde la pedagogía crítica se puede aportar decisivamente a la construcción de la igualdad de género. Un enfoque muy relevante en esta tarea es la coeducación. Tal como afirma Simón (2010), la coeducación debe darse desde todos los agentes socializadores:

la coeducación es una necesidad urgente, responsabilidad obligada para todas las instancias socializadoras, como mecanismo de intervención que valorice lo femenino y lo eleve a categoría de humano universal, arrebatando el monopolio al androcentrismo, oriente proyectos mixtos de vida, destruya mitos negativos para ellas y ellos, proponga modelos de innovación, reconocimiento y pacto y complete los saberes. Muchos y buenos métodos, prácticas y descubrimientos son necesarios para que esta intervención dé sus frutos en forma de igualdad, libertad, diversidad, paz, salud y convivencia. (p.98)

Y entre todos los agentes socializadores, la escuela tiene un peso fundamental. En Guatemala, es imprescindible colocar la mirada sobre la escuela, es decir, sobre el sistema educativo. Partiendo de valorar la importancia de la educación para los cambios sociales que demanda el país, Guatemala debe asumir la responsabilidad de transformar el sistema educativo, invirtiendo los recursos necesarios para convertirlo en una herramienta del Estado para responder a su compromiso constitucional de construir una sociedad más equitativa.

Las transformaciones profundas que requiere el sistema educativo guatemalteco comienzan en la propia ideología de la educación. En el debate sobre qué ideología debe contener la educación para estar orientada hacia la equidad, es necesario retomar las problemáticas de la democracia liberal que identifica Arnot (2009), citadas por Aguilar (2006b): debemos apostar por una educación que transforme el contrato sexual que divide las esferas privada y pública, que resignifique la categoría politica de "mujer” con atributos y prácticas basados en la igualdad de los géneros y, en definitiva, que elimine la generización del Estado. La coeducación con enfoque interseccional es muy pertinente para materializar 
estas transformaciones y empujar el cambio cultural urgente hacia la equidad de género, de etnia y social en Guatemala.

En la transformación del sistema educativo guatemalteco, la atención debe centrarse muy especialmente en el sector público, por dos motivos principales: a) lo público es el ámbito de responsabilidad del Estado, el terreno en el que éste debe cumplir su rol como titular de obligaciones desde el enfoque de Derechos Humanos; b) actualmente, lo público concentra el mayor porcentaje de población estudiantil del país y no puede obviar su compromiso de seguir creciendo en cobertura y calidad, ya que 4 de cada 10 niñas y niños en edad escolar continúan sin estar escolarizados.

En Guatemala hoy, más de 20 años después de la firma de los Acuerdos de Paz, la Reforma Educativa, que incluye cambios orientados a la equidad en general, no se ha llegado a realizar en su totalidad. La falta de compromiso del Estado de Guatemala con la educación es flagrante y se refleja claramente en la insuficiente inversión anual de presupuesto. Además, la propia Reforma Educativa debe ser revisada y mejorada desde la perspectiva de género y de coeducación con enfoque interseccional. Sin embargo, es importante visibilizar que existe un marco jurídico e instrumentos que hacen viable comenzar a trabajar desde ya en la educación para la equidad de género, de etnia y social en las aulas, desde el nivel Inicial al Diversificado. Y esto contribuirá, paralelamente, a abordar otros cambios para transformar el sistema educativo y el sistema social, político y económico del país.

Subirats (1998) insiste en que las transformaciones de los sistemas educativos deben ser graduales, sin despreciar los pequeños cambios y avances en aras de una transformación total. Respecto a la realidad de América Latina, Subirats (1998) realiza una apreciación muy adecuada para el contexto guatemalteco actual:

en América Latina, dado que en muchos países coexisten sectores de mujeres analfabetas o de niñas no escolarizadas junto a un acceso ya amplio de las mujeres a 
las Universidades, hay que establecer un sistema de prioridades. Prioridades que, si partimos de la necesidad de utilizar la educación como instrumento de desarrollo económico y de lucha contra la pobreza, tanto a nivel individual como colectivo, supone enfatizar en primer lugar la extensión de la educación a todas las niñas y la alfabetización y formación ocupacional de las mujeres adultas, como primer paso para alcanzar la igualdad, siguiendo después hacia medidas que no incidan ya sólo en el acceso de las mujeres a la educación sino en la modificación del sistema educativo. (p.14)

Subirats (1998) propone una tabla que resulta útil para realizar un análisis sistemático de las necesidades del sistema educativo guatemalteco para abordar su transformación hacia la coeducación. La autora señala una serie de dimensiones de los sistemas educativos en las que es necesario intervenir y cuatro niveles de políticas o fases de prioridad que deben implementarse progresivamente.

\begin{tabular}{|c|c|c|c|c|c|}
\hline & & \multicolumn{4}{|c|}{ Fases de prioridad } \\
\hline & & Acceso & Unificación & $\begin{array}{l}\text { Visibilidad } \\
\text { mujeres }\end{array}$ & Coeducación \\
\hline \multirow{3}{*}{ 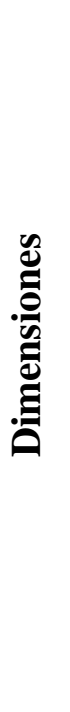 } & Legislación & $\begin{array}{l}\text { Remoción de } \\
\text { obstáculos y } \\
\text { escuela } \\
\text { obligatoria }\end{array}$ & $\begin{array}{l}\text { Prohibición } \\
\text { discriminaciones }\end{array}$ & $\begin{array}{l}\text { Énfasis en } \\
\text { igualdad }\end{array}$ & $\begin{array}{l}\text { Inclusión } \\
\text { aprendizajes } \\
\text { "femeninos" } \\
\text { Transversalidad }\end{array}$ \\
\hline & $\begin{array}{l}\text { Acceso } \\
\text { alumnas }\end{array}$ & $\begin{array}{l}\text { Campaña } \\
\text { institucional }\end{array}$ & $\begin{array}{l}\text { Seguimiento } \\
\text { estadístico }\end{array}$ & $\begin{array}{l}\text { Seguimiento } \\
\text { estadístico }\end{array}$ & $\begin{array}{l}\text { Seguimiento } \\
\text { estadístico }\end{array}$ \\
\hline & Estructura & Cobertura & Centros mixtos & Momentos & Unificación \\
\hline
\end{tabular}




\begin{tabular}{|c|c|c|c|c|}
\hline centros & máxima & & separados & espacios \\
\hline $\begin{array}{l}\text { Estructura } \\
\text { curricular }\end{array}$ & $\begin{array}{l}\text { Adaptación a } \\
\text { posibilidades } \\
\text { mujeres }\end{array}$ & $\begin{array}{l}\text { Unificación } \\
\text { curricular }\end{array}$ & $\begin{array}{l}\text { Análisis de } \\
\text { carencias } \\
\text { para las } \\
\text { mujeres } \\
\text { e introducción } \\
\text { temas } \\
\text { "femeninos" }\end{array}$ & $\begin{array}{l}\text { Transversalidad } \\
\text { valores y } \\
\text { materias } \\
\text { relativos a } \\
\text { reproducción }\end{array}$ \\
\hline $\begin{array}{l}\text { Libros de } \\
\text { texto }\end{array}$ & $\begin{array}{l}\text { Adaptación } \\
\text { niveles } \\
\text { culturales de } \\
\text { las } \\
\text { mujeres }\end{array}$ & $\begin{array}{l}\text { Unificación de } \\
\text { los libros de } \\
\text { texto }\end{array}$ & $\begin{array}{l}\text { Análisis } \\
\text { lenguaje y } \\
\text { ausencia de } \\
\text { mujeres }\end{array}$ & $\begin{array}{l}\text { Equilibrio de } \\
\text { presencia } \\
\text { y temas } \\
\text { masculinos } \\
\text { y femeninos }\end{array}$ \\
\hline $\begin{array}{l}\text { Curriculum } \\
\text { oculto }\end{array}$ & $\begin{array}{l}\text { Análisis } \\
\text { tratamiento } \\
\text { de las } \\
\text { mujeres }\end{array}$ & $\begin{array}{l}\text { Inclusión de } \\
\text { las mujeres en } \\
\text { actividades } \\
\text { valoradas }\end{array}$ & $\begin{array}{l}\text { Análisis } \\
\text { práctica } \\
\text { educativa: } \\
\text { atención, } \\
\text { espacios }\end{array}$ & $\begin{array}{l}\text { Equilibrio de } \\
\text { valores } \\
\text { y tratamiento }\end{array}$ \\
\hline Lenguaje & $\begin{array}{l}\text { Eliminación } \\
\text { términos } \\
\text { peyorativos }\end{array}$ & $\begin{array}{l}\text { Eliminación } \\
\text { términos } \\
\text { peyorativos }\end{array}$ & $\begin{array}{l}\text { Análisis } \\
\text { ausencia } \\
\text { referencia a } \\
\text { mujeres } \\
\text { e introducción } \\
\text { de cambios }\end{array}$ & $\begin{array}{l}\text { Lenguaje con } \\
\text { presencia } \\
\text { equilibrada } \\
\text { femenina y } \\
\text { masculina }\end{array}$ \\
\hline $\begin{array}{l}\text { Actividades } \\
\text { deportivas }\end{array}$ & $\begin{array}{l}\text { Realización } \\
\text { actividades } \\
\text { "femeninas" }\end{array}$ & $\begin{array}{l}\text { Inclusión en } \\
\text { actividades } \\
\text { mixtas }\end{array}$ & $\begin{array}{l}\text { Revaloración } \\
\text { actividades } \\
\text { femeninas }\end{array}$ & $\begin{array}{l}\text { Inclusión de los } \\
\text { hombres en } \\
\text { actividades }\end{array}$ \\
\hline
\end{tabular}




\begin{tabular}{|c|c|c|c|c|}
\hline & & & & femeninas \\
\hline $\begin{array}{l}\text { Capacitación } \\
\text { y formación } \\
\text { profesional }\end{array}$ & $\begin{array}{l}\text { Adaptación a } \\
\text { posibilidades } \\
\text { inmediatas. } \\
\text { Reciclajes y } \\
\text { formación } \\
\text { continua }\end{array}$ & $\begin{array}{l}\text { Unificación } \\
\text { formación } \\
\text { profesional }\end{array}$ & $\begin{array}{l}\text { Estímulos } \\
\text { diversificación } \\
\text { profesional }\end{array}$ & $\begin{array}{l}\text { Equilibrio } \\
\text { hombres } \\
\text { mujeres } \\
\text { en todos los } \\
\text { estudios } \\
\text { profesionales }\end{array}$ \\
\hline Profesorado & $\begin{array}{l}\text { Adecuación } \\
\text { a } \\
\text { necesidades } \\
\text { mujeres }\end{array}$ & $\begin{array}{l}\text { Unificación } \\
\text { profesorado }\end{array}$ & $\begin{array}{l}\text { Análisis } \\
\text { situaciones } \\
\text { diferenciales y } \\
\text { promoción } \\
\text { profesoras }\end{array}$ & $\begin{array}{l}\text { Equilibrio } \\
\text { hombres } \\
\text { mujeres } \\
\text { en todas las } \\
\text { posiciones } \\
\text { docentes }\end{array}$ \\
\hline
\end{tabular}

Figura 11. Niveles de políticas y dimensiones de intervención para transformar un sistema educativo hacia la coeducación. Subirats (1998:16)

Como se puede observar, el enfoque de Subirats está centrado en la equidad de género. En el caso guatemalteco, es necesario ampliarlo hacia la equidad de género, de etnia y social, al menos. A continuación, se propone una adaptación de los cuatro niveles de políticas de Subirats (1998), orientados hacia la coeducación con enfoque interseccional.

1. Acceso: políticas que promuevan el acceso de las mujeres, principalmente indígenas, y colectivos excluidos a las diferentes dimensiones del sistema educativo.

2. Unificación: políticas que eliminen cualquier tipo de acción educativa segregada por sexo, etnia, clase y otras categorías.

3. Visibilidad: políticas que permitan visibilizar en todos los niveles del sistema educativo a las mujeres, principalmente indígenas, y colectivos excluidos. 
4. Coeducación: políticas que visibilicen en todos los niveles del sistema educativo los aportes de mujeres y hombres, de los diversos pueblos y de toda la diversidad existente.

La tabla de Subirats (1998) nos ayuda a identificar cuál es el estado del sistema educativo guatemalteco en la actualidad. Podríamos afirmar que los avances en la dimensión legislativa son muy aceptables, a pesar de que sería deseable mayor concreción en las políticas educativas con el objetivo de eliminar de la ideología y práctica educativa todas las discriminaciones por género, etnia, clase social y otras categorías. Así mismo, sería deseable que en el CNB la equidad de género, de etnia y social no constituyera solo un eje transversal, sino que también se concretara en contenidos específicos para darle más fuerza y aplicabilidad.

En la dimensión del acceso, se puede afirmar que la educación de todas las niñas es una meta casi alcanzada solo hasta el nivel primario, que es totalmente insuficiente. Además, las profundas deficiencias en la calidad educativa menoscaban los logros de la cobertura, limitando el potencial liberador y transformador de la educación. Así mismo, queda muchísimo por hacer en materia de alfabetización de mujeres adultas y, mucho más, en formación ocupacional. En cuanto al registro estadístico, es muy deficiente en el país en general. En materia de educación existen datos desagregados por sexo, etnia y ruralidad/urbanidad, fundamentalmente, pero hay debilidades en su seguimiento sistemático, dificultando la generación de información periódica sobre categorías relevantes para la mejora continua y sobre la cual basar el diseño de políticas públicas.

La estructura de centros educativos ha superado el nivel de unificación, pero existen rezagos en la cobertura máxima, como se ha explicado, y mucho más en la visibilidad de mujeres y colectivos excluidos.

En la dimensión de la estructura curricular, el CNB constituye una herramienta progresista que brinda muchas posibilidades, incluyendo el trabajo en equidad de género, de 
etnia y social propuesto como eje transversal. El principal escollo para su aplicación se encuentra en la formación docente.

En todas las demás dimensiones que propone Subirats (1998), la situación actual del sistema educativo guatemalteco se corresponde con los niveles de acceso o de unificación.

En definitiva, el sistema educativo guatemalteco tiene interesantes fortalezas para la aplicación de la educación para la equidad de género, de etnia y social, pero también presenta debilidades de diversa índole que dificultan esta labor. Sin duda, el elemento más determinante son las debilidades en la formación docente.

Una de las perspectivas para comenzar a abordar el reto de la transformación del sistema educativo es la formación del profesorado en pedagogía crítica y coeducación con enfoque interseccional. Exigir que este esfuerzo provenga del propio sistema liderado por el Ministerio de Educación, lo que Subirats (1998:32) llama un cambio desde arriba, coloca una carga demasiado pesada sobre este ente y su débil estructura, que no cuenta con los recursos para responder ni siquiera a políticas de mínimos y que, además, se presume cooptado por intereses afines al mantenimiento del estatus quo en el país. Sin embargo, hay otro conjunto de actores que tienen mucho que aportar a la formación crítica del profesorado en Guatemala desde espacios educativos públicos, privados, formales y no formales. Uno de ellos son las universidades, que pueden organizar los curriculum de estudios con amplia autonomía, introduciendo formación en género, interseccionalidad, coeducación, metodologías de aula y de organización escolar ligadas a la pedagogía crítica. La Universidad de San Carlos de Guatemala, como ente rector del nivel universitario en el país, es una institución de tradición progresista que históricamente ha sido bastión de importantes luchas sociales. Sin duda, está llamada a liderar un cambio hacia la pedagogía crítica y la coeducación con enfoque interseccional en la formación universitaria del profesorado. Otro actor fundamental son las organizaciones de la sociedad civil que tienen mucho que aportar a procesos de formación 
crítica para el profesorado desde el ámbito no formal e incluso llevando experiencias y metodologías a las aulas universitarias. Una de las expertas entrevistadas en la fase de recolección de información previa de esta investigación (anexo 5) enfatizaba el papel que deben tener las organizaciones feministas en la transformación del sistema educativo: necesitamos estar más pendientes de lo que está ocurriendo dentro de las clases. E iríamos más allá: también intervenir en las aulas, a través de la formación del profesorado.

Todo lo anterior significa, en palabras de Subirats (1998), impulsar un cambio desde abajo. La autora lo define como:

aquellas situaciones en las que el impulso de cambio se inicia en la sociedad civil, ya sea en instituciones $\mathrm{u}$ organizaciones intermedias — sindicatos, organizaciones religiosas o civiles, organizaciones no gubernamentales, asociaciones de mujeres, movimientos de renovación pedagógica- ya sea en grupos de mujeres o de docentes que consideran necesario modificar las condiciones de educación de las mujeres. (p.32)

El cambio desde abajo presenta muchas dificultades, entre ellas la de tener un alcance más limitado que el cambio impulsado desde la institucionalidad educativa y de igualdad de un país (Subirats, 1998). Para enfrentar estas dificultades, Subirats (1998) recomienda: a) que las acciones coeducativas partan siempre de un diagnóstico, asegurando que están bien orientadas, b) que los agentes que impulsan el cambio hacia la coeducación cuenten con argumentación suficiente para legitimar su intervención ante probables resistencias, siendo las recomendaciones de organismos internacionales una buena fuente de argumentación, y c) aprovechar todos los recursos humanos y metodológicos existentes para evitar el desgaste de las personas y organizaciones.

En Guatemala, es fundamental que la transformación de la educación impulsada desde abajo se realice con un fuerte componente de incidencia política para empujar cambios en las 
instituciones del Estado vinculadas a la educación y la equidad: el Ministerio de Educación y la SEPREM, entre otras. Subirats (1998) expresa la conveniencia de que esto sea así:

aunque hemos distinguido entre los cambios generados desde el gobierno y los generados desde la base, es posible y deseable que se dé una combinación de ambos, de modo que puedan sumarse las acciones al nivel macro y al nivel micro social. Cuando ello es así, es sumamente recomendable que los gobiernos incorporen a las mujeres que han trabajado y han reflexionado sobre este tema a las acciones institucionales. En efecto, ellas son, de hecho, las expertas, las personas más capacitadas para llevar a cabo estas transformaciones, dado que han acumulado un saber y una experiencia que no suele encontrarse en ningún otro ámbito de la sociedad, y que generalmente no se mide en titulaciones académicas. (p.34)

En cuanto a los énfasis que debe tener la coeducación con enfoque interseccional en Guatemala, una de las personas expertas entrevistadas en el marco de esta investigación (anexo 5) asegura que la coeducación es educación política y que en Guatemala debe integrar necesariamente la educación integral en sexualidad, la interculturalidad y la formación política y ciudadana. Esta visión amplia es muy pertinente al contexto de profundas exclusiones que se vive en el país, analizado desde la interseccionalidad. Respecto a la educación integral en sexualidad, equivalente a la educación afectivo-sexual, otra de las expertas recuerda que es precisamente en la sexualidad donde se explota a las personas, especialmente a las mujeres, y por eso la educación integral en sexualidad es imprescindible. Este aporte puede enlazarse con la defensa del territorio cuerpo-tierra del feminismo comunitario y nos ayuda a recuperar la centralidad del cuerpo en la toma de conciencia feminista de "lo personal es político".

En conclusión, podemos afirmar que en Guatemala es necesario consolidar una masa crítica de sociedad civil que demande al Estado un giro en el sistema educativo hacia la 
pedagogía crítica y la coeducación con enfoque interseccional y que aporte a la formación del profesorado a través de sus organizaciones y de su capacidad de incidencia política. Maestras y maestros formados en estos enfoques pueden transformar su práctica en las aulas y contribuir con ello a transformar el sistema educativo, formando ciudadanas y ciudadanos críticos y comprometidos con un Estado más justo e incluyente, construido desde la pluralidad y la igualdad de las diferencias.

\subsection{3. ¿En qué se concreta un proyecto coeducativo desde el enfoque interseccional?}

Un proyecto coeducativo con enfoque interseccional puede realizarse a nivel de un centro educativo, generando una experiencia piloto que brinda aprendizaje y que puede ser replicable. Siguiendo a Simón (2010:195), observamos la siguiente clasificación de ámbitos escolares en los que trabajar la coeducación: "la organización del centro -escuela-, sus componentes (docentes, estudiantes, familias y personal no docente), el propio proyecto educativo y curricular, las actividades de aula”. En todos estos ámbitos es necesario trabajar tanto desde el curriculum explícito como -muy especialmente- desde el curriculum oculto. Así, el proyecto de coeducación con enfoque interseccional necesariamente debe partir del diagnóstico y reflexión crítica sobre las prácticas que se llevan a cabo en la realidad de un aula o escuela, pasándolas del plano inconsciente en el que se sitúan los estereotipos al plano de lo consciente y planificado.

Tras el diagnóstico, llegamos al momento de pensar estrategias y acciones para transformar las prácticas existentes y/o introducir prácticas nuevas. Algunas ideas para la reflexión y diseño de estrategias de coeducación con enfoque interseccional son:

a. Organización de la escuela: ¿quiénes ocupan los cargos de responsabilidad en la escuela? ¿Cómo se asignan estos cargos? En las directivas que puedan formarse para 
representación de aulas o realización de actividades, ¿participan chicas y chicos por igual y de todas las procedencias étnicas y sociales y otras categorías de diversidad? ¿Chicas y chicos utilizan de forma equitativa los espacios de recreación de la escuela? ¿Con base en qué se asignan responsabilidades como limpieza, preparar o servir comida, cargar muebles o transportar útiles, etc.? ¿Qué valores promueven y qué estereotipos refuerzan las actividades que se organizan desde la escuela?

b. Docentes, estudiantes, familias y personal no docente: ¿las y los maestros se relacionan con las y los estudiantes de forma equitativa y sin fomentar prejuicios? ¿Qué tareas se asignan a maestras y a maestros para el buen funcionamiento de la escuela? ¿Cómo participan maestras y maestros de las diferentes etnias si las hubiera en las directivas, reuniones, etc.? ¿Se dan situaciones de acoso sexual y, en su caso, cómo se interviene sobre ellas? ¿Se premian o castigan las mismas actitudes y comportamientos en chicas y chicos? ¿Existe permisividad hacia pequeños abusos de fuerza, poder, acoso, etc. que se consideran "cosas de chicos”? ¿Se convoca a madres y padres de familia por igual a las reuniones? ¿Qué temas se tratan con ellas y ellos? ¿Existen prejuicios hacia la educación en los hogares que reciben las chicas y los chicos en función de su etnia y procedencia social? ¿Y en función del tipo de familia en el que viven -madre y padre, solo madre, solo padre, etc.-? ¿Qué funciones realizan las mujeres y hombres del personal no docente de la escuela -guardianía, limpieza, secretariado, atención al público, etc.-de las diferentes etnias y procedencias sociales?

c. Proyecto educativo y actividades de aula: ¿se destaca en las diferentes materias el aporte de científicas, literatas, investigadoras, etc. de todas las etnias y procedencias sociales? ¿Maestras y maestros se dirigen a las y los estudiantes con lenguaje inclusivo, sin utilizar palabras, expresiones, etc. que desvaloricen a ningún grupo? ¿Se promueve que chicas y chicos, de las diferentes etnias y procedencias sociales y otras categorías de diversidad 
realicen todas las actividades y materias por igual como deportes, costura, cocina, tecnología, etc.? ¿Se promueve que tanto chicas como chicos expresen sus sentimientos y emociones y sean cariñosos y no agresivos? ¿Se trabaja con materiales didácticos que presenten ejemplos de cambio de roles tradicionales de género? ¿Se aplican metodologías y actividades de aula que promuevan la convivencia mixta y el conocimiento mutuo de chicas y chicos de todas las etnias y procedencias sociales?

Para comenzar a trabajar la implementación del eje de equidad de género, de etnia y social una premisa importante es dejar a un lado posturas absolutistas que defiendan el "todo o nada", pues solo llevan al bloqueo de iniciativas. Seguimos en este sentido la postura de Subirats (1998): por supuesto, lo ideal sería la transformación total del sistema educativo guatemalteco o, al menos, la implementación de proyectos coeducativos con enfoque interseccional a nivel departamental o municipal. Sin embargo, se puede comenzar por un proyecto de educación con enfoque interseccional en una escuela, promovido por un pequeño grupo de docentes o incluso por una sola maestra o maestro. Se trata de ir abriendo camino, experimentando y fortaleciendo experiencias que después puedan replicarse.

\subsubsection{Experiencias significativas en educación para la equidad de género en}

\section{Guatemala.}

La implementación del eje curricular de equidad de género, etnia y social se está llevando a cabo de diversas formas en Guatemala. Desde el Ministerio de Educación, como ente encargado de orientar y supervisar los procesos educativos del país, no existe un lineamiento específico para llevar a la práctica el eje curricular que nos ocupa. En cuanto a la forma de aplicación de este eje en cada escuela, la falta de concreción del CNB al respecto hace que la iniciativa quede actualmente en manos de cada directora o director de escuela o de cada maestro o maestra. En la región estudiada en esta investigación (Quetzaltenango y 
Totonicapán), entre las maestras y maestros se aprecian niveles dispares de conocimiento sobre el eje y también de compromiso con la implementación del mismo. No se ha tenido noticia de ninguna escuela pública que cuente con un proyecto de centro orientado a la educación para la equidad de género, etnia y social. Cabe destacar que, coordinadas por la Unidad de Género y Pertinencia Étnica -UNEGEPE- del Ministerio de Educación, en las escuelas públicas se realizan programas encaminados a la reducción de la violencia y la educación sexual, pero con una implementación irregular y sometida a las derivas causadas por los posicionamientos de sectores ultraconservadores.

Las experiencias más significativas que se han hallado en la región estudiada pertenecen al ámbito de las organizaciones no gubernamentales. Para identificar las experiencias, se realizó una investigación amplia, contactando con 10 organizaciones de las cuales 2 son feministas y otra constituye una red que aglutina a 22 organizaciones feministas del país.

Las experiencias encontradas corresponden a PRODESSA, Fe y Alegría e IGER, organizaciones mixtas de origen vinculado con congregaciones religiosas. Es sumamente interesante comprobar el papel de la sociedad civil en el impulso de los cambios culturales que el Estado no quiere realizar, demostrando una vez más en la historia de Guatemala y de América Latina que las transformaciones se realizan desde la lucha comprometida de la sociedad civil organizada.

Dentro de la acción de las ONG dedicadas a la educación encontramos tres tipos de posicionamiento respecto al Estado, que se derivan de la propia misión de cada organización: a) las ONG que funcionan de forma desvinculada del Ministerio de Educación, ofreciendo un servicio complementario en ámbitos a los que lo público no llega; b) las que trabajan de la misma forma pero con convenios por los cuales el Ministerio de Educación financia parte de su actividad y c) las que refuerzan la acción de las escuelas públicas, generando una alianza 
público-privada entre la ONG y el Ministerio de Educación. Cada una de las experiencias que se explica a continuación se enmarca en uno de los posicionamientos explicados.

\subsubsection{Avance de la Reforma Educativa: PRODESSA.}

\begin{tabular}{|c|c|}
\hline $\begin{array}{l}\text { Nombre de la } \\
\text { organización }\end{array}$ & Proyecto de Desarrollo Santiago -PRODESSA. \\
\hline $\begin{array}{l}\text { Intervención general en } \\
\text { educación }\end{array}$ & $\begin{array}{l}\text { Apoyo a la calidad educativa e implementación de la Reforma } \\
\text { Educativa en escuelas públicas; formación superior de docentes; } \\
\text { incidencia en políticas públicas relacionadas con la educación. }\end{array}$ \\
\hline $\begin{array}{l}\text { Intervención en } \\
\text { educación para la } \\
\text { equidad }\end{array}$ & $\begin{array}{l}\text { Formación de docentes para la aplicación de la Reforma } \\
\text { Educativa en las aulas (equidad de género, interculturalidad, } \\
\text { etc.). Acompañamiento técnico- pedagógico en el aula. }\end{array}$ \\
\hline Modalidad & $\begin{array}{l}\text { Programa de lectoescritura comprensiva con énfasis en } \\
\text { Derechos Humanos, interculturalidad y equidad de género. } \\
\text { Personal de PRODESSA que coordina el proyecto en cada } \\
\text { región del país capacita a las y los docentes sobre la Reforma } \\
\text { Educativa, la aplicación de las aulas del material específico del } \\
\text { proyecto y da seguimiento a esta aplicación. Actividades con } \\
\text { padres y madres de familia, comunidad y autoridades educativas } \\
\text { del Estado en cada región. }\end{array}$ \\
\hline Área de intervención & A nivel nacional. \\
\hline $\begin{array}{l}\text { Relación con el } \\
\text { MINEDUC }\end{array}$ & Alianza para reforzar la formación docente. \\
\hline ¿El proyecto incluye & Sí. \\
\hline
\end{tabular}




\begin{tabular}{|c|c|}
\hline $\begin{array}{l}\text { actividades con docentes } \\
\text { y alumnado? }\end{array}$ & \\
\hline Actividades & $\begin{array}{l}\text { Docentes aplican estrategias pedagógicas en las aulas, } \\
\text { planificadas para educar en la equidad de género, de etnia y } \\
\text { social, apoyándose en material didáctico y asesoramiento } \\
\text { facilitado por el proyecto. }\end{array}$ \\
\hline $\begin{array}{l}\text { ¿El proyecto cuenta con } \\
\text { material didáctico } \\
\text { específico? }\end{array}$ & Sí. \\
\hline $\begin{array}{l}\text { Tipo de material y su } \\
\text { aplicación }\end{array}$ & $\begin{array}{l}\text { Libro “¿Podrá ser diferente?” con lecturas para construir la } \\
\text { equidad de género dirigidas a alumnado de primaria. Guía } \\
\text { docente para trabajar en el aula con las lecturas. }\end{array}$ \\
\hline
\end{tabular}

El Proyecto de Desarrollo Santiago -PRODESSA- es una ONG de tradición lasallista que desde 1989 apoya procesos de desarrollo integral entre la población indígena de Guatemala. Tal y como indica su misión ${ }^{\text {xxiv }}$, la educación y la incidencia en las políticas públicas que "aseguren la equidad y la calidad de vida para contribuir a la construcción de una sociedad intercultural, equitativa y justa" son parte esencial de su quehacer. En coherencia, PRODESSA apoya la implementación de la Reforma Educativa a través de diversos programas como el programa de lectoescritura comprensiva con énfasis en Derechos Humanos, interculturalidad y equidad de género titulado Kemon Ch'ab'äl, que cuenta con material educativo en cinco idiomas mayas y se aplica en 14 departamentos del país. Se busca que la educación sea realmente un proceso liberador de los pueblos, para lo cual debe cumplir los requisitos de "calidad, criticidad y pertinencia cultural". 
2.9.4.2. Fe y Alegría, apuesta institucional por la equidad de género.

\begin{tabular}{|c|c|}
\hline Nombre de la organización & Fe y Alegría Guatemala. \\
\hline $\begin{array}{l}\text { Intervención general en } \\
\text { educación }\end{array}$ & $\begin{array}{l}\text { Movimiento de educación popular y promoción social. } \\
\text { Co-gestión de escuelas en las áreas más excluidas } \\
\text { (comunidad, Estado y Fe y Alegría). }\end{array}$ \\
\hline $\begin{array}{l}\text { Intervención en educación para } \\
\text { la equidad }\end{array}$ & $\begin{array}{l}\text { Aplicación de la política de género institucional al } \\
\text { proyecto educativo de un internado mixto. }\end{array}$ \\
\hline Modalidad & $\begin{array}{l}\text { Educación presencial directa mediante maestras y } \\
\text { maestros contratados por la organización. } \\
\text { Acompañamiento por parte de personal coordinador de } \\
\text { Fe y Alegría en cada región. }\end{array}$ \\
\hline Área de intervención & Departamento de Huehuetenango. \\
\hline Relación con el MINEDUC & Convenio de pago de docentes por parte del Estado. \\
\hline $\begin{array}{l}\text { ¿El proyecto incluye } \\
\text { actividades con docentes y } \\
\text { alumnado? }\end{array}$ & Sí. \\
\hline Actividades & $\begin{array}{l}\text { Capacitaciones sobre equidad de género a docentes; } \\
\text { diseño de un proyecto de centro de educación para la } \\
\text { equidad. }\end{array}$ \\
\hline $\begin{array}{l}\text { ¿El proyecto cuenta con } \\
\text { material didáctico específico? }\end{array}$ & Sí, especialmente dirigido a docentes. \\
\hline
\end{tabular}


Fe y Alegría, fundada en 1960 por el jesuita José María Vélaz, es un movimiento internacional de educación popular integral y promoción social "basado en los valores de justicia, libertad, participación, fraternidad, respeto a la diversidad y solidaridad, dirigido a la población empobrecida y excluida, para contribuir a la transformación de las sociedades", como indica su misión institucional ${ }^{\mathrm{xxv}}$. Fe y Alegría a nivel mundial se caracteriza por su defensa del derecho universal a una educación pública, gratuita y de calidad y por su visión progresista y transformadora de las realidades de exclusión, entre las que se encuentra la exclusión de género. En Guatemala, en los últimos años Fe y Alegría está dando prioridad al trabajo en pro de la equidad de género en las escuelas en las que está presente. La organización cuenta con una Política de Género institucional que se circunscribe en su ideario general y que considera la equidad de género como una cuestión de justicia. Se pretende que la Política de Género alcance el quehacer diario de las escuelas de Fe y Alegría a través de políticas específicas en cada centro educativo. El internado de Chiantla, Huehuetenango, es un ejemplo de ello. La política de género de este centro abarca la paridad de chicas y chicos (un internado mixto constituye un reto en sí mismo en la cultura de la región), la formación de docentes en equidad de género, cambios en la oferta formativa y actividades de aula, entre otros.

\subsubsection{Equidad de género en educación a distancia: IGER.}

\begin{tabular}{|l|l|}
\hline Nombre de la organización & $\begin{array}{l}\text { Instituto Guatemalteco de Educación Radiofónica - } \\
\text { IGER. }\end{array}$ \\
\hline $\begin{array}{l}\text { Intervención general en } \\
\text { educación }\end{array}$ & $\begin{array}{l}\text { Educación formal a distancia para personas jóvenes y } \\
\text { adultas excluidas del sistema educativo. }\end{array}$ \\
\hline Intervención en educación para & Libros de texto con enfoque de género. \\
\hline
\end{tabular}




\begin{tabular}{|l|l|}
\hline la equidad & $\begin{array}{l}\text { Los libros de texto, base fundamental de la educación a } \\
\text { distancia, se entregan a cada estudiante inscrito/a. Están } \\
\text { diseñados con enfoque de género en cuanto a } \\
\text { contenidos, imágenes, ejemplos, etc. }\end{array}$ \\
\hline Área de intervención & A nivel nacional. \\
\hline Relación con el MINEDUC & $\begin{array}{l}\text { Acuerdo ministerial que da validez a los títulos } \\
\text { extendidos por el IGER. }\end{array}$ \\
\hline $\begin{array}{l}\text { ¿El proyecto incluye } \\
\text { actividades con docentes y } \\
\text { alumnado? }\end{array}$ & $\begin{array}{l}\text { No de forma sistemática. A criterio de las y los } \\
\text { animadores de cada grupo. }\end{array}$ \\
\hline $\begin{array}{l}\text { ¿El proyecto cuenta con } \\
\text { material didáctico específico? }\end{array}$ & No. \\
\hline
\end{tabular}

Desde 1979, el IGER ofrece una oportunidad de educación a distancia a las guatemaltecas y guatemaltecos que por razones económicas, de edad, de etnia, de género, de ubicación geográfica, etc. se encuentran excluidas del sistema educativo del país. El programa más importante que desarrolla el IGER es el de educación formal en Primaria, Básico y Bachillerato apoyándose en libros de texto, radio o internet y círculos de estudio animados por personas voluntarias de las comunidades. Cada curso escolar, se inscriben alrededor de 20.000 estudiantes de todo el territorio nacional. La organización elabora sus propios libros de texto que son altamente valorados en los entornos educativos del país por su calidad, capacidad comunicativa y pertinencia cultural. El enfoque de género está presente en estos libros a través de: visibilización de los aportes de las mujeres científicas, literatas, 
pensadoras, etc., utilización de lenguaje inclusivo, ilustraciones y ejemplos que fomentan cambio en roles de género tradicionales, propuestas de actividades que fomentan participación equitativa de mujeres y hombres en los círculos de estudio de cada comunidad. La realización de actividades específicas relacionadas con la equidad de género en los círculos de estudio de cada comunidad queda a criterio de las y los animadores $\operatorname{voluntarios}^{\mathrm{xxvi}}$. 


\section{Metodología}

\subsection{Metodología Comunicativa Crítica}

La presente investigación está planteada desde la Metodología Comunicativa Crítica, enmarcada en el enfoque cualitativo. Tanto este enfoque como esta metodología son idóneos para el abordaje del tema y propósito de la investigación: comprender las oportunidades y barreras que encuentran maestras y maestros de Quetzaltenango y Totonicapán, Guatemala, para educar en la equidad de género, de etnia y social, así como las perspectivas de madres de alumnado, con la mirada puesta en la transformación del sistema educativo hacia la coeducación con enfoque interseccional.

El enfoque cualitativo permite abordar la realidad desde la profundidad de la experiencia de sus protagonistas y la Metodología Comunicativa Crítica, por su parte, da voz a los sujetos más excluidos, que en este caso son maestras y maestros guatemaltecos y madres de alumnado, mayoritariamente indígenas, de las regiones del estudio. Desde un análisis interseccional de la realidad de Guatemala, encontramos que estas personas están excluidas del discurso dominante sobre la educación y la equidad de género, de etnia y social, liderado por élite académicas e institucionales centralizadas en la capital del país, que se identifican mayoritariamente con el pueblo ladino y que operan bajo intereses de las élites empresariales y económicas. Desde una perspectiva más amplia, estas maestras y maestros y madres de alumnado también se encuentran excluidos del pensamiento hegemónico mundial en general y feminista en particular, dominado por las epistemologías de los países del norte.

La apuesta por la transformación educativa, avanzando hacia la educación para la equidad de género, de etnia y social desde contextos eminentemente indígenas, exige posicionarse desde un paradigma crítico de investigación que dé cabida a pensamientos alternativos a los hegemónicos y, sobre todo, que permita la participación horizontal y dialógica de las y los 
protagonistas de la realidad. Por eso, la presente investigación se enmarca en el paradigma crítico. Esto se refleja en la opción por la Metodología Comunicativa Crítica y en la opción ideológica del marco teórico, que se orienta a los feminismos dialógico y decolonial y a la pedagogía crítica y feminista, en las que puede situarse la coeducación.

El feminismo dialógico permite abordar el giro dialógico que presenta la sociedad en general y que es patente en Guatemala. Siguiendo a Aitor Gómez y Javier Díez-Palomar (2009), el giro dialógico se plasma en el mayor uso del diálogo para la toma de decisiones en el ámbito familiar, escolar, en la sociedad en general y en los procesos de construcción del conocimiento a través de la investigación. Además, dentro de las corrientes de pensamiento feminista, el feminismo dialógico es un paradigma crítico que, como subrayan Aubert, Adriana; Flecha, Ainhoa; García, Carme; Flecha, Ramón y Racionero, Sandra (2010:102), "recoge la voz de todas las mujeres desde la igualdad de las diferencias", promoviendo luchas conjuntas basadas en la solidaridad como elemento esencial para el respeto de estas diferencias. La realidad multicultural y de profunda desigualdad de Guatemala tiene consecuencias directas sobre la construcción de las identidades de género, de etnia y de clase en el país y también sobre la forma en la que esta diversidad es tratada en las aulas.

La Metodología Comunicativa Crítica, por su parte, es una herramienta muy pertinente para el feminismo dialógico. Permite dar voz a las personas más excluidas de los discursos dominantes, como son las maestras y maestros y madres de alumnado participantes en esta investigación. Siguiendo a Gómez et al. (2009), la Metodología Comunicativa Crítica

es una nueva perspectiva de trabajo que responde a las exigencias metodológicas del momento en el que vivimos en el que las dinámicas sociales se decantan cada vez más por la participación amplia de las personas en la construcción de discursos, de alternativas de acción y en la toma de decisiones. (p.106) 
Con la Metodología Comunicativa Crítica nos alejamos del enfoque positivista en el que, según Mikko Ojala y Teresa Sordé (2010:380), “el diálogo que se entabla entre el personal investigador y los sujetos se encuentra marcado por actos comunicativos de poder", para adentrarnos en una relación horizontal y participativa, en la que "se crean condiciones para que las interacciones que predominen sean las dialógicas" (Ojala et al., 2010:384).

Además, según Jesús Gómez, Antonio Latorre, Montse Sánchez y Ramón Flecha (2006) la Metodología Comunicativa Crítica nos permite alcanzar el objetivo superior de transformar la realidad, ya que no solo da voz a las personas protagonistas de la misma, sino que las convierte en sujetos de transformación. Según Aitor Gómez y Sandra Racionero - Plaza (2008:120), la Metodología Comunicativa Crítica “coincide plenamente con metodologías como la investigación - acción y la investigación participativa”, de manera que sirve para incorporar el conocimiento de todas las personas al corpus científico y que las mismas personas generen acciones para mejorar sus vidas.

La concepción epistemológica que propone la Metodología Comunicativa Crítica es especialmente relevante para el tema de investigación que nos ocupa -la educación para la equidad de género, de etnia y social en Guatemala-. Una profundización real en esta temática desde el compromiso de la transformación social inevitablemente requiere partir de que la equidad de género, de etnia y social en Guatemala, y todo el conocimiento que se ha construido en torno a ella, es una construcción intersubjetiva, fruto del diálogo como concepto amplio de interacción social entre personas y grupos sociales. La vivencia de las y los docentes y madres de alumnado sobre la equidad de género, de etnia y social resignifica las teorías educativas, aunando el sistema y el mundo de la vida, es decir, creando sinergias entre los conocimientos académicos acumulados en forma de teorías de las Ciencias Sociales (estructuras) y los sujetos con sus voces y conocimientos propios, tal y como refieren Gómez et al. (2008). 
En el contexto de la investigación, la Metodología Comunicativa Crítica permite partir de las experiencias de maestras $\mathrm{y}$ maestros $\mathrm{y}$ madres de alumnado para apostar por la transformación de la realidad a través de la transformación del sistema educativo. Esta metodología permite construir, de forma dialógica, un aprendizaje sobre la equidad de género, de etnia y social situado en el contexto del área de estudio, sobre el papel de la educación en el cambio social y sobre el papel de de ellas y ellos en la transformación de la violencia cultural y simbólica, que contribuye a la transformación del patriarcado.

La aplicación de la Metodología Comunicativa Crítica en este trabajo ha tenido consecuencias fundamentales para su diseño, para la redefinición de las categorías de sujeto y objeto de la investigación, para la aplicación de técnicas de recogida de datos y para la concepción de la veracidad de los resultados. Así, el trabajo de investigación planteado desde la Metodología Comunicativa Crítica rompe con la tradicional dicotomía investigador/a sujetos investigados, pasando a ser una relación sujeto-sujeto. El proceso investigador se basa en la interacción horizontal de las y los participantes y la investigadora, aportando a la construcción de conocimiento sobre la educación para la equidad de género, de etnia y social en Guatemala a partir de sus propias experiencias de vida. Se cumple así el postulado del conocimiento dialógico de la Metodología Comunicativa Crítica señalado por Ojala et al. (2010:385), que explica que, siguiendo a Beck, Giddens y Lash (1997), “el conocimiento no es ni solo objetivo ni solo subjetivo, sino que es dialógico, es decir, se crea intersubjetivamente a través del diálogo y la capacidad de reflexión y autorreflexión”. El aporte horizontal sujeto-sujeto solo es posible abordando la recogida de datos con herramientas dialógicas, como la entrevista comunicativa y el grupo de discusión comunicativo, en las que se profundizará más adelante.

Por otro lado, el diálogo, en su calidad de motor de la interacción humana, genera caminos siempre nuevos para la comprensión de la realidad y arroja conclusiones sorpresivas que 
frecuentemente se alejan de lo que se han considerado "resultados veraces" desde los postulados científicos tradicionales. Sin embargo, la Metodología Comunicativa Crítica apuesta por crear "conocimiento científico a través de validar tanto el discurso de los expertos, como el discurso de las personas no expertas" (Gómez et al., 2009:108), en un acto de legitimación de todos los conocimientos, con "argumentos contrastados en base a pretensiones de veracidad, no por la posición de poder de quien presenta tales argumentos" (Gómez et al., 2009:108). Se hace realidad así uno de los postulados de la Metodología Comunicativa Crítica que propone Ojala et al. (2010):

la capacidad de análisis de la realidad no es exclusiva de los investigadores, sino que partiendo de los diferentes conocimientos -desde la ciencia o desde la experiencia de vida $^{-}$ambos colectivos [investigadores y participantes] tienen capacidad de interpretar la realidad que se estudia y ambas interpretaciones son necesarias para avanzar en el conocimiento de la misma.(p.386)

Entendemos por acto comunicativo todos los usos del lenguaje verbal o no verbal que realizamos las personas en nuestra interacción social y que, siguiendo los postulados de Habermas y su teoría de la acción comunicativa, construyen la realidad a través de los consensos que sobre ella se van alcanzando con la forma de nombrarla. Así, los actos comunicativos relacionados con la educación para la equidad de género, de etnia y social que las maestras y maestros llevan a cabo en el aula, junto con los actos comunicativos de madres del alumnado, construyen el universo de significados de género en el que se socializan las niñas, niños y jóvenes. Debemos detenernos a reflexionar sobre la importancia que esto tiene porque los actos comunicativos que construyen significados de género, de etnia y social son casi todos: el lenguaje con el que maestras y maestros se dirigen al grupo (¿inclusivo o excluyente?), el impulso a la participación del alumnado en las actividades, el 
establecimiento de unas pautas de comportamiento (¿igualitarias o segregadas?) y un largo etc.

Los motivos de esta elección de maestras y maestros y madres de alumnado como protagonistas del diálogo son los siguientes: por un lado, se considera que el espacio escolar es clave para la socialización de género y que las maestras y maestros son actores que con su acción cotidiana, sus palabras y su ejemplo hacen que esta socialización sea transformadora del modelo hegemónico patriarcal o, por el contrario, reproductora del mismo. Por otro lado, el propio Curriculum Nacional Base otorga a maestras y maestros la capacidad de contextualizar y concretar pedagógicamente todo el proceso educativo, incluyendo los ejes transversales como el que nos ocupa, según los entornos socioculturales de sus aulas. Además, en las fases de acercamiento a la realidad educativa de la región, se ha detectado que en la educación pública no se cuenta con propuestas para la implementación del eje de equidad de género, de etnia y social que partan de las autoridades educativas regionales y lleguen así a todos los centros educativos del área y no se ha tenido noticia de ninguna escuela que tenga un proyecto educativo de centro en esta línea, quedando nuevamente la iniciativa en manos de las maestras y maestros. Por último, las concepciones y expectativas de madres de alumnado sobre el aprendizaje en la escuela determinan el universo socializador en el que se desenvuelven las niñas, niños y jóvenes.

Recuperando lo desarrollado en el estado de la cuestión, la sociedad guatemalteca precisa un cambio cultural hacia la equidad de género, de etnia y social que conlleva necesariamente un giro hacia la coeducación con enfoque interseccional en las aulas, como motor de ese cambio. Añadiendo las constataciones realizadas en la realidad educativa, las maestras y maestros son quienes en la actualidad tienen más posibilidades de promover ese giro hacia la educación para la equidad en el proceso educativo formal. Desde la Metodología Comunicativa Crítica, apostamos decididamente por la transformación de la realidad y para 
ello los actos comunicativos de maestras y maestros y madres de alumnado relacionados con la educación para la equidad de género, de etnia y social son muy relevantes: construyen los parámetros cotidianos de socialización de niñas, niños y jóvenes en la escuela, un espacio en el que viven muchas horas al día y muchos días de sus vidas.

\subsection{Interrogantes de la investigación}

La investigación que aquí se presenta surgió de una preocupación personal por los modelos de socialización de género, de etnia y social en las aulas guatemaltecas y de un cuestionamiento muy concreto: las escuelas de Quetzaltenango y Totonicapán ¿cómo están contribuyendo a la construcción de la equidad de género, de etnia y social en la sociedad? Con la orientación de esta pregunta y de las reflexiones anteriormente expuestas sobre el protagonismo de maestras y maestros en este proceso, se establecieron los siguientes objetivos:

\subsubsection{Objetivo general.}

- Estudiar las oportunidades y limitaciones de la educación para la equidad de género, de etnia y social para la transformación del patriarcado en Guatemala.

\subsubsection{Objetivos específicos.}

- Identificar actos comunicativos de maestras y maestros que potencian la educación para la equidad de género, de etnia y social en las aulas y los actos comunicativos que reproducen la discriminación patriarcal en la socialización. Es decir, actos comunicativos ligados a una dimensión transformadora y a una dimensión exclusora. 
- Identificar actos comunicativos de madres de alumnado que potencian la transformación hacia la equidad de género, de etnia y social vinculada a la educación y los actos comunicativos que reproducen la discriminación patriarcal.

- Identificar las barreras y las oportunidades que encuentran las maestras y maestros para implementar el eje curricular de equidad de género, de etnia y social en las aulas de Pre Primaria, Primaria y Básico.

\subsubsection{Preguntas de investigación.}

Partiendo del interrogante inicial y de los objetivos establecidos, se abrió todo un horizonte de indagación que dio lugar a preguntas de investigación mucho más concretas, circunscritas en la realidad sociocultural de la región estudiada, la realidad educativa del país y la cotidianidad de las aulas de la región:

- ¿Cuál es la concepción sobre la equidad de género que tienen las maestras y maestros?

- ¿Cómo se significa la equidad de género en la cultura maya?

- ¿Qué entienden las maestras y maestros por equidad de género, de etnia y social?

- ¿Qué importancia otorgan las maestras y maestros a la educación para la equidad en las aulas como motor de un cambio cultural hacia una sociedad más equitativa desde un enfoque interseccional?

- El eje curricular transversal de equidad de género, de etnia y social, ¿se implementa en las aulas y cómo?

- ¿Qué dificultades encuentran maestras y maestros para esta implementación?

- ¿Qué experiencias educativas concretas se pueden destacar al respecto tanto a nivel nacional como en la región de Quetzaltenango y Totonicapán?

- ¿Cuál es la concepción de madres de alumnado sobre la equidad de género, de etnia y social? 
- ¿Qué expectativas colocan las madres del alumnado sobre la escuela respecto a la educación para la equidad de género, de etnia y social?

Estos interrogantes formaron parte del proceso de diálogo llevado a cabo con las y los maestros y las madres de alumnado participantes, quienes lo dirigieron por caminos propios según sus conocimientos y sus experiencias docentes y de vida. Así, en el diálogo construido a la luz de las anteriores preguntas generadoras, aparecieron muchos nuevos interrogantes.

Es importante destacar algunas características particulares que presentó este proceso dialógico: por un lado, los temas fueron abordados de manera circular, partiendo de un lento acercamiento de ubicación en la temática de interés y recorriendo un camino contante de lo general a lo particular y viceversa; de esta forma, la reflexión sobre los temas se construyó progresivamente, añadiendo nuevos elementos a medida que avanzaba el diálogo. Esta es una característica propia del estilo comunicativo guatemalteco, especialmente de las personas indígenas, e implica que el abordaje de cualquier tema no se realice de entrada de forma directa y que, por lo tanto, haya lugar para múltiples enfoques, en ocasiones inesperados.

El diálogo se construyó desde la libre interpretación que cada participante realizó de la temática, posibilitando una visión amplia y enriquecedora de la vivencia de la misma. Por último, el hecho de que las y los maestros y las madres de alumnado participantes no sean personas expertas en coeducación, hizo que el diálogo se plantease desde lo empírico, sin entrar en debates teóricos que pudieran romper la horizontalidad. Esto permitió rescatar lo positivo de la experiencia concreta de cada persona y resaltar sus capacidades transformadoras como agente educativo.

\subsection{Desarrollo del proceso investigador}

El desarrollo de esta investigación se dio en varias etapas, abarcando algo más de cuatro años. Las limitaciones derivadas de la ubicación geográfica distante de las personas 
participantes y de su disponibilidad de tiempos impidieron organizar el equipo investigador de forma comunicativa. Sin embargo, se diseñaron algunas acciones encaminadas a ampliar la participación y retroalimentación de todas las personas.

Las etapas del proceso investigador que a continuación se describirán no sucedieron de forma lineal sino solapada y circular, de manera que en ocasiones varias etapas tuvieron lugar a la vez y, en otras ocasiones, fue necesario regresar a etapas anteriores para revisar, perfeccionar e incorporar nuevos hallazgos de la investigación.

a. Concretar la intuición: para delimitar el objeto de investigación, se contaba con elementos de reflexión que eran fruto de la observación de los procesos educativos formales y su papel como agentes socializadores en Guatemala. Sin embargo, era necesario validar tales observaciones a través del contacto directo con docentes de los diferentes niveles educativos y otras personas relacionadas con el mundo de la educación. Pudo constatarse, en primer lugar, que la idea de educación para la equidad de género, de etnia y social que se manejaba entre las y los agentes educativos era diversa. El término coeducación era desconocido para la mayoría de docentes con los que se tuvo contacto. Además, se identificaron escasas experiencias concretas de implementación del eje curricular de equidad de género, de etnia y social eje por la falta de concreción y formación sobre la transversalidad, unida a la escasa prioridad que se le otorga al tema de equidad en las aulas. A la luz de estas constataciones, se decidió plantear un proceso investigador que partiera de las experiencias de las y los docentes en el tema de educación para la equidad de género, de etnia y social, potenciando las fortalezas con las que cuentan y resaltando lo positivo de cualquier intervención docente en esta línea. Así mismo, se consideró importante contar con el punto de vista de madres de alumnado. Se evitó plantear un marco de características que debiera cumplir una acción para ser considerada "de educación para la equidad" con el objetivo de no limitar 
los aportes y abrir aún más el diálogo. Este planteamiento, en consonancia con los postulados de la educación popular, otorga validez a lo empírico como forma cotidiana de dar vida a las intuiciones y los conocimientos teóricos, potencia el protagonismo de las y los participantes y, algo fundamental, es una rica fuente de motivación para que cada participante, al sentir reconocida su experiencia y conocer la experiencia de otras y otros, se comprometa con mayor convicción con el tema. Este posicionamiento fue clave para el proceso, ya que permitió plantearlo en positivo, evitando caer en el pesimismo que podría generar el constatar las deficiencias que presenta el sistema educativo. Este tipo de actitudes derrotistas con frecuencia impregnan los análisis de procesos sociales en Guatemala, fruto de las dificultades estatales, institucionales, presupuestarias, formativas, de gobernabilidad, etc. que vive el país, llevando con facilidad al inmovilismo y la resignación. Por todo lo anterior, el proceso investigador se centró en la implementación -cualquiera que fuera- en las aulas por parte de maestras y maestros del eje curricular de equidad de género, etnia y social y en las expectativas de madres de alumnado sobre la educación para la equidad de género, de etnia y social.

b. Revisión bibliográfica: el propósito de esta etapa fue acercarse a las teorías feministas, abordando el feminismo decolonial, comunitario y dialógico, que aportan especialmente a la realidad de Guatemala. También se realizó la revisión bibliográfica sobre coeducación en general y sobre los aportes que se han realizado desde Guatemala en materia de educación para la equidad de género, de etnia y social. Es importante explicar que el acceso a material bibliográfico especializado sobre el tema es sumamente difícil en Guatemala, más aún en los departamentos de Quetzaltenango y Totonicapán que se encuentran alejados de la capital del país que concentra las bibliotecas, librerías y fondos bibliográficos de instituciones especializadas. Esto hizo que la fuente principal de acceso a bibliografía fuera internet: bibliotecas digitales, repositorios de universidades, páginas 
especializadas que publican artículos periódicamente, etc. En diferentes desplazamientos a la ciudad de Guatemala, se pudo acceder a algunos libros y materiales facilitados por instituciones especializadas como la Facultad Latinoamericana de Ciencias Sociales FLACSO- y el Instituto Universitario de la Mujer -IUMUSAC-, a quienes se agradece sinceramente la atención y apoyo. Cabe destacar que la literatura de autoras y autores guatemaltecos sobre el tema de educación para la equidad de género, de etnia y social es escasísima, siendo necesario basarse mayoritariamente en fuentes extranjeras. Como es habitual en todo proceso investigador, la revisión bibliográfica acompañó a todas las etapas siguientes, a medida que se iban hallando más materiales relevantes.

c. Visitas y entrevistas de acercamiento a la realidad: confirmada la complejidad del tema que nos proponíamos abordar, la estrategia más adecuada era acercarse al sentir y al actuar de actores protagonistas de la educación para la equidad, de manera que el diseño del proceso investigador fuera más atinado. El objetivo fue arrancar el proceso investigador desde el conocimiento de las experiencias existentes en la región estudiada (o en su defecto en el país). Para ello, se realizaron contactos personales en varios sentidos:

- Visitas y contactos con personas de instituciones y organizaciones sociales relacionadas con el tema para identificar experiencias significativas tanto desde la educación pública como desde la privada: Unidad de Género con Pertinencia Étnica -UNEGEPE- del Ministerio de Educación, Instituto Universitario de la Mujer IUMUSAC-, coordinadoras y docentes de la carrera de Pedagogía con diferentes énfasis de la Universidad de San Carlos de Guatemala -USAC- sede de Totonicapán (única universidad pública del país) y de la Universidad Rafael Landívar, Campus de Quetzaltenango, personal del programa de género de la Facultad Latinoamericana de Ciencias Sociales -FLACSO- y coordinadoras y coordinadores de las ONG 
educativas Fe y Alegría, PRODESSA e IGER. Además, se establecieron contactos electrónicos y telefónicos con más organizaciones sociales que facilitaron nuevos contactos e información.

- Conversas con maestras y maestros y aplicación de una encuesta de acercamiento: esta actividad se realizó con el objetivo de sondear de forma muy somera, rápida y directa la apropiación que docentes de la región estudiada tenían sobre la temática de educación para la equidad de género, la motivación sobre ella y si estaban poniendo en práctica estrategias concretas para implementar el eje curricular de equidad de género, de etnia y social. Se mantuvo una conversación grupal con 4 mujeres docentes de Pre-Primaria y 1 de Primaria sobre la importancia de la educación para la equidad de género y el papel de la escuela al respecto y se aplicaron 48 encuestas de acercamiento general a los conocimientos, sentires y acciones que se realizan sobre el tema. El formato de encuesta aplicada, la tabulación de los resultados, la guía de conversación grupal y la síntesis de resultados de la misma se encuentran en el anexo 5.

- Visita y observación en aulas de Pre-Primaria y primaria: a lo largo del proceso investigador se tuvo la oportunidad de acceder a varias aulas de la región. Esto permitió observaciones muy generales pero valiosas acerca de prácticas cotidianas relevantes para la educación para la equidad de género, de etnia y social.

- Entrevistas a 5 personas expertas en educación y género en el país: ex rectora de la Universidad Rafael Landívar, investigadoras de la unidad de género de FLACSO, consultora del Ministerio de Educación especializada en Educación Integral en Sexualidad, ex viceministro de educación. Las transcripciones de estas entrevistas se encuentran en el anexo 5 y se han utilizado para enriquecer el estado de la cuestión de la investigación. 
d. Diseño del proceso: los resultados de las fases anteriores permitieron diseñar con más certeza un proceso investigador pertinente a la realidad educativa de Quetzaltenango y Totonicapán. El diseño incluyó, además, la profundización en la Metodología Comunicativa Crítica que estructura todo el proceso investigador, vinculada al feminismo dialógico en el que se enmarca ideológicamente. La elección de participantes para el proceso investigador también se realizó desde los presupuestos de la Metodología Comunicativa Crítica, como se explicará más adelante.

e. Estado de la cuestión y su revisión: se realizó una primera redacción del estado de la cuestión que posteriormente fue modificada y enriquecida en estructura y contenido. Las modificaciones realizaron a la luz de las revisiones de personas expertas, la profundización permanente en las teorías existentes y la ampliación de conceptos obtenida en los procesos dialógicos.

f. Aplicación de herramientas dialógicas: en esta etapa se realizaron 10 entrevistas comunicativas, 4 grupos de discusión comunicativos con maestras y maestros y 2 entrevistas comunicativas con madres de alumnado, tal como se explica en el apartado de "herramientas de investigación".

g. Análisis, reflexión, contraste con las teorías y redacción - revisión -corrección de informe: el núcleo principal de esta etapa fue el análisis de los actos comunicativos de las personas participantes en el proceso investigador, identificando dimensiones exclusoras y transformadoras en los discursos, tal y como propone la Metodología Comunicativa Crítica. Esto dio lugar a la construcción de conocimiento acerca de las categorías y subcategorías estudiadas, que adquirieron nuevos significados enriquecidos por el conocimiento teórico y empírico de las y los participantes. Los resultados dialógicos se contrastaron con las teorías estudiadas, generando una nueva revisión y enriquecimiento 
del marco teórico. Se extrajeron conclusiones de todo el proceso investigador. Finalmente, se abordó la redacción estructurada del presente informe de investigación.

h. Planteamiento de acciones transformadoras: el compromiso con la transformación de la realidad desde sus protagonistas fue el punto de partida de este proceso investigador, lo que implica consecuencias importantes tanto a nivel metodológico (opción por la aplicación de la Metodología Comunicativa Crítica), como a nivel de seguimiento una vez concluido el presente informe. La motivación, expectativas y actitud propositiva demostradas por las personas participantes compromete al diseño de acciones de continuidad de este proceso investigador que ofrezcan un pequeño acompañamiento en el paso a la acción. Así, se realizó una acción formativa sobre coeducación con maestras y maestros y un intercambio de experiencias de coeducación con la participación de tres ONG dedicadas a la educación y un instituto público.

\subsection{Participantes y herramientas de investigación utilizadas}

Como herramientas de recogida de datos se utilizaron la entrevista comunicativa y el grupo de discusión comunicativo, que permiten profundizar en la experiencia y concepción de las y los participantes acerca del tema de investigación.

La siguiente tabla resume el número de aplicaciones y participantes en entrevistas comunicativas y grupos de discusión comunicativos: 


\section{Tabla 6}

Entrevistas comunicativas y grupos de discusión comunicativos con maestras y maestros

\section{Participantes}

Número de Mujeres Hombres Total
aplicaciones

Entrevista comunicativa a

10

5

5

10

maestras y maestros

Grupo de discusión

4

22

6

28

comunicativo con maestras

y maestros

Total de personas diferentes participantes

22

6

28

NOTA: 5 mujeres y 5 hombres participaron tanto en entrevistas como en grupos de discusión.

Además, se realizaron 2 entrevistas grupales a madres de alumnado de una de las escuelas de las maestras y maestros participantes y 4 talleres de discusión sobre educación para la equidad de género, de etnia y social con madres y padres y con maestras y maestros.

\section{Tabla 7}

Entrevistas comunicativas con madres de alumnado

Número de Ubicación Participantes
aplicaciones

\begin{tabular}{lll}
\hline $\begin{array}{l}\text { Entrevista comunicativa a } \\
\text { madres de alumnado }\end{array}$ & 2 & $\begin{array}{l}\text { Aldea de Cantel, } \\
\text { Quetzaltenango }\end{array}$ \\
\end{tabular}

NOTA: en cada entrevista participaron dos madres. 


\section{Tabla 8}

Participantes en técnicas de recogida de información complementaria

\begin{tabular}{lcll}
\hline & $\begin{array}{c}\text { Número de } \\
\text { aplicaciones }\end{array}$ & Ubicación & Participantes \\
\hline $\begin{array}{l}\text { Talleres de discusión con } \\
\text { madres y padres de niñas y } \\
\text { niños escolarizados }\end{array}$ & 2 & Aldea de Cantel, & 20 mujeres y \\
Quetzaltenango & 5 hombres \\
$\begin{array}{l}\text { Talleres de discusión con } \\
\text { maestras y maestros }\end{array}$ & 2 & Casco urbano de & 37 maestras y \\
\end{tabular}

Las entrevistas a madres de alumnado fueron transcritas y analizadas a través la herramienta de cuadro de análisis. La información de los talleres de discusión se encuentra sistematizada en el anexo 5. En el análisis de resultados, se ha incluido como una referencia complementaria.

\subsubsection{Entrevistas comunicativas.}

Se realizaron 10 entrevistas comunicativas a 5 maestras y 5 maestros de las regiones de Quetzaltenango y Totonicapán, docentes en activo de los niveles de Pre Primaria, Primaria, Básico y Diversificado. Un maestro del nivel Diversificado ejerce docencia en un centro educativo del departamento de Chimaltenango. Este participante fue incluido en el proceso porque las características de la educación en centros educativos privados de nivel Diversificado son muy similares en Chimaltenango y en el área de estudio, tratándose de centros más bien pequeños y creados por iniciativa personal de algún maestro o maestra. Con este grupo de participantes se logró abarcar experiencias docentes en todos los niveles educativos. De los 10 participantes, 9 pertenecen al pueblo maya, principalmente k'iche', y 1 pertenece al pueblo ladino. Además, se realizaron 2 entrevistas a 4 madres de alumnado de 
una de las escuelas de las maestras y maestros participantes, con el objetivo de tener un acercamiento a su punto de vista sobre la educación para la equidad de género. En cada entrevista participaron dos mujeres.

En la selección de las maestras y maestros participantes, se buscó contar con un número más o menos equilibrado de participantes mujeres y hombres, para que este elemento pudiera enriquecer el análisis de actos comunicativos comparados por sexo. El encuentro con cada participante para realizar la entrevista comunicativa se dio en un ambiente de confianza, en las instalaciones de las mismas escuelas en las que trabajan o de la universidad en la que estudian.

Las entrevistas se realizaron entre 2014 y 2017, contando con un protocolo elaborado previamente. Todas ellas fueron grabadas en audio con el consentimiento de las y los participantes, para su posterior transcripción y análisis de actos comunicativos.

En el caso de las entrevistas a maestras y maestros, a cada transcripción se le asignó un código que refleja que se trata de una entrevista (E), el número correlativo que le corresponde de 1 a 10, las iniciales del nivel en el que imparte docencia la persona y $\mathrm{M}$ o $\mathrm{H}$ según sea mujer u hombre.

Las entrevistas realizadas a madres de alumnado se codificaron con la letra E, seguida del correlativo 11 y 12 y las letras $\mathrm{M}$ de madre y $\mathrm{M}$ de mujer.

El protocolo de preguntas fue modificado en el transcurso del diálogo con todas y todos los participantes, ya que cada persona mostró mayor o menor conocimiento, experiencia o importancia otorgada a diferentes aspectos de los reflejados en la guía. El protocolo diseñado y las transcripciones de cada una de las entrevistas se encuentran en los anexos 1 y 2 respectivamente. 


\subsubsection{Grupos de discusión comunicativos.}

Se realizaron 4 grupos de discusión comunicativos en los que participaron 28 personas en total, 22 mujeres y 6 hombres. De las 28 personas, 10 habían sido previamente participantes de las entrevistas comunicativas. Esta herramienta se planteó con el objetivo de construir un discurso colectivo sobre la educación para la equidad de género, de etnia y social.

Previamente se había elaborado protocolo para la dinamización de este diálogo conjunto (ver anexo 1). Sin embargo, éste hubo de ajustarse al curso propio del diálogo, marcado por las diversas experiencias de vida y profesionales de las y los participantes. Las características particulares del estilo comunicativo guatemalteco que tiende a respetar el orden de intervención y palabra, unidas a la timidez de algunas personas participantes por sentimientos de inferioridad respecto a sus conocimientos o por motivos de género, hizo que la investigadora tuviera que intervenir con frecuencia para propiciar la participación de todas las personas.

Los grupos de discusión comunicativos se realizaron entre 2014 y 2017. Su desarrollo fue grabado en audio con el consentimiento de las y los participantes y posteriormente fueron transcritos en el documento que se encuentra en el anexo 2. Se les asignó el código de identificación GD y número correlativo de 1 a 4.

\subsection{Análisis de actos comunicativos}

El análisis de la información obtenida con las herramientas de recogida de datos se realizó aplicando la Metodología Comunicativa Crítica. Se trata de identificar los actos comunicativos de las maestras y maestros y madres de alumnado respecto al tema de investigación, actos que plasman su concepción sobre la educación para la equidad de género, de etnia y social y que trasladan barreras u oportunidades para la transformación. Para este 
análisis se construyeron los siguientes elementos: las transcripciones literales de las entrevistas y grupos de discusión comunicativos (ver anexo 2), una relación de las categorías y subcategorías relativas al tema de investigación (ver anexo 3) y cuadros de análisis de las entrevistas y grupos de discusión que identifican dimensiones transformadoras y exclusoras en el discurso de cada persona ligadas a cada subcategoría (ver anexo 4).

Las categorías de análisis se establecieron con criterio de progresividad en la comprensión del tema de investigación, comenzando por la vertebración social de Guatemala, siguiendo con los agentes socializadores y terminando con la educación para la equidad de género, etnia y social en la educación formal.

Para poder analizar en profundidad cada una de las categorías, éstas se dividieron en las diversas subcategorías que se describen más adelante. Finalmente, el discurso de las y los participantes acerca de cada subcategoría se analizó identificando las dimensiones exclusoras y transformadoras que manifiestan al respecto. Siguiendo a Ramón Flecha, Julio Vargas y Andrés Dávila (2004:29), definimos las dimensiones exclusoras "como las barreras que encuentran las personas o grupos para incluirse en una situación social o para adquirir un beneficio social", sabiendo que estas barreras pueden ser impuestas externamente (como legislaciones, normas sociales, etc.) o pueden ser interiorizaciones de las mismas personas (como la creencia de no tener capacidades para hacer algo, no sentirse al nivel de las demás personas, etc.). Las dimensiones transformadoras, por su parte, "se definen en función de los exclusores, y son por oposición, aquellos que permiten superar las barreras (externas e internas) que dificultan la inclusión igualitaria” (Flecha et al., 2004:30). Para el análisis que nos ocupa, se consideran dimensiones exclusoras todas aquellas que reproducen la hegemonía del modelo patriarcal en la sociedad y en las aulas, generando desigualdad de oportunidades en los procesos educativos y en la vida en general y constituyendo barreras para la implementación del eje de equidad de género, de etnia y social en las aulas. Estas barreras se 
manifestarán tanto de forma externa a las aulas como de forma interna. Por el contrario, son consideradas dimensiones transformadoras las concepciones positivas en torno al avance hacia la equidad de género, de etnia y social, las posibilidades de educación para la equidad que ven, así como las acciones concretas que para ello se realizan en las aulas. En definitiva, los factores transformadores son todas aquellas ventanas de oportunidad identificadas por las maestras y maestros y madres de alumnado para avanzar hacia la equidad de género, de etnia y social en la sociedad en general y en los procesos de educación formal en particular.

\subsection{Descripción de categorías y subcategorías}

Las subcategorías establecidas para la categoría de "vertebración social" fueron “construcción del género", "pertenencia étnica", "clase social” y "concepción de equidad en la cultura maya".

La subcategoría de construcción del género nos permite identificar los elementos que, en la concepción de maestras y maestros, son determinantes en la adquisición de la identidad de género de mujeres y hombres.

En la subcategoría de pertenencia étnica se analizan los aportes relacionados con las

relaciones inter étnicas y la construcción de la identidad alrededor de la pertenencia a uno u otro pueblo, dentro de la diversidad cultural de Guatemala.

La subcategoría de clase social hace referencia a la construcción de las relaciones de clase, muy vinculadas en el contexto de estudio al nivel socioeconómico y a la urbanidad/ruralidad.

Analizar la concepción de equidad en la cultura maya, por su parte, implica dar voz a una construcción del género al margen de los discursos dominantes, construcción que permea la vida de gran parte de la población guatemalteca y que a su vez, rescatándola, tiene importantísimos aportes que realizar al discurso occidental dominante sobre el género. 
Para la categoría de agentes socializadores de género, se establecieron las subcategorías de "violencia de género", "racismo", “sexismo", "discriminación”, “expectativas de futuro", “valores", “escuela", “familia”, “comunidad”, “religión” y “medios de comunicación”. La identificación de dimensiones exclusoras y transformadoras en cada una de estas subcategorías permitió identificar los rasgos relacionados con la violencia de género, racismo, sexismo, discriminación y expectativas de futuro diferenciadas para mujeres y hombres presentes en la sociedad y en la socialización de niñas, niños y jóvenes. Estos rasgos se identifican en la dinámica de los agentes socializadores de género, siendo fundamental la conocer la percepción de las maestras y maestros sobre las barreras y las potencialidades de transformación hacia la equidad que identifican en cada agente socializador, especialmente en la escuela.

La categoría de educación para la equidad de género, etnia y social en la educación formal se dividió en las subcategorías de "eje de equidad de género, de etnia y social del CNB", "formación inicial y permanente de maestras y maestros", "gerencia del sistema educativo", "compromiso de maestras y maestros", "familias y comunidad" y "actividades concretas relacionadas con educación para la equidad". Estas subcategorías pretenden reflejar todas las dimensiones que abarca un proyecto coeducativo con enfoque interseccional.

El análisis del "eje de equidad de género, de etnia y social del CNB", que al final de cuentas es la propuesta más concreta que realiza el sistema educativo guatemalteco en materia de educación para la equidad, posibilitó conocer qué oportunidades encuentran las maestras y maestros en este eje curricular, si forma parte de su quehacer educativo y, en cualquier caso, qué manejo consciente o inconsciente realizan de esta temática en su intervención docente. 
La subcategoría de "formación inicial y permanente de maestras y maestros" permite identificar si cuentan con formación concreta sobre estrategias de educación para la equidad y qué percepciones tienen al respecto.

Con "gerencia del sistema educativo" nos referimos a todas aquellas acciones que tienen que ver con la coordinación del proceso educativo por parte de las autoridades competentes.

La subcategoría de "compromiso de maestras y maestros" se refiere al grado de empoderamiento e involucramiento en el trabajo en educación para la equidad de género, de etnia y social que manifiestan tener las maestras y maestros.

La subcategoría de "familias/comunidad" se vincula con las implicaciones que tienen estos actores en la educación para la equidad en las aulas, ya sea como elementos favorecedores o entorpecedores del proceso o como destinatarios de acciones de educación para la equidad.

Por último, se incluyó la subcategoría de "actividades concretas" para conocer qué acciones exitosas o fallidas de educación para la equidad realizan las maestras y maestros, entendiendo que referirlas como actividades implica una planificación consciente de las mismas y, por lo tanto, una concreción en el curriculum explícito del proceso de socialización de género en la escuela.

\subsection{Cuadro de análisis}

El primer paso del análisis fue agrupar la información del discurso de las y los participantes según su pertenencia a cada subcategoría. Una vez hecho esto, los fragmentos de discurso de cada subcategoría se ordenaron en "dimensión exclusora" o "dimensión transformadora", según constituyeran una barrera para la equidad entre mujeres y hombres o una posibilidad de avance hacia esta equidad. Para facilitar esta tarea, se elaboró un cuadro de análisis con las aportaciones literales de las entrevistas comunicativas y de los grupos de discusión comunicativos. 
Cada aportación proveniente de una entrevista comunicativa o grupo de discusión comunicativo se colocó en la celda correspondiente del cuadro de análisis seguido de su código identificativo. La estructura del cuadro de análisis es la siguiente:

\begin{tabular}{|c|c|c|c|}
\hline Categoría & Subcategorías & $\begin{array}{l}\text { Dimensión } \\
\text { exclusora }\end{array}$ & $\begin{array}{l}\text { Dimensión } \\
\text { transformadora }\end{array}$ \\
\hline \multirow{4}{*}{$\begin{array}{l}\text { Vertebración } \\
\text { social }\end{array}$} & Construcción del género & & \\
\hline & Pertenencia étnica & & \\
\hline & Clase social & & \\
\hline & $\begin{array}{l}\text { Concepción de equidad en } \\
\text { la cultura maya }\end{array}$ & & \\
\hline \multirow{11}{*}{$\begin{array}{l}\text { Agentes } \\
\text { socializadores } \\
\text { de género }\end{array}$} & Violencia de género & & \\
\hline & Racismo & & \\
\hline & Sexismo & & \\
\hline & Discriminación & & \\
\hline & Expectativas de futuro & & \\
\hline & Valores & & \\
\hline & Escuela & & \\
\hline & Familia & & \\
\hline & Comunidad & & \\
\hline & Medios de comunicación & & \\
\hline & Religión & & \\
\hline \multirow{5}{*}{$\begin{array}{l}\text { Educación } \\
\text { para la } \\
\text { equidad de } \\
\text { género, etnia y } \\
\text { social en la } \\
\text { educación } \\
\text { formal }\end{array}$} & $\begin{array}{l}\text { Eje de equidad de género, } \\
\text { de etnia y social del CNB }\end{array}$ & & \\
\hline & $\begin{array}{l}\text { Formación inicial y } \\
\text { permanente de maestras y } \\
\text { maestros }\end{array}$ & & \\
\hline & $\begin{array}{l}\text { Gerencia del sistema } \\
\text { educativo }\end{array}$ & & \\
\hline & $\begin{array}{l}\text { Compromiso de maestras y } \\
\text { maestros }\end{array}$ & & \\
\hline & Familias y comunidad & & \\
\hline
\end{tabular}




\begin{tabular}{|l|l|l|l|}
\hline Categoría & Subcategorías & $\begin{array}{l}\text { Dimensión } \\
\text { exclusora }\end{array}$ & $\begin{array}{l}\text { Dimensión } \\
\text { transformadora }\end{array}$ \\
\hline & $\begin{array}{l}\text { Actividades concretas } \\
\text { relacionadas con educación } \\
\text { para la equidad }\end{array}$ & & \\
\hline
\end{tabular}

Figura 12. Estructura del cuadro de análisis.

Los fragmentos de discurso así ordenados permitieron analizar sistemáticamente la experiencia de cada participante y extraer resultados concretos de investigación. Los códigos asignados a cada entrevista y grupo de discusión comunicativos identifican las citas literales del discurso de cada participante en el apartado de resultados de la investigación. El cuadro de análisis completo se incluye en el anexo 4.

\subsection{Descripción de las y los participantes}

Las personas participantes de la investigación fueron seleccionadas de acuerdo al perfil que se describe a continuación.

Las madres de alumnado fueron seleccionadas con el criterio de ser madres de alumnas y alumnos de una de las escuelas en las que trabajan maestras y maestros participantes. Las madres participantes son mujeres indígenas y la escuela es una escuela pública de PrePrimaria y Primaria ubicada en una comunidad rural.

Para la selección de maestras y maestros, el primer criterio fue que se tratara de docentes en activo de todos los niveles educativos de escuelas públicas de la región de Quetzaltenango y Totonicapán, desde el nivel de Pre Primaria al Diversificado. Se contó con 1 maestro del departamento de Chimaltenango, del nivel Diversificado. Fue incluido en el proceso porque las características de la educación en el nivel Diversificado son muy similares en Chimaltenango y en el área de estudio. 
Se decidió contar hombres y mujeres de cada nivel educativo, de manera que se pudiera dar voz a los dos sexos y analizar así las diferencias en los discursos sobre la educación para la equidad en cada uno de ellos.

El criterio de autoidentificación étnica no fue determinante para la selección de las y los maestros. Los departamentos de Quetzaltenango y Totonicapán son eminentemente indígenas, con mayoría de población maya-k’iche'. De esta forma, sin que se orientara la selección de participantes con criterio de autoidentificación étnica, del grupo resultante solo una de las maestras se identificaba como ladina.

En cuanto al carácter público o privado de los centros educativos donde ejercen docencia las y los maestros, se dio prioridad a los públicos. Sin embargo, no se descartó la participación de una maestra y un maestro que ejercen docencia en centros educativos privados en Básico y Diversificado porque, como se ha explicado, la cobertura pública desciende drásticamente en el nivel Básico y mucho más en Diversificado. Estos niveles son cubiertos mayoritariamente por centros educativos privados ubicados en cascos urbanos, a los que deben desplazarse las y los jóvenes de las áreas rurales que puedan permitirse continuar sus estudios. Además, los centros educativos privados también tienen la obligación de aplicar el CNB.

La ubicación de los centros educativos en área rural o urbana tampoco fue criterio de selección. Se tomó esta decisión teniendo en cuenta la realidad laboral de muchos docentes, a quienes la precariedad del salario ${ }^{\text {xxvii }}$ que devengan por el trabajo en un solo centro educativo, ya sea público o privado, les obliga a trabajar en más de un centro educativo a la vez. Esto es posible porque las jornadas de estudio son vespertinas o matutinas de lunes a viernes (incluso nocturnas en los niveles Diversificado y Universitario) y en plan sabatino e incluso en domingo. Así, muchas de las personas participantes trabajaban como maestras en el sector público por la mañana y en el privado por la tarde y/o los sábados y quienes lo hacían solo en 
el sector privado se desempeñaban en más de un centro educativo. De la misma forma, es frecuente que la misma persona pueda trabajar en área rural en un centro educativo y en área urbana en otro. Puesto que el discurso de cada persona es fruto de su sentir de vida y se construye con todas las experiencias cotidianas, no se consideró relevante que el tipo de centro educativo y su ubicación fueran criterios de selección.

En cuanto al nivel formativo de las y los maestros participantes, de las 28 personas, 6 estaban cursando la carrera universitaria de Educación Intercultural en la Universidad de San Carlos de Guatemala, sede de Totonicapán, en el momento de las entrevistas. Se trata de una carrera de reciente implantación que cualifica como agente educativo no solo en educación formal sino también en el ámbito no formal. Otra de las maestras participantes era licenciada en Educación y, además de ser maestra de Pre-Primaria en activo, impartía docencia en una universidad privada en la carrera de Educación Pre-Primaria, en la materia de Coeducación (hay que resaltar que es la única universidad que cuenta con esta materia en su curriculum de estudios de la carrera de Educación Pre-Primaria). Entre las demás maestras y maestros participantes, es común que hubieran cursado algún año en la Universidad, habiendo terminado o no la carrera. En algunos casos, habían participado en los programas de actualización docente del MINEDUC, que periódicamente ofrece incluso programas de formación universitaria exclusivos para la "profesionalización” de docentes en activo.

La clasificación de maestras y maestros participantes por nivel donde imparten docencia, tipo de centro educativo, ubicación, sexo y código asignado a cada entrevista es la siguiente: 


\begin{tabular}{|c|c|c|c|c|c|}
\hline & & & & Part & tes \\
\hline Código & $\begin{array}{l}\text { Nivel } \\
\text { educativo de } \\
\text { docencia }\end{array}$ & $\begin{array}{l}\text { Tipo de centro } \\
\text { educativo }\end{array}$ & $\begin{array}{l}\text { Ubicación del } \\
\text { centro }\end{array}$ & $\mathbf{M}$ & $\mathbf{H}$ \\
\hline E01/PrPr/M & Pre-Primaria & Público & $\begin{array}{l}\text { Aldea de } \\
\text { Quetzaltenango }\end{array}$ & 1 & \\
\hline E02/PrPr/H & Pre-Primaria & Público & $\begin{array}{l}\text { Aldea de } \\
\text { Totonicapán }\end{array}$ & & 1 \\
\hline E03/Pr/M & Primaria & Público & $\begin{array}{l}\text { Aldea de } \\
\text { Totonicapán }\end{array}$ & 1 & \\
\hline E04/Pr/H & Primaria & Público & $\begin{array}{l}\text { Aldea de } \\
\text { Totonicapán }\end{array}$ & & 1 \\
\hline E05/B/M & Básico & $\begin{array}{l}\text { Privado con } \\
\text { financiamiento } \\
\text { público }\end{array}$ & $\begin{array}{l}\text { Aldea de } \\
\text { Quetzaltenango }\end{array}$ & 1 & \\
\hline E06/B/H & Básico & Privado & $\begin{array}{l}\text { Casco urbano de } \\
\text { Totonicapán }\end{array}$ & & 1 \\
\hline E07/D/H & Diversificado & Privado & $\begin{array}{l}\text { Casco urbano de } \\
\text { Chimaltenango }\end{array}$ & & 1 \\
\hline E08/P/M & Primaria & Público & $\begin{array}{l}\text { Aldea de Cantel, } \\
\text { Quetzaltenango }\end{array}$ & 1 & \\
\hline E09/P/H & Primaria & Público & $\begin{array}{l}\text { Aldea de Cantel, } \\
\text { Quetzaltenango }\end{array}$ & & 1 \\
\hline E10/P/M & Primaria & Público & $\begin{array}{l}\text { Aldea de Cantel, } \\
\text { Quetzaltenango }\end{array}$ & 1 & \\
\hline \multicolumn{4}{|c|}{ Total desagregado por sexo } & 5 & 5 \\
\hline \multicolumn{4}{|l|}{ TOTAL } & \multicolumn{2}{|c|}{10} \\
\hline
\end{tabular}

Figura 13. Clasificación de participantes en entrevistas comunicativas dirigidas a maestras y maestros. 
La clasificación de madres participantes es la siguiente:

\begin{tabular}{|l|l|l|c|c|c|}
\cline { 3 - 5 } \multicolumn{2}{c|}{} & \multicolumn{3}{c|}{ Participantes } \\
\hline Código & $\begin{array}{l}\text { Tipo de centro } \\
\text { educativo }\end{array}$ & $\begin{array}{l}\text { Ubicación del } \\
\text { centro }\end{array}$ & M & H & Total \\
\hline E11/M/M & Público & $\begin{array}{l}\text { Aldea de Cantel, } \\
\text { Quetzaltenango }\end{array}$ & 2 & 0 & 2 \\
\hline E12/M/M & Público & $\begin{array}{l}\text { Aldea de Cantel, } \\
\text { Quetzaltenango }\end{array}$ & 2 & 0 & 2 \\
\hline TOTAL & & 4 & 0 & 4 \\
\hline
\end{tabular}

Figura 14. Clasificación de participantes en entrevistas comunicativas dirigidas a madres de alumnado.

\begin{tabular}{|c|c|c|c|c|c|c|}
\hline \multirow[b]{2}{*}{ Código } & \multirow[b]{2}{*}{$\begin{array}{l}\text { Nivel } \\
\text { educativo de } \\
\text { docencia }\end{array}$} & \multirow[b]{2}{*}{$\begin{array}{l}\text { Tipo de centro } \\
\text { educativo }\end{array}$} & \multirow[b]{2}{*}{$\begin{array}{l}\text { Ubicación del } \\
\text { centro }\end{array}$} & \multicolumn{3}{|c|}{ Participantes } \\
\hline & & & & $\mathbf{M}$ & $\mathbf{H}$ & Total \\
\hline GD01 & Primaria & Público & $\begin{array}{l}\text { Varios } \\
\text { municipios de } \\
\text { Totonicapán y } \\
\text { Quetzaltenango }\end{array}$ & 3 & 3 & 6 \\
\hline GD02 & $\begin{array}{l}\text { Pre-Primaria } \\
\text { y Primaria }\end{array}$ & Público & $\begin{array}{l}\text { Quetzaltenango } \\
\text { cabecera }\end{array}$ & 6 & 0 & 6 \\
\hline GD03 & $\begin{array}{l}\text { Pre-Primaria } \\
\text { y Primaria }\end{array}$ & Público & $\begin{array}{l}\text { Aldea de Cantel, } \\
\text { Quetzaltenango }\end{array}$ & 6 & 1 & 7 \\
\hline GD04 & $\begin{array}{l}\text { Pre-Primaria } \\
\text { y Primaria }\end{array}$ & Público & $\begin{array}{l}\text { Almolonga } \\
\text { cabecera, } \\
\text { Quetzaltenango }\end{array}$ & 7 & 2 & 9 \\
\hline \multicolumn{4}{|l|}{ TOTAL } & 22 & 6 & 28 \\
\hline
\end{tabular}

Figura 15. Clasificación de participantes en grupos de discusión comunicativos dirigidos a maestras y maestros. 


\subsection{Contexto de las y los participantes}

Abordaremos ahora la descripción de los departamentos de Quetzaltenango y Totonicapán para que sirva de marco contextualizador de las interacciones de las y los participantes, ayudando a comprender mejor sus discursos.

Guatemala tiene una población proyectada para 2019 de 17.689 .642 personas, según datos del Instituto Nacional de Estadística $-\mathrm{INE}^{\mathrm{xxviii}}$. Es una población joven. Se calcula que más del $60 \%$ de las personas tienen menos de 30 años $^{\text {xxix }}$. Según Naciones Unidas (2014), el 60\% de la población de Guatemala se auto identifica como indígena, siendo el k’iche' el pueblo maya mayoritario, seguido del mam. El resto de la población se auto identifica como ladina y una pequeña parte es extranjera.

Siguiendo los datos ofrecidos por el PNUD (2016), en 2014 en Guatemala el 66.7\% de la población vivía en pobreza o pobreza extrema, siendo la población indígena la más afectada debido a la exclusión histórica a la que se ha visto sometida. La brecha de pobreza entre población indígena y no indígena es muy significativa: el $86.6 \%$ de la población indígena sufría pobreza o pobreza extrema en 2014, frente a un 53.9\% de la población no indígena.

Siguiendo datos estadísticos del mismo informe del PNUD (2016), en 2014 en Guatemala había un $22 \%$ de hogares no conectados a una red de distribución de agua, un 55\% no conectado a red de drenaje y casi un $20 \%$ sin suministro de energía eléctrica. Estás carencias se concentran en las áreas rurales. Sin embargo, respecto al suministro de agua, es importante resaltar que la conexión a una red de distribución de agua, generalizada en las áreas urbanas, no garantiza el suministro. Esto se debe a la ingobernabilidad existente en materia de agua: los sistemas de agua, a excepción de la ciudad capital y algunos cascos urbanos, no son construidos y operados por las Municipalidades u otros entes del Estado desde una planificación global y orientada por el derecho humano al agua, sino que se realizan, operan y mantienen por iniciativa privada de comités de vecinos, sufragados por las personas 
asociadas a cada comité. El agua es tomada directamente de nacimientos en las montañas o a través de la perforación de pozos, sin control respecto al impacto medioambiental y llega a los hogares sin tratamiento de potabilización. En el casco urbano de Totonicapán, que es además cabecera departamental, se registran muchos hogares en los que el abastecimiento de agua llega cada 2 o 3 días.

Los departamentos de Quetzaltenango y Totonicapán pertenecen a la región suroccidente de Guatemala, denominada región VI según la división realizada por la Secretaría General de Planificación -SEGEPLAN- (ver mapa de ubicación en el anexo 6). Sus cabeceras departamentales, las ciudades de Quetzaltenango y Totonicapán respectivamente, se encuentran a 45 kilómetros de distancia entre sí. La ciudad de Quetzaltenango es la segunda ciudad más importante del país después de la ciudad capital -de la que la separan 200 kilómetros- y atrae a cientos de estudiantes de toda la región occidental del Guatemala que llagan a sus centros de educación superior, fundamentalmente. Ambas ciudades, Quetzaltenango y Totonicapán, se ubican a más de 2.200 metros sobre el nivel del mar, en el altiplano guatemalteco, lo que hace que se caractericen por un clima extremo, de sol abrasador durante el día y frío por la noche.

El Índice de Desarrollo Humano -IDH- de los dos departamentos estudiados presenta diferencias importantes, con indicadores más altos para Quetzaltenango en los tres componentes que mide: salud, educación y nivel de vida. Según el PNUD (2016), en 2014 el IDH de Quetzaltenango se situaba en 0.529, estando sensiblemente por encima del IDH nacional. En el mismo año, Totonicapán presentaba un IDH de 0.432 .

El departamento de Quetzaltenango cuenta con 24 municipios y una población total de 940.159 personas, según la proyección del INE para 2019. Según la misma fuente, la densidad de población para 2019 es de 482 personas por km2. El departamento presenta una zona alta y fría en la que se ubica su cabecera y una zona baja y caliente, lindando con la 
costa sur del país. Los municipios más poblados son Quetzaltenango y Coatepeque, este último ubicado en la zona baja. Según el PNUD (2011), el 42\% de la población de Quetzaltenango vive en áreas rurales.

El departamento de Totonicapán tiene una población total de 601.837 personas, distribuidas en 8 municipios, con una densidad poblacional de 567 personas por km2, según la proyección del INE para 2019. Según el PNUD (2011), el 56\% vive en áreas rurales, siendo los municipios más poblados Totonicapán y Momostenango. La población de Totonicapán es eminentemente indígena, con un $97.9 \%$ de personas que se auto identifican como maya-kiche'.

Nos detendremos ahora en los datos relativos a educación. Los avances en educación han sido importantes en las últimas décadas, tanto en la reducción de la tasa de analfabetismo como en la extensión de la cobertura educativa. Es importante recordar la relación que existe entre el avance de los indicadores educativos y el avance de otro tipo de indicadores como los de salud, siendo la educación un elemento básico para el desarrollo global de los países. Según el PNUD (2016), en Quetzaltenango el 78.6\% de las mujeres y el $88.9 \%$ de los hombres mayores de 15 años eran alfabetos en 2014. En Totonicapán, la brecha de género era mucho mayor en ese año: el $82.2 \%$ de los hombres mayores de 15 años eran alfabetos frente al $62.5 \%$ de las mujeres. Los años promedio de escolaridad varían muy sensiblemente de un departamento al otro. En Quetzaltenango, en 2014 los hombres tenían 7 años promedio de escolaridad, un año por encima del promedio nacional, y las mujeres tenían 5.6 años promedio de escolaridad, casi igualada con 5.3 promedio nacional. En Totonicapán, sin embargo, para el mismo año 2014, los hombres presentaban 5.2 años promedio de escolaridad y las mujeres, 4.1 .

Como se ha indicado, los esfuerzos en la ampliación de la cobertura educativa en el nivel de Primaria han sido muy significativos en las últimas décadas a nivel nacional. Sin embargo, 
quedan retos muy importantes en la cobertura de los niveles Inicial, Básico y Diversificado y, en todos los niveles, en la capacidad de retención del sistema educativo y la calidad educativa. Según datos del anuario estadístico del MINEDUC ${ }^{\mathrm{xxx}}$, en 2018 se encontraban escolarizados 6 de cada 10 niños en edad escolar, con unas tasas brutas de cobertura $^{\text {xxxi }}$ del 91.41\% en Primaria, en torno al $70 \%$ en Pre Primaria y Básico y de solo el $37.23 \%$ en Diversificado.

En Quetzaltenango, la escolarización de niñas y niños en edad escolar se encontraba en 2018 en 6 de cada 10, mientras que en Totonicapán estaban escolarizados 5 de cada 10. En cuanto a tasas de cobertura brutas por nivel de escolaridad, los porcentajes fueron muy diferentes en ambos departamentos, con un rezago muy importante en el departamento de Totonicapán, como muestra la siguiente tabla:

\section{Tabla 9}

Tasa bruta de cobertura por nivel educativo en Quetzaltenango y Totonicapán, 2018

\begin{tabular}{lll}
\hline Nivel & Quetzaltenango & Totonicapán \\
\hline Pre Primaria & 70.77 & 47.43 \\
Primaria & 88.7 & 64.99 \\
Básico & 77.35 & 36.5 \\
Diversificado & 53.76 & 12.87 \\
\hline
\end{tabular}

Fuente: MINEDUC (2018).http://estadistica.mineduc.gob.gt/Anuario/home.html\#

La exclusión centro-periferia es muy notable en los departamentos de Quetzaltenango y Totonicapán, tal y como ocurre a nivel nacional. Así, las oportunidades educativas se concentran en las cabeceras departamentales, seguidas de las cabeceras municipales, quedando las áreas rurales carentes de servicios. En Totonicapán, de sus 8 municipios solo 3 contaban en 2018 con un centro educativo público de nivel Diversificado, según datos del anuario estadístico del MINEDUC. Destaca el hecho de que el MINEDUC no cuente con 
datos de cobertura desagregados por etnia y ruralidad/urbanidad. Sin embargo, los resultados de aprendizaje de estudiantes de Diversificado, analizados con enfoque interseccional, revelan que estudiantes indígenas y de áreas rurales obtienen peores resultados que estudiantes ladinos y de áreas urbanas ${ }^{\text {xxxii }}$. 


\section{Resultados de la investigación}

Nos proponemos ahora exponer los resultados de la investigación. Analizar las aportaciones de las maestra y maestros participantes en las entrevistas comunicativas y grupos de discusión comunicativos a la luz de la Metodología Comunicativa Crítica (MCC) nos permite identificar las barreras y oportunidades que encuentran para que la educación en equidad de género, de etnia y social sea impulsada desde la escuela, aportando a la reconfiguración de un nuevo orden social basado en la equidad.

El análisis de resultados se ha realizado sobre la base de cuadros de análisis que permiten clasificar los actos comunicativos de cada participante utilizando categorías y subcategorías y las dimensiones exclusora y transformadora. Los cuadros de análisis realizados se encuentran en el anexo 4.

Los resultados de la investigación, generados a partir de las aportaciones de las personas participantes, se exponen a continuación con la siguiente estructura: comenzaremos abordando la vertebración de la sociedad guatemalteca desde la experiencia de las y los maestros, analizando la construcción social del género, de la pertenencia étnica etnia y de la clase social y analizando la concepción de equidad desde la cosmovisión maya; a continuación nos acercaremos a la percepción de las maestras y maestros sobre la socialización de género, de etnia y de clase social y sobre los agentes socializadores de género, entre ellos la escuela; por último, profundizaremos en el quehacer docente en materia de educación para la equidad de género, de etnia y social, tomando en cuenta las múltiples dimensiones que abarca la coeducación. El análisis de las acciones coeducativas que ellas y ellos realizan en las aulas se complementa con la visión de madres y padres de alumnado PrePrimaria y Primaria, que expresan cuáles son las expectativas que depositan en la escuela en cuanto a la socialización de género para sus hijas e hijos en el mundo cambiante en que vivimos. 


\subsection{Análisis de la vertebración social}

El género, la pertenencia étnica y la clase social son elementos que configuran la sociedad guatemalteca. Desde una perspectiva interseccional, nos acercamos a la experiencia de las y los maestros participantes respecto a las implicaciones que tienen estos elementos en la realidad de inclusión o exclusión vivida por mujeres y hombres.

\subsubsection{Construcción del género.}

Maestras y maestros participantes en las entrevistas y grupos de discusión coinciden en señalar que las relaciones de género giran en torno a la supremacía masculina, que se manifiesta en todas las esferas sociales.

"Por diversas razones políticas, culturales e históricas la equidad de género no se ha logrado aplicar, diría yo, en la mayoría de los ámbitos tanto social, político, religioso, inclusive cultural, predomina el hombre sobre la mujer" $(\mathrm{E} 09 / \mathrm{P} / \mathrm{H})$

La supremacía masculina es el eje del patriarcado que, como señala Marcela Lagarde (2014:266), es una “forma de organización social (prácticas, relaciones e instituciones) basadas en la dominación del género masculino sobre el género femenino”. Lagarde (2014) siguiendo a Amorós (1994), explica que el sistema patriarcal tiene la característica de unir a todos los hombres por el hecho de serlo en una suerte de pacto de género que excluye a las mujeres y se configura en contraposición de sus intereses.

El patriarcado podría considerarse una especie de pacto interclasistametaestable, por el cual se constituye en patrimonio del genérico de los varones, en cuanto ellos se auto instituyen en sujetos del contrato social ante las mujeres que son, en principio, "las pactadas" (p.267) 
El mantenimiento del sistema patriarcal está asociado a la práctica de un determinado tipo de masculinidad. La masculinidad, evidencian Walda Barrios y Ana Lucía Ramazzini (2016:31), siguiendo a Luna (2010), “es el proceso subjetivo a través del que se internalizan las formas, significados y símbolos de ser hombres, resultado del proceso de socialización y desde allí se ocupa un lugar en el mundo". La masculinidad está estrechamente ligada a la construcción social del género asignada a los hombres en un contexto dado. Por lo tanto, la masculinidad no es única, hay diversas masculinidades dentro de cada sociedad y, además, su construcción es histórica. Sin embargo, el sistema patriarcal, en su ejercicio de poder excluyente y dominador, establece un modelo de masculinidad hegemónica que se impone en cada momento histórico de cada sociedad. Nicolás Schongut (2012) analiza el concepto de masculinidad hegemónica desarrollado por Connell (1987), principal precursora del mismo, explicando que:

es el sustento del poder que se ejerce desde la superioridad masculina, asimismo implica una gran cantidad de hombres y mujeres que estén dispuestos a sostener la hegemonía, pues al no ser un dominio impuesto desde la exterioridad (dígase por la fuerza) implica un consentimiento de parte importante de la sociedad. (p.48)

Schongut (2012), siguiendo a Demetriou (2001), destaca que existen dos formas y funciones de la masculinidad hegemónica: una hegemonía externa, que daría cuenta de la institucionalización de la dominación masculina sobre las mujeres y una hegemonía interna que se refiere a la ascendencia social de un grupo de hombres sobre todos los otros hombres. Este planteamiento es especialmente relevante en sociedades diversas como la guatemalteca, donde existe una masculinidad hegemónica que podría decirse nacional, con la clara supremacía de los hombres ladinos o de ascendencia extranjera, de clase alta y urbanos. Sin embargo, es importante analizar que existen otras masculinidades que, aun siendo 
subordinadas en la escala general, se convierten en hegemónicas en las regiones y contextos en las que se desarrollan.

En el contexto de los departamentos de Guatemala estudiados, la masculinidad hegemónica tiene la característica de basarse en la servidumbre de las mujeres para satisfacer todas las necesidades de los hombres, construidas desde el ego de considerarse merecedores del servicio, llegando, dentro de la violencia de género, a la violencia física como exhibición extrema del control. La violencia contra las mujeres es una de las características que Barrios y Ramazzini (2016), basadas en Kaufmann (1989), identifican en la masculinidad hegemónica, en una tríada de violencias compuesta por: violencia contra las mujeres y las niñas, violencia contra otros hombres y violencia contra sí mismos.

La investigación ha podido determinar que la masculinidad hegemónica, con el rasgo de la violencia contra las mujeres y las niñas, se reproduce a sí misma en la socialización de género de las niñas, niños y jóvenes de la zona estudiada. Así, se visibilizan machismo y violencia de género:

"Hablarle de Santa María Chiquimula [Totonicapán], es hablarle de mucho machismo, los hombres, los señores, los padres de familia, tienen 2, 3 o 4 mujeres y con cada mujer tiene 6, 7 niñitos, niños que no crecen con su papá, los niños sufren de mucha desnutrición, tenemos mucho problema porque hay mucha desintegración familiar, el señor llega y le pega a la señora" $(\mathrm{E} 03 / \mathrm{Pr} / \mathrm{M})$.

Este modelo, además, aparece naturalizado:

"Yo a veces he escuchado en familias que la mamá al educar a los chiquitos, como los niños pegan, dicen: todos los hombres son así. Entonces las niñas ya se van metiendo eso en la cabeza, eso de que los hombres son así. No es así, todos tienen los mismos derechos, igualdad" (GD03) 
Y se culpabiliza a la propia víctima:

"Y usted por qué le permitió que le pegara [su hijo, niño], usted es la mamá... es que como mira lo que hace el papá, seño..." (GD03)

El férreo control sobre las mujeres que ejerce esta masculinidad hegemónica basada en la violencia se manifiesta en roles de género muy diferenciados que tienen que ver con la asignación a las mujeres de todo el trabajo reproductivo y un ejercicio total de poder de los hombres sobre el destino y la vida de las mujeres, respaldado en el rol tradicional de hombreproveedor. Esto se evidencia desde, por ejemplo, hábitos y rutinas domésticas:

"Pude estar en un hogar donde la mujer es la encargada de servir la comida y el hombre aunque se estuviese muriendo de hambre, no se levantaba a servir la comida porque era una obligación de la mujer hacerlo" (GD01)

También se evidencia en la invisibilización de las mujeres desde criterios estrictamente económicos que obvian el trabajo público de la mujer unido, además, al trabajo de cuidado.

"Soy maestra, estudiante universitaria, tengo hijos y me desenvuelvo en muchos papeles, pero aun así mi esposo no me trata como tal, ya algunas veces que me ha dicho que yo no le puedo darle órdenes a él, porque jél gana más que yo! ¡Imagínese!” (E03/Pr/M)

Así mismo, esta masculinidad hegemónica perpetúa el control de los recursos económicos y su producción en manos de los hombres y, con ello, sigue controlando la vida de las mujeres y familias. Esto da lugar a la exclusión hacia las mujeres en el ámbito laboral, en el que tienen poca presencia y, cuando la tienen, son discriminadas. Esta situación se da en muchas otras culturas, como la europea.

“A un hombre ingeniero le pagan mejor que a una mujer, pero ingeniero y los dos tienen la capacidad, la inteligencia y tienen el mismo puesto prácticamente verdad, pero no hay igualdad" (GD02) 
Avanzamos en el análisis constatando que el género no solo establece roles diferenciados para mujeres y hombres que dan lugar a exclusión de las mujeres, sino que también construye un sistema normativo que actúa como potente mecanismo de reproducción del sistema patriarcal. Siguiendo a Barrios y Ramazzini (2016), encontramos que se pueden delimitar tres niveles:

el relacionado con la formación de la identidad, en el que la sexualidad tiene un papel fundamental. La construcción del campo social que tiene que ver con la asignación de roles masculinos y femeninos y la asignación de valores, que nos conduce al tercer nivel, el género como sistema normativo. (p.19)

La investigación ha encontrado que en los departamentos estudiados el nivel normativo del género ha desarrollado mandatos de género incuestionables que se aplican a toda la vida social, revestidos incluso de aspectos místicos y religiosos. Por ejemplo, desde el contacto físico, como señala la siguiente aportación:

“Aquí [Almolonga] las mujeres se sientan a parte y los varones se sientan a parte o sea no pueden estar juntos. [...] Cuando vamos a física o vamos alguna actividad, nosotros colocamos una niña y un niño agarrados de la mano, para que ellos aprendan a convivir con el género opuesto [...] pero es algo que no podrían hacer afuera porque sería marcado como algo malo, no es correcto, entonces la discriminación se maneja por cuestiones más de costumbre” (GD04)

El sistema patriarcal que excluye a las mujeres se reproduce a través de diversos mecanismos. Uno de ellos es culpar a las mujeres de su propia de exclusión, justificándola y reforzándola. Es un mecanismo perverso que ignora deliberadamente que el patriarcado es un sistema del que formamos parte tanto hombres como mujeres. Culpar a las mujeres de su propia exclusión es una forma de violencia cultural del patriarcado hacia las mujeres que 
legitima la violencia estructural en forma de exclusión que ejercen contra ellas todas las estructuras sociales y, por supuesto, también legitima la violencia directa. Como explica Galtung, "se puede identificar un flujo causal de la violencia cultural a la violencia directa, pasando por la estructural" (Galtung, 2003a:13). Y continúa advirtiendo que "una de las mayores formas de violencia cultural en la que incurren las élites gobernantes es la de culpar, marcándola de agresora, a la víctima de la violencia estructural” (Galtung, 2003a:13).

Podemos aportar algunos ejemplos en los que se contextualiza la negativa de la mujer a ocupar espacio, poder, como consecuencia de todo lo expuesto con anterioridad:

"Yo trabajo con la adolescencia e intentamos darle el espacio a la mujer, pero la mujer es la misma que cede ese espacio para que sea el hombre quien protagonice. Se le da la oportunidad y no lo asume” (GD03)

Y también:

"La igualdad entre hombre y mujer es fundamental para muchos procesos, pero cuando la mujer misma no aprovecha o no se da ese espacio ahí radica el problema. Pero yo pienso que eso es una herencia de los padres, es la ideología familiar, que aún lo llevan" (GD03)

Los mandatos de género son de obligado cumplimiento, so pena de estigmatización y separación de las mujeres en la vida familiar y comunitaria. Las mujeres que transgreden las fronteras del género son duramente criticadas y castigadas con el propósito de que regresen al lugar establecido para ellas. Tanto es así, que las propias mujeres identifican la trasgresión del papel sumiso a las órdenes de los hombres como "libertinaje", sustantivo de connotación negativa que se asocia con un uso abusivo de la libertad, causante de mala reputación, caso del siguiente ejemplo: 
"Porque a veces también a las mujeres se les deja hacer y exageran y si vemos en las noticias muchas mujeres con esa libertad ellas lo tomaron como libertinaje y no se dan a respetar y hacen las cosas que quieren" (GD03)

El término libertinaje también es utilizado para designar las acciones de las mujeres que buscan cambiar los roles de género en el hogar:

"Hay que tener siempre el cuidado porque existe también la cuestión de que las mujeres reviertan el papel muy liberal. Porque no hay que negar que existen también mujeres que dominan en el hogar y hasta manejan a los hombres, entonces, como todo requiere un equilibrio" (GD03)

Incluso, la denuncia de la violencia de género es difamada utilizando el término libertinaje: "Nos dieron la libertad y utilizamos el libertinaje. En mi casa hay una oficina jurídica, llegan problemas de que las mujeres pegan a sus maridos y el hombre no se defiende por vergüenza, pero hay mujeres que exageran y meten a sus maridos en problemas" (GD03)

También el término "feminismo" se asocia al libertinaje, definiéndolo como contrario del machismo e igual de pernicioso que éste.

"El machismo sobresale en muchas comunidades, en otros lugares no es el machismo si no el feminismo verdad, como yo ya tengo derechos como mujeres vamos también a levantarnos, levantemos nuestro movimiento y se ha vuelto como un campo de batalla hombres contra mujeres, mujeres contra hombres" (GD01)

La estigmatización del feminismo es la consecuencia de toda una estrategia de deslegitimación de los avances de las mujeres que proviene de las élites económicas y religiosas. Se acusa al movimiento feminista de inmoral, con duras acciones por parte del Congreso, las iglesias y otros sectores que pretenden frenar el avance de los derechos de las 
mujeres y generar una opinión pública confundida respecto al verdadero significado del feminismo para que se convierta en adversa a él y, por lo tanto, aliada de los intereses del sistema patriarcal- neoliberal. En palabras de Lagarde (2014),

nunca antes en la historia el antifeminismo había contado con la conjunción de acciones poderosas, de fuerzas económicas, políticas y religiosas: ideologías conservadoras, antidemocráticas y misóginas descalifican, ridiculizan y deslegitiman la feminismo y a las mujeres; organismos, instituciones y personas - mujeres y hombres, pero mayormente hombres- nos hostilizan de manera permanente y sofisticada desde posiciones de verdad (poder) a través de acciones y mensajes hegemónicos, visibles o implícitos; promueven la enajenación femenina en torno al feminismo.(p.307)

Una de las peores consecuencias del sistema patriarcal es que mina la autoestima de las mujeres desde niñas. Retomamos aquí el nivel de la formación de identidad en el que actúa el género: la baja autoestima, ligada a la subordinación y a la no construcción de deseos y proyectos propios, se convierte en un elemento común en la formación de la identidad de las niñas y mujeres. Una identidad femenina basada en la baja autoestima es otro fuerte mecanismo reproductor del propio sistema: debilita la agencia de las niñas, jóvenes y mujeres adultas y coloca un techo muy bajo para sus expectativas de vida. Así se expresa en la siguiente aportación:

"Las niñas se menosprecian, en el sentido que ellas son las que tienen que ayudar a la mamá, o sea su lugar está solo en la casa, y se menosprecian porque no creen tener la capacidad de poder hacer más o de llegar a hacer tal vez lo que un hombre hace” (E01/PrPr/M)

A pesar de la dureza de la realidad descrita, es evidente que la construcción tradicional del género, especialmente en lo relacionado con los roles diferenciados por sexo, se encuentra en 
un proceso de cambio cultural hacia la equidad, como muestran las siguientes aportaciones en las que se reconoce el avance:

"Si hemos avanzado bastante en que ya gracias a Dios, muchas de nuestras niñas asisten a la escuela, ya conocen y ya hay un poquito de igualdad, no la que desearíamos verdad, pero ya se ha logrado bastante” (GD02)

Destacándose nuevos roles de la mujer, desde nuevas acciones:

"Ahorita veo yo a mujeres manejando carros, manejando motos. Cosa que no se daba antes verdad y también yo estoy viendo ahora que ya hay profesionales mujeres en cambio más antes no había profesionales mujeres había más hombres que mujeres y en cuanto también a la política decía la compañera, si miramos que los que gobiernan son hombres a como dé lugar, no hay mujeres. Pero, siempre ya están saliendo algunas candidaturas mujeres, pues yo estoy viendo que se está tratando la manera de tener igualdad" (GD03)

O incluso el papel protagonista para iniciar un acercamiento:

"En mi época si yo recuerdo que nunca busqué a un muchacho, uno espera que lo buscan a uno, pero ahora ya las muchachas no les da pena, y ya son ellas las que buscan a los patojos [jóvenes] y nos damos cuenta que ahora ya las muchachas salen. Antes le dan permiso a uno solo si uno va a acarrear agua, nada más, ahora ya no, entonces todo se está cambiando” (GD03)

Se constata que, además del cambio que se está produciendo en las familias hacia prácticas más incluyentes con las niñas, hay un cambio actitudinal y relacional en las nuevas generaciones.

"Yo creo que los jóvenes tienen una idea a veces mucho mejor que gente de más edad en cuanto al respeto, [...] hay grupos de jóvenes que han entendido ya esto y que lo están manejando muy bien” (E07/D/H) 
Respecto a las percepciones diferenciadas de mujeres y hombres sobre estos avances hacia la equidad que se están dando en la actualidad, es importante destacar que los maestros manifiestan una percepción más optimista que las maestras. Esto revelaría la posición de ventaja de los hombres en la sociedad, que les confiere una percepción que minimiza el problema social de la exclusión hacia las mujeres, mientras que las mujeres, como sujetos oprimidos, tienen una percepción más amplia sobre la gravedad de la situación, como puede apreciarse en las siguientes aportaciones:

"Desde el punto de vista de equidad de género pues la verdad de que sí actualmente hay oportunidad para todos" (E06/B/H)

Un maestro observa que en la aldea en la que trabaja ya se ha superado la inequidad de género entre niñas y niños:

"He visto que allá [en aldea donde trabaja] casi tienen la misma equidad de género tanto niños como niñas, o sea, allá valen lo mismo lo que pasa es que hay circunstancias allá que los padres de familia a veces no es la prioridad los hijos " $(\mathrm{E} 02 / \mathrm{PrPr} / \mathrm{H})$

Otro maestro considera que las mujeres ya están incluidas en la toma de decisiones comunitarias:

“Ahora se está dando la oportunidad a ambas personas de igual manera la participación también se le está dando al hombre y a la mujer toma de decisiones por ejemplo verdad, en la comunidad se toma en cuenta la opinión de ambas personas" $(\mathrm{E} 06 / \mathrm{B} / \mathrm{H})$

El cambio cultural hacia la equidad genera tensiones y resistencias, que pueden interpretarse como parte normal de todo proceso que tiene implicaciones en la redistribución del poder. Así lo muestra la siguiente aportación: 
“El género se ha convertido en una división, la religión y la cultura yo pienso que ya es el momento de empezar a edificar y no seguir dividiendo más, verdad" (GD01)

Es importante el hecho de que el diálogo es identificado como una forma de enfrentar estas tensiones:

"Yo siento que en lugar de estar en ese campo de batalla debemos sentarnos a dialogar" (GD01)

Destaca la aportación de un maestro, que en medio de este cambio que se está produciendo, cuestiona su propio rol como hombre.

"Entonces siento yo que el celo como hombres tenemos que dejarlo a un lado también, verdad, de que una mujer sea superior a mí en ámbito académico, en ámbito profesional, eso no debe hacerme sentirme inferior, al contrario, debe ser un reto para mi” (GD01)

De las aportaciones de las y de los participantes acerca de la equidad de género podemos extraer varias conclusiones interesantes. En primer lugar, la manifestación explícita del sistema patriarcal en forma de férreos mandatos de género que sitúan a las mujeres en el ámbito privado y al servicio de los hombres, cuyo incumplimiento es castigado, especialmente en las mujeres que transgreden las fronteras del género. El sistema binario se transmite a niñas y niños desde la infancia, contribuyendo a la reproducción en los niños de la masculinidad hegemónica basada en la violencia y en las niñas de una identidad femenina caracterizada por la baja autoestima. Esto condiciona la agencia de las mujeres en su vida infantil, juvenil y adulta, e inocula el ejercicio de la dominación y la violencia en los niños.

En segundo lugar, encontramos los mecanismos de reproducción del sistema de exclusión hacia las mujeres: culpabilización de las mujeres respecto a su propia exclusión, estigmatización a las mujeres que no cumplen el papel que les ha sido asignado, castigo al 
incumplimiento del nivel normativo del género y respaldo de los mandatos de género en el terreno de lo irracional a través de creencias místicas les imprimen el sello de lo incuestionable: la prohibición de que la ropa de hombres y mujeres se junte, la creencia de que una mujer que se sube a un árbol lo deja sin fruto o la premisa bíblica de que el hombre tiene autoridad sobre la mujer. Esto forma parte del centro simbólico de valores de la sociedad guatemalteca (Galarza, Cobo y Esquembre, 2016) y constituye violencia cultural o simbólica contra las mujeres. A continuación, algunos ejemplos:

"Es prohibido que se tienda la ropa del varón con la ropa de la mujer. Es aparte, hay que lavar la ropa del hombre y aparte hay que lavar la ropa de la mujer, hay que asolearlo aparte [...] A veces hablan del corte de la mujer (falda tradicional indigena), dicen que no encuentre (toque) la ropa del hombre" (GD03)

O la identificación de la mujer con aspectos negativos desde creencias tradicionales:

"Tú no puedes subirte a un árbol [creencia tradicional sobre las mujeres], por ejemplo, verdad, porque el árbol ya no va a dar fruto” (GD01)

O la segregación en los espacios:

"Yo he participado en la iglesia evangélica y en la iglesia católica. Se apartan todas las mujeres y todos los hombres... rara vez cuando van en pareja se sientan hombres y mujeres" (GD03)

Todo ello, basado en premisas irracionales desde la religión:

"Este tema de discriminación es bíblico, la cabeza de la familia es el hombre y eso es bíblico, y la mujer tiene que estar sumisa al marido, eso es bíblico" (GD03)

Por último, se evidencia que se está produciendo un cambio cultural hacia mayor equidad de género, pero de manera lenta y no exenta de las tensiones, controversias y 
resistencias propias de la remoción de los cimientos del status quo. Las acciones de las mujeres en favor de sus derechos son interpretadas como agresivas al romper el orden imperante y esta transgresión conlleva además una deslegitimación del feminismo al confundirlo con esta "batalla" entre sexos. Las y los participantes ratifican que el cambio cultural hacia la equidad es una necesidad y se pone la vista en las nuevas generaciones como motores del mismo. Esto nos conduce directamente a cuestionarnos cuál debe ser el papel de los agentes socializadores de género en los cambios que se desean en las nuevas generaciones. Se profundizará en este tema en el apartado segundo de este análisis de resultados.

\subsubsection{Pertenencia étnica.}

La exclusión por motivo de la pertenencia étnica es patente en Guatemala. El racismo es un elemento vertebrador de la sociedad que surgió en la época de la Colonia y que se perpetúa en la actualidad, siendo funcional para el sistema neoliberal. Lorena Cabnal (2010) explica que el racismo

ha nacido, se ha engrosado y se ha alimentado en la colonia, luego se ha ido fortaleciendo en la conformación de la estructura de países y repúblicas, donde ha creado y sigue creando condiciones para que su existencia hegemónica continúe siendo una sostenedora de dominación y subyugación de los pueblos, a través de instituciones y leyes occidentales masculinas.(p.20)

El racismo es la exclusión más fácilmente identificada por las y los maestros participantes, por delante de la discriminación de género. Esto está probablemente influido, por un lado, por el hecho de que la gran mayoría de las y los participantes se autoidentifica como indígena e identifica a la población indígena como víctima del racismo y, por otro lado, porque el discurso de la existencia de discriminación étnica es un discurso socialmente aceptado e inocuo para la vida cotidiana de las familias y comunidades homogéneas cohesionadas por su 
pertenencia étnica, al no cuestionar directamente las bases de poder basado en el género sobre las que se asientan estas estructuras sociales.

Desde una mirada interseccional, se constata que la pertenencia étnica no puede ser separada del género, la clase social, la ruralidad o urbanidad, la identidad sexual y otras características que marcan las experiencias vitales de las personas. La confluencia de las condiciones de mujer, indígena, de área rural y de clase social baja configura una experiencia de máxima exclusión en la estructura social guatemalteca.

Es importante reparar en que los elementos indígena, rural y clase social baja se asocian entre sí de forma estereotipada en el imaginario social guatemalteco, obviando la existencia de personas indígenas de áreas urbanas, personas indígenas con alto poder adquisitivo y otras combinaciones de estos elementos vertebradores de la sociedad. Esta generalización estereotipada constituye violencia cultural hacia los pueblos indígenas, que legitima la violencia estructural a la que están sometidos en la configuración socioeconómica del país, basada en una exclusión centro-periferia que coloca a los pueblos indígenas siempre en las periferias tanto territoriales como del imaginario. Esto queda patente en las dos aportaciones siguientes:

"Sí existe la discriminación. Nuestro país es totalmente indígena. Españoles así ladinos tal vez hay un $30 \%$ y un $70 \%$ indígena. Ya ahí si nos vamos más localmente nuestra comunidad es netamente indígena, pero ahí sí que, cómo combatir esto, llevaría mucho tiempo" (GD04)

"Los de Xela discriminan a tal municipio, el otro municipio discrimina a otro, a no, que yo soy de Toto, que se discriminan ... total que es como un cáncer que no se puede curar" (GD04)

En el caso de las mujeres indígenas, el estereotipo social asocia la condición de mujer indígena, con ruralidad, clase social baja, analfabetismo, falta de comprensión de la realidad y 
susceptibilidad de manipulación política y social. Esto refuerza una percepción sobre las mujeres indígenas englobadas en un cliché colectivo que las deshumaniza y despoja de su individualidad, permitiendo así obviar la heterogeneidad de sus experiencias de vida, de sus necesidades, capacidades y demandas como mujeres.

En medio del escenario descrito, las y los participantes coinciden en que también se está produciendo un cambio cultural hacia mayor equidad étnica.

"Por ejemplo entre indígenas y ladinos, yo me recuerdo que años atrás había muchas situaciones en las que las personas indígenas no podían entrar a estudiar, vean a ustedes ahora ellos [indígenas] ya se han superado un montón ya tienen el poderío también, ya han cambiado" (GD02)

La población indígena, relegada históricamente incluso con la aplicación de políticas segregacionistas y un genocidio cometido contra ella, se muestra más empoderada en la defensa de los sus derechos y esto es visible en acciones concretas.

“Una persona de Quetzaltenango habia peleado una demanda internacional porque no lo dejaron entrar a un restaurante, por llevar el traje típico” (GD04)

El proceso de cambio cultural hacia mayor equidad étnica que se vive permite el surgimiento de reflexiones cuestionadoras de la discriminación:

"Qué mundo le vamos a dejar a nuestros hijos si no aprendemos a convivir en equidad y no discriminar a las personas, qué va a pasar entonces, esa es una situación que debemos concientizar a las personas desde pequeños, pero también concientizar a las personas grandes para que ayuden al proceso para que se logre y camine” (GD04)

Sin embargo, siguiendo a Cabnal (2010), un cuestionamiento del racismo como factor externo a los pueblos indígenas no sería suficiente para su superación. Cabnal (2010) explica que las mujeres indígenas, y extensivamente toda la población indígena, habría internalizado 
el efecto de la desventaja histórica que les han impuesto el patriarcado y el racismo, sufriendo lo que ella llama la victimización histórica situada. Transformar este racismo en relaciones de equidad implicaría una reflexión crítica sobre esta victimización histórica situada "para poder trascender el racismo internalizado y posibilitarnos verlo en nuestra construcción cultural" (Cabnal, 2010:20).

\subsubsection{Clase social.}

Las profundas brechas de desigualdad que desgarran a la sociedad guatemalteca encuentran una de sus aristas más visibles en la estratificación socioeconómica de la población. En Guatemala, el Estado está ausente de los territorios y su enfoque dista de cumplir el papel constitucional de satisfacer las necesidades básicas de la población: se trata de un Estado creado para privilegiar a las élites. Según Julieta Paredes (2017), este enfoque del Estado es recurrente en la mayoría de países de América Latina, sometidos a medidas de ajuste estructural. El neoliberalismo actual solo puede hacer que las brechas de desigualdad sigan creciendo y arrasando la vida de los grupos de población más vulnerables, en los que cada vez se engloban más personas y comunidades, y se entronca con el patriarcado para someter y explotar aún más a las mujeres. Según Paredes (2017):

el Estado se desentendió de todos los deberes de seguridad social, como la salud, la educación, la vivienda, la jubilación, la inamovilidad laboral, conseguidos por las luchas y conquistas sociales del pueblo trabajador. Esto ha significado, en los hechos, que las mujeres han sido las encargadas de cubrir estas necesidades sociales desde las familias y comunidades rurales. (p.114)

En Guatemala, la ausencia del Estado se plasma con crueldad en el acceso a servicios de salud. Así lo muestra, por ejemplo, la siguiente aportación: 
"Incluso hasta en salud porque hay clínicas que son especiales para personas de alto nivel, clínicas para personas de nivel medio y el puesto de salud [público] que es a donde vamos todos, verdad, ahí revueltos” (GD04)

La mirada interseccional nos permite visibilizar que las brechas de desigualdad por clase social están estrechamente ligadas a la exclusión por motivo de pertenencia étnica, configurando un escenario en el que los pueblos indígenas son relegados a todas las periferias $\mathrm{y}$, dentro de ellas y de forma transversal también en los centros, las mujeres son dominadas y excluidas. Por lo tanto, la justicia de género pasa por una transformación total de la configuración racista, clasista, urbano centrista y machista del Estado. Al respecto, Lagarde (2014) afirma que

la justicia hacia las mujeres implica otra distribución de los recursos, los bienes y las oportunidades y el Estado está llamado a dejar de ser garante y gestor de desigualdades y a transformarse en un Estado del bienestar, un Estado justo. (p.273)

Una de las maestras participantes expone con claridad el abismo entre la igualdad formal y la igualdad real en el ejercicio de los Derechos Humanos, ratificados con inclusión para los pueblos indígenas en los Acuerdos de Paz que pusieron fin al conflicto armado interno de Guatemala.

"Con respecto a derechos humanos e igualdad, pues existen en documentos, en los Acuerdos de Paz, donde dice que todos somos iguales, pero ya en la realidad existe mucha diferencia, ya que por la posición social que tiene cada grupo social y económico hay desigualdad” (E10/P/M)

Así mismo, se enlaza esta realidad con el panorama de exclusión centros-periferias que prevalece en el orden internacional.

"Inclusive ya a nivel de países, países con países, nación con nación, también sigue [la discriminación] (GD04) 
La discriminación por clase social y ligada a la pertenencia étnica y la ruralidad, configura el sistema de relaciones sociales, prestación de servicios, dedicación laboral, etc. en Guatemala.

"Más lo vemos en las instituciones: cuando uno tiene que hacer trámites, ya sea por el traje de las personas, porque son ladinas o clase social o van presentables, entonces sí siempre existe esa discriminación y falta de equidad de género al momento que uno va a la ciudad” (GD04)

Las iglesias, principalmente las evangélicas situadas en la teología de la prosperidad que divulgan la premisa de que cuanto más dinero entregue la persona en ofrendas, para enriquecimiento de sus autoridades, más dinero recibirá como "bendición", se convierten en socializadores de la exclusión por clase social y en reproductoras de la jerarquía de clases.

"A nivel de iglesias también hay discriminación, esa es una situación en la que el niño está acostumbrado a vivir ya que es parte de su entorno. Ellos saben de que la tal iglesia son los de más dinero, la tal iglesia ahí solo van los pobrecitos, los que no dan diezmo" (GD04)

La discriminación por clase social se produce también dentro de los pueblos indígenas. "Nosotros los mismos indígenas nos discriminamos, o sea que no es necesario que venga alguien de afuera para discriminarnos, sino nosotros mismos marcamos esa situación ya sea por cuestiones de ideales, cuestiones económicas o académicas también, hasta incluso de salud" (GD04)

La pobreza provocada por la desigualdad se sufre gravemente en las comunidades donde se encuentran las escuelas de las maestras y maestros participantes en la investigación. Afecta a la salud y al desarrollo tanto físico como social de las niñas, niños y jóvenes y merma sus oportunidades. 
"La clase baja, que está dividida en subclase: [...] los trabajadores que tienen una casa pero que son obreros, por ejemplo, aquí hay microempresas de tejeduría y ellos tienen sus obreros, sus trabajadores, esos trabajadores tienen una casita donde vivir, cómo sostenerse y cómo sostener a sus hijos para que vengan a la escuela [y] aquellas personas que no tienen trabajo, no tienen como sostenerse económicamente, no tienen nada seguro. Ellos durante el día solo comen dos veces, ven qué buscar, un pequeño trabajo, tal vez planchada, tal vez lavada, pero no es todos los días. Entonces los vemos tan bonitos en la calle, porque todos luchan por tener el traje, usar el traje, pero con respecto a sus alimentos mucho sufren porque solo comen dos veces o una vez, eso es una triste realidad" (E10/P/M)

La pobreza, al unirse con la masculinidad hegemónica, genera consecuencias devastadoras en la dinámica de las familias.

"He visto la realidad en nuestra comunidad de Pachaj: las familias que logran estar unidas y buscar una salida al sostenimiento de la economía, lo van logrando y los niños son los que tienen para venir a la escuela, para entregar sus tareas y su estado emocional es equilibrado. Pero las familias que no saben sobrellevar la decadencia de la pobreza existente en nuestro país, por ejemplo, sufren alcoholismo, al ver que no hay cómo sobrevivir, no hay trabajo, el hombre se inclina al alcoholismo porque ya no hay salida" (E10/P/M)

En definitiva, se ha podido constatar que el contexto de las comunidades indígenas en el que se impulsa la educación para la equidad de género, de etnia y social está caracterizado, desde una mirada interseccional, por fuertes exclusiones de género, de etnia y de clase social que se reproducen a través de un férreo sistema de agentes socializadores. Las maestras y maestros, indígenas en su gran mayoría, son protagonistas de una lucha por apoyar, desde la 
educación, una transformación hacia la equidad de género en las niñas, niños, jóvenes, familias y comunidades, cuya necesidad va siendo cada vez más sentida por las mujeres y secundada por algunos hombres. Estos empujes hacia el cambio son dignos de ser rescatados porque se producen dentro de un sistema de educación pública raquítico en recursos, excluyente desde su concepción y no enfocado a la superación de las barreras que excluyen a la población más pobre (indígena y rural) de los procesos de desarrollo.

\subsubsection{Concepción de género en la cultura maya.}

El pueblo indígena mayoritario de Guatemala es el pueblo maya. Este pueblo también es el mayoritario en los departamentos en los que se ha desarrollado este estudio. El pueblo maya cuenta con un enorme acervo cultural propio y diferenciado de la cultura occidental dominante en el país. Resulta fundamental indagar en la concepción y experiencia sobre la equidad en la cultura maya, ya que un proyecto coeducativo en las escuelas públicas de Guatemala, basado en la transversalización del eje de equidad de género, de etnia y social, necesariamente debe apegarse a los criterios de contextualización y pertinencia cultural que aconsejan la Reforma Educativa y el propio Curriculum Nacional Base.

La concepción sobre la equidad de género desde la cultura maya tradicionalmente ha quedado excluida de los discursos hegemónicos sobre el género y el feminismo, por no ubicarse en el pensamiento occidental. La cosmogonía del pueblo maya plantea elementos que permitirían un marco místico favorable a la equidad de género, según la interpretación de uno de los participantes, diferente a la visión patriarcal que predomina en la tradición judeocristiana. Así se observa en las siguientes aportaciones:

"Vayamos al tema de la cultura maya. Yo sostengo que existen muchas debilidades de la cultura, pero también muchas cosas que hay que rescatar. Por 
ejemplo, cuando hablamos de tzacol y bitol, estamos hablando de dios hombre y dios mujer" (GD03)

"Desde la creación se habla de la creación del hombre con la abuela Ixmukane, está haciendo un papel fundamental en ese proceso" (GD03)

Por otra parte, la cosmovisión maya contempla los valores de la dualidad y la complementariedad, vinculados con la equidad.

"Lo de la equidad, yo lo asimilaría más sobre un valor muy importante de la cultura maya que es la dualidad y la complementariedad, porque son dos valores importantes" (E05/B/M)

Los valores de la dualidad y la complementariedad están relacionados con el concepto de equidad de género, como muestra la siguiente aportación:

“A veces sí se escucha extraño [equidad de género] porque solo nos han dado estas son como teorías o pensamiento que dicen que lo occidental [...] entonces para otras personas entonces la equidad de género entraría más en lo occidental, podríamos decir, pero viéndolo desde el punto de vista de los mayas también lo tenemos solo que tal vez de otro nombre, pero llega a lo mismo, sí es un mismo concepto" (E05/B/M)

En cuanto al significado de los valores de dualidad y complementariedad para la vida cotidiana, una maestra afirma:

"La complementariedad es que todo el trabajo de un hombre no lo puede hacer a veces... digamos una idea, y la idea de la mujer llega a ser más grande cuando se unen verdad"; "Considero que eso es la complementariedad, es la fuerza, la unión de padres, hijos, integrantes de una sociedad para llegar a hacer algún proyecto" (E05/B/M) 
Concluyendo:

"Los mayas, o nosotros en nuestra cultura, decimos que todo lo que existe a nuestro alrededor tiene importancia y tanto hombre y mujer se complementan, es una dualidad, son dos para ser uno” (E05/B/M)

Desde el feminismo comunitario de Bolivia, Julieta Paredes hace una dura crítica al valor de la complementariedad (chacha-warmi u hombre-mujer para los pueblos indígenas bolivianos) afirmando que "no incorpora la denuncia del género en la comunidad, naturaliza la discriminación [hacia las mujeres]" (Paredes, 2017, p.123). De la misma forma, la complementariedad en la cosmovisión maya hace referencia a una complementariedad de roles de género marcados desde la división sexual del trabajo y la dicotomía de las esferas pública y privada. Por lo tanto, apelar a los valores tradicionales no significaría una transformación hacia la equidad de género.

La interpretación de que el machismo es consecuencia de la colonización cultural y religiosa sufrida por Guatemala y América Latina está muy extendida, acompañada de una idealización de la sociedad maya precolombina en la que los valores culturales serían practicados y no existiría ningún tipo de dominación de género, destacándose:

"Esto [la exclusión de las mujeres] lo trae la cultura occidental porque este tema de discriminación es bíblico” (GD03)

Sin embargo, al respecto es importante iluminar la historia desde las reflexiones del feminismo comunitario: se demuestra la existencia del llamado patriarcado originario ancestral o sistema de dominación de los hombres sobre las mujeres en las sociedades indígenas precolombinas, que se entronca con el patriarcado occidental traído por los conquistadores. Cabnal (s/f) argumenta que

el patriarcado originario ancestral se refuncionaliza con toda la penetración del patriarcado occidental, y en esa coyuntura histórica se contextualizan, y van 
configurando manifestaciones y expresiones propias que son cuna, para que se manifieste el nacimiento de la perversidad del racismo, el capitalismo, neoliberalismo, globalización y más. (p.5)

Teniendo en cuenta todo lo anterior, una verdadera transformación hacia la equidad de género solo será posible abordando la comprensión del patriarcado originario ancestral (Cabnal, 2010) y su deconstrucción desde una mirada crítica del género. "El chacha-warmi no tiene el instrumento de la denuncia del género, necesitamos esa denuncia género para poder entender y develar las causas de las condiciones históricas, de la opresión de las mujeres en nuestros pueblos y cambiarlas" (Paredes, 2017:124).

La brecha entre los preceptos culturales tradicionales y añorados y la práctica de vida que se plantea en el estado de la cuestión de esta investigación es percibida por las y los participantes:

"Desde la escuela es inculcarles valores que nuestros antepasados nos han enseñado, el respeto a la madre naturaleza, el respeto a nuestros hermanos mayores, el sol, la tierra, a todo lo creado, a los animales, que para nosotros como mayas son los hermanos mayores. Y luego entre nosotros, respetando lo ajeno, respetando las cosas de los demás. Nuestros antepasados nos han enseñado que debemos respetar a los mayores y colaborar con ellos en el trabajo que se realiza en el campo. Pero lamentablemente en estos tiempos estos valores se han perdido ya” (E10/P/M)

Es interesante observar que la reflexión sobre la pérdida de valores tradicionales se produce en todas las culturas, con una brecha patente entre el ideal moral, que frecuentemente se analiza como en decadencia o extinguido, y la práctica cotidiana, que se estigmatiza como expresión de los males de la vida moderna. Esta interpretación de la realidad también se constata en la cultura maya, tanto en los discursos de personas mayas como en los discursos 
de personas no pertenecientes a este pueblo y que se atreven a juzgarlo. Sin embargo, es importante reparar en que los pueblos más cohesionados a través de culturas propias y minoritarias, como son los pueblos indígenas, frecuentemente son acusados de incoherencia al no practicar sus valores tradicionales, como si fueran los depositarios de una suerte de moral de la humanidad o no vivieran exactamente las mismas dinámicas de cambio y continuidad que todas las sociedades del mundo.

Una de las participantes reflexiona sobre esta afectación de los valores en todas las culturas:

"Ahora tal vez es como que, si se abriera una grieta entre todas las culturas, porque ya no se practica como se practicaba antes y a veces considero que todo lo que pasa ahora, tanta violencia tantas cosas que están pasando es por esa ruptura que tuvo cada una de las culturas, porque ya los valores no se practican como antes" (E05/B/M)

Ante la percepción de pérdida de valores culturales es frecuente defender el miedo y el castigo como medida correctiva de la desviación moral. Sobre esto aporta una de las participantes, ahondando en el papel que desearía de la escuela como transmisora de valores y mostrando también el sincretismo entre los preceptos culturales mayas y los pertenecientes al cristianismo.

"Mi hijo estuvo con esta maestra y les decía lo del awas, lo que es pecado, y esto venía de los abuelos, y entonces ella les hablaba del Popol Vuj [libro sagrado maya], los mandó a leer, y los niños van cambiando, yo miraba a mi hijo y él me explicaba del awas, de que esto es pecado, y entonces son cosas que a los niños les queda de una u otra forma pues aprenden algo" (GD03)

Al hilo de lo anterior, destaca la necesidad sentida por las y los participantes de que la escuela forme en valores a las niñas y a los niños. La equidad de género, de etnia y social 
necesariamente debe ser uno de esos valores que empape todo el quehacer educativo, vinculada a los valores mayas de la dualidad y la complementariedad y, debemos añadir, al valor de la armonía entre todo lo que existe, tierra, cosmos, personas. Es fundamental rescatar el potencial que tienen los valores de la dualidad y la complementariedad para ser resignificados dialógicamente por los pueblos mayas y servir de base para el avance hacia la equidad de género. En este sentido, el feminismo comunitario lanza un reto: sería una incoherencia cosmogónica y política de los pueblos indígenas defender el territorio tierra y no luchar contra las atrocidades cometidas contra las niñas y las mujeres dentro de este mismo territorio. Como evidencia Cabnal (2010:23):"las violencias históricas y opresivas existen tanto para mi primer territorio cuerpo, como también para mi territorio histórico, la tierra. En ese sentido todas las formas de violencia contra las mujeres, atentan contra esa existencia que debería ser plena".

\subsection{Análisis de los agentes socializadores de género}

Las percepciones de las maestras y maestros acerca de los agentes socializadores de género, el peso específico de cada uno de ellos en la formación de género de mujeres y hombres y las barreras y oportunidades para la equidad presentes en cada uno de estos agentes socializadores resultan especialmente relevantes para esta investigación. Además, reflexionar sobre el papel de la escuela en la socialización de género implica un ejercicio de metacognición para las maestras y maestros, al situarse a sí mismos como agentes de esta socialización, y por lo tanto es un campo lleno de posibilidades para generar alternativas que promuevan la equidad de género.

Es importante aclarar que el análisis de los agentes socializadores se abordó con las maestras y maestros solo desde la perspectiva del género y no de la etnia y la clase social, facilitando así que el discurso se centrara en un núcleo -el género- que, por ser más intangible 
y cuestionador del orden social que la etnia y la clase social, es más difícil de abordar. Sin embargo, las aportaciones de las y los maestros se han analizado desde una perspectiva interseccional.

De las aportaciones de las y los participantes se extrae que el orden de importancia de los agentes socializadores de género según mayor o menor incidencia en la formación de niñas y niños es: la familia, la escuela, la comunidad, la religión y los medios de comunicación. Subraya una de las aportaciones:

"Digo e insisto de que la base es el hogar, sigue la escuela, sigue la sociedad" (GD01)

La línea divisoria entre estos agentes socializadores resulta muy confusa, ya que todos forman parte de un mismo engranaje social en el cual las interacciones entre agentes socializadores son constantes, conformando un sistema complejo de continuidad y cambio: transmisión de lo tradicional y promoción de cambios culturales. Así, una familia se circunscribe en la cultura de una comunidad determinada, funcionando internamente, con más o menos variaciones, según las reglas de esa comunidad y según los consensos sociales establecidos a través de interacciones sociales en esa comunidad. Sin embargo, a lo interno del pensamiento de las personas y familias se producen cambios, propiciados por la evolución del contexto social, por influencias externas, por el sistema educativo, por el acceso a otras oportunidades, etc. Estos cambios influyen en la modificación de las reglas comunitarias y éstas, a su vez, producirán cambios en las reglas familiares. Las reglas familiares y comunitarias, además, están influidas por elementos religiosos, por ejemplo, y son reforzadas o debilitadas por los mensajes de los medios de comunicación, de las instituciones públicas y otros.

Es importante tener en cuenta que los agentes socializadores también operan de forma diferenciada según los condicionantes de etnia, ruralidad - urbanidad y clase social. El 
análisis que nos ocupa está circunscrito a los agentes socializadores en ámbitos indígenas y rurales y de estrato socioeconómico bajo o muy bajo.

A continuación, se aborda el análisis de cada uno de los agentes socializadores de género en el orden de relevancia establecido por las y los maestros.

\subsubsection{La familia.}

Martín Martín-Cala y Minervy Tamayo-Megret (2013:63), basados en Blanco (1996) destacan que la familia se diferencia de otras instituciones sociales por su configuración basada en el parentesco, por la diferenciación de funciones espirituales y materiales y por su carácter histórico, normativo y activo, que moldea a sus miembros. Martín-Cala et al. (2013:64) explican que las funciones de la familia pueden clasificarse en biosocial, económica y educativa-cultural-espiritual. En esta última función de la familia encontramos su acción como agente socializador de género: la familia, sea cual sea la forma en la que esté estructurada, educa a sus miembros en los valores, actitudes, comportamientos y creencias que considera válidos y que, generalmente, se corresponden con los imperantes en la sociedad en la que está inmersa.

Niñas y niños reciben una socialización diferenciada por sexo dentro de su familia en todos los contextos y sociedades. María Ángeles Espinosa (s/f:6) indica que "desde el momento en que una pareja recibe la noticia de que van a ser padres el sexo biológico de la futura criatura genera una serie de expectativas diferentes sobre su comportamiento, su desarrollo, sus capacidades, etc.”. En el contexto de Quetzaltenango y Totonicapán, esta realidad es muy marcada: generalmente hay una preferencia hacia la concepción de un bebé de sexo masculino, sobre todo si se trata del primogénito. Incluso, se identifican prácticas al respecto, que actualmente son residuales, pero sitúan el calado de la socialización diferenciada desde la concepción y el nacimiento: un precio más alto cobrado por la comadrona por atender el 
nacimiento de un niño que de una niña, o el hecho de que la mujer que acaba de dar a luz a un niño sea agasajada con mejores comidas que la que da a luz a una niña.

El agente al que maestras y maestros otorgan mayor peso en la socialización de género es la familia. Se considera que la educación en valores que reciben las niñas y los niños en sus familias es la que define qué actitudes y roles de género asumirán en sus vidas. Así se señala el papel de la familia:

"La familia siento yo que juega el papel, si no el más importante pero donde pesa aún más la formación de la persona, como maestros solo venimos a tratar de modificar algunas cosas que están marchando mal o querer quizás modificar el modelo. Pero ya los primeros años de vida están hechos, en los primeros añitos de vida se grabó todo verdad y es difícil que se borre algo, que se modifique algo" (GD01)

Y cómo esa actitud se traslada a la escuela:

“Los padres de familia, porque ellos los forman [a las niñas y niños], ya llegan a la escuela con la idea que solo los varones son lo que tienen más derechos que las niñas y hasta cierto punto humillan a las niñitas cuando ellas participan”(E03/Pr/M)

Además, se considera que las familias no solo son el agente socializador de género por excelencia, sino que tienen la obligación de serlo para que la equidad pueda ser una realidad social. Así lo muestra la siguiente aportación:

"La base fundamental son los primeros años de vida con la que uno crece en la casa, en el hogar, como le enseñan a uno a tratar a la persona opuesta a su género ¿verdad?” (GD01) 
Las madres y los padres, tendrían la responsabilidad de educar en equidad de género: "Los padres de familia ellos también tienen, y es la obligación de ellos demostrarles, que los niños y las niñas valen lo mismo” (E02/PrPr/H)

Esta reflexión se traslada a la vida personal de las maestras y maestros en la siguiente aportación:

"Nosotros mismos desde ahorita como padres de familia, para poder ya eliminar en sí y romper el hielo de esta situación de que solo el varón puede realizar las cosas, sino de que también la mujer es capaz de realizarlo”(GD01)

Esta visión de la familia como base única de la formación en valores está estrechamente relacionada con el carácter conservador y moralista de la sociedad guatemalteca, alimentado por posiciones religiosas retrógradas y por líderes políticos interesados en mantener a la población en condiciones de escasa o nula criticidad hacia el enfoque anti desarrollo social del Estado. La premisa de la familia como base única de formación en valores contiene tres falacias fundamentales que es preciso develar:

a) En primer lugar, apela a un concepto unívoco de familia, desde la biparentalidad y heteronormatividad, que no se corresponde con la multiplicidad de modelos familiares existentes en Guatemala, muy especialmente las familias monoparentales encabezadas por una mujer.

b) En segundo lugar, generaliza que todas las familias cuentan con las capacidades y herramientas necesarias para educar en valores a las niñas, niños y jóvenes, obviando las situaciones de extrema vulnerabilidad, violencia y disfuncionalidad que padecen muchos núcleos familiares como consecuencia de la ausencia de políticas públicas de desarrollo social.

c) Por último, esta premisa aparenta que las familias tengan la capacidad realizar las transformaciones estructurales que en realidad solo pueden realizarse desde el Estado. 
La visión familiarista socava el fortalecimiento de un modelo de desarrollo basado en los Derechos Humanos y el bien común: colocar en las familias el origen de los problemas de desarrollo del país (pérdida de valores, falta de capacidad, etc.) es una estrategia funcional para el neoliberalismo económico que culpa a las familias para hacer recaer en ellas el peso de las soluciones sin la intervención del Estado. El mensaje, de fondo neoliberal, es que cada uno obtiene en su vida lo que se merece, según su esfuerzo. Esta filosofía está impregnada en gran parte de la población y es reforzada por la influencia estadounidense, a conveniencia del Estado. Este pensamiento des responsabiliza a las instituciones públicas respecto de sus obligaciones, incluyendo al sistema educativo, despolitiza la acción social al desmovilizar a los titulares de derechos y, en definitiva, rompe con el enfoque de Derechos Humanos y bien común que debe prevalecer en el quehacer de todo Estado.

A la luz de lo anterior, no resulta extraño que las maestras y maestros participantes, como parte de la población y del sistema de educación pública promovida por el Estado, sitúen a la familia como principal agente socializador de género y ubiquen sobre ella el grueso de la responsabilidad respeto a las transformaciones hacia la equidad.

En cuanto a las características de la socialización de género que se produce en las familias, encontramos que frecuentemente se reproducen los roles tradicionales que subordinan a las mujeres bajo el poder de los hombres. Una de las maestras aporta su experiencia personal al respecto, analizando cómo estos roles se han transmitido de generación en generación en su familia:

“En la casa, por ejemplo, mi mamá, le sirve a mi papá. Mi papá no puede lavar un vaso, él no se puede servir con una cuchara, se sienta y todo tiene que ser servido... ¡mi papá! Y así fue formando a mis hermanos, ellos no se pueden levantar a agarrar un vaso porque para ellos es una humillación y existe el machismo, y así pasa en las comunidades también" (E03/Pr/M) 
La violencia de género está presente en la socialización en la familia, según la siguiente aportación:

“Mi mamá me cuenta... bueno es muy triste y a la vez duele y a veces uno dice, bueno cómo puede tener uno un papá así, entonces mi mamá me dice no... [la mamá, recordando su juventud] me levanto a las tres de la mañana a acarrear agua, a lavar ropa a cocinarle y a veces no me da mi leña, no me dan gasto, pero ellos sí me exigen y si no lo tengo a la hora, me pegan"(E03/Pr/M)

Por otra parte, se expresa que el orgullo y la honra de las familias se continúa disputando en el cuerpo de las mujeres, entendidas como seres susceptibles de ser pactados para el beneficio de la familia y renunciando a sí mismas.

“Cuando una niña es entrada a pedir a corta edad el orgullo es para los padres, porque ;híjole! se fijaron en mi hija desde chiquitita... entonces la niña se ve en la necesidad de decir: bueno, yo soy el orgullo de mis papas y me voy a casar. $Y$ a qué conlleva esto, a una vida infeliz, una vida sin sentimientos, una vida con responsabilidades que no le corresponden" (GD04)

Uno de los elementos más visibles en la socialización diferenciada de niñas y niños dentro de las familias es el acceso a la educación de las niñas. Tradicionalmente, se ha privilegiado la educación de los niños, desde el esquema de la división sexual del trabajo: ellos necesitan estudiar porque cuando se casen serán los proveedores de la familia, mientras que las niñas no lo necesitan porque se dedicarán a oficios domésticos. Esta visión, además, de limitar gravemente las expectativas base del desarrollo personal y del futuro profesional de las niñas, fortalece el desprecio hacia las capacidades de las niñas dentro de las mismas familias e incide directamente en la conformación de una identidad de género en las niñas basada en la baja autoestima. Retomamos aquí una de las aportaciones analizadas anteriormente en relación a la construcción de la identidad de género de las niñas: 
"Las niñas se menosprecian, en el sentido que ellas son las que tienen que ayudar a la mamá, o sea su lugar está solo en la casa, y se menosprecian porque no creen tener la capacidad de poder hacer más o de llegar a hacer tal vez lo que un hombre hace” (E01/PrPr/M)

Las personas participantes manifiestan que la limitación del acceso a la educación de las niñas es algo que está cambiando en la actualidad. Se trata de un cambio cultural significativo porque una mayor equidad en las expectativas académicas que las familias tienen sobre sus hijas e hijos muestra una visión más amplia sobre las posibilidades de desarrollo de las mujeres, comenzando a flexibilizar los férreos patrones de división sexual del trabajo. Esta tensión entre lo tradicional y lo moderno, característica de todos los procesos de cambio social y cultural, se plasma en el siguiente extracto de discurso:

"Ya cambió ese pensamiento de que eres mujer ya no vas a la escuela porque te quedas cocinando, cuidas a tus hermanos, ya no hay tal vez, existen algunos, pero ya la mayor parte no" (E05/B/M)

Sin embargo, desde una mirada interseccional, no se puede afirmar que ese cambio sea generalizado. La condición de ruralidad o urbanidad tiene un peso determinante en el acceso a la educación de las niñas. Algunas aportaciones así lo muestran.

“En otras comunidades lejanas no les dan educación a las mujeres. En nuestro caso [Pachaj muy cerca de los cascos urbanos de Cantel y Quetzaltenango], tengo 3 niñas y a ellas les vamos a dar educación hasta terminar, hasta donde ellas dejen de estudiar" (E11/M/M)

Las expectativas estereotipadas de las familias sobre las niñas determinan su continuidad en el sistema educativo. Las siguientes aportaciones señalan el matrimonio como destino ineludible para las niñas e incompatible con la formación académica, desde el rol reproductivo y dependiente que se espera que desempeñen: 
"Yo platicaba con las niñas, les preguntaba por qué no seguian estudiando después de terminar la Primaria y ellas decían que no, que mi papá dice que las mujeres se van muy rápido [se casan] y es en vano que estudien, entonces solo a mis hermanos" (GD04)

"La niña siempre es dejada a un lado en el proceso educativo porque los papas argumentan de que las niñas por ser niñas se van a casar, entonces que no necesitan estudiar” (E01/PrPr/M)

El cambio cultural hacia la equidad que se está gestando en la sociedad guatemalteca también se refleja en la concepción de las y los participantes sobre cómo debe ser la nueva educación de niñas y niños dentro de sus propias familias. Esto es especialmente relevante porque indica que las y los maestros comienzan a trasladar los presupuestos teóricos sobre la equidad que han recibido en el marco del desempeño de su trabajo docente al ámbito de la acción en su propia vida. Una muestra son las siguientes aportaciones:

“A mi hijito, [...] para enseñarle de que es capaz, él ya puede cocinar, él cocina, se pone su gabacha, y le digo ipapa ayúdame a lavar los trastos! Ta bueno me dice y lo hace. Pero mi mamá y mi papá... ipara ellos es un problema! $Y$ me dicen: ¡es que no sos una mamá responsable! ¿Y dicen como lo vas a mandar a cocinar a él? ¡Si él es hombrecito!” (E03/Pr/M)

"Mis hermanos ellos hacen de todo, ellos pueden hacer de todo porque así les enseñaron cuando ellos crecieron, en el caso de ellos son mayores, son hombres, pero ellos si saben hacer la labor de una mujer y la labor de un hombre en este caso" (GD04)

Es interesante destacar que las maestras y maestros relacionan el cambio hacia la equidad en las familias con el nivel educativo de la pareja y que una convivencia con equidad es considerada como un "buen hogar". Esto implica avances hacia un cambio de paradigma en el 
que la dominación de los hombres sobre las mujeres se desnaturaliza y ya no constituye lo deseable.

"Hay algunas familias que tratan la manera de ayudar a la esposa y el esposo a la esposa, como trabajo en equipo, ayuda mutua entre ellos, pero... son raros, entonces yo me doy cuenta que sí, la preparación académica les ayuda mucho a que ellos formen un buen hogar, a que ellos traten la manera de tener igualdad" (GD03)

\subsubsection{La escuela.}

La Ley de Educación Nacional, Decreto 12-91, establece en su cuarto considerando considerandos que "el ser humano guatemalteco debe consolidar una sociedad justa que coadyuve en la formación de niveles de vida donde impere la igualdad, la justicia social, y la auténtica libertad que permita la consecución del bien común”. Para dar respuesta a este reto, uno de los principios de la educación en Guatemala es "ser un instrumento que coadyuve a la conformación de una sociedad justa y democrática" (Ley de Educación Nacional, art. 1). Llama la atención que este texto legal no aborda la equidad de género, de etnia y social como una de las claves para esa sociedad justa y democrática. Por otro lado, también resalta el enfoque marcadamente conservador de la ley, que establece entre los fines de la educación "fortalecer en el educando la importancia de la familia como núcleo básico social y como primera y permanente instancia educadora" (Ley de Educación Nacional, art. 2).

Sin embargo, años más tarde, con la promulgación de la Ley de Promoción Educativa contra la Discriminación, Decreto 81-2002, como parte de las reformas legales de operativización de la Reforma Educativa en Guatemala, se incluye la eliminación de la discriminación étnica y de género entre de los propósitos de la educación, recogidos en el artículo 1: 
Los ministerios de Educación y de Cultura y Deportes, promoverán y difundirán, el respeto y la tolerancia hacia la Nación guatemalteca que es pluricultural, multilingüe y multiétnica. Asimismo, promoverán y difundirán programas tendientes hacia la eliminación de la discriminación étnica o racial, de género y toda forma de discriminación, con el objeto de que todos los guatemaltecos vivamos en armonía.

Desde el marco legal que norma la educación en Guatemala, la escuela tiene la competencia de educar para la equidad de género, de etnia y social y esto se concreta a través del eje de equidad de género, de etnia y social del Curriculum Nacional Base (CNB), que debe ser aplicado de forma transversal en las aulas.

Las maestras y maestros participantes resaltan una dificultad para llevar a cabo la educación en equidad de género en las escuelas que es generalizada en otros contextos y sociedades, según advierte Subirats (2010). Se refiere a la creencia de que

niños y niñas llegas a la escuela con una socialización primaria, obtenida básicamente a través de la familia, en la cual permanecen muchos elementos de desigualdad por razón de sexo que ya han configurado muchos trazos de su personalidad; por lo tanto, tendrá poco efecto, e incluso puede ser negativo, poner en crisis los modelos recibidos. (p.74).

Subirats denomina a esta dificultad y otras, "resistencias ante un proyecto de este tipo [coeducativo], que subvierte muchos valores arraigados en la sociedad" (Subirats, 2010:73).

En las maestras y maestros participantes prevalece la visión sobre la escuela como un agente secundario en cuanto a la socialización de género, otorgando el protagonismo de esta socialización a la familia, como se analizó en el apartado anterior. Las siguientes aportaciones así lo argumentan:

“La familia siento yo que juega el papel si no el más importante, pero sí donde pesa más la formación de la persona. Como maestros solo venimos a tratar de modificar algunas cosas que están marchando mal” (GD01) 
Se aprecian incluso posturas deterministas:

"Yo pienso que la escuela tiene un papel secundario. No es el espacio principal para este tipo de transformaciones. Porque se mira bien en la actitud de los niños, que eso ya lo traen. Por ejemplo, solo un ejemplo, la refacción [merienda de media mañana o media tarde]. Yo les digo, bueno chicos ahora les toca. No profe, nosotras" (GD03)

Según la percepción de las personas participantes, la socialización de género que reciben las niñas y niños en la familia incidiría directamente en las actitudes que llevan a la escuela, ante las que las maestras y maestros en general se sienten con poca capacidad de incidir: "La familia siento yo que juega el papel, si no el más importante pero donde pesa aún más la formación de la persona, como maestros solo venimos a tratar de modificar algunas cosas que están marchando mal o querer quizás modificar el modelo. Pero ya los primeros años de vida están hechos, en los primeros añitos de vida se grabó todo verdad y es difícil que se borre algo, que se modifique algo" (GD 01)

Incluso la socialización en violencia de género dentro de la familia sería difícilmente cambiable por la escuela según la siguiente aportación:

"En la casa los niños ven como los papás le pegan a las mamás y ellos van recibiendo esa educación de parte de los papás cuando llegan a la escuela, por eso le digo no permiten que las niñas hablen o si hablan, pues empiezan a insultarla y decirle que lo que ella dijo no está bien" (E03/Pr/M)

Parece que los mismos niños y niñas otorgan mayor credibilidad a los mensajes que reciben en su familia que a los recibidos en la escuela.

“A veces dicen [las niñas y niños], bueno papá no me dice eso, por qué usted me lo dice, ¿verdad? [referido a educación en valores]” (E05/B/M) 
Siguiendo a Subirats (2010), reparamos en la debilidad de la argumentación de la imposibilidad de cambiar la socialización de género que las niñas y niños traen de su familia: "invalida la misma existencia del sistema educativo y es difícil de sostener por un educador" (Subirats, 2010:74). La supuesta debilidad de la escuela como agente socializador de género, aparece cuestionada por Subirats (2010), siguiendo a Montero (s/f):

Imaginad por un momento que esta misma actitud fuera mantenida por los maestros en el terreno intelectual. Que, guiados por un no intervencionismo aséptico, decidieran no influir para nada en la manera de pensar de sus alumnos en matemáticas, en lengua, en física y en otras materias escolares [...] esta postura solo sería correcta si el carácter de los individuos no experimentara ninguna modificación por influencias externas, es decir, si la escuela fuera total y absolutamente innecesaria. (p.74)

En el contexto guatemalteco, la visión sobre la escuela como agente secundario es reforzada, además, por la des responsabilización del Estado en cuando a la intervención social, unida a la invisibilización de la exclusión de género dentro de la escuela, tejida en un entramado de valores, normas, acciones, omisiones y formas de relación naturalizadas que reproducen el patriarcado. En este sentido, llama la atención el hecho de que dos de los participantes, una maestra y un maestro, manifiesten que la inequidad de género no es un problema en las escuelas, lo cual constituiría sin duda una de las principales barreras para la superación de la inequidad de género.

"No, no la he visto reflejada todavia" [alguna situación que reproduzca inequidad en la escuela] (E02/PrPr/H)

“Un problemita que tenemos más es sobre la alimentación de los estudiantes, [...] sobre la equidad de género no hemos tenido ningún problema” (E05/B/M)

Ante la debilidad en la comprensión de la escuela como espacio de socialización determinante para la formación en equidad de las niñas y niños, será necesario que en 
acciones de formación docente se reflexione sobre el hecho de que la escuela "puede ser laboratorio de la igualdad, pero también crisol de desigualdades; espacio adecuado para la corresponsabilidad, pero también para la exclusión o la jerarquía ilegítima; cancha de innovación relacional, pero también estadio de competitividad destructiva" (Simón, 2010:128).

Algunas maestras y maestros identifican discriminación dentro de las aulas desde el ámbito de lo étnico, que parece ser más fácilmente identificable que la discriminación de género.

"Cuando yo estudié el Básico estudié un año en un centro urbano, específicamente en Salcajá y solo por pertenecer a la etnia k'iche', era obviado tanto por los compañeros como por los maestros, entonces en ese momento cuando uno ya está directamente en esa etapa y está laborando ya, uno dice no, esto no es correcto" (E04/Pr/H)

Es importante rescatar que estas situaciones de discriminación étnica pueden ser aprovechadas con fines pedagógicos para educar en la equidad.

"Hemos aprovechado esos espacios [situaciones de discriminación] para decirle a ellos [alumnado] que la situación del idioma muchas veces nos marca a nosotros diferencias en cuanto al trato y la forma verdad, pero que debemos aprender a respetar esas diferencias para poder tener una mejor convivencia, pienso que el mejor curso donde lo he podido practicar es en Seminario" $(\mathrm{E} 07 / \mathrm{D} / \mathrm{H})$

La discriminación por motivos de clase social, por su parte, también es una realidad en las aulas, identificada por maestras y maestros.

“Entonces ellos dicen ¿y yo por qué me tengo que juntar con ellos? Yo mejor me junto con él, entonces ya tienen sus grupitos y yo en ese momento intervengo y les digo que no, hay que compartir con todos, no solo porque uno no es superior 
o no solo porque uno tiene ciertas posibilidades va a obviar a los demás" $(\mathrm{E} 04 / \mathrm{Pr} / \mathrm{H})$

Así mismo, destaca la crítica que realiza una de las docentes sobre el papel de las maestras y maestros en cuanto a la profundización de esta exclusión por clase social.

"Vienen los niños y hay niños que le roban al corazón a uno y esa es una discriminación, porque el que viene más feíto, viene más shuquito [sucio],también tiene corazón, pero como a mí me robo el corazón el otro, yo beso y abrazo al que a mí me gusta, pero qué pasa con el niño pequeño que necesita de cariño y necesita la misma atención que el niño que viene perfumadito y cambiado" (GD04)

Estas situaciones de discriminación por clase social también han sido aprovechadas con fines pedagógicos por las y los maestros.

“Entonces tenemos que ser por lo menos justos y comprensivos y decirles que eso no es correcto [discriminación por estrato socioeconómico] y ellos van aprendiendo poco a poco” (E04/Pr/H)

Resulta significativo desde el punto de vista educativo que las y los maestros de primaria, consideran que con la edad que tienen las niñas y niños en esos grados (entre 7 y 13 años, generalmente) ya poco se puede hacer para educar en la equidad. Como recogen las siguientes aportaciones:

"Ya los primeros años de vida están hechos, en los primeros añitos de vida se grabó todo verdad y es dificil que se borre algo, que se modifique algo" (GD01) "Trabajar sobre la equidad de género al grado en que llevo ahorita, que es segundo grado, pues cuando vienen los niños a la escuela yo creo que vienen formados desde el hogar. Nosotros quisiéramos que se comience a trabajar equidad de género desde muy pequeños” (E08/P/M) 
Esta visión determinista se corresponde con las resistencias al cambio coeducativo identificadas por Subirats (2010). Por otro lado, es importante recordar que la educación inicial y preprimaria pública, a pesar de estar establecida por ley, tiene una presencia residual en el país, lo que alimenta en las familias la deslegitimación de su utilidad e importancia crucial en el desarrollo de las niñas y niños. Es común la afirmación de que es una lástima que las niñas y niños se escolaricen antes de los 5 o 6 años, al tiempo que la escolarización antes de esa edad frecuentemente es utilizada para estigmatizar a sus madres por incumplimiento del mandato de género de dedicarse plenamente al cuidado de sus hijos.

Sobre los niveles educativos más cruciales para la formación en equidad, una de las maestras participante señala las "malas costumbres" de evadir responsabilidades.

"Solemos echarle la culpa a alguien más y nosotros no asumimos la responsabilidad de lo que hacemos [respecto a la escuela como agente socializador de género], entonces si están en pre primaria, decimos que la mamá tuvo la culpa, si están en primero primaria decimos que la de párvulos tuvo la culpa y esto se vuelve un círculo vicioso” (E01/PrPr/M)

Las mayores posibilidades de incidencia de la escuela en la educación para la equidad parecen concentrarse en los niveles educativos en los que los alumnos son más pequeños y disminuir a medida que aumentan en edad. Según las siguientes aportaciones, el nivel de PrePrimaria (6 años) sería el ideal para trabajar equidad de género:

"El nivel de Pre-Primaria es la base fundamental para implementar eso, para eliminar lo que es el machismo, el racismo hacia la mujer” (E02/PrPr/H)

Se identifica la etapa de Pre-Primaria como el momento de formación del carácter en las niñas y niños:

“El nivel pre primario es donde más se puede potencializar [la educación para la equidad] porque es cuando los niños desarrollan su carácter y su 
personalidad, entonces si nosotros logramos que el niño cambie esa percepción que trae de la casa" (E01/PrPr/M)

Trabajar la educación para la equidad desde esta etapa les ayudará a superar el machismo en edades posteriores:

"Desde mi punto de vista lo recomendable es que desde chiquitos desde pequeños desde nivel pre-primario, primario verdad se venga hablando de estos temas para que ya cuando ellos lleguen al Básico no tengan problemas de indole de género" $(\mathrm{E} 06 / \mathrm{B} / \mathrm{H})$

En cualquier caso, uno de los maestros participante señala que la educación para la equidad es un mandato del propio Curriculum Nacional Base y que, como tal, debe implementarse. Esto es importante porque muestra avances hacia la institucionalización de las acciones, al menos desde el punto de vista de la comprensión de la naturaleza obligatoria de las mismas.

"Si yo como hombre creo que no me conviene que las mujeres manden o que sean iguales a mí, no lo voy a reproducir, lo puedo ignorar, pero el tema es demasiado amplio y desde el CNB sí está y en la mayoría de lo que yo conozco sí se impulsa ese tema" (GD03)

Dentro del escenario descrito, se aprecia que hay cambios en la percepción de algunos docentes que van otorgando a la escuela un potencial transformador más poderoso. Así lo muestra la siguiente aportación:

"Pues fijese que ya las bases hechas es dificil pero no imposible cambiar digamos algunos paradigmas que han venido desde la niñez desde el hogar por ejemplo, desde la casa" $(\mathrm{E} 06 / \mathrm{B} / \mathrm{H})$

Por un lado, se destaca la importancia de la escuela como agente socializador por el extenso tiempo que pasan las niñas y niños en ella: 
"El agente principal, después de la familia, es la escuela, es el mayor espacio y tiempo que el niño esta socializado, con un grupo diferente al que el está acostumbrado" (GD04)

La escuela puede ser un espacio para crear nuevos paradigmas de vida:

“Creo que el papel de la escuela es mucho y también es poco. Es mucho en el sentido de que aquí se pueden ir creando nuevos paradigmas de vida, nuevas ideologías de vida, lo cual veo yo que sí es bien recepcionado [recibido] por parte de los niños y las niñas, especialmente de las niñas [...]. Por otro lado, poco porque muchas veces los patrones familiares que traen los niños es mucho más poderoso que el papel de la escuela” (E09/P/H)

Además, la capacidad de transformación de la escuela aumenta si se da el apoyo de las familias:

"En cuanto encontremos gente, padres de familia, que vean bien el papel de buscar la igualdad, entonces creo que el papel de la escuela cae en buena semilla” $(E 09 / P / H)$

La confusión entre educación mixta y educación para la equidad de género, es decir de la coeducación, es una realidad en Guatemala

Uno de los participantes de la investigación considera que la educación mixta que se promueve actualmente desde lo público y que también es mayoritaria en el sector privado, da lugar por sí misma a mayor equidad de género en el ámbito escolar.

"Los establecimientos [centros educativos] son mixtos entonces en este caso se le da también la oportunidad a más personas y al menos se practica la convivencia verdad que es muy importante y eso ayuda a que se entiendan ambos géneros, hombres y mujeres” (E06/B/H) 
En definitiva, la educación para la equidad de género, o sea la coeducación, no parece ser una prioridad dentro del ámbito escolar, debilitando el potencial transformador de la escuela como agente socializador hacia la equidad de género. Esto se sustenta en dos elementos fundamentales: en primer lugar, la falta de sensibilidad hacia la inequidad de género dentro de la escuela, originada por el modelo de educación ciego al género recibido por las y los docentes; en segundo lugar, la percepción de que la familia tiene mucho más peso que la escuela en la socialización de género, lo que en cierta medida descargaría a maestras y maestros de la responsabilidad de educar para la equidad, resultando una percepción inmovilizadora. Sin embargo, se aprecian cambios que indican un avance hacia mayor conciencia sobre la necesidad de un cambio cultural hacia la equidad de género y también mayor conciencia sobre la necesidad de educar en equidad desde la escuela, para que esto actúe como motor de cambios hacia la equidad en las familias y la sociedad. Sin duda, la formación inicial y permanente del profesorado en materia de coeducación es un nudo fundamental para el impulso definitivo a estos cambios.

\subsubsection{La comunidad.}

El agente socializador de género que, según la percepción de las maestras y maestros, sigue en importancia después de la escuela es la comunidad, medio social en el que se encuentran las familias y la escuela. Hablamos de una comunidad no necesariamente asociada a lo rural, sino de comunidades "entendidas éstas como modelos de organización colectivos que se dan a todos los niveles, desde lo más local y rural, a lo más global y urbano, en respuesta a la sociedad individualista occidental” (Begoña Dorronsoro, s/f: 4).

La comunidad es la portadora de la cultura dominante en cada zona y en ella se circunscribe el proceso educativo de las niñas y niños, tanto en el nivel familiar como en el escolar. 
La percepción de dos de las maestras es que en las comunidades en las que trabajan la dominación de los hombres sobre las mujeres es una realidad que abarca diferentes ámbitos de la vida, desde lo familiar a lo social. La violencia de género, además, aparece como expresión cruel de esta inequidad, como muestran las siguientes aportaciones:

“Allá [en la comunidad en la que trabaja] las señoras no saben comprar, los señores son los que compran, no conocen ni siquiera el mercado” (E03/Pr/M)

"La señora lo fue a denunciar, le estuvo dando gasto [manutención] y las autoridades [ancestrales indígenas] le prohibieron al señor acercarse a la señora por los golpes que le dio, pero ya resulta que fue culpa de la señora volver a regresar a vivir con el señor también” (E03/Pr/M)

Una de estas maestras relaciona la inequidad de género con el sistema patriarcal dominante:

"Podemos decir que es de uso social que el patriarcado que hay: lo que el hombre dice eso se hace y la mujer no opina" (E01/PrPr/M)

Resulta interesante cómo una de las maestras observa que los presupuestos del sistema patriarcal se albergan en el interior de cada persona, de manera que, si no se producen cambios a nivel individual, difícilmente lo comunitario podrá forzarlos. La maestra se refiere a los 48 cantones de Totonicapán como organización de autoridades ancestrales indígenas (48 alcaldías indígenas reunidas en una junta directiva) quienes frecuentemente realizan la atención primaria de casos de violencia de género física, psicología, patrimonial, etc. que se producen en sus comunidades. Estas autoridades tienen la capacidad de imponer sanciones acordes a la gravedad de cada hecho. Según su interpretación, la percepción individual sería más fuerte que la estructura: 
“Toto es el departamento que estaría mejor, que está organizado por los 48 cantones [autoridades ancestrales indígenas], pero en la mente de las personas es donde esta eso [machismo] y no se puede cambiar” (E03/Pr/M)

Sin embargo, desde un análisis sistémico, no se puede obviar que hombres, mujeres y comunidad forman parte de un sistema y que los cambios y continuidad se retroalimentan entre todos los elementos del mismo. Nos encontramos de nuevo ante una percepción que des responsabiliza a las instituciones y al Estado, invisibilizando lo estructural.

Para comprender los alcances de la comunidad como agente socializador es necesario analizarla desde un enfoque interseccional. Las discriminaciones por género, etnia y clase social están estrechamente ligadas entre sí y minan el avance hacia una equidad que abarque todos los ámbitos de la vida social y comunitaria. Según la aportación de una de las maestras, la percepción de discriminación parece ser una constante entre los diversos grupos sociales, o más bien los señalamientos de discriminación podrían servir para generar confrontación y división en un ambiente en el que la violación de derechos fundamentales de todas las personas es una realidad cotidiana.

"Aqui todos dicen que son discriminados. Que si somos ladinos, que nos discriminan cuando vienen becas que son solo para indígenas, que si somos indígenas que nos discriminan porque no nos dejaron entrar a determinado lugar, o sea todos nos quejamos de todo. No vivimos contentos con nada." $(\mathrm{E} 01 / \operatorname{PrPr} / \mathrm{M})$

Por otro lado, nuevamente aparece el elemento de cambio cultural en el sistema patriarcal por el que tradicionalmente se rige la comunidad como agente socializador de género. Las mujeres están participando más en todas las instituciones y organizaciones comunitarias, en medio de las dificultades externas que encuentran por el machismo imperante y las dificultades internas derivadas de la baja autoestima que les confieren siglos de 
subordinación. En uno de los grupos de discusión, una maestra manifestaba la necesidad de que las mujeres tomen los espacios públicos para ir generando cambios, aunque sitúa esta necesidad no como derecho propio de las mujeres sino como concesión de terceras personas.

“Cuando existe [oportunidad de participación para mujeres] es de aprovechar verdad y de seguir fortaleciendo en ese sentido, en cualquier ámbito, ya sea en lo educativo o en lo religioso o en alguna organización donde nosotros podamos participar o podamos llegar... poder llegar y dar nuestras opiniones verdad" (GD01)

Unido a lo anterior, es necesario retomar la alerta sobre la tendencia de responsabilizar a las mujeres de su propia exclusión, con argumentos que refuerzan la idea de que ellas no participan porque no quieren. Estas posturas invisibilizan la realidad histórica de exclusión estructural que viven las mujeres y también el hecho de que el patriarcado es un sistema, en el que tanto hombres como mujeres estamos inmersos y que, por lo tanto, la responsabilidad del cambio recae en hombres, mujeres, instituciones y estructuras sociales y en el Estado.

A pesar de no contar con información primaria en profundidad sobre cómo se produce la socialización de género en las diversas instancias comunitarias, podemos concluir que la comunidad está asentada sobre normas patriarcales que se materializan en férreos mandatos de género, con mecanismos de control para asegurar su cumplimiento que son más duros cuanto más pequeña y rural es la comunidad. Indudablemente, en el nivel comunitario se está produciendo un cambio cultural hacia mayor equidad, diálogo y participación de todos los grupos sociales, especialmente de las mujeres, que además luchan fuertemente por su inclusión. Julieta Paredes advierte sobre lo crucial de este cambio al recordar que es necesario entender que "al someter a la mujer se somete a la comunidad, porque mujer es la mitad de la comunidad y al someter a una parte de la comunidad, los hombres se someten a sí mismos porque ellos también son la comunidad" (Paredes, 2017:126). 


\subsubsection{La religión.}

La religión es concebida por las y los maestros participantes como un agente socializador de género de mucho peso, reproductor de dogmas incuestionables que subordinan a las mujeres respecto al poder de los hombres.

"Yo lo observo en la vida religiosa y en la vida social hay muchos hombres todavía practicando machismo. Eso influye bastante de que a la mujer no se le deja hacer lo que quiere hacer" (GD03)

Analizando las religiones desde los postulados de la violencia cultural de Galtung, encontramos que éstas contribuyen a una cultura de "los elegidos" y los "no elegidos", que tiene severas consecuencias en términos de inequidad y legitimación de diversas formas de exclusión y violencia hacia grupos sociales.

\section{Tabla 10}

Los elegidos y los no elegidos

\section{Dios elige Y le deja a Satanás Con estas consecuencias}

\section{Especie humana}

Hombres

Su pueblo

Raza blanca

Clases altas

Verdaderos creyentes
Animales, plantas, naturaleza

Mujeres

Los otros

Pueblos de otras razas

Clases bajas

Herejes, paganos
Especismo, ecocodio

Sexismo, quema de brujas

Nacionalismo, imperialismo

Racismo, colonialismo

Clasismo, explotación

Meritismo, Inquisición

Fuente: Galtung (2003a:16)

El poder de los hombres sobre las mujeres se respalda en las religiones católica y protestante predominantes en Guatemala desde el momento en el que Dios “elige" a los 
hombres para ser "cabezas y guías de la familia", dejando a las mujeres relegadas a la condición de "ayuda ideal". Esto da lugar a un potente sustrato de violencia cultural y deriva en estereotipos y prejuicios sexistas, en la dominación de las mujeres y en la justificación de su exclusión de todos los ámbitos de toma de decisión, manejo de recursos y poder. En cuanto a la posición de las mujeres en la religión maya, no encontraríamos la discriminación de las mujeres en la elección por parte de la deidad, pero sí una concepción subordinada de ellas arraigada en la cosmovisión del pueblo maya, que constituye el patriarcado ancestral originario (Cabnal, 2010).

La sociedad guatemalteca es muy religiosa, con un $89 \%$ de la población que expresa profesar alguna religión: $45 \%$ católica, $42 \%$ evangélica, $2 \%$ otras denominaciones entre las que se encuentra la maya. El 11\% expresa no profesar religión ${ }^{\text {xxiii }}$. Esta realidad contextualiza el peso que los mensajes religiosos, generalmente de corte conservador y patriarcal, tienen en la sociedad. El peso moral de las iglesias católica y protestantes sobre las familias, comunidades y vida política de Guatemala, las convierte en piezas de gran potencial para una posible transformación social hacia la equidad. Sin embargo, no se aprecian pasos en este sentido. Más bien al contrario, se asiste a una radicalización de los discursos y al regreso a fundamentalismos religiosos. Las y los maestros participantes identifican la responsabilidad transformadora que recae sobre las iglesias y se la devuelven a las mismas.

"Yo pienso que en las iglesias sería una fuente muy importante de como socializar géneros y también erradicar la discriminación que es la más complicada" (GD04)

Existen discursos críticos sobre el papel de las religiones en la socialización de género que refuerzan la idea extendida de que el patriarcado fue impuesto por la colonización y uno de sus mecanismos de imposición fue la religión católica. Así lo muestra la siguiente aportación: 
"Esto [discriminación hacia las mujeres] lo trae la cultura occidental porque este tema de discriminación es bíblico, la cabeza de la familia es el hombre y eso es bíblico, y la mujer tienen que estar sumisa al marido, eso es bíblico. Entonces de dónde viene la religión, retrocedamos un poquito, lo trajeron los españoles. Porque si usted no hacía el padre nuestro usted era fusilado, entonces la religión es una cuestión impuesta” (GD03)

Desde el feminismo comunitario (Cabnal, 2010 y Paredes, 2017), se desmonta este mito y se evidencia la existencia de un patriarcado ancestral originario que, a la luz de las reflexiones de Cabnal (2010), era la forma de dominación de los hombres sobre las mujeres que prevalecía en las sociedades precolombinas mayas, e indígenas en general, y que se entroncó con el patriarcado occidental en la colonización y, más tarde, con el neoliberalismo.

A nivel de las implicaciones que tiene la práctica de las religiones en la vida cotidiana de las escuelas, se identifica la división que éstas producen, ligada a discursos fundamentalistas que determinan actuaciones permitidas y prohibidas para las personas participantes en cada religión. Cabe destacar que las iglesias protestantes, que han aumentado exponencialmente en número y feligresía en los últimos años, suelen promover rígidas normas de comportamiento para sus seguidores. Una maestra conceptualiza las religiones como un elemento limitador del desarrollo de las potencialidades de las niñas y los niños.

"Si tú eres cristiana [evangélica] tienes que tener este perfil, si tú eres católica tienes este perfil, entonces sí marca bastante y yo lo veo por ejemplo cuando vamos a tener un desfile y llegan las señoras y dicen: mi hijo o mi hija no desfila, porque mi religión no me lo permite, entonces ya desde ahí estamos limitando las capacidades de los niños" (E01/PrPr/M) 


\subsubsection{Los medios de comunicación.}

La IV Conferencia Mundial de la Mujer en Beijing (1995), consideró a los medios de comunicación como una de las doce áreas de especial interés para conseguir la igualdad entre mujeres y hombres. De esta forma, se identificaba y reconocía el papel crucial de los medios como agentes socializadores de género. El ámbito de la comunicación se convirtió en un ámbito estratégico de intervención para la equidad, al mismo nivel que la economía, la violencia, la salud o la participación política. Sin embargo, 20 años más tarde, en 2015, el Informe Global de Monitoreo de Medios en América Latina ${ }^{\text {xxxiv }}$, estableció que el $87 \%$ de las notas periodísticas refuerza los estereotipos de género. Olga Villalta (2017) señala que los estereotipos de género que reproducen los medios de comunicación están relacionados con:

- la objetivación de la mujer, cuyo cuerpo se fragmenta y utiliza preconizando una imagen de juventud,

- la normalización de la subyugación de la mujer, que es presentada como posición de apoyo o respaldo a otros, como adorno sexual o como ser vulnerable y

- la desvalorización de lo femenino.

Los medios de comunicación aparecen en el discurso colectivo de las maestras y maestros participantes como agentes de cambio hacia la equidad y amenaza al mismo tiempo. Tradicionalmente, el medio de comunicación por excelencia para las áreas rurales de Guatemala había sido la radio. Sin embargo, actualmente, el acceso a la televisión e internet está prácticamente generalizado en todas las áreas del país. Merece la pena detenerse en los contenidos televisivos, ya que un somero análisis de los mismos muestra imágenes y mensajes de género que reproducen los modelos tradicionales más recalcitrantes, generadores de relaciones de poder absolutamente inequitativas que llegan a la violencia física. Ante la ausencia en Guatemala de regulación de las imágenes y mensajes televisivos, radiales y de la prensa escrita desde una perspectiva de género e interseccional, abunda la utilización del 
cuerpo de la mujer como objeto sexual, la profundización de los estereotipos relacionados con la división sexual del trabajo y las expectativas de vida de las mujeres reducidas a los mandatos de género. Además, se utiliza la manipulación de las imágenes de personas indígenas asociadas a la pobreza y el folclor, reproduciendo así lo que Paredes (2017) llama el colonialismo interno, es decir, la asunción de un

imaginario estético racista, prejuicioso y discriminador, que ha lastimado cotidianamente los cuerpos, especialmente los de las mujeres indígenas o de origen indígena. Este imaginario ético y estético de los cuerpos asigna criterios de belleza, educación y buen vestir. Un imaginario que, por un lado, tilda de bonitas, educadas, limpias y bien vestidas a las mujeres blancas o blanquecinas con rasgos occidentales. Por otro lado, estigmatiza como feas, maleducadas, sucias y mal vestidas a las mujeres morenas con rasgos indígenas. (p.113)

En las percepciones de las maestras y maestros participantes acerca de los medios de comunicación hay una connotación negativa, considerándolos perjudiciales para la educación en valores de niñas, niños y jóvenes, valores entre los que se incluyen los relacionados con la equidad de género.

"El área urbana tiene mucho potencial en ese aspecto, tiene mucho acceso a muchas vías de comunicarse verdad, radio televisión, internet, teléfono, celular y por ese medio entra mucha información y perjudica en algún momento los programas que ven verdad" (GD01)

Y las áreas urbanas estarían influenciando a las rurales:

"Los medios de comunicación influencian en las áreas urbanas, pero el área urbana es muchas veces influencia para el área rural" (GD01)

Así mismo, se expresa con preocupación la amenaza de violencia sexual en los medios digitales. Cabe destacar que se responsabiliza a las niñas y niños, principalmente las niñas, de 
ser víctimas de abusos sexuales a través de internet, des responsabilizando a las personas que comenten estos delitos y más, aún, a las empresas tecnológicas que presentan deficientes regulaciones para evitarlos.

"Otro agente socializador, en la tecnología el niño tiene su facebook y tiene amigos de todo el mundo y participa con sus amigos de una forma igual, amigoamiga porque no hay un contacto directo (...) muchas veces las niñas caen en errores muy grandes como lo son acosos sexuales en internet o de maltrato en internet verdad y en el caso de las mujeres no denuncian porque es una vergüenza, en el caso de los varones tampoco denuncian por que también es una vergüenza” (GD04)

Se visibiliza la necesidad de formación de los y las docentes en una lectura crítica de los medios para que, a su vez, puedan formar a su alumnado y evitar que éste sea impactado por la información procedente de los mismos.

Como conclusión sobre el análisis de la familia, la escuela, la comunidad, la religión y los medios de comunicación como los agentes socializadores de género podemos afirmar que conforman un complejo conjunto de carácter sistémico en el que todos los elementos se refuerzan entre sí y reproducen el sistema patriarcal. Lo importante de esta constatación es que en el funcionamiento sistémico el cambio en un solo elemento tiene la capacidad de mover el resto del sistema. Como destaca Subirats (2010)

Si bien es cierto -y los análisis sociológicos lo han mostrado repetidamente - que el sistema educativo no puede eliminar las desigualdades individuales cuando están insertas en el conjunto social, también es cierto que no ha cambio social si no empieza a producirse en algún punto de la sociedad y que todo cambio habido en una parte del sistema repercutirá en las otras partes. (p.73) 
El análisis sistémico del cambio social y cultural refuerza la idea de la capacidad transformadora de la escuela -y por ende de las maestras y maestros- en la tarea de hacer avanzar a la sociedad hacia la equidad, más aún a la vista de que los cambios hacia mayor inclusión de las mujeres ya son deseados y palpables en los niveles familiar y comunitario, según el discurso de las y los maestros participantes.

\subsection{Análisis de la educación para la equidad de género, de etnia y social en la escuela}

El análisis de esta categoría nos acerca precisamente al núcleo de la investigación, aterrizando las percepciones de las y los maestros sobre la equidad de género, de etnia y social y sobre de los agentes socializadores a la realidad de las aulas en materia de educación para la equidad.

Como se ha explicado en el estado de la cuestión de esta investigación, el término coeducación está poco extendido en Guatemala y no forma parte de la definición de enfoques del sistema educativo. En este sentido, siguiendo a Subirats (1998), podríamos decir que en el país no se ha abordado una estrategia de educación en equidad "desde arriba", que "se produce en aquellas situaciones en las que un gobierno asume la necesidad del cambio y tiende a impulsarlo desde los organismos gubernamentales, sin que haya en la sociedad una movilización expresa en este sentido" (Subirats, 1998:29). Es interesante analizar con Subirats (1998) que las estrategias de "cambio desde arriba" suelen darse en coyunturas de Reforma Educativa que son favorables para la inclusión de objetivos de relacionados con las mujeres y la igualdad dentro de la educación de un país. En el caso de Guatemala, la Reforma Educativa es un esfuerzo inconcluso en su aplicación y rodeado de controversia ideológica que en definitivas cuentas solo sirve a los intereses conservadores de las élites económicas. Pero, en 
cualquier caso, la propia Reforma Educativa no incluye con claridad la equidad de género, quedando ésta diluida en la equidad étnica y pertinencia cultural de la educación.

A pesar de lo anterior, la existencia del eje transversal de equidad de género, de etnia y social en el Curriculum Nacional Base es una oportunidad que viene desde "arriba" con poca fuerza, recursos y seguimiento, pero permite también generar el cambio hacia la educación en equidad "desde abajo", desde las y los maestros comprometidos con la causa (Subirats, 1998).

Tomando en cuenta las etapas del cambio educativo que establece Subirats (1998), podemos determinar que el sistema educativo guatemalteco se encuentra en un estadio que mezcla rasgos de las etapas de acceso, de unificación y de visibilidad de las mujeres, sin llegar a la etapa de coeducación en ninguna de las dimensiones.

A continuación vamos a analizar las percepciones de maestras y maestros en torno a los elementos del sistema educativo que constituyen oportunidades para avanzar hacia la educación en equidad: el eje de equidad de género, de etnia y social como concreción curricular de obligado cumplimiento en el proceso educativo; la formación de docentes, que constituye una de las claves de éxito de cualquier innovación educativa; la familia y comunidad como miembros de la comunidad educativa y agentes fundamentales para un proyecto coeducativo y las actividades concretas en el aula, que son una de las expresiones prácticas relevantes y tangibles de cualquier intervención coeducativa.

\subsubsection{Eje de equidad de género, de etnia y social del Curriculum Nacional} Base.

Las maestras y maestros conocen la existencia del eje de equidad de género, de etnia y social en el Curriculum Nacional Base, de carácter transversal para todo el proceso de enseñanza-aprendizaje, desde el nivel de Pre-Primaria a Diversificado. Su existencia y 
aplicación con carácter obligatorio es bien valorada como elemento que se convierte en motor de los cambios necesarios hacia la equidad.

"El que lo hayan incluido dentro del CNB [eje de equidad de género, de etnia y social] eso es una ventaja, porque no estuviera incluido como eje, fuera un Curriculum nada más, un fantasma que pareciera de vez en cuando ahí, en cambio al estar incluido en el CNB ya es una ventaja porque forcivoluntariamente todos tenemos que trabajar" (GD04)

La necesidad de que exista este eje dentro del proceso educativo queda probada en las aportaciones de las y los participantes, que identifican discriminación en las aulas desde diferentes perspectivas:

"No lo notamos en muchas ocasiones, pero siento que la discriminación se sigue dando [en las aulas] tal vez con menor porcentaje, pero si”' (E06/B/H)

La discriminación hacia niñas y niños pertenecientes a estratos socioeconómicos bajos y al pueblo indígena parece estar presente en las expectativas de las y los docentes hacia su alumnado. Desde un enfoque interseccional, no se pueden separar estas discriminaciones de la discriminación de género. Por lo tanto, la existencia de discriminaciones étnicas y de clase social, evidenciaría la existencia de discriminaciones de género en las expectativas de las y los maestros hacia las niñas y niños. Como se destaca a continuación:

"Hay maestros que son... aquí se les llama ladinos, que no usan traje... y ellos no quieren ir a trabajar a un área indígena, porque dicen "hay no es que los niños son más tontos",” (E01/PrPr/M)

Retomamos aquí una aportación anterior:

“Vienen los niños y hay niños que le roban al corazón a uno y esa es una discriminación, porque el que viene más feíto, viene más shuquito [sucio], también tiene corazón, pero como a mí me robo el corazón el otro, yo beso y 
abrazo al que a mí me gusta, pero qué pasa con el niño pequeño que necesita de cariño y necesita la misma atención que el niño que viene perfumadito y cambiado" (GD04)

La equidad en todas sus dimensiones (étnica, social y, especialmente, de género) continúa produciendo controversia social en una sociedad muy marcada por diferentes expresiones de discriminación. Esto quedó patente en las aportaciones de las maestras y maestros analizados en apartados anteriores de esta investigación. Por eso, el abordaje de la equidad en las aulas resulta complicado. Sin embargo, parece que trabajar la equidad étnica en el aula es más accesible para las maestras y maestros que el trabajo en equidad de género. De cualquier forma, muchas veces la equidad étnica solo se aborda desde un enfoque folklórico, sin ahondar en las relaciones de poder entre las culturas y en cómo avanzar hacia la igualdad dentro del respeto a las diferencias.

“El promover la cultura se hace también, pero por ejemplo este mes tenemos concurso de bailes folclóricos, entonces esto es para ensayar un baile folclórico y ahí se acabó, entonces por eso es muy superficial también” (E01/PrPr/M)

Quizá con la intención de evitar la controversia, la equidad de género no es nombrada directamente, o se engloba en conceptos más amplios, con el riesgo de quedar invisibilizada en el proceso educativo y no ser una prioridad para las maestras y maestros, como se muestra en las siguientes aportaciones:

"Siempre salen a veces comentarios sobre esto, pero no específicamente tratamos de decirle equidad de género, esto obviamente lo miramos con otro nombre, igualdad o convivencia, convivencia entre el aula, convivencia en los niños” $(\mathrm{E} 04 / \mathrm{Pr} / \mathrm{H})$ 
Resulta difícil abordar la práctica de la equidad:

"Normalmente nos inclinamos dentro de la planificación, si queremos tocar algún punto, en tocar conocimientos, en tocar temas que se tienen que impartir, metodologías muchas veces para impartir a los jóvenes, tiempos incluso, actividades, recursos, pero en el tema de equidad muchas veces no vamos a la parte práctica esto verdad y es algo que de alguna manera tal vez sí se hace, pero no metodológicamente dentro del plan" (GD01)

Recuperando la última parte del discurso anterior "es algo que de alguna manera tal vez sí se hace, pero no metodológicamente dentro del plan", llegamos a un punto clave para nuestra reflexión: dentro de la escuela se educa en equidad o inequidad se quiera o no, es decir, como parte del curriculum explícito -que es lo deseable- o, en cualquier caso, como parte del curriculum oculto. Todo lo que forma parte del curriculum oculto generalmente pertenece a lo no reflexionado, a lo que da miedo abordar, a lo problemático. En el caso de la equidad de género, es decir de la coeducación, siempre se corre el riesgo de reproducir involuntariamente los estereotipos contra los que a nivel racional estamos convencidos de querer luchar. Sin duda, las posibilidades de visibilizar y transformar el curriculum oculto en la educación están muy relacionadas con la formación docente.

A pesar de que la discriminación está presente en las aulas y que el profesorado expresa que su existencia es perjudicial, las maestras y maestros entrevistados expresan aplicar muy escasamente el eje de equidad de género, de etnia y social. Manifiestan obstáculos de diversa índole para su aplicación. En primer lugar, dificultades ligadas a las propias características de Curriculum Nacional Base, que no estaría contextualizado a la realidad de las zonas donde se ha realizado la investigación.

"Puede que sea un apoyo (el CNB) pero tal vez con un porcentaje un poquito bajo porque ya ve que el CNB lo han hecho no a nuestra realidad sino a la 
realidad de ciudad, está basado a la realidad de ciudad. Trabajando nosotros aquí tenemos que acoplarlo a nuestra realidad” (E08/P/M)

Sin embargo, como las propias maestras y maestros indican, la flexibilidad y la posibilidad de contextualización son características del propio Curriculum, con lo que el obstáculo anteriormente expresado no tendría que ser tal. Así lo muestran las siguientes aportaciones: "Unos dicen que no está bien, pero yo la considero bonita [el CNB como herramienta] porque nos permite contextualizarlo todo, nos permite utilizar lo nuestro a ver lo que tenemos y lo que no tenemos cerca verdad, utilizar todos los recursos necesarios para hacer la educación, antes posiblemente no había esa opción verdad” (E05/B/M)

La flexibilidad del curriculum supone mayor responsabilidad de cada docente:

"Tenemos en nuestras manos, el hacer que nuestras clases estén involucradas también lo que son los ejes que el Curriculum nos indica, porque ya sabemos verdad que el Curriculum nos da la característica de ser flexibles, por lo tanto, nosotros como docentes debemos de involucrar contenidos que tengan que ver con lo que... o tenga que fomentar lo que es la equidad de género" (GD 01)

Por otro lado, encontramos dificultades relacionadas con la comprensión del Curriculum por parte de las y los maestros y su capacidad de operativizarlo en las aulas, aspecto que está directamente relacionado con la formación docente.

"Hay un poquito de desinformación y desbalance en la situación esa de ponernos de acuerdo, realmente que objetivos tiene el CNB, o sea si está bien tiene todo nuestro trabajo, todo lo que tenemos que hacer, el problema es entenderlo, saberlo llevar y encadenarlo como realmente debe trabajarlo" (GD04) 
A lo anterior se suman dificultades vinculadas con la planificación de las clases siguiendo las premisas del Curriculum Nacional Base. En el nuevo planteamiento curricular se introduce la educación por competencias dentro del sistema educativo guatemalteco, dejando atrás el enfoque tradicional de educación como transferencia de conocimientos teóricos y enriqueciendo el proceso de enseñanza - aprendizaje con la introducción de tres tipos de contenidos: declarativos, procedimentales y actitudinales. Los contenidos declarativos hacen referencia a los conocimientos teóricos sobre un tema, los procedimentales a las formas de hacer y aplicar ese tema a la vida diaria y los actitudinales, a la motivación y valores que mueven a las y los estudiantes en torno al tema de estudio. Sin embargo, este nuevo planteamiento del proceso educativo implica retos importantes para la tarea de planificación de las maestras y maestros. Tomando como referencia el caso del sistema educativo español, este modelo educativo ligado a objetivos conceptuales, procedimentales y actitudinales ya ha sido utilizado, demostrando que no es suficiente para conseguir una igualdad educativa real; se necesita compromiso docente y una agenda política educativa comprometida con la igualdad.

"Y no llegar a cumplir lo que es los actitudinales [contenidos] y ni llegamos mucho a lo que son los procedimentales, solamente contenidos y que aprendan, muy tradicionales" (E05/B/M)

Como se analizó en el estado de la cuestión de esta investigación, el planteamiento de educación para la equidad que realiza el CNB solo se desarrolla hasta el nivel de eje transversal, pero no se concreta en el desarrollo curricular de cada una de las materias de los diferentes grados. Los ejes transversales, entre ellos el de equidad que nos ocupa, deben atravesar los tres tipos de contenidos -declarativos, procedimentales y actitudinales- en la planificación diaria de cada materia. Este ejercicio queda a criterio de las maestras y maestros, quienes presentan dificultades para poder hacerlo. 
También encontramos la dificultad que entraña la transversalidad en sí misma. Una de las maestras participantes, docente de Pre-Primaria, define lo que para ella es un eje transversal y habla de las dificultades que observa en otras maestras (sus alumnas en la universidad) para la comprensión de lo que el CNB les demanda. Se evidencia la necesidad de que la reforma curricular no sea tan conceptual, sino que se traslade a acciones educativas concretas con un profesorado formado y capaz de trabajar la igualdad. Estas aportaciones lo demuestran:

"Transversal, de forma transversal es que en los contenidos que yo estoy dando, yo siempre considere todos estos aspectos [...] el problema es que las docentes medio trabajan los contenidos, mucho menos ni siquiera saben que esos ejes tienen que trabajarlos de una forma paralela a sus contenidos, es que ese es el detalle, que no tienen todavía bien claro cómo trabajar el CNB” $(\mathrm{E} 01 / \mathrm{Pr} \operatorname{Pr} / \mathrm{M})$ “Pero esos ejes nadie los trabaja, ;no saben trabajarlos! ;De verdad! Les digo yo ¿cómo podemos aplicar un eje transversal? Se quedan en la luna, entonces la verdad desafortunadamente la formación que hemos tenido como docentes ha sido muy mala..." (E01/PrPr/M)

En la docencia de Básico y Diversificado, en la que maestras y maestros solo imparten las materias de su especialidad, el asunto de la transversalidad parece complicarse aún más.

“En el caso del Básico y Diversificado, como lo manifestaba, lamentablemente no tenemos toda la mañana con ellos verdad o toda la tarde con ellos, sino que son episodios, momentos nada más los cuales podemos compartir, pero sin embargo esos minutos de nuestra estancia en el salón de clases es un compromiso nuestro poder involucrar a los dos géneros" (GD01)

La falta de claridad sobre la transversalidad puede llegar a interpretaciones rígidas en la planificación docente, tal y como se aprecia en el discurso de uno de los maestros participantes. Éste expresa que realizará actividades de educación para la equidad en el 
momento que toque abordar esa unidad, lo que va en contra del propio concepto de transversalidad.

"Por el momento no [sobre realizar actividades de educación para la equidad] porque como vamos en relación a trabajo de unidad que se hace entonces, todo tiene un proceso en la unidad en que sí se va a trabajar" (E02/PrPr/H)

Por último, la aportación de un maestro revela otra de las dificultades existentes para la aplicación del eje de equidad de género, de etnia y social: la voluntad de esfuerzo y actualización de las y los docentes.

"Pues el eje de equidad de género e igualdad de género, está plasmado en el CNB, pero los comprometidos a que esto se socialice somos nosotros los docentes" (E10/P/M)

El análisis realizado en este apartado nos lleva a uno de los nudos principales encontrados para que la implementación del eje de equidad sea una realidad: la formación docente. Este aspecto se tratará con más profundidad a continuación.

\subsubsection{Formación inicial y permanente de maestras y maestros.}

La formación docente se presenta como una carencia fundamental para poder hacer realidad la educación para la equidad de género en las aulas. La carencia formativa detectada parece abarcar lo conceptual y lo metodológico: el manejo de los conceptos de género, equidad de género, curriculum oculto y transversalidad, por un lado, y la comprensión del CNB, la planificación de clases y la aplicación del eje de equidad de género, de etnia y social en las aulas, por otro. La mayoría de las y los maestros entrevistados afirma no haber recibido ninguna formación sobre equidad de género ni sobre las posibilidades de implementación del eje en el aula. Así aparece en las siguientes aportaciones que lo ilustran:

“No, no hemos recibido charlas de eso casi, no" (E02/Pr/H) 
La equidad de género quedaría invisibilizada dentro de la temática general de los Derechos Humanos:

“No, no hemos trabajado en ningún momento, tal vez se ha tocado dentro de los cursos de la universidad, tal vez en algún momento en Derechos Humanos, es en donde vemos un poquito el derecho de equidad y otras cosas" (E07/D/H)

Maestras y maestros no identifican ninguna especialidad de Magisterio en la que se reciba formación en equidad de género:

"Incluso en nuestra formación como docentes, no involucran o no toman en cuenta este tema [equidad de género], no es un tema principal, solo nos forman como para atender a los niños y planificar y todo, [...] como que los temas de género, casi no se platican, entonces no importando que carrera usted elije como que ese tema no se da a conocer" (GD04)

La formación docente estaría orientada a elevar la calidad educativa reforzando las áreas instrumentales de matemáticas y lenguaje:

"No, lo único que nos han dado la oportunidad de poder formarnos es cómo trabajar multigrado, por ejemplo, como la lecto-escritura, matemática [...] para equidad de género no" (E03/Pr/M)

“No, por el momento sí no, únicamente solo nos han hablado sobre más... educación en lectura y escritura y únicamente” (E04/Pr/H)

La formación en lecto-escritura y matemática que refieren dos de las personas participantes responde a las estrategias que está aplicando el Ministerio de Educación para elevar el nivel de las y los docentes y el alumnado en las áreas instrumentales de la educación, sobre las que las pruebas diagnósticas que se realizan tanto a alumnado como a profesorado revelan niveles muy bajos, al punto de limitar el éxito del proceso educativo. 
Solo dos maestras y un maestro participantes afirman haberse formado en equidad de género. Destaca el hecho de que esta formación solo ha sido brindada por el plan de estudios de Magisterio en uno de los casos.

"En el magisterio sí, vimos lo que es la equidad de género y cómo fomentar lo que es la equidad de género en los estudiantes verdad, cómo aplicar la equidad de género en los grupos y cómo aplicar la equidad de género a nivel del [centro educativo] para que no haya distinción de personas, ni de raza ni de color como lo dice lo que es la Constitución Política” (E05/B/M)

A este respecto, una maestra que a su vez es docente universitaria en la carrera de Magisterio Pre-Primaria, afirma que sus alumnas universitarias, la mayoría de ellas docentes en activo a través de la carrera de Magisterio de nivel no universitario, llegan a la universidad sin formación sobre equidad de género y su aplicación en el aula.

"La verdad es que no tienen ninguna formación en cuanto a este tema" [referido a maestras y maestros] (E01/PrPr/M)

Continuando con las fuentes a través de las que maestras y maestros se han formado en educación para la equidad de género, en otro de los casos la maestra expresa ser autodidacta. Ella comenzó a investigar sobre el tema al encontrarse frente al reto de facilitar un curso llamado "Coeducación" en la carrera de Magisterio Pre-Primaria en una universidad privada (la única que por el momento incluye la materia en el curriculum de estudios de esta carrera). Respecto a su propia experiencia de formación al cursar la licenciatura, expresa:

"Yo no sé porque acá con nosotros nunca nos han formado para que trabajemos así, incluso yo soy licenciada en Educación Inicial de Pre-Primaria, pero el curso [de Coeducación] a mí no me lo dieron asi'”(E01/PrPr/M)

Cabe resaltar que el material sobre educación para la equidad de producción guatemalteca es prácticamente inexistente. Esto dificultaría la labor de autoformación de maestras y 
maestros, que deberían hacerlo con material extranjero, con el riesgo de falta de contextualización y de pertinencia que esto implica.

“Encontré en España [materiales sobre coeducación], encontré en diferentes lugares, pero de aquí no, y allá es un tema que se está trabajando no en estos años, si no que ya tiene años de venirse trabajando” (E01/PrPr/M)

El tercer maestro que expresa contar con formación en equidad de género afirma haberla recibido gracias al aporte de una ONG.

"La institución donde trabajo estaba incluida en un programa de una ONG, y la verdad que ha sido un programa de mucho beneficio aparte de los materiales que nos han dado, las técnicas de cómo involucrar la equidad, digamos, en el aula, verdad, estrategias de cómo trabajar en grupo” $(\mathrm{E} 06 / \mathrm{B} / \mathrm{H})$

En el estado de la cuestión de esta investigación se pudo apreciar la enorme importancia que tiene el aporte de las ONG en el trabajo de educación para la equidad de género, cubriendo las carencias que presenta el Estado para hacer efectiva esta formación. El aporte de las ONG es decisivo para los avances hacia la equidad de género que se están dando en el país, con intervenciones en la educación no formal de niñas, niños, jóvenes, mujeres, hombres y comunidades y en la educación formal tanto en el sistema público como a través de iniciativas privadas. Los aportes de las ONG guatemaltecas en educación para la equidad de género dentro del sistema de educación formal se producen en diferentes niveles: formación de docentes y generación de materiales (PRODESSA), proyectos educativos de centro (Fe y Alegría e IGER), capacitación a niñas, niños y jóvenes dentro de las aulas por parte de personal o voluntariado de ONG (Paz Joven, AMLUDI y otras muchas). Es importante destacar que las ONG realizan esta labor decisiva y transformadora de vidas en un escenario de criminalización de su trabajo, con intentos del Estado de aprobar leyes regresivas que impedirían las acciones de las organizaciones de la sociedad civil y salvando múltiples 
obstáculos burocráticos para acceder a las aulas públicas o para que un material educativo sea aprobado para poder ser utilizado por maestras y maestros. El apoyo de las ONG parece ser bien valorado entre las y los maestros, como muestra esta aportación.

"También es necesario que existan organizaciones en las que apoyen los centros educativos para dar esos temas" (E05/B/M)

Las maestras y maestros identifican que la formación es un nudo fundamental para poder aplicar la educación para la equidad de género, de etnia y social y, adecuadamente, sitúan sobre el Ministerio de Educación la obligación de facilitar formación a las y los docentes.

"Nos falta preparación [maestras y maestros], nos faltan estrategias, conocimientos para poder llevar esta situación de una manera correcta, porque cuando nosotros como docentes no somos abiertos, no buscamos una preparación caemos en el error de que colaboramos a la equidad o inequidad de género, entonces hay situaciones en las que deberíamos participar, primero en el ministerio de educación, verdad, fortalecer ese programa, abrir más capacitaciones, charlas conferencias para que el docente esté preparado y sepa conllevar esta situación no importa el pueblo, la sociedad en la que se esté viviendo" (GD04)

Sin duda, lo deseable sería que la formación en equidad de género e implementación del eje transversal en las aulas formara parte del curriculum de estudios de las carreras de Magisterio a nivel no universitario y universitario o que, en todo caso, se promoviera desde el Ministerio de Educación en forma de cursos de actualización docente. Sin embargo, también es cierto que la autoformación y aprendizaje continuos son componentes esenciales de la vida profesional de toda persona que quiera dedicarse a la docencia y, por lo tanto, el hecho de no haber recibido formación sobre una temática no debe ser un argumento inmovilizador que 
impida acercarse a la misma, profundizar en ella y aplicarla. Así lo expresan dos de las maestras entrevistadas:

"Si uno tiene el hábito de investigar y de formarse y uno lo puede aplicar" $(\mathrm{E} 01 / \operatorname{Pr} \operatorname{Pr} / \mathrm{M})$

"Pero lo que nos queda a nosotros como docentes es tener preparación y tener retos para poder hacer cambios también, porque depende también de nosotros” $(\mathrm{E} 05 / \mathrm{B} / \mathrm{M})$

\subsubsection{Gerencia del sistema educativo.}

Abordamos ahora la gerencia del sistema educativo como factor que incide directamente en la educación para la equidad en las aulas. Con este término nos referimos a la feminización del Magisterio, a las formas de organización de las escuelas, a sus estilos directivos, a los estilos docentes y de participación en los equipos que presentan las maestras y maestros y al curriculum de estudios de cada grado propuesto desde el Ministerio de Educación.

A pesar de los avances que se aprecian en Guatemala en el cambio de roles de género en las profesiones, la feminización o masculinización de algunas carreras, y por tanto de ámbitos profesionales, sigue siendo evidente.

“Nuestro sistema enmarcó verdad, las diferencias, hay carreras especificamente dirigidas hacia varones y hay carreras dirigidas específicamente para hombres. Creo que se tiene que hacer ya un rompimiento en cuanto a ese sistema" (GD01)

Un caso a resaltar es el de las carreras media y universitaria de Educación Pre-Primaria, en las que la presencia de hombres es escasísima, al punto de que en las mismas escuelas sorprende que a un hombre se le haya asignado un puesto de maestro de Pre-Primaria. 
"Cuando empecé a estudiar, de que éramos pocos los varones, estábamos hablando de una cantidad de 7 varones y 40 féminas o mujeres"; "cuando llegué yo al momento de presentarme a la escuelita, me dijeron ¿a qué grado viene? Yo vengo de Pre Primaria (y el compañero se me quedo viendo) ¿usted de Pre Primaria? Sí, ¿por qué? Porque es el nivel del que yo me he graduado, le dije" (E02/PrPr/H)

En las fases de acercamiento al tema de esta investigación se sostuvo una conversa grupal con 4 maestras de Pre-Primaria y 1 maestra de Primaria, que no pudo ser grabada (ver notas en anexo 5). Según las experiencias compartidas por las maestras, los hombres cuya vocación es la enseñanza Pre-Primaria frecuentemente enfrentan prejuicios y señalamientos en su ejercicio profesional. Las participantes afirmaron que cuando a una escuela llega un maestro de Pre-Primaria, en el claustro se tiende a pensar que es homosexual, al tiempo que es cuestionada la conveniencia de su cargo con el argumento de que las y los niños de PrePrimaria necesitan una maestra que ejerza un rol maternal. Incluso cuando un maestro de PrePrimaria demuestra su excelencia docente, puede ser rechazado por sus mismas compañeras, tal y como informó el grupo sobre un caso en el que un maestro de Pre-Primaria ganó el premio "Maestro 100 puntos" y sus compañeras no estuvieron de acuerdo por tratarse de un hombre. Quedan claros, por tanto, el sexismo implícito en la ideología educativa, la feminización de la docencia en Pre-Primaria y los prejuicios de género existentes.

Por otro lado, la docencia en los niveles más altos del proceso educativo (como el nivel Diversificado), está copada por hombres. Esto parece dar lugar a situaciones que van en contra de la educación para la equidad de género.

"Porque dentro del mismo claustro de docentes hay más varones impartiendo clases que mujeres, y a veces siempre se da ese favoritismo de algunos docentes 
hacia el género femenino verdad [...] sí a veces se marca eso a veces en cuanto a favoritismo de profesores por las señoritas" (E07/D/H)

El favoritismo referido por este participante señala relaciones docentes-alumnado marcadas por el componente sexual. Es necesario poner atención a este aspecto porque este favoritismo en algunos casos podría derivar en palabras, actitudes y actos sexistas, que presumiblemente podrían incurrir en el delito de discriminación e incluso de violencia sexual. Hay que señalar que la incidencia de abuso sexual de personal docente y administrativo hacia alumnas, principalmente, es alta. En 2018, el Ministerio Público y el Ministerio de Educación identificaron $33 \operatorname{casos}^{\mathrm{xxxv}}$ de profesores en activo con antecedentes de agresión sexual. Tres de ellos, además, habían recibido una condecoración nacional por su labor docente. El subregistro de casos de agresiones sexuales en las escuelas a causa de la falta de denuncia podría ser elevado.

En la organización escolar la paridad de género en los claustros de docentes es, sin duda, un elemento importante de la gerencia del sistema educativo de cara a la coeducación porque permite la socialización de niñas, niñas y jóvenes con modelos masculinos y femeninos, al tiempo que revela la existencia de una estructura organizativa en la que mujeres y hombres desempeñan todo tipo de roles, se relacionan en igualdad y su trabajo es valorado sin distinciones. El avance hacia la paridad de género en el ejercicio del Magisterio en los niveles de Pre-Primaria, especialmente, y también de Primaria, está condicionado por múltiples factores como la valoración social de la profesión docente, la construcción y aceptación de la masculinidad hegemónica, los salarios asignados a la misma que dejan ver la relevancia social que se le otorga desde las autoridades estatales, etc. Biológicamente, mujeres y hombres tenemos las mismas capacidades para el ejercicio de la docencia, con lo que solo la construcción social del género nos limita. Sin duda, el cambio cultural necesario para que un hombre sea aceptado como educador de las niñas y niños más pequeños, pasa por el cambio 
de las concepciones de género en el ámbito familiar, el reparto de los roles reproductivos y la valoración social de los mismos. En cualquier caso, mientras este cambio se produce, la vocación de algunos hombres llega a pasar por encima de los estereotipos de género.

“[Ser maestro de Pre-Primaria] es la esencia que yo siento que quería trabajar, con los niños pequeños"; "los hombres también somos capaces de poder educar a los niños, porque muchas veces a nosotros los hombres se nos toma como machistas, a veces hasta abusamos de los niños, pero aquí nos podemos dar cuenta que también, que los hombres o los varones tenemos ese cariño o esa esencia de querer a los niños también” (E02/PrPr/H)

Respecto a la asignación de plazas de trabajo en la educación pública en el área geográfica de estudio, existe un elemento que de forma solapada menoscaba la calidad del proceso y lo impregna del sexismo violento característico de un sistema patriarcal: el tráfico de influencias pagadas con dinero y/o con favores sexuales. Este tema no ha sido abordado en las entrevistas y grupos de discusión comunicativos por ser extremadamente delicado y de difícil comprobación, pero resulta de obligada mención en el análisis por ser vox populi como parte del marco en el que se producen las contrataciones de personal docente.

Uno de los elementos fundamentales del sistema educativo es el planteamiento que el Ministerio de Educación realiza sobre el curriculum de cada uno de los grados de estudio. En este sentido, maestras y maestros aprecian potencialidades importantes para educar en equidad. Ejemplo de ello es el hecho de que las asignaturas de artes industriales y educación para el hogar, anteriormente segregadas para chicos y chicas respectivamente, ahora se trabajen de forma mixta en la mayor parte de los centros educativos. Recordemos, sin embargo, que la educación mixta es diferente de la coeducación. En la primera se comparten espacios, en la segunda, además, se generan expectativas y posibilidades igualitarias en todos los campos para los niños y niñas, independientemente de su sexo biológico. Las siguientes 
aportaciones destacan la buena valoración que hacen maestras y maestros de la ruptura de la segregación por sexo que se practicaba antes en algunas asignaturas:

"Desde el CNB es mixto y se trabaja [asignatura de artes industriales]. Porque incluso aquel curso hogar, que se llamaba, también lo trabajan hombres y mujeres" (E07/D/H)

"Cuando realmente se practica la equidad de género ve algo hermoso, bonito, porque imaginémonos en las aulas de hogar o de artes industriales actualmente, se ve lindo, se ve emocionante como ver a un niño o a un jovencito agarrando una olla, un sartén, lavando alguna fruta [...] y también se ve bonito ver a una señorita, agarrando el serrucho, el martillo, para hacer algún material o algún objeto que, aunque nos han dicho que solo el hombre lo podia hacer"(GD01)

Por otro lado, a juicio de una de las maestras participantes, existe debilidad en la supervisión hacia el trabajo de las maestras y maestros dentro del sistema público, lo que promovería el acomodamiento, al eliminar el miedo a perder el trabajo, y daría lugar a desmotivación, necesidad de presión externa para implementar nuevas estrategias y poco compromiso en general en el ejercicio docente, en medio de una realidad de escasez de recursos didácticos en las aulas:

“Lo primero que una maestra del sector público dice aquí en nuestro país, es: "ustedes [autoridades educativas] solo nos vienen a dar órdenes porque trabajan en un escritorio, pero no están en el contexto" es lo primero que ellas dicen, pero si llega alguien y les dice, miren esto funciona [actividades de coeducación] por esto, esto y esto y vean, les mostramos videos que sí hay cambios y todo y si hay también un convenio con el Ministerio de Educación, porque muchas veces hacen las cosas solo si las presionan” (E01/PrPr/M)

La presión parece ser mayor en centros privados que en públicos: 
"Y yo siempre les digo aquí a las señoritas les digo yo, por qué cuando están en un colegio que les paga Q700 al mes [82 euros aprox.], y el director les dice que se pongan de cabeza, se ponen de cabeza, si se tiene que llevar tantos carteles los llevan y no les importa gastar, no les importa... y por qué cuando entran al sector público ya no hacen nada... y ganan el triple, pero así estamos..." (E01/PrPr/M)

La escasez de materiales y recursos didácticos que se desprende del discurso anterior tiene un peso específico importante para el tema que nos ocupa, ya que el desarrollo de un proyecto educativo integral, como el Curriculum Nacional Base, precisa una estructura humana que lo haga posible (cuerpo docente con su organización y supervisión pertinentes y efectivas), en un medio físico adecuado para el éxito de este proyecto educativo. Hablar de medios físicos adecuados para los procesos educativos abarca elementos básicos como el diseño de las escuelas con una disposición óptima de aulas y espacios de recreo, la seguridad de las infraestructuras en un territorio sísmico, la dotación de mobiliario y materiales en las aulas, etc. Hay que señalar que, en algunas escuelas, especialmente en áreas rurales, la precariedad de las infraestructuras y la escasez de mobiliario, materiales y recursos son severas, a pesar de los esfuerzos realizados por el Ministerio de Educación en este ámbito. Así, en muchos casos sería imposible realizar un análisis de los libros de texto de PrePrimaria y Primaria desde la perspectiva de la equidad de género porque en las aulas se trabaja sin ellos. Así lo muestra la siguiente aportación:

"No, con decirle que en mi escuela no hay pizarrones" [ni libros] (E03/Pr/M)

En cualquier caso, la implementación de un proyecto de centro de educación para la equidad sería posible en medio de cualquier precariedad, con la voluntad y compromiso de la dirección y claustro de una escuela. De forma ideal, requeriría el involucramiento de la dirección del centro, así como la coordinación docente. En este sentido, el estilo de autoridad 
y coordinación de cada directora o director de escuela parece ser determinante para la calidad del trabajo que realizan las y los docentes en las aulas. En los discursos de las maestras y maestros, todos ellos referidos al sector público, encontramos realidades contrapuestas al respecto:

"La directora no se involucra en el trabajo del aula, entonces yo puedo planificar las actividades que yo desee" (E0/PrPr/M)

"El trabajo es muy duro de parte de nosotros porque el director nos exige mucho" (E03/Pr/M)

En la realidad que estamos describiendo, en la que la implementación del eje curricular de equidad de género, de etnia y social no parece ser una prioridad, la falta de injerencia de la directora o director de una escuela en la planificación diaria de las y los docentes es vista como un elemento positivo que permite que en las aulas pueda trabajarse cualquier aspecto curricular, aunque no sea prioritario para la dirección. Las siguientes aportaciones así lo indican:

"Una ventaja que sí tenemos en el magisterio es la libertad de cátedra, entonces ahí usted tiene libertad para mejorar les digo yo, no para empeorar..." $(\mathrm{E} 01 / \mathrm{PrPr} / \mathrm{M})$

"Y por más a mi llegara la directora y me dice mire no lo trabaje [equidad de género], pues tenemos libertad de cátedra y si yo estoy convencida que eso es lo mejor para mis alumnos, tengo el derecho de trabajarlo y nadie me puede decir que no" (E01/PrPr/M)

Las concepciones tradicionales de la educación, así como el acomodamiento de maestras y maestros en el sistema público anteriormente mencionado, parecen afectar negativamente a la posibilidad de implementar proyectos de educación para la equidad ya no de centro, sino de aula, según indican dos maestras: 
"Porque a veces ellos [docentes] todavía tienen la mentalidad yo vengo a dar mis cursos, o yo vengo a dar la teoría que me corresponde y hasta ahí terminó todo [...] no todos hemos llegado a entender eso de que tenemos que utilizar o traer los ejes para el aula” (E05/B/M)

"El problema que tenemos [maestras y maestros] es que a veces tenemos mucha desidia, mucho acomodamiento" (E01/PrPr/M)

La organización interna de las escuelas en forma de consejos estudiantiles, juntas directivas de aula, etc. también es importante de cara a la eliminación de sesgos androcéntricos y la vivencia de la equidad. En este sentido, se han producido avances, pero se continúa encontrando escollos en forma de resistencias y baja autoestima, normales por la dificultad de producir un cambio cultural en la segregación de género arraigada en las escuelas por años de educación segregada por sexo, primero, y educación mixta pero no coeducativa, en la actualidad. Maestras y maestros hacen memoria:

"Yo me recuerdo cuando estudié el Básico, los consejos estudiantiles debían ser formados por hombres, no por mujeres y si en caso había una mujer, pero que estuviera de vocal, verdad, que estuviera de última" [referido a que actualmente ha cambiado la situación] (GD01)

"En el Básico a veces conformamos lo que son juntas directivas de aula, y así como decían, a veces solo los hombres valoran, ahora vienen muchas veces que se propone a la mujer, pero a veces la mujer también no lo quiere aceptar, yo veo que ese es un error también que la mujer hace [...]” (GD01)

A pesar de las dificultades que presenta la gerencia del sistema educativo de cara a la educación para la equidad, las actitudes positivas y propositivas del personal docente, la valoración del aporte propio como parte importante del sistema, así como una visión de largo alcance respecto a la educación, son piedras angulares para el avance hacia la educación para 
la equidad. Maestras y maestros expresan su compromiso con el cambio en las siguientes aportaciones:

“Tenemos que comenzar nosotros [maestras y maestros] mismos porque nadie puede dar lo que no tiene, verdad, y si no tenemos una visión amplia de lo que queremos no podemos exigirle a nadie, pero si es importante en la educación manejar la situación de equidad” (GD04)

Se trata de asumir la responsabilidad en cada nivel educativo:

"Yo soy la responsable, entonces aporto lo que tengo que aportar, pero no le echo la culpa al que esta atrás" (E01/PrPr/M)

Y avanzar hacia la escuela ideal:

"La escuela con participación de mujer y hombre, involucramiento también de mujer y hombre verdad, donde la mujer opine, donde el hombre opine y donde sean tomados en cuenta sus opiniones, es soñar con una escuela ideal” (GD01)

\subsubsection{Actividades concretas relacionadas con la educación para la equidad.}

Abordamos ahora las actividades concretas de educación para la equidad que las maestras y maestros participantes realizan en sus aulas, o que ven factible realizar. El análisis de actividades puntuales resulta interesante y relevante para esta investigación porque estas actividades constituyen la máxima concreción de la intervención educativa en educación para la equidad, a la vista de que no se ha encontrado ninguna escuela en los departamentos estudiados que plantee un proyecto coeducativo de centro, ni que aborde sistemáticamente la implementación del eje transversal de equidad de género, de etnia y social.

El planteamiento principal que expresan las maestras y maestros para abordar la educación para la equidad de género tiene que ver con la forma de organizar las actividades de aula. 
Así, organizar grupos mixtos de chicas y chicos aparece como la medida más extendida entre maestras y maestros para promover la equidad:

“Grupos mixtos, saben que tienen que estar hombres y mujeres, 4 hombres y 4 mujeres, entonces de esa manera vamos a ir inculcándoles que deben relacionarse ambos géneros" (GD01)

"Haciéndolos mixtos [organización de actividades de aula] porque, así como ahorita los tengo yo, los tengo así un varón una niña, un varón una niña... Entonces ahí yo también les estoy inculcando que pueden trabajar no importando el género" (E02/PrPr/H)

"Desde primer grado empiezo a formar grupitos, donde se involucran hombres y mujeres y cuando ya están ellos acostumbrados así, iqué bonito!, se ve muy bonito cuando los niños tratan muy bien a sus compañeras y empiezan a dibujar, a pintar y a pensar juntos” (E03/Pr/M)

"Grupos de trabajo mixtos verdad, para ir promoviendo esa equidad entonces armamos grupos de trabajo y esos grupos de trabajo son mixtos y tratan de estar hombres y mujeres juntos verdad, más que todo para que se vayan adaptando a que la sociedad necesita eso verdad, que ambas personas se relacionen” (E06/B/H)

Una maestra y un maestro agregan, además, que el tipo de trabajos que proponen realizar en el aula no están marcados por connotaciones de género ni de etnia, de manera que todas y todos los alumnos los realicen sin distinción. Así lo demuestra la siguiente aportación:

"Yo trabajo con los jóvenes utilizando los grupos mixtos y haciendo trabajos que los hombres pueden hacer y que las mujeres pueden hacer, entonces no permito que haya grupos así de hombres o de mujeres que sean mixtos, porque donde trabajo es una escuela donde hay hombres y mujeres verdad, y también es 
una población que también podríamos decir indígena y no hay discriminación también hacia otra cultura o hacia otra etnia." (E05/B/M)

Entre las acciones concretas de educación para la equidad de género que se han abordado en las aulas de las maestras y maestros participantes encontramos: charlas o comentarios directos sobre igualdad, temas de educación afectivo-sexual y cuentos coeducativos. Así parece en las siguientes aportaciones:

"Yo me he sentado con ellos [niños] y les he explicado que todas las personas somos iguales, y yo le pregunto a los niños, ¿tu mamá es mujer? Sí, ¿quién te cocina? Mi mamá, y si tú por ejemplo vas a crecer ¿te vas a casar con una mujer o con un hombre? No, con una mujer, entonces a tu esposa no le vas a hacer eso”; "entonces yo les digo a ellos: y ustedes con lavar trastos, ¿se van a convertir en mujeres? ¡No!, con barrer ¿se van a convertir en mujeres? ¡No! [...] el martes les enseñé a cocinar, involucré a los niños, vayan a lavarse las manos, llénenme esto de agua, háganme esto, esto y usted póngame esto, involucré a los hombrecitos, ¿pueden cocinar? ¡Sí! ¿Ya vieron que pueden?” $(\mathrm{E} 03 / \mathrm{Pr} / \mathrm{M})$

Respecto a la educación afectivo-sexual:

"[referido a educación afectivo-sexual] ya con imágenes, dibujos ya hasta los niños hacen otras preguntas, entonces ya hay como que más apertura, pero eso sí se ha trabajado un poquito más" (E01/PrPr/M)

En relación con los cuentos coeducativos:

"Los niños se sorprenden cuando yo les he contado cuentos co-educativos", "el miércoles trabajo los co-educativos y ya tengo bastantes cuentos coeducativos"; "entonces se dan cuenta que sí [con los cuentos co-educativos], 
que las mujeres tienen la misma capacidad de poder hacer lo que un hombre puede y vamos generando polémica con ellos desde chiquitos" (E01/PrPr/M)

Al hilo de la utilización de cuentos coeducativos, una maestra realiza la reflexión de los prejuicios que ella misma enfrenta para manejar esta herramienta. Esto es importante porque refleja capacidad autocrítica:

"Eso de los cuentos no sexistas yo he estado leyéndolos un poquito y cuesta un poquito porque hasta uno mismo termina diciendo: ¡no, hombre! ¡Pero si no termina así el cuento el cuento! Pero igual hay que aprender a que los niños manejen sus propios criterios y que tengan sus propios finales a como ellos crean, o sea que no es como diga yo, si no como ellos piensan y lleguen a consolidar su propio criterio" (GD04)

Respecto al trabajo en equidad de género y de etnia, una de las maestras afirma trabajar la valorización de la cultura k’iche' a través de la recuperación de aspectos tradicionales, promoviendo la participación de chicas y chicos por igual:

"Yo llego al aula, todos hacemos una invocación, y esa invocación la hacemos de manera rotativa, un hombre y una mujer, un hombre y una mujer [...] luego cantamos el himno nacional en k'iche," (E05/B/M)

Las maestras y maestros entienden la educación en valores relacionada con la educación para la equidad de género. Esto es relevante, pero implica el riesgo de que la equidad de género quede diluida entre los valores del respeto, la convivencia, entre otros, y no sea abordada directamente.

"En mi caso yo trabajo un valor durante un mes, por ejemplo, la convivencia, tratar de que convivan todos, el respeto, yo creo que ha sido muy bueno a nivel de escuela trabajar los valores" (GD03) 
Por otro lado, algunas medidas correctivas que aplican las maestras y maestros con la intención de educar en normas de cortesía contravienen la educación para la equidad de género y evidencian, además, el arraigo de la violencia cultural contra las mujeres en el imaginario social: ser vestido de mujer es un castigo porque atenta contra la masculinidad. Así aparece en la siguiente aportación:

"En mi caso yo les digo: si pasan primero los hombres, calzón y chongo les voy a poner. Y se quedan quietos, ninguno pasa y todas las mujeres pasan. Para enseñarles que deben darles su espacio a las damas, porque aparte es la liberación femenina y aparte es la educación, verdad" (GD02)

Respecto a las asignaturas en las que más se facilita el trabajo en educación para la equidad, destaca el Seminario que realizan las y los estudiantes del nivel Diversificado. Éste consiste en un proyecto de intervención comunitaria fundamentado en un proceso previo de reflexión sobre la identidad personal, social y nacional.

"Dentro de una de las partes que se trabaja en Seminario hay nueve ámbitos que se trabajan, y uno de los ámbitos precisamente es equidad, verdad, ahí se trabaja equidad laboral, de género y social, entonces ahí es donde nosotros lo fomentamos, hay grupos de Seminario que han trabajado este tema ya específicamente para su proyecto y cuando nosotros lo damos a conocer a padres de familia y al colegio en general ahí aprovechamos para de alguna manera hacer un hincapié fuerte, en que los jóvenes puedan retomar eso y se cambia la mentalidad" (E07/D/H)

También se valora la asignatura de Educación Física como oportunidad para la educación en equidad de género, es decir, para la coeducación.

"En las actividades de educación física, por ejemplo, ponemos a brincar caballito a los niños. Antes pasarse las niñas encima de niños eso es un pecado 
grandísimo, eso no se hace, es pecado grande. Pero ahora ellas ya lo hacen, verdad, hacen el caballito y se pasan encima de los varones, [...] ahora la inclusión, como dice el compañero, ya se ven los niños jugando con las niñas, las niñas juegan fútbol, los varones incluso juegan rodas con las niñas” (GD04)

La libertad para que chicas y chicos elijan el deporte que les gusta se valora como importante:

"Hay niños que les gusta practicar baloncesto y no mucho les gusta el futbol, y hay niñas que les gusta más el futbol y no el basketbol. Entonces se les deja la libertad a ellas para que elijan de qué les gusta, pero sí tratar la manera de practicar no solo el deporte, también otras actividades sociales" (GD03)

Los espacios informales dentro de la jornada escolar son valorados como fundamentales para la labor coeducativa:

"Crear actividades en donde todos participen, tomar en cuenta a hombres y mujeres por igual, la participación igual, en todas las actividades comisiones de limpieza, de refacción [merienda de media mañana o media tarde], gobierno escolar, patrulla de limpieza, que participen tanto niñas como niñas por igualdad, de una vez decirles a ellos. Incluso en cómo se sientan, como tienen su escritorio, revueltitos verdad" (GD02)

Por último, el trabajo con padres y madres, desde las Escuelas de Madres y Padres, aparece como actividad concreta que se está realizando en algunas escuelas para avanzar hacia la equidad y también como necesidad a implementar en otras:

"Tenemos la escuela de padres con los papás, les explicamos de que por lo menos ellos [sus hijas e hijos] deben de tener una mejor oportunidad" $(\mathrm{E} 03 / \mathrm{Pr} / \mathrm{M})$ 
Se resalta la importancia del formato de Escuela de Madres y Padres para avanzar en la educación para la equidad, considerando que las reuniones son insuficientes:

"Una actividad que debemos de implementar, en los centros educativos, como lo mencioné en la mañana, la escuela de padres, es una escuela de padres, no reunión con padres, porque en los centros educativos no se implementa eso, simplemente es una reunión [...] pienso que tal vez pueda funcionar la implementación de escuelas de padres a nivel nacional" (GD01)

Trabajar la equidad de género, de etnia y social con madres y padres permite acelerar los cambios culturales necesarios para avanzar en la equidad:

"Si se logra implementar la escuela de padres, yo digo que sí se puede lograr un cambio mucho más acelerado, tal vez a unos 30 a 40 años" (GD01)

\subsubsection{Las familias y la comunidad.}

Un proyecto coeducativo, de forma ideal, abarca a las familias y la comunidad en la que se inserta la escuela, con la convicción de que los actores del hecho educativo no solo son el alumnado y profesorado, sino también las familias y la comunidad, además del personal administrador a nivel ministerial y escolar, tal y como lo establece el nuevo paradigma educativo del Curriculum Nacional Base (MINEDUC, 2008:17).

Las maestras y maestros participantes expresan que el trabajo con las familias es fundamental en la educación para la equidad porque consideran que las concepciones tradicionales de género se encuentran fuertemente arraigadas en ellas y constituyen el principal escollo para la educación en equidad en la escuela. Recordemos que, desde la concepción de las y los maestros, la familia es el principal agente socializador de género. Así se evidencia: 
"Hicimos un trifoliar [tríptico informativo] verdad, para poder educar a los padres de familia para que conocieran un poquito sobre el tema, ¿verdad? Cómo tratar el tema de la coeducación desde el hogar, hicimos una planificación para poder trabajar con padres de familia, yo les decía a ellas [maestras] que cada unidad que ustedes entreguen las tarjetas den una pequeña plática de lo que es la coeducación, de la importancia de promover, de erradicar el sexismo" (E01/PrPr/M)

Entre los temas que maestras y maestros consideran que se deben trabajar con las familias para avanzar en la equidad de género, se encuentran el acceso a la educación de las niñas y adolescentes en igualdad de condiciones que los chicos, especialmente en los grados más elevados:

"En Diversificado el nivel de diferencia que tenemos con las mujeres verdad, me atrevería a decir que más o menos un $70 \%$ a un $75 \%$ de hombres y el resto de mujeres verdad [...] me acabo de topar precisamente con un caso que me decía la señora, ¿para qué va a estudiar mi hija? Si se va a casar” (E07/D/H)

Así mismo, la educación afectivo-sexual en las escuelas, llamada educación integral en sexualidad, también es una prioridad detectada por maestras y maestros. Sin embargo, el avance de esta temática encuentra resistencias en algunas familias:

"Dimos clases sexuales [de educación sexual] a una niña de 10 de 11 años en adelante y resulta que se organizaron todas las mamás [...] para ellos fue inadecuado darles esta clase a las niñas, que para ellas fue un pecado, me dijeron a mí: ¡¿cómo se te ocurre hablarle de esos temas a las niñas?! Si esos temas, a ellos por ejemplo ayer se casaron jen la misma noche les explicamos cómo es esto! porque ellas no deben de saber nada” (E03/Pr/M) 
A pesar de las resistencias expuestas, es importante destacar que las prioridades identificadas por maestras y maestros de promover el acceso a la educación para las niñas en los niveles más altos y avanzar en la educación afectivo-sexual coinciden con las expectativas que las madres y padres, principalmente madres, tienen sobre la escuela. Las madres entrevistadas también expresan apertura a que la escuela sea un agente socializador de peso para sus hijas e hijos en educación para la equidad de género. Un aspecto muy relevante es el deseo de que la escuela brinde educación afectivo-sexual, coincidiendo con la necesidad detectada por maestras y maestros. Así lo muestra la aportación de la madre de una alumna, perteneciente a una de las escuelas donde se realizaron entrevistas a maestras y maestros:

"Tal vez un poco más en educación sexual. En casa los orientamos, pero un poquito más en la escuela, pienso” (E12/M/M)

El Ministerio de Educación de Guatemala cuenta con enfoques muy pertinentes para la educación integral en sexualidad desarrollados con la asesoría del Fondo de Población de las Naciones Unidas -UNFPA. Este enfoque aborda las relaciones de género y la formación para relaciones de género equitativas. Estos contenidos, a pesar de ser de obligada aplicación en las escuelas, en la práctica se cumplen muy escasamente y una de las excusas fundamentales que se esgrimen desde el Ministerio de Educación son las reticencias de las familias. Sin embargo, se identifica que estas reticencias si bien existen, no son insalvables, como muestran las madres y maestras y maestros entrevistados. Los obstáculos para el trabajo en educación integral en sexualidad en las escuelas se encuentran, probablemente, en la propia ideología del Ministerio de Educación, caracterizada por el conservadurismo y moralismo que demandan las élites económicas y religiosas del país. Se evidencia aquí la des responsabilización del Estado respecto a la educación y el desarrollo, colocando deliberadamente la responsabilidad de la educación sobre las familias que, debilitadas y 
carentes de herramientas en muchos casos, se configuran como culpables del subdesarrollo en el imaginario político y social.

Detectado que la educación afectivo-sexual es una prioridad en común entre madres y maestras y maestros, esta formación se podría convertir en el punto de partida para el desarrollo de proyectos coeducativos para las escuelas.

Por otro lado, las madres manifiestan la necesidad de que desde la escuela se motive a las niñas a no abandonar sus estudios en los grados más avanzados. Esto también coincide con las expectativas de maestras y maestros que afirman que es necesario trabajar por el acceso de las niñas a la educación en los grados más altos.

"Mi hija la más grande ella ya no quiere estudiar porque ya no alcanza que le dé estudio. Y ella ya no está muy motivada que ella se va a la escuela. Entonces, yo quiero que si pudieran hay que motivar a los jóvenes para que ellos sí vayan a la escuela" (E12/M/M)

Durante el trabajo de campo de la investigación se realizaron 2 talleres de discusión sobre equidad de género con madres y padres del alumnado de una de las escuelas de las maestras y maestros participantes. El perfil general de las madres y padres era de personas jóvenes, indígenas, de nivel académico muy bajo, de área rural y clase social baja. En estos espacios, las madres y padres expusieron sus expectativas de futuro para hijas e hijos, dibujándolas y escribiéndolas (ver anexo 5). Destaca el hecho de que entre las expectativas para sus hijas e hijos se mantiene el patrón tradicional del matrimonio y la separación de roles productivos y reproductivos, pero se expresa el deseo de que las hijas también sean profesionales y que tengan familias con menor número de hijos ( 2 o 3 ).

Todo lo anterior nos habla de la necesidad sentida por las familias de que el cambio cultural que ya se está dando y que desean impulsar sea empujado también desde las escuelas, impidiendo que las niñas sean arrastradas por los patrones patriarcales existentes y 
que todavía tienen más fuerza que la tendencia al cambio. Esto rebate la percepción de maestras y maestros sobre la escuela como un agente socializador secundario que solo podría actuar si previamente la sociedad ya ha cambiado. Se demuestra que, como explica Subirats (2010), esta percepción en realidad constituye una resistencia para el avance de los proyectos coeducativos.

Una de las dificultades que se encuentran para el trabajo en educación para la equidad de género con familias es que generalmente las que acuden a las convocatorias de actividades de la escuela son las madres, siendo muy pocos los padres que lo hacen. Precisamente los padres $\mathrm{u}$ hombres de las familias (abuelos, tíos, hermanos mayores) son uno de los objetivos prioritarios de la sensibilización, ya que en el esquema tradicional predominante en las familias de las zonas estudiadas los hombres ostentan el poder de decisión en la familia y, en ausencia del papá, es el abuelo, tío o hermano mayor el que toma las decisiones.

"Lo que miro es que lo que sí necesitamos aquí en nuestra comunidad de Pachaj es mucha sensibilización, capacitación a madres y padres de familia porque a madres siempre hablamos con ellas y todo” (GD03)

La atención a actividades escolares forma parte del rol de género asignado a las mujeres, siendo difícil contar con la participación de los padres, con quienes precisamente es muy necesario trabajar en función de la equidad:

"Lo importante es programar pláticas de orientación a madres y padres de familia, de repente un día con mamás, otros con papás, eso es lo malo que los papás casi no llegan” (GD03)

Respecto a la concentración del poder sobre las decisiones familiares en la figura de un hombre es interesante el fenómeno de control a través del teléfono y redes sociales que ejercen algunos padres migrantes en Estados Unidos sobres sus esposas y sobre todas las 
decisiones de la familia, perpetuando modelos familiares basados en el control patriarcal aún en la distancia.

A pesar de las dificultades, las y los maestros participantes se muestran convencidos de que el trabajo con familias forma parte del nuevo paradigma educativo, de que es un trabajo necesario para la convivencia social, es factible y permitirá que se den cambios culturales hacia la equidad de género, con la lentitud generacional y a la vez con la fuerza propia de lo educativo. Las siguientes aportaciones muestran este contexto:

"Yo veo que sí es un tema [educación para la equidad] que sí se puede trabajar con ellos [familias], porque yo sé que son personas ya mayores, razonantes, si saben que es algo interesante, porque ellos mismos son los perjudicados si ven que los niños, a ellos no se les habla esto también porque su comunidad va a estar desintegrada y no van a poder convivir como seres humanos” (E02/Pr/H)

El trabajo con familias y comunidad alimenta la concepción de comunidad educativa que propone el CNB:

"Padres de familia, estudiantes, personas de la escuela, los estudiantes verdad formamos una comunidad, y esa comunidad es lo que tratamos de hacer, tratamos de tener el desarrollo o un cambio integral en el estudiante, y eso es lo que pretende ahora lo que es el Curriculum Nacional Base” (E05/B/M)

Recopilando los puntos más relevantes del análisis del eje de equidad de género, de etnia y social, establecido como categoría para esta investigación, podemos resaltar tres aspectos:

a) El primero, que las maestras y maestros perciben la existencia de discriminación en las aulas y esto haría necesaria la implementación del eje que nos ocupa. Sin embargo, la discriminación por motivos de género no se nombra específicamente como tal, tanto por falta de sensibilización de las maestras y maestros como por miedo a que se generen controversias. Esto es una dificultad fundamental para su abordaje, requiriendo una 
intensa labor de formación docente. Precisamente la formación inicial y permanente de maestras y maestros se revela como una de las principales carencias y, por lo tanto, un reto ineludible a abordar para avanzar en la coeducación.

b) El segundo, que el eje de equidad de género, de etnia y social es conocido para las maestras y maestros, pero su aplicación es muy escasa. Entre las causas, podemos señalar, por un lado, evitar la presumible controversia con madres, padres y otros miembros de la comunidad educativa; por otro lado, la falta de formación docente inicial y permanente en materia de género y educación para la equidad -la coeducación solo forma parte del curriculum de estudios de la carrera de Educación Pre-Primaria en una universidad y es privada-, que produciría poca sensibilización y capacidad pedagógica al respecto; y por último, la falta de formación docente en el manejo de la transversalidad curricular, que daría lugar a que el eje transversal que nos ocupa $-\mathrm{y}$ presumiblemente los demás ejes transversales del Curriculum- sea obviado en el día a día de las aulas. Cabe subrayar que en el aspecto de la formación el aporte de las ONG es bien valorado, aporte que complementaría la actualización docente que ofrece el Ministerio de Educación.

c) Y tercero, en cuanto a la composición y motivación del cuerpo docente, encontramos que está feminizado en los grados bajos de la educación y masculinizado en los altos, es decir el número de mujeres desciende según aumenta la jerarquía académica contextual, y que, al menos en el sector público, parece que una tendencia al acomodamiento afecta la implementación de innovaciones educativas. La autoridad efectiva y propositiva de la persona directora de cada escuela pública parece ser muy variable, dando lugar a un amplio margen de libertad para que cada maestra y maestro plantee la intervención educativa dentro de su aula según su propio criterio. Señalar que esta libertad, conferida por la libertad de cátedra que ampara a maestras y maestros y la poca injerencia ejercida 
por algunas direcciones escolares, es vista como un potencial para que cada docente de forma autónoma pueda autoformarse y desarrollar innovaciones sin ninguna restricción. Sin embargo, al mismo tiempo, esta libertad va acompañada de una importante carencia en el acompañamiento pedagógico y supervisión a las y los maestros, que daría lugar a importantes vacíos conceptuales $y$, consecuentemente, metodológicos en la planificación e implementación de sus clases.

Por último, se aprecia un cambio hacia mayor equidad de género en la organización escolar del alumnado, con mayor participación de chicas en las juntas escolares y directivas.

Respecto a la comunidad educativa, el trabajo con las familias -en forma de Escuela de Madres y Padres o reuniones- se revela como muy necesario para avanzar en equidad de género, siendo una tarea que ya se está desarrollando por parte de algunas maestras y maestros, con mayor o menor sistematicidad y apoyo de la dirección de la escuela.

Entre las actividades concretas dirigidas a la educación para la equidad encontramos un esfuerzo en las aulas por organizar grupos de trabajo mixtos y por plantear actividades no segregadas por sexo; además, encontramos el uso de cuentos coeducativos por parte de una maestra. Desde algunas escuelas se están realizando actividades dirigidas a madres y padres en forma de charlas sobre igualdad y educación sexual.

Podemos concluir que existe, pues, una grave carencia de formación docente que se traslada a la invisibilización del género en la práctica. La esperanza de transformación va unida al compromiso que destaca uno de los docentes:

"En el caso del Básico y Diversificado, como lo manifestaba lamentablemente no tenemos toda la mañana con ellos verdad o toda la tarde con ellos, sino que son episodios, momentos nada más los cuales podemos compartir, pero sin embargo esos minutos de nuestra estancia en el salón de clases es un compromiso nuestro poder involucrar a los dos géneros” (GD01 


\section{Conclusiones}

El análisis de categorías y subcategorías que se ha desarrollado en el punto anterior y su contraste con el estado de la cuestión nos permite llegar a las conclusiones que se exponen a continuación.

1. En Guatemala, el género, la etnia, la clase social, el carácter neoliberal, elitista, centralista y monocultural del Estado y el orden internacional en el que se sitúa el país se encuentran imbricados, siendo imprescindible un enfoque interseccional para comprender la experiencia de exclusión / privilegio en la vida de las personas, especialmente las mujeres.

2. El patriarcado en Guatemala puede ser analizado a la luz de un triángulo interseccional de violencias. Las violencias estructural y directa por motivos de género, de etnia y de clase social, entre otras categorías, es legitimada por la violencia cultural patriarcal: todo un imaginario estereotipado que infravalora a las mujeres y a todos los hombres que no encarnan el patrón de masculinidad hegemónica.

3. La transformación de las exclusiones de género, etnia, clase y otras en Guatemala pasa por la transformación de la violencia cultural patriarcal. Y esto coloca el foco de atención sobre los agentes socializadores, especialmente el sistema educativo.

4. La construcción del género, según maestras y maestros de Quetzaltenango y Totonicapán, gira alrededor de la supremacía masculina propia del sistema patriarcal. Esto conlleva discriminación contra las mujeres y las niñas y violencia de género, que se manifiestan en:

a. Sistema binario de género, con roles muy diferenciados que ligan a las mujeres a lo reproductivo y a los hombres al rol proveedor.

b. Férreos mandatos de género, respaldados en premisas irracionales y místicas, cuya transgresión es castigada con la estigmatización social. 
c. Servidumbre de mujeres y niñas hacia los hombres.

d. Violencia directa contra mujeres, niñas y niños dentro de los hogares.

e. Violencia cultural o simbólica contra las mujeres. Uno de sus mecanismos es la culpabilización de las mujeres de su propia exclusión.

5. Los valores de la dualidad y la complementariedad de la cultura maya, resignificados dialógicamente por el feminismo comunitario y los pueblos indígenas, pueden constituir una base para el avance hacia la equidad de género desde una epistemología decolonial.

6. Se está produciendo un cambio cultural hacia la equidad de género, de forma lenta. Se evidencia en: a) las familias, que brindan más oportunidades de educación para las hijas y la expectativa de que las generaciones jóvenes convivan con más equidad de género; b) las escuelas, con más paridad en espacios de participación estudiantil; c) las comunidades, con más participación de las mujeres en espacios comunitarios, aunque con un avance muy lento; d) la incorporación de las mujeres a nuevos roles y profesiones.

7. El cambio cultural hacia la equidad de género es visto de forma positiva, pero no está exento de las tensiones, controversias y resistencias propias de la remoción de los cimientos del status quo. El diálogo se identifica como un mecanismo para resolver estas tensiones.

8. El racismo vertebra las relaciones sociales en el área estudiada, siendo la población indígena, de clase social baja y de áreas rurales la más excluida. La discriminación racista es más fácilmente identificada que la discriminación de género. Sin embargo, desde un enfoque interseccional, ambas no pueden separarse.

9. También se está produciendo un cambio cultural hacia la equidad étnica, que se refleja en: a) más empoderamiento de la población indígena sobre sus derechos y b) cuestionamiento de los perjuicios que la discriminación ocasiona a la sociedad. 
10. La sociedad de Quetzaltenango y Totonicapán se encuentra estratificada en clases sociales, con profundas brechas de desigualdad. Esto responde al enfoque neoliberal del Estado, con pocos servicios públicos y de mala calidad. El acceso a la satisfacción de las necesidades básicas depende del poder adquisitivo individual, lo que produce enormes desigualdades y hace vulnerables a amplios sectores.

11. Maestras y maestros colocan a la familia como principal agente socializador e incluso se le asigna la obligación de serlo, obviando las dificultades estructurales que puedan tener las familias para educar en la equidad. Esto se relaciona con el carácter conservador y moralista de la sociedad, pero a la vez es una estrategia del Estado para des responsabilizarse de su rol como titular de obligaciones.

12. Maestras y maestros perciben la escuela en segundo lugar de importancia como agente socializador de género. Se identifican: a) pensamientos deterministas en cuanto a la socialización de género recibida por las niñas y niños en el hogar; b) invisibilización de la inequidad de género $\mathrm{y}$, por lo tanto, de la necesidad de educar en la equidad; c) debilidad en la comprensión del peso de la escuela como agente socializador; d) confusión entre educación para la equidad de género, es decir coeducación, y educación mixta.

13. Se aprecian avances en cuanto a mayor sensibilidad de maestras y maestros acerca del peso socializador de la escuela, lo que supone una oportunidad para la educación para la equidad.

14. La comunidad está en tercer lugar de importancia como agente socializador de género. Presenta dinámicas de exclusión de género, etnia, clase y otras y se encuentra inmersa en un cambio lento hacia la equidad.

15. Las religiones católica y protestante, principalmente, son identificadas como elementos limitadores de la educación para la equidad porque generan divisionismo y determinan 
conductas sexistas en niñas y niños. Se considera que tendrían la responsabilidad de contribuir con la erradicación de las discriminaciones por el peso moral que tienen en la población.

16. Los medios de comunicación, especialmente internet, se identifican como agentes de cambio y amenaza de riesgos como la violencia sexual. Su uso está cada vez más extendido a pesar de que persiste una gran brecha digital entre áreas urbanas y rurales. Se evidencia la necesidad de formación en las escuelas sobre análisis crítico de los contenidos de los medios de comunicación.

17. El Estado de Guatemala está comprometido con la educación para la equidad a través de la firma de la CEDAW y en virtud de la Ley Educativa contra la Discriminación, la Política Nacional de Desarrollo Integral de las Mujeres, la Reforma Educativa y en el Curriculum Nacional Base (CNB). Los instrumentos nacionales precisan incluir el enfoque de género e interseccional con más contundencia y operatividad, pero conforman un marco que respalda y permite la educación para la equidad.

18. El sistema educativo guatemalteco requiere ser transformado ideológicamente hacia la pedagogía crítica y feminista y la coeducación con enfoque interseccional. En las fases de prioridad establecidas por Subirats (1998:16) para que un sistema educativo avance hacia la coeducación, el sistema educativo guatemalteco se encuentra entre las fases de acceso y unificación en la mayoría de las dimensiones, siendo necesario avanzar hacia las fases de visibilidad de las mujeres y coeducación.

19. El sistema educativo guatemalteco también precisa ser transformado en su estructura en relación a: a) avanzar hacia la paridad de género en todos los ámbitos del sistema, b) cambiar la feminización la docencia en niveles educativos más bajos (Pre-Primaria y Primaria) y masculinización en los niveles más altos (Básico, Diversificado), c) 
democratizar los espacios de participación y d) generar sistemas de supervisión y mejora continua que motiven al profesorado y eviten el acomodamiento.

20. En el sistema educativo persisten deficiencias que obstaculizan el avance de la educación para la equidad. Estas deficiencias se corresponden con el enfoque del Estado antes descrito: a) insuficiente asignación presupuestaria a la educación que redunda en insuficiente y deficiente infraestructura escolar, escasez de materiales y baja calidad educativa en general; b) deficiencias en la formación inicial y permanente de maestras y maestros, especialmente en género, que invisibilizan la necesidad de educar para la equidad y dejan las acciones en educación para la equidad a merced de la autoformación y compromiso individual; c) deficiencias en la supervisión docente. Todo ello tiene como consecuencia resultados educativos muy bajos en las y los estudiantes del sistema público y limita el potencial de la educación para transformar las inequidades.

21. La mayor concreción de la educación para la equidad se encuentra en el eje transversal de equidad de género, de etnia y social que contiene el CNB y que es aplicable desde el nivel Inicial al Diversificado. El CNB no presenta estrategias para aplicar la transversalidad ni metodologías para aplicar este eje en los contenidos declarativos, procedimentales y actitudinales de cada una de las materias por nivel educativo.

22. El CNB y el eje de equidad de género, de etnia y social son bien valorados por las maestras y maestros, por la flexibilidad y posibilidades de contextualización que presentan. Sin embargo, maestras y maestros identifican debilidades en sus capacidades para aplicar esta herramienta: dificultad para comprender las implicaciones del nuevo paradigma educativo, para planificar por competencias y para aplicar la transversalidad.

23. La falta de aplicabilidad del eje transversal de equidad de género, de etnia y social unida a las carencias en la formación docente, a la complejidad de la transversalidad per se y a la falta de prioridad hacia esta temática por parte del propio sistema educativo, hacen que 
el trabajo con este eje en las aulas sea superficial. Se han identificado acciones puntuales realizadas por algunas maestras y maestros por iniciativa propia, mayoritariamente relacionadas con el trabajo en grupos mixtos.

24. La formación inicial y permanente de maestras y maestros es una de las principales debilidades del sistema educativo y una de las claves para poder mejorarlo. Es imprescindible continuar los esfuerzos para: a) elevar toda la formación docente a nivel universitario; b) mejorar el conocimiento, comprensión y manejo del CNB por parte de maestras y maestros; c) formar a maestras y maestros en estrategias para aplicar la transversalidad; c) incorporar la formación en género, análisis interseccional de la exclusión / privilegio y estrategias de educación para la equidad de género, de etnia y social en todas las carreras que facultan para ejercer la docencia.

25. El trabajo educativo con las familias -en forma de Escuelas de Madres y Padres- se revela como muy necesario para acelerar el cambio cultural hacia la equidad de género, de etnia y social. Incorporar a las familias en el proceso educativo encaja en el paradigma que presenta el $\mathrm{CNB}$, con una concepción amplia de la comunidad educativa. Algunas maestras y maestros ya están desarrollando esta tarea, con mayor o menor sistematicidad y apoyo por parte de la dirección de cada escuela.

26. Ante las debilidades del sistema educativo para hacer realidad la educación para la equidad de género, de etnia y social, el aporte de las ONG en capacitación docente, generación de materiales educativos y educación en equidad desde el ámbito no formal es muy importante y bien valorado por maestras y maestros.

27. La educación para la equidad con enfoque interseccional puede parecer secundaria en un sistema educativo que tiene otras carencias más visibles. Sin embargo, es fundamental rescatar su carácter prioritario porque es el punto medular para construir un sistema educativo que responda a la imperiosa necesidad de justicia social en Guatemala. 
Tras la investigación realizada, nos atrevemos a proponer algunas líneas de acción orientadas a la transformación, con el convencimiento sobre potencial que tiene la investigación cualitativa y dialógica, desde la Metodología Comunicativa Crítica, para aportar a la superación de las exclusiones:

a. Promover el feminismo dialógico como teoría feminista que contribuye a superar las desigualdades para, desde ella, avanzar hacia un proyecto común de las mujeres guatemaltecas para mejorar sus condiciones de vida, que pueda contribuir a la transformación de Guatemala y formar parte de un proyecto feminista global.

b. Promover el diálogo entre actores sociales y políticos sobre la relación que existe entre la transformación del sistema educativo y la transformación del Estado de Guatemala.

c. Realizar incidencia política desde las organizaciones sociales de todo tipo para la aplicación de la Reforma Educativa, poniendo énfasis en la educación para la equidad de género, de etnia y social desde una pedagogía crítica y feminista.

d. Promover el diálogo sobre la educación para la equidad de género, de etnia y social en Guatemala entre organizaciones feministas, organizaciones de mujeres indígenas, otras organizaciones sociales y mujeres y hombres no académicos para generar pensamiento situado y pertinente a la realidad guatemalteca que sirva de base para elaborar propuestas pedagógicas de educación para la equidad de género, de etnia y social.

e. Elevar la formación docente inicial y permanente en todos sus ámbitos y, especialmente, introducir formación en género, equidad de género de etnia y social y aplicación del eje transversal del mismo nombre.

f. Visibilizar la educación para la equidad de género, de etnia y social en la gerencia del sistema educativo, con medidas promovidas desde sus autoridades:

i. Promover la paridad de género en los cuerpos directivos y docentes de las escuelas. 
ii. Promover que las escuelas diseñen proyectos de educación para la equidad, con el apoyo, capacitación, monitoreo y evaluación del Ministerio de Educación. Para ello, pueden facilitarse: a) herramientas sencillas de autodiagnóstico en materia de educación para la equidad de género, de etnia y social; b) guías para el diseño de un proyecto coeducativo con enfoque interseccional para el centro educativo o para un aula; c) materiales de apoyo para trabajar cuentos coeducativos, actividades de intercambio de roles, actividades de educación afectivo-sexual, etc.; c) sugerencias de acciones que pueden realizarse para aplicar la coeducación en espacios de recreo, deportes y otras actividades escolares.

iii. Consolidar el trabajo con Escuelas de Madres y Padres e incorporar el tema de educación de género, de etnia y generando materiales y metodologías pertinentes al contexto de cada escuela.

iv. Fortalecer las comunidades educativas incluyendo a las autoridades comunitarias (alcaldías indígenas, Consejos Comunitarios de Desarrollo, líderes religiosos, etc.), planteando sinergias entre las acciones formativas de la escuela y la intervención comunitaria de las autoridades. 


\section{Referencias bibliográficas}

Aguilar, Consol (2015a). Mirando a nuestro alrededor: cotidianeidad en educación, género y ciudadanía. En Aparicio, Marina e Corella, Iolanda (eds.). Nuevos contextos y prácticas en la educación permanente. Mujeres y hombres en el cotidiano educativo (pp. 39-70). Ediciones del Instituto Paulo Freire.

(2015b). Igualdad, género y diversidad sexual en la Formación Inicial de Maestro/a en la Universidad Jaume I (UJI). Temas de Educación, 21 (1). Disponible en: http://repositori.uji.es/xmlui/bitstream/handle/10234/159004/aguilar_2015_Igu.pdf?sequen $\underline{\text { ce }=1 \& \text { isAllowed }=y}$

(2013). Género y formación crítica del profesorado: una tarea urgente y pendiente. Revista Interuniversitaria de Formación de Profesorado, 27 (3), 177-183. Disponible en:

http://repositori.uji.es/xmlui/bitstream/handle/10234/95110/27430309012.pdf?sequence=1 \&isAllowed $=\mathrm{y}$ (2009) ¿Por qué es importante el género en la Pedagogía Crítica? Revista Interuniversitaria de Formación de Profesorado, 64 (23,1), 121-138. Disponible en: http://www.aufop.com/aufop/uploaded_files/revistas/1234883102.pdf

Aubert, Adriana; Duque, Elena; Fisas, Montserrat y Valls, Rosa (2006). Dialogar y transformar: pedagogía crítica del siglo XXI. Barcelona: Graó.

Aubert, Adriana; Flecha, Ainhoa; García, Carme; Flecha, Ramón y Racionero, Sandra (2010). Aprendizaje dialógico en la sociedad de la información. Barcelona: Hipatia.

Barrios, Walda y Ramazzini, Ana Lucía (2016). La masculinidad hegemónica y su impacto en la vida de las niñas, adolescentes y jóvenes. ¿Cuál es el problema? Cuaderno 1. Guatemala: FLACSO Guatemala. 
Bastos, Santiago (2010). Desigualdad y diferencia: ideas para el estudio del racismo y sus consecuencias en Guatemala. En Brett, Roddy y Casáus, Marta Elena (ed.). El racismo y la discriminación étnica en Guatemala: una aproximación hacia sus tendencias históricas y el debate actual. Disponible en:https://www.lai.su.se/polopoly_fs/1.135170.1368787822!/menu/standard/file/SRoLAS _No6_2010.pdf

Blanco, Pilar (2004). La perspectiva de género, una necesidad en la construcción de la ciudadanía. Algunas actividades en la formación del profesorado. En Vera-Muñoz, María Isabel y Pérez i Pérez, David (coord.). Formación de la ciudadanía: las TICs y los nuevos problemas. Disponible en: https://dialnet.unirioja.es/servlet/articulo?codigo=1454213

Barber, Michael y Mourshed, Mona (2008). Cómo hicieron los sistemas educativos con mejor desempeño del mundo para alcanzar sus objetivos. Buenos Aires: Programa de Promoción de la reforma Educativa en América Latina y el Caribe. Disponible en: http://www.oei.es/pdfs/documento_preal41.pdf

Beck-Gernsheim, Elisabeth; Butler, Judith y Puigvert, Lidia. (2001). Mujeres y transformaciones sociales. Barcelona: El Roure.

Borrayo, Ana Patricia (2005). Mujeres pioneras en la educación superior: primera mitad del siglo XX. Revista Mujeres y Universidad, 1. Guatemala: Instituto Universitario de la Mujer de la Universidad de San Carlos.

Cabnal, Lorena (2010). Acercamiento a la construcción del pensamiento epistémico de las mujeres indígenas feministas comunitarias de Abya Yala. Madrid: ACSUR - Las Segovias. Disponible en: https://entrepueblosvalladolid.files.wordpress.com/2012/10/feminismocomunitario-lorena-cabnal.pdf (s/f). Documento en Construcción para aportar a las reflexiones continentales desde el feminismo comunitario, al paradigma ancestral originario del 
"Sumak Kawsay" - Buen Vivir. Guatemala: Asociación de Mujeres Indígenas de Santa María Xalapán Jalapa -AMISMAXAJ. Disponible en:

https://amismaxaj.files.wordpress.com/2012/09/buen-vivir-desde-el-feminismocomunitario.pdf

Calderón, Percy (2009). Teoría de conflictos de Johan Galtung. Revista de Paz y Conflictos, (2), 60-81. Disponible en: http://www.redalyc.org/pdf/2050/205016389005.pdf

Camisón, Miren (s/f). Feminismo dialógico. Revista Internacional de Creatividad Aplicada Total del grupo IACAT. Santiago de Compostela: IACAT. Disponible en: http://www.iacat.com/revista/recrearte/recrearte07/Seccion1/1.\%20FEMINISMO\%20DIA L\%C3\%93GICO.pdf

Carosio, Alba (2009). Feminismo latinoamericano: imperativo ético para la emancipación. En Girón, Alicia (coord.) Género y globalización (pp. 229 - 252). Buenos Aires: CLACSO. Disponible en:http://biblioteca.clacso.edu.ar/clacso/gt/20100611120315/GyG.pdf

Casaús, Marta Elena (2011). Genocidio: ¿La máxima expresión del racismo en Guatemala? Cuadernos del presente imperfecto, 4. Guatemala: F\&G editores.

(2010). Del Estado racista al Estado plural: un nuevo debate de las

elites intelectuales en Guatemala. En Brett, Roddy y Casáus, Marta Elena (ed.). El racismo y la discriminación étnica en Guatemala: una aproximación hacia sus tendencias históricas y el debate actual. Disponible en:https://www.lai.su.se/polopoly_fs/1.135170.1368787822!/menu/standard/file/SRoLAS _No6_2010.pdf

Castillo, Beverly y Vílchez, Mayela (2013). Del feminismo post colonial al dialógico: implicaciones para construir una cultura de paz. Revista Multiciencias, 13, (3), 267-273. Venezuela: Red de Revistas Científicas de América Latica, el Caribe, España y Portugal. Disponible en: http://www.redalyc.org/articulo.oa?id=90429040006 
CEPAL (2012). Construyendo economía. Compromisos e indicadores de género. Santiago de Chile: CEPAL.

Colás, María Pilar (2006). Género, interculturalidad e identidad. Teoría y práctica. En Rebollo, M.A. (coord.), Género e interculturalidad: educar para la igualdad (pp.27-55). Madrid: La Muralla.

Comisión Paritaria de Reforma Educativa -COPARE- (1998). Diseño de Reforma Educativa. Guatemala: COPARE.

Connell, Raewyn (1995). La organización social de la masculinidad. En Valdés, Teresa y José Olavarría (eds.). Masculinidad/es: poder y crisis, 24, (pp. 31-48). Santiago de Chile: FLACSO. Disponible en:

http://joseolavarria.cl/wp-content/uploads/downloads/2014/08/Masculinidad-poder-ycrisis-Valdes-y-Olavarria.pdf

Confluencia Nuevo B'aqtun (2014). El Raxnaquil K'aslemal "El Buen Vivir" de los Pueblos de Guatemala. Guatemala: Confluencia Nuevo B'aqtun. Disponible en: https://www.alainet.org/images/Buen\%20Vivir\%20Guatemala-pdf.pdf

De la Cruz, Carmen (2007). Género, derechos y desarrollo humano. San Salvador: PNUD. Disponible en:

$\underline{\text { http://estudioscriticosdesarrollo.com/desarrollohumano/delaCruzGeneroDesarrolloHuman }}$ o.pdf

Delors, Jacques (1996). La educación encierra un tesoro. Informe a la UNESCO de la Comisión Internacional de la Educación para el siglo XXI. Ediciones UNESCO. Disponible en http://www.unesco.org/education/pdf/DELORS_S.PDF

Díaz, Guillermo (2011). Estratificación y movilidad social en Guatemala. Nova Scentia, 4 (1), 205 - 236. Disponible en: http://www.scielo.org.mx/pdf/ns/v4n7/v4n7a9.pdf 
Díez, Enrique (2019). Deconstruir y cambiar la masculinidad hegemónica en el sistema educativo. Revista con la A (62). Disponible en: https://conlaa.com/deconstruir-cambiar$\underline{\text { la-masculinidad-hegemonica-en-el-sistema-educativo/ }}$

Dorronsoro, Begoña (s/f).El territorio cuerpo-tierra como espacio-tiempo de resistencias y luchas en las mujeres indígenas y originarias. Coimbra: Universidad de Coimbra. Disponible en: https://ces.uc.pt/myces/UserFiles/encontros/1097_Begona\%20Dorronsoro.pdf

Duek, Celia e Inda, Graciela (2006). La teoría de la estratificación social de Weber: un análisis crítico. Revista Austral de Ciencias Sociales, 11, 5-24. Disponible en: https://dialnet.unirioja.es/servlet/articulo?codigo=2251314

Elboj, Carmen y Flecha, Ainhoa (2002). Mujeres, aprendizaje dialógico y transformación social. Revista de educación Contextos educativos, 5, 159-172. Disponible en: https://publicaciones.unirioja.es/ojs/index.php/contextos/article/view/510

Espinosa, María Ángeles (s.f.). La construcción del género desde el ámbito educativo: una estrategia preventiva. Documentos del Programa Nahiko. País Vasco: EMAKUNDE. Disponible en: http://www.emakunde.euskadi.net/u72-nahiko10/es/

Espinosa, Yuderkys (2009). Etnocentrismo y colonialidad en los feminismos latinoamericanos: complicidades y consolidación de las hegemonías feministas en el espacio transnacional. Revista venezolana de estudios de la mujer, 14 (33), 37 - 54. Disponible en:

http://www.bibliotecafragmentada.org/wp-content/uploads/2014/03/Espinosa-YuderkisETNOCENTRISMO-Y-COLONIALIDAD-EN-LOS-FEMINISMOS-

LATINOAMERICANOS-COMPLICIDADES-Y-CONSOLIDACI\%C3\%93N-DE-LASHEGEMON\%C3\%8DAS-FEMINISTAS-EN-EL-ESPACIO-TRANSNACIONAL.pdf 
Federación Española de Trabajadores de la Enseñanza -FETE- (2103).Diccionario on line de coeducación, educando en igualdad. Disponible en:

http://www.educandoenigualdad.com/portfolio/diccionario-online-de-coeducacion/

FLACSO Guatemala (2015, 16 de marzo). La escuela y la reproducción de las diferencias de género. Revista electrónica Diálogo. Recuperado de: http://www.flacso.edu.gt/dialogo/?p=867

Flecha, Ramón; Vargas, Julio y Dávila, Andrés (2004). Metodología comunicativa crítica en la investigación en Ciencias Sociales: la investigación Workaló. Revista Lan Harremanak, 11, 21-33. Disponible en:

http://faparioja.info/comunidad/comunidadesdeaprendizaje/recurso/metodologiacomunicativa-critica-en-la-investigaci/b117b969-76f2-41b2-81ad-06c9faedb0ce

García, Adela (2009). Género y desarrollo humano. Una relación imprescindible. Material de la campaña Muévete por la igualdad, es de justicia. Madrid: Ayuda en Acción, Entreculturas, Intered.

Galarza, Emelina; Cobo, Rosa y Esquembre, Mar (2016). Medios y violencia simbólica contra las mujeres. Revista Latina de Comunicación Social, (71),818 - 832. doi: $\underline{10.4185 / R L C S-2016-1122}$

Galtung, Johan (2003a).Violencia cultural. Documentos de trabajo Gernika Gogoratuz, 14. Gernika - Lumo: Gernika Gogoratuz.

(2003b). Paz por medios pacíficos. Paz y conflicto, desarrollo y civilización. Bilbao: Bakeaz y Gernika Gogoratuz.

Gandarias, Itziar (2017). ¿Un neologismo de moda?: Repensar la interseccionalidad como herramienta para la articulación política feminista. Revista Investigaciones Feministas, 8 (1), 73-93. Disponible en: https://revistas.ucm.es/index.php/INFE/article/view/54498

Giddens, Anthony (1991). Sociología. Madrid: Alianza Editorial. 
Giménez, Carlos (2003). Pluralismo, multiculturalismo e interculturalidad. Educación y futuro: revista de investigación aplicada y experiencias educativas, 8, 11-20. Disponible en: https://dialnet.unirioja.es/servlet/articulo? codigo=2044239

Gómez, Jesús (2008). El amor en la sociedad del riesgo, una tentativa educativa. Barcelona: El Roure.

(2004). Metodología Comunicativa Crítica. En Bisquerra, R. (coord.) Metodología de la investigación educativa. Madrid. La Muralla.

Gómez, Jesús; Latorre, Antonio; Sánchez, Montse y Flecha, Ramón (2006). Metodología comunicativa crítica. Barcelona. El Roure.

Gómez, Aitor y Díez-Palomar, Javier (2009). Metodología comunicativa crítica: transformaciones y cambios en el S. XXI. Revista Teoría de la Educación. Educación y Cultura en la Sociedad de la Información, 10 (3), 103-118. Disponible en: http://revistas.usal.es/index.php/eks/article/view/3964

Gómez, Aitor y Racionero-Plaza, Sandra (2008). El paradigma comunicativo crítico. Revista UT, diciembre 2008, 117-129. Disponible en: http://pedagogia.fcep.urv.cat/revistaut/revistes/desembre08/UT_desembre08.pdf

González, Ana Isabel (2014). Violencias de género constitutiva de crímenes de lesa humanidad y genocidio: El caso de Guatemala. Aletheia, 5 (9). Disponible en: http://www.memoria.fahce.unlp.edu.ar/art_revistas/pr.6431/pr.6431.pdf

Grupo Guatemalteco de Mujeres-GGM y Red de la No Violencia contra las MujeresREDNOVI (2019). Aportes en el marco de los 25 años del mandato de la Relatora Especial sobre Violencia contra las Mujeres sus causas y consecuencias, de Naciones Unidas. Guatemala: GGM y REDNOVI. Disponible en: https://www.ohchr.org/Documents/Issues/Women/SR/Celebrating25Years/GrupoGuatema ltecodeMujeres.pdf 
Guzmán, Adriana (2015). Feminismo comunitario - Bolivia. Un feminismo útil para la lucha de los pueblos. Revista digital Con la A, (38). Disponible en:

https://conlaa.com/feminismo-comunitario-bolivia-feminismo-util-para-la-lucha-de-lospueblos/

Hernández, Rosalva (2018). Hacia una antropología socialmente comprometida desde una perspectiva dialógica y feminista. En Prácticas de conocimiento(s) entre crisis, entre guerras. México: CLACSO. Disponible en:

http://biblioteca.clacso.edu.ar/clacso/se/20180515110853/Practicas_Otras_2.pdf\#page=83 (2014). Hacia la construcción de un feminismo descolonial. Revista

digital Con la A, (24). Disponible en: https://conlaa.com/wpcontent/uploads/2014/09/24_feminismo_decolonial.pdf

Humanistas Guatemala, Incide Joven y REDLAC (2018). Informe Alternativo sobre el cumplimiento de la Convención Sobre la Eliminación de Todas las Formas de Discriminación Contra la Mujer-CEDAW-. Guatemala: Humanistas Guatemala, Incide Joven y REDLAC. Disponible en:

https://tbinternet.ohchr.org/Treaties/CEDAW/Shared\%20Documents/GTM/INT_CEDAW _NGO_GTM_29095_S.pdf

Iturralde, Carlos (2019). Los paradigmas del desarrollo y su evolución: del enfoque económico al multidisciplinario. Retos, 9 (17). Disponible en: https://retos.ups.edu.ec/index.php/retos/article/view/17.2019.01

Jaramillo, Nathalia (2014). El feminismo decolonial: una breve introducción. Revista digital Con la $\quad$ (24). Disponible en:https://conlaa.com/wpcontent/uploads/2014/09/24_feminismo_decolonial.pdf 
La Barbera, María Caterina (2016).Interseccionalidad, un "concepto viajero": orígenes, desarrollo e implementación en la Unión Europea. Revista Interdisciplina, 4 (8), 105-122. Disponible en: http://www.revistas.unam.mx/index.php/inter/article/view/54971

Lagarde, Marcela (2014). El feminismo en mi vida; hitos, claves y topías. Madrid: Horas y horas.

(2011). Los cautiverios de las mujeres. Madresposas, monjas, putas, presas y locas. Madrid: Horas y horas.

Lillo, Juan (2014). La coeducación es la didáctica de la igualdad de género. Revista digital Con la $\quad$ A,(29). Disponible en: $\quad$ https://conlaa.com/wpcontent/uploads/2014/09/29_educacion_y_genero.pdf

Maceira, Luz María (2006). Más allá de la coeducación: pedagogía feminista. Revista Educar, 36, 27-36. Disponible en:

https://www.academia.edu/3348187/M\%C3\%A1s_all\%C3\%A1_de_la_coeducaci\%C3\%B 3n_pedagog\%C3\%ADa_feminista

Macleod, Morna (2011). Nietas del fuego, creadoras del alba: luchas político-culturales de mujeres mayas. Guatemala: Facultad Latinoamericana de Ciencias Sociales.

Martín - Cala, Martín y Tamayo - Megret, Minervy (2013). Funciones básicas de la familia. Reflexiones para la orientación psicológica educativa. Revista EduSol, 13 (44), 60 - 71. Disponible en: https://www.redalyc.org/pdf/4757/475748683007.pdf

Martínez Martín, Irene (2016). Construcción de una pedagogía feminista para una ciudadanía transformadora y contra-hegemónica. Foro de Educación, 14(20), 129-151. doi: http://dx.doi.org/10.14516/fde.2016.014.020.008

Menéndez, Luis Antonio (2006). La educación en Guatemala 1954-2004, enfoque históricoestadístico. Guatemala: Universidad de San Carlos de Guatemala. 
Ministerio de Educación de Guatemala -MINEDUC- (2016). Plan Estratégico de Educación 2016-2020. Guatemala: MINEDUC. Disponible en:

https://www.mineduc.gob.gt/portal/contenido/menu_lateral/quienes_somos/politicas_educ ativas/pdf/PLAN-EDUCACION.pdf

(2012). Plan de Implementación

Estratégica de Educación 2012-2016. Guatemala: MINEDUC. Disponible en: http://infopublica.mineduc.gob.gt/mineduc/images/7/71/DIPLAN_Plan_de_Implementaci on_Estrategica_de_Educacion_2012-2016.pdf

(2008). Curriculum Nacional Base.

Guatemala: MINEDUC. Disponible en: http://www.mineduc.gob.gt/DIGECUR/

Monzón, Ana Silvia (2008). Mujeres, género y etnia en Guatemala. Aproximaciones conceptuales. San Salvador: XI Congreso Centroamericano de Sociología.

(2001). Rasgos históricos de la exclusión de las mujeres en

Guatemala. Cuadernos de Desarrollo Humano, 6. Guatemala: PNUD.

Moreno, Emilia; Padilla, Teresa; López, Isabel y Martín, Mercedes (2001). Procesos sociales de desarrollo de los roles sexuales: hacia la igualdad hombre-mujer en el sistema educativo. Pedagogía Social, Revista Interuniversitaria, 6-7, 145.

Ojala, Mikko y Sordé, Teresa (2010). Actos comunicativos dialógicos y actos comunicativos de poder en investigación. Revista Signos, 43(2), 377-391. Chile: Red de Revistas Científicas de América Latica, el Caribe, España y Portugal. Disponible en: http://www.redalyc.org/pdf/1570/157020580008.pdf

Paredes, Julieta (2017). Hilando fino desde el feminismo comunitario. En de Santiago, Alejandra, Caballero, Edith y González, Gabriela (ed.), Mujeres intelectuales: feminismos y liberación en América Latina y el Caribe (pp. 111 - 140). Buenos Aires: CLACSO. 
Disponible en: https://sjlatinoamerica.files.wordpress.com/2013/06/paredes-julietahilando-fino-desde-el-feminismo-comunitario.pdf

Pibernat, Marina (2017). ¿Nuevas socializaciones, viejas cuestiones? Adolescencia y género en la era audiovisual. Investigaciones Feministas, 8 (2), 529-544 https://doi.org/10.5209/INFE.54976

PNUD (2016). Más allá del conflicto. Luchas por el bienestar. Informe de desarrollo humano de Guatemala 2015/2016. Guatemala: PNUD. Disponible en: http://desarrollohumano.org.gt/wp-content/uploads/2016/04/INDH_Completo_digital$\underline{1 . p d f}$

(2013). Informe Nacional de Desarrollo. Guatemala: PNUD. Disponible en http://www.undp.org.gt/frmNewsDetailsR.aspx?CODN=3\&idnoticia=118

(2011). Cifras para el desarrollo humano. Colección estadística departamental, fascículos 08 y 09. Guatemala: PNUD. Disponible en: http://desarrollohumano.org.gt (2000). Guatemala: la fuerza incluyente del desarrollo humano. Informe nacional de desarrollo. Guatemala: PNUD. Disponible http://desarrollohumano.org.gt/content/informes-nacionales-1

Puigvert, Lidia (2006a). Relaciones dialógicas en las estructuras familiares del siglo XXI. Revista ARXIUS de Ciencias Sociales (15), 123-141. Disponible en: https://www.uv.es/ sociolog/arxius/arxius15.pdf (2006b). La inclusión de las otras mujeres. Feminismo dialógico en sociedades multiculturales. En Soriano, E. (coord.) La mujer en la perspectiva intercultural (pp.83-107). Madrid: La Muralla. (2001). Las otras mujeres. Barcelona: El Roure.

Ramazzini, Ana Lucía (2013). A desaprender también se aprende. Guatemala: Instituto de la Mujer de la Universidad de San Carlos. 
Rosales, José Miguel (2006). Análisis crítico de la ley de educación Nacional decreto no. 1291 y la realidad Educativa de Guatemala. Tesis de licenciatura no publicada. Universidad San Carlos de Guatemala.

Santos, Boaventura de Sousa (2010). Descolonizar el saber, reinventar el poder. Montevideo: Ediciones Trilce. Disponible en:

http://www.boaventuradesousasantos.pt/media/Desconolizar\%20el\%20saber_TRILCE.pdf

Schongut, Nicolás (2012). La construcción social de la masculinidad: poder, hegemonía y violencia. Revista Psicología, Conocimiento y Sociedad, 2 (2), 27-65. Disponible en: https://revista.psico.edu.uy/index.php/revpsicologia/article/download/119/73

Secretaría Presidencial de la Mujer -SEPREM- (2010). Informe para la Undécima Conferencia sobre Mujer en América Latina. Guatemala: SEPREM. Disponible en: http://www.eclac.cl/mujer/noticias/paginas/6/38906/Guatemala.pdf (2009). Política Nacional de Promoción y

Desarrollo Integral de las Mujeres -PNPDIM- y el Plan de Equidad de Oportunidades 2008-2023 -PEO. Guatemala: SEPREM. Disponible en: http://www.segeplan.gob.gt/downloads/clearinghouse/politicas_publicas/Derechos\%20Hu manos/Politica\%20Promoci\%C3\%B3n\%20\%20y\%20desarrollo\%20Mujeres\%2020082023.pdf

Sémbler, Camilo (2006): Estratificación social y clases sociales. Una revisión analítica de los sectores medios. Santiago de Chile: CEPAL. Disponible en: https://www.cepal.org/es/publicaciones/6130-estratificacion-social-clases-sociales$\underline{\text { revision-analitica-sectores-medios }}$

Simón, María Elena (2010). La igualdad también se aprende. Cuestión de coeducación. Madrid: Narcea. 
Subirats, Marina (2010).La coeducación hoy: objetivos pendientes. Documentos del Programa Nahiko. País Vasco: EMAKUNDE. Disponible en: http://www.emakunde.euskadi.net/u72-nahiko10/es/ (1998). La educación de las mujeres: de la marginalidad a la coeducación; propuestas para una metodología de cambio educativo. Santiago de Chile: Naciones Unidas.

(1994). Conquistar la igualdad: la coeducación hoy. Revista Iberoamericana de Educación (6), 49 - 78. doi: 10.35362/rie601207 (s/f). La coeducación hoy: 10 ideas base. 8 de marzo, igualdad de género

y educación. Disponible en: https://vdocuments.mx/la-coeducacion-hoy-10-ideas$\underline{\text { base.html }}$

Tomé, Amparo (2011). Los valores que sustentan la coeducación: una reflexión sobre el valor de la autonomía. Revista Clave XXI, Reflexiones y experiencias en educación, 5.

Toro, Jose María (2011).La necesidad de la pedagogía coeducativa en la escuela del siglo XXI. Revista Clave XXI, Reflexiones y experiencias en educación, 5.

Torres-Rivas, Edelberto (2008). Introducción a un análisis de estratificación social. Cuadernos del Pensamiento Crítico Latinoamericano, 12. Buenos Aires: CLACSO. Disponible en: http://bibliotecavirtual.clacso.org.ar/ar/libros/secret/cuadernos/torresri/torresri.pdf Vega, Silvia (2017). La sostenibilidad de la vida como eje para Otro Mundo Posible. En Varea, Soledad y Zaragocín, Sofía (comp.) Feminismo y Buen Vivir: utopías decoloniales (pp. 44 - 52). Ecuador: ed. Pydlos. Disponible en: http://dspace.ucuenca.edu.ec/bitstream/123456789/27831/1/feminismo\%20y\%20buen\%20 vivir\%20pdf\%20PARA\%20IMPRESION\%20(1).pdf 
Velásquez, Irma Alicia (2019). La justicia nunca estuvo de nuestro lado. Peritaje cultural sobre conflicto armado y violencia sexual en el caso Sepur Zarco, Guatemala. País Vasco: Hegoa, Universidad del País Vasco.

Villalta, Olga (2017). Los estereotipos de género en los medios de comunicación. En López, Guisela (coord.) Comunicación para la equidad, aportes teórico - metodológicos con enfoque de género e intercultural (pp.21 - 24). Guatemala: Instituto Universitario de la Mujer de la Universidad de San Carlos de Guatemala -IUMUSAC.

Viveros, Mara (2016). La interseccionalidad: una aproximación situada a la dominación. Revista Debate Feminista (52), 1 - 17. Disponible en:

http://www.debatefeminista.cieg.unam.mx/wpcontent/uploads/2016/12/articulos/052_completo.pdf

Yuval-Davis, Nira (2012). Más allá de la dicotomía del reconocimiento y la redistribución. En Zapata, Martha, García, Sabina y Chan Jennifer (ed.) La interseccionalidad en debate, 14-20. Berlín: Proyecto Medidas para la Inclusión Social y Equidad en Instituciones de Educación Superior en América Latina (MISEAL).

Zaragocín, Sofía (2017). Feminismo decolonial y Buen Vivir. En Varea, Soledad y Zaragocín, Sofía (comp.) Feminismo y Buen Vivir: utopías decoloniales (pp. 17- 25). Ecuador: ed. Pydlos. Disponible en:

http://dspace.ucuenca.edu.ec/bitstream/123456789/27831/1/feminismo\%20y\%20buen\%20 vivir\%20pdf\%20PARA\%20IMPRESION\%20(1).pdf

\section{Convenios y declaraciones internacionales, leyes y políticas nacionales}

Acuerdos de Paz firme y duradera en Guatemala, 1996. Disponible en: https://www.sepaz.gob.gt/images/Descargas/Acuerdos-de-Paz.pdf

Convención sobre la eliminación de todas las formas de discriminación contra la mujer CEDAW, 1979. Disponible en: 
https://www.unicef.org/panama/spanish/MujeresCo_web.pdf

Curriculum Nacional Base -CNB- de Guatemala, 2008. Disponible en: http://cnbguatemala.org/wiki/Bienvenidos_al_Curr\%C3\%ADculum_Nacional_Base

Declaración de Lima "Mujeres indígenas hacia la visibilidad e inclusión”, 2013. Disponible en: https://ukhamawa.wordpress.com/2013/11/13/declaracion-de-lima-mujeres-indigenashacia-la-visibilidad-e-inclusion/

Ley Marco de los Acuerdos de Paz, Decreto Gubernativo 52 - 2005.

Ley Nacional Educación Guatemala, Decreto Gubernativo 12-91. Disponible en: http://www.mineduc.gob.gt/estadistica/2010/data/Conozcanos/Ley_Educacion_Nacional.p $\underline{\mathrm{df}}$

Política Nacional de Promoción y Desarrollo Integral de las Mujeres y Plan de Equidad de Oportunidades (2008-2023). Disponible en:

http://www.segeplan.gob.gt/downloads/clearinghouse/politicas_publicas/Derechos\%20Hu manos/Politica\%20Promoci\%C3\%B3n\%20\%20y\%20desarrollo\%20Mujeres\%2020082023.pdf

\section{Webs}

América Latina Genera: http://americalatinagenera.org/

Comisión Económica para América Latina y el Caribe -CEPAL: http://www.cepal.org/

Fe y Alegría: http://www.feyalegria.org.gt/

Grupo Guatemalteco de Mujeres -GGM: http://ggm.org.gt/

IGER: http://www.iger.edu.gt/

Instituto Nacional de Estadística -INE-: http://www.ine.gob.gt/

Ministerio de Educación -MINEDUC-: http://www.mineduc.gob.gt/portal/index.asp

Ministerio de Salud Pública y Asistencia Social -MSPAS-: http://www.mspas.gob.gt/

Naciones Unidas: http://www.un.org/ 
Observatorio de Salud Reproductiva -OSAR: http://www.osarguatemala.org/

PRODESSA: http://www.prodessa.net/

Secretaría Presidencial de la Mujer-SEPREM-: http://www.seprem.gob.gt 


\section{Anexos}

\section{Anexo 1: Protocolos de entrevistas comunicativas y grupos de discusión comunicativos}

\subsection{Protocolo A de entrevistas comunicativas a maestras y maestros}

- ¿Qué importancia tiene la educación para la equidad en Guatemala? ¿Y la equidad de género?

- ¿De qué forma se encuentran unidas la equidad de género, de etnia y social en la realidad del país?

- ¿Qué papel tiene la escuela en el aprendizaje de ser mujeres y hombres en la sociedad?

- ¿Ha podido identificar usted alguna situación de discriminación en la escuela? ¿Cuál y qué tipo de discriminación?

- Las y los maestros, ¿qué expectativas tienen sobre niñas y niños, indígenas y ladinos, de áreas urbanas o rurales?

- ¿Qué protagonismo tiene la educación para la equidad de género, de etnia y social en las aulas?

- ¿Implementa usted de alguna manera este eje? ¿Conoce alguna experiencia concreta de implementación de este eje?

- ¿Qué se necesita para mejorar en la implementación del eje curricular de equidad de género, de etnia y social sea una realidad en las aulas? (profesorado, direcciones de establecimientos, MINEDUC, transversalidad curricular...) 


\subsection{Protocolo $B$ de entrevistas comunicativas a maestras y maestros}

- Comencemos platicando sobre la igualdad entre mujeres y hombres, entre indígenas y ladino, entre ricos y pobres: ¿consideran que existe igualdad en nuestro medio?

- ¿Podríamos poner algunos ejemplos que refuercen su respuesta?

- Desde su experiencia, ¿cuáles son los agentes socializadores principales donde las niñas y niños aprenden lo que serán de adultos?

- ¿Creen que la escuela puede hacer algo para educar en la igualdad?

- Desde su experiencia, ¿qué es lo que puede hacer la escuela para educar en igualdad?

- ¿Qué experiencias tienen ustedes respecto al curriculum oculto?

- ¿Qué experiencias tienen respecto al eje de equidad de género, de etnia y social que tiene el CNB?

- En esta escuela, ¿de alguna forma trabajan la educación para la igualdad en las aulas?

- ¿Con qué apoyos cuentan para esta tarea?

- $\quad$ ¿qué limitantes encuentran para esta tarea?

- ¿Qué acciones específicas se podrían hacer para implementar el eje de equidad de género, de etnia y social? 


\subsection{Protocolo de entrevistas comunicativas a madres de alumnas y alumnos}

- En relación a cómo les están educando para ser iguales entre mujeres y hombres, niñas y niños, ¿en la escuela les enseñan a ser guales? ¿Qué piensa usted de la igualdad entre mujeres y hombres, niños y niños?

- En la vida adulta, ¿hay igualdad entre mujeres y hombres?

- ¿Aquí en la escuela puede percibir usted alguna actividad que se haga para que los niños aprendan a respetarse por igual?

- ¿En qué le gustaría que la escuela le colabore en la formación de sus hijos respecto a la equidad de género? 


\subsection{Protocolo A de grupo de discusión comunicativo con maestras y maestros}

- ¿Qué importancia tiene la educación para la equidad en Guatemala? ¿Y la equidad de género?

- ¿De qué forma se encuentran unidas la equidad de género, de etnia y social en la realidad del país?

- ¿Qué papel tiene la escuela en el aprendizaje de ser mujeres y hombres en la sociedad?

- ¿Ha podido identificar usted alguna situación de discriminación en la escuela? ¿Cuál y qué tipo de discriminación?

- Las y los maestros, ¿qué expectativas tienen sobre niñas y niños, indígenas y ladinos, de áreas urbanas o rurales?

- ¿Qué protagonismo tiene la educación para la equidad de género, de etnia y social en las aulas?

- ¿Implementa usted de alguna manera este eje? ¿Conoce alguna experiencia concreta de implementación de este eje?

- ¿Qué se necesita para mejorar en la implementación del eje curricular de equidad de género, de etnia y social sea una realidad en las aulas? (profesorado, direcciones de establecimientos, MINEDUC, transversalidad curricular...) 


\subsection{Protocolo B de grupos de discusión comunicativo con maestras y maestros}

- Comencemos platicando sobre la igualdad entre mujeres y hombres, entre indígenas y ladino, entre ricos y pobres: ¿consideran que existe igualdad en nuestro medio?

- ¿Podríamos poner algunos ejemplos que refuercen su respuesta?

- Desde su experiencia, ¿cuáles son los agentes socializadores principales donde las niñas y niños aprenden lo que serán de adultos?

- ¿Creen que la escuela puede hacer algo para educar en la igualdad?

- Desde su experiencia, ¿qué es lo que puede hacer la escuela para educar en igualdad?

- ¿Qué experiencias tienen ustedes respecto al curriculum oculto?

- ¿Qué experiencias tienen respecto al eje de equidad de género, de etnia y social que tiene el CNB?

- En esta escuela, ¿de alguna forma trabajan la educación para la igualdad en las aulas?

- ¿Con qué apoyos cuentan para esta tarea?

- $\quad$ ¿qué limitantes encuentran para esta tarea?

- ¿Qué acciones específicas se podrían hacer para implementar el eje de equidad de género, de etnia y social? 


\title{
Anexo 2: Transcripciones de entrevistas comunicativas y grupos de discusión comunicativos
}

\subsection{Transcripción de entrevistas comunicativas}

\section{Entrevista E01/PrPr/M}

\author{
E: Entrevistadora \\ M: Maestra
}

Subrayado: extractos literales tomados en el análisis

E: Bueno pues un poco largo, la primera cosa sería desde su experiencia, ¿qué importancia le ve a esto de la educación para la equidad de género?

M: bueno en el sentido de nuestro país, que ha destacado por practicar mucho el machismo, entonces en las comunidades especialmente en lo que es el área rural se ha creído que la niña $\underline{\text { siempre es dejada a un lado en el proceso educativo, por que los papas argumentan de que las }}$ niñas por ser niñas se van a casar, entonces que no necesitan estudiar, si no aprender a ser amas de casa y para que van a invertir en ellas en educación si ellas no... Osea es perder el tiempo por una parte y por otra parte las herencias no se las dan a las mujeres si no solo a los varones, entonces necesitan ellas estudiar, entonces el hecho de que la mujer en el tema de coeducación desde la educación, va a ser que las nuevas generaciones tengan una forma diferente de ver esta problemática, porque son estereotipos que están bien marcados en nuestra sociedad.

Hoy en día ha cambiado un poco pero todavía se ve bastante en el área rural. Entonces yo ahí veo que es importante poder trabajar ese tema, no solo a nivel pre primario si no a nivel general en educación.

E: Y ya hablando del nivel pre primario, ¿qué ventaja le ve a ese nivel o que potencialidades para trabajar?

M: que el nivel pre primario es donde más se puede potencializar por que es cuando los niños desarrollan su carácter y su personalidad, entonces si nosotros logramos que el niño cambie 
esa percepción que trae de la casa, vamos a hacer bastante, porque ellos va a crecer ya con esa nueva forma de ver la sociedad, entonces va a ser más significativo.

E: en lo que usted puede ver precisamente con esto de la percepción que ellos traen, hay percepciones ya marcadas en esa edad?¿Qué tipo de percepciones?

M: Sí, por ejemplo hay niños que dicen: las mujeres son shucas, es un lenguaje que hablan ellos acá, por decir... las mujeres son sucias verdad y ipor qué dices eso? Porque mi papá dice que las mujeres son shucas, o sea ya vienen ellos con la misma mentalidad de los papas.

E: y las niñas ¿con qué ideas?

M:Las niñas, se menosprecian, en el sentido que ellas son las que tienen que ayudar a la mamá, o sea su lugar está solo en la casa, y se menosprecian por qué no creen tener la capacidad de poder hacer más o de llegar a hacer tal vez lo que un hombre hace. Y también depende del hogar donde vienen, también se va al otro extremo verdad, donde la mamá es muy feminista y la mamá es la autoritaria en el hogar, las hijas también quieren seguir ese patrón, entonces se da por ambos lados.

E: Y en lo que ha podido ver también, ¿cree que influye de alguna forma, tiene influencia las expectativas que los docentes tienen sobre los niños y niñas, o sea si los docentes llevan expectativas distintas, sobre un varón que sobre una mujer o no se da?

M: si se da, por ejemplo hay docentes que su percepción es machista o feminista, entonces aunque ellos no se den cuenta, siempre tratan de hacer actividades donde hacen esa separación verdad, incluso lo podemos ver cuando hacen grupos dentro del aula, a las niñas las dejan de este lado y a los niños de este lado, o sea no mezclan a los niños para un juego o para diferentes actividades si no al contrario, lo que hacen es separar.

E: Y mire a mi me llama la atención también la parte bien interesante que en el curriculum nacional base está unido verdad, el eje es equidad de género, cultural y social verdad, entonces ¿de qué manera ve usted también esa relación entre género, la cultura y el origen social? 
M: definitivamente que está afectando mucho la equidad de género, la forma en que las culturas se han manifestado, podemos decir que es de uso social que el patriarcado que hay donde lo que el hombre dice eso se hace y la mujer no opina o sea se va marcando de esa manera y eso influye en lo que es la equidad de género, verdad, porque no podemos decir que se queda solo en la cultura, es decir, bueno solo los kiches practican esas costumbres, no, si no que se va generalizando, entonces sí que a veces también confunde, porque ellos creen que conservar su cultura es seguir como están y seguirle negando esas oportunidades a los niños y eso no debe ser así. (E: Cuando las culturas precisamente deben de evolucionar) deben evolucionar, pero ellos no quieren evolucionar, quieren estancarse donde están y ellos dicen que quieren salir recuperando, pero si son aspectos positivos que bueno, pero si son aspectos que afectan al desarrollo integral del niño es algo pues incorrecto.

E: Claro, mire y con esta cuestión que hablábamos un poquito de las expectativas, ¿también cree que las expectativas de los maestros varían en función de la cultura y de la procedencia social?

M: si, si por ejemplo hay maestros que son... aquí se les llama ladinos, que no usan traje... y ellos no quieren ir a trabajar a un área indígena, porque dicen "hay no es que los niños son más tontos”, o sea tienen prejuicios, ya digamos discriminan a los niños, hay maestros que todo lo contrario, tienen ganas de trabajar solo con mujeres, o solo con varones, pues como que cada maestro muestra un interés particular hacia cierto grupo y habemos otros que no nos importa donde trabajemos verdad, si no que poder apoyar a todos los niños por igual.

E: y yo creo que ahí caemos un poco a la formación de los docentes verdad, que es la otra parte de todo esto verdad, (M: Correcto) ¿Cómo ve usted la formación que reciben los docentes respecto a estos temas de promoción de la equidad, coeducación y demás?

M:La verdad es que no tienen ninguna formación en cuanto a este tema, por ejemplo las que están estudiando, por ejemplo la carrera que es el profesorado en educación inicial en nivel pre primaria, en el profesorado no tienen ningún curso, es un solo curso en la licenciatura y esta hasta el final, está en el último año.

E: hay gente que solo hace el profesorado y ya no continúa ¿verdad? 
M: Ya no continúan, y en Diversificado que tendría que ser un área donde habría que retomar este tema, porque ellas son las que tienen el primer contacto con los niños, entonces ahí no aparece en el pensum. (E: En el de magisterio de Diversificado, no hay nada?) En el de magisterio, es que este tema pero no como equidad de género, si no como equidad pero dentro de la cultura, o sea que haya igualdad entre niños ladinos, indígenas, mayas, xincas, garífunas y no la igualdad que debe de haber entre niño-niña, hombre y mujer. (E: ¿O sea que solo se le da énfasis a la parte cultural? M: Si a lo cultural)

E: y yo tengo la sensación, pero es una percepción mía que a lo cultural también se le ve como lo folclórico verdad, tal vez ni siquiera profundizando en...

M: Por ejemplo ahorita se está trabajado en las escuelas, dos tipos de actos cívicos y digamos un día está enfocado a trabajar todo lo que son valores-símbolos patrios y por ejemplo un día se trabajan símbolos patrios y otro día en la semana se trabajan valores, pero los valores se trabajan en el acto cívico pero no llegan a reforzase en el aula. Por un lado, por otro lado el promover la cultura se hace también, pero por ejemplo este mes tenemos concurso de bailes folclóricos, entonces esto es para ensayar un baile folclórico y ahí se acabo, entonces por eso es muy superficial también, (E: el aspecto de convivencia, de conocer al otro, verdad, de valorar) no, no se dan el tiempo para eso es más superficial, como le digo lo hacen más como un acto cívico, como una actividad general, pues hagamos un concurso de estampas folclóricas, entonces como que recuperamos un poquito las estampas y recordad verdad, como lo hacían antes, pero hasta ahí nada más.

E:Y hablando de concursos, los concursos de belleza verdad eso es algo que está bien arraigado en los establecimientos?

M: Por ejemplo acá si se hace un concurso de belleza, tiene que presentarse la niña, con traje típico, es uno de los trajes, con traje casual y su traje de gala, traje de fantasía y que a veces no está en el contexto. (E: y cómo ve usted eso, respecto a la coeducación y este tipo de...

M: lo que pasa es que estamos promoviendo que... nuestra sociedad tiene dos polos opuestos verdad, en el sentido de lo que es la cultura, cuando es por ejemplo una elección de una reina indígena, no hay traje casual, solo es el ceremonial, es un traje muy especial que se usa aquí en Guatemala y el traje de diario, verdad, ellos escogen un traje y por lo regular pasan con 
una estampa folklórica y la otra contra parte, que es donde ya le digo que incluso el traje de gala que el casual, y todo eso tratan de ver a las niñas como princesas, como que una mujer debe ser así ,muy perfecta, muy arreglada, muy femenina, entonces se van al otro extremo.

Entonces incluso más se ve en el Básico que a veces hacen también elección del príncipe, pero estamos tan acostumbrados verdad, a que solo la reina de la escuela, verdad y eso hace que sigamos con esa división de roles que yo no me puedo meter a lo que tú haces como hombre y tu como hombre no te puedes meter a lo que yo hago, cuando el algo erróneo, verdad? Todos tenemos las mismas capacidades y las mismas habilidades y se contribuye mucho a que la mujer se vea solo como objeto sexual, entonces si usted ve la prensa verdad, que saca ahí a las señoritas en bikini verdad, la publicidad tiene un bombardeo tal que la mujer esta solo como un objeto publicitario.

Y las niñas que vienen desde pequeñitas que quieren ser reinas de belleza, que cuando yo sea grande quiero ser modelo verdad y me voy por esa línea, entonces sí afecta en la cultura, en ese sentido.

E:y otra de las cosas que me ha sorprendido un poquito en algunas platicas así con docentes, es que entre los espacios de socialización donde los niños y las niñas van formándose en su identidad de género, suelen colocar a la escuela, no en primer lugar verdad si no bastante atrás verdad?

M: $\mathrm{Si}$, lo que pasa es que nosotros los guatemaltecos tenemos malas costumbres, solemos echarle la culpa a alguien más y nosotros no asumimos la responsabilidad de lo que hacemos, entonces si están en pre primaria, decimos que la mamá tuvo la culpa, si están en primero primaria decimos que la de párvulos tuvo la culpa y esto se vuelve un circulo vicioso, entonces nadie toma la responsabilidad que tiene, o sea yo atiendo a estos niños en esta etapa y en esta etapa yo soy la responsable, entonces aporto lo que tengo que aportar, pero no le echo la culpa al que esta atrás, al contrario oriento a los involucrados y eso así ha sido...

E: Muchas personas también señalaban y yo me quedaba con esa duda, que la comunidad está en primer lugar como espacio de socialización, las estructuras comunitarias donde se hablaba por ejemplo de asociaciones, iglesias etc. Verdad yo pensaba ahí, que tanto peso realmente tienen esas estructuras comunitarias? 
M: Si por que por ejemplo, si nos vamos a las religiones, hay religiones que nos marcan mucho, que la niña solo tiene que usar vestido, que no se tienen que pintar, o sea va marcando ya ciertos estereotipos de acuerdo a la religión, entonces si tu eres cristiana tienes que tener este perfil, si tu eres católica tienes este perfil, entonces si marca bastante y yo lo veo por ejemplo cuando vamos a tener por ejemplo un desfile y llegan las señoras y dicen mi hijo o mi hija no desfila, porque mi religión no me lo permite, entonces ya desde ahí estamos limitando las capacidades de los niños, porque de repente el niño tiene capacidades no se destrezas para bailar, para cantar, pero por el hecho de que los papas quieren seguir digamos un patrón muy místico en lo religioso, los niños se limitan en desarrollar las capacidades, entonces en ese sentido si afecta bastante la religión.

La comunidad... es que en Guatemala tenemos tanta variedad de culturas, porque todos los lugares son diferentes, si va aquí a Almolonga, las niñas se casan de trece años, 14 años, si llegan a los 18 años ya no se pueden casar, porque quedan para los divorciados y para los viudos verdad. (E. Ya se les paso el arroz, decimos haya) Ya aquí en Quetzaltenango el nivel de educación es un poco más alto y encontramos a veces extremos de mujeres que ya ni se quieren casar. Así como encontramos lugares donde hay un atraso bien marcado, hay otras con mentes muy abiertas y así es en todo, no vamos a encontrar una comunidad que tenga las mismas costumbres, verdad, como le digo en Almo longa es así... A la par esta Zunil, en Zunil a las jovencitas se las roban, si no llega a dormir es porque mañana hay casamiento y la municipalidad tiene una habitación, donde la señorita duerme ahí, esa noche y ya el siguiente día ya todos saben que va a haber boda, por que la niña no llego a dormir a su casa... y son de los lugares que están al otro lado. Pero sí es muy diferente.

E. Si y que están también en un momento de cambio social, creo yo verdad bastante marcado, porque al final en todos los contextos, incluso estos más conservadores también se están produciendo cambios ¿verdad?

M: si, si yo cuando compartí el curso de coeducación les decía yo a las señoritas: que nos estamos yendo a los extremos, en un principio queríamos conservar los valores a como diera lugar y el que se salía de este patrón era el más pecador, que era el merecedor de que lo juzgaran, de todo lo peor y ahorita nos estamos yendo al otro extremo, pero no guardamos el equilibrio y ese es el problema que tenemos como sociedad verdad, le digo yo, los valores se han perdido tanto que le digo yo, a mi me da temor hasta que desaparezca el matrimonio les 
digo yo, porque ya los hombres ya que son muy preparados entonces ya no se quieren casar, las mujeres igual, dicen, no yo quiero ser profesionista y voy dejando el matrimonio en un segundo plano, o juntémonos y si nos va bien pues nos casamos y si no pues hay nada más quedamos, o sea y el matrimonio es la base pues de la sociedad y comenzamos a ver que eso también está en cambio.

E: Y bueno yo creo que la coeducación puede ser un punto para ese equilibrio que usted dice. Ahí está el punto...

M: si, mire a mi me encanta mucho trabajar con ese tema, por eso, y generamos bastante polémica, incluso habían alumnas que decían no, es mejor que las niñas estudien solitas y los varones por su lado, porque hay escuelas de niñas y escuelas de varones y entonces decía yo no, por qué no mezclarlos o sea porque no convivir y yo les compartía mi experiencia que yo en mi infancia, en toda la primaria yo me juntaba solo con varones y les digo yo casi no me pinto, o sea usar maquillaje, mis deportes eran más rudos por las juntas que yo tenía, pero si hubiera tal vez estudiado solo con mujeres hubiera sido más delicadita, como que tal vez no estuviera donde estoy, porque uno como que se encierra más... entonces pero generar todo este tipo de polémica para que ellas traten de cambiar la forma en que enseñan, es importante.

E: Y en su criterio qué elementos debería tener un proyecto coeducativo, ya sea de aula o de centro de manera ideal, verdad, o sea ¿con qué elementos tenemos que trabajar para decir que estamos implementando coeducación?

M: Por ejemplo que se vea, primero las actividades que la maestra desarrolla en cuanto a dar el tema, pero que también haya evidencia en el aula y que hayan cambios, verdad, porque de nada nos sirve trabajar algo solo porque tengo que hacerlo si yo no estoy comprometida, entonces primero la docente tiene que estar comprometida, verdad, dominar el tema.

Yo de vez en cuando capacito a docentes y yo les digo que si nosotros vamos a trabajar algo que nosotros no conocemos, no vamos a tener ningún éxito porque no dominamos el tema, pero si nosotros dominamos el tema, nos apasiona el tema nos comprometemos más y o sea los niños perciben esa seguridad que yo tengo, ese entusiasmo que yo tengo de hablar sobre un tema se lo voy a transmitir a mis alumnos y eso es lo que va a producir los cambios y yo lo he visto... los niños se sorprenden cuando yo les he contado cuentos coeducativos y les digo 
¡a ver chicos, sentémonos a platicar, vamos a contar un cuento! y el cuento se llama... y cuando les doy el titulo se me quedan viendo... así no es... sii, porque les conté el de tarzana, no sé si lo ha escuchado (E: no) es buenísimo, y les digo les voy a contar el cuento de Tarzana y todos noooo, es tarzán. En ese cuento tal vez, pero en el mío es tarzana les digo yo, entonces como vamos a platicar el cuento empiezo a contar todo y al terminar les digo yo, bueno les digo yo platiquemos cosas sobre el cuento les digo yo... las mujeres pueden reinar? Y entonces ellos entran en conflicto entre que sí o no porque si los reyes y tarazan pues que un hombre verdad.

Entonces se dan cuenta que sí, que las mujeres tienen la misma capacidad de pode hacer lo que un hombre puede y vamos generando polémica con ellos desde chiquitos. Y también con otro cuento que me paso así porque les hice preguntas antes del cuento y les hice después del cuento, me dijeron que las mujeres no podían ser ingenieras y que no podían ser chofer, solo los hombres y empezamos a ver las profesiones y no, que eran solo para hombres y otras que eran solo para mujeres, entonces les conté el cuento y después del cuento... ahora que piensan? Que si... hay mujeres!, entonces ellos van cambiando la percepción que ellos tienen, del ambiente que les rodea y eso favorece bastante la coeducación-

E: Exacto, y digamos ha encontrado dificultades para implementar esto en la escuela donde trabaja o hay apoyo o no?

M: lo que pasa es que en mi caso personal, es el primer año que yo estoy ahorita en esa escuela y la directora no se involucra en el trabajo del aula, entonces yo puedo planificar las actividades que yo desee, lo que yo hago es que como nosotros trabajamos con un programa que se llama leamos juntos, que incluso en la escuela en donde estoy nadie más lo aplica solo yo (E: Pero ese es un programa del ministerio de educación?) es un programa del ministerio de Educación, pero el problema que tienen las maestras es que si no les piden nada, no lo hacen, entonces por ejemplo yo hice mi planificación el año pasado y me funciono muy bien, entonces este año decidí trabajarlo igual, entonces el día lunes en ese programa tenemos que trabajar media hora, todos los días de lectura, pero es demasiado tiempo media hora porque ellos son muy pequeños y sus periodos de atención son como de 15 minutos, entonces yo no puedo trabajar lectura media hora, todos los días, entonces lo que opte fue trabajarlo en el horario que trabajo rincones de aprendizaje, entonces los cuentos duran de 5 a 10 minutos comentamos sobre el librito y pasamos a otra actividad, pero todos los días. 
Entonces lo que hago es que los lunes trabajamos cuentos clásicos o cualquier cuento, el día martes trabajamos cuentos con valores, el miércoles trabajo los coeducativos y ya tengo bastantes cuentos coeducativos, los jueves trabajamos con alguna técnica para contar cuentos, les cuento cuentos con guantes o con títeres, diferentes técnicas para contar cuentos y los viernes lo dejo libre, que ellos me pidan el cuento que ellos quieren, porque a veces a ellos les gusto en particular un cuento más que otro y ellos quieren que lo repitamos, entonces el viernes es libre ellos escogen que cuento quieren y trabajo los cuentos cada día, toda la semana, pero los coeducativos los empecé a trabajar hasta este año por que decidí separar un día para cada contenido...

E: O sea que sí encuentra libertad digamos, en ese sentido...

M: es que en ese sentido, digamos aquí en Guatemala no nos limita, pero muchas veces $\underline{\text { tampoco no nos enseñan, entonces si uno tiene el habito de investigar y de formarse y uno lo }}$ puede aplicar, o sea yo lo encuentro... y por ejemplo y por más a mi llegar la directora y me dice mire no lo trabaje, pues tenemos libertad de cátedra y si yo estoy convencida que eso es lo mejor para mis alumnos, tengo el derecho de trabajarlo y nadie me puede decir que no, el problema que tenemos es que a veces tenemos mucha desidia, mucho acomodamiento, entonces eso influye también en que ellos hagan las cosas. Porque la apertura, yo siento que apertura siempre va a haber, si la maestra tiene la disposición de hacerlo. Ahí está el detalle.

E: Otra cosa, de encontrar ya como un claustro digamos, varios compañeros que quisieran estar en el mismo tema, también saber ¿verdad?

M: Yo generé algo así, pero no en este tema, si no en material didáctico y entonces fue aquí en la universidad, las señoritas comenzaron a ver el material que yo hacía y... ¡hala! Que ese material esta bonito y les decía no se quiere juntar con nosotras una tarde para hacer material? con gusto juntémonos... nos estuvimos juntando casi alrededor de un año todos los miércoles, y cada miércoles hacíamos diferente técnica y yo les enseñé como cuatro o cinco, bueno les dije yo ya no les enseño más. Ahora ustedes generen, entonces ellas poco a poco empezaron. Bueno a mí se me ocurre que hagamos tal y tal cosa, Pues hagámoslo! si funciona o no funciona, lo vamos a probar con los niños y si no funciona pues lo mejoramos y vemos qué hacemos... y desarrollamos bastantes técnicas en material didáctico y ahora aquí en la universidad estuvimos trabajando, dentro del curso trabajamos... les di cuentos, hicimos 
dramatizaciones, les di cuentos coeducativos incluso hicimos un trifoliar verdad, para poder educar a los padres de familia para que conocieran un poquito sobre el tema, verdad? Cómo tratar el tema de la coeducación desde el hogar, hicimos una planificación para poder trabajar con padres de familia, yo les decía a ellas que cada unidad que ustedes entreguen las tarjetas den una pequeña plática de lo que es la coeducación, de la importancia de promover, de erradicar el sexismo, verdad, tratamos de educar en la igualdad, entonces si trabaje bastante con ellas digamos aspectos prácticos para poder plasmar en el aula, incluso hicimos memorias, para juegos con los niños, hicimos de oficios, donde estaba el bombero, la bombera, el doctor, la doctora, entonces así para niños desde tres años para adelante. Estuvo muy bonito el curso, espero que algo haya logrado.

E: esta cuestión entonces usted ve que si es factible digamos y así como para animar a otros docentes, ¿por dónde aconsejaría comenzar?

M: lo que usted hablaba de las experiencias, por que cuando ellas... mire... cuando nosotras les damos algo por escrito y no les explicamos, ellas no entienden, no se motivan por aplicarlo, pero si ellas ven... lo primero que una maestra del sector público dice aquí en nuestro país, es; "ustedes solo nos vienen a dar órdenes, por que trabajan en un escritorio, pero no están en el contexto" es lo primero que ellas dicen, pero si llega alguien y les dice, miren esto funciona por esto, esto y esto y vean, les mostramos videos que si hay cambios y todo y si hay también un convenio con el ministerio de educación, porque muchas veces hacen las cosas solo si las presionan, si no las presionan no lo hacen... o sea lo hacen de dos formas: si están motivadas o si hay una presión superior: si el jefe me dijo que lo tengo que hacer, pues ni modo verdad, lo hago, pero si no, no. Entonces son dos situaciones verdad. Uno, que ellas de verdad se enamoren del tema, pero para eso usted tiene que buscar un buen facilitador, o sea buscar las estrategias adecuadas para el nivel y facilitarles todas las herramientas y los escenarios para que ellas puedan trabajar.

E: Entonces, respecto al también tan llevado y tan traído verdad educación sexual y toda esta parte más de educación afectiva y toda eso, ¿usted lo ve en relación con esto de la coeducación? o digamos...

M: Tiene cierta relación, porque por ejemplo en cuanto es el valor degenerativo que se le da a la mujer, como que se le ve solo como un objeto sexual, entonces cambiar ese concepto, 
entonces ahí está relacionado un poco lo que es la sexualidad, aunque ese tema si se trabaja un poco más, el tema de la sexualidad porque está en el curriculum nacional base, antes cuando no estaba como que daba un poco más de miedo de trabajarlo, porque de repente era una comunidad en donde... por ejemplo yo llegaba y hablaba de eso en Zunil, me linchaban porque ahí los niños hasta la fecha, no se pueden ni agarrar la mano, o sea platican de lejitos y si la comunidad ve que están muy juntos, llegan y los amenazan, entonces depende del contexto, pero ahora que ya están en este nivel pues ya con imágenes, dibujos ya hasta los niños hacen otras preguntas, entonces ya hay como que más apertura, pero eso sí se ha trabajado un poquito más.

E: Porque es que a mí me da mucha pena verdad, cuando hay posturas muy radicales sí, que ven la educación sexual como que quisiéramos estar enseñándoles saber qué cosas a los niños, pero tal vez yo creo que hay que verlo desde una manera mucho más amplia, desde la parte afectiva también, o sea cómo nos vamos construyendo afectivamente, porque creo que ahí hay una de las partes muy fuertes, luego de como las mujeres también a veces solo viven en función de que me vaya a querer un hombre, de que un hombre me valore.

M: Depende, hay un cuento muy bonito, que es el de la cenicienta que comía codornices, creo que es...es bien buenísimo por que la cenicienta se casa con el príncipe y ella cree que al casarse con el príncipe se le van a acabar todos sus problemas pero no, entonces el príncipe, que si al príncipe resulta que no le gustaba la comida que hacia la cenicienta, entonces ella comienza a hartarse tanto del príncipe, que termina dejándolo y para ser ella misma, por que el príncipe no la aceptaba como ella era, entonces vamos a que nuestra sociedad tiene ya un patrón establecido: como usted es ama de casa y como ama de casa tiene que hacer esto, esto y esto o se van al otro extremo verdad si no es ama de casa verdad, ven a la mujer como un objeto sexual, entonces se dan otras situaciones y como mujeres muchas veces decimos, bueno si yo soy objeto sexual, entonces tomo como que un papel desviado o verdaderamente la esencia de ser mujer y si dejo que el esposo me denigre y que sea la sirvienta, la chofer la... verdad, porque también que oficio tiene tu mama dicen... mi mamá es chofer porque me va a dejar al colegio, mi mamá es secretaria por que trabaja en una oficina, mi mamá es cocinera porque me cocina, o sea es todo, entonces, pero sin que la mujer pierda su esencia, su personalidad verdad, y no que lo haga solo por complacer a su pareja, si no que lo haga con amor y que las tareas sean compartidas. 
E: Exactamente y lo mismo en el caso de los hombres, verdad, que a veces emocionalmente se forman de una manera también muy... de necesitar que lo adoren verdad a que lo sirvan... y de que mi mamá me tiene así verdad? Entonces como mi mamá me tiene así tan.... (M: y de repente me caso, y ipam! entonces viene el cuentazo) es que es tan triste, porque digo esa formación emocional... o sea decir como desarrollamos nuestros valores (M: porque estamos formándolos con machismo) es decir cómo afecta luego...

M: Entonces como la mujer ya no lo trata, como lo trataba la mujer entonces no lo quiere, entonces mi esposa no me quiere por que no tiene todo en la casa brillando, porque no me da a mí el pedazo más grande de comida por qué no... Entonces... (E: entonces ahí mejor a buscarme a otra y entonces... se vienen otros problemas, esa es la realidad)

E: A bueno de esto yo creo ya hemos hablado un poquito no... o sea que veíamos que sí, que los que salen, o se forman como docentes, bueno y ya en el nivel universitario, ya es otra cosa, pero que salen con bastante deficiencia entonces. O sea respecto a estos temas...

M: si por que este tema no es algo que este en la curricula, o sea no se trabaja, la verdad es que no se trabaja y mucho menos se va a llevar a la práctica si no se conoce, cuando yo comencé a hablar con ellas el primer día de clases, recuerdo que les digo yo que es coeducación? Y no...o sea el concepto no lo habían escuchado o sea el tema no.. Ya cuando empezamos a platicar y a ver el tema por concepto, que era un estereotipo, entonces ya como que se fueron abriendo más al tema y con ellas nos dimos cuenta que hay mucho que hacer, en cuanto al tema en educación y yo les dije el año pasado, miren este tema en nuestro país, yo busque información y no les digo yo..encontré en España, encontré en diferentes lugares pero de aquí no, y allá es un tema que se está trabajando no en estos años, si no que ya tiene años de venirse trabajando, y le digo yo no sé porque acá con nosotros nunca nos han formado para que trabajemos así, incluso yo soy licenciada en educación inicial de PrePrimaria, pero el curso a mi no me lo dieron así, o sea a nosotros no nos dijeron coeducación, tal concepto... el concepto de machismo, de sexismo, o sea fue todo bien teórico, entonces pero nunca nos dijeron, miren esto hay que aplicarlo en el aula, hay que trabajarlo con los niños chiquitos, para nada (E: de hecho esta el eje de equidad en el curriculum... ) pero esos ejes nadie los trabaja, no saben trabajarlos! De verdad! Les digo yo cómo podemos aplicar un eje transversal? Se quedan en la luna, entonces la verdad desafortunadamente la formación que hemos tenido como docentes ha sido muy mala... 
E: Y en ese sentido por ejemplo, ¿cómo se puede aplicar este eje de equidad de género, cultural y social como se puede aplicar así transversalmente?

M: Transversal, de forma transversal es que en los contenidos que yo estoy dando, yo siempre considere todos estos aspectos, hablar por ejemplo de que yo procure ir erradicando el sexismo, que mis niños vayan aprendiendo a tener un equilibrio emocional verdad, no ser ni machistas ni... que solo las niñas bajen, que solo los niños... si no que irlo trabajando de una forma integrada con mis contenidos a eso se refiere, digamos lo que es un eje transversal, el problema es que las docentes medio trabajan los contenidos, mucho menos ni siquiera $\underline{\text { saben que esos ejes tienen que trabajarlos de una forma paralela a sus contenidos, es que ese }}$ es el detalle, que no tienen todavía bien claro como trabajar el CNB.

E:Claro y por ejemplo incluso respecto a esto de los contenidos, una cuestión que está muy... o sea que se le ha dado muchas vueltas en España sobre lo de la coeducación es el tema de cómo visibilizar también el rol social de las mujeres dentro de los contenidos puramente declarativos Hay madre mía! Es decir por ejemplo en ciencias sociales, claro! Los de prepa son muy chiquitos verdad, pero a veces encontramos que solamente se habla de escritores, de inventores de personajes históricos que son hombres y está todo el papel de las mujeres... (M: es que tengo entendido que en España, solo se manejan los contenidos declarativos y los procedimentales, no se trabajan los actitudinales, están inmersos en los otros dos.) Supuestamente son transversales, se supone...

M: Aquí no, pero no los aplican, por eso le digo... en Pre-Primaria las maestras no quieren hacer planificación (E: ¿Y entonces?)...planificación diaria y la diaria no se puede meter tanto el eje si usted, digamos no toma de una forma general o en cuenta, todo lo que usted va a trabajar como eje trasversal.

E: y si no hacen planificación, ¿cómo le hacen?

M: Solo hacen una agenda diaria, donde escriben lo que van a hacer en el día, digamos que integran contenidos de un área que en este caso es medio social y natural, pero ahí no están tomando en cuenta si es un contenido procedimental, si es un declarativo o si es un actitudinal, si no que lo toman como que ah! Esto es el contenido... y pero usted llega y les 
pregunta, mire el contenido que usted dio es procedimental o es actitudinal, o es...? y no saben... entonces regresamos a la formación del docente.

Y yo les digo... me pidieron ahorita que coordináramos unas capacitaciones en Zunil, con respecto a la planificación y una de las estudiantes de aquí me dice: planificación anual... esta dice... y me levanta el CNB!... y le dije yo: esa es una maya curricular, si hay contenidos inmersos, es un esqueleto pero a ese esqueleto hay que darle forma con actividades le digo yo, con recursos, con evaluación, con que usted se siente y se detenga a pensar qué metodología va a aplicar, qué estrategias usted va a utilizar, que usted analice el contexto donde lo va a ejecutar, o sea una planificación va mucho más allá... entonces o sea ese es el concepto que tienen...

E: O sea que sí falta mucho, y hablando ya aquí de los docentes, o sea ¿qué implementaría usted o qué ideas se le... en la formación de docentes como para que tengan más presencia y que salgan más capacitados?

M: Primero habría que mejor ese curso de planificación y desarrollo curricular por que lo han recibido con física y mate, entonces a ellos les enseñan más a como planificar a nivel medio, entonces ahí tendríamos que comenzar por que si el maestro genera esa capacidad de poder organizar una buena planificación, definitivamente su trabajo nadie lo va a cambiar, o sea si tiene claro todo lo que tiene que hacer como profesional, el va a hacer un trabajo diferente pero si no conoce... y aquí no le estoy echando tanto la culpa a las alumnas, si no que nosotros a veces como docentes no orientamos de la forma correcta, como le digo si yo me hubiera quedado solo con esa orientación que me dio a mí el licenciado que me dio coeducación, hasta el momento yo no lo trabajara, pero yo lo comencé a trabajar en la escuela por la universidad o sea por el curso que yo ya di aquí, entonces me di cuenta que sí está bonito y a motivar a las patojas y hagamos algo diferente. Las hice hacer una planificación para poder trabajar el tema todo el año con los padres de familia, entonces actividades en el aula y con los papas y entonces les digo yo, y si llegan ustedes a poner en práctica, échenlo a andar o sea nadie les puede decir miren aquí no aplica nada, porque una ventaja que si $\underline{\text { tenemos en el magisterio, es la libertad de cátedra, entonces ahí usted tiene libertad para }}$ mejorar les digo yo, no para empeorar....

(E: esta la libertad de cátedra y en este caso está el eje del CNB, o sea esta uno respaldado) 
M: por eso le digo... fíjese que fui a dar un taller de planificación y les puse una frase célebre que habla un poquito sobre, que el que tiene el conocimiento tiene el poder y decían; mire y eso que tiene que ver eso con la planificación? Que si usted conoce lo que está haciendo nadie le va a poder mentir le digo, ya le supervise quien le supervise usted está fundamentada teóricamente, científicamente, entonces y aparte usted está haciendo un buen trabajo, quién quiere buenos trabajadores? Entonces le digo si usted tiene el conocimiento tiene el poder, de poder hacer lo mejor para sus alumnos y eso es lo que yo les dije pues, que si no estamos seguras de poder trabajar un tema, el ambiente lo percibe, los alumnos lo perciben y nosotros inseguras, y ellos quedan peor, quedan confundidos, entonces no...

E: y mire ya igual para terminar un poquito, cuáles son como las peores prácticas, que usted se ha podido dar cuenta en el sentido de que generan más desigualdad, o sea que en vez de mejorar en coeducación generamos más...

M: es decir, nosotros fortaleciendo esa desigualdad, por ejemplo hay todavía, eh, bueno yo lo he visto mucho por ejemplo en primero primaria, dicen los maestros: aquí los que saben y aquí los que no saben...entonces estamos marcando, o sea ni el docente está practicando la equidad, si no está ya separando... a nuestros alumnos y que el docente no tenga vocación, no va a poder trabajar, porque cuando un docente no tiene vocación va por amor al sueldo, no por amor a los niños, entonces a él no le interesa si los niños están aprendiendo, si no están aprendiendo. En Pre-Primaria se tiene la idea de que como los niños ganan por la edad, entonces ahh! no importa si aprenden o no aprenden, es la seño de primero la que tiene que enseñar a leer, la que tiene que enseñar a escribir y yo aquí solo le voy a desarrollar una habilidades con juegos, con cantitos, o se van por las hojas de trabajo, o sea, y la verdad es que a veces les digo yo y se ríen, están violando el derecho del niño les digo yo, porque no les estamos dando una educación o sea de calidad y que llene ni los estándares educativos.

E: A mí me da una pena porque es una edad tan bonita, en la que ellos necesitan, quieren aprender la estimulación, tienen tantas cosas para desarrollar y si nosotros no les estimulamos, no les enseñamos como... o sea se pierde una oportunidad... (M: están desaprovechando ese recurso) ahí yo me quede sorprendida!, estaba leyendo un artículo, pero ya tiene meses sobre no me acuerdo que país es si es Noruega o Finlandia, pero uno de estos países de estos europeos (M: Finlandia que creo tiene mejor educación en el mundo) que tiene los altísimos niveles de desarrollo de educación, resulta que ellos a la etapa que más le 
invierten es a la Pre-Primaria, en recursos, en profesorado, en materiales, en tiempo... pero hay algo increíble! (M: Es que es la base!)Increíble! Y además las metodologías que utilizan, como eso... con mucho juego todo es muy libre, o sea no es que sea una didáctica muy opresora (M: ellos aprenden jugando) pero ni modo le dedican una cantidad de recurso y de verdad de tiempo de calidad...

M: mis compañeros de trabajo cuando ven lo que yo hago, me dicen hala! Y vaya que usted tiene tiempo, y vaya que usted invierte recursos, si no nos mandan nada, y yo siempre les digo aquí a las señoritas les digo yo, por qué cuando están en un colegio que les paga Q.700 al mes, y el director les dice que se pongan de cabeza, se ponen de cabeza, si se tiene que $\underline{\text { llevar tantos carteles los llevan y no les importa gastar, no les importa... y por qué cuando }}$ entran al sector publico ya no hacen nada... y ganan el triple, pero así estamos...

E: muchísimas gracias, le agradezco un montón, que yo creo que sí es un campo donde hay un montón por desarrollar verdad, yo como le decía el otro día yo no soy docente soy trabajadora social, pero me gusta mucho el tema (M: el tema genera cambios sociales) y hay como que un campo ahí, que es como un espacio vacío, donde en Guatemala ahorita hay un montón por hacer ... (M: y es por el tipo de culturas que hay, es muy marcada esa discriminación que hay, aquí todos dicen que son discriminados. Que si somos ladinos, que $\underline{\text { nos discriminan cuando vienen becas que son solo para indígenas, que si somos indígenas }}$ que nos discriminan por qué no nos dejaron entrar a determinado lugar, o sea todos nos quejamos de todo. No vivimos contentos con nada.

E; si como usted dice, a veces pasando la chibola a otros verdad (M; Si, son los círculos viciosos verdad, bueno yo no tengo la culpa verdad de allá viene, entonces allá tienen la culpa, entonces se vuelven los círculos viciosos, cuando nosotros deberíamos cortar esos círculos viciosos y hacer lo que nosotros podamos hacer en el momento que nos toca hacerlo, verdad, por eso es coeducación.

Pues muchísimas gracias entonces, (M: Espero que le sirva mi experiencia) mucho... porque no es fácil encontrar personas motivadas y entusiasmadas con el tema verdad? 


\section{Entrevista E02/PrPr/H}

\section{E: Entrevistadora}

M: Maestro

Subrayado: extractos literales tomados en el análisis

E. Pues bienvenido docente de preprimaria en una aldea de Santa María Chiquimula, Totonicapán. En primer lugar cómo mira usted la situación de la equidad de género, etnia y social ahí en la Aldea Pacham en Santa María Chiquimula.

M. Bueno, antes que todo, una buena mañana. Pues la equidad de género la que yo veo pues, le puedo decir que es poca porque yo el tiempo que llevo laborando ya es apenas un tiempo no es bastante pero, si la he visto que allá casi tienen la misma equidad de género tanto niños como niñas, o sea, allá valen lo mismo lo que pasa es que hay circunstancias allá que los padres de familia a veces no es la prioridad los hijos, o sea, que a los padres a veces poco les interesa los hijos, o sea, entre niños ellos comparten no ven la identidad que si ella es mujer o el es hombre, ellos niños comparten ellos no ven la raza ni color ni de dónde vienen pero, así como le repito que donde se ve la dificultad es en el padre porque el padre a veces muchas veces tiene problemas con los padres de otros niños entonces el papa le inculca eso al niño. Y el niño hace vea a ese otro niño como su enemigo porque el papá es enemigo del papá entonces, el niño también es enemigo del niño entonces, ahí es donde se ve que sí hay un poco de dificultad de equidad de género pero, si no hubiera ese problema estaríamos hablando de que la equidad de género sería lo máximo porque no habría discriminación ninguna.

E. ¿Qué edades tienen los niños de su aula?

M. Bueno, las edades que tienen los niños que están con migo es de cinco y seis años.

E. Usted implementa de alguna manera específica con estos niños chiquitos actividades o formas de planificar o cosas que usted hace en el aula directamente para promover la equidad, ¿o no? 
M. Por el momento no porque como vamos en relación a trabajo de unidad que se hace entonces, todo tiene un proceso en la unidad en que sí se va a trabajar pero, si lo tengo planificado porque es algo importante y necesario que se trabaje con los niños.

E. Y como lo piensa hacer cuando ya llegue el momento.

M. bueno, primero darles una charla de que todos somos iguales, valemos lo mismo podemos hacer las mismas actividades tanto mujeres como varones de ahí, darles actividades de que niños y niñas lo hagan al mismo tiempo porque sabemos que solo así lo pueden lograr ellos aunque también pueden haber muchas circunstancias más de que ellos pueden lograr eso. De allí también sería a través del juego, del canto así haciéndolos mixtos porque así como ahorita los tengo yo, los tengo así un varón una niña, un varón una niña... Entonces ahí yo también les estoy inculcando que pueden trabajar no importando el género.

E. ¿Usted ve en su escuela una situación que produce inequidad, o sea, más que ayudarnos a la equidad como que nos lleva más a la inequidad, o en la manera de trabajar de otros profesores o algo así?

M. No, no la he visto reflejada todavía.

E. O sea, que si más o menos sí se esta... desde la dirección de la escuela está consciente de trabajar en favor de la equidad. Les promueven algo al grupo de docentes para que trabajen sobre estos temas, ¿o no?

M. No, no hemos recibido charlas de eso casi, no.

E: Digamos que será iniciativa de cada uno, que cada docente en su aula trabaja. Qué metodologías utiliza usted, como son tan chiquititos, los niños, por ejemplo me imagino que hacen bastantes dibujos, pintan, colorean, usted planifica actividades iguales para todos para niños y niñas, o son distintas, por ejemplo el tipo de dibujos que unos ocupan, o el tipo de juegos que unos hacen, ¿cómo lo hacen? 
M. no, ahí para todos es lo mismo, porque no puedo yo hacerle esto una niña y esto a otro niño, entonces yo ahí veo que no hay la equidad de género, para todos es lo mismo, porque yo se que todos lo pueden hacer de la misma forma que uno quiere que ellos lo hacen.

E. Muy bien, con los padres de familia, cómo se da, este es un tema que se puede llegar a platicar o a trabajar con ellos o hay dificultades? ¿Ha encontrado dificultades?

M. bueno, tal vez dificultades siempre van a ver, pero sí yo veo que sí es un tema que si se puede trabajar con ellos, porque yo sé que son personas ya mayores, razonantes, si saben que es algo interesante, porque ellos mismos son los perjudicados si ven que los niños, a ellos no se les habla esto también porque su comunidad va a estar desintegrada y no van a poder convivir como seres humanos.

E. Y digamos ¿hay actividades para padres de familia, dentro de su escuela?

M. sí, hay reuniones, convivios así como por ejemplo, ya se acerca lo que es el día de la madre, pero nosotros no celebramos el día de la madre si no que vamos a celebrar en general lo que es el día de la familia, esas con las actividades, y están otro tipo de actividades, de reuniones que tenemos con ellos, ya para las fiestas patrias también se reúne toda la familia, llegan a la escuelita.

E. Qué bueno, mire y una curiosidad también, ¿qué tal se ha sentido usted, en esta profesión de pre primaria? Le digo esto porque ahí vemos que generalmente la mayor parte son mujeres verdad, las maestras de pre primaria, y que a veces esta la idea de que solo las mujeres, o los mismos padres de familia o los mismos establecimientos, hasta los mismos compañeros docentes, solo las mujeres vamos a poder realizar bien ese trabajo de pre primaria, entonces a usted qué lo motivo a estudiar maestro de pre primaria y cómo se siente en este ámbito que esta feminizado?

M. Si, la mera verdad es algo que yo no lo tenía en mente cuando venía estudiando Básico, pero sí tenía en mente desde la primaria yo ser maestro, pero lo que no estaba decidido es si quería ser maestro o docente de primaria o pre primaria. De ahí con el tiempo vine, llego el Básico, salí de tercero Básico ya decidiendo que carrera llevar, pero yo como traía esa mentalidad de niño de ser docente, de ahí surgió la idea de ser docente de pre primaria, y 
cierto como dice usted es más el género femenino el que se adapta más a los niños pequeños, y eso es lo que yo vi reflejado cuando empecé a estudiar, de que éramos pocos los varones, estábamos hablando de una cantidad de 7 varones y 40 féminas o mujeres, con las que estábamos compartiendo, pero de ahí poquito a poco le fui agarrando el modo, dándome cuenta que si el algo que a mí me gusta, porque los niños es como que con ellos se siente una alegría, con ellos así a veces nosotros tenemos problemas, penas pero con ellos, como dice un dicho, los problemas de la casa se quedan en la casa, y los problemas de la escuela se quedan en la escuela, y en este caso los niños allá son una maravilla, para decirle que son una maravilla, con ellos se olvida uno de problemas, de penas, a veces a uno hasta a veces lo llegan a sorprender con las actitudes que ellos tienen, y eso era lo que a mí me decían, pero porque tu a maestro de pre primaria si eres un varón, y cuando llegue yo al momento de presentarme a la escuelita, me dijeron ¿a qué grado viene? Yo vengo de pre primaria (y el compañero se me quedo viendo) ¿usted de pre primaria? Si, ¿por qué? Porque es el nivel del que yo me he graduado le dije, a bueno... de ahí el también me hizo esa misma pregunta y por qué de pre primaria me dijo, por qué es el campo que me gustó y que me llamó la atención y es donde yo quiero laborar, quiero desempeñarme y quiero, ahí sí que quiero enseñarle a los niños lo poco que yo sé, pero yo se que ellos me van a enseñar muchísimo más, entonces sí, de esa parte que usted decía que a veces los maestros se quedan con esa duda de por qué? Pero como le vuelvo a repetir, es lo que a mí me llamo la atención, es la esencia que yo siento que quería trabajar, con los niños pequeños.

E: Qué bueno, yo lo felicito de verdad, porque para mí es un error bastante grande el pensar que solo las mujeres nos vamos a dedicar a eso.

M: Si y ahí se puede dar cuenta uno que los hombres también somos capaces de poder educar a los niños, porque muchas veces a nosotros los hombres se nos toma como machistas, a veces hasta abusamos de los niños pero aquí nos podemos dar cuenta que también, que los hombres o los varones tenemos ese cariño o esa esencia de querer a los niños también.

E, Claro que sí, y eso es bien importante para la formación de los niños, ver tanto el rol de las mujeres, de las maestras, como el rol de los hombres ¿verdad?, tenemos que ir rompiendo con ese paradigma de que solo los chiquitos solo tienen que ser atendidos o apoyados por mujeres, eso no es así ¿verdad? Entonces qué bueno, me alegro mucho y lo felicito, que siga adelante en esta tarea, y bueno ya solamente para ir terminando, digamos o sea que 
importancia le ve usted a esta cuestión de la equidad en el grado de pre primaria, o sea cree que es un momento importante para comenzar a trabajarlo? O que desde ahí se van sentando algunas bases, o mira usted que en la familia es donde prácticamente todo se define verdad, o ¿cómo lo ve?

M; Pues yo lo veo que tanto en la familia como en los niños sí se pueden asentar las bases, porque solo así lograríamos este tipo de problemas como el machismo, porque a veces desde chiquito el hombre se siente superior a la mujer, pero no (E. ¿Eso lo ha visto usted en los pequeñitos?) ajá muchas veces eso se ve cuando le explicaba que a veces los papas tienen problemas con los papas de otros niños, entonces sí el nivel de pre primaria es la base fundamental para implementar eso, para eliminar lo que es el machismo, el racismo hacia la mujer, por que la mujer también es capaz de todo, y también con los padres de familia ellos también tienen, y es la obligación de ellos demostrarles, que los niños y las niñas valen lo $\underline{\text { mismo, }}$

E. Pues muchísimas gracias, yo le agradezco mucho. 


\section{Entrevista E03/Pr/M}

E: Entrevistadora

M: Maestra

Subrayado: extractos literales tomados en el análisis

E: Bienvenida y bueno como le platicaba, vamos a platicar un poquito sobre cómo ve usted esta cuestión de cómo educar en la equidad de género, de etnia y social, que es uno de los ejes que tiene nuestro curriculum nacional base

M: si de hecho lo menciona en repetidas ocasiones y nos orienta a formar a los niñitos, en el sentido de que todas las personas somos iguales, pero tristemente más en las comunidades lejanas, como no decir de Santa María Chiquimula (.. .) y existe mucha pobreza, y sobre ello hay bastante machismo, es algo que se está trabajando con los niños, con los padres de familia... porque no es solo con los niños, con los padres de familia, porque ellos los forman, ya llegan a la escuela con la idea, que solo los varones son lo que tienen más derechos que las niñas y hasta cierto punto humillan a las niñitas cuando ellas participan o de la misma manera cuando es educación física, las niñas no quieren usar sus implementos deportivos, porque según ellas los papás las han formado desde su casa de que no se debe usar en ningún momento ropa que sea parecida a la de los hombres, entonces cuando se trabaja en las aulas, es difícil por que cuando uno trata de unificar o trabajar en equipo, no se puede y si se pudiera pues requiere de bastante esfuerzo, porque las niñas no quieren participar y los niños no les dan participación, se alejan de las niñas.

Me ha pasado en el caso de quinto primaria, cuando tengo que trabajar en equipo y trabajar con primero, tengo una niña y cinco niños y los niños se aíslan de la niña, no quieren trabajar con ella, entonces con estos problemas que se dan ahí, las niñas ya no tienen oportunidad de seguir estudiando el Básico solo los niños, si es que tuvieran posibilidad y si no pues se quedan ahí.

E: ¿Eso lo ha visto usted cuando llegan a sexto primaria? ¿Qué es lo que ocurre ahí?

M: Que al final, los niños se aíslan de la niña, que al menos estoy viendo yo ahora, que no quieren trabajar con ella, porque en sus casas los han formado así, que el hombre es el que 
debería de tener más oportunidades que la mujer y muchas veces las niñas superan las capacidades de los niños, eso puedo decirle... en primero prácticamente como los niños son chiquititos y como son pequeñitos, entonces uno los va orientando a trabajar en equipo y decirles que todos somos iguales y que así como nosotros existen muchas personas más y como ellos van creciendo, por ejemplo van a la plaza, van a ser comerciantes, van a encontrar a mucha gente y en el que ellos van a tener que respetar y nunca humillarlos... eso es...

E: mire y usted a lo largo de su formación, primero estudio magisterio en Diversificado me imagino, verdad y hasta ahora está aquí en la universidad, entonces ha recibido formación en alguna asignatura que le haya podido ayudar a cómo implementar estrategias en el aula, para trabajar esta equidad de género, de etnia y social.

M: mmm no, lo único que nos han dado la oportunidad de poder formarnos es cómo trabajar multigrado por ejemplo, como la lecto-escritura, matemática siempre y cuando para multigrado, por que como son dos grados, nos falta bastante. Eso, ahora para equidad de género no.

E:pero digamos como es un eje transversal el que está en el curriculum, sobre cómo aplicar los ejes transversales si han podido recibir alguna capacitación o de qué manera se trabaja cuando uno mira, bueno esto es un eje transversal pero que vamos a hacer no? ¿Cómo lo vamos a trabajar?

M: bueno, lo único que sí hemos hecho nosotros, como escuela porque no nos han dado círculos docentes para poder trabajar eso, pero lo que podemos hacer ahí es jugar, cuando jugamos entonces damos a explicar a los niños al final de que todos somos capaces y que todos tenemos las mismas oportunidades también, entonces círculos docentes no nos han brindado, pero como escuela hemos implementado trabajar con los padres de familia, disminuir el nivel de analfabetismo que existe entre los papás y decirle a ellos que es importante que se involucren en el proceso de sus niñitos. Eso es lo único que nosotros hemos hecho como escuela. (E: si, si ya por iniciativa de la propia escuela, reciben apoyo de la dirección de la escuela para este tipo de...) Sí de la dirección sí.

E: ¿Qué bueno!, mire y desde su punto de vista, cree que sería importante profundizar, en cómo aplicar este eje 
M: la verdad sí, porque bueno no es que uno no lo... en realidad tal vez lo poquito que aprendemos y a veces no lo aprendemos para la vida, nos da la poca oportunidad de replicar este proceso en las escuelas. Imagínese que ahora... bueno ahora no sé cómo están las áreas de aquí, las cercanas el área urbana de aquí de Toto, pero sí ha bajado el nivel de discriminación, aquí, pero allá no. Allá en esas áreas, hablarle de Santa María Chiquimula, es hablarle de mucho machismo, los hombres, los señores, los padres de familia, tienen dos, tres o cuatro mujeres y con cada mujer tiene 6,7 niñitos, niños que no crecen con su papá, los niños sufren de mucha desnutrición, tenemos mucho problema porque hay mucha desintegración familiar, el señor llega y le pega a la señoras, tuvimos un caso en el que la señora se fue, dejo a los niños, entonces los niños no terminaron de estudiar y al menos el niñito que estaba conmigo en primero, ese año era muy pilas, pero se fue, debido a que tuvo un golpe emocional podríamos decir, entonces nos dimos cuenta cuando regreso el niño ya estaba muy cambiadito, ya no se relacionaba con los amiguitos y fue bastante problema, fueron secuelas bastante fuertes.

E: y viendo o imaginemos que tuviéramos todas las posibilidades del mundo verdad, que tuviéramos los recursos, la capacitación y todo, cuál cree usted que podría ser de manera ideal el papel de la escuela en esta situación, que usted describe de Santa María Chiquimula, o sea es un contexto social difícil, cree usted que (M:Emocionalmente también) en todo? (M:En todo...) y la escuela qué podría hacer ahí, soñando digamos, si se pudiera hacer todo lo que nosotros quisiéramos?

M: bueno... ¿será que puede repetirme la pregunta?

E: sí, claro que sí, digo que como hay muchas dificultades en Santa María Chiquimula, sociales, económicas como usted dice que machismo, el montón de situaciones, la escuela cree usted que pudiera ser como una semillita de cambio.

M: ah sí, lo hemos hecho ahora y no contamos con todos los recursos, el profe el director él creó... bueno no lo creó si no que más se implementó, entonces nosotros como somos tres, dividimos a todos los papás y a todas las mamás y jóvenes que no saben leer ni escribir y les dimos clases, los orientamos y les dijimos de que apoyarán el proceso formativo de los niños de la comunidad, es un trabajo muy difícil porque es más cansado trabajar con ellos que con los niños. (E: ¡Sí seguro!) 
M: si más cansado trabajar con ellos, entonces cuando se trabajó con ellos, nos dimos cuenta de que tal vez no nos apoyaban enseñándoles a leer o a escribir o algo, pero ya los llegan a ir a traer, los llegan a ir a dejar y como ahí podríamos decir que ellos no saben los hábitos de higiene, no se saben lavar las manos, no se saben cepillar, no saben bastantes cosas, entonces nosotros les explicamos a los papás, los niños deben lavarse las manos, practicar hábitos de higiene, les explicamos en la escuela de padres, entonces cuando llegan a la escuela, llevan su tambito de agua, entonces se llevan su cepillo, se llevan su toallita, su palangana, entonces en ese sentido nosotros recibimos apoyo y los señores ya más o menos van entendiendo que no solamente ellos únicamente ellos tienen el valor.

E: Y con los papás ¿se ha podido abordar, de alguna manera platicar de estos temas, sobre la igualdad de oportunidades?

M: No, (E: Cuál es la dificultad que encuentran ahí?) que ellos no permiten esos temas, ellos, no lo permiten, por ejemplo el año pasado yo tuve una dura experiencia por que dimos clases sexuales a una niña de 10 de 11 años en adelante y resulta que se organizaron todas las mamás y cuando ellas se organizan pues, como no tienen, como le puedo explicar... para ellos fue inadecuado darles esta clase a las niñas, que para ellas fue un pecado, me dijeron a mí: ¡como se te ocurre hablarle de esos temas a las niñas? Si esos temas, a ellos por ejemplo ayer $\underline{\text { se casaron en la misma noche les explicamos cómo es esto, por que ellas no deben de saber }}$ nada.

Entonces yo llegue un sábado aquí y le explique a la licenciada, licenciada yo me siento muy mal le dije, porque me pasó esto, esto y esto, entonces la licenciada medio me controló un poquito pero sí fue muy difícil... imagínese ya los papás cuando se les habla de igualdad de género, les pegan mucho a las señoras, en la casa los niños ven como los papás le pegan a las mamás y ellos van recibiendo esa educación de parte de los papás cuando llegan a la escuela, por eso le digo no permiten que las niñas hablen o si hablan, pues empiezan a insultarla y decirle que lo que ella dijo no está bien, desde ahí imagínese el problema, desde ahí del hogar viene y afecta bastante.

E: y cuando usted ve ese tipo de situaciones, por ejemplo en su aula verdad, que los niños empiezan a discriminar a las niñas o a no permitir que participen, ¿qué hace? ¿O qué se puede hacer? 
M: yo me he sentado con ellos y les he explicado que todas las personas somos iguales, y yo le pregunto a los niños, ¿tu mamá es mujer? Si, ¿Quien te cocina? Mi mamá, y si tu por ejemplo vas a crecer ¿te vas a casar con una mujer o con un hombre? No, con una mujer, entonces a tu esposa no le vas a hacer eso, porque tienen los mismos derechos y obligaciones, para salir a trabajar por ejemplo, porque allá las señoras no saben comprar, los señores son los que compran, no conocen ni siquiera el mercado, entonces es bastante, es mucho, entonces hemos querido nosotros trabajar y abordar estos temas.

Por ejemplo yo formé en el año 2012 el gobierno escolar y quise hacer como un tipo capacitación, una conferencia con las niños, con los niños sobre la discriminación a las niñas, pero ya no lo pude realizar porque no tenía nada de tiempo, el director me ponía a ayudar a convocar a los padres, pero no teníamos cañonera por ejemplo para proyectar una película, sobre cómo el señor masacraba a la señora y cuáles eran las consecuencias en los niños y todo, pero ya no pude hacerlo porque no teníamos los recursos necesarios. Yo pienso que desde ese punto podríamos ayudar aunque eso, al final podemos cosechar el fruto hasta un largo plazo, pero no lo estamos haciendo, verdad, yo pienso

E: Que eso es lo importante al final la escuela está dentro de la misma sociedad, está la casa, digamos la familia, está la escuela, está la comunidad, hay varios elementos que van haciendo el problema verdad, pero si uno de los elementos cambia, de alguna manera va ir haciendo cambiar a los demás.

M: si por ejemplo, como ahí en el CNB nos habla sobre equidad de género, ya sea por diferente cultura que tenga el niño, o la niña, iguales oportunidades en el aula, por ejemplo los niños tienen que participar, entonces lo que yo hago desde primer grado empiezo a formar grupitos, donde se involucran hombres y mujeres y cuando ya están ellos acostumbrados así, que bonito!, se ve muy bonito cuando los niños tratan muy bien a sus compañeras y empiezan a dibujar, a pintar y a pensar juntos, cuando dan una respuesta, todos hablan lo mismo, todos comprendieron lo mismo y participan de la misma manera. Eso es lo que se puede hacer, pero si sería bueno que nos enseñaran otras formas más de poder trabajar.

E: Sobre los materiales didácticos, ¿trabajan con libros ustedes o no hay libros en la escuela? 


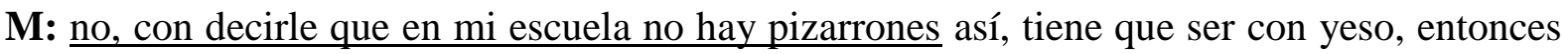
la pizarra ya no sirve porque ya ni nos sirve el yeso.

E: Si pues, mire y por parte de sus compañeros, digamos, de los años que usted tiene de trabajo en magisterio ha visto que, si hay maestros que ellos mismos reproducen esta misma situación. O se han dado esas situaciones de decir, híjole es que a veces también puede ser que no estemos implementando las estrategias adecuadas. O digo no sé si ha visto situaciones así especificas donde los mismos maestros, reproducen la discriminación o el machismo o algo así o no. ¿O piensa usted que por la parte de los docentes, está como que más... más clara?

M: pues en todas las escuelas en las que he estado, porque estuve trabajando por contrato, no, los compañeros docentes no le abren camino a la discriminación y al machismo. Pero en esta escuela donde estoy laborando yo llevo tres años ya. La diferencia que tuvo con las demás escuelas es que involucro a los padres, esa es la diferencia, en otras escuelas si se trabaja, por ejemplo se le da oportunidad a los niños y a las niñas pero hay una cierta separación entre padres de familia y maestros, pero esta escuela, sí puedo decirle que el trabajo es muy duro de parte de nosotros, porque el director nos exige mucho, nos exige bastante pero a la hora de implementar reuniones, los papás llegan, están activos y no se toma decisión alguna sin el involucramiento de los papás, entonces eso ayuda. (E:¡Qué bueno! Sí, eso es importantísimo)

M: ayuda mucho y esa es la diferencia que yo hasta hoy le puedo decir, entre escuelas, ahora entre docentes, discriminación alguna no, porque fíjese que lo duro de estar en Santa María Chiquimula, es que hasta nosotras por ser mujeres, por ser mujeres nosotras no les podemos dar órdenes a los señores (E: nos les pueden dar órdenes, a los papás) si, por que por ejemplo los papás dicen: ¡ah no! A ustedes no las obedecemos porque xaixoquib’ nos dicen en su idioma que solamente somos mujeres y que no. Ellos cómo decirle no pueden recibir alguna sugerencia o algo, entonces eso cuesta más. (E: ¿Y de los compañeros que son hombres?) En cambio a los hombres si los obedecen, y allá con los señores es duro porque cuesta la coordinación de actividades, las otras escuelas, no colaboran, no llegan, no llegan a preguntar cómo está el proceso de sus hijos, nada y yo si he tenido la oportunidad de estar en comunidades en donde los señores, lo discriminan a uno por ser mujer. 
Fui directora de una escuelita, bueno estaba por contrato y me costaba mucho convocar a los señores, porque no llegaban, pero fui descubriendo de que era por el hecho de que yo soy mujer (E: usted los convocaba?, si pues) eso es lo que yo le puedo decir. Entonces de que cuesta, cuesta, más en ese municipio por que hay mucho machismo, imagínese ahora en el sector Toto, yo le puedo decir que todavía en mi propia familia, en mi papá existe algo de machismo, algo, a pesar de que nosotros sus hijos le hemos dicho que no lo haga, que mi papá y mi mamá, o sea ellos dos tienen los mismos derechos y obligaciones... en mi familia, ¡imagínese! Y tanto allá que todos, todos, absolutamente todos, no saben leer y escribir, los niños se retiran en tercero primaria, cuarto primaria, 13 o 14 años.

14 años ya se casaron, ahí en la comunidad, hay varias niñas de 14 años que están a punto de tener bebé y eso es lo que nosotros queremos cambiar como maestros, queremos cambiar ese sentimiento, y no solo el sentimiento si no el pensamiento desde que ellos tengan pequeña edad, entonces cuando tenemos la escuela de padres con los papás, les explicamos de que por lo menos ellos deben de tener una mejor oportunidad, porque a ellos les gusta ser comerciantes, entonces van a las plazas, entonces tener una mejor vida para sus familias, porque ellos empiezan a tener hijitos a los 15 , son papás bien jovencitos y eso nos genera mucho problema a nosotros, llegan los niños con mucha desnutrición, a veces, imagínese que a veces no les van a asentar su nombre así como nosotros al mes, o a los 20 días. Lo van a hacer hasta los 3 años. Mucho problema tenemos, que tristemente es la realidad de Guatemala. E: si pues, la verdad que si o sea que el análisis es así verdad solo que ojalá que... M: y las autoridades, nuestras autoridades guatemaltecas, sí ven el problema porque sí lo ven, pero no hacen nada...

E: y por ejemplo en Santa María Chiquimula, ¿hay algún tipo de, digamos de relación de trabajo con las autoridades indígenas, con los alcaldes no, o creen que sería importante involucrarlos a ellos?

M: sí, llegan las autoridades nos dicen, bueno Maestras, Maestras ¿qué necesitan? Tienen apoyo?¿Tienen algún problema? Nos dicen en el sentido de... cómo le puedo explicar... llegan a preguntarnos que si estamos bien, pero de ahí ya no pasa, no podemos recibir ningún tipo de apoyo. Porque igual las autoridades no saben leer ni escribir, entonces lo que sí hemos recibido apoyo ahorita, es de parte de la municipalidad, por que el señor el alcalde se preocupa un poquito por mejorar las instalaciones de la escuela, porque nosotros ahí el 
patiecito donde juegan los niños es de tierra, cuando llueve se pone lodo todo y a veces no hay agua, entonces hemos aprendido a ser autosostenibles con el agua, porque ya les enseñamos a lavarse sus manitas, a lavarse los dientes, a lavarse la cara, entonces cuando no hay agua, ellos mismos sienten la necesidad de llevar su agüita en un tambito.

Entonces es un trabajo que le digo que esperamos que a largo plazo nos vaya a dar resultados, entonces yo le platico al profe y yo le digo: profe ¿será que nos está funcionando este trabajo que estamos realizando con los papás? Porque de veras es cansado le digo yo. Miré seño me dice; con los papás de ahorita nos va a costar, pero los niños que ahorita nosotros estamos formando, cuando ellos sean papás, ahí vamos a ver los resultados (E: es cierto) va a ser difícil, va a ser muy difícil, porque ahorita recibir por ejemplo ese cambio de parte de los papás no... Pero sí podemos lograr el cambio cuando estos niñitos vayan a ser papás. (E: Así es) entonces decirle que, todo el peso lo tiene uno como maestro, porque las autoridades igual, no saber leer y escribir, cómo decirle un apoyo trabaje así o háganlo así o... nosotros tenemos muchas veces que, hasta inventar como trabajar...

E: le decía esto porque sabemos que a veces las autoridades, reciben casos por ejemplo de violencia intrafamiliar verdad, cuando... no sé si es el caso de Santa María Chiquimula, pero yo conozco otros municipios por acá, que a veces las mujeres se abocan con la autoridad para decirle; fíjese que me pasa esto. Me está pegando mi esposo me maltrata o algo así y a veces no sabemos o bueno sería interesante saber cómo responden las autoridades ante eso, si ellos también se sensibilizan o no verdad ¿o simplemente dejan los casos así?

M: bueno, en el proceso formativo de las comunidades, de las autoridades comunales podríamos decir que sí se les ha dado ese tipo de información y las autoridades sí tratan los casos, pero muchas veces no se dan a conocer (E: Si eso también es cierto) sí porque las mamás aguantan y yo aprendí en el caso de esta señora que se fue, el señor le pegaba mucho, entonces el director le dijo a la señora que lo podía denunciar y se fue con otra señora. Entonces que por lo menos reciba el gasto de los niños, porque la señora no trabaja, ¿de dónde los va a alimentar? Entonces que por lo menos reciba para la alimentación de los niños, y la señora lo fue a denunciar. Y a veces nos dimos cuenta que también es culpa de las señoras, la señora lo fue a denunciar, le estuvo dando gasto y las autoridades le prohibieron al $\underline{\text { señor acercarse a la señora por los golpes que le dio, pero ya resulta que fue culpa de la }}$ 


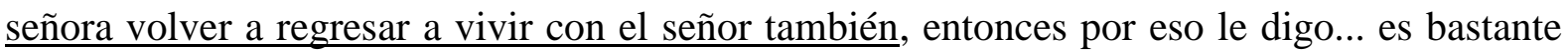
problema.

E: sí, pero mire yo siento que ahí es una parte muy importante donde entra en juego la educación, también desde chiquitos la educación emocional, o sea cómo, como mujeres tenemos que hacernos valer y no estar ahí así como que uno dependiendo del hombre verdad?

M: sí pero nosotros nos pusimos a analizar y dijimos, ¿por qué habrá regresado con el señor? Y dijimos; ¿quién la va a mantener? (E: Sí, no la dependencia económica, definitivamente) como si el señor de plano algo le ha de haber hecho, porque volvió a regresar o sea y nosotros a veces, yo la otra vez le lleve... tuvo otro bebé, entonces le llevé ropita, le llevé sabanas, le llevé frazadas, porque el bebito nació y lo único que tenía era un sudadero, sin pañuelo ni nada, así. Entonces fui a visitar a la señora y me sorprendió bastante porque digo, así en un cuartecito más pequeño que esto, pero tenían... no era cama, eran tablas sobre trozos y todos dormían en esa misma, la señora dio a luz, tenía a sus demás hijitos, todos durmiendo en la misma, entonces nunca me imagine que fuera así.

Entonces la realidad es bastante pues, entonces las señoras se conforman digamos con ser, primera mujer, segunda mujer, tercera mujer, cuarta mujer y la característica de allá es que los hombres pueden tener cuantas mujeres puedan y nadie les puede prohibir, estuve en otra escuelita, donde esta se llamaba "canasta seca", si queda muy retirado, igual se organizo una plática con los padres de familia para planificación familiar, (E: ah! pero que bueno ve) qué si saber ni como se enteraron los papás de que esa iba a ser la reunión, nos recibieron? No nos recibieron, nos dijeron que nosotros quienes somos para ir a prohibirles a ellos cuántos hijos iban o no a tener. Si ellos como hombres tienen el derecho a tener cuantas mujeres y cuántos hijos ellos quieran y que no somos nosotras quienes les vamos a ir a dar de comer a sus hijos y no pudimos hacer nada. (E: ¿No se pudo hacer la actividad?) No, pero se puede decir que se puede lograr el cambio formando desde chiquititos pero es un resultado... (E: a largo plazo, así es, si la educación es a largo plazo generacional ¿verdad?)

M: pero también me pongo a pensar así como dice usted, por ejemplo, nosotros como escuela hacemos nuestro esfuerzo en ese pequeño paraje, lo estarán haciendo las demás escuelas? saber... cómo lo estarán implementando? (E: Pues sí, ahí sí que no sabemos, pero ojalá que se pueda ir creando esa conciencia de que es necesario) le puedo decir que el $\mathrm{CNB}$, nos orienta a 
una equidad, puede ser que nosotros demos la oportunidad de trabajar a los niños, les decimos que tal esto y que tal lo otro, pero podemos decir que solo ahí queda y no hacemos ningunas otras actividades como comprobar si realmente ellos lo aprendieron o lo están aplicando verdad? Nosotros hacemos como que si eso no tuviese valor porque yo me incluyo y decimos nosotros porque puede ser que en alguna oportunidad yo no haya hecho eso de decir: cómo puedo probar que realmente lo que estoy haciendo, está sin efecto, cómo puedo aprobar que el proceso de los niños está cayendo en una buena tierra, y decir bueno, el niño que diga a conciencia, todos somos iguales, ninguno es más ni menos, ¿cómo puedo probar eso? No lo sé y sinceramente decir ahorita idea de cómo hacerlo, no la tengo...

E: Esa entonces sería una parte, digamos, como que a desarrollarla más, verdad de su profesión como docente, es decir bueno, ¿qué estrategias puedo aplicar? ¿Cómo las voy a evaluar? Cómo voy a comprobar como usted dice...

M: cómo comprobar lo que realmente o sea, una temática directamente en la equidad de género, pero si se han hecho los esfuerzos, pero una evaluación directamente de ello no, y con decirle hasta incluso lo único que pueden decir las autoridades es: ¡ah! ¡Si! Como resultado tenemos la participación de la mujer, se han creado instituciones que defienden sus derechos, que ya no se dejen maltratar y todo, pero es encima, pero alguna vez han intentado meterse abajo para ver si en realidad eso se cumple, no sabremos decirlo... es difícil.

E: Muy bien, yo le agradezco mucho, todo lo que hemos compartido...

M: Mi mamá no sabe leer, ni mi abuelita, pero mi abuelo si y mi papá sí, entonces mi abuelita me cuenta, no pero si antes nosotras las mujeres cocinábamos, lavábamos y en ese tiempo no había agua, nos íbamos al rio, teníamos que lavar y traer agua para tomar, nos levantábamos a las 3 de la mañana... y mi mamá me cuenta... bueno es muy triste y a la vez duele y a veces uno dice, bueno cómo puede tener uno un papá así, entonces mi mamá me dice no... Me levanto a las tres de la mañana a acarrear agua, a lavar ropa a cocinarle y a veces no me da mi leña, no me dan gasto pero ellos sí me exigen y si no lo tengo a la hora,

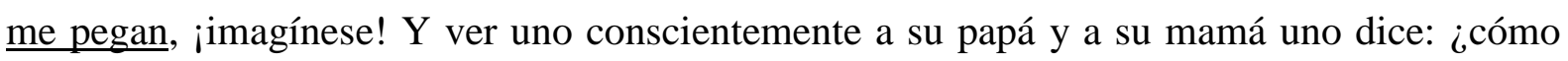
fue capaz de hacerle eso a mi mamá pues? $\underline{Y}$ aún mi papá cambió, podríamos decir, en el

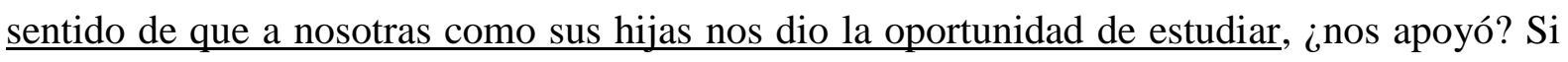
nos apoyó y yo le pregunto a mi papá: ¿papá y a usted le gustaría que a mí como su hija, 
viniera un hombre y viniera a pegarme? $\mathrm{Ni}$ aún podríamos decir que eso es algo que no se ha podido eliminar de la mente de los hombres. (E: ¿y él que dice ya cuando le pregunta eso?) No contesta.

Pero podríamos decirle que yo con mi esposo, porque yo ya soy casada, yo soy maestra, estudiante universitaria, tengo hijos y me desenvuelvo en muchos papeles, pero aún así mi esposo no me trata como tal, ya algunas veces que me ha dicho que: yo no le puedo darle ordenes a él, porque él gana más que yo!;Imagínese! Y no valora el hecho de decir, bueno te valoro como mi esposa, te valoro como tal, pero tú no me vas a dar órdenes a mí, y créame que eso duele, es decir, es que no te estoy dando órdenes, es una sugerencia.

E: pues sí, es compartir criterios, entre los dos tenemos que tomar las decisiones...

M: Pero no se puede, fíjese que podríamos decir que yo a veces me pongo a pensar... Yo teniendo claro el panorama de que todos podemos ser iguales, pero a mí no me dan la oportunidad de tener un trato igual, eso es lo que yo le puedo decir, aquí en el área de Toto se supone que Toto es el departamento que estaría mejor, que está organizado por los 48 cantones, pero en la mente de las personas es donde esta eso y no se puede cambiar. Por ejemplo mi esposo dejó de estudiar tercero primaria, por ignorancia tal vez, puedo decirle que es ignorante y a veces mi mamá me dice: iy por qué te casaste con un hombre que no tenía tu mismo nivel de conocimiento? Es que hay más comprensión y en serio hay más comprensión, me comprende, y le digo me tardé por tal cosa o me tarde porque tuve tal reunión, supongo me entendería porque es un hombre que tiene mi mismo nivel académico, pero un hombre que no entiende qué es una reunión, que tengo que hacer estos compromisos normales, no me va a entender, me va a presionar y dinero pueden tener, porque así son... pueden tener mucho más dinero y ganar mucho más que uno, pero cuánto quisiera uno como mujer, ser comprendida como tal y no ser humillada y decir... por ejemplo la otra vez yo le dije: mirá este, fijate, necesito... es que tu no me vas a dar órdenes! Porque yo soy el que genero todo, me dijo.

Bueno entonces está bien, pero reconoce que yo también te he ayudado económicamente te he ayudado, y si pero, te puedo escuchar, ipero no me vayas a dar órdenes! (E: seguro, no solo lo ha ayudado económicamente, usted seguramente mantiene unido su hogar, hace un montón de cosas en la casa...) ¡imagínese! Es mi caso, mi caso soy más consciente y tengo 
sentimientos y eso duele. Imagínese las señoras que no se pueden pronunciar, imagínese trabajar este problema en las comunidades, en las escuelas, meter las manos, eso es meter las manos al fuego y de una vez darse cuenta de la realidad que se vive... (E: pero como usted dice, es de cambiar las cabecitas verdad....) es cambiar todo (E: y por eso la educación es bien importante en todo ese proceso por que la educación sí cambia las cabezas, a largo plazo, pero es lo único que podemos hacer para ir cambiando las cabezas).

Entonces nosotros en la casa, por ejemplo mi mamá, le sirve a mi papá. Mi papá no puede lavar un vaso, él no se puede servir con una cuchara, se sienta y todo tiene que ser servido... ¡mi papá! Y así fue formando a mis hermanos, ellos no se pueden levantar a agarrar un vaso porque para ellos es una humillación y existe el machismo, y así pasa en las comunidades

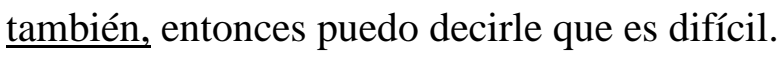

Mi esposo él es un hombre que si me ayuda en los quehaceres de la casa cuando yo no estoy, pero a veces yo me pongo a pensar ¿será que soy yo la que está exigiendo más?...No lo creo, entonces yo digo, ¿será que por que tengo más conciencia me duele más? ... (E: ¡Eso sí!) Me duele muchísimo... (E: eso sí, porque a medida que uno va reflexionando, va aprendiendo nuevas cosas, es más consciente de lo que no funciona bien) imagínese yo... entonces yo me pongo a pensar: yo sufriendo aquí... el trabajo que realiza uno como docente y ver las realidades de las señoras, duele bastante, duele mucho.

Entonces ahí venimos y nos hemos sentado con los maestros y decimos ¿cómo atacar ese problema? Y nosotros en la escuela vemos a los niños desnutridos, no llegan desayunados y sobre ellos viene a recaer este problema de la que no haya igualdad, es bastante, entonces ¿aquí está cambiando la situación? Si, se ha logrado cambiar en un porcentaje le daría yo el $50 \%$. Sí porque platico yo con mis hermanos y me dicen: si que las mujeres salen con sus derechos, que las mujeres aquí, que las mujeres allá... ¡ ¡está bueno! Pero también ¡pónganme el dinero en la mesa! Porque no es justo que solo el hombre... que el hombre no tiene derechos... todo, todo las mujeres con sus derechos... que la igualdad de género también, entonces como existe igualdad de género, entonces ya no solo yo voy a poner todo, también la mujer.

E: Y entonces también no solo yo voy a hacer todo lo del hogar, compartamos... esa es la situación porque fíjese que en otros lugares, por ejemplo en España, el proceso que precisamente se ha dado, ha sido ese, las mujeres nos hemos ido incorporado a la economía, 
digamos al trabajo, somos profesionales, con licenciaturas con todo lo que sea y trabajando, aportamos dinero a la casa, pero en ese mismo proceso no se ha dado el hecho de que los hombres también se hayan incorporado al trabajo domestico, eso no verdad? (M:cuesta!) nosotras nos hemos incorporado al trabajo fuera de la casa, pero ellos no al de adentro, entonces qué pasa que las mujeres tienen doble jornada, triple jornada y hasta cuatro jornadas?

M: yo he trabajado con los niños, esta semana trabajé, desarrollo y productividad entonces en la escuela los mandamos a barrer porque ellos en su casa no barren, para ellos es... son hombres, ellos no tienen que hacer lo mismo que una mujer, varías veces yo le repito a los niños de quinto yo les digo... como es en su idioma ¿verdad? Entonces yo les digo a ellos: y ustedes con lavar trastos, se van a convertir en mujeres?¡No!, con barrer se van a convertir en mujeres? ¡No! Y les empiezo a dar un montón de reflexiones y yo a veces me les quedo viendo y digo: ¿será que hará efecto esta pequeña reflexión en ellos? Y yo les digo... ustedes pueden barrer, pueden lavar, cuando lleguen con su ropa shuca, laven ustedes, la mamá no lo puede hacer, laven ustedes, lleguen a la escuela limpios, con hacer los oficios ¡no se van a convertir en mujeres!

Entonces el martes les enseñe a cocinar, involucré a los niños, vayan a lavarse las manos, llénenme esto de agua, háganme esto, esto y usted póngame esto, involucré a los hombrecitos, ¿pueden cocinar? ¡Si! ¡Ya vieron que pueden? (E: y les gusto la actividad?) les gusto porque les enseñé a preparar una comida, entonces yo les dije; háganlo ustedes y también con el otro objetivo de que aprendan un oficio, que preparen ese bocadillo para venderlo y que generen ellos dinero para su familia cuando sean grandes... yo digo ¿se acordaran de mi? O de algo que les haya enseñando que digan: bueno, gracias a mi maestra ahora tengo... me pongo, los veo y digo ojalá, ojalá que se les haya quedado para el bien de ellos y para el bien de sus familias y los involucre y todo a los niños, entonces les digo, los turne, usted me saca agua tal día, tal día, tal día y usted me da jabón, entonces les doy un peso de responsabilidad también y aprenden a tratar a sus compañeritos de primero, les he puesto reglas, los grandes de quinto no me molesten a los de primero, ellos son más chiquititos... por que se insultan, se ponen apodos, se ponen todo y siento yo que desde ahí se debe de empezar a educarlos, digo no! Ella no se llama así. 
Tiene un nombre, ¿o les gusta que los trate así? No, yo no les he enseñado eso, no les he enseñado a pelear, no les he enseñado nada, entonces me está costando, porque me está costando, pero puedo decirle de que tengo fe en que algún día se van a acordar de mí vayan a decir; bueno me enseño tal cosa mi maestra...

E: y mire esto de la equidad de género, bueno de etnia social, o sea la equidad digamos en general por una parte la podemos trabajar con contenidos, pero a veces las platicas y todo eso no es lo que más influye lo que más influye precisamente son estos contenidos actitudinales y como usted es un modelo para ellos también, de ser distinto, verdad, no es lo mismo, por ejemplo yo no les voy a permitir así como usted dice, que estén insultando, que estén poniendo apodos, que estén haciendo esto a las niñas, o los niños a las niñas o estoy proponiendo esto que todos juntos cocinemos, que hagamos cosas, eso modela, es un modelo que a ellos se les va muchas veces a quedar más, que precisamente el darles una plática por ejemplo o tener una asignatura especifica que se llame equidad, esas cosas sabemos que a veces no nos sirven mucho, verdad, entonces hay un abanico tan amplio de cosas que se pueden hacer desde eso, desde los turnos de limpieza, hasta la plática con los papás hasta...

Bueno por ejemplo me comentaban, a veces en prepa, les dan para colorear dibujos distintos, ¿verdad? A las niñitas sus princesitas y a los niñitos su superman o su, no sé qué ¿verdad? Eso es algo que no... (M: Es una separación psicológica del hombre de la mujer) y que no tiene sentido y que tan sencillo es decir, hagamos todos el mismo dibujo ¿verdad?

M: si por ejemplo lo platicábamos con mis hermanos y decíamos, porque a los hombres... nosotros como papas... que pelotas, que solo carros y a las niñas sus ollitas, sus sartenes, su muñeca y desde pequeños como que solo naciste para ser mamá, o ahí está tu cocina, prepárate desde pequeñita, porque a las niñas no les damos una pelota, porque no les compramos una moto, los orientamos para hacer y decir que ellos mismos empiecen a educar su mente y decir soy capaz para todo. (E:;claro! Y quiero ser ingeniera, o quiero ser doctora o quiero ser...) ;si! Pero en realidad... porque yo he tratado a mi hijo y que mire como es esto; a mi hijito, como no me estoy...pero no es tanto porque no me estoy, sino para enseñarle de que es capaz, él ya puede cocinar, él cocina, se pone su gabacha, y le digo papa ayúdame a lavar los trastos! Ta bueno me dice y lo hace, pero mi mamá y mi papá... para ellos es un problema. Y me dicen: ¡es que no sos una mamá responsable! Y dicen ¿cómo lo vas a mandar a cocinar a él? ¡si él es hombrecito! ¿Cómo se te ocurre?, pero dentro de mi hay un objetivo, 
explicándoles a ellos y ellos no me van a entender, pero ellos consideran de que soy una mala mamá, porque lo mando a cocinar.

Pero por otro lado, me preocupa el hecho de... si me preocupa porque me he puesto a pensar... qué pasaría si en realidad ellos tienen razón. Yo digo que va a pasar el día que mi hijito vaya a formar una familia y todos los oficios los haga él por ejemplo, porque se da el hecho de que si hay mujeres que no quieren cumplir con su responsabilidad... ¿qué voy hacer? ¿Qué estoy haciendo? ¿Estaré formando bien a mi hijo en el sentido de que cocine, aprenda a hacer sus oficios? Entonces ¿estaré haciendo bien? (E: lo importante es que sepa y luego él ya en su vida familiar, tendrá que negociar, será la relación con su esposa donde ellos...) tienen que entenderse en ese sentido.

E: ¡Claro! Y así les decimos a los jovencitos, miren las cosas han cambiado mucho ya, el que no sepa cocinar, no sepa barrer, no sepa lavar no se va a casar, les digo yo a algunos ¿verdad? Porque han cambiado mucho las cosas, una mujer ya no va a querer de usted, que no sepa nada... ¡va a querer que sepa pues! ¿Verdad?

M: por ejemplo mi hijito sabe cocinar, él sabe juntar el fuego, porque aquí con nosotros es fuego y se calienta su tamalito, él no me espera... si él ve que yo estoy trabajando, estoy estudiando, se sale, se va a la cocina, se sirve, se sienta a comer, pero para mis papás no está bien, porque ellos dicen que yo como mamá tengo que cumplir con mi obligación, uno. Dos es de que él es hombre, que en ningún momento debe de cocinar...

E: pero ya vio cómo ahí en su caso familiar, se está dando el cambio generacional, sus papás tienen una mentalidad, usted tiene otra, su hijo va a tener otra y lo mismo va a pasar con los muchachitos de la escuela.

M: Entonces sí, ojalá... puede ser que solo yo esté haciendo eso... ¿verdad? Puede ser que solo yo sea, en el caso de mi hermano, él tiene un nene, tres nenas, el nene le barre, el nene, él se lo lleva a trabajar con él y en la casa sus tres hijitas, la molida... y todo, todo... y a veces mi nene, como yo le digo a mi mamá: ¡que se vaya él al molino! No, me dijo, como vas a pensar que lo voy a mandar, él es hombre... 


\title{
Entrevista E04/Pr/H
}

\author{
E: Entrevistadora \\ M: Maestro
}

Subrayado: extractos literales tomados en el análisis

E: Bienvenido, Maestro de primero primaria, en el área Rural en San Francisco el Alto. Sería comenzar a compartir un poquito, sobre cómo ve usted precisamente, esta cuestión de equidad de género, de etnia y social en la educación.

M: bueno, primero que todo cuando hablamos de equidad, hablamos de igualdad, bien sabemos que también en esa área, hay ciertas complicaciones que uno logra encontrar en su camino, porque en algunos el lenguaje es puro y en otros ya no, hablamos sobre el idioma materno que es el idioma k'iche'. Yo por lo menos en mi cantidad de niños, al tratarlos tengo que hablar los dos idiomas, tengo que hablarles en castellano y en el idioma total de ellos, que es el k'iche', para poder darles clases. Yo trato de darles mi clase de esa manera, porque he encontrado un problema de que incluso yo, no sé tanto el idioma materno, o sea que yo aprendo con ellos y ellos aprenden conmigo, yo veo ahí ya una equidad de que tanto ellos aprenden como uno también, trato a los niños y las niñas de igual manera no importando su condición económica, su condición física también y tampoco el lenguaje, porque también hay unos niños que hablan el castellano pero con dificultad, ellos utilizan mucho las palabras de (la o los ) entonces desde ese momento hay que tratar de orientarlos a cambiar.

E: Una pregunta, a lo largo de su formación, me imagino que usted estudio magisterio a nivel Diversificado y ahora ya esta acá verdad en la universidad, ha recibido alguna formación específica sobre como implementar este eje en el aula, o este eje o los ejes transversales del curriculum?

M: no, por el momento si no, únicamente solo nos han hablado sobre más... educación en lectura y escritura y únicamente...

E: y usted cómo hace, se plantea de alguna manera en su ejercicio, bueno digamos cómo voy a hacer yo para promover esta equidad de género de etnia y social, lo hace de alguna forma, 
hace alguna actividad que cree usted que puede ayudar para eso, digamos lo tiene presente en su planificación de alguna manera o no lo ha logrado.

M: Bueno como le decía, que cuando hacíamos alguna actividad no obviamos a muchos, como hacen otros, déjeme contarle que cuando yo estudie el Básico estudie un año en un centro urbano, específicamente en Salcajá y solo por pertenecer a la etnia k'iche', era obviado tanto por los compañeros como por los maestros, entonces en ese momento cuando uno ya está directamente en esa etapa y está laborando ya, uno dice no, esto no es correcto, entonces las actividades que uno hace son los juegos para motricidad, juegos de recreación (...) se relacionan unos con otros para poder decirles que todos somos iguales y nadie es superior a nadie.

E: Muy bien, ha encontrado alguna dificultad, así especifica en su escuela a la hora de abordar la equidad de género, por ejemplo a la hora de decir, bueno los niños y las niñas son iguales en oportunidades, de repente ha visto usted alguna situación en la que eso no es así o en la que por parte de sus familias vienen con otras ideas, ¿ha encontrado dificultades para poder trabajar este tema?

M: Solamente en tres niños, como decía ellos no... Solo en el área rural, pero la situación económica de ellos nos ha favorecido, entonces ellos dicen y yo ¿porqué me tengo que juntar con ellos? Yo mejor me junto con él, entonces ya tienen sus grupitos y yo en ese momento intervengo y les digo que no, hay que compartir con todos, no solo porque uno no es superior o no solo porque uno tiene ciertas posibilidades va a obviar a los demás, entonces tenemos que ser por lo menos justos y comprensivos y decirles que eso no es correcto y ellos van aprendiendo poco a poco.

E: Por parte de la dirección de su escuela y del grupo de maestros que está ahí, reciben alguna... digamos este es un tema al que se les da importancia o la dirección no... Digamos ¿cómo lo viven ustedes? Se puede trabajar entre el grupito de maestros sobre cómo trabajar ¿o no?

M: de que se puede, se puede siempre salen a veces comentarios sobre esto, pero no específicamente tratamos de decirle equidad de género, esto obviamente lo miramos con otro 
nombre, igualdad o convivencia, convivencia entre el aula, convivencia en los niños, no hablamos únicamente.

E: Muy bien, mire cuál cree usted, ya para terminar verdad que sería como el papel, o que sería lo mejor que podemos hacer desde este grado de primero primaria, qué cosas, si tuviéramos todos los recursos, todas las posibilidades del mundo en la mano digamos, usted cree que si se pueden hacer cosas en primero primaria como para ir mejorando ir generando un cambio social hacía la equidad

M: pues a veces no es necesario tener todos los materiales para ejercer la igualdad, únicamente es crearle conciencia al niño desde pequeño, formarlo con valores, con valor, respeto, armonía y amor para poder darle un cimiento desde pequeño y mantener la mentalidad de que no todo lo que se dice o se ve es lo que realmente es, los actos que uno le va formando o les va dando a conocer, ellos lo absorben como una esponjita, y es lo que ellos utilizan desde ahí hasta esto.

E: Eso es bien importante que usted dice, porque al final son esos contenidos actitudinales o ese también a veces curriculum oculto, no es exactamente lo que estamos diciendo si no lo que damos a entender, como maestros somos un modelo para ellos verdad, no solo en los contenidos de las materias si no en toda nuestra forma de ser y de actuar. Muy bien pues yo le agradezco mucho, entonces esta plática. 


\title{
Entrevista E05/B/M
}

\author{
E: Entrevistadora \\ M: Maestra
}

Subrayado: extractos literales tomados en el análisis

E: bueno, pues bienvenida, docente en primero y segundo Básico en Pasac I, Cantel, bueno la idea es poder compartir un poquito sobre cómo ve usted, en primer lugar la cuestión de la equidad de género, de etnia y social que así nos lo dice el curriculum nacional base, verdad, en la educación, que ideas tiene usted sobre esto, ¿cómo lo ve?

M; prácticamente la equidad verdad, ya desprendiéndonos de la equidad, es de que haiga un equilibrio entre hombre y mujer, y que todas cosas que la mujer hace, el hombre lo puede hacer, así a nivel general, y así en la educación, nosotros vamos a ampliar o aplicar lo que es la equidad de género, en el momento de cuando nosotros estamos trabajando con los estudiantes verdad?, en primer lugar vemos a veces en los centros educativos o en las escuelas de que los hombres creen que ellos pueden con una cierta actividad discriminando a las mujeres, pero yo trabajo con los jóvenes utilizando los grupos mixtos y haciendo trabajos que los hombres pueden hacer y que las mujeres pueden hacer, entonces no permito que haya grupos así de hombres o de mujeres que sean mixtos, porque donde trabajo es una escuela donde hay hombres y mujeres verdad, y también es una población que también podríamos decir indígena y no hay discriminación también hacia otra cultura o hacia otra etnia.

E: O sea que la discriminación hacia otra etnia no se da, porque no, y la discriminación hacia digamos niveles económico o social podríamos decir, verdad, o si vienen de una aldea más favorecida o menos favorecida eso lo ha podido ver ¿o no?

M: prácticamente no existe esa discriminación, porque nosotros en el establecimiento tenemos a jóvenes de diferentes comunidades, tenemos a jóvenes de Pasac I, Pasac II, hasta tenemos jóvenes que vienen más para acá que son de Chirijquiac, Choquiac, Pachaj, son de diferentes lugares, pero en el establecimiento se hacen amigos y no hay distinción de que tu eres de esa comunidad y no te hablo verdad, no, ellos tienen esa comunicación. 
E. ¡ah qué bueno! Mire y usted en su formación como docente ¿ha recibido algún curso o alguna orientación específica sobre cómo aplicar este eje de equidad de género, de etnia y social?

M: específicamente alguna capacitación, no tenemos verdad (E; o dentro del pensum de magisterio que usted ha estudiado?) en el magisterio sí, vimos lo que es la equidad de género y cómo fomentar lo que es la equidad de género en los estudiantes verdad, cómo aplicar la equidad de género en los grupos y cómo aplicar la equidad de género a nivel del establecimiento para que no haya distinción de personas, ni de raza ni de color como lo dice lo que es la constitución política y así mismo lo que tenemos todos los convenios verdad, no existe al menos donde yo estoy, donde yo estoy hay un ambiente agradable, en armonía, porque eso es lo que se pretende.

E: Mire y entonces usted ya en lo concreto digamos, cuando llega ¿qué materias son las que imparte?

M: Idioma Maya, (E: que sería k'iche' en este caso?) sí k'iche'.

E: Digamos cuando usted ya llega a su aula, ¿qué cosas hace específicamente para poder implementar este eje transversal?

M: Yo llego al aula, todos hacemos una invocación, y esa invocación la hacemos de manera rotativa; un hombre y una mujer, un hombre y una mujer... de acuerdo a un listado que tengo, verdad, yo siempre lo he hecho así y de esa manera luego cantamos el himno nacional en k'iche', todos cantamos el himno nacional y para la formación de grupos hacemos algunas dinámicas, pero ya doy las indicaciones concretas verdad, de que la formación de grupos tiene que ser mixto, y los estudiantes ya saben verdad de que así quiero los grupos y ellos ya van formando los grupos como deben de ser verdad? Y yo trabajo, ahorita estoy trabajando por que la población donde estoy ya casi esta en un proceso de recuperación de lo que es el k'iche' porque ya no se habla, entonces ahorita estoy trabajando con lo que es la tejiendo algunas palabras o algunas oraciones para ir formando lo que es el k'iche'. Pero prácticamente yo trabajo con grupos seño, la mayor parte de mi trabajo es con grupo porque así individualmente a veces se puede trabajar, pero a veces se pierde la atención del otro grupo. 
E: Ha encontrado alguna dificultad, para esta cuestión de la equidad de género, por ejemplo con los padres de familia, o con situaciones de la comunidad o algo así, que han estado en contra de cómo han trabajado ustedes o no sé, hay alguna dificultad que encuentren o no?

M: Hasta ahora no (E: y desde el colegio ¿involucran a los padres de familia en algún tipo de actividad? ¿Qué es lo que hacen con ellos?) involucramos a los padres de familia en las capacitaciones, damos capacitaciones sobre lo que es ehh... ya vimos lo que es la alimentación, el próximo mes vamos a dar sobre lo que es la identidad de los estudiantes, en eso involucramos a padres y estudiantes, entonces llegan los padres de familia a recibir esa capacitación para que puedan también ayudarnos a formar a los estudiantes verdad, y yo no sé pero un problemita que tenemos más es sobre la alimentación de los estudiantes, en la equidad de género casi no hemos tenido, más sobre porque los estudiantes ya no permiten.. Ellos dicen que no comen por que se engordan... solo ese es el problema que he tenido yo hasta ahora, sobre la equidad de género no hemos tenido ningún problema.

E: situaciones que usted haya podido ver, por ejemplo no sé si dan situaciones de violencia intra familiar, o sea que sepa usted que hay estudiantes que están sufriendo ese problema en sus hogares ¿o no?

M. No, todavía no, pero en mi comunidad sí hemos visto eso, hay problemas más por el alcohol verdad, pero de eso también se van perjudicando los hijos, el año pasado un padre de familia ya no dejó o ya no permitió que estudiaran sus niños, tenía tres niños y ya no porque tenían mucho trabajo, entonces lo que el padre de familia hizo, es de que los hijos lo ayudarán en el trabajo y no los mando a la escuela y eso es un retraso, un año es bastante para el aprendizaje de un niño por que conforme el tiempo avanza, el estudiante o el niño también avanza en edad y cada edad, es una etapa en la vida del ser humano verdad, entonces en eso yo me puse a pensar, porque ese padre de familia no permitió el año pasado que estudiaran los niños, hasta este año volvieron a reingresar a la escuela, pero yo pienso en cómo perjudica cuando uno deja de estudiar un año, y vuelve al centro educativo uno pierde la secuencia de lo que estaba haciendo verdad, porque uno cuando está en el campo, está en la casa no hace nada verdad, ahí sí trabajamos, jugamos como niños verdad, juegan pero nunca se acuerdan del cuaderno, ni de un libro cuando estaban en casa y no van a la escuela, en eso sí yo creo que tal vez ese si es un problema, por la situación económica tal vez, o por que los padres, 
según los comentarios que nosotros tenemos de ellos es de que el padre decía; yo no tuve educación, entonces eso es como limitar a ellos.

E: mire, ya en ciclo Básico se da la dificultad o la situación de que ingresen menos jovencitas que jóvenes o digamos en esa situación, de bueno terminan primaria y ya no se les da oportunidad, ¿o no ha vivido usted eso?

M. No al menos en el Básico quizás son algunas pero ya no todas, son algunas las que llegan a ya no estudiar, pero a veces también por la situación económica, pero a veces también por el comportamiento de nosotras como mujeres, unas tienen algo en la mente nuestros padres, de que nosotras a veces las mujeres no terminamos el estudio, ellos gastan en nosotras y nosotras nos casamos, ese es el problema verdad, yo prácticamente yo he visto en el colegio donde yo estoy ahora ya hay más mujeres que hombres, pero así específicamente yo creo que con eso de decir, ya no hay ese desequilibrio entre hombre y mujer; o porque ella es mujer ya no va a la escuela ya no existe, pero otra situación es que los padres desconfían, tienen el temor de gastar en vano, porque eso es lo que decía mi papá, yo entré al Básico, mi papá decía vas a seguir? Y yo le dije que sí, yo tenía ganas de estudiar y me dijo pero será que vas a terminar tus estudios, porque tus hermanas no terminaron, yo tengo tres hermanas y ellas no terminaron, dejaron, una dejo primero, otra terminando sexto se casó, entonces en eso mi papa tuvo el temor de que yo hiciera lo mismo. Eso me lo preguntó cuando yo termine sexto, me lo preguntó cuando terminé mi tercero Básico y empezando mi carrera, en el año cuando ya me tenía que inscribir me dice ¿te vas a ir a estudiar? Si papa me tengo que ir... ¿pero vas a terminar? Voy a gastar bastante, que voy hacer si no terminas... y yo le dije, Papá ese es mi compromiso con usted, y no solo con usted, conmigo misma es el compromiso. Entonces al principio cuando yo estaba en cuarto, mi papá desconfió un poco de mí y como que si le costaba darme dinero para ir a estudiar, ya en quinto mi papa con más facilidad me dio dinero, en sexto magisterio ya mi papa estaba totalmente cambiado... pero a veces depende de nosotros, ya cambió ese pensamiento de que eres mujer ya no vas a la escuela porque te quedas cocinando, cuidas a tus hermanos, ya no hay tal vez, existen algunos pero ya la mayor parte no. Ese es el temor de los padres ahora, es de que sus hijas se les vayan o sus hijos se les casen, esa es la mayor dificultad ahora, pero ya no es tanta la discriminación que hay entre el hombre y la mujer, o la preferencia, ya hay un cambio. 
E: y mire por ejemplo, bueno sabemos que en otros contextos o bueno de que todas maneras siga existiendo la necesidad de ir profundizando más en ese cambio, que de verdad podamos avanzar para que podamos convivir hombres y mujeres en armonía, para que se acaben todos los tipos de violencia que hay, tanto contra las mujeres, como contra todas las personas verdad, o sea necesitamos avanzar todavía bastante en ese aspecto y sabemos que tal vez en otras áreas, mucho más, como me estaban comentando algunos compañeros acá en Santa María Chiquimula y en algunos lugares en los que todavía hay que avanzar mucho... entonces la pregunta es: cómo cree usted que desde el ciclo Básico, o sea el ciclo Básico es un momento importante para seguir profundizando en esta cuestión de la equidad, o que cambios cree usted que se pueden lograr desde el ciclo Básico, y que necesitaríamos para que esos cambios se puedan dar?

M. pues yo considero que el ciclo Básico es una etapa muy fundamental tanto en la vida de los estudiantes, porque en eso ellos van formando ya su carácter para ir introduciéndose más a la sociedad (E. Ya son adolescentes) y en ese caso nuestro papel como docentes es concientizarlos a ser buenos ciudadanos y para ser buenos ciudadanos, tienen que tener un equilibrio, o tienen que tener eso de respetar lo que son los derechos y los deberes de ellos mismos y de los demás y para ello también es importante eso de concientizarlos sobre la equidad de género. Por que como le digo cada generación es diferente, entonces el ser humano va ir formando su propio pensamiento y su propio carácter verdad, aunque uno no se lo imponga, uno puede ser muy diferente a otro, entonces siempre es necesario tener esos temas entre los contenidos que uno va a ir dando en el transcurso del modulo o del año en que va ir dando las clases, siempre es necesario y para también fomentar un poquito, también es necesario que existan organizaciones en las que apoyen los centros educativos para dar esos temas, porque también es muy diferente que yo como docente les doy ese tema, que otra persona venga a darles ese tema, también es muy diferente porque el interés se despierta, se reciben nuevas experiencias y nuevos conocimientos de los demás.

E: ¿ustedes han tenido esa oportunidad ahí en el colegio de contar con el apoyo de contar con alguna institución o de algún programa o algo así?

M: bueno hasta ahora no, lo único que tenemos es el apoyo de ACEM, pero ACEM es lo que nos está apoyando para fortalecer lo que es la cultura y el idioma, es la única institución que nos está apoyando ahora en el establecimiento. 
E: pues muy bien, le agradezco un montón, poder compartir un poquito porque la verdad yo creo que es un tema bastante importante, que lo podamos ir siempre teniendo presente, porque a veces no solo es que hablemos contenidos verdad, sobre equidad, sino que también qué modelo les estamos dando nosotros, porque los jóvenes se fijan, somos un modelo para ellos y nuestra manera de actuar, nuestra manera de relacionarnos incluso dentro de los mismos docentes, ellos lo están viendo verdad?, están tomando nota, están cachando que forma de ser tenemos y con eso también los estamos educando verdad, es tan amplio, la educación es un proceso tan amplio pero que si logra cambiar mentalidades, cambiar las cabecitas de las personas que eso es lo más importante verdad.

M. si eso es cierto, no solo son contenidos, también hay que motivarlos, porque a la juventud de ahora hay que llevarlos un poquito más de la mano que hay tantas cosas que los van presionando, a veces ellos van desviándose un poquito del carril de la educación diría yo, pero hay que motivarlos hay que darles, como usted dice verdad, que uno debe ser modelo, uno debe de aprender primero para poder enseñar, pero también como docente uno no aprende, mientras que uno no llega a practicar lo que tiene o lo que aprende, el maestro también se forma en las aulas con los estudiantes, el docente también ahí se forma, ahí se cimientan los conocimientos que también tenemos, de esa manera también llegamos a ampliar también nuestros conocimientos, porque si no laboramos si no llegamos a las aulas, nunca vamos a conocer la necesidad de los estudiantes y tampoco conocemos la carencia que también tenemos nosotros como docentes.

E. así es, mire ya otra cosita esto es un poquito aparte, bueno no aparte, es sobre lo mismo pero a mí me interesa conocer bastante cómo mira usted que su establecimiento promueve bastante la cultura maya, como mira usted la cuestión de los valores de la cultura maya que si van en la...son lo mismo verdad, que son la equidad en realidad, verdad, porque a veces he sentido yo en algunos espacios que cuando uno habla de equidad de género, hay algunas personas a las que les suena como algo raro verdad, como que esto saber qué eso es algo extraño, pero cuando uno conoce un poquito más la cultura maya se da cuenta que dentro de los valores de la cosmovisión maya en realidad está la equidad, verdad.

M. prácticamente seño lo de la equidad, yo lo asimilaría más sobre un valor muy importante de la cultura maya que es la dualidad y la complementariedad, porque son dos valores importantes, en donde los mayas, o nosotros en nuestra cultura decimos que todo lo que 
$\underline{\text { existe a nuestro alrededor tiene importancia y tanto hombre y mujer se complementan, es una }}$ dualidad, son dos para ser uno, ese es el pensamiento maya y ese es un valor que yo lo asimilaría con la equidad de género, la complementariedad o la dualidad, si yo lo considero así. Porque a veces sí se escucha extraño, porque solo nos han dado estas son como teorías o pensamiento que dicen que lo occidental y lo que son los contenidos mayas verdad, entonces para otras personas entonces la equidad de género entraría más en lo occidental, podríamos decir, pero viéndolo desde el punto de vista de los mayas también lo tenemos solo que tal vez de otro nombre, pero llega a lo mismo, sí es un mismo concepto.

E: Usted tiene conocimiento cómo digamos... ¿cómo se puede llegar a experimentar este valor de la dualidad y de la complementariedad, los dos valores como se llevan a la práctica de la vida?

M. bien, la dualidad es de que según lo que yo observo es de que cuando nosotros apoyamos a alguien más, la dualidad, entonces si las cosas que esa persona necesita, si ella no lo tiene yo no puedo tenerlo verdad, se lo puedo dar voy a ir apoyándola en ese sentido. La complementariedad es de que todo el trabajo de un hombre no lo puede hacer a veces... digamos una idea, y la idea de la mujer llega a ser más grande cuando se unen verdad, entonces a veces en las familias solo existe el papá, no es lo mismo que tener papá y mamá, siempre es necesario tener a la mama y en eso se complementa de que se vuelve como un triangulo en la vida de que tanto padres, hijos y padre madre e hijos se vuelven como ese triangulo de que encierra todo para que quede fuerte, verdad. Considero que eso es la complementariedad, es la fuerza, la unión de de padres hijos, integrantes de una sociedad para llegar a hacer algún proyecto, llegar a hacer algo para la sociedad, para la familia o para alguien que lo necesite. Eso es lo que yo lo considero así, porque prácticamente, lo que se practicaba antes era mucho apoyo, era unidad ya no había lo que... tal vez si se dio pero lo que se practicaba era de unificar pensamientos para que se llegara a acuerdos...

E: y en realidad eso sería lo mismo verdad que esta equidad de género que estamos hablando. Es exactamente lo mismo, me parece interesante esta parte porque creo que también una parte importante es ir cómo viendo que en el fondo hay grandes propósitos humanos o grandes metas de la humanidad, que todas las culturas la pueden, la deben lograr ¿verdad? Ya sea por ejemplo desde la visión maya de la dualidad o complementariedad, desde estos otros nombres teóricos como usted dice, porque son teóricos de equidad de género, no importa la situación 
es que toda la humanidad, en cualquier país, en cualquier cultura necesitamos practicarlo, necesitamos avanzar hacia la armonía la paz, la comprensión verdad, que se elimine la violencia, entonces ahí el aporte de todas las culturas es importante ¿verdad?

M. Sí es bastante, pero hasta ahora tal vez es como que si se abriera una grieta entre todas las culturas, porque ya no se practica como se practicaba antes y a veces considero de que todo lo que pasa ahora, tanta violencia tantas cosas que están pasando es por esa ruptura que tuvo cada una de las culturas, porque ya los valores no se practican como antes, ya ese respeto a los padres se perdió, ya ese respeto al abuelo al atit o al mam como nosotros le decimos acá, se ha perdido, ya no se practica, pasa un abuelo ya no le decimos sakarik, buenos días xeij, buenas tardes, xokacab buenas noches, ya no se saluda, pasa el joven como que si estuviera pintado el señor ahí, ya no se hace eso. Antes según nuestros padres o nuestros abuelos se decía que si uno no pasaba haciendo eso era como que si uno era un desconocido o alguien fuera de la sociedad, pero realmente cuando uno practica eso, se siente esa armonía y eso es lo que se ha perdido, muchos jóvenes ya no lo hacen.

E: Claro, también va cambiando mucho la sociedad verdad, qué tipo de trabajos tenemos ahora, dónde vivimos, cómo vivimos o sea todo va cambiando pero eso no quiere decir que se vayan a perder los valores, hay que seguir cultivándolos.

M. Pero como se dice que la casa es la primera escuela, mientras que en la casa se logre enseñarlo, se logre fomentar los valores, antes de que el joven salga, se lleva eso, pero si en la casa se pierden esos valores, ya el joven afuera va ir aprendiendo otros valores que no aprendió en la casa, ahora cuando ya lleva los valores él los va ir practicando, tal vez llega a tener cambios pero no es totalmente no va a ser tan grande.

E. ese es el reto que tenemos creo yo muy fuerte, en la educación en las escuelas, porque vamos a recibir a algunos alumnos que sí traen de la casa ciertos valores y otros que ya no, verdad y entonces es decir, bueno entonces la escuela tiene un papel muy importante, porque tenemos que lograr que los que ya no, también los retomen verdad.

M. si porque eso es lo que platica la directora con nosotros, de que vienen muchos jóvenes que vienen demasiado fuera de lo común podríamos decir verdad, pero qué podemos hacer para que ese grupito, no llegue a tener dificultades con el otro grupo, porque pueden 
dividirse, pero así fomentando valores, practicando nosotros, como docentes en el aula y hacer que ellos lo practiquen van aprendiendo también, aunque cuesta un poquito llevarlos a retomar un camino que no se practica desde la casa, si porque a veces dicen, bueno papa no

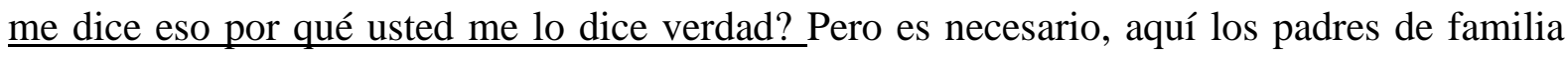
juegan un papel muy importante, acá en las escuelas porque son los que nos ayudan a que los estudiantes tengan un mejor desempeño y así mismo en el curriculum dice de que tanto padres de familia, estudiantes, personas de la escuela, los estudiantes verdad formamos una comunidad, y esa comunidad es lo que tratamos de hacer, tratamos de tener el desarrollo o un $\underline{\text { cambio integral en el estudiante, y eso es lo que pretende ahora lo que es el curriculum }}$ nacional base.

E; y la verdad es que es una herramienta bien bonita verdad, que nos da muchas posibilidades. Bastante...

M. sí porque unos dicen que no está bien, pero yo la considero bonita porque nos permite contextualizarlo todo, nos permite a utilizar lo nuestro a ver lo que tenemos y lo que no tenemos cerca verdad, utilizar todos los recursos necesarios para hacer la educación, antes posiblemente no había esa opción verdad, porque a veces llegábamos hasta un lugar extremo, pero no conocíamos lo nuestro primero, pero esta podemos desprender de lo nuestro para llegar a lo grande verdad, es bonito, muy bonito yo lo considero muy importante todo lo que se está haciendo en la educación, pero lo que nos queda a nosotros como docentes tener preparación y tener retos para poder hacer cambios también, porque depende también de nosotros.

E: Usted qué cree, por lo que ha podido observar también en el tiempo de experiencia y en otros compañeros, que se facilita aplicar los ejes transversales ¿o es difícil? Digo esto, porque lo de la equidad es un eje transversal ¿verdad? Pero no sé qué tanto todos los compañeros tienen como que las herramientas para que ese eje transversal llevarlo a la práctica y que no se quede solo así, ¿volando verdad?

M. Tal vez no en todos o con todos los docentes se practica, porque a veces ellos todavía $\underline{\text { tienen la mentalidad yo vengo a dar mis cursos, o yo vengo a dar la teoría que me }}$ corresponde y hasta ahí terminó todo, siempre existe eso, no todos hemos llegado a entender

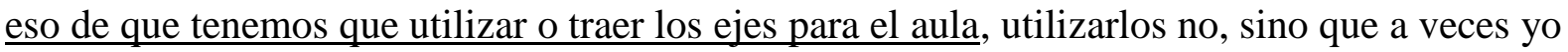


he visto a algunos maestros de que bueno yo solo vengo a lo mío y hasta ahí termina todo, porque lo creo necesario.

E: el contenido declarativo podríamos decir más verdad, más lo teórico.

M: si y no llegar a cumplir lo que es los actitudinales y ni llegamos mucho a lo que son los procedimentales, solamente contenidos y que aprendan, muy tradicionales.

E: O sea que tenemos retos entonces por delante, pues muchísimas gracias. 


\title{
Entrevista E06/B/H
}

\author{
E: Entrevistadora
}

M: Maestro

Subrayado: extractos literales tomados en el análisis

E. Ahí está. Bueno pues bienvenido, docente en Básico y Diversificado entonces, en primer lugar platicar un poquito sobre cómo mira usted eso de la equidad de género de etnia y social en la educación en Guatemala.

M. Bueno, desde el punto de vista de equidad de género pues la verdad de que sí actualmente hay oportunidad para todos; según cuentan en la comunidad donde trabajo en la tarde que anteriormente solo a los hombres les daban oportunidad de prepararse y a las mujeres solo les daban hasta por ejemplo en educación verdad, sexto primaria nada más de ahí en adelante ellas tenían que ayudar en la casa sin embargo pues ahora se está dando la oportunidad a ambas personas de igual manera la participación también se le está dando al hombre y a la mujer toma de decisiones por ejemplo verdad, en la comunidad se toma en cuenta la opinión de ambas personas.

E.Y dentro de sus aulas en Básico y Diversificado donde usted trabaja cómo ve esta parte de la equidad.

M. Los establecimientos son mixtos entonces en este caso se le da también la oportunidad a más personas y al menos se practica la convivencia verdad que es muy importante y eso ayuda a que se entiendan ambos géneros, hombres y mujeres.

E. Usted ha recibido a lo largo... me imagino que estudió primeramente magisterio a nivel Diversificado y ahora está estudiando... Si, es así verdad. Entonces ha recibido algún tipo de formación en los años de estudio que ha tenido como docente sobre cómo implementar la equidad en el aula dentro de los pensum que ha estudiado.

M. Pues fíjese que aparte de los cursos que aquí en la carrera de interculturalidad recibimos, también de parte de la institución donde trabajo estaba incluido en un programa de una $\mathrm{ONG}_{\text {}}$ y la verdad que ha sido un programa de mucho beneficio aparte de los materiales que nos han 
dado las técnicas de como involucrar la equidad digamos, en el aula verdad estrategias de cómo trabajar en grupo de como los grupos se relacionen ha ayudado demasiado. Ha sido uno de los programas que más me ha beneficiado durante este tiempo.

E. Entonces usted específicamente en sus aulas pone en práctica algún tipo de planificación que le ayude a trabajar en la equidad, o cómo lo hace. O pone en práctica estos materiales o estas estrategias.

M. Sí, en su mayoría sí porque la mayor parte de tareas que realizamos en el aula son más que todo de desarrollo ahí mismo verdad, entonces hagamos grupos de trabajo mixtos verdad, para ir promoviendo esa equidad entonces armamos grupos de trabajo y esos grupos de trabajo son mixtos y tratan de estar hombres y mujeres juntos verdad, más que todo para que $\underline{\text { se vayan adaptando a que la sociedad necesita eso verdad, que ambas personas se relacionen }}$ y que se lleven de la mejor manera entonces, en el aula si, al menos yo lo trabajo de esa manera verdad se le da oportunidad a las dos personas hombres y mujeres verdad, y tengo la oportunidad también de tener estudiantes de diferentes comunidades y hasta incluso de diferentes municipios de Totonicapán y fuera de y también se les da la misma oportunidad.

E. Ha podido ver usted alguna situación de discriminación que se dé en el establecimiento verdad, donde trabaja ya sea entre los mismos alumnos o entre docentes y alumnos puede ser discriminación de género digamos entre los jóvenes y las jovencitas o también discriminación por donde proceden si uno es de un cantón y otro es del centro si... discriminación podríamos decir.

M. Tuve una experiencia precisamente el día jueves una estudiante se acerco a mí y me dice: fíjese profe que he sido muy discriminada por ser de otra comunidad. La mayor parte uno no lo... Por la estancia que uno está en el salón con los estudiantes es un periodo, media hora tal vez cinco minutos una hora máximo que uno puede estar porque trabaja por periodos no puede estar toda la tarde ahí pero, esta señorita se acerca a mí y me dice he sido muy discriminada y la verdad me preocupo mucho porque no lo notamos en muchas ocasiones pero siento que la discriminación se sigue dando tal vez con menor porcentaje pero sí, de diferentes líneas, de diferentes ángulos si uno quiere verlo de esa manera se da por aspecto físico por ejemplo verdad hay alguien que es muy moreno por ejemplo o muy gordo verdad lo discriminan y se siente tal vez en algún momento separado del grupo. Es un poquito difícil 
notarlo, solo cuando en algún momento se da a conocer por esa persona y algunos que son muy evidentes verdad pero, en la mayoría de casos que yo he podido tener experiencia durante el tiempo de labor docente no ha sido notable simplemente se da en un tiempo de ausencia del maestro tal vez entonces eso a veces se da en ausencia del maestro y es el mismo estudiante que a veces lo da a conocer porque ya no soporta la discriminación que ahí se da entonces, sí se da la verdad que si se da en los establecimientos, lo difícil es hablar y dar a conocer que se está dando la discriminación. Algunos lo callan verdad por miedo, por temor, por vergüenza tal vez.

E.Y cuando se da un caso de estos que ya se da a conocer, usted por ejemplo como docente de qué manera interviene o como...

M. Pues fíjese que ahorita lo que procede primero es hablar con el joven verdad que está haciendo este tipo de discriminación, hablar con él verdad estar bajo observación en determinado tiempo una semana, dos semanas. Verificar por qué es así él verdad por qué trata... El caso de este joven es que no solamente es con una persona si no que es un poquito tal vez tener un remordimiento hacia las mujeres y entonces su problema ya es que viene desde la familia verdad ¿por qué? Habría que hacer una investigación o un diagnóstico, por qué tiene ese tipo de actitudes hablar con él, darle seguimiento. Si el caso sigue llamar al papa verdad en este caso comentarle o preguntarle por qué, si el caso digamos llegara a mayores buscar ayuda psicológica verdad.

E. Mire y qué dificultades encuentra usted para implementar este eje de equidad de género, etnia y social ya en los ciclos Básico y Diversificado que las características también son un poquito diferentes que en primaria por ejemplo, en preprimaria verdad donde uno como que tiene más de tiempo con los alumnos y todo. Encuentra usted dificultades para esto, para incluirlo en su planificación de alguna manera o se le hace sencillo.

M. Pues yo siento que depende mucho de la confianza que uno les dé a sus estudiantes el carácter del maestro... bueno el maestro debe ser aparte del maestro amigo del estudiante. Como usted menciona los niveles son distintos por ejemplo el nivel Diversificado es un poquito más profesional, las personas son más grandes tengo estudiantes que son mayores que yo, pero, sin embargo también tienen problemas entonces, yo siento que más que todo es fomentar o promover la comunicación. Al menos yo hasta incluso a veces sacrifico mis 
momentos de receso porque, como le digo una media hora, una hora no alcanza para tratar de cubrir todas las necesidades pero, siempre les he dicho a mis estudiantes. Mire yo, más allá de ser maestro no me miren solo como un maestro sino como un amigo en donde ustedes cuando necesiten de un consejo, de una ayuda, de alguna consulta pues, acudan a mí y sí han acudido algunos. Entonces es ahí donde yo aprovecho a veces verdad para comentarles sobre los problemas que tienen. Dentro de mi planificación de trabajo pues lo tengo contemplado es una utilización de metodología activa, participativa verdad donde puedan relacionarse, donde puedan convivir, donde puedan hasta incluso a veces bromear, divertirse tal vez en la clase. La educación ahora ya no es tanto tradicional donde el maestro va y dicta, sino que el maestro va da los parámetros de la actividad a trabajar y los estudiantes a veces sienten como que no estuvieran en la escuela verdad, como que estuvieran en un momento de convivencia en un día de campo verdad entonces, yo siento que... Al menos yo no he tenido tanto problema en ese sentido pero, depende mucho del maestro si el maestro ha cambiado o ha implementado todas las estrategias que ahora por ejemplo el Curriculum Nacional Base pide pues, siento que no tendría problemas. Ahora si el maestro sigue con la guía tradicionalista entonces, ahí $\underline{\text { si hay problemas porque hay un distanciamiento entre el alumno y el docente. }}$

E. En Diversificado en qué carrera imparte clases.

M. Trabajo con bachilleres y secretarias, secretariado.

E.Y secretariado, muy bien... Y bueno, ya para ir terminando no se me imagino que en estos niveles trabajan con material didáctico, o sea, si tienen libros o no se manejan libros de texto.

M. Sí, en cuanto al docente sí tiene sus libros verdad, a nosotros nos han recomendado bastante que estudiemos y nos preparemos muy bien para las clases. Los libros de texto en mi caso personal yo los uso en la casa por ejemplo para estudiar, para preparar mi tema, para la planificación por ejemplo de clases, estructurar bien mi tema el desarrollo del tema y luego la actividad como le digo; la actividad que va a realizar verdad por lo tanto... Vamos a ver un tema escribamos. Sino más allá bueno, fíjense que el tema es este ahora hagámoslo entonces, los libros de texto los utilizo yo en lo personal verdad por la naturaleza de los cursos que tengo los utilizo más en mi casa para mis clases.

E. Qué cursos son los que imparte perdón. 
M. Yo tengo por ejemplo, el área de expresión artística, tengo el área de psicología y redacción.

E. Y los estudiantes cuentan con un libro cada uno o no.

M. En el caso de redacción sí, el problema es de que el libro a veces los encierra a ellos solo a un modelo verdad cuando en realidad hay otras bibliografías que pueden ampliar los temas entonces, usamos el libro como referencia pero, de allí hay muchas tareas más que ellos tienen que buscar verdad tienen que crear su propio conocimiento.

E. Le decía esto porque no sé usted qué valoración puede hacer de los libros de texto, referente a la equidad. Si el mismo libro tiene contenidos, tiene tipos de actividades que se proponen, imágenes, ejemplos que promueven la equidad, o sea, si usted ha tenido la oportunidad de analizar un poquito el material en ese sentido o no, o son libros que de alguna manera no hacen mención en absoluto a este tema o que incluso en determinado momento promueven lo contrario. No lo se...

M. Pues por ejemplo hablemos de secretariado. En cuanto a secretariado pues como son cursos de redacción prácticamente no habla casi nada de equidad de género. Psicología pues tenemos un material que sí verdad tiene imágenes donde aparecen la comprensión donde aparece por ejemplo la tolerancia verdad como desde el punto de vista de la psicología es importante ser tolerante, ser respetuoso. En el caso de expresión artística no tenemos un libro pero los trabajos que realizamos siempre aparecen imágenes donde hay un hombre y una mujer verdad y están platicando están relacionándose. En el caso del Básico ahí tengo el área de ciencias sociales, en el área de ciencias sociales el libro que utilizamos es un libro de Santillana y ahí pues aparecen demasiadas gráficas verdad donde sí, se practica por ejemplo: la interculturalidad, la identidad, la cultura, la relación hasta incluso de culturas, idiomas por ejemplo como hablar distintos idiomas, cómo relacionarnos con personas de distintos lugares.

E. Pues muy bien, ya solo por último digamos para concluir. Usted cree que, o sea, qué tan importante es el aporte de la educación desde estos ciclos que usted imparte verdad. Básico y Diversificado que ya son un poquito elevados, usted cree que sí tiene un papel importante para ir cambiando la sociedad hacia un modelo de sociedad más equitativo digamos, donde podamos ir eliminando el machismo, donde podamos ir eliminando la discriminación por 
motivo de etnia por motivo de procedencia social. Como lo considera, cree que el papel si, o sea, si hay una posibilidad de hacer cambios desde estos niveles o considera que de otros niveles es mayor el cambio o no hay posibilidad, no sé, como lo ve.

M. Pues fíjese que ya las bases hechas es difícil pero no imposible cambiar digamos algunos paradigmas que han venido desde la niñez desde el hogar por ejemplo, desde la casa. Me he encontrado con señoritas verdad que no se atreven a acercarse a un joven por ejemplo porque en su casa les han dicho que los hombres son malos verdad que los hombres solo las quieren tocar por ejemplo entonces, viven aisladas en su mundo solamente feminista esos parámetros, esos paradigmas cuesta cambiarlos pero, me he topado con experiencias muy bonitas donde ya terminando la carrera, terminando el Básico salen con una idea distinta. Se puede lograr desde ese punto de vista. Desde ese nivel perdón, se puede lograr digamos en nivel Básico se puede lograr mucho todavía. En el nivel Diversificado que ya están hechas aún más las bases pero, se puede lograr yo siento de que el maestro tiene que dar un poco más pero si se puede lograr pero, sí desde mi punto de vista lo recomendable es que desde chiquitos desde pequeños desde nivel pre primario, primario verdad se venga hablando de estos temas para que ya cuando ellos lleguen al Básico no tengan problemas de índole de género por ejemplo verdad entonces, ir enseñándole por ejemplo a los niños y a las niñas que ambos tienen las mismas oportunidades que los dos tienen la misma igualdad, que hombre y mujer valen lo mismo verdad que tienen las mismas oportunidades de opinar, de participar, de ser tomados en cuenta que el hombre y la mujer son dos seres que Dios creó para que convivan en paz verdad el problema es que de niños les enseñan que el hombre es una persona y la mujer otra persona distinta entonces, ahí cuesta un poquito cambiar eso pero, el maestro debe de dar un poquito más y detectar el problema si es grave pues tratar de buscar ayuda profesional.

E. Muchas gracias, pues yo le agradezco un montón todos sus aportes. 


\title{
Entrevista E07/D/H
}

\author{
E: Entrevistadora \\ M: Maestro
}

Subrayado: extractos literales tomados en el análisis

E. Bienvenido, docente de Diversificado y Básico en Chimaltenango, la idea es compartir un poquito sobre en primer lugar cómo mira usted que está la equidad.

M. muy bien, bueno yo creo que uno de los primeros acercamientos que podemos tener y que podemos pensar, verdad, es el hecho de que todavía en algunas áreas, específicamente en donde yo me desenvuelvo veo por ejemplo un porcentaje mucho mayor de hombres en los niveles educativos cualquiera que fuera desde primaria a Básico y Diversificado el nivel de diferencia que tenemos con las mujeres verdad, me atrevería a decir que más o menos un $\underline{70 \%}$ a un $75 \%$ de hombres y el resto de mujeres verdad, siempre ha habido mucha diferencia me acabo de topar precisamente con un caso que me decía la señora, para qué va a estudiar mi hija? Si se va a casar. Entonces no, los muchachos sí que estudien entonces eso ya nos muestra a nosotros de alguna manera la forma en que la gente a veces ve el que una mujer estudie y se prepare y eso hace mucho la diferencia y eso hace que se enfoque mucho en el ámbito familiar, de ahí surge a veces la idea de que el hombre si estudie y la mujer no.

E. No sé si usted ve esto como más grave en estos niveles, o en el nivel Diversificado un poquito alto $0 .$.

M. Es mucho más alto porque normalmente si se le va a dar educación a la niña, se le da en $\underline{\text { los niveles de preprimaria y primaria y se piensa que con eso ya es suficiente para ella, como }}$ para desenvolverse, ya lo demás ya no es tan útil como para ella, entonces sobre todo en una carrera muchas veces se piensa que ya no siga estudiando.

E. Mire, me imagino yo que estudió primeramente magisterio, el nivel Diversificado y después se incorpora en la universidad, ¿así es?

M. No, no es así, no yo tengo un bachillerato en diseño gráfico, en nivel medio y hasta ahora que estoy trabajando con el profesorado y la licenciatura. 
E. Ah bueno, pero entonces digamos en el tiempo que está ya estudiando específicamente la materia, o sea en el campo del magisterio, ha recibido información sobre cómo implementar este eje de equidad de género y de etnia social, es un eje transversal, ha recibido formación sobre cómo hacerlo dentro del pensum?

M. Dentro, así como una capacitación específicamente o (E: o digamos me imagino que tienen asignaturas asignadas con curriculum, didáctica y esas cosas) M: no, no hemos $\underline{\text { trabajado en ningún momento, tal vez se ha tocado dentro de los cursos de la universidad, tal }}$ vez en algún momento en derechos humanos, es en donde vemos un poquito el derecho de equidad y otras cosas, que es ahí donde lo hemos visto más que todo, específicamente ahorita estamos trabajando un poco con la licenciada que está trabajando con nosotros de la equidad, precisamente y tal vez mayor acercamiento...

E. Sí pues, digamos ya en su práctica docente, las iniciativas que usted implementa pues es por iniciativa, o sea digamos es usted mismo en su planificación el que tiene que decir: bueno, de qué manera voy a tomar yo en cuenta esta educación en la equidad, ¿cómo lo hace? ¿Lo hace no lo hace? ¿O las materias que usted imparte casi no se prestan mucho o poco?

M. Bueno yo creo como docente que sí cualquier materia se puede prestar para el hecho de trabajar lo que es la equidad y en el caso de seminario que es uno de los cursos que nos abre mucho el panorama para trabajar esto, creo que es ahí donde se puede desarrollar mucho verdad, tengo la oportunidad de tener estudiantes directamente del área central de Chimaltenango, del área urbana, pero tenemos mucha gente en el colegio que viene de las áreas rurales, entonces como estamos hablando de equidad, allá hay diferencias, desgraciadamente nuestra sociedad se marcan verdad, de una persona que está en el área urbana, de una persona que está en el área rural y tengo la oportunidad por ejemplo de tener a un joven estudiante de Santiago Atitlán, que él está en área con nosotros, por ejemplo y ahí hay bastante más diferencia por que normalmente allá, aunque nosotros no impartimos en el idioma maternos que es el kakchiquel, que se supone que ese es el idioma materno, el viene de un idioma materno tzjutujil, entonces hay diferencia, increíblemente se ha dado las situaciones verdad, yo me he dado cuenta y me han preguntado algunos estudiantes porque él habla así, verdad, porque ellos tienen un acento diferente, tiene una forma de expresarse muy diferente y entonces hemos aprovechado esos espacios para decirle a ellos que la situación del idioma muchas veces nos marca a nosotros diferencias en cuanto al trato y la forma 
verdad, pero que debemos aprender a respetar esas diferencias para poder tener una mejor convivencia, pienso que el mejor curso donde lo he podido practicar es en seminario, pero vuelvo a lo mismo, creo que incluso por que con esto que le decía precisamente tengo unas niñas de Básico las que se me acercaron verdad, y él este chico esta por graduarse de sexto de electricidad ahorita entonces hay diferencias pero ellos preguntan y creo que hay mucho respeto, yo creo que los jóvenes tienen una idea a veces mucho mejor que gente de más edad en cuanto al respeto, es increíble pero en áreas de jóvenes en donde si se respetan mucho, no importando el traje, el lugar de donde se proviene, yo creo que hay grupos de jóvenes que han entendido ya esto y que lo están manejando muy bien.

E. Es muy interesante eso que usted dice porque precisamente estos cambios que son más cambios de mentalidad son generacionales ¿verdad? Y entonces qué bueno que podamos ver que la juventud sí... tal vez sus papás no, en los papás vamos a encontrar en los abuelitos algunas ideas que pues que son unas antiguas pero qué bueno que ahora pueda haber y esto me parece interesante porque precisamente es decir, bueno que papel cree usted que tiene la educación, en los establecimientos en ese cambio actitudinal de las generaciones.

M. Bueno yo creo (E; específicamente lo que usted en sus grados, verdad porque ya no es lo mismo pre primaria podríamos decir que Diversificado) yo creo que definitivamente la educación en este caso juega un papel Básico e importante yo siempre he pensado que el docente, que es el que está apegado al estudiante tiene la gran oportunidad de marcar un cambio, verdad, muchas veces, como usted decía al principio, en lo teórico existe un eje verdad y nos lo marca y nos dice que lo trabajemos pero muchas veces no se llega a eso en la práctica, yo creo que el docente tiene ese espacio abierto para precisamente trabajarlo y una de las cosas creo yo que son básicas en el docente es que el docente no llegue a un aula con un nivel superior a sus estudiantes, si no que tenemos que tener la capacidad de nivelarnos hacía ellos para poder elevarlos desde ahí a un nivel que queremos llevarlos, entonces desde ahí vamos a trabajar la equidad, verdad, porque no está viendo, es cierto por un título el estudio, pero yo creo que eso en ningún momento nos hace más, porque nosotros el proceso es enseñanza-aprendizaje, entonces creo que tenemos que ponernos al nivel de los estudiantes y desde ahí llevarlos a un mejor nivel, creo que existe ese espacio y creo como le decía anteriormente que cualquier curso nos da a nosotros la opción para poder ampliarnos, abrirnos y trabajar esto verdad, sobre todo se marca y a veces por ejemplo la denigración que se le hace a la mujer verdad, y a veces nosotros marcamos mucho eso, yo tengo jóvenes de 
fin de semana que ellos laboran ya, que tienen una vida ya casi hecha, trabajos, responsabilidades y hemos trabajado mucho con ellos en cualquier curso porque se da que muchas veces ven a una señorita y la molestan verdad, el "tststst", el adiós muñequita y cosas así... pero hay cosas que a veces salen de los varones que denigran a la mujer, entonces también creo que desde ese área a veces tratamos de enrolarlos, decirles del respeto y algo que es base también creo yo, es fomentar en las señoritas y niñas el respeto que ellas mismas $\underline{\text { se tienen que tener, para que entonces se les dé el respeto de parte de los varones hacia ellas }}$ verdad, y eso es fundamental para que pues provoquemos un poquito más de equidad en nosotros.

E. Esto lo ha podido hacer usted, ¿a través de alguna actividad particular o alguna manera particular de trabajar en el aula o algo así?

M. Bueno, dentro de una de las partes que se trabaja en seminario hay nueve ámbitos que se trabajan, y uno de los ámbitos precisamente es equidad verdad, ahí se trabaja equidad laboral, de género y social, entonces ahí es donde nosotros lo fomentamos, hay grupos de seminario que han trabajado este tema ya específicamente para su proyecto y cuando nosotros lo damos a conocer a padres de familia y al colegio en general ahí aprovechamos para de alguna manera hacer un hincapié fuerte, en que los jóvenes puedan retomar eso y se cambia la mentalidad.

E. En el establecimiento o establecimientos donde labora ha podido observar usted alguna situación, ya sea por ejemplo de la forma en cómo se organiza el establecimiento, podríamos decir la forma como se utilizan los espacios de recreo, los espacios comunes del establecimiento, la forma o la metodología como se imparten las clases, ha podido observar usted cosas que cree que mas favorecen la inequidad o no se están dando situaciones de ese tipo.

M. Bueno, gracias a Dios en el tiempo que tengo, no se ha dado, precisamente esta semana a nosotros nos estaban haciendo una evaluación docente y encontramos que muchos jóvenes se quejaban de un profesor, precisamente porque decían verdad él les da educación física y decían los jóvenes: es que él se pone a platicar con las señoritas y a todos los demás los tiene corriendo y haciendo ejercicio y sudando, mientras él está ahí y decían ellos los varones; y por qué a ella no la ponen a hacer ejercicio y por qué ella solo esta platicando (E; solo es una 
señorita entre tantas? ) no hay en ese grupo hay dos o tres señoritas, pero ella específicamente esta así como que muy mimada por el profesor y ella tiene, bueno en algunos casos por ejemplo que hemos tenido en el colegio, pues algunas señoritas definitivamente no pueden hacer educación física, pero en el caso de ella no tienen ningún problema, entonces eso se da y a veces en este caso es contrario pero se da más y los hombres lo resienten de alguna manera, dicen por qué ella sí, por qué ella tiene ese privilegio? Y se da también a veces porque dentro del mismo claustro de docentes hay más varones impartiendo clases que mujeres, y a veces siempre se da ese favoritismo de algunos docentes hacia el género femenino verdad, esperando no sé por otras situaciones peores, verdad (E: que también lamentablemente se pueden dar) desgraciadamente y ahí estaríamos nosotros cayendo en una situación mucho más grave (E: en un delito definitivamente) hasta ese punto, pero sí a veces

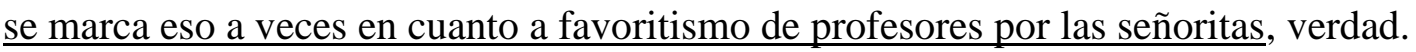

E. Mire y ya una curiosidad, este curso de artes industriales es mixto ¿o es solo para jóvenes?

M. Bueno, nosotros lo trabajamos diferente, desde el CNB es mixto y se trabaja. Porque incluso aquel curso hogar, que se llamaba, también lo trabajan hombres y mujeres, este curso es mixto, en el caso por el tipo de establecimiento en el que yo trabajo, que es un instituto tecnológico, nosotros trabajamos con ellos, por ejemplo las carreras de diseño gráfico, mecánica, electricidad y electrónica, entonces a mi me encomendaron trabajar esas 4 áreas en el curso de artes industriales, o sea acabo yo de terminar precisamente el día de ayer, de trabajar con un grupo donde presentaron proyectos de diseño grafico a nivel general, tal vez donde se marca o se va a marcar un poquito más la diferencia podría ser, es en cuanto a mecánica y electricidad, estas son carreras que van dirigidas hacia los varones, pero pienso que también ahí tenemos otro espacio para trabajar porque conozco dos instituciones en la capital donde hay mujeres que están con su overol, trabajando como mecánicas sin ningún problema y yo creo que eso es algo que también se está abriendo en nuestro país, verdad, ver mujeres en carreras que normalmente no eran y desde ahí desde el CNB ya hay a veces diferencia de género verdad, carreras para varones y carreras para mujeres, y yo creo que desde ahí se debe romper y se debería de trabajar esas situaciones verdad. (E; así es, así es, fundamental, además) 
E. Bueno pues yo creo que ya mas o menos con esto estamos con todo lo que estamos platicando, no sé si hay algo más que usted en esta plática que tenemos le haya ido surgiendo sobre el tema ¿no?

M. Pues no sé, yo creo que es un tema muy importante verdad, yo veo diferencias muy grandes en cuanto a lo que yo vengo a estudiar aquí y lo que veo haya del otro lado verdad, haciendo una comparación increíblemente en el centro universitario nosotros tenemos lo contrario, tenemos un $60 \%$ de mujeres y solo un $40 \%$ de varones, a diferencia de estos sectores verdad y creo que lo veo así; Quetzaltenango, Totonicapán por estar cerca de esta área, está tratando de cambiar esa mentalidad y creo que la gente ya lo está haciendo, en áreas como Chimaltenango, yo siempre he dicho que es increíble, estamos a la par de la capital, pero tenemos un rechazo mucho más grande que departamentos del suroccidente donde ya se ha cambiado eses pensamiento verdad, sin embargo creo también que es un espacio abierto para trabajar precisamente verdad, porque si nos presenta problema creo que tenemos las situaciones para poder trabajar verdad.

E. Exactamente, yo si le animo bastante, porque además creo que es un tema que a veces también cuando se habla de equidad de género bueno, como que somos las mujeres las que lo vamos a trabajar verdad, o como que tenemos más sensibilidad hacía ese tema, y yo pienso que uno no es así, todos podemos sentirnos sensibilizados y sentirnos con ganas de aportar y otro, es importante el aporte de ustedes los hombres, porque también son un modelo para los jóvenes, para las jovencitas, es decir no solo las mujeres sino los hombres también defienden la equidad, verdad.

M. Si exacto, bueno y también habría que modificar cosas de estructura que nos llaman y nos llevan a eso, porque después del machismo que hemos vivido, desgraciadamente creo yo que estamos viviendo en un traslape, donde podríamos caer en todo lo contrario del machismo a un feminismo que también nos va a traer efectos negativos, porque no va a haber equidad otra vez y eso se marca desde las leyes de nuestro país, porque sencillamente a veces el hombre por ejemplo, tienen muy pocos derechos a veces relativamente con la mujer, lógicamente, históricamente por el trato que la mujer ha tenido que eso es normal, pero hasta cierto punto entonces ya no deberíamos irnos hasta el otro extremo, si no desde ahí ordenar para que exista equidad, y es lo que creo que podríamos trabajar nosotros como docentes. 
E. Pues muchísimas gracias.... 


\title{
Entrevista E08/P/M
}

\author{
E: Entrevistadora \\ M: Maestra
}

Subrayado: extractos literales tomados en el análisis

E: Estamos con seño Miriam de la escuela de Pachaj, que es maestra del grado de $2^{\circ}$. Estamos ampliando un poco lo que ya trabajamos con los padres de familia y quisiéramos que nos pueda compartir un poco cuál es su experiencia respecto a la equidad de género aquí en el aula.

P: Pues la verdad es que trabajar sobre la equidad de género al grado en que llevo ahorita, que es segundo grado, pues cuando vienen los niños a la escuela yo creo que vienen formados desde el hogar. Nosotros quisiéramos que se comience a trabajar equidad de género desde muy pequeños. En párvulos, en preprimaria ellos siempre juegan niñas y niños, siempre. Ya en segundo, a veces se da en primero, como que se van a apartando. Los niños dicen, no mi mamá dice que yo solo con los niños tengo que estar, con las niñas no. Y cuando salimos por ejemplo a algún trabajo en grupo o se les da a ellos la oportunidad de que trabajen en grupo, se escogen solo varones y solo niñas. Entonces en mi caso yo he trabajado y yo les digo que tienen que estar niños y niñas. Pero cuando tenemos educación física ellos salen y los varones no quieren ni que las niñas los toquen. Es que mi mamá dice que con los niños tengo que jugar. Pero entonces nosotros tenemos ese trabajo de que ellos puedan socializarse con las niñas. A veces exposiciones en que pasan un niño, una niña. Ellos ya saben, cuando vamos a física y tenemos que jugar, formen u círculo saben que tienen que quedarse intercalados los niños y las niñas. Ya cuando van recreciendo tercero, cuarto y quinto ya entre ellos mismos se escogen. Entonces todo esto viene del hogar porque siempre ha existido mucho machismo, donde no se le da oportunidad a las mujeres en la participación en la sociedad o en cualquier grupo, entonces lo mismo quieren hacer con sus hijos. Y se ve donde hay familias muy sociables, muy abiertas, a veces cuando tienen trabajos vienen en grupo. Yo lo que hago es poner en una fila a las niñas y en otra a los niños y enumerarlos y al momento de hacer grupos tienen que quedar los niños con las niñas. Entonces ya lo he logrado, gracias a Dios ya ellos ya saben, los grupos, no la seño nos va a regañar porque estamos más niñas aquí o más niños allí, cambiémonos. 
E: Seño Miriam, ¿cómo visualiza el CNB, considera que encuentra apoyo para trabajar esta cuestión de equidad entro del $\mathrm{CNB}$, porque está el eje transversal, cómo ha sentido su aplicación, es un apoyo?

P: Pues, puede que sea un apoyo pero tal vez con un porcentaje un poquito bajo porque ya ve que el CNB lo han hecho no a nuestra realidad sino a la realidad de ciudad, está basado a la realidad de ciudad. Trabajando nosotros aquí tenemos que acoplarlo a nuestra realidad. Hay que trabajar de acuerdo a nuestro entorno y condiciones. Pero sí, en eso pues hay una ayuda.

E: Muy bien seño Miriam, muchas gracias. Nos ha explicado cómo desde el hogar viene la educación pero cómo también aquí en la escuela se puede aportar.

P: Se puede aportar bastante porque si nosotros permitimos que los niños hagan lo que ellos tienen que hacer a como les dicen es muy difícil lograrlo. Pero ya conforme ellos van aprendiendo y llegan a los grados más altos, ellos ya se organizan solos, participan, saben que tienen los mismos derechos, las mismas oportunidades y van creciendo, van a la secundaria y van al Diversificado y tienen un cimiento, vayan a donde vayan ellos siempre saben que tienen sus derechos. 


\title{
Entrevista E09/P/H
}

\author{
E: Entrevistadora \\ M: Maestro
}

Subrayado: extractos literales tomados en el análisis

E: Estamos nuevamente en la escuela de Pachaj y le pedimos al profesor que por favor se presente y en qué grado labora.

P: Buenos días mi nombre es Víctor Felipe Baquiax, soy de la comunidad de Chuatroj y laborando para la escuela de Pachaj y actualmente estoy impartiendo 6o grado, que es el último grado del nivel primario.

E: Víctor, ¿cómo considera usted el tema de la igualdad de género, de etnia y social en nuestro medio?

P: Bueno creo que es un tema muy complejo hablar de la equidad porque por diversas $\underline{\text { razones políticas, culturales e históricas la equidad de género no se ha logrado aplicar, diría }}$ yo, en la mayoría de los ámbitos tanto social, político, religioso, inclusive cultural, predomina el hombre sobre la mujer; en ese sentido, entonces eso es lo que yo puedo hablar de ese tema.

E: Y al respecto de la desigualdad que existe en el medio, ¿cómo ve usted el papel de la escuela, qué peso tiene o de qué manera interviene?

P: $\underline{\text { creo que el papel de la escuela es mucho y también es poco. Es mucho en el sentido de que }}$ aquí se pueden ir creando nuevos paradigmas de vida, nuevas ideologías de vida, lo cual veo yo que sí es bien recepcionado por parte de los niños y las niñas, especialmente de las niñas, entonces creo yo que eso de algún modo va poniendo las primeras semillas para poder cambiar la mentalidad. Eh, aunque deja en tela de duda la continuidad en otros niveles pero a mi consideración pienso que es un tema generalizado que sí está teniendo sus frutos. $\underline{\text { Por otro }}$ $\underline{\text { lado, poco porque muchas veces los patrones familiares que traen los niños es mucho más }}$ poderoso que el papel de la escuela. Entonces yo creo que por eso es que repito que tiene mucho el papel de la escuela y tiene que ver poco. En cuanto encontremos gente, padres de $\underline{\text { familia, que vean bien el papel de buscar la igualdad, entonces creo que el papel de la escuela }}$ cae en buena semilla. Ahora cuando no, entonces se vuelve difícil por ese lado. Entonces 
obviamente los niños, que están más en la casa, el patrono de la desigualdad sigue predominando.

E: Y mire el $\mathrm{CNB}$, en él encuentra alguna fortaleza, ¿cómo ve usted el CNB como herramienta que nos pueda ayudar a intervenir en esta educación en equidad?

P: Yo siento que este tema no es que sea, yo no lo miro como contenido, lo miro como acción, como ejemplos de vida, porque el CNB contempla en un contenido la equidad de género. Si yo lo quiero abordar en 2, 3 clases, ahí se murió. Ahora, la cotidianidad que vivimos con los niños, por ejemplo de ir a traer refacción, que solo las mujeres, que la limpieza solo las mujeres, entonces yo siento que eso si tieneque ver mucho con el tema del CNB pero siento que a equidad es más cotidiana, por supuesto con las experiencias, el aporte desde la docencia.

E: Y cómo ve usted, hablando de eso, la verdad que me parece interesante esa cotidianidad acá en la escuela, ¿cómo la mira desde el punto de vista de la equidad?

P: pues yo desde mi quizás la formación mía ya sea un poco más amplia y desde inicio de clases aquí ya tengo los lineamientos de trabajo. Desde el inicio voy tratando de fomentar esa actitud de equidad. Barren tanto hombres como mujeres, van a ir a traer refacción tanto hombres como mujeres, entonces si desde el inicio cimientas eso ya no tienes complicaciones, pero si inicias y después quieres cambiar algo ya es muy complicado. Entonces, esa cotidianidad debe trabajarse desde el inicio, al menos a mí me ha funcionado.

E: muy bien profe Víctor, le agradecemos mucho los aportes y mucho ánimo en esta tarea que va mucho más allá de los contenidos. 


\title{
Entrevista E10/P/M
}

\author{
E: Entrevistadora \\ M: Maestra
}

Subrayado: extractos literales tomados en el análisis

\author{
E: ¿Cuál es su nombre? \\ P: Irma Catarina Xep García.
}

E: ¿Usted considera que existe igualdad en nuestro medio?

P: Igualdad no existe, en este caso porque nuestra manera de pensar, de ver las cosas, no es igual. Ahora con respecto a derechos humanos e igualdad, pues existe en documentos, en los acuerdos de paz, donde dice que todos somos iguales, pero ya en la realidad existe mucha diferencia, ya que por la posición social que tiene cada grupo social y económico hay desigualdad. Desde las clases sociales altas, medias y bajas sabemos que hay desigualdad tanto altas, medias y bajas. En las altas conocemos que hay medias y bajas también dentro de la clase social alta. Y en la media, igual. En la división social de las clases. En la clase social baja en la que estamos nosotros, con la economía que tenemos, también está la alta, media y baja. Ahora voy a hablar sobre la clase baja, que está dividida en subclases, gente que tiene una casa donde vivir o un negocio que les está dejando cómo sostenerse. Y la media pues son $\underline{\text { los trabajadores que también tienen una casa pero que son obreros dentro de una casa, por }}$ ejemplo aquí hay microempresas de tejeduría y ellos tienen sus obreros, sus trabajadores, esos trabajadores tienen una casita donde vivir, cómo sostenerse y cómo sostener a sus hijos para que vengan a la escuela. La clase baja son aquellas personas que no tienen trabajo no $\underline{\text { tienen como sostenerse económicamente, no tienen nada seguro, ellos durante el día solo }}$ comen dos veces, ven qué buscar, un pequeño trabajo, tal vez planchada, tal vez lavada, pero no es todos los días. Entonces aunque los vemos tan bonitos en la calle, porque todos luchan por tener el traje, usar el traje, pero con respecto a sus alimentos, pues mucho sufren porque solo comen 2 veces o $1 \mathrm{vez}$, eso es una triste realidad que no se miraba antes porque antes aunque tamalito, o tamalito con atol, con el mismo maíz per había qué comer, hoy ya no es así. Me da tristeza escuchar a muchas madres de familia cuando me dices no tenemos comida. Solo nos sostenemos con un vasito de atol en el desayuno y en el almuerzo si encontramos hierbas o alguna verdura y en la tarde a veces sin cenar. Es una triste realidad en 
una tierra tan rica, que deja, pero pienso que hace falta educación, orientación y conciencia de la realidad.

E: Y precisamente como la educación es un factor clave, desde la escuela qué visualiza que se puede hacer por la igualdad, tanto de clases como entre mujeres y hombres, etnias...

P: Desde la escuela es inculcarles valores, valores que nuestros antepasados nos han enseñado, el respeto a la madre naturaleza, el respeto a nuestro hermanos mayores, el sol, la tierra, a todo lo creado, a los animales, que para nosotros como mayas son los hermanos mayores y luego entre nosotros, respetando lo ajeno, respetando las cosas de los demás. Nuestros antepasados nos han enseñado que debemos respetar a los mayores y colaborar con ellos en el trabajo que se realiza en el campo. Pero lamentablemente en estos tiempos estos valores se han perdido ya, ya los valores de nuestros ancestros ya en el CNB o valores que están puestos ya por medios de comunicación como el internet, puyes ya no se está educando con esos valores. Pienso que las familias están en una decadencia, en un caos de desvalorización de ellos mismos. He visto la realidad en nuestra comunidad de Pachaj, las familias que logran estar unidas y buscar una salida al sostenimiento de la economía, lo van logrando y los niños acá son los que tienen para venir a la escuela, para entregar sus tareas y hacen las tareas y su estado emocional es equilibrado. Pero en las familias que no saben sobrellevar la decadencia de la pobreza existente en nuestro país, por ejemplo, sufren alcoholismo, al ver que no hay cómo sobrevivir, no hay trabajo, el hombre se inclina al alcoholismo porque ya no hay salida. La esposa lucha con ellos y trata de ver qué encuentra con algún trabajito porque aquí con los tejidos de cortes hay mucho trabajo que hacer con los que tejen los cortes, entonces ellos se meten en este trabajo a henchir que le llaman, cada área del trabajo, otros a desatar, otros a amarrar y mujeres que se dedican a esto le dan más o menos el sustento a sus hijos aunque no completo porque lo que alcanzan ganar son como Q1, 10 centavos, o que vale un cordel para estar desatando, entonces al día van ganando como Q10 para poder sostener y comprar algo. Niños venidos de estas familias con decadencia, con desintegración con alcoholismo, son los que bien a afectar esta orientación. Aunque por medio de esta realidad nosotros logramos orientar a los niños y a través de esta realidad les hacemos conciencia que es necesario que nuestra sociedad tiene que cambiar, con ustedes, ustedes sufren hambre, sufren miseria, tienen que trabajar en las tardes, no hacen la tarea en la tarde porque tienen que ir a trabajar. Y yo les platico esto, yo sé que ustedes sufren, la mayoría son los que sufren. Yo les hablo de esta realidad. Entonces, trabajemos con ganas en la escuela, las 5 horas que tenemos de trabajo aprovechémoslo al máximo. Entonces 
trato de hacerles conciencia de lo que ellos piden y que es necesario que a través de estos sufrimientos salgan de donde están. Trabajamos juntos para salir de donde estamos. Entonces a través de diagnosticar la realidad, gracias a Dios a principios de año sembramos, hacemos huertos escolares en las casas de ellos, les enseño a sembrar rábano, hierbas, lechuga, todas las verduras y gracias a Dios han respondido. Y los que no tienen un pedazo de tierra donde cultivar les he dado algunas técnicas. Los plásticos desechables que mucha gente los deja tirados, se pueden abrir agujeros y meter tierra y sembrar dentro de ellas y ponerlo en un lugarcito donde los pollos no lo logren alcanzar. Porque he visto que algunos lo que no tienen tierra lo hacen en botellas y así pueden comer. Porque de qué me sirve, yo acá me esfuerzo porque yo también estudio para mejorar mis clases dentro de mi aula y conocer a situación que vivimos y a base de esto mejorar. Ah sabemos que ellos sufren una realidad muy fuerte por lo económico. Entonces, vamos a sus casas y vamos a sembrar los rábanos, ellos se dedican al cultivo, les doy las técnicas de cómo cultivarlo. Ellos vienen hasta con sus papás y dicen, mire mi hijo ya puede producir. Esto es lo que yo hago, está a mi alcance, pero en igualdad de género siempre está un poco difícil porque siempre como que existe el machismo en nuestra comunidad. Aunque ya está bajando y estamos tratando dentro del aula que el $\underline{\text { trabajo sea equitativo, que sea igualitario, hombres y mujeres valemos igual, los alumnos lo }}$ ponen en práctica acá. El problema está en el hogar. Los padres de familia necesitan también orientación. Necesitan una escuela donde educarse y cómo educar a los hijos. No existe porque estos padres a veces no llegaron a sacar el sexto grado, o no llegaron a estudiar, entonces ellos no están instruidos en valores, en ser verdaderos padres.

E: Decía usted que el curriculum tiene algunos ejes, valores, uno de ellos es el de equidad de género, etnia y social. ¿Ha tenido usted alguna experiencia de implementar este eje? ¿Ha recibido capacitación?

P: Pues el eje de equidad de género e igualdad de género, está plasmado en el CNB pero los comprometidos a que estos se socialice somos nosotros los docentes. En dónde aplicamos este eje es dentro de las aulas y fuera de ellas. Dentro de las aulas los trabajos son grupales, por eso los escritorios son así. Trabajamos muchas técnicas, mesas redondas, exposiciones, danzas, juegos, donde niñas y niños están involucrados, lo hacen tanto hombres, tanto mujeres. Todos los trabajos en grupo siempre hay 3 varones, 3 mujeres, o 2 varones, 2 mujeres. Cuando los niños vienen a la escuela tienen esa costumbre, se juntan solo los varones o solo las mujeres, y ahí es en donde nosotros trabajamos esta equidad donde el trabajo en grupo lo tienen que hacer entre 3 niñas y 3 varones, estamos integrando varones y 
mujeres. Los juegos, por ejemplo en educación física, también. Basquetbol lo juegan los varones y mujeres. El futbol, también. A las mujeres también les gusta el futbol y el basquetbol. Porque antes el basquetbol es solo para mujeres, el futbol solo para varones, pero ahora gracias a Dios, ahora no, con este eje, es un cambio que estamos dando.

E: le agradezco mucho todo lo que ha compartido. 


\section{E11/M/M}

E: Entrevistadora

M1: madre 1 de niña de primaria

M2: madre 2 de niña de primaria

Subrayado: extractos literales tomados en el análisis

E: Doña Catalina y doña Ruth, escuela de Pachaj. En qué grado están sus hijos.

M1: en cuarto primaria, tengo una hija nada más.

E: el tema que venimos platicando es cómo sienten las mamás la educación que se da en la escuela, referido a cómo educan a las niñas y a los niños, será que los estamos educando por igual, vemos alguna diferencia, qué pensamos nosotros de esa igualdad, ¿cómo lo mira usted?

M1: pues está bien porque mi niña siempre ha sido destacada, abanderada. Pensamos que la educación no solo es aquí, también es en la casa, si nosotros la educamos bien, aquí viene bien.

E: ¿Qué piensa usted de la igualdad entre mujeres y hombres, niños y niños?

M1: aquí los tratan igual.

E: y en la vida adulta, ¿hay igualdad entre mujeres y hombres?

M1: sí, valen igual, porque en otras comunidades lejanas no les dan educación a las mujeres, en nuestro caso, tengo 3 niñas y a ellas les vamos a dar educación hasta terminar, hasta donde ellas dejen de estudiar.

M2: Pues bueno yo creo que depende cada familia, cada familia educamos de diferente forma a nuestros hijos y yo veo que ahora ya es poquito más amplio que ya es casi la igualdad, no como antes que había más diferencia, verdad, había un poquito más de machismo, digámoslo así, pero ahora ya es diferente.

E: ¿Y aquí en la escuela puede percibir usted alguna actividad que se haga para que los niños aprendan a respetarse por igual? 
M2: pues fíjese que aquí tanto no le puedo decir, porque mi hija estudia en otra escuela que está allá arriba. Pero yo he visto que allá las actividades que hacen tratan de mantener que tanto las mujeres deben de respetar a los hombres y los hombres a las mujeres.

E: ¿Y hay algo en lo que les gustaría que la escuela les colabore en la formación de sus hijos respecto a la equidad de género?

M2: tal vez un poco más en educación sexual. En casa los orientamos, pero un poquito más en la escuela, pienso.

M1: estoy de acuerdo. Yo creo que ahora ya no es un tema de ocultarlo, ya es amplio y platicarlo bien. Yo ya hablo de todo eso con mi nena y le digo los cambios que va a tener su cuerpo. Ella tiene 9 años pro ya pregunta, ella ya dice mama por qué pasa esto. Yo creo que es mejor hablarles en casa, ser claros a que después ellos experimenten de otras formas y por eso pasan las cosas. Si, así como dice ella, que ellos (maestras y maestros) platiquen también con ellos. Uno les enseña, pero que también vean que también la seño, el profesor, les enseñe. 


\section{E12/M/M}

\section{E: Entrevistadora}

M1: madre 1 de niña de primaria

M2: madre 2 de niña de primaria

Subrayado: extractos literales tomados en el análisis

E: ¿Cómo se llaman ustedes?

M1: Yo me llamo Fernanda.

E: Estamos compartiendo sobre la educación de los hijos. ¿Consideran que les están enseñando valores, respetarse ser buenas personas?

M1: Yo más que todo pienso que sí les están enseñando bien, saben respetar. Los niños miro yo que tienen respeto a sus maestros, en el caso de mi nene durante el tiempo que él está aquí nunca he tenido quejas de él.

M2: Todo bien están sus hijos en la escuela (traducido del K'iche' por otra señora).

E: y en relación a cómo les están educando para ser iguales entre mujeres y hombres, niñas y niños, ¿les enseñan a ser guales?

M1: yo digo que sí.

Niño: nos tratan igual.

Niña: No.

Niño: si nos respetamos.

$\mathbf{E}:$ ¿Cómo les enseñan los maestros a respetar?

Niño: hay que saludar, buenos días, buenas tardes, buenas noches...

E: ¿Y a ustedes como niños qué les gusta hacer?

Niño: estudiar y un poco jugar.

E: y en la casa, ¿Qué tareas hacen ustedes? no tareas de la escuela, sino de la casa 
Niño: yo hago mis oficios, tiendo mi cama y barro mi cuarto y arreglo.

Niño 2: yo no hago nada porque trabajo en henchido de hilo.

$\mathbf{E}$ : entonces, no le da tiempo a hacer cosas de las casa, ¿y quién las hace?

Niño 2: ni hermana y mi mamá.

E: y ustedes nenas, ¿qué hacen en la casa?

Niña 1: hacemos tareas de la escuela.

E: ¿En qué cosas les gustaría a ustedes como mamás que la escuela les apoye?

M1: en el caso mío es de que más que todo mi forma de pensar yo quiero que le esfuercen más a mi niño porque yo tengo una niña que salió de aquí en sexto y ella ya no quiso estudiar. A veces dicen ellos que nos cuesta un poco entender lo que nos aprenden los maestros. Entonces yo digo que porque hay muchos niños ellos ya no aprenden. En el caso mío yo quiero que los apoyen para que ellos puedan seguir sus estudios. En el caso mío, seño, estoy un poco bajo de lo económico, pero ya mi hija la más grande ella ya no quiere estudiar porque ya no alcanza que le dé estudio. Y ella ya no está muy motivada que ella se va a la escuela. Entonces, yo quiero que si pudieran hay que motivar a los jóvenes para que ellos sí vayan a la escuela. 


\subsection{Transcripción de grupos de discusión comunicativos}

\section{GD01}

\section{Totonicapán, abril 2014}

E: Entrevistadora

P: Participantes: 3 mujeres y 3 hombres, maestras y maestros de Pre-Primaria y Primaria.

Subrayado: extractos literales tomados en el análisis

E: Pues tenemos reunido al con 6 compañeras y compañeros, que son docentes en los diferentes grados de Pre-Primaria hasta Diversificado, tenemos presencia de docentes del municipio de Santa María Chiquimula, también de Quetzaltenango, Cantel Quetzaltenango y de Chimaltenango. Así que bueno, vamos a empezar a compartir un poquito sobre el tema de equidad de género, etnia y social en la educación, en las diferentes etapas educativas, cómo lo miran, qué experiencias han tenido. ¿Cómo ven que se implementa el eje o no se implementa? Podemos ahí romper el hielo.... Hablen un poquito recio para que se pueda registrar el sonido, si no, no se va a oír...

P: Bueno para romper un poquito el hielo, un poquito aquí con los compañeros, pues platicábamos un momento verdad, que en generalidades podríamos decir que sí es un tema que es bastante importante y que de alguna manera no se le ha dado un tratamiento especial. Verdad, normalmente nos inclinamos dentro de la planificación, si queremos tocar algún punto, en tocar conocimientos, en tocar temas que se tienen que impartir, metodologías muchas veces para impartir a los jóvenes, tiempos incluso, actividades, recursos, pero en el tema de equidad muchas veces no vamos a la parte practica esto verdad y es algo que de alguna manera tal vez sí se hace, pero no metodológicamente dentro del plan, si no solamente como algo que deseamos hacer nosotros, porque creemos que es importante verdad, solo para comenzar...

E:¿cómo lo ven los demás compañeros compañeras?

P: yo manejo la idea que, bueno según el CNB, quiere implementar verdad la igualdad, la equidad, la no discriminación del punto de vista del involucramiento del estudiante dentro del salón de clases como platicábamos hace un instante, el docente tiene en sus manos al grupo 
de estudiantes, en el horario correspondiente, en el caso del Básico y Diversificado, como lo manifestaba lamentablemente no tenemos toda la mañana con ellos verdad o toda la tarde con ellos, si no que son episodios, momentos nada más los cuales podemos compartir, pero sin embargo esos minutos de nuestra estancia en el salón de clases es un compromiso nuestro poder involucrar a los dos géneros, en este caso en el trabajo educativo.

P: pero considero que tenemos en nuestras manos, el hacer que nuestras clases estén involucradas también lo que son las ejes que el curriculum nos indica, porque ya sabemos verdad que el curriculum nos da la característica de ser flexibles, por lo tanto nosotros como docentes debemos de involucrar contenidos que tengan que ver con lo que... o tenga que fomentar lo que es la equidad de género.

E:¿Cómo podríamos hacer eso? O sea ya teniendo bien presente, ahí está el eje ¿ahora qué? ¿Qué ideas surgen acá entre todos para decir bueno yo me voy a llevar este eje a mi aula?

P: Es más práctico, en los documentos podemos escribir un sin fin de estrategias, métodos, formas, pero practicando con los estudiantes, esto va a cambiar, no es de la noche a la mañana es un proceso muy largo que de hecho el proceso formativo de los niños ya en el establecimiento, inicia desde Pre-Primaria si se inicia ese cambio desde ese nivel, podríamos decir que obtendríamos un resultado eficaz, pero es a largo plazo. Culturalmente ahora, culturalmente nosotros como docentes podemos estar en los establecimientos pero recordemos que con la cultura no es fácil, el caso de acá.

P: otra de las situaciones es en lo que yo he visto reflejado, una vez llegó una cierta persona a supervisar y giró esta pregunta también... cómo es las cosas verdad, me dijo ... por qué? le dije yo, porque si usted se da cuenta ahora los niños y las niñas juegan fútbol, pero no van a jugar niñas y niños, si no que ya juegan niños contra niñas, entonces ahí ya se rompió ese eje que solo porque es niña va a jugar con niñas, solo porque es niño, va a jugar con niños y como decía usted, desde la Pre-Primaria es la base fundamental para fomentarles ese eje de que todos somos los mismos, todos valemos por igual y ahí vamos a ver lo que es la realidad, identidad de género.

P: tal vez no tanto desde un nivel educativo, lo manifestaba en la mañana y decía que la base $\underline{\text { fundamental son los primeros años de vida con la que uno crece en la casa, en el hogar, como }}$ 
le enseñan a uno a tratar a la persona opuesta a su género ¿verdad? Como me enseñan a mí a tratar a una mujer desde niño, cómo me enseñan a tratar a un hombre desde niña, en este caso, verdad para las mujeres, hay paradigmas hechos ya en la persona y lo manifestaba, a veces el ciclo que por ejemplo nosotros atendemos, Básico y Diversificado es un tanto difícil cambiar la ideología que ya traen desde pequeños, la escuela solo es el reflejo de una formación verdad, los niños están casi entre de uno a cinco o seis años en la casa con los papas y de ahí depende mucho la formación, en la escuela si se da la formación puramente académica, pero los primeros años, entre uno a cinco años es la base fundamental de la formación del niño o de la niña y desde ahí se le debe de enseñar cómo tratar a la persona opuesta a su género. Cómo tratarla.

E: Miren, fíjense que cuando hablamos de socialización de género verdad, de cómo aprendemos a ser mujeres y como aprendemos a ser hombres, tenemos varios agentes, uno sería la escuela, pero otro sería la familia que por supuesto es el primero, digamos, el inicial como usted dice, pero también tenemos ahí involucrados y sobre todo hoy en día otros agentes, como son los medios de comunicación, como lo son también otras estructuras que hay en la comunidad, iglesias, asociaciones, lugares donde participan los niños y las familias que también influyen mucho en esa forma que vamos aprendiendo de ser mujeres y de ser hombres.

Por qué les digo esto, porque digamos, no sé en donde ven ustedes que esta el papel central o a nivel de decir ¿qué dificultades encontramos? Solo las dificultades están en la familia, solo están en la escuela o también se involucran estos otros agentes como los medios, como las iglesias, como las estructuras comunitarias... porque al final sabemos que la educación es un proceso integral, nos estamos educando toda la vida y en todos los espacios y yo estoy aprendiendo tanto ahorita de ustedes, como de lo que me pasa después... no sé, en la calle en otro lugar, estoy aprendiendo formas de lo que puedo y de lo que no puedo hacer verdad? De lo que puedo hacer como mujer y de lo que no puedo hacer como hombre, entonces ¿cómo miran esa parte? ¿Creen que hay otras cuestiones en la comunidad que también influyen? Además de la familia la escuela...

P: tal vez uno de los medios fuertes en algunos lugares dependiendo el contexto donde esté ubicado el niño o la niña o persona, en muchos hogares hay mucha migración por ejemplo,

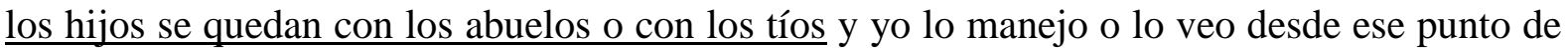


vista, no hay mejor guía o mejor cuidador y guardador de la integridad de la persona que el propio padre y madre de familia, puede estar el tío por mucho que lo quiera, el abuelo, la abuela pero no va a cuidar al $100 \%$ en sí de que es lo que esté haciendo el niño verdad. Usted mencionaba algo importante a cerca de los medios de comunicación, dependiendo del contexto donde esté, si hablamos del área urbana, el área urbana tiene mucho potencial en ese aspecto, tiene mucho acceso a muchas vías de comunicarse verdad, radio televisión, Internet, teléfono, celular y por ese medio entra mucha información y perjudica en algún momento los programas que ven verdad, o lo que estén haciendo, hay dentro de la persona un subconsciente que va grabando todo, como un disco duro verdad de una computadora y que al final refleja en sus actitudes lo que ha guardado en ese disco duro.

P: yo le agregaría a lo que dice [el compañero] verdad, que es muy cierto que en el área rural quizás tenemos menos influencia, podríamos decirlo aunque a veces no es tan real eso verdad, pero si lo tomamos desde el punto de vista de lo que dice [el compañero] los medios de comunicación influencian en las áreas urbanas, pero el área urbana es muchas veces influencia para el área rural verdad, desde el área muchas veces se tiene la óptica de que ahí está el desarrollo, de que ahí está el crecimiento y de que es un modelo a seguir, entonces viene siendo una cadena, porque muchas veces desde ahí se enfoca lo que se ve en la realidad. Retrocediendo un poquito, pienso también que la realidad de la sociedad en que estamos ahorita y lo que estamos viviendo, va a ser el mejor ejemplo que nosotros vamos a poder tener para poder enseñarles a los estudiantes desde el área en el que nosotros estemos y decirles esta es la realidad, y esto es lo que se ha vivido de acuerdo a la historia y a lo que ha pasado, ¿qué vamos a hacer nosotros con esta realidad? Y cómo la vamos a cambiar. Platicábamos que los jóvenes tienen una visión diferente y creo yo que esa visión diferente nos va a ayudar a nosotros a unirnos porque desgraciadamente nuestro país en los niveles sociales lo único que se ha hecho y se hace con todos los medios que se puede es una terrible división, verdad. El género se ha convertido en una división, la religión y la cultura yo pienso que ya es el momento de empezar a edificar y no seguir dividiendo más verdad y haciendo eso yo creo que es un eje que podemos pues desarrollarlo bien con nuestros estudiantes.

P: Bueno nosotros, aquí apoyando a los compañeros es un eje que está claramente contemplado dentro del CNB, ¿pero en realidad se realiza?... no lo sabemos, en los diferentes contextos y niveles se puede decir que se podrían pasar desapercibidos, podemos pensar de que, bueno ellos ya saben o ya conocen de eso, entonces ya no se la da seguimiento a esta 
situación, también con lo que respecta a la religión. Pienso que ahí sí muchas veces se nos enseña el amor y el apoyo hacia nuestro prójimo, independientemente de que este sea hombre o mujer... pienso.

P: solo tal vez para completar, como docentes tenemos siento yo la tarea ardua que como lo mencionaba, que es difícil, pero no imposible soñar, soñar tal vez es ver más allá verdad o soñar es nuestra meta, ahora convertir ese sueño en una realidad, soñamos con que nuestro país tenga paz, tenga armonía, tenga tranquilidad, quién no sueña eso verdad, quién no sueña que haya armonía, que haya tranquilidad o lo que dice el compañero acá que no haya división verdad, que haya armonía, que haya humildad y pienso que iniciando con ese sueño, podemos llegar a alcanzar muchas cosas, en nuestras manos tenemos a niños, tenemos adolescentes, tenemos a jóvenes y siento que tenemos una tarea ardua de formarlos verdad, de enseñarles a ellos, de tratar tal vez no de cambiar la idea de ellos, pero dejar esa chispita verdad, esa semilla en el corazón de ellos para poder cambiar.

Situaciones que hoy vivimos verdad, situaciones difíciles que hoy vivimos, hemos marcado una línea de separación, una línea de separación diría yo de género en muchas comunidades, el machismo sobresale en muchas comunidades, en otros lugares no es el machismo si no el feminismo verdad, como yo ya tengo derechos como mujeres vamos también a levantarnos, levantemos nuestro movimiento y se ha vuelto como un campo de batalla hombres contra mujeres, mujeres contra hombres y yo siento que en lugar de estar en ese campo de batalla debemos sentarnos a dialogar y a pensar miren nuestros derechos como hombres son estos y los derechos de ustedes como mujeres son estos, y nuestras obligaciones como hombres son estas y nuestras obligaciones como mujeres son estas, dialogar y tener en mente que todos tenemos derechos y tenemos obligaciones, no yendo tan lejos verdad, en la casa quienes ya estemos casados en algún momento tenemos derechos como hombres, como esposos, como padres, tenemos obligaciones también, igual las mujeres verdad tienen también sus derechos y sus obligaciones, entonces siento yo que todos jugamos un papel importante, solo es tener marcada la línea verdad y decir sigamos todos en la misma línea, todos en la misma línea, no estar a un lado, acá derecha a un lado, izquierda a otro lado y convertirnos nada más en esas personas que están haciendo batalla en un campo verdad, cuando vamos a terminar, hasta que le pongamos fin a esa cuestión.

P: Para retomar el tema, por ejemplo menciona [el compañero] de que muchas veces hay un campo de batalla, pero pienso por qué hay alguno... por ejemplo en un matrimonio se vuelve 
un campo de batalla, es porque uno de los dos no está cumpliendo, supongo, que si el esposo o la esposa están claros de sus derechos y obligaciones, en algún momento solo somos buenos para exigir nuestros derechos y lentos para cumplir nuestras obligaciones. Hago este comentario sin ofender a ningún compañero pero considero y pregunto si ellos en algún momento han incumplido con sus obligaciones como esposos o padres y si mejor aún conocen, verdad para ir formando un cambio en esto, también hay que dialogar y formar a los padres de familia para que este resultado, como lo vuelvo a repetir no es a corto plazo, puede $\underline{\text { ser un resultado de varias poblaciones. }}$

E: Claro y una de las cosas que me vienen a la cabeza, pensando en esto es decir, bueno tal vez la reflexión también tiene que partir de qué tan diferentes son nuestros derechos y nuestras obligaciones como mujeres y como hombres, porque igual nos damos cuenta de que en realidad, casi son los mismos verdad, que no se trata de decir qué tiene que hacer cada uno, si no decir cómo podemos sacar adelante las obligaciones y derechos familiares en armonía, colaborando, apoyándonos y no diciendo bueno, como a uno le toca esto y a otro le toca esto y lo otro, nos vamos a pelear si tu no cumples con uno y con el otro, verdad?

P: Hay lugares por ejemplo...eh... por eso le digo yo que la familia siento yo que juega el papel, si no el más importante pero donde pesa aún más la formación de la persona, como maestros solo venimos a tratar de modificar algunas cosas que están marchando mal o querer quizás modificar el modelo. Pero ya los primeros años de vida están hechos, en los primeros añitos de vida se grabó todo verdad y es difícil que se borre algo, que se modifique algo. Pero retomando el tema hay lugares por ejemplo donde a mi me sorprendió mucho, pude estar en $\underline{\text { un hogar donde la mujer es la encargada de servir la comida y el hombre aunque se estuviese }}$ muriendo de hambre, no se levantaba a servir la comida, porque era una obligación de la mujer hacerlo verdad, ahora la pregunta es, como hombres, yo siendo hombre, será que me cuesta tanto agarrar la olla de la comida, servirme el plato de comida y comer, ¿verdad? Pero como son estereotipos que ya han sido formados desde niños verdad, desde la familia, en el seno del hogar. Mirá la mujer es la encargada de ir a echar la molida, ¿por qué no vamos los hombres a ir a moler el maíz? ¿Por qué no vamos nosotros los hombres al río o al tanque a ir a lavar, lo lavamos en nuestra casa verdad?¿Por qué no lo hacemos como lo hacen las mujeres? Yo he visto mujeres que van con su baño de la molida o con su baño de lavada a ir a lavar o en caso de las mujeres, ahora me he dado cuenta de que la mujer también se ha involucrado en el trabajo de los hombres, entonces en el caso de las mujeres hay cuestiones 
que no que tal vez por fuerza verdad no lo pueden hacer, pero desde ahí empiezan esos estereotipos, la mujer no puede hacer esto porque no tiene suficiente fuerza. Tú no puedes subirte a un árbol, por ejemplo verdad, porque el árbol ya no va a dar fruto, desde ahí empieza a hacerse la diferencia entre hombre y mujer.

E: Miren una cosa fundamental que yo creo es que, en la escuela ciertamente no vamos a poder cambiar digamos a una persona tampoco ese es el objetivo, pero la realidad es que con nosotros los jóvenes y los niños conviven alrededor de que... sus 5 horas digamos diariamente, tal vez en los niveles ya más elevados no son tantas horas, pero sí es cierto que la escuela, escuela no solo conmigo como docente, si no con toda la escuela es una experiencia que nos marca y que yo creo que a todos nosotros si ahora nos pensamos para atrás nos ha marcado en nuestro proceso educativo, nos ha marcado el tipo de reglas que había en ese espacio que es un espacio distinto al de mi casa, y a veces ha habido reglas. A mi... yo me recuerdo de eso verdad, que igual yo en mi casa yo podía hacer algunas cosas que en la escuela no me dejaban verdad y eso lo marca a uno. Si esas reglas que hay en el espacio escolar están bien orientadas, sí podemos estar haciendo cambios en los jovencitos, no van a ser inmediatos como dice [la compañera], pero seguro en el futuro se van a acordar, a mí en el espacio escolar, donde yo 5 horas estaba todos los días, se funcionaba así y eso me ha enseñado a ser una persona de determinadas maneras, verdad, entonces miren, pensando un poquito en eso, lo que yo les quería lanzar también es, en ese sueño que decía [el compañero] de poder hacer un mejor país con mayor equidad, cómo sería, cómo soñamos que sería nuestro establecimiento ideal, o sea que establecimiento educativo nos gustaría tener para que ese sueño sea posible?... y puede ser de muchas maneras, desde el espacio físico, hasta el tipo de profesores, hasta cómo trabajamos, hasta que actividades realizamos, cómo son los directores del establecimiento, cómo es el ministerio de educación, en fin qué estamos soñando para que de verdad podamos tener un establecimiento donde decimos si estamos promoviendo cambios en favor de la equidad.

P: Hablamos hace un momento verdad, que incluso nuestro sistema enmarcó verdad, las diferencias, hay carreras específicamente dirigidas hacia varones y hay carreras dirigidas específicamente para hombres. Creo que se tiene que hacer ya un rompimiento en cuanto a ese sistema ¿verdad? Porque no hay en ningún momento verdad, ninguna situación que nos enmarque eso, revisando un poquito, yo creo que la base que nos da nuestra casa es fundamental, verdad, y lo digo por experiencia propia verdad, tengo el... soy padre de tres 
niños, mi esposa falleció, increíblemente pues en un momento tome la decisión, de decir bueno... en muchas cosas como decía usted que me fueron inculcadas verdad, que me fueron enseñadas y que hoy estoy utilizando, yo les cocino a mis hijos, dedico mucho tiempo a ellos en cuanto a eso, pero también hago la otra parte, verdad y a veces lo que usted decía, no es que exista una gran diferencia verdad, somos como una tuerca y un tornillo que somos diferentes en cuanto a hombre y mujer, pero las diferencias lo único que hacen es llevarnos a un mismo fin. Entonces si esas diferencias que nos dividen las podemos llevar a un mismo fin, también en el plano educativo eso va a servir mucho, porque entonces tanto el jovencito va a tener mejor comprensión de lo que es la mujer, como la mujer va a tener mejor comprensión de lo que es un varón verdad, tenemos un pensamiento completamente distinto que culturalmente así no lo han enmarcado como lo decía [el compañero], eso es muy cierto, pero que también tiene que ir evolucionando y las mismas necesidades que existan como seres humanos nos van a ir dando a veces, el hacer cosas que en cierto momento no lo creíamos verdad, eso creo que tiene que estar abierto en educación, creo que ya están habiendo algunos cambios verdad, antes veíamos al director y era el director, porque tenía que ser un varón verdad, desde ahí a veces... o sea hablamos de sistema, pero hablemos también de estructura, de cómo están los puestos y muchas veces, muy pocas veces veíamos a una mujer. Hoy gracias a lo que se ha trabajado y al estimulo que la mujer tiene, ya hay mujeres que están en puestos altos y que están dirigiendo varones, eso a veces es difícil de manejar todavía en algunos estratos sociales, pero que ya se está dando y creo que eso está abriendo espacios, verdad, para eso. Creo que eso nos va a ir cambiando la mentalidad a nosotros y sobre todo decía [el compañero] el sueño más grande es poder tener equidad en lo educativo y en todo nivel, verdad, que nosotros como hombres también no nos sintamos menores por que en un momento hay una mujer que está dirigiendo, que en un momento la mujer este tomando las decisiones, creo que eso en ningún momento nos pone a nosotros en un menor estado si no que creo que lo que él decía, el dialogo y la plática nos va a llevar a nosotros a alcanzar esos objetivos que nosotros tenemos, verdad, y el sueño nuestro que no se tiene que terminar...Tal vez llegar a la luna en algún momento fue un sueño verdad, y se cumplió, hoy tal vez son sueños más de tipo social, son quizás hasta utopías podríamos decir verdad, pero que si nosotros ya las empezamos a plantear en cierto momento de la historia de nuestro país o de donde estemos, se puede empezar a dar verdad, si nosotros no quitamos el pie de ese sueño que queremos tener y queremos verdad: 
P: Considero que es de aprovechar muchas cosas, cuando se dan, ejemplo cuando hay organizaciones que en ellas se involucran ya ambos sexos verdad, hombre y mujer y es de aprovechar, es de fortalecer, porque hay organizaciones que aún todavía no se les ha llegado ese pensamiento de que también la mujer lo puede hacer verdad, pero cuando existe es de aprovechar verdad y de seguir fortaleciendo en ese sentido, en cualquier ámbito, ya sea en lo educativo o en lo religioso o en alguna organización donde nosotros podamos participar o podamos llegar a... poder llegar y dar nuestras opiniones verdad.

P: Soñar con una escuela... tal vez no la ideal. Siento yo que debe ser una escuela donde... el compañero acá dice algo real... me sorprendió mucho ver dentro de mi grupo de estudiantes a un joven estudiando secretariado, ver a un hombre estudiando una carrera de mujeres hasta incluso con un profesional me sorprendí, dije un joven estudiando esta carrera, porque en realidad nos han dejado enmarcado, como usted dice en la vida, desde hace mucho verdad, que hay cosas que solo las mujeres pueden hacer, y hay cosas que solo los hombres pueden hacer, en realidad soñar con escuelas en donde todos, todos estén involucrados en todas las actividades, en todo verdad? Por ejemplo algo que mencionaban los compañeros acá, es que hay consejos estudiantiles, donde también desde hace mucho, yo me recuerdo cuando estudié el Básico, los consejos estudiantiles debían ser formados por hombres, no por mujeres y si en caso había una mujer, pero que estuviera de vocal, verdad, que estuviera de última. Pero uno se sorprende cuando están los consejos estudiantiles, la mujer es la presidenta ¿verdad? No es un presidente si no es una mujer la que está conduciendo y dirigiendo a todo el grupo de estudiantes, entonces siento yo que el celo como hombres tenemos que dejarlo a un lado también, verdad, de que una mujer sea superior a mí en ámbito académico, en ámbito profesional, eso como dice el compañero no debe hacerme sentirme inferior, al contrario verdad, debe ser un reto para mí. Si una mujer pudo llegar, yo puedo llegar verdad, igual la mujer, siento yo que ambos no deben nunca sentirse inferiores, pienso que es parte de la autoestima de uno verdad, o la aceptación de uno, yo me siento feliz porque soy hombre, usted siéntase feliz porque es mujer y soñar con una escuela en donde todos esos condimentos, es como una comida verdad, se le echan todos los condimentos y se siente bien rico sazonado, siento yo que la escuela con participación de mujer y hombre, involucramiento también de mujer y hombre verdad, donde la mujer opine, donde el hombre opine y donde sean tomados en cuenta sus opiniones, es soñar con una escuela ideal, entonces yo siento de que vamos por ese camino, de que si [la compañera] decía algo real, es un sueño a largo plazo, tal vez ni lo vamos a lograr a ver nosotros, tal vez nos muramos en el camino, pero 
nuestros hijos o nuestros nietos, van a lograr ver el fruto de nuestro inicio de trabajo lo cual estamos haciendo. Vuelvo a decir, estamos dejando la semilla verdad, y la semilla lleva un proceso hay que cuidarla, hay que abonarla, hay que darle mantenimiento y así ver el fruto. Entonces estamos dejando la semilla, esa semillita que a largos años vamos a verlo aunque sea desde el cielo, nuestro fruto, verdad.

E: Yo solo una cosita que no se nos olvide, que importante es que esta formación emocional que ha sacado el compañero, digo emocional porque es del autoestima, o sea, esa formación, como me auto valoro, como me auto respeto como mujer y como hombre, forma parte precisamente de la educación en la equidad de género, porque si no partimos de ahí, desde que somos chiquitos, tener una formación que nos permita valorarnos en lo que somos, sentirnos orgullosos de lo que somos, y desde lo que somos, relacionarnos con los demás en respeto y en equidad, no vamos a poder ir más allá, por eso este tema es tan amplio por que podríamos estar abarcando desde eso, desde el concepto del autoestima al cómo nos valoramos hasta eso, hasta que en el consejo estudiantil hayamos número igual de hombres y de mujeres por ejemplo, es amplio verdad, pero lo de la formación emocional creo que no hay que perderlo de vista, porque luego nos hace tanto daño cuando somos mayores verdad, y cuando establecemos a veces relaciones de pareja desequilibradas, donde solamente prevalecen los celos, donde prevalece que yo quiero dominarlo a él y el quiere dominarme a mí, viene mucho a veces desde ese origen que emocionalmente no nos han enseñado a ser mujeres y hombres en un equilibrio verdad, y eso en la escuela también se puede trabajar. Bueno no sé si para terminar alguna conclusión o alguna cosa que se nos ha quedado por ahí...

P: bueno yo tal vez, algo que quería complementar es... como usted quería cambios de la escuela oficiales y aquí como decían los compañeros tiene mucha realidad y así como dijo el compañero, nosotros tenemos que dejar sembrado esa semilla, en el caso de ellos tanto de Básico, como nosotros de primaria, en nosotros tiene que ver esa situación que en nuestras aulas también le tenemos que dar la oportunidad a nuestros jóvenes y niños, porque si ustedes bien saben en el Básico a veces conformamos lo que son juntas directivas de aula, y así como decían, a veces solo los hombres valoran, ahora vienen muchas veces que se propone a la mujer, pero a veces la mujer también no lo quiere aceptar, yo veo que ese es un error también que la mujer hace, porque no acepta ese derecho que ella tiene de ser, de que ella tiene esa capacidad de llevar en si un aula, ya imagínese si una mujer va a poder manejar un aula, que 
no va a poder hacer ya pudiendo manejar una sociedad, hasta incluso un país, entonces donde tenemos que partir también es de nuestras aulas, y dándole tal vez otra prioridad, tal vez sería a nosotros mismos desde ahorita como padres de familia, para poder ya eliminar en sí y romper el hielo de esta situación de que solo el varón puede realizar las cosas, sino de que también la mujer es capaz de realizarlo.

E: ¡Muchas gracias!

P: Muy bien tal vez, fíjese que yo me he dado cuenta desde que uno ha entrado en el salón de clases, cómo están las filas de los estudiantes, no sé si algunos de nosotros nos hemos podido dar cuenta, todo el grupito de niñas y todo el grupito de niños, están mire separados ahí está mire! Cómo se marca la cuestión.

E: Aquí estamos las tres y los tres... risas... y no hemos hecho nada... risas

P: Pareciera risa pero a veces son estereotipos hechos desde nuestra niñez, por eso le digo e insisto de que la base es el hogar, sigue la escuela, sigue la sociedad, lamentablemente uno entra al salón ve prácticamente la división, grupo de niñas, grupo de niños, grupo de jóvenes, grupo de señoritas, entonces pienso de que como maestros debemos de empezar a romper ese hielo también ahí verdad, empezar a intercalarlos, yo lo he hecho en algún momento. ¡Muy bien! ¡Hoy hay rompimiento de hielo! Ya saben ellos que cuando yo menciono eso es un niño o sea una señorita un joven, una señorita un joven y así involucrarlos o hay grupos mixtos, $\underline{\text { saben que tienen que estar hombres y mujeres, } 4 \text { hombres y } 4 \text { mujeres, entonces de esa }}$ manera vamos a ir inculcándoles que deben relacionarse ambos géneros.

E: muy bien, alguna conclusión [hacia una compañera]

P: yo solo imaginándome lo que dice [el compañero], respecto a las aulas, bueno en los niñitos no se ve esa división, al contrario ellos juegan solos, de hecho cuando los involucramos el trabajo de grupo, de equipos de trabajo el nivel primario es más orientación de parte del docente, uno tiene que estar ahí viendo el trabajo, cuidándolos pero sobre todo dándoles instrucciones claramente sobre cómo deben trabajar en equipo, no insultándose, no poniéndose apodos, no faltándole el respeto a sus compañeritas, porque nosotros como docentes escuchamos un apodo. Ah! Es que son niños, es que son niños y es que ellos son así, 
pero realmente es un error fatal porque hay que corregirlo desde esa edad o así van a ir creciendo así y cuando sean jóvenes no vamos a poder hacer nada.

E: O sea que están en el momento propicio en Pre-Primaria, primaria pero bueno también en los demás...

P: sí los compañeros que trabajan en el Básico no me van a dejar mentir... ahí los jóvenes se tratan de apodos, muchos se faltan el respeto... bueno a mí me pasó... desde que yo estaba en la primaria, como yo tengo un cuerpo gordito me decían gorda pero no me lo decían con el buen humor sino que lo hacían con ganas de molestarme y humillarme y eso nunca fue frenado también, por la maestra, si hubiese hecho algo en ese momento, si nos hubiese enseñado a respetar y a cuidar sobre todo mi autoestima en ese momento, cosas que como docentes podemos, como docentes de primaria podemos ver, cuidar ese aspecto por que los niños muchas veces lo traen de su casa.

E: Muy bien, ya solamente para terminar, en su formación como docentes que están recibiendo ahorita en la $U$ [universidad] o también quienes estudiaron magisterio a nivel Diversificado, qué pedirían o que... tal vez lo digo porque en general todos han comentado que ha sido poco la formación que han recibido en todo el pensum para ser docente, respecto a cómo implementar este eje de equidad, entonces qué pedirían, qué han sentido que hace falta o de qué manera podríamos mejorar en el sentido de decir, bueno yo puedo salir de la universidad tal vez con un poquito mayor preparación en este aspecto.

P: tal vez en la enseñanza de nuevas técnicas didácticas tal vez, verdad, porque siento yo que si ya estamos hablando un poquito de familia, nos vamos a ver un poquito más en la tarea de conducir a nuestros hijos, de enseñarles a llevar la equidad de género, pero siento yo que en la clase en las aulas necesitamos nuevas actividades, nuevas estrategias, un poquito más de innovación verdad, para poder llegarle no con represión a los estudiantes. Mire usted tiene que relacionarse porque tiene que relacionarse no, a manera... sin querer verdad... tratar de relacionarlos. Entonces estrategias nuevas, metodologías nuevas, actividades nuevas donde podamos involucrar a los estudiantes, yo me he dado cuenta que aprenden mucho jugando y tal vez la enseñanza de algunos juegos, no sé, algunas estrategias diferentes verdad, hasta incluso en el nivel universitario, todavía se llega el maestro a dictar, llega el maestro a veces todavía con su metodología tradicional verdad, entonces desde aquí debe partir también el 
cambio verdad para nosotros, porque nosotros somos ejes que vamos a ir a poner en práctica a las nuevas generaciones, siento yo que debe haber nuevas estrategias, nuevos lineamientos también para nosotros, para que sintamos esa motivación verdad de decir, voy con esto nuevo que aprendí hoy, voy a implementarlo.

P: y algo que yo quisiera comentar es de que, considero que cuando realmente se practica la equidad de género ve algo hermoso, bonito, porque imaginémonos en las aulas de hogar o de artes industriales actualmente, se ve lindo, se ve emocionante como ver a un niño o a un jovencito agarrando una olla, un sartén, lavando alguna fruta para la preparación de algún alimento o agarrando el cuchillo, jugando el papel de una mujer podríamos decir y también se ve bonito ver a una señorita, agarrando el serrucho, el martillo, para hacer algún material o algún objeto que aunque nos han dicho que solo el hombre lo podía hacer. Pero de verdad yo me siento muy feliz o muy emocionada al ver esas actividades, cuando los jovencitos comparten, se rompió eso de que en todavía, hace tal vez como unos dos años se implementó eso de que los jovencitos ya tienen que llevar hogar, las señoritas artes industriales, se ve bonito y yo veo, yo tengo hermanas y dicen ¡ay yo hoy corte una madera y me salió bien! Verdad y a veces dicen no se torció el clavo y se ve emocionante, yo creo que eso es bonito ¿verdad? Yo digo que hay que fortalecer eso...

P: bueno yo pienso de que una actividad que debemos de implementar, en los centros educativos, como lo mencioné en la mañana, la escuela de padres, es una escuela de padres, no reunión con padres, por que en los centros educativos no se implementa eso, simplemente es una reunión. Decirle en qué falla, en qué no falla, si están cumpliendo o no están cumpliendo, pero en realidad como le mencioné, implementar una escuela de padres es importante porque puedo decirle que trabajar con papas no es fácil, es difícil, se siente el peso trabajar con ellos, pero considero que vale la pena, entonces pienso que tal vez pueda funcionar la implementación de escuelas de padres a nivel nacional verdad, porque aunque nosotros, por ejemplo nosotros como nueva generación puedo decirle que nuestros papas no son profesionales, entonces entre ellos hay una cierta separación, en mis papás, decirle que formar a mis hijos en un valor en equidad de género, sí se puede en mi caso, pero en otros casos, en otros contextos es diferente, puede ser de que no lo hagan, puede ser de que si se conozca de que el eje es importante, de que es transversal, los documentos me pueden dar técnicas, me pueden dar estrategias pero cómo saber que realmente se cumplen o no se cumplen, si realmente está funcionado o no está funcionando. Pienso que sería bueno 
implementar en otros establecimientos, en otras regiones la escuela de padres. Una mañana o una tarde deben de ir a clases todos los papas, como si fuera un estudiante y si funciona, la verdad es que si funciona.

\section{E: gracias [compañera]}

P: Si este... lo que dice [la compañera], es una realidad, la verdad es que los padres descuidan mucho ese papel responsable de ser papas, yo me he dado cuenta de que solo llegan cuando los inscriben, inscriben a sus hijos, aparecen cuando entregan notas cada dos meses, al año hacen si mucho unas 6 visitas, una cuando inscriben, cuando entregan tareas y una al final cuando reclaman por qué perdió, sería bueno la escuela de padres, yo apoyo esa idea, esa situación está muy bien, donde los padres se sientan como sus hijos verdad, en un momento como estudiantes y que en ese momento aprovechemos nosotros para hablarles de su responsabilidad verdad, de su compromiso que tienen, que no están formando un objeto, verdad, no es como yo, soy carpintero voy a formar mi ropero si no lo tracé bien, lo puedo desarmar y lo puedo volver a trazar, si no lo tracé bien lo puedo desarmar verdad y lo puedo volver a trazar nuevamente, un ser humano no es así. Un ser humano fue formado y así como lo formamos va a ir siguiendo toda la vida, entonces muy buena la idea de [la compañera] de una escuela de padres sería excelentísimo.

P: es que nosotros ya lo hemos implementado, nosotros lo implementamos hasta hemos hecho nuestro plan de trabajo, estructuramos los temas y si es difícil por que estudiamos los temas, los damos a conocer y muchas veces para que llegaran los papas tuvimos que gestionar refacciones.

P: Ese es el problema, fíjese que las áreas no llegan, hay una organización o una asociación o no sé como le llaman a esta de FUNDAP, que también a nosotros nos ofreció charlas y charlas sobre autoestima para padres, el rol de padres, temas muy interesantes, pero citar a los padres, no sé cómo sea con [la compañera] verdad, pero al menos donde trabajo es difícil. ¡Muchos padres han emigrado ya no están! Verdad, ya no están los papás, segundo solo llegan las mamás, por que los papás tienen que matarse todo el día trabajando, porque la vida pues económica esta difícil, entonces habría que buscar, si ellos ya lo implementaron, que excelentísimo si lo lograron verdad, porque en serio, juntar a todos los papás, es difícil, lo hemos logrado en algunas ocasiones pero hasta los mismos papás se aburren a veces de 
escuchar una exposición, de escuchar un tema ya están ahí como que... cuándo va a terminar esto!... pero en realidad es muy bueno, ojalá todos lo podamos implementar verdad, que a nivel del sistema del MINEDUC, exista eso.

E: Y de hecho yo creo que el CNB, que como decía [la compañera] es flexible verdad y perfectible también, dice, lo tenemos que perfeccionar entre todos. El CNB sí nos da esa posibilidad, o sea ya está diciendo que la comunidad educativa está formada por estudiantes docentes y padres de familia, ya de una vez esta marcando esa pauta, abriendo la puerta, para que los papás también estén involucrados o deben estar involucrados y esto es muy coherente con lo que decíamos que los niños no solo se van a formar en la escuela, se van a formar también en la familia, se van a formar con los medios de comunicación, se van a formar en un montón de espacios verdad, y entonces es coherente que nosotros tratemos de hacer una estrategia integral, donde involucremos a todos los actores posibles ojalá, a las autoridades comunitarias también, como decíamos verdad en algunos momentos.

P: Yo siento que tal vez los encargados directos, son los que forman parte del personal administrativo, por ejemplo o todos, no sé cómo decirlo pero en algún momento cuando van a inscribir a su hijo verdad, de una vez ponerle el parámetro, las indicaciones ... algo que usted mencionó hace ratos... las condiciones del padre de familia, verdad, de decir mire desde que inscribe a su hijo usted va a tener que asumir verdad, la responsabilidad y cuando lo llamemos tiene que estar verdad, tiene que estar porque se puede llamar verdad, pero y si no llega que... de balde vamos a preparar todo. Entonces siento yo que el director también tiene que jugar un papel importante, hay directores que... no sé si pasa en todos... hay directores que no les interesa esa parte, solo ven ellos a su conveniencia, lo que puedan sacan la tarea y ya estuvo, los directores siento que también juegan ese papel importante y darle la libertad del maestro también de hacerlo, porque también uno como maestro reúna a los padres y el director venga y me diga ipor qué los reunió usted?

P: sí porque sí se puede lograr la escuela para padres, porque a nosotros sí nos fue difícil, no difícil en el sentido de convocar a los papás, pero ahí sí llegaba mamá igual se la tomaba en cuenta, si llegaba papá también se le tomaba en cuenta y si llegaba el representante igual se le tomaba en cuenta, pero en nuestra planificación que nosotros hicimos, estaba primero, como primer punto la concentración si... y desde ahí empezamos o arrancamos y sentimos que si nos dio resultado, o sea si se dieron cuenta ellos en donde estaban fallando y si estaban 
cumpliendo o no, en muchos casos se comete el error más tal vez por estas áreas se comete más el error de que los papás se concentran más por el factor económico y piensan de que el dinero lo es todo y de que lo cubre todo pero en realidad no es así y dejan pasar otros puntos importantes. Si se logra implementar la escuela de padres, yo digo que sí se puede lograr un cambio mucho más acelerado, tal vez a unos 30 a 40 años se puede porque llegarían los papás a escuchar, eso si se forman los temas, se van analizando los temas, cuántos temas y por ejemplo nosotros hicimos los papas que saben leer, los que no saben leer, los que medio pueden leer, los que.... y aquí puede hacerse así, los que son profesionales, los no profesionales, los que son eso... se puede hacer desde ahí, porque no son todos, porque no todos manejan el mismo contexto, otros se nos van a aburrir, otros no.. Me entiende, porque así fue lo que nosotros trabajamos.

E: ¡Qué bueno! Pues excelente, miren mucho animo a todos, yo como ya hemos venido platicando con cada uno, creo que esto es una construcción, que sobre todo parte de la motivación de cada uno de nosotros como profesionales verdad, también como cada uno de los valores con los que nosotros trabajamos, así que ojalá que estas reflexiones nos sirvan para motivarnos más, es decir yo en mi aula puedo hacer cosas muy interesantes, en favor de la equidad y ojalá también se lo podamos transmitir a nuestros compañeros de las escuelas, aquí mismo en la universidad, porque esto es una construcción donde solo vamos a poder avanzar si todos nos implicamos, vamos a ir dando nuestras ideas, compartimos nuestras vivencias, así como Sabina nos estaba comentando ahora y seguro que en años adelante vamos a ver los frutos. Yo por lo menos espero que mi beba que va a nacer pueda ver algo, tal vez de lo que yo no voy a ver ¿verdad? Así que bueno muchísimas gracias. 


\section{GD02}

Pacajá Centro, Quetzaltenango, septiembre 2016

E: Entrevistadora

P: Participantes: 6 mujeres maestras de Pre-Primaria y Primaria.

Subrayado: extractos literales tomados en el análisis

E: Comencemos platicando sobre la igualdad entre mujeres y hombres, entre indígenas y ladino, entre ricos y pobres: ¿consideran que existe igualdad en nuestro medio? ¿Podríamos poner algunos ejemplos que refuercen su respuesta?

P: Pues sí, a un hombre ingeniero le pagan mejor que a una mujer, pero ingeniero y los dos tienen la capacidad, la inteligencia y tienen el mismo puesto prácticamente verdad, pero no hay igualdad, hace falta mucho.

P: cuando vamos al mercado, que querés le dicen a uno verdad: cuando no tendría que ser así porque la manera de hablar, es que es lo que quiere... porque estamos hablando verdad, tiene que ser reciproco.

P: pero si hemos avanzado bastante en que ya gracias a Dios, muchas de nuestras niñas asisten a la escuela, ya conocen y ya hay un poquito de igualdad, no la que desearíamos verdad, pero ya se ha logrado bastante.

P: Pero es ahí donde entra el papel del maestro, porque en este caso nosotros somos parte de ello verdad, porque está en el curriculum y entonces tenemos que practicarlo, saber cómo emplearlo en determinado momento, por lo menos han habido logros verdad, en el caso de hacer que las niñas lleguen la mayoría a la escuela, existen cambios, pero estamos en el proceso del cambio verdad, para que exista una verdadera igualdad o equidad entre hombres y mujeres, inscribimos igual indígenas y ladinos y ricos y pobres.

E: ¿Podríamos poner algunos ejemplos?

P: por ejemplo ya se ha logrado que la mayoría de las niñas ya lleguen a la escuela, ha aumentado el número de niñas estudiantes, en el nivel primario gracias a Dios ya lo logramos, en el nivel primario también, es en las dos etapas. Por ejemplo entre indígenas y 
ladinos, yo me recuerdo que años atrás habían muchas situaciones en las que las personas indígenas no podían entrar a estudiar, vean a ustedes ahora ellos ya se han superado un montón ya tienen el poderío también, ya han cambiado. Se han dado casos también en restaurantes en discotecas, que por portar un traje típico no podían ingresar ahí y ahora ya no es así. Se ha ampliado la oportunidad en colegios y en lugares públicos y asistir a lugares exclusivos.

E: Desde su experiencia cuales han sido los agentes socializadores principales, donde las niñas y niños aprenden lo que serán de adultos.

P: los padres, el hogar, los maestros, la escuela. En el hogar y la escuela, ah, pero también en la sociedad, porque en el hogar pueden ser algo y luego en... por eso... en el hogar, la escuela y la sociedad.

E: Desde su experiencia ¿qué es lo que puede hacer la escuela para educar en igualdad?

P: crear actividades en donde todos participen, tomar en cuenta a hombres y mujeres por igual, la participación igual, en todas las actividades comisiones de limpieza de refacción, gobierno escolar, patrulla de limpieza, que participen tanto niñas como niñas por igualdad, de una vez decirle a ellos.

$\underline{\text { Incluso en cómo se sientan, como tienen su escritorio, revueltitos verdad. }}$

E: ¿Que experiencias tienen ustedes en cuanto al curriculum oculto?

P: que no está, pero si lo ponemos en práctica, lo que no está planificado. Los niños aprenden mejor con el ejemplo. Pueden tener mucho en el cuaderno y a veces no saben qué escribieron...

E: ¿Que experiencias tienen respecto al eje de equidad de género, etnia y social que tiene el CNB?

P: eso prácticamente nosotros lo hemos visto, que no le echamos de una vez todo andar, pero si hablamos de eso. Esté o no esté en el CNB, siempre lo hemos aplicado. No hay necesidad de que esté, aun cuando no venía lo hemos aplicado, toda la vida lo hemos aplicarlo. Incluso 
que surgió cuando se firmaron los acuerdos de paz verdad, se reforzó en el CNB pero nosotros ya lo aplicábamos ahorita ya le están dando más énfasis. Para nosotros no es nuevo, siempre lo hemos aplicado en diferentes áreas.

Por ejemplo, yo llevo 6 años trabajando, cuando empecé tenía 8 alumnos, de los 8 solo 2 mujeres y 6 varones, se veía eso verdad, conforme uno de maestro fue inculcándoles a los padres de familia la importancia de que mandaran a las niñas a la escuela, la importancia de que era de prepararse a la mujer yo pienso que ahí también, uno cambia.

Yo siempre cuento la experiencia que tuve allá en San Martín, fíjense que cuando yo les decía a los niños, yo les decía vengan les voy a calificar, salían corriendo y a veces salían antes las mujeres, verdad y de veras que las empujaban y ellos se ponían de primero, se enojaban tanto hasta que aprendieron.

Sabe que es lo que hacía yo cuando hacían eso, les decía: mis hijas, dejen que pasen primero los caballeros y se quedaban ellos verdad, porque decirle la palabra caballero significa que es un niño respetuoso y que le tiene que dar el lugar a las demás personas verdad, desde chiquitos se inculca esto verdad.

Si en mi caso yo les digo si pasan primero los hombres, calzón y chongo les voy a poner y se quedan quietos, ninguno pasa y todas las mujeres pasan, al principio para enseñarles que deben darles su espacio a las damas, porque aparte es la liberación femenina y aparte es la educación verdad. 
GD03

Pachaj, Cantel, Quetzaltenango, septiembre 2016

E: Entrevistadora

P: Participantes: 6 mujeres y 1 hombre, maestras y maestro de Pre-Primaria y Primaria.

Subrayado: extractos literales tomados en el análisis

E: Bueno, ya estamos entonces. Nos encontramos en la escuela de Pachaj, escuela que tiene párvulos, Pre-Primaria y primaria, Aldea Pachaj, Cantel, Quetzaltenango con un grupo de seis maestras y un maestro. Entonces, la idea sería comenzar platicando sobre la igualdad como ven ustedes el tema de la igualdad en la sociedad. La igualdad entre mujeres y hombres entre indígenas y ladinos, entre ricos y pobres. Pero, cuando hablamos de igualdad es un tema muy amplio verdad se trata de que todas las personas pudiéramos ser iguales no solo en la ley sino también en la vida real no importando sexo no importando cultura no importando condición social. Como ven ustedes el tema, consideran que hay igualdad social en nuestro medio o que opiniones tienen sobre esto... sin miedo aquí no hay respuestas buenas ni malas lo que hay es realmente lo que sienten su experiencia, lo que han podido ver lo que ven en la noticia también experiencias personales que tiene uno verdad.

P: Pues yo siento que la mayoría de la nueva generación está enterada lo que es la equidad de género y sí se sabe pero en la realidad no se practica, en su mayoría yo veo que no se practica porque siempre hay violencia, violencia física, discriminación si nos referimos a las mujeres hay discriminación y pienso que aunque se sepa, se ha leído, se ve en los medios de comunicación pero no se vive en la realidad, quizás sí se puede practicar, quizás lo practican poco, podríamos decir que tal vez hasta un 40 , si no exagero, un $40 \%$ el resto pues no practica la equidad de género aunque sí se acepta.

E: ¿Iba a compartir usted?

P: Sí, en lo personal lo que yo estaba viendo es como lo que decía la compañera, verdad, que sí sabemos, sabemos que es importante pero, no lo practicamos la mayoría no lo practicamos. En lo religioso, en lo social, en la vida política tampoco se practica verdad. Hay muchas leyes aquí en Guatemala hay muchas leyes pero no lo practicamos y si nos damos cuenta pues en 
toda actividad pues los que dirigen, los que guían los grupos son hombres y no en si las mujeres pero, eso tiene su historia verdad porque antes la mayoría de nuestros padres nos dicen que eso no lo debe de hacer usted porque usted es mujer verdad entonces yo pienso que eso influyo bastante en que nosotros seamos así ahora y nos está costando bastante verdad de hablar de defendernos porque muchas mujeres lo que decía la compañera verdad de que nos discriminan sino que también nosotros nos dejamos de que nos dicen las cosas que no se deben nos dejamos en muchas cosas y no nos... como dijera nosotros con esa historia que traemos verdad nosotros también nos quedamos así sin buscar manera verdad para salir adelante. La mayoría por ejemplo aquí en Guatemala yo lo observo en la vida religiosa y en la vida social hay muchos hombres todavía practicando machismo eso influyo bastante también de que a la mujer no se le deja hacer lo que quiere hacer y ya sabemos ahora pues de que si hay igualdad tanto mujer como hombre tiene su derecho a hablar, opinar o hacer lo que quiere verdad siempre y cuando equilibrado porque a veces también a las mujeres se les deja hacer y exageran y si vemos en las noticias verdad de que muchas mujeres de que con esa libertad ellas lo tomaron como libertinaje y no se dan a respetar y hacen las cosas que quieren porque no creo yo de que ese presidente influya en hacer las cosas malas sino que somos los que hacemos las cosas indebidas y como mujer tenemos que tener un equilibrio para que nos respeten y no perdemos esa oportunidad que nos dan ahora pues de tener un espacio en nuestra vida social y en nuestra vida comunitaria de dirigir algún grupo pero hay muchas mujeres que a veces esa libertad lo están utilizando para otras cosas malas porque lo vemos en la noticia no necesariamente ellos las tienen que ir a traer a sus casas pasan las cosas cuando uno no se fija. Esa es mi manera de pensar las cosas.

E: Muchas gracias, ¿alguna opinión más?

P: Si licenciada, fíjese que en cuanto al tema de la igualdad pues yo tengo esta opinión; estoy viendo yo que en la nueva generación que se está preparando ahorita yo miro que están tratando la manera ya de tener igualdad. Ahorita veo yo a mujeres manejando carros, manejando motos. Cosa que no se daba antes verdad y también yo estoy viendo ahora que ya hay profesionales mujeres en cambio más antes no habían profesionales mujeres habían más hombres que mujeres y en cuanto también a la política decía la compañera, si miramos que los que gobiernan son hombres a como de lugar, no hay mujeres. Pero, siempre ya están $\underline{\text { saliendo algunas candidaturas mujeres, pues yo estoy viendo que se está tratando la manera }}$ de tener igualdad. Gracias al trabajo de los maestros también que están inculcando en los 
niños la igualdad de derechos, verdad, aquí en la comunidad de Pachaj yo estoy viendo que lo que existe aquí mucho es el machismo es el que existe aquí, que la mujer haga su tarea de la casa y que el hombre sale a trabajar. Pero, fíjese que hay algunas familias porque yo me doy cuenta que hay algunas familias que tratan la manera de ayudar a la esposa y el esposo a la esposa como trabajo en equipo ayuda mutua entre ellos pero, solo... son raros, entonces yo me doy cuenta que sí, la preparación académica les ayuda mucho a que ellos formen un buen hogar a que ellos traten la manera de tener igualdad. Pero si, no estamos viendo un $90 \%$ de igualdad, no, no hay pero pienso que tal vez hay un poquito, $20 \%$ le digo yo pero, tratan la manera. En mi casa trabajamos en equipo, en mi casa no hay hombre ni mujer pero, estamos tratando la manera pues de tener esa equidad de género pero yo hablo con mis hijos, platicamos, nos relacionamos con mi esposo y todo pues... entonces tratamos la manera de trabajar en equipo y todo pero, si estoy viendo en varias familias aquí en la comunidad de Pachaj porque como trabajo con los niños pequeños entonces vienen las mamas a dejar a los niños verdad entonces, si nos damos cuenta que vienen mas mamas que papas en reuniones vienen solo mamas en las... como le dijera yo, cuando los niños terminan de estudiar sexto grado pues una parte van a estudiar solo varones y las niñas no que mejor aprendan el oficio porque seguro se casan y para qué verdad entonces... pues lo que miro es que lo que si necesitamos aquí en nuestra comunidad de Pachaj es mucha sensibilización, capacitación a madres y padres de familia porque a madres siempre hablamos con ellas y todo, pero los papas no los miramos no nos podemos comunicar con ellos para hablarles de la igualdad y todo. Y tal vez lo que pasa con los varones es que como ellos se dedican mucho a trabajar entonces eso es lo que a ellos no les da tiempo de relacionarse con un grupo de personas entonces... no les da tiempo de recibir capacitación entonces, mas es el trabajo, trabajo, trabajo.

E: Me ha recordado a unas compañeras de San Lucas Tolimán que dicen: tenemos que trabajar con los hombres porque si no, ahí tenemos siempre el obstáculo. ¿Alguna opinión más? ¿Qué nos dice el compañero?

P: Pues yo creo que lo que se ha expresado no es extraño a mi opinión, tal vez coincidimos en ese sentido. Lo único que yo quiero resaltar es que tendrá que pasar muchos procesos, tendrán que haber muchas incidencias para trascender en este tema porque yo trabajo con la $\underline{\text { adolescencia y intentamos darle es espacio a la mujer pero la mujer es la misma que cede ese }}$ espacio para que sea el hombre quien protagonice. Muchas veces la misma mujer como dice 
la seño tiene un proceso histórico. Se le da la oportunidad y no lo asume. Son pocas las patojas mujeres que sí se atreven a ir rompiendo este paradigma. Entonces yo a lo que voy es que tendrá que venir también muchas veces de las mujeres hacia las mismas mujeres. Porque como dice la seño nosotros que hemos tenido la oportunidad de estudiar y compartimos que la equidad, la igualdad entre hombre y mujer es fundamental para muchos procesos pero cuando la mujer misma no aprovecha o no se da ese espacio ahí radica el problema. Pero yo pienso que eso es una herencia de los padres, es la ideología familiar, que aún lo llevan. Y dicen ahora a vos te toca hacer esto y dice, ay no, porfa, que sea él. Bueno, hagamos gobiernos escolares o consejos educativos de estudiantes y se hacen planillas y todo eso y siempre la mujer, no, yo prefiero ser secretaria y siempre van delegando, dándole el espacio al hombre. Entonces yo pienso que es todavía un proceso muy temprano para ver grandes resultados, pero de que se hace el intento, se hace el intento. En el caso aquí de la escuela pues yo con mis alumnos trato de concientizar a las mujeres para que sepamos que todos tenemos los mismos derechos y por supuesto las mismas obligaciones. Es un proceso lento, eh, por supuesto que hay que tener siempre el cuidado porque existe también la cuestión de que las mujeres también reviertan el papel muy liberal. Porque no hay que negar que existen también mujeres que dominan en el hogar y hasta manejan a los hombres, entonces, como todo requiere un equilibrio. Es un proceso lento, poco a poco, quizá en especial las comunidad nuestras, es un proceso histórico, traído desde las invasiones y todo eso.

E: Salía otra discusión con otro grupo de maestros, precisamente si esto viene de las invasiones o de antes, porque no sabemos qué tanta equidad había en los antiguos mayas, verdad. $\mathrm{Y}$ es un tema que es difícil investigarlo porque no hay muchas evidencias, pero podemos sospechar que también eran sociedades patriarcales porque la mayoría de las sociedades del mundo han sido así. Bueno...

Vemos que en nuestro medio hay desigualdad, pero ¿dónde es que como personas aprendemos a ser así, a no ser iguales? ¿Cuáles son los principales agentes de socialización?

P: La familia, la iglesia, la sociedad, la escuela...

E: Ahí en ese caso, ¿qué papel ven ustedes que tiene a escuela? ¿Será que tiene peso o que no tiene tanto? Es decir, ¿podemos hacer algo acá? ¿Cómo miran el papel de la escuela? ¿Ustedes se ven con herramientas, con poder para cambiar las cosas? Desde la experiencia real... 
P: Yo pienso que la escuela tiene un papel secundario. No es el espacio principal para este

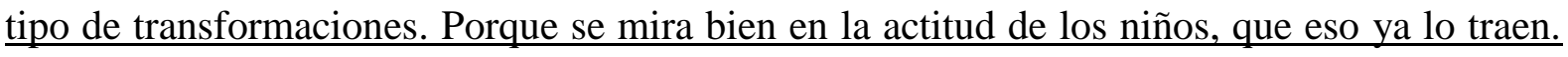
Por ejemplo, solo un ejemplo, la refacción. Yo les digo, bueno chicos ahora les toca. No profe, nosotras. Y desde el hogar, verdad... se intenta hacer el esfuerzo y algunas cosas funcionan pero la mayoría no porque el hogar es la primera escuela y acá muchas de las cosas no es posible cambiarlas porque nosotros jugamos un papel secundario en la vida del niño. Entonces pienso yo, que yo por lo menos desde que he trabajado he entendido el tema y siempre lo he tratado de aplicar, lo decíamos hace ratos que los agentes multiplicadores de estos procesos no es precisamente la escuela, tal vez la escuela tradicional sí, pero la escuela moderna de hoy en día, con las nuevas corrientes pedagógica, yo no creo que exista ya ese reto y si existiera ha de ser maestros que no están al día con las nuevas cosas. Yo sí pienso que desde la escuela ha comenzado ya este trabajo pero no es una cuestión primordial.

E: ¿Alguna idea más?

P: Sí, fíjese que lo que ha dicho el compañero es real. También en las aulas cuando formamos a los niños, rapidito se apartan las niñas y rapidito se apartan los varones. Cuando nos sentamos nosotros tratamos la manera de que se sientan en sus sillas en orden alfabético, un varón, una niña... pero ya luego ellos se buscan, cambian lugares y se apartan los varones. Pues es algo como dice el compañero que viene de la casa, que viene del hogar. Porque en varias ocasiones yo me he dado cuenta, fíjese, que es prohibido que digamos que se tiende la ropa del varón con la ropa de la mujer. Es aparte, hay que lavar la ropa del hombre y aparte hay que lavar la ropa de la mujer, hay que asolearlo aparte. Hay que, cuidado, que a veces juegan las niñas y los niños, verdad y a veces una niña saltea a un niño y dicen, eso es pecado, no hay que hacer eso. A veces hablan del corte de la mujer, dicen ellos que no, que $\underline{\text { no encuentre la ropa del hombre, la ropa de la mujer, el corte pues. }}$

E: Y ¿qué es lo que pasa si se llegan a mezclar?

P: Risas... pero son costumbres que algo traen. Pues ahí sí que saber qué idea tienen, pero eso me hace ver como que no se puede acercarse, pues. Pero hay mucha idea, nosotros contamos que qué tiene que ver eso, de hecho las parejas ellos viven, ahí sí que los dos, pero... Pero es un proceso que yo pienso que la escuela puede ayudar a un cambio, ayudar, pero de que lo haga, cambiar de la noche a la mañana, tal vez es un poco problemático. Se 
puede trabajar, se puede inculcar, pero cuesta que se rompan esos paradigmas, porque media vez es una costumbre, dice que la costumbre se vuelve ley, media vez ellos ya lo traen en la casa... yo muchas veces les digo a los niños: bueno, ahorita sí, se tiene que sentar una mujer, un hombre, una mujer, un hombre... va, muy bien, por obediencia lo hacen, pero ya al rato, otra vez. Cuesta pero sí, la escuela puede ayudar.

P: Yo trabajo con los chiquitos y hasta en los colores se ve la discriminación. Las niñas manejan un color rojo o rosado. Los niños un color azul, celeste o verde. Pero no mezclan esos colores del rosado porque según ellos el rosado es para niñas y los colores verde, azul son para varones. Pero eso es cierto que desde la familia, el papá ya le está inculcando al niño el machismo y ya los está separando, lo que yo hago que les digo: los colores son libres, no son para hombres no para mujeres, pero según así, así se ha marcado en la sociedad de que el rosado es para mujeres. Entonces ahí se ve la desigualdad.

E: Claro, y parece algo sencillito pero de esas cositas sencillitas va creciendo la separación de roles que tenemos en la sociedad. Y al final terminamos mujeres adentro de la casa, con el oficio como comentaban antes y los hombres ya protagonizando espacio políticos, sociales, culturales... y ese poder que adquieren los hombres, lleva incluso a la violencia física, psicológica, control... da lugar a situaciones graves de violación de derechos humanos.

P: Eso sí se da dentro de la familia, como decían los compañeros. $\underline{\text { Yo a veces he escuchado }}$ en familias que la mamá al educar a los chiquitos, como los niños pegan, dicen: todos los hombres son así. Entonces las niñas ya se van metiendo eso en la cabeza, eso de que los hombres son así. No es así, todos tienen los mismos derechos, igualdad.

E: Hay muchas ideas...

P: No solo en la familia, en la sociedad, en las iglesias... yo he participado en la iglesia evangélica y en la iglesia católica. Se apartan todas las mujeres y todos los hombres... rara vez cuando van en pareja se sientan hombres y mujeres. Pero cuando van solos, solo es el hombre y solo la mujer. En la escuela, también solo señoritas y aquí solo varones. Y yo les he dicho, por qué no todos juntos. Y las niñas dicen, ay no. Pero cuál es el problema que se siente cerca de una compañera o un compañero. Todos somos iguales, pero ahí tenemos el rollo de que nosotros (maestros) también somos partícipes, no culpables, partícipes de esa 
situación. Entonces, en un cumpleaños, todos los invitados si es señorita o si es niña, todos llevan color rosado. Qué dirán si lleva un celeste. Entonces, el ambiente, que estamos. Yo creo que la escuela es un apoyo, como decía el compañero, pero si nosotros lo hacemos, pero si no lo hacemos, queda también...

E: Con todos los grupos de maestros que hemos platicado dicen que la escuela no tiene ese poder de transformación, que es un apoyo, pero yo sí quisiera hacerles la puntualización de que creo que el poder de la escuela cada vez es mayor porque si nos damos cuenta las familias lamentablemente cada vez están más desestructuradas. Cada vez hay más niños que no tienen un hogar estable. Situaciones de todo tipo donde cambia el modelo familiar... Así que cada vez la escuela ojalá pueda ser agente con más peso, donde las niñas y niños encuentren un espacio de igualdad, no solo de género, sino también a las personas que vienen de los cantones o de familias más pobrecitas... que la escuela pueda ser espacio de igualdad. Entonces con esta intencionalidad el Ministerio introdujo en el CNB el eje de equidad de género, de etnia y social, para ir introduciendo normas, actividades, que promuevan la equidad. ¿Conocen ustedes este eje? ¿Qué experiencias tienen respecto a este eje, que es un eje transversal, que lo atraviesa todo?

P: Pero yo vuelvo a recalcar el tema. El tema de equidad de género está en el CNB y pienso yo que la escuela moderna ya debe de estarlo inculcando, verdad. Debe, en teoría, en la práctica no sé, habría que hacer una diagnóstico para tener una opinión en ese sentido, pero yo vuelvo a insistir que la escuela no es el eje fundamental para estos cambios. Y vuelvo ya a retomar mi opinión de hace ratos que esto lo trae la cultura occidental porque este tema de discriminación es bíblico, la cabeza de la familia es el hombre y eso es bíblico, y la mujer tienen que estar sumisa al marido, eso es bíblico. Entonces de dónde viene la religión, retrocedamos un poquito, lo trajeron los españoles. Porque si usted no hacía el padre nuestro usted era fusilado, entonces la religión es una cuestión impuesta, ahora, vayamos al tema de la cultura maya. Yo sostengo que existen muchas debilidades de la cultura pero también muchas cosas que hay que rescatar. Por ejemplo cuando hablamos de tzacol y bitol, estamos hablando de dios hombre y dios mujer, cuando hablamos de ukux ulew estamos siempre hablando de en pareja, cuando hablamos es una cuestión un poco más, siento yo, más centrada en lo que estamos hablando. Porque hay un dios hombre y dios mujer, pero muchas veces por el mismo desconocimiento que tenemos nosotros decimos tzacol y bitol pero ¿quién es? el papel que ha jugado, desde la creación se habla de la creación del hombre con la 
abuela Ixmukane, está haciendo un papel fundamental en ese proceso. Entonces yo vuelvo a la pregunta y no es malo el tema, entonces yo pienso que la escuela moderna lo debe estar implementando, sin embargo creo que desde nosotros, si yo como hombre creo que no me conviene que las mujeres manden o que sean iguales a mí, no lo voy a reproducir, lo puedo ignorar, pero el tema es demasiado amplio y desde el CNB sí está y en la mayoría de lo que yo conozco sí se impulsa ese tema. Porque la juventud ahora es muy distinta, por supuesto que tiene sus propios rollos, verdad, que sería otro tema de discusión, pero la mayoría lo está practicando. Y no es necesariamente trabajo de la escuela. Quizá ha habido contribución, pero los medios de comunicación y todo eso también han servido para cambiar esa mentalidad a la juventud.

E: Muchas gracias, a ver la compañera, alguna opinión sobre este eje.

P: Viera que estaba analizando la situación con el poder que tiene la escuela de cambiar este problema. Comparto la opinión del compañero de que tenemos la buena intención de cambiar, pero el problema es de que lo que enseñamos aquí muchas veces solo lo practican aquí, lo que hacen en casa, la situación... muchas veces yo les pregunto, hay familias que solo tiene hijos varones, yo les pregunto qué hicieron ayer en la tarde, hicieron tal cosa, hicieron tal cosa, pero son raros los que dicen ayudé a mi mamá a lavar trastos, ayudé a hacer tal cosa... entonces por qué no hacen eso, porque la mamá no quiere. Entonces, si queremos que haya un cambio, nosotras como mujeres, nosotras como maestras, como madres de familia tenemos que darnos a respetar porque si no lo hacemos nosotras quién lo va a hacer... $\underline{\text { si nosotros queremos cambiar no para gobernar la casa tampoco. En la familia debe haber }}$ igualdad, hombre y mujer educar a los hijos, cambiar el pañal a los hijos, tiene que ser equitativo el trabajo, pues. En mi casa así lo hemos hecho, pero yo le digo a mi hijo, las niñas no hay que pegarlas, no hay que maltratarlas, son seres humanos. Es que a veces los niños tienen u poquito más de fuerza, molestan más a las niñas... ustedes tiene que respetar a sus compañeras, todos somos iguales... o hay diferencias: sí, solo porque tal cosa, buscan pretextos, pero nosotros tenemos que sembrar esa semillita. Si desde chiquitos se empieza a sembrar, cuando salgan de la Primaria yo sí pienso que no los vamos a cambiar de la noche a la mañana, pero más o menos hay un cambio. Con respecto a hacer limpieza yo he visto muchas veces que los varoncitos como que sí les cuesta: nooo tienen manos, así que a agarrar la escoba, agarrar la cubeta... todos tenemos que colaborar. Porque como decía yo, si nosotras no les inculcamos eso y en la casa igual, no vamos a llegar a nada, no hay cambio. 
Yo les decía a las niñas, ustedes también se tiene que valorar, se tienen que dar a respetar, porque un varón llega hasta donde la mujer le permite. Si en mi casa a mí me pegan es porque yo así lo he permitido. Porque si cuando levantó la mano lo detengo, pues el hombre también se va a acostumbrar a respetar a la esposa porque hay casos que son así, hay señores que maltratan a sus esposas hasta dejarlas moradas porque ellas así lo han querido. Yo digo de que es cuestión de uno, no permitir, igual inculcar a los niños desde chiquitos no golpear a las niñas, cierto tienen el cabello largo pero no para estar halando los chonguitos porque de todo se hace. $\mathrm{O}$ porque trajo una ropa diferente, no, porque esos son mis gustos. Yo les digo: si yo traigo una ropa diferente es porque a mí me gusta vestirme así, no es porque me estén inculcando, no, ustedes también tienen que respetar a sus compañeras... yo pienso que sí se logrará pero sí en un largo tiempo, no de la noche a la mañana.

E: Si... son cambios generacionales... ¿alguna idea más sobre el eje de equidad de género, de etnia y social?

P: es que yo estoy pensando el tema y cuesta un poquito porque viera que también hay niños que también se transforman negativamente en la escuela. Cuando traen principios y valores, entonces como que la escuela pensándolo bien, de algún modo tiene incidencia. He visto casos de gente que viene bien formada, pero como que lo malo pega más rápido y ya regresan alguna vez en una mentalidad distinta, que no es necesariamente en el aula, es precisamente en el espacio de recreo o de otro lugar. Y después no lo hacen en casa porque saben que está prohibido, pero sí en la escuela, como que llevan esa doble vida.

E: y ustedes hacen alguna actividad, como escuela se habían plateado en alguna oportunidad esto, qué podemos hacer para minimizar la desigualdad, inequidad, hacen alguna acción o dentro de las aulas por iniciativa personal, cada quien...

P: Físeje que a mí me interesa mucho el tema. Yo no sé pues la verdad me interesa que las personas tengan esa igualdad. Fíjese que a mí me gusta mucho trabajar con las mamás, ellas vienen casi diario por los niños, hay algunos que no los vienen a dejar, que vienen con los hermanitos, pero hay una mayoría que viene, A mí me gusta hablar siempre con las madres de familia sobre ese tema porque es muy importante, se dan muchas situaciones en la vida de las familias, verdad, porque no es solo una cosa, se dan muchas cosas. Pues el CNB nos exige y también nosotros tenemos que poner de nuestra parte para ayudar porque de repente las 
personas quieren cambiar pero hay mucho desconocimiento, entonces ese es el rol de nosotros como maestras, ver qué hacer, fíjese que es muy importante programar en todas las aulas pláticas para las madres de familia porque lo que hacen en casa es lo que los niños traen. Hace poco a un niño lo vinieron a dejar a la escuela y dice que no se quería quedar porque lo levantaron muy temprano y no se quería quedar y entonces comenzó a pegar la mamá y yo observaba qué reacción era de la mamá y viera usted que la mamá solo se defendía ante el niño, le dieron patadas en la rodilla, le halaron y se quedó la señora solo desquitándose y a mí me llamó la atención, eso no se le puede permitir, de veras, que la mamá tiene que poner en su lugar al niño. Viera que es el primer caso que yo veo que un niño pega a su mamá de esa manera. Entonces cuando vino la mamá al segundo día yo le digo a la mamá, qué pasó al fin, es que fíjese que lo levanté muy temprano seño y por eso se enojó conmigo. $\underline{Y}$ usted por qué le permitió que le pegara, usted es la mamá... es que como mira lo que hace el papá, seño. Entonces, fíjese que yo miro que aquí lo importante es programar pláticas de orientación a madres y padres de familia, de repente un día con mamás, otros con papás, eso es lo malo que los papás casi no llegan.

E: ¿Alguna experiencia más de sus aulas?

P: En mi caso, yo la agenda nos exige trabajar un valor. En mi caso yo trabajo un valor durante un mes, por ejemplo la convivencia, tratar de que convivan todos, el respeto, yo creo que ha sido muy bueno a nivel de escuela trabajar los valores.

E: qué bueno, ¿alguna idea más?

P: deportes, también. Es la manera de involucrar a niños y niñas en los deportes. Ya se sabe que los deportes es una buena práctica para la salud, entonces, se practica el deporte con los varones y con las niñas. Tiene que ser también el deporte que les gusta porque no les podemos también obligar a las niñas a jugar fut si no les gusta. En mi caso a mí no me gusta ese deporte, practicarlo, porque lo he practicado y no lo puedo. Entonces, igual los varones, hay niños que les gusta practicar baloncesto y no mucho les gusta el futbol, y hay niñas que les gusta más el futbol y no el basquetbol. Entonces se les deja la libertad a ellas para que elijan de qué les gusta pero sí tratar la manera de practicar no solo el deporte, también otras actividades sociales. 
E: ¿Aquí en el recreo que es lo que se juega? Les cuento una experiencia de algunas escuelas de España en este tema: se vio que el futbol en el recreo era un problema porque los niños ocupaban todo el campo y las nenas solo en la orillitas. En algunos centros ya tomaron la decisión que cada día de la semana es un juego diferente pero a para jugar todos. Bueno, pues tenemos bastantes elementos... una última cosita, rescatando el aporte sobre la cultura maya, hay valores importantísimos como la complementariedad, la dualidad. Sería bien importante rescatar esto y de qué manera se vive en el aula, porque este tema más que todo es vivencial.

P: eso de los valores que hablaba el profe, fíjese que hay una compañera que sí lo inculca. $\underline{\mathrm{Mi}}$ hijo estuvo con esta maestra y les decía lo del awas, lo que es pecado, y esto venía de los abuelos, y entonces ella les hablaba del popol vuj, los mandó a leer, y los niños van cambiando, yo miraba a mi hijo y él me explicaba del awas, de que esto es pecado, y entonces son cosas que a los niños les queda de una u otra forma pues aprenden algo.

P: yo lo que veo aquí es que hay esfuerzos muy separados. Yo cuando me tocan los temas de la mujer y todo esto lo abordo, pero en la práctica no lo hago, no lo quiero ver, trato, pero es complicado. Yo siento que lo que estamos haciendo son esfuerzos separados. Y que debería haber un eje o una política institucional.

E: ¿Dentro de la escuela dice usted?

P: Sí.

E: Me parece muy interesante eso, ¿qué piensan?

P: Pues fíjese que yo estaba analizando de todo lo que estaban diciendo y yo creo que todas las compañeras y compañeros están haciendo un esfuerzo para orientar al alumno y hacer todo lo que tienen que hacer, pero el problema del guatemalteco es que todo queda en palabras. Porque no es verdad que eso que nos han dicho que los maestros no enseñan nada, pero no es cierto, nosotros luchamos y nos esforzamos para orientar a los niños pero el problema es que yo les decía siempre a mis alumnos: nosotros en la escuela tenemos las tareas de labores, formación ciudadana, tratamos de orientar a los niños, de enseñar, es que nosotros no lo practicamos, no es que el maestro no enseña nada. A veces hay familias que tienen buena, si se dedican mucho a la iglesia, están bien preparados, pero sus hijos se 
desvían. No es que no enseñen nada, no dicen nada a sus hijos, ya problema del guatemalteco que solo escuchamos y no practicamos. Les decía yo a los niños, si practicamos todos los valores que nos enseñan, no necesitamos de policía, pero si nosotros nos damos cuenta, dejamos una bicicleta y ya mañana, saber. Saben que tenemos que respetar, pero no lo practican. El problema es que cómo se hace para que le niño practique y nosotros lo practiquemos. Nosotros en nuestra familia tratamos de practicar y diferenciamos qué es bueno y malo, pero la mayoría no lo practica. Sabemos que la mujer no tiene que dejar que le hacen, pero la mujer se deja. Pero no, esa mujer se deja, aunque ya conoce sus derechos, pero no lo practica y es por eso que la mayoría de los hombres se aprovecha. Yo tengo una experiencia y es de que ahora dije al principio hable de que nos dieron la libertad y utilizamos el libertinaje. En mi casa hay una oficina jurídica, llegan problemas de que las mujeres pegan a sus maridos y el hombre no se defiende por vergüenza pero hay mujeres que exageran y meten a sus maridos en problemas. A mí me extraña, entonces yo digo no solo el hombre tiene ese problema sino que ahora las mujeres también damos lugar a que haya problema en la familia. Ahora si nos damos cuenta, yo tengo dos muchachas, ahora ya no son ellos lo que llaman por teléfono, ahora en mi época si yo recuerdo que nunca busqué a un muchacho, uno espera que lo buscan a uno, pero ahora ya las muchachas no les da pena, y ya son ellas las que buscan a los patojos y nos damos cuenta que ahora ya las muchachas salen. Antes le dan permiso a uno solo si uno va a acarrear agua, nada más, ahora ya no, entonces todo se está cambiando. Hay que ver eso también que ya no solo el hombre manda en la casa, ya no solo el hombre pega, sino que también ya las mujeres exageraron, no entendieron el mensaje sino que también ellas pegan sus maridos, entones para mí no es bueno. 


\title{
GD04
}

\author{
Almolonga, Quetzaltenango, septiembre 2016 \\ E: Entrevistadora \\ P: Participantes: 7 mujeres, 2 hombres, maestras y maestro de Pre-Primaria y Primaria \\ y estudiante de magisterio en prácticas.
}

Subrayado: extractos literales tomados en el análisis

E: Buenos días, la dinámica que tenemos planteada es una conversación, una plática, compartir sobre el eje de equidad de género, de etnia y social. Lo primero sería compartir cómo miran ustedes la discriminación de género, de etnia y social, si es algo que está presente, si lo miran como un problema al que es necesario responder o no, no sé, tal vez no se da, tanto a nivel de la escuela como a nivel de la sociedad.

P: Pues yo sí quiero comentar algo, al menos yo, mi papá es de aquí de Almolonga y mi mamá es de Quetzaltenango. Yo he compartido un poquito en cada localidad. Pero me he dado cuenta de que el género influye mucho en la vida de las personas. En el tiempo en que yo estaba estudiando y era niña a mis papás les decían que las niñas eran para la casa, que no estudiaran. Mi papá luchó un poco contra la corriente de esa situación y nos dio estudio. Ahorita ya no es tan marcado, pero aún se ve con los niños. Tengo un parito de gemelitos y la mamá le compra todo al niño, al varón, y a la niña no. El niño tiene uniforme de física, la niña no. Hay una actividad, el niño viene, la niña no. O sea ella tiene que escoger entre los dos y a quien escoge es al varón, o sea marca la diferencia de género, hay una discriminación. Esa es mi experiencia.

E: Muchas gracias seño Mayra. ¿Alguien más?

P: Bueno, permítanme compartir algo sobre la equidad de género. Antes de que yo viniera a dar clases acá estuve en otro lado dando clases, en la primaria entonces pude darme cuenta de que sí prácticamente en Almolonga todavía existe esa discriminación y no existe todavía la equidad de género. Como decía seño Mayra yo platicaba con las niñas, les preguntaba por qué no seguían estudiando después de terminar la Primaria y ellas decían que no, que mi papá dice que las mujeres se van muy rápido y es en vano que estudien, entonces solo a mis hermanos. Ahí es donde yo me daba cuenta que hay un desequilibrio porque entonces a las $\underline{\text { niñas no se les sigue apoyando en sus estudios. Algunas tienen ese deseo de seguir estudiando }}$ 
pero como no tienen el apoyo de sus papás entonces no tienen posibilidades de seguir superándose y no así los niños, que reciben apoyo de sus papás y de esa manera podemos ver que existe inequidad de género en esta población.

E: Muchas gracias.

P: Anteriormente se marcaba mucho que trae una trascendencia que dice que el hombre es el que manda en la casa entonces todo eso como que lo repiten mucho, entonces los que vienen atrás ya dicen el hombre, el hombre... entonces se da más énfasis en el hombre que en la mujer. Pero estamos tratando de que la mujer también salga adelante con los proyectos que se hacen, con participación de la mujer.

E: ¿Cómo ven la parte de discriminación étnica y por procedencia social?

P: Así como usted decía sí existe la discriminación. Nuestro país es totalmente indígena. Españoles así ladinos tal vez hay un 30\% y un $70 \%$ indígena. Ya ahí si nos vamos más localmente nuestra comunidad es netamente indígena, pero ahí sí que, cómo combatir esto, llevaría mucho tiempo. Tendríamos que empezar con los niños chiquitillos, educarlos, cambiarles la mentalidad, pero también nos damos cuenta que aquí les decimos así es, pero llegan en la casa y ya no les ponen atención. Entonces lo poquito que aquí les enseñamos ya no lo practican y como viven en una sociedad ahí sí que, lo ven tan normal... y esto también se ve de pueblo a pueblo, por ejemplo los de Xela discriminan a tal municipio, el otro municipio discrimina a otro, a no, que yo soy de Toto, que se discriminan... total que es como un cáncer que no se puede curar. La única esperanza que está y que yo miro que está en los niños, pero tendríamos que tener conciencia tanto los maestros como los padres de familia que poco a poco vayamos educando a los niños, para erradicar un poco porque por completo no creo que sea posible, aunque sea un 50\%. Inclusive ya a nivel de países, países con países, nación con nación, también sigue. Así como usted decía, yo soy rico y aquí están los ricos y aquí están los pobres. Es una cadena de inequidad de género y discriminación que trasciende fronteras, inclusive con religiones, es una problemática que no se puede erradicar más que poco a poco educando a los niñitos y a las personas, quizás, haya una solución.

E: Claro... es que estamos hablando prácticamente de crear una ciudadanía nueva, de una nueva forma de ser ciudadanas y ciudadanos... 
P: Y el futuro está en los niños pero lo malo es que unos somos conscientes y tratamos de cambiar a los niños, pero ya llegando en la casa ya es... ya no, ya no hay continuación de lo que nosotros estamos tratando de hacer.

E: Muchas gracias. Miren y algún ejemplo que puedan ver ya pensando aquí, en lo que pasa diariamente en el aula. ¿Qué ejemplos miran donde se pueda visualizar esta inequidad de género, de etnia y social?

P: No se si puedo... de la pregunta anterior... cuando usted decía a nivel global, también existe discriminación y no existe equidad de género y lo vemos mas en las instituciones, $\underline{\text { cuando uno va a las instituciones hay fila lo atienden más rápido a una persona de clase social }}$ alta en comparación de un indígena que va ahí, como que lo ignoran, no lo atienden, entonces podemos ver y a nosotros nos sucede también o sea que sí existe a nivel global todavía existe la discriminación, pero más lo vemos en las instituciones, cuando uno tiene que hacer

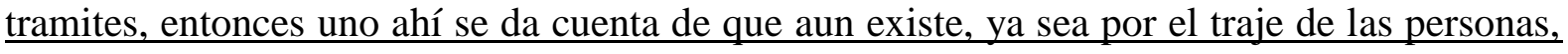
ya sea porque son ladinas o clase social o van presentables, entonces si siempre existe esa discriminación y falta de equidad de género al momento que uno va a la ciudad.

P: lo que tal vez influya mucho es la cultura de nuestros propios pueblos, porque se marca en que nosotros los mismos indígenas nos discriminamos, o sea que no es necesario que venga alguien de afuera para discriminarnos, sino nosotros mismos marcamos esa situación ya sea por cuestiones de ideales, cuestiones económicas o académicas también, hasta incluso de

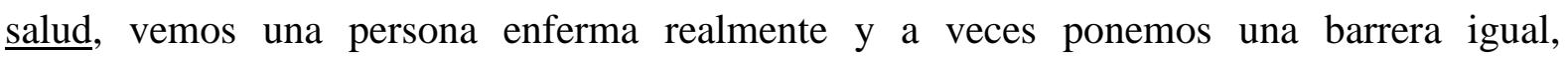
discriminamos a la persona cuando debería de ser una situación totalmente diferente, porque ahí es donde debemos mostrar un apoyo incondicional. Aquí en nuestra comunidad si se marca la discriminación, pero no es porque quiera hacerse un problema si no esa ha sido parte de la cultura, aquí las mujeres se sientan a parte y los varones se sientan a parte o sea no pueden estar juntos. Eso lo hemos trabajado al menos aquí en mi aula poco a poco, cuando vamos a física o vamos alguna actividad, nosotros colocamos aquí a los niños, una niña y un $\underline{\text { niño agarrados de la mano, para que ellos aprendan a convivir con el género opuesto verdad, }}$ entonces se colocan, al principio no se toman de la mano... hacer eso no... los niños no... es malo, ellos no pueden. Ahora a estar alturas ya, cada quien con su pareja y salen y todos buscan su pareja, pero es algo que no podrían hacer afuera tampoco, porque sería marcado como algo malo, no es correcto, entonces la discriminación, entonces muchas veces se 
maneja por cuestiones más de costumbre y que no es un problema, pero sin querer las generaciones vienen con las costumbres que hacen daño a las personas de los pueblos, hace daño porque entonces cuando salimos al mundo nos dan pena muchas cosas que para el mundo es natural, pero para nosotros no, por ejemplo el beso en la mejilla para muchos es natural verdad, hola! ¡Hola! Y nos saludamos verdad, pero si lo hacen ciertas personas... malísimo, está haciendo algo realmente malo, entonces hay cosas que se hacen que son malas pero parecen buenas o buenas que parecen malas.

P: lo que pasa que en nuestra cultura indígena, hay costumbres que se podrían cambiar, pero lamentablemente esas costumbres están muy arraigadas, cambiarlas no se puede así como decía ella (maestra 1) las mujeres a parte y los hombre a parte, todavía no existe esa convivencia tan natural que podría darse de convivir tanto un hombre con una mujer o socializarse y como los niños también lo han visto en la casa, les cuesta adaptarse al ambiente porque nosotros tratamos de sentarlos en su grupo pero ya cuando miramos tres, cinco niñas acá y el grupito de hombres halla, o sea cuesta erradicarlo por qué no colaboran los papas con nosotros y como a ellos así los fueron educando, los abuelos así fueron educando, entonces es una cadena que es muy difícil erradicarla.

E: Muy bien y que más ejemplos de este tipo de discriminación visualizan aparte de eso que se separan niños y niñas por ejemplo que otras cosas visualizan:

P: por ejemplo en el caso mío a la hora de pasar la refacción, no lo pueden hacer los niños... o sea sí lo pueden hacer pero no lo quieren hacer porque su educación no se lo permite... no porque yo soy niño, que lo haga la niña, que lo haga ella, si hay mas niñas... no pero les corresponde... y yo considero que uno como docente tiene que ser así verdad, sumergir a los niños e incluirlos en el grupo por que recuerden que ellos mismos se apartan y se les dice, no pero si lo puedes hacer, tenés tus dos manitas y si lo puedes hacer... ahora si ya lo hacen pero anteriormente no porque para ellos era malo, era incorrecto habiendo niñas que podían servirles y no ellos servirse sólitos verdad, porque recuérdense que yo así les digo a ellos que la comida no va a llegar a su mesa porque aquí no tienen a una niña como sirvienta, si no usted también tiene manitas y usted se puede servir solito, pero en ocasiones no es así verdad, porque ellos ya traen costumbres, traen una educación diferente de su casa, porque ellos mismos comentan y dicen que sus mamas les sirven y si no están sus hermanas y si no

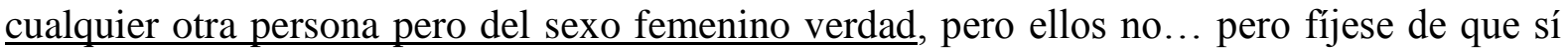


cuesta, pero no es imposible, porque si se logra y se ve el cambio en ellos pues porque digamos en mi clase, ellos van de turno en turno ya sea niño o niña, le corresponde porque le tiene que corresponder, entonces ellos mismos ya se toman la idea aquí en la clase pero ya en su casa es muy diferente pues, por que recuerde que es una cosa lo que nosotros les decimos y lo que ellos hacen aquí en la clase es muy diferente a lo que ellos hacen allá en su casa pues, porque ellos están acostumbrados a que todo se les sirva verdad.

E: a las compañeras que se están incorporando bienvenidas, y como ven estamos hablando un poco de la equidad de género, etnia y social, si tienen algún aporte lo pueden dar.

P: pues buenos días a cada uno. Pues fíjese que si, lamentablemente es como lo que cada compañera expuso, lo que cada quien sabe, o sea de que si se da, lamentablemente donde existe eso, por ejemplo en el caso de los niños a veces es un poco difícil, porque desde la casa les enseñan a ellos que como supuestamente son varones, no pueden hacer tal cosa, porque precisamente tiene que ser la mujer, pero eso influye desde el hogar no precisamente aquí, porque desde el hogar es donde les deben inculcar ahí que ellos deben de apoyar, de que no solo la mujer debe hacer todo, si no que un hombre también lo puede hacer, porque como decía la otra compañera, ambos tenemos la capacidad de hacerlo, ya es diferente que no quieran, aunque si puedan pero no quieran. Y lamentable si he visto en algunos casos que por ejemplo las mamas los miman mucho, porque como es varón no lo puede hacer, que lo haga la hermana, peor si tienen hermanas mayores y son mujeres, pues de plano a la mujer le corresponde y también he visto otros casos donde si lo hacen, por ejemplo en mi familia, $\underline{\text { mis }}$ hermanos ellos hacen de todo, ellos pueden hacer de todo porque así les enseñaron cuando ellos crecieron, en el caso de ellos son mayores, son hombres pero ellos si saben hacer la labor de una mujer y la labor de un hombre en este caso, pero he visto también otros casos donde lo que le corresponde hacer a la mujer, lo tiene que hacer, lo que le corresponde hacer al hombre lo tiene que hacer. Sin embargo una mujer también puede hacer lo que un hombre puede hacer porque tenemos esa capacidad, solo que algunos no lo quieren hacer.

E: Miren yo creo que vamos sacando o por lo menos lo que vamos enfocando en la conversación la conclusión de que cuestión de educación, en realidad todo esto de la discriminación ya sea de la equidad o de la inequidad, estamos en el punto de la educación verdad y esto nos va influir mucho de qué tipo de ciudadanos somos como estamos diciendo, incluso que país es el que tenemos y demás, o sea estamos en el punto de la educación como 
sabemos, bueno y mayormente ustedes que son especialistas en este área, hay agentes socializadores o espacios donde nos educamos, estamos hablando de la familia, de la escuela pero como ven ustedes esta cuestión de los agentes socializadores, donde aprendemos a ser mujeres y hombres actualmente, esta la familia, la escuela, pero hay otros elementos que también nos educan en esa parte de ser equitativos y ser inequitativos, a que agente socializador le darían más peso ustedes en la realidad, generalmente cuando decimos esto, decimos la familia la que más peso tiene, pero también bien sabemos que actualmente hay mucha desestructuración en muchas familias y tal vez ya no podemos pensar en la familia como ese espacio ideal donde se conviven valores, a veces no verdad lamentablemente, entonces como ven ustedes esa parte, que agentes pondríamos sobre la mesa y cuales tienen más peso.

P: El agente principal, después de la familia, es la escuela, es el mayor espacio y tiempo que el niño esta socializado, con un grupo diferente al que el está acostumbrado, pero viera que o nos falta preparación, nos faltan estrategias, conocimientos para poder llevar esta situación de una manera correcta, por que cuando nosotros como docentes no somos abiertos, no buscamos una preparación caemos en el error de que colaboramos a la equidad o inequidad de género, entonces hay situaciones en las que deberíamos participar, primero en el ministerio de educación verdad, fortalecer ese programa, abrir más capacitaciones, charlas conferencias para que el docente este preparado y sepa conllevar esta situación no importa el pueblo, la sociedad en la que se esté viviendo, se puede, se puede es cuestión de poner un poco mas de empeño y ser un poquito más abierto, por que los niños de ahora tienen la tecnología, y en la tecnología es como si se vivieran dos tipos de sociedades diferentes. Otro agente socializador, en la tecnología el niño tiene su facebook y tiene amigos de todo el mundo y participa con sus amigos de una forma igual, amigo-amiga porque no hay un contacto directo, es una libertad que ellos toman a esa situación de la tecnología, entonces aprovechar eso también, fomentar más en los niños un poquito más de consciencia y de cuidado a esas situaciones, por que como no se tiene la consciencia de socializar, muchas veces las niñas caen en errores muy grandes como lo son acosos sexuales en internet o de maltrato en internet verdad y en el caso de las mujeres no denuncian porque es una vergüenza, en el caso de los varones tampoco denuncian por que también es una verguiza, entonces hay situaciones en las que debemos tener un poquito más de expectativa, ampliar mayormente nuestra visión de mente para poder colaborar pero si un factor importante es la escuela. 
P: en mi humilde opinión, yo pensaría que un agente principal o que tendría más peso, seria por ejemplo el ministerio de educación ya que si el impulsara nuevos proyectos o programas para apoyar tanto a los maestros como a las comunidades tanto indígenas ya que en algunos pueblos muy lejanos se vive esto que es la discriminación de hombre y mujer esto porque abarca todo lo que había dicho anteriormente de que los hombres tienen más peso que las mujeres o sea que al hombre se le considera como un agente muy importante digamos así, pero yo pensaría que esto tendría que ver con nuestro presidente de nuestra república, para impulsar nuevos proyectos para capacitar a los maestros, a los docentes para que asa puedan impartir nuevas ideas, nuevas estrategias o abriendo nuevos caminos para fortalecer la educación de los niños que vienen detrás de nosotros.

E: muy bien, alguien más... estábamos hablando de los agentes socializadores verdad, cuales tienen más peso, que me dicen también de las iglesias , sobre todo de aquí de nuestro medio, de aquí de Almolonga, que han podido observar de ese respecto... medios de comunicación también como decía la compañera Mayra. ¿Qué piensan?

P: la verdad de que la religión marca mucha diferencia también, o sea que sería una herramienta muy hábil para erradicar el problema que estamos viviendo, porque eso se vive a todo nivel o sea que vamos y salimos a alguna situación exterior fuera de nuestro globito, de nuestro mundo y vamos a vivir un montón, una de ellas es la educación que tenemos también verdad, la no preparación es también uno de los factores muy importantes, yo pienso que en las iglesias seria una fuente muy importante de como socializar géneros y también erradicar la discriminación que es la más complicada que es la discriminación no importa de género, si no que siempre existe la discriminación, como decía tal vez yo pensaría que tal vez no solo es un proyecto de educación, salud de todos los ministerios, si no de todas las empresas, trabajarlo como una ética, trabajarlo como un plan a llevar diario, de que todas las empresas, todas las oficinas, tiendas supermercados, mercados tratar a las personas con un mismo $\underline{\text { respeto verdad, }}$ porque al menos hasta en los supermercados nos podemos dar cuenta verdad de que las personas buscan su propio grupo de personas con su mismo estándar verdad, como quien dice la fila de halla están todos los bien vestidos y perfumaditos, los de allá están los que traen sucios los pies verdad, o los de allá los que no se quitan el pelo verdad, o sea que nosotros mismos marcamos la diferencia y se da a nivel de religión, a nivel de educación, a nivel de salud, incluso hasta en salud porque hay clínicas que son especiales para personas de alto nivel, clínicas para personas de nivel medio y el puesto de salud que es a donde vamos 


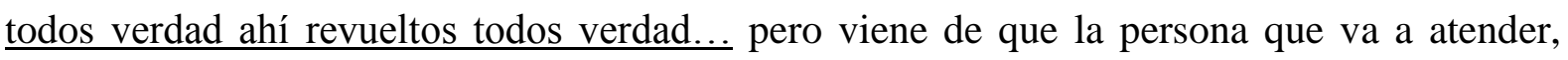
también tiene su forma de pensar y es ahí donde rebotamos, entonces es un problema es un monstruo invencible que nos aqueja a todos y que en determinado momento todos agachamos la cabeza, porque no tenemos la capacidad ya le digo intelectual tal vez o de educación como para poder luchar contra esta situación, hace poco escuchaba yo de que una persona de Quetzaltenango había peleado una demanda internacional porque no lo dejaron entrar a un restaurante, por llevar el traje típico, entonces esas son situaciones en las que por ejemplo uno dice: no a mí no me va a pasar, porque total yo ni salgo, verdad, pero esa soy yo que no está saliendo a una sociedad, pero que va a pasar con nuestros hijos, que mundo le vamos a dejar a $\underline{\text { nuestros hijos si no aprendemos a convivir en equidad y no discriminar a las personas, que va }}$ a pasar entonces, esa es una situación que debemos concientizar a las personas como decíamos desde pequeños, pero también concientizar a las personas grandes para que ayuden al proceso para que se logre y camine, si caminamos dos pasos pues las personas grandes que nos ayuden a encaminar tan siquiera medio paso más, pero que no retrocedan, que nos ayuden a echarle para adelante y es una situación en la que debemos de luchar todos. Porque aquí todos podemos decir, yo no discrimino pero si en un momento de la vida hemos discriminado a alguien y lo hemos hecho tal vez consciente o inconscientemente pero lo hemos hecho hasta con los niños, yo muy personalmente lo digo que mi persona digo, vienen los niños y hay niños que le roban al corazón a uno y esa es una discriminación, porque el que viene más feíto, viene mas shuquito, también tiene corazón, pero como a mí me robo el corazón el otro yo beso y abrazo al que a mí me gusta ese ishto, pero que pasa con el niño pequeño que necesita de cariño y necesita la misma atención que el niño que viene perfumadito y cambiado, o sea nosotros también hemos contribuido a esa situación también, o sea hemos caído a ese juego y como no hemos tenido algo o ese lineamiento que nos diga, no eso no se debe de hacer, no se marca, eso no es correcto o sea puede traer consecuencias a largo plazo, porque la discriminación no solo afecta ahorita, si no afecta al individuo a largo plazo verdad, en su comportamiento, en su desempeño y hasta en salud mental.

E: Claro ¡muchas gracias! Yo creo que ha puesto algunos elementos bien importantes aquí sobre la mesa. 1. lo que ya veníamos hablando que entre los agentes socializadores la escuela si tiene mucho peso, yo la verdad si quisiera dejarles un mensaje de mucha motivación en ese sentido por que como bien dice la compañera parece que esto de la discriminación es un gran monstruo que no sabemos cómo combatirlo pero en realidad tenemos que darle mucho valor al espacio en el que estamos, que es en la parte educativa que es donde si tenemos algo que 
aportar, por supuesto no podemos cambiar el mundo que eso quisiéramos verdad, que diera un giro verdad, no se puede pero si es un espacio bien importante porque los niños y las niñas pasan muchas horas con nosotros, bastante verdad, pasan aquí muchas veces hasta más horas que con sus papas, porque ya después en la casa casi no conviven o ni están los papas o ni les ponen atención y sin embargo aquí si es un espacio donde tienen una atención de nuestra parte, yo creo que eso si es bien importante, poner en alto el valor que tiene la escuela para poder educar en igualdad o desigualdad, que ahí esa la clave y yo creo que ese es el otro elemento, la reflexión crítica que podamos hacer, de decir bueno yo qué tipo de persona estoy siendo hacia mis alumnos, que tipo de ejemplo estoy siendo porque ellos nos están tomando como mama, máxima a esta edad verdad, nos toman como el ejemplo de una mama o un papa en el caso de los compañeros, entonces qué ejemplo estoy dando yo, será que tengo capacidad crítica para reflexionar sobre mi propia práctica docente, soy igualitaria con todos, soy justa o me estoy dejando llevar por favoritismo, o me estoy dejando llevar por la costumbre de ahí es más fácil separar niños de niñas o reproducir cosas que no son adecuadas o veo cosas que no están bien en otro compañero pero no digo nada verdad, por no hacer problema porque me siento mal, yo creo que ahí es algo muy importante.

P: si, fíjese que en cuanto a las actividades aquí dentro de la escuela, quizás nosotros hasta peleamos con los papas, porque aquí en junio se celebra la feria de aquí de Almolonga y por las diversas religiones que se manejan aquí en Almolonga, también ya solo salen poquitos niños, cuando no se le exige al papa, pero es por lo mismo que por lo de la religión también venimos con eso de la discriminación verdad, porque son diferentes religiones y como en junio se celebra aquí el día de San Pedro y como es católico, ya no participan los demás niños, entonces también eso lo hemos visto como discriminación.

E: como división de la comunidad verdad, porque cuantas iglesias hay en Almolonga... es bárbaro verdad...

P: a nivel de iglesias también hay discriminación, esa es una situación en la que el niño está acostumbrado a vivir ya que es parte de su entorno, de que ellos saben de que la tal iglesia son los de más dinero, la tal iglesia ahí solo van los pobrecitos, los que no da diezmo... entonces es algo que los niños ya... y como se educa con el ejemplo o sea los niños traen esa visión y nosotros también ya lo tenemos claro, cuando decimos a veces que nosotros tratamos de erradicar, muchas veces si funciona el erradicar la discriminación y muchas veces no. Yo 
me he dado cuenta aquí con mis niños, como yo por lo menos si soy así, pongo un niño y una niña, en el semestre pasado pusimos así a los niños revueltos, pero realmente cuesta más a que tener a los niños divididos varones y niñas, hay mayor control y menos desorden, en cambio cuando están juntos Jesús! Entonces uno también por buscar estrategias cae en situaciones que no son sanas, pero fomentando un poquito también la igualdad por que ya le digo se toman de la mano niñas y niños y que tiene que ser algo normal para ellos verdad, pero para eso tenemos que comenzar nosotros mismos también verdad porque nadie puede dar lo que no tiene verdad y si no tenemos una visión amplia de lo que queremos no podemos exigirle a nadie verdad, pero si es importante en la educación manejar la situación de equidad. Ahorita estamos viendo que hay juegos sexistas o sea que las niñas ya no se vean como princesas nada mas, o que ya no existe verdad, o sea que yo soy esto y esto pero en la realidad no vamos a llegar nunca a eso porque es un personaje ficticio verdad, o como los cuentos de blanca nieves, que la bruja es la bruja y blanca nieves es la buena, verdad ahora se trata la manera de que los niños vean la situación de una manera diferente verdad y de que están todas las personas buenas, que por sus actos son buenas y están las personas malas que por sus actos también verdad pero que no todo lo bueno es bueno y no todo lo malo es malo verdad, tienen que aprender a distinguir. $\mathrm{Y}$ eso de los cuentos no sexistas yo he estado leyéndolos un poquito y cuesta un poquito porque hasta uno mismo termina diciendo: ¡no, hombre! Pero si no termina así el cuento el cuento, pero igual hay que aprender a que los niños manejen sus propios criterios y que tengan sus propios finales a como ellos crean, o sea que no es como diga yo, si no como ellos piensan y lleguen a consolidar su propio criterio.

E: ¡Claro! Además bien interesante eso que comenta la compañera, porque eso de los cuentos por ejemplo a esta edad, nos puede dar un montón para trabajar, si nosotros nos ponemos analizar los cuentos tradicionales generalmente son muy machistas, pero mucho verdad, y nos damos cuenta que si estamos trabajando sobre esos cuentos tradicionales, lo que estamos transmitiendo es un mensaje de lo mismo, las mujeres solamente están en temas del hogar, en labores domesticas, sumisas, llorando por el amor de su vida, su príncipe azul y no sé qué cosa. Y los hombres en ese papel de héroes que ellos son los que luchan los trabajan. Pero la verdad eso es grave porque profundizamos mucho en ese papel, de la mujer como un ser pasivo que solo está esperando a que la elijan y a mí eso me parece muy grave principalmente en este contexto que la jovencita se casa muy pronto. No es que ya vinieron a pedirla o a robarla... pero entonces qué papel tiene ahí esa niña, solo un papel pasivo como esa princesita que está esperando al príncipe. 
P: Cuando una niña es entrada a pedir a corta edad el orgullo es para los padres, porque híjole $\underline{\text { se fijaron en mi hija desde chiquitia... entonces la niña se ve en la necesidad de decir, bueno }}$ yo soy el orgullo de mis papas y me voy a casar y a qué conlleva esto, a una vida infeliz, una vida sin sentimientos, una vida con responsabilidades que no le corresponden, porque lo primero que vienen después del matrimonio, son los niños y esos niños que tienen papas inmaduros, que no tienen cimientos en valores, que no tienen amor, que no tienen comprensión y ahí viene otra vez... o sea que todo lleva a otra cosa...

E: Claro pero vemos que son mensajes que se transmiten por muchos medios y ya no digamos televisión ni demás, donde nos ponemos a ver que la mayor parte de las telenovelas el mensaje es el mismo... bueno y miren sobre el eje de equidad de etnia y social que pueden decir ustedes desde su experiencia yo aquí les traigo un material donde viene la historia de donde surgió esto, por si les parece interesante, porque claro esto surge del análisis pero ahí si que de un análisis de los académicos, de los curriculistas que hicieron el curriculum. Valga la redundancia. De decir como la sociedad tiene estas características, entonces es necesario introducir este eje para o para educar en otro tipo de ciudadanía mucho más igualitaria, mucho mas de justicia, mucho más sin discriminación, pero como lo ven ustedes, como ven de que el eje este en el curriculum, consideran que sirve, lo logran implementar, o no se entiende, o no recibieron formación en su magisterio o en su carrera universitaria respecto a esto...

P: el CNB en sí ha venido cambiando desde hace mucho tiempo, o sea se ha venido transformando y el problema ha sido de que el ministerio ha estado cambiando de capacitadores, viene un capacitador y nos dice una cosa, viene otro capacitador y nos dice otra cosa y en fin, o sea han cambiado mucho los términos, aunque el CNB sea la misma estructura o la misma base. No se ha tomado de la misma manera, o sea que cada quien ha jugado un poquito el teléfono descompuesto verdad, comenzamos con una información general, llaman a las bases, a los enlaces les dan un información, vienen los enlaces y van a transmitir una información diferente a las bases más grandes y ahí se va desinformando la situación. El CNB en si es interesante el eje que tiene de equidad de género, es realmente importante, al menos nos ayuda no a cumplirlo al cien por cien, es un tanto difícil, pero yo siento de que nos ayuda al menos a contribuir con un granito de azúcar, pero al final es un poquito más interesante que los curriculistas, los que apoyaron a esta situación, den un 
poquito más de ampliación a lo que ellos pensaron querer lograr para que nosotros los docentes entendamos cual es el objetivo principal.

E: ¡Claro! Que piensan las demás compañeras y el compañero, lo conocen o no lo conocen, porque además el CNB es muy amplio verdad, tampoco nos lo sabemos de memoria.

P: como lo estaba usted dando a conocer, incluso en nuestra formación como docentes, no involucran o no toman en cuenta este tema, no es un tema principal, solo nos forman como para atender a los niños y planificar y todo, pero dejan ese tema a un lado, entonces incluso en educación no se toca ese tema verdad, no solo digamos en el Diversificado si no en todos

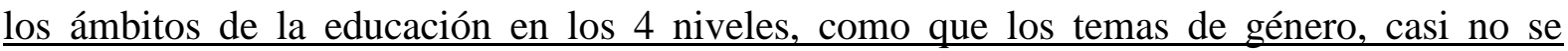
platican, entonces no importando que carrera usted elije como que ese tema no se da a conocer.

E: alguno de ustedes se ha especializado en la universidad, ya sea con el programa este del ministerio o no... Ilse usted si... ¿ahí se toco ese tema o no?

P: Prácticamente no, específicamente que se lleve un curso, que se lleve un tema específico $\underline{\text { de todo eso no, prácticamente solo son como pinceladas, simplemente se ven de pasadita pero }}$ así darle énfasis o un valor importante como se debería de hacer no.

E: no verdad, y sobre todo herramientas, porque uno ya lo que quiere son cosas prácticas verdad, que le sirvan ya en su aula verdad a la hora de estar ahí. En las platicas que llevamos con maestros, básicamente esto es lo que se ha visto verdad, que no hay, y lo mismo que equidad de género esta lo otro ejes transversales que quedan en el aire. Eso de lo transversal qué difícil es llevarlo a la práctica, y hablando de práctica, alguien tiene alguna practica así especifica que haga en su aula, algo así como la compañera de poner juntos niñas y niños, además de eso hacen alguna cosa así especifica, aunque sea por su propia iniciativa aunque nadie se lo haya dicho ni la supervisión o nadie, hacen alguna cosa especifica que ustedes digan eso me está ayudando para educar en igualdad a los niños y a las niñas.

P: Sí ¡lo hacemos con los niños! Como usted comentaba a veces no, específicamente viendo ese tema pero si lo hacemos, las actividades que hacemos se involucran los niños y las niñas no solo las niñas, o sea hasta la forma de ubicarlos en sus sillas, una niña y un niño, de la 
misma manera en los juegos, en las dinámicas que se realizan la participación esta para todos, de esa forma nosotros estamos fomentando la equidad de género, aparte se pueden ver los frutos en la hora de receso, ya juegan niños y niñas, ya hacen grupos y juegan ya no hay discriminación...

E: ¡Qué bueno! ¿Alguna experiencia más?

P: pues así como usted decía, hacemos muchas actividades en el aula, solo que no les ponemos atención, me estaba recordando de todo lo que hacemos y en el caso mío pongo yo por decirle a la hora de utilizar algún material, nombro a alguien diferente, entonces hay niños que no están acostumbrados a hacer actividades, les cuesta. Por decirle, ir a traer hojas, pasar materiales, tapitas, semillitas, les cuesta más a los niños, en el caso de las niñas no les cuesta por que ya tienen la habilidad de servir, los niñitos no y terminando la refacción tienen que meter a veces el vaso dentro de la cubeta, y cuando los niños lo hacen su vuelven así... podríamos decir, más torpes no agarran las cosas con delicadeza como hacen las niñas con facilidad y guardarlo en la cubeta, en cambio a los niños si les cuestan actividades que no lo practican, de ahí materiales nos ponemos a jugar materiales, o saltar, primero va una niña después un niño y así, y a veces los niños dicen, no nosotros los hombres primero y las niñas después, entonces son actividades que nosotros hacemos pero nunca nos ponemos a pensar, pero también estamos contribuyendo a que los dos sean iguales al mismo tiempo.

P: Nosotros trabajamos en base al CNB y aquí viene lo que es la equidad de género de etnia y social, entonces ya dándonos cuenta como usted dicen nosotros trabajamos y no sabemos lo que trabajamos verdad, pero nos damos cuenta que dentro de las cinco áreas que nos están mandando trabajar, siempre incluye una inclusión de género y hay una forma de erradicar esta situación, no en todo se puede, por ejemplo yo tengo la experiencia de estar aquí ya un tiempecito y al principio cuando yo empecé a trabajar había más afluencia de niños que de niñas. Ahora ya no, ahora ya hay una equidad de niños y niñas, donde se ve un poquito más marcada la situación de la discriminación es en los grados más altos, cuarto y quinto de aquí salen 200 niños, llegan a sexto 35, 40 si mucho llegan a 60 pero ya hay una gran mayoría que por esas situaciones de discriminación, se van rezagando en el camino y ahora con esta situación de la integración de este eje de equidad de género, ya vienen las actividades ya vemos por ejemplo en las actividades de educación física por ejemplo ponemos a brincar caballito a los niños, antes pasarse las niñas encima de niños eso es un pecado grandísimo, 
eso no se hace, es pecado grande o sea que como pasarse una niña encima de un niño, pero ahora ellas ya lo hacen verdad, hacen el caballito y se pasan encima de los varones verdad, en el caso de comunicación y lenguaje, antes hablar con varones... hablábamos mas entre mujeres, no podemos platicar tanto con hombres, ahora la inclusión como dice el compañero ya se ven los niños jugando con las niñas, las niñas juegan fútbol, los varones incluso juegan rodas con las niñas, pero ya hay un poquito más de diferencia, si han habido avances de que no nos hemos puesto a pensar que tanto hemos avanzado o que tanto hemos retrocedido no lo hemos hecho pero si dentro de las cinco áreas podemos notar que si hay avance.

E: miren y si nos damos cuenta en la sociedad han habido avances también verdad, porque no podemos decir que la situación actual también sigue habiendo discriminación pero no es la misma que hace años, con nuestros papas o nuestros abuelos verdad, entonces nos damos cuenta la sociedad va cambiando y digo que bueno que desde la escuela, desde la educación podamos ser un motor para acelerar ese cambio, de alguna manera aquí podemos hacer cosas que contribuyan a que ese cambio se vaya dando más rápido y en la dirección buena, no que los cambios se vayan por otro lado verdad, yo solo por rescatar algo que estaban diciendo, este tema de la equidad de género de etnia y social, es bien bonito pero también de mucho compromiso personal por que casi todo lo que me va a requerir a mí como educadora es mi propia reflexión crítica, que estoy haciendo, como lo podría hacer de otra manera, esto que estoy haciendo porque lo hago y como lo hago y nos damos cuento que involucra no solo el contenido, o sea no solo las actividades que ustedes hacen dentro del aula si no toda la vida del centro, lo que pasa en el recreo lo que ustedes dicen, ahora ya juegan juntos, que bueno que juegan juntos pero de repente ustedes pueden intervenir para que en los juegos no haya abusivez, no hayan cosas que no deben haber verdad, que está pasando a la hora de la refacción, como estos detalles tan sencillos de quien levanta el vaso, eso ya no pertenece al curriculum, propiamente explicito, sino mas bien a ese curriculum oculto que es toda la cultura escolar o sea de que manera nos comportamos aquí, estamos demostrándoles que este es un espacio de igualdad o nosotros mismos estamos demostrándoles que no es un espacio de igualdad verdad, por ahí un poquito, entonces es algo que a mí me parece muy interesante el tema, pero que nos lleva mucho a mucha reflexión y eso a veces también cuesta, incluso encontramos maestras y maestros, que no es el caso de aquí , pero que también no quieren entrar a reflexionar estas cosas verdad, porque se sienten,,, parece que lo están acusando a uno y no, no es así verdad. 
P: al final es nuestra responsabilidad verdad, queramos tomarlo o no, porque somos responsables de lo que los niños vayan a llevar en su cabecita, o sea de que tanta información vayan a llevar somos responsables de eso, o sea como usted dice hay mucho hogar desintegrado, los niños a veces buscan el amor y el apoyo a veces en la escuela.

E: y miren desde la supervisión reciben algún apoyo sobre esto o los acompañantes pedagógicos que hay, sobre estas cuestiones de curriculum oculto.

P: realmente si, estamos trabajando y si como le digo, el curriculum se ha venido cambiando y se han venido dando capacitaciones que a mi realmente me ha pasado por que yo estuve trabajando un tiempo como enlace, entonces íbamos a la capital y nos decían, que si que las competencias, que los contenidos, que los indicadores de logro, que esto y lo otro, veníamos nosotros y compañeros fíjense que los indicadores de logro... íbamos a otra capacitación y no que los indicadores de logro ya no son los indicadores de logro, que ahora son las competencias... y entonces.... Ahora que les decimos, como si ya les dije una cosa ahora como les voy a decir otra, entonces hay un poquito de desinformación y desbalance en la $\underline{\text { situación esa de ponernos de acuerdo, realmente que objetivos tiene el CNB, o sea si está bien }}$ $\underline{\text { tiene todo nuestro trabajo, todo lo que tenemos que hacer, el problema es entenderlo, saberlo }}$

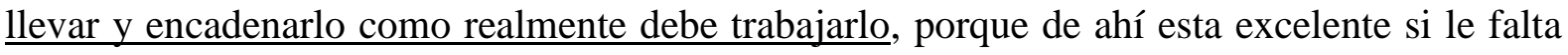
pero es todo lo que usted dice que nosotros le agregamos y el curriculum oculto que trabajamos verdad.

E: ¡Claro! Así que la limitante principal si entiendo bien es la formación, digamos como acompañamiento o una formación más específica, más clara, están de acuerdo todas....si... Ahora como ventajas encuentran alguna potencialidad donde dicen si, esto si se puede, alguna ventaja o alguna tarea.

P: el que lo hayan incluido dentro del CNB eso es una ventaja, porque no estuviera incluido como eje, fuera un curriculum nada más, un fantasma que pareciera de vez en cuando ahí, en cambio al estar incluido en el CNB ya es una ventaja porque forci-voluntariamente todos tenemos que trabajar.

E: pues si es una forma de visibilizar verdad que este ahí presente, muchas gracias y una última cosita, pero ahí si que para el compañero, como se siente usted y sobre todo como 
maestro de este grado de preprimaria, y les digo porque yo encontrado en vario sitios donde dicen este es un trabajo de mujeres porque es una edad maternal, donde los niños lo que buscan es una figura maternal, entonces cual es su experiencia y los padres de familia como lo han recibido a usted, como se ha sentido en este espacio etc.

P: fíjese que la verdad he trabajado bien, no he sentido ningún cambio porque es solo para mujeres no, recibo el mismo cariño de los niños de las niñas, también las mamas o sea que confían en mí, entonces prácticamente aquí yo veo que haya una falta de equidad de género y me siento bien trabajando con los compañeros o sea que no tengo problemas con eso. Entonces ha sido una bonita experiencia que he tenido.

E: ¡Qué bueno! Entonces yo animarlo verdad, porque creo que es necesario cada vez que hayan más hombres en este tipo de tareas, porque como decían acá no solo es la figura materna, si no que con mayor razón, tiene mucho peso la paternal.

P: como vemos que hay diferentes grupos, sabemos que hay niños que tienen mama, pero no tienen papa o que tiene papa y no tienen mama, y yo creo y confirmo lo que dice la biblia, cada hoja del árbol cae por que es su voluntad, entonces a veces nos caen niños y vienen porque en el caso del compañero puede llegar un niño que no tenga papa, entonces lo arropa él, en el caso mío hay llegado niñas que me dicen mama o sea se confunden tanto y llegan y se apropian tanto de ese término y nos dicen mama. Verdad, es un titulo que nos queda demasiado grande pero igual el niño lo apropia a su necesidad verdad, entonces aquí yo $\underline{\text { siento que la carrera no se trata de mujeres, porque al final hombres y mujeres hemos sido }}$ creados con ese merito con esa facultad de ayudarnos los seres humanos unos a otros pues. $\mathrm{O}$ sea que si. Ahora que no tengamos la vocación eso es otra cosa totalmente a parte. La vocación aunque seamos mujeres, pero si no tenemos la vocación, estamos realmente mal, perdidas en el espacio.

E: Y también que ya si lo vemos en un plano más amplio de la sociedad, hay carreras muy feminizadas, pero precisamente por lo mismo, que son carreras principalmente relacionadas con el cuidado con la educación, que eso tradicionalmente es el rol de las mujeres, como enfermería también, otra carrera feminizada verdad, cuidar enfermos, magisterio, ojala más hombres tengan más vocación por la educación verdad. 
Muy bien, no sé si alguien tiene algo más que agregar, alguna inquietud que le ha quedado ahí o que quiera aportar,

P: Bueno yo pensando así como lo comentaba seño Mayra que la falta de equidad de género, existe incluso entre la misma comunidad indígena, por que digamos ya viendo la clase social económica, entre el mismo pueblo indígena no importando que sea el mismo traje, el mismo idioma pero ahí hay discriminación, también en las iglesias hay discriminación, hay iglesias que van los que tienen dinero usted los mira ahí con buena ropa, pero en la otra iglesia va la humilde, pero si en todos los ámbitos, en todos los niveles existe la falta de equidad de género, entonces no podemos decir que no, en casi todos los niveles y si hay que trabajar muchísimo verdad, hay que iniciar la inclusión en las escuelas, instituciones, empresas e iglesias también.

P: yo en conclusión digo que aun digo que es lamentable verdad que a estas alturas aun este la erradicación de la discriminación verdad, porque hay un caso que tal vez es bastante cercano verdad, de dos jóvenes que fueron discriminados y a raíz de ello, ellos buscaron ayuda y fueron con los de derechos humanos y buscaron otras ayudas, sin embargo no hicieron nada por ellos, y hoy en si se puede decir que aun se ve eso verdad que muchos ignoran lo que le puede pasar a otras personas o quizás nosotros no hemos vivido este momento, pero yo considero que nosotras como educadoras que somos, tratar la manera de romper esa barrera, ese límite marcador que quizás aun la mentalidad de cada persona de la sociedad han marcado verdad de decir que las niñas lo pueden hacer y lo niños no, si no que romper esa barrera y decir no importando la equidad de género niños y niñas, Dios nos ha dotado con las mismas capacidades, es decir que si valemos todos iguales y asumir esos derechos verdad y más que todo no dejarnos verdad, ahí si que más adelante tratar la manera de fomentar tal vez en la educación aun mas en pequeños, ya que si abarca en lo que es nuestra herramienta de trabajo, pero si aun el ministerio de educación no le ha dado mucho énfasis a este tema, pues yo considero que tal vez retomarlo nosotros verdad, ahí si que darle un poquito más de espacio a esta situación y de esa manera nosotros poder contribuir a erradicar lo que es todo este tema.

E: muchas gracias, así es algo mas... 
P: Yo considero que nosotros tenemos que predicar con el ejemplo, porque nosotros los seres humanos somos muy apáticos a veces, regularmente los niños ven lo que nosotros hacemos y es fácil decir, yo lo hago, yo lo sé, yo aquí, yo haya y es muy difícil hacerlo y realmente es más difícil ponerlo en práctica por que es como sucede en muchas ocasiones de que nosotros de que todo... bueno yo considero que todo ser humano su naturaleza en parte es así verdad uno dice, yo nunca discrimino yo no hago tal cosa, yo no hago tal cosa, a mi me enseñaron valores en mi casa yo soy diferente y todo eso pero en ocasiones es muy fácil decir, yo, yo, yo. $\mathrm{Y}$ es más difícil hacerlo verdad yo considero que es no solo decirlo yo, yo, yo verdad. Sino que otras personas lo digan por uno que uno predique con el ejemplo no necesariamente que nosotros tengamos... como le dijera yo valores positivos o negativos en nuestras casas, en nuestra educación, como fuimos formados, como fuimos educados nosotros, sino que, yo considero de que es mucho más difícil ponerlo en práctica y que... imagínense de que para nosotros que nosotros hemos estudiado un poquito verdad es difícil, cuanto más para la gente que no ha entrado en una escuela verdad de que le cuesta un poquito y que su educación ha sido así verdad de que ha sido de tradición en tradición de generación en generación de que, prácticamente pues existe la discriminación en nuestras propias casas en los hogares de los distintos niños yo sé de qué es difícil pero no es imposible así como usted dice quizás en ocasiones nosotros lo estamos haciendo lo estamos compartiendo y viviendo en nuestras aulas verdad en integrar a niños y niñas en... por decirle en darles tareas o asignarles algunas pequeñas situaciones que lo puede hacer el niño como lo puede hacer la niña verdad. Yo considero de que ese es nuestro pequeño granito de arena nuestro pequeño aporte en lo mucho o en lo poco que uno le enseña a los niños ellos lo aprenden y lo aprenden mucho más si uno lo hace verdad si uno predica con el ejemplo.

E: claro... muchas gracias Ilse que bueno que pueda hacer aquí la escuela eso, un espacio muy diferente que haya otras normas diferentes a las de la familia verdad y que las normas aquí si sean de igualdad si luego en otros espacios no tienen la posibilidad de vivir con esas normas bueno... pero por lo menos aquí si es nuestra responsabilidad ese tipo de normas. A mí me llama mucho la atención el hecho de los niñitos y las niñitas que expectativas tienen, que quiero ser de mayor verdad ese tipo de cosas. Que de repente también forma mucho parte de nuestra labor el irles concienciando que pueden alcanzar otras metas, que una niña por ejemplo su sueño no tiene por qué ser casarse ni que vengan a pedirla ni con 12 ni con 13 ni con cuanto verdad ese no es un sueño, de qué manera vamos rompiendo que ese no es el sueño de una jovencita ni mucho menos, que ella pueda aspirar a otro tipo de vida y otro tipo 
de cosas casarse en su momento y con quien ella elija verdad... no con quien la haya elegido a ella, no sé, yo en ese sentido claro aquí con ustedes son muy chiquitos pero ya en otros grados se marca mucho eso como usted decía que llegan a sexto y ya, dejan de estudiar se marca ahí mucho ese trabajo de cómo podemos promover que eso vaya cambiando verdad, que vaya evolucionando de otra manera. Bueno, pues miren yo les agradezco mucho este espacio esta apertura. 
Anexo 3: Categorías

\begin{tabular}{|c|c|}
\hline Categoría & Subcategorías \\
\hline \multirow{4}{*}{ Vertebración social } & Construcción del género \\
\hline & Pertenencia étnica \\
\hline & Clase social \\
\hline & Concepción de equidad en la cultura maya \\
\hline \multirow{11}{*}{$\begin{array}{l}\text { Agentes socializadores de } \\
\text { género }\end{array}$} & Violencia de género \\
\hline & Racismo \\
\hline & Sexismo \\
\hline & Discriminación \\
\hline & Expectativas de futuro \\
\hline & Valores \\
\hline & Escuela \\
\hline & Familia \\
\hline & Comunidad \\
\hline & Medios de comunicación \\
\hline & Religión \\
\hline \multirow{6}{*}{$\begin{array}{l}\text { Educación para la equidad de } \\
\text { género, etnia y social en la } \\
\text { educación formal }\end{array}$} & Eje de equidad de género, de etnia y social del CNB \\
\hline & $\begin{array}{l}\text { Formación inicial y permanente de maestras y } \\
\text { maestros }\end{array}$ \\
\hline & Gerencia del sistema educativo \\
\hline & Compromiso de maestras y maestros \\
\hline & Familias y comunidad \\
\hline & $\begin{array}{l}\text { Actividades concretas relacionadas con educación } \\
\text { para la equidad }\end{array}$ \\
\hline
\end{tabular}




\section{Anexo 4: Cuadros de análisis}

\subsection{De entrevistas comunicativas}

\begin{tabular}{|c|c|c|c|}
\hline Categoría & $\begin{array}{l}\text { Sub- } \\
\text { categorías }\end{array}$ & Dimensiones exclusoras & Dimensiones transformadoras \\
\hline $\begin{array}{l}\text { Vertebración } \\
\text { social }\end{array}$ & $\begin{array}{l}\text { Construcción } \\
\text { del género }\end{array}$ & $\begin{array}{l}\text { "Las niñas, se menosprecian, en el sentido que ellas son } \\
\text { las que tienen que ayudar a la mamá, o sea su lugar está } \\
\text { solo en la casa, y se menosprecian porque no creen tener } \\
\text { la capacidad de poder hacer más o de llegar a hacer tal } \\
\text { vez lo que un hombre hace” (E01/PrPr/M) } \\
\text { "Hablarle de Santa María Chiquimula, es hablarle de } \\
\text { mucho machismo, los hombres, los señores, los padres de } \\
\text { familia, tienen } 2,3 \text { o } 4 \text { mujeres y con cada mujer tiene } 6 \text {, } \\
7 \text { niñitos, niños que no crecen con su papá, los niños } \\
\text { sufren de mucha desnutrición, tenemos mucho problema } \\
\text { porque hay mucha desintegración familiar, el señor llega } \\
\text { y le pega a la señora” (E03/Pr/M) } \\
\text { "Soy maestra, estudiante universitaria, tengo hijos y me } \\
\text { desenvuelvo en muchos papeles, pero aún así mi esposo } \\
\text { no me trata como tal, ya algunas veces que me ha dicho }\end{array}$ & $\begin{array}{l}\text { "Cuando hablamos de equidad, hablamos de igualdad" } \\
(\mathrm{E} 04 / \mathrm{Pr} / \mathrm{H}) \\
\text { "La equidad es de que haiga un equilibrio entre hombre y } \\
\text { mujer, y que todas cosas que la mujer hace, el hombre lo puede } \\
\text { hacer, así a nivel general, y así en la educación" (E05/B/M) } \\
\text { "Desde el punto de vista de equidad de género pues la verdad } \\
\text { de que sí actualmente hay oportunidad para todos" (E06/B/H) }\end{array}$ \\
\hline
\end{tabular}




\begin{tabular}{|c|c|c|c|}
\hline Categoría & $\begin{array}{l}\text { Sub- } \\
\text { categorías }\end{array}$ & Dimensiones exclusoras & Dimensiones transformadoras \\
\hline & & $\begin{array}{l}\text { que yo no le puedo darle ordenes a él, porque ¡él gana } \\
\text { más que yo! ¡Imagínese!” (E03/Pr/M) } \\
\text { “A veces mi mamá me dice: ¿y por qué te casaste con un } \\
\text { hombre que no tenía tu mismo nivel de conocimiento? } \\
\text { [...] le digo me tardé por tal cosa o me tardé porque tuve } \\
\text { tal reunión, supongo me entendería porque es un hombre } \\
\text { que tiene mi mismo nivel académico, pero un hombre que } \\
\text { no entiende qué es una reunión, que tengo que hacer estos } \\
\text { compromisos normales, no me va a entender, me va a } \\
\text { presionar y dinero pueden tener, porque así son... pueden } \\
\text { tener mucho más dinero y ganar mucho más que uno, } \\
\text { pero cuánto quisiera uno como mujer, ser comprendida } \\
\text { como tal y no ser humillada” (E03/Pr/M) } \\
\text { "Platico yo con mis hermanos y me dicen: sí que las } \\
\text { mujeres salen con sus derechos, que las mujeres aquí, que } \\
\text { las mujeres allá... ¡está bueno! ¡Pero también pónganme } \\
\text { el dinero en la mesa!” (E03/Pr/M) } \\
\text { "Por diversas razones políticas, culturales e históricas la }\end{array}$ & $\begin{array}{l}\text { la mujer toma de decisiones por ejemplo verdad, en la } \\
\text { comunidad se toma en cuenta la opinión de ambas personas" } \\
\text { (E06/B/H) } \\
\text { "Yo creo que los jóvenes tienen una idea a veces mucho mejor } \\
\text { que gente de más edad en cuanto al respeto, es increíble pero en } \\
\text { áreas de jóvenes en donde sí se respetan mucho, no importando } \\
\text { el traje, el lugar de donde se proviene, yo creo que hay grupos } \\
\text { de jóvenes que han entendido ya esto y que lo están manejando } \\
\text { muy bien" (E07/D/H) }\end{array}$ \\
\hline
\end{tabular}




\begin{tabular}{|c|c|c|c|}
\hline Categoría & $\begin{array}{l}\text { Sub- } \\
\text { categorías }\end{array}$ & Dimensiones exclusoras & Dimensiones transformadoras \\
\hline & & $\begin{array}{l}\text { equidad de género no se ha logrado aplicar, diría yo, en la } \\
\text { mayoría de los ámbitos tanto social, político, religioso, } \\
\text { inclusive cultural, predomina el hombre sobre la mujer" } \\
\text { (E09/P/H) }\end{array}$ & \\
\hline & & $\begin{array}{l}\text { "Con respecto a derechos humanos e igualdad, pues } \\
\text { existe en documentos, en los acuerdos de paz, donde } \\
\text { diceque todos somos iguales, pero ya en la realidad existe } \\
\text { mucha diferencia, ya que por la posición social que tiene } \\
\text { cada grupo social y económico hay desigualdad" } \\
\text { (E10/P/M) }\end{array}$ & \\
\hline & & $\begin{array}{l}\text { "La clase baja, que está dividida en subclases, gente que } \\
\text { tiene una casa donde vivir o un negocio que les está } \\
\text { dejando cómo sostenerse. Y la media pues son los } \\
\text { trabajadores que también tienen una casa pero que son } \\
\text { obreros dentro de una casa, por ejemplo aquí hay } \\
\text { microempresas de tejeduría y ellos tienen sus obreros, sus }\end{array}$ & \\
\hline
\end{tabular}




\begin{tabular}{|c|c|c|c|}
\hline Categoría & $\begin{array}{l}\text { Sub- } \\
\text { categorías }\end{array}$ & Dimensiones exclusoras & Dimensiones transformadoras \\
\hline & & $\begin{array}{l}\text { trabajadores, esos trabajadores tienen una casita donde } \\
\text { vivir, cómo sostenerse y cómo sostener a sus hijos para } \\
\text { que vengan a la escuela. La clase baja son aquellas } \\
\text { personas que no tienen trabajo no tienen como sostenerse } \\
\text { económicamente, no tienen nada seguro, ellos durante el } \\
\text { día solo comen dos veces, ven qué buscar, un pequeño } \\
\text { trabajo, tal vez planchada, tal vez lavada, pero no es todos } \\
\text { los días. Entonces aunque los vemos tan bonitos en la } \\
\text { calle, porque todos luchan por tener el traje, usar el traje, } \\
\text { pero con respecto a sus alimentos, pues mucho sufren } \\
\text { porque solo comen } 2 \text { veces o } 1 \text { vez, eso es una triste } \\
\text { realidad" (E10/P/M) } \\
\text { "He visto la realidad en nuestra comunidad de Pachaj, las } \\
\text { familias que logran estar unidas y buscar una salida al } \\
\text { sostenimiento de la economía, lo van logrando y los niños } \\
\text { acá son los que tienen para venir a la escuela, para } \\
\text { entregar sus tareas y hacen las tareas y su estado } \\
\text { emocional es equilibrado. Pero en las familias que no } \\
\text { saben sobrellevar la decadencia de la pobreza existente en } \\
\text { nuestro país, por ejemplo, sufren alcoholismo, al ver que }\end{array}$ & \\
\hline
\end{tabular}




\begin{tabular}{|c|c|c|c|}
\hline Categoría & $\begin{array}{l}\text { Sub- } \\
\text { categorías }\end{array}$ & Dimensiones exclusoras & Dimensiones transformadoras \\
\hline & & $\begin{array}{l}\text { no hay cómo sobrevivir, no hay trabajo, el hombre se } \\
\text { inclina al alcoholismo porque ya no hay salida" } \\
\text { (E10/P/M) }\end{array}$ & \\
\hline & \multirow[t]{2}{*}{$\begin{array}{l}\text { Concepción } \\
\text { de equidad } \\
\text { en la cultura } \\
\text { maya }\end{array}$} & $\begin{array}{l}\text { "Ahora tal vez es como que si se abriera una grieta entre } \\
\text { todas las culturas, porque ya no se practica como se } \\
\text { practicaba antes y a veces considero de que todo lo que } \\
\text { pasa ahora, tanta violencia tantas cosas que están pasando } \\
\text { es por esa ruptura que tuvo cada una de las culturas, } \\
\text { porque ya los valores no se practican como antes" } \\
(\mathrm{E} 05 / \mathrm{B} / \mathrm{M})\end{array}$ & $\begin{array}{l}\text { "Lo de la equidad, yo lo asimilaría más sobre un valor muy } \\
\text { importante de la cultura maya que es la dualidad y la } \\
\text { complementariedad, porque son dos valores importantes, en } \\
\text { donde los mayas, o nosotros en nuestra cultura decimos que } \\
\text { todo lo que existe a nuestro alrededor tiene importancia y tanto } \\
\text { hombre y mujer se complementan, es una dualidad, son dos } \\
\text { para ser uno" (E05/B/M) }\end{array}$ \\
\hline & & $\begin{array}{l}\text { "Desde la escuela es inculcarles valores, valores que } \\
\text { nuestros antepasados nos han enseñado, el respeto a la } \\
\text { madre naturaleza, el respeto a nuestro hermanos mayores, } \\
\text { el sol, la tierra, a todo lo creado, a los animales, que para } \\
\text { nosotros como mayas son los hermanos mayores y luego } \\
\text { entre nosotros, respetando lo ajeno, respetando las cosas } \\
\text { de los demás. Nuestros antepasados nos han enseñado que } \\
\text { debemos respetar a los mayores y colaborar con ellos en } \\
\text { el trabajo que se realiza en el campo. Pero } \\
\text { lamentablemente en estos tiempos estos valores se han }\end{array}$ & $\begin{array}{l}\text { "A veces sí se escucha extraño [equidad de género], porque } \\
\text { solo nos han dado estas son como teorías o pensamiento que } \\
\text { dicen que lo occidental [...] entonces para otras personas } \\
\text { entonces la equidad de género entraría más en lo occidental, } \\
\text { podríamos decir, pero viéndolo desde el punto de vista de los } \\
\text { mayas también lo tenemos solo que tal vez de otro nombre, } \\
\text { pero llega a lo mismo, sí es un mismo concepto" (E05/B/M) } \\
\text { "La complementariedad es de que todo el trabajo de un hombre } \\
\text { no lo puede hacer a veces... digamos una idea, y la idea de la }\end{array}$ \\
\hline
\end{tabular}




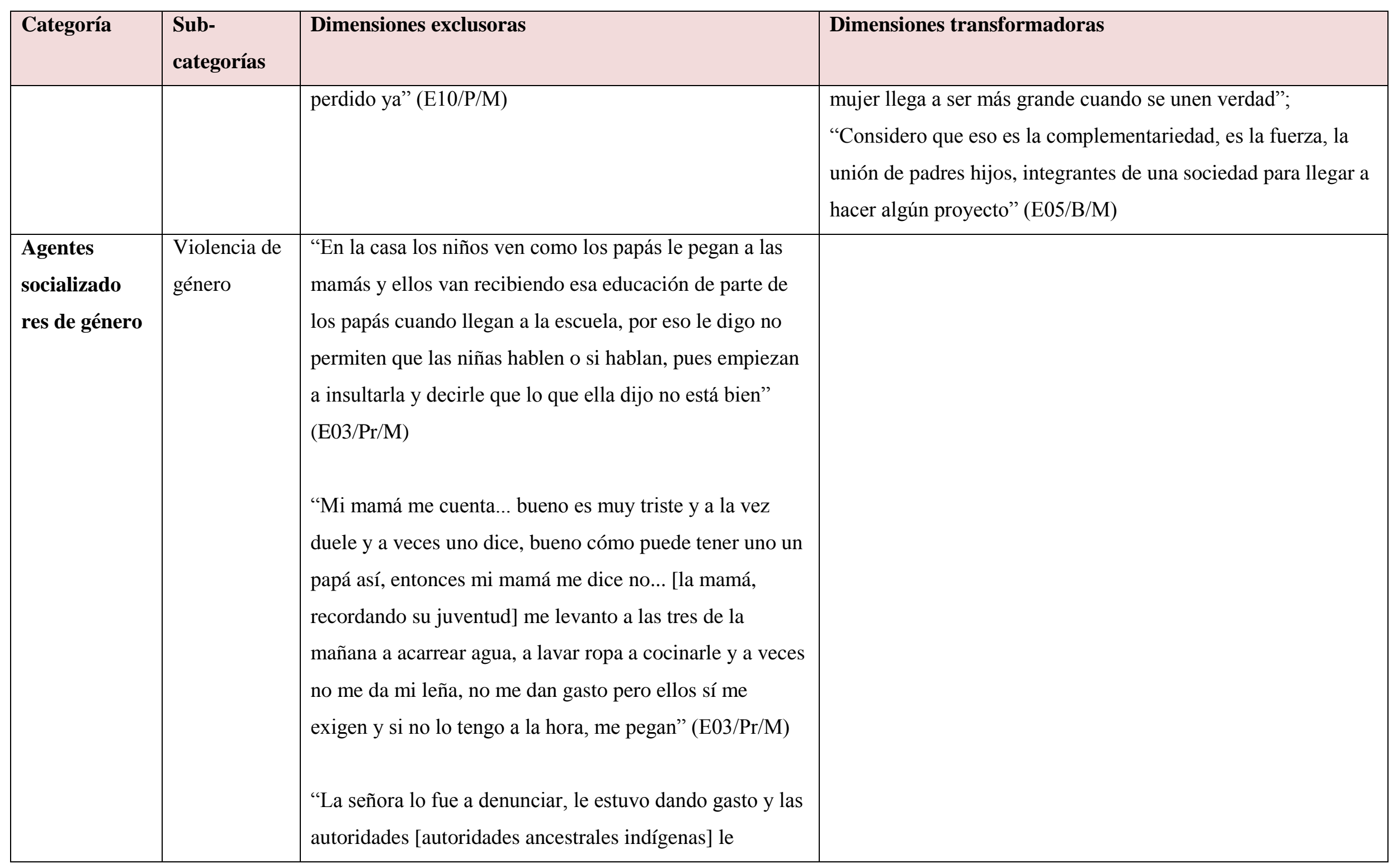




\begin{tabular}{|c|c|c|c|}
\hline Categoría & $\begin{array}{l}\text { Sub- } \\
\text { categorías }\end{array}$ & Dimensiones exclusoras & Dimensiones transformadoras \\
\hline & & $\begin{array}{l}\text { prohibieron al señor acercarse a la señora por los golpes } \\
\text { que le dio, pero ya resulta que fue culpa de la señora } \\
\text { volver a regresar a vivir con el señor también" } \\
(\mathrm{E} 03 / \mathrm{Pr} / \mathrm{M})\end{array}$ & \\
\hline & Racismo & $\begin{array}{l}\text { "Cuando yo estudié el Básico estudié un año en un centro } \\
\text { urbano, específicamente en Salcajá y solo por pertenecer } \\
\text { a la etnia k’iche', era obviado tanto por los compañeros } \\
\text { como por los maestros, entonces en ese momento cuando } \\
\text { uno ya está directamente en esa etapa y está laborando ya, } \\
\text { uno dice no, esto no es correcto" (E04/Pr/H) }\end{array}$ & $\begin{array}{l}\text { "Hemos aprovechado esos espacios [situaciones de } \\
\text { discriminación] para decirle a ellos [alumnado] que la situación } \\
\text { del idioma muchas veces nos marca a nosotros diferencias en } \\
\text { cuanto al trato y la forma verdad, pero que debemos aprender a } \\
\text { respetar esas diferencias para poder tener una mejor } \\
\text { convivencia, pienso que el mejor curso donde lo he podido } \\
\text { practicar es en seminario" (E07/D/H) }\end{array}$ \\
\hline & Valores & & $\begin{array}{l}\text { "Entonces ellos dicen ¿y yo porque me tengo que juntar con } \\
\text { ellos? Yo mejor me junto con él, entonces ya tienen sus } \\
\text { grupitos y yo [profesor] en ese momento intervengo y les digo } \\
\text { que no, hay que compartir con todos, no solo porque uno no es } \\
\text { superior o no solo porque uno tiene ciertas posibilidades va a } \\
\text { obviar a los demás, entonces tenemos que ser por lo menos } \\
\text { justos y comprensivos y decirles que eso no es correcto y ellos } \\
\text { van aprendiendo poco a poco" (E04/Pr/H) }\end{array}$ \\
\hline & Sexismo & $\begin{array}{l}\text { "La niña siempre es dejada a un lado en el proceso } \\
\text { educativo, porque los papas argumentan de que las niñas }\end{array}$ & \\
\hline
\end{tabular}




\begin{tabular}{|c|c|c|c|}
\hline Categoría & $\begin{array}{l}\text { Sub- } \\
\text { categorías }\end{array}$ & Dimensiones exclusoras & Dimensiones transformadoras \\
\hline & & $\begin{array}{l}\text { por ser niñas se van a casar, entonces que no necesitan } \\
\text { estudiar"(E01/PrPr/M) }\end{array}$ & \\
\hline & Escuela & $\begin{array}{l}\text { "Solemos echarle la culpa a alguien más y nosotros no } \\
\text { asumimos la responsabilidad de lo que hacemos [respecto } \\
\text { a la escuela como agente socializador de género], } \\
\text { entonces si están en Pre-Primaria, decimos que la mamá } \\
\text { tuvo la culpa, si están en primero Primaria decimos que la } \\
\text { de párvulos tuvo la culpa y esto se vuelve un circulo } \\
\text { vicioso" (E01/PrPr/M) } \\
\text { "A veces dicen, bueno papá no me dice eso, por qué usted } \\
\text { me lo dice, ¿verdad?" [referido a educación en valores] } \\
\text { (E05/B/M) } \\
\text { "En la casa los niños ven como los papás le pegan a las } \\
\text { mamás y ellos van recibiendo esa educación de parte de } \\
\text { los papás cuando llegan a la escuela, por eso le digo no } \\
\text { permiten que las niñas hablen o si hablan, pues empiezan } \\
\text { a insultarla y decirle que lo que ella dijo no está bien" } \\
\text { (E03/Pr/M) }\end{array}$ & $\begin{array}{l}\text { "Que el nivel pre primario es donde más se puede potencializar } \\
\text { [la educación para la equidad] porque es cuando los niños } \\
\text { desarrollan su carácter y su personalidad, entonces sí nosotros } \\
\text { logramos que el niño cambie esa percepción que trae de la } \\
\text { casa" (E01/PrPr/M) } \\
\text { "No, no la he visto reflejada todavía" [alguna situación que } \\
\text { reproduzca inequidad en la escuela] (E02/PrPr/H) } \\
\text { "Pues yo lo veo que tanto en la familia como en los niños } \\
\text { [referido a la escuela] sí se pueden asentar las bases" } \\
\text { (E02/PrPr/H) } \\
\text { "Desde mi punto de vista lo recomendable es que desde } \\
\text { chiquitos desde pequeños desde nivel pre-primario, primario } \\
\text { verdad se venga hablando de estos temas para que ya cuando } \\
\text { ellos lleguen al Básico no tengan problemas de índole de } \\
\text { género" (E06/B/H) }\end{array}$ \\
\hline
\end{tabular}




\begin{tabular}{|c|c|c|c|}
\hline Categoría & $\begin{array}{l}\text { Sub- } \\
\text { categorías }\end{array}$ & Dimensiones exclusoras & Dimensiones transformadoras \\
\hline & & $\begin{array}{l}\text { "Trabajar sobre la equidad de género al grado en que } \\
\text { llevo ahorita, que es segundo grado, pues cuando vienen } \\
\text { los niños a la escuela yo creo que vienen formados desde } \\
\text { el hogar. Nosotros quisiéramos que se comience a trabajar } \\
\text { equidad de género desde muy pequeños" (E08/P/M) } \\
\text { "Cuando yo estudié el Básico estudié un año en un centro } \\
\text { urbano, específicamente en Salcajá y solo por pertenecer } \\
\text { a la etnia k’iche', era obviado tanto por los compañeros } \\
\text { como por los maestros, entonces en ese momento cuando } \\
\text { uno ya está directamente en esa etapa y está laborando ya, } \\
\text { uno dice no, esto no es correcto" (E04/Pr/H) }\end{array}$ & $\begin{array}{l}\text { "Pues fijese que ya las bases hechas es difícil pero no imposible } \\
\text { cambiar digamos algunos paradigmas que han venido desde la } \\
\text { niñez desde el hogar por ejemplo, desde la casa”(E06/B/H) } \\
\text { "El nivel de Pre-Primaria es la base fundamental para } \\
\text { implementar eso, para eliminar lo que es el machismo, el } \\
\text { racismo hacia la mujer" (E02/PrPr/H) } \\
\text { "Un problemita que tenemos más es sobre la alimentación de } \\
\text { los estudiantes, [...] sobre la equidad de género no hemos } \\
\text { tenido ningún problema" (E05/B/M) } \\
\text { "Los establecimientos son mixtos entonces en este caso se le da } \\
\text { también la oportunidad a más personas y al menos se practica } \\
\text { la convivencia verdad que es muy importante y eso ayuda a que } \\
\text { se entiendan ambos géneros, hombres y mujeres" (E06/B/H) } \\
\text { "En cuanto encontremos gente, padres de familia, que vean } \\
\text { bien el papel de buscar la igualdad, entonces creo que el papel } \\
\text { de la escuela cae en buena semilla" (E09/P/H) } \\
\text { "Creo que el papel de la escuela es mucho y también es poco. }\end{array}$ \\
\hline
\end{tabular}




\begin{tabular}{|c|c|c|c|}
\hline Categoría & $\begin{array}{l}\text { Sub- } \\
\text { categorías }\end{array}$ & Dimensiones exclusoras & Dimensiones transformadoras \\
\hline & & & $\begin{array}{l}\text { Es mucho en el sentido de que aquí se pueden ir creando } \\
\text { nuevos paradigmas de vida, nuevas ideologías de vida, lo cual } \\
\text { veo yo que sí es bien recepcionado por parte de los niños y las } \\
\text { niñas, especialmente de las niñas, entonces creo yo que eso de } \\
\text { algún modo va poniendo las primeras semillas para poder } \\
\text { cambiar la mentalidad [...] Por otro lado, poco porque muchas } \\
\text { veces los patrones familiares que traen los niños es mucho más } \\
\text { poderoso que el papel de la escuela" (E09/P/H) } \\
\text { "Entonces ellos dicen ¿y yo porque me tengo que juntar con } \\
\text { ellos? Yo mejor me junto con él, entonces ya tienen sus } \\
\text { grupitos y yo en ese momento intervengo y les digo que no, hay } \\
\text { que compartir con todos, no solo porque uno no es superior o } \\
\text { no solo porque uno tiene ciertas posibilidades va a obviar a los } \\
\text { demás, entonces tenemos que ser por lo menos justos y } \\
\text { comprensivos y decirles que eso no es correcto y ellos van } \\
\text { aprendiendo poco a poco" (E04/Pr/H) } \\
\text { "Hemos aprovechado esos espacios [situaciones de } \\
\text { discriminación] para decirle a ellos [alumnado] que la situación } \\
\text { del idioma muchas veces nos marca a nosotros diferencias en }\end{array}$ \\
\hline
\end{tabular}




\begin{tabular}{|c|c|c|c|}
\hline Categoría & $\begin{array}{l}\text { Sub- } \\
\text { categorías }\end{array}$ & Dimensiones exclusoras & Dimensiones transformadoras \\
\hline & & & $\begin{array}{l}\text { cuanto al trato y la forma verdad, pero que debemos aprender a } \\
\text { respetar esas diferencias para poder tener una mejor } \\
\text { convivencia, pienso que el mejor curso donde lo he podido } \\
\text { practicar es en seminario" (E07/D/H) }\end{array}$ \\
\hline & Familia & $\begin{array}{l}\text { "La niña siempre es dejada a un lado en el proceso } \\
\text { educativo, porque los papas argumentan de que las niñas } \\
\text { por ser niñas se van a casar, entonces que no necesitan } \\
\text { estudiar”(E01/PrPr/M) } \\
\text { “Se está trabajando con los niños, con los padres de } \\
\text { familia... porque no es solo con los niños, con los padres } \\
\text { de familia, porque ellos los forman, ya llegan a la escuela } \\
\text { con la idea, que solo los varones son lo que tienen más } \\
\text { derechos que las niñas y hasta cierto punto humillan a las } \\
\text { niñitas cuando ellas participan” (E03/Pr/M) }\end{array}$ & $\begin{array}{l}\text { "Los padres de familia ellos también tienen, y es la obligación } \\
\text { de ellos demostrarles, que los niños y las niñas valen lo mismo" } \\
\text { (E02/PrPr/H) } \\
\text { “A mi hijito, como no me estoy...pero no es tanto porque no me } \\
\text { estoy, sino para enseñarle de que es capaz, él ya puede cocinar, } \\
\text { él cocina, se pone su gabacha, y le digo ¡papa ayúdame a lavar } \\
\text { los trastos! Ta bueno me dice y lo hace, pero mi mamá y mi } \\
\text { papá... ¡para ellos es un problema! Y me dicen: ¡es que no sos } \\
\text { una mamá responsable! ¿Y dicen como lo vas a mandar a } \\
\text { cocinar a él? ¡Si él es hombrecito!” (E03/Pr/M) }\end{array}$ \\
\hline & & $\begin{array}{l}\text { "Se organizó una plática con los padres de familia para } \\
\text { planificación familiar [...] nos dijeron que nosotros } \\
\text { ¿quiénes somos para ir a prohibirles a ellos cuántos hijos } \\
\text { iban o no a tener? Si ellos como hombres tienen el } \\
\text { derecho a tener cuantas mujeres y cuántos hijos ellos }\end{array}$ & $\begin{array}{l}\text { "Ya cambió ese pensamiento de que eres mujer ya no vas a la } \\
\text { escuela porque te quedas cocinando, cuidas a tus hermanos, ya } \\
\text { no hay tal vez, existen algunos pero ya la mayor parte no" } \\
(\mathrm{E} 05 / \mathrm{B} / \mathrm{M})\end{array}$ \\
\hline
\end{tabular}




\begin{tabular}{|c|c|c|c|}
\hline Categoría & $\begin{array}{l}\text { Sub- } \\
\text { categorías }\end{array}$ & Dimensiones exclusoras & Dimensiones transformadoras \\
\hline & & $\begin{array}{l}\text { quieran y que no somos nosotras quienes les vamos a ir a } \\
\text { dar de comer a sus hijos y no pudimos hacer nada" } \\
\text { (E03/Pr/M) } \\
\text { "Mi mamá me cuenta... bueno es muy triste y a la vez } \\
\text { duele y a veces uno dice, bueno cómo puede tener uno un } \\
\text { papá así, entonces mi mamá me dice no... [la mamá, } \\
\text { recordando su juventud] me levanto a las tres de la } \\
\text { mañana a acarrear agua, a lavar ropa a cocinarle y a veces } \\
\text { no me da mi leña, no me dan gasto pero ellos sí me } \\
\text { exigen y si no lo tengo a la hora, me pegan" (E03/Pr/M) } \\
\text { "Los niños dicen, no mi mamá dice que yo solo con los } \\
\text { niños tengo que estar, con las niñas no" (E08/P/M) } \\
\text { "En la casa, por ejemplo mi mamá, le sirve a mi papá. Mi } \\
\text { papá no puede lavar un vaso, él no se puede servir con } \\
\text { una cuchara, se sienta y todo tiene que ser servido... imi } \\
\text { papá! Y así fue formando a mis hermanos, ellos no se } \\
\text { pueden levantar a agarrar un vaso porque para ellos es } \\
\text { una humillación y existe el machismo, y así pasa en las }\end{array}$ & \\
\hline
\end{tabular}




\begin{tabular}{|c|c|c|c|}
\hline Categoría & $\begin{array}{l}\text { Sub- } \\
\text { categorías }\end{array}$ & Dimensiones exclusoras & Dimensiones transformadoras \\
\hline & & $\begin{array}{l}\text { comunidades también” (E03/Pr/M) } \\
\text { "Si se le va a dar educación a la niña, se le da en los } \\
\text { niveles de Pre-Primaria y Primaria y se piensa que con } \\
\text { eso ya es suficiente para ella, como para desenvolverse, } \\
\text { ya lo demás ya no es tan útil como para ella, entonces } \\
\text { sobre todo en una carrera muchas veces se piensa que ya } \\
\text { no siga estudiando" (E07/D/H) } \\
\text { "Estamos tratando dentro del aula que el trabajo sea } \\
\text { equitativo, que sea igualitario, hombres y mujeres } \\
\text { valemos igual, los alumnos lo ponen en práctica acá. El } \\
\text { problema está en el hogar. Los padres de familia } \\
\text { necesitan también orientación. Necesitan una escuela } \\
\text { donde educarse y cómo educar a los hijos" (E10/P/M) }\end{array}$ & \\
\hline & Comunidad & $\begin{array}{l}\text { "Aquí todos dicen que son discriminados. Que si somos } \\
\text { ladinos, que nos discriminan cuando vienen becas que son } \\
\text { solo para indígenas, que si somos indígenas que nos } \\
\text { discriminan porque no nos dejaron entrar a determinado } \\
\text { lugar, o sea todos nos quejamos de todo. No vivimos } \\
\text { contentos con nada." (E01/PrPr/M) }\end{array}$ & \\
\hline
\end{tabular}




\begin{tabular}{|c|c|c|c|}
\hline Categoría & $\begin{array}{l}\text { Sub- } \\
\text { categorías }\end{array}$ & Dimensiones exclusoras & Dimensiones transformadoras \\
\hline & & $\begin{array}{l}\text { "Allá las señoras no saben comprar, los señores son los } \\
\text { que compran, no conocen ni siquiera el mercado" } \\
\text { (E03/Pr/M) } \\
\text { "La señora lo fue a denunciar, le estuvo dando gasto y las } \\
\text { autoridades [autoridades ancestrales indígenas] le } \\
\text { prohibieron al señor acercarse a la señora por los golpes } \\
\text { que le dio, pero ya resulta que fue culpa de la señora } \\
\text { volver a regresar a vivir con el señor también" } \\
\text { (E03/Pr/M) }\end{array}$ & \\
\hline & & $\begin{array}{l}\text { "Toto es el departamento que estaría mejor, que está } \\
\text { organizado por los } 48 \text { cantones [autoridades ancestrales } \\
\text { indígenas], pero en la mente de las personas es donde esta } \\
\text { eso [machismo] y no se puede cambiar" (E03/Pr/M) }\end{array}$ & \\
\hline & Religión & $\begin{array}{l}\text { "Si tú eres cristiana tienes que tener este perfil, si tú eres } \\
\text { católica tienes este perfil, entonces sí marca bastante y yo }\end{array}$ & \\
\hline
\end{tabular}




\begin{tabular}{|c|c|c|c|}
\hline Categoría & $\begin{array}{l}\text { Sub- } \\
\text { categorías }\end{array}$ & Dimensiones exclusoras & Dimensiones transformadoras \\
\hline & & $\begin{array}{l}\text { lo veo por ejemplo cuando vamos a tener por ejemplo un } \\
\text { desfile y llegan las señoras y dicen mi hijo o mi hija no } \\
\text { desfila, porque mi religión no me lo permite, entonces ya } \\
\text { desde ahí estamos limitando las capacidades de los niños" } \\
(\mathrm{E} 01 / \mathrm{PrPr} / \mathrm{M})\end{array}$ & \\
\hline $\begin{array}{l}\text { Educación } \\
\text { para la } \\
\text { equidad de } \\
\text { género, etnia } \\
\text { y social }\end{array}$ & $\begin{array}{l}\text { Eje de } \\
\text { equidad de } \\
\text { género, de } \\
\text { etnia y social } \\
\text { del CNB }\end{array}$ & $\begin{array}{l}\text { “Pero esos ejes nadie los trabaja, ¡no saben trabajarlos! } \\
\text { ¡De verdad! Les digo yo ¿cómo podemos aplicar un eje } \\
\text { transversal? Se quedan en la luna, entonces la verdad } \\
\text { desafortunadamente la formación que hemos tenido como } \\
\text { docentes ha sido muy mala...” (E01/PrPr/M) } \\
\text { "Hay maestros que son... aquí se les llama ladinos, que no } \\
\text { usan traje... y ellos no quieren ir a trabajar a un área } \\
\text { indígena, porque dicen "hay no es que los niños son más } \\
\text { tontos"” (E01/PrPr/M) } \\
\text { “Por otro lado el promover la cultura se hace también, } \\
\text { pero por ejemplo este mes tenemos concurso de bailes } \\
\text { folclóricos, entonces esto es para ensayar un baile } \\
\text { folclórico y ahí se acabo, entonces por eso es muy } \\
\text { superficial también” (E01/PrPr/M) }\end{array}$ & $\begin{array}{l}\text { "Sí porque unos dicen que no está bien, pero yo la considero } \\
\text { bonita [el CNB como herramienta] porque nos permite } \\
\text { contextualizarlo todo, nos permite utilizar lo nuestro a ver lo } \\
\text { que tenemos y lo que no tenemos cerca verdad, utilizar todos } \\
\text { los recursos necesarios para hacer la educación, antes } \\
\text { posiblemente no había esa opción verdad” (E05/B/M) } \\
\text { “Al menos yo no he tenido tanto problema en ese sentido } \\
\text { [incluir la equidad en la práctica docente] pero, depende mucho } \\
\text { del maestro si el maestro ha cambiado o ha implementado todas } \\
\text { Base pide pues, siento que no tendría problemas. Ahora si el } \\
\text { maestro sigue con la guía tradicionalista entonces, ahí sí hay } \\
\text { problemas porque hay un distanciamiento entre el alumno y el } \\
\text { docente” (E06/B/H) }\end{array}$ \\
\hline
\end{tabular}




\begin{tabular}{|c|c|c|c|}
\hline Categoría & $\begin{array}{l}\text { Sub- } \\
\text { categorías }\end{array}$ & Dimensiones exclusoras & Dimensiones transformadoras \\
\hline & & $\begin{array}{l}\text { "Transversal, de forma transversal es que en los } \\
\text { contenidos que yo estoy dando, yo siempre considere } \\
\text { todos estos aspectos [...] el problema es que las docentes } \\
\text { medio trabajan los contenidos, mucho menos ni siquiera } \\
\text { saben que esos ejes tienen que trabajarlos de una forma } \\
\text { paralela a sus contenidos, es que ese es el detalle, que no } \\
\text { tienen todavía bien claro como trabajar el CNB" } \\
\text { (E01/PrPr/M) } \\
\text { "Por el momento no [sobre realizar actividades de } \\
\text { educación para la equidad] porque como vamos en } \\
\text { relación a trabajo de unidad que se hace entonces, todo } \\
\text { tiene un proceso en la unidad en que sí se va a trabajar" } \\
\text { (E02/PrPr/H) } \\
\text { "Siempre salen a veces comentarios sobre esto, pero no } \\
\text { específicamente tratamos de decirle equidad de género, } \\
\text { esto obviamente lo miramos con otro nombre, igualdad o } \\
\text { convivencia, convivencia entre el aula, convivencia en los } \\
\text { niños" (E04/Pr/H) }\end{array}$ & $\begin{array}{l}\text { "Pues el eje de equidad de género e igualdad de género, está } \\
\text { plasmado en el CNB pero los comprometidos a que estos se } \\
\text { socialice somos nosotros los docentes" (E10/P/M) }\end{array}$ \\
\hline
\end{tabular}




\begin{tabular}{|c|c|c|c|}
\hline Categoría & $\begin{array}{l}\text { Sub- } \\
\text { categorías }\end{array}$ & Dimensiones exclusoras & Dimensiones transformadoras \\
\hline & & $\begin{array}{l}\text { "No lo notamos en muchas ocasiones pero siento que la } \\
\text { discriminación se sigue dando [en las aulas] tal vez con } \\
\text { menor porcentaje pero sí" (E06/B/H) }\end{array}$ & \\
\hline & & $\begin{array}{l}\text { "Hay diferencias, desgraciadamente nuestra sociedad se } \\
\text { marcan verdad, de una persona que está en el área urbana, } \\
\text { de una persona que está en el área rural" (E07/D/H) } \\
\text { "En lo teórico existe un eje verdad y nos lo marca y nos } \\
\text { dice que lo trabajemos pero muchas veces no se llega a } \\
\text { eso en la práctica" (E07/D/H) }\end{array}$ & \\
\hline & & $\begin{array}{l}\text { "Puede que sea un apoyo [el CNB] pero tal vez con un } \\
\text { porcentaje un poquito bajo porque ya ve que el CNB lo } \\
\text { han hecho no a nuestra realidad sino a la realidad de } \\
\text { ciudad, está basado a la realidad de ciudad. Trabajando }\end{array}$ & \\
\hline
\end{tabular}




\begin{tabular}{|c|c|c|c|}
\hline Categoría & $\begin{array}{l}\text { Sub- } \\
\text { categorías }\end{array}$ & Dimensiones exclusoras & Dimensiones transformadoras \\
\hline & & $\begin{array}{l}\text { nosotros aquí tenemos que acoplarlo a nuestra realidad" } \\
\text { (E08/P/M). } \\
\text { "El CNB contempla en un contenido la equidad de } \\
\text { género. Si yo lo quiero abordar en } 2,3 \text { clases, ahí se } \\
\text { murió. Ahora, la cotidianidad que vivimos con los niños, } \\
\text { por ejemplo de ir a traer refacción, que solo las mujeres, } \\
\text { que la limpieza solo las mujeres, entonces yo siento que } \\
\text { eso si tiene que ver mucho con el tema del CNB pero } \\
\text { siento que a equidad es más cotidiana" (E09/P/H) }\end{array}$ & \\
\hline & $\begin{array}{l}\text { Formación } \\
\text { inicial y } \\
\text { permanente } \\
\text { de maestras y } \\
\text { maestros }\end{array}$ & $\begin{array}{l}\text { “Pero esos ejes nadie los trabaja, ¡no saben trabajarlos! } \\
\text { ¡De verdad! Les digo yo ¿cómo podemos aplicar un eje } \\
\text { transversal? Se quedan en la luna, entonces la verdad } \\
\text { desafortunadamente la formación que hemos tenido como } \\
\text { docentes ha sido muy mala...” (E01/PrPr/M) } \\
\text { "La verdad es que no tienen ninguna formación en cuanto } \\
\text { a este tema” [referido a maestras y maestros]; “cuando yo } \\
\text { comencé a hablar con ellas el primer día de clases, } \\
\text { recuerdo que les digo yo ¿qué es coeducación? Y no...o } \\
\text { sea el concepto no lo habían escuchado o sea el tema no” }\end{array}$ & $\begin{array}{l}\text { "Entonces si uno tiene el hábito de investigar y de formarse y } \\
\text { uno lo puede aplicar" (E01/PrPr/M) } \\
\text { "En el magisterio sí, vimos lo que es la equidad de género y } \\
\text { cómo fomentar lo que es la equidad de género en los } \\
\text { estudiantes verdad, cómo aplicar la equidad de género en los } \\
\text { grupos y cómo aplicar la equidad de género a nivel del } \\
\text { establecimiento para que no haya distinción de personas, ni de } \\
\text { raza ni de color como lo dice lo que es la constitución política" } \\
\text { (E05/B/M) }\end{array}$ \\
\hline
\end{tabular}




\begin{tabular}{|c|c|c|c|}
\hline Categoría & $\begin{array}{l}\text { Sub- } \\
\text { categorías }\end{array}$ & Dimensiones exclusoras & Dimensiones transformadoras \\
\hline & & $\begin{array}{l}\text { (E01/PrPr/M) } \\
\text { "Encontré en España [materiales sobre coeducación], } \\
\text { encontré en diferentes lugares pero de aquí no, y allá es } \\
\text { un tema que se está trabajando no en estos años, si no que } \\
\text { ya tiene años de venirse trabajando, y le digo yo no sé por } \\
\text { qué acá con nosotros nunca nos han formado para que } \\
\text { trabajemos así, incluso yo soy licenciada en Educación } \\
\text { Inicial de Pre-Primaria, pero el curso a mí no me lo } \\
\text { dieron así" (E01/PrPr/M) } \\
\text { "No, no hemos recibido charlas de eso casi, no" } \\
\text { (E02/PrPr/H) } \\
\text { "No, lo único que nos han dado la oportunidad de poder } \\
\text { formarnos es cómo trabajar multigrado por ejemplo, } \\
\text { como la lecto-escritura, matemática [...] para equidad de } \\
\text { género no" (E03/Pr/M) } \\
\text { hablado sobre más... educación en lectura y escritura y } \\
\text { únicamente” (E04/Pr/H) }\end{array}$ & 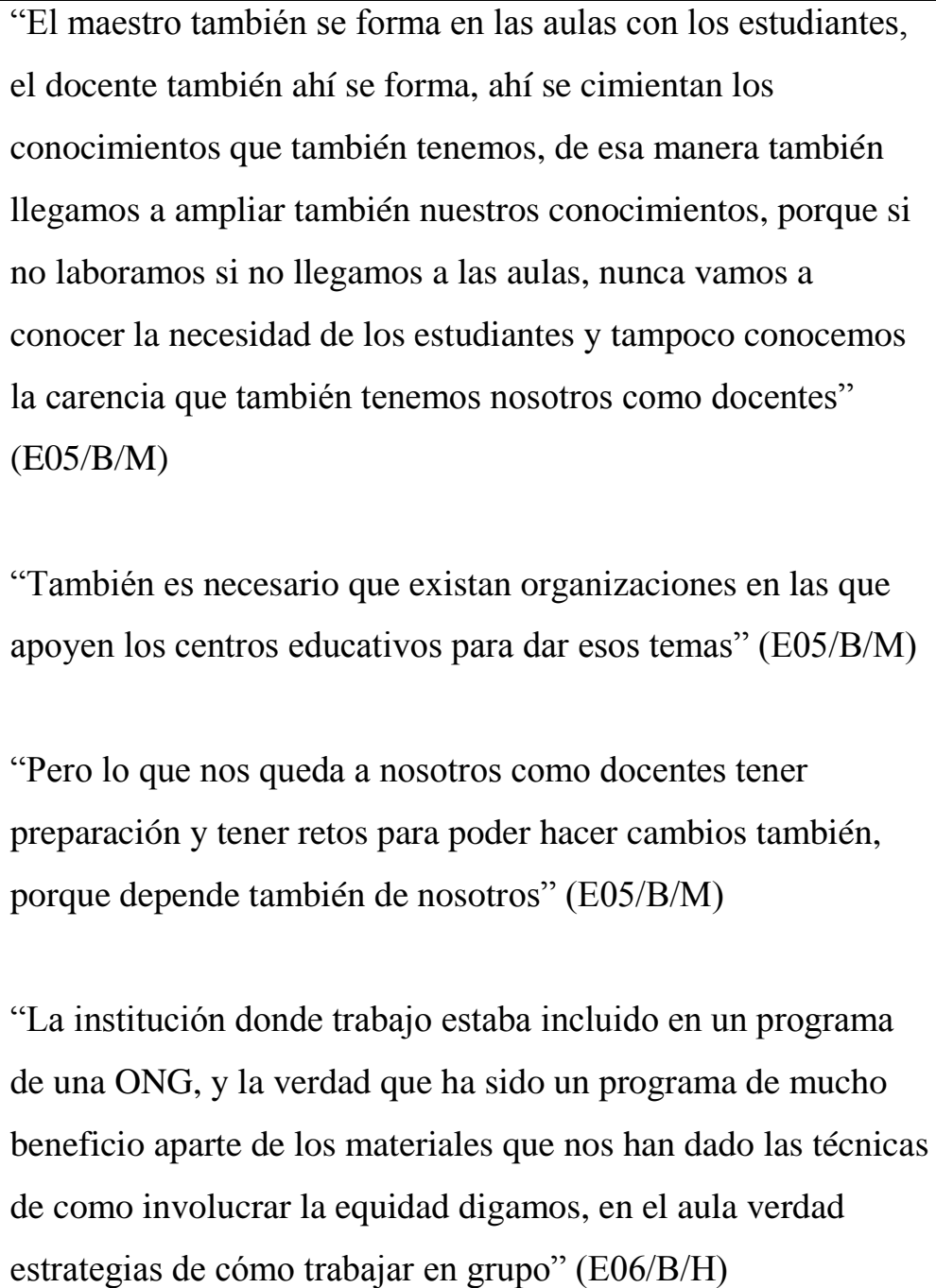 \\
\hline
\end{tabular}




\begin{tabular}{|c|c|c|c|}
\hline Categoría & $\begin{array}{l}\text { Sub- } \\
\text { categorías }\end{array}$ & Dimensiones exclusoras & Dimensiones transformadoras \\
\hline & & $\begin{array}{l}\text { "No, no hemos trabajado en ningún momento, tal vez se } \\
\text { ha tocado dentro de los cursos de la universidad, tal vez } \\
\text { en algún momento en Derechos Humanos, es en donde } \\
\text { vemos un poquito el derecho de equidad y otras cosas" } \\
(\mathrm{E} 07 / \mathrm{D} / \mathrm{H})\end{array}$ & \\
\hline & $\begin{array}{l}\text { Gerencia del } \\
\text { sistema } \\
\text { educativo }\end{array}$ & $\begin{array}{l}\text { "Y por más a mi llegar la directora y me dice mire no lo } \\
\text { trabaje [equidad de género], pues tenemos libertad de } \\
\text { cátedra y si yo estoy convencida que eso es lo mejor para } \\
\text { mis alumnos, tengo el derecho de trabajarlo y nadie me } \\
\text { puede decir que no" (E01/PrPr/M) } \\
\text { "La directora no se involucra en el trabajo del aula, } \\
\text { entonces yo puedo planificar las actividades que yo } \\
\text { desee"; "aquí en Guatemala no nos limita, pero muchas } \\
\text { veces tampoco no nos enseñan" (E01/PrPr/M) }\end{array}$ & $\begin{array}{l}\text { "Yo soy la responsable, entonces aporto lo que tengo que } \\
\text { aportar, pero no le echo la culpa al que esta atrás" } \\
\text { (E01/PrPr/M) } \\
\text { "Una ventaja que sí tenemos en el magisterio, es la libertad de } \\
\text { cátedra, entonces ahí usted tiene libertad para mejorar les digo } \\
\text { yo, no para empeorar.... "(E01/PrPr/M) } \\
\text { "Es lo que a mí me llamo la atención, es la esencia que yo } \\
\text { siento que quería trabajar, con los niños pequeños" } \\
\text { (E02/PrPr/H) }\end{array}$ \\
\hline & & $\begin{array}{l}\text { "El trabajo es muy duro de parte de nosotros, porque el } \\
\text { director nos exige mucho" (E03/Pr/M) } \\
\text { "El problema que tenemos [maestras y maestros] es que }\end{array}$ & $\begin{array}{l}\text { "Los hombres también somos capaces de poder educar a los } \\
\text { niños, porque muchas veces a nosotros los hombres se nos } \\
\text { toma como machistas, a veces hasta abusamos de los niños } \\
\text { pero aquí nos podemos dar cuenta que también, que los }\end{array}$ \\
\hline
\end{tabular}




\begin{tabular}{|c|c|c|c|}
\hline Categoría & $\begin{array}{l}\text { Sub- } \\
\text { categorías }\end{array}$ & Dimensiones exclusoras & Dimensiones transformadoras \\
\hline & & $\begin{array}{l}\text { a veces tenemos mucha desidia, mucho acomodamiento" } \\
\text { (E01/PrPr/M) } \\
\text { "Lo primero que una maestra del sector público dice aquí } \\
\text { en nuestro país, es;"ustedes solo nos vienen a dar órdenes, } \\
\text { por que trabajan en un escritorio, pero no están en el } \\
\text { contexto" es lo primero que ellas dicen, pero si llega } \\
\text { alguien y les dice, miren esto funciona por esto, esto y } \\
\text { esto y vean, les mostramos videos que sí hay cambios y } \\
\text { todo y si hay también un convenio con el Ministerio de } \\
\text { Educación, porque muchas veces hacen las cosas solo si } \\
\text { las presionan" (E01/PrPr/M) } \\
\text { "Y yo siempre les digo aquí a las señoritas les digo yo, } \\
\text { por qué cuando están en un colegio que les paga Q700 al } \\
\text { mes [70 euros aprox.], y el director les dice que se pongan } \\
\text { de cabeza, se ponen de cabeza, si se tiene que llevar } \\
\text { tantos carteles los llevan y no les importa gastar, no les } \\
\text { importa... y por qué cuando entran al sector publico ya no } \\
\text { hacen nada... y ganan el triple, pero así estamos...” } \\
\text { (E01/PrPr/M) }\end{array}$ & $\begin{array}{l}\text { hombres o los varones tenemos ese cariño o esa esencia de } \\
\text { querer a los niños también" (E02/PrPr/H) } \\
\text { "Yo le platico al profe [director] y yo le digo: profe ¿será que } \\
\text { nos está funcionando este trabajo que estamos realizando con } \\
\text { los papás? Porque de veras es cansado le digo yo. Miré seño me } \\
\text { dice, con los papás de ahorita nos va a costar, pero los niños } \\
\text { que ahorita nosotros estamos formando, cuando ellos sean } \\
\text { papás, ahí vamos a ver los resultados" (E03/Pr/M) } \\
\text { "Desde el CNB es mixto y se trabaja [asignatura de artes } \\
\text { industriales]. Porque incluso aquel curso hogar, que se llamaba, } \\
\text { también lo trabajan hombres y mujeres" (E07/D/H) }\end{array}$ \\
\hline
\end{tabular}




\begin{tabular}{|c|c|c|c|}
\hline Categoría & $\begin{array}{l}\text { Sub- } \\
\text { categorías }\end{array}$ & Dimensiones exclusoras & Dimensiones transformadoras \\
\hline & & $\begin{array}{l}\text { "Cuando empecé a estudiar, de que éramos pocos los } \\
\text { varones, estábamos hablando de una cantidad de } 7 \\
\text { varones y } 40 \text { féminas o mujeres"; "cuando llegue yo al } \\
\text { momento de presentarme a la escuelita, me dijeron ¿a qué } \\
\text { grado viene? Yo vengo de Pre-Primaria y el compañero } \\
\text { se me quedo viendo ¿usted de Pre-Primaria? Si, ¿por qué? } \\
\text { Porque es el nivel del que yo me he graduado le dije" } \\
\text { (E02/PrPR/H) } \\
\text { "No, con decirle que en mi escuela no hay pizarrones" [ni } \\
\text { libros] (E03/Pr/M) } \\
\text { "Porque a veces ellos [docentes] todavía tienen la } \\
\text { mentalidad yo vengo a dar mis cursos, o yo vengo a dar la } \\
\text { teoría que me corresponde y hasta ahí terminó todo [...] } \\
\text { no todos hemos llegado a entender eso de que tenemos } \\
\text { que utilizar o traer los ejes para el aula" (E05/B/M) } \\
\text { "Porque dentro del mismo claustro de docentes hay más } \\
\text { varones impartiendo clases que mujeres, y a veces } \\
\text { siempre se da ese favoritismo de algunos docentes hacia }\end{array}$ & \\
\hline
\end{tabular}




\begin{tabular}{|c|c|c|c|}
\hline Categoría & $\begin{array}{l}\text { Sub- } \\
\text { categorías }\end{array}$ & Dimensiones exclusoras & Dimensiones transformadoras \\
\hline & & $\begin{array}{l}\text { el género femenino verdad [...] sí a veces se marca eso a } \\
\text { veces en cuanto a favoritismo de profesores por las } \\
\text { señoritas" }(\mathrm{E} 07 / \mathrm{D} / \mathrm{H})\end{array}$ & \\
\hline & $\begin{array}{l}\text { Familias / } \\
\text { comunidad }\end{array}$ & $\begin{array}{l}\text { "Fui directora de una escuelita, bueno estaba por contrato } \\
\text { y me costaba mucho convocar a los señores, porque no } \\
\text { llegaban, pero fui descubriendo de que era por el hecho } \\
\text { de que yo soy mujer" [...] "sí, porque por ejemplo los } \\
\text { papás dicen: ah no! a ustedes no las obedecemos porque } \\
\text { xaixoquib" nos dicen en su idioma que solamente somos } \\
\text { mujeres y que no. Ellos cómo decirle no pueden recibir } \\
\text { alguna sugerencia o algo" (E03/Pr/M) } \\
\text { "Dimos clases sexuales [de educación sexual] a una niña } \\
\text { de } 10 \text { de } 11 \text { años en adelante y resulta que se organizaron } \\
\text { todas las mamás [...] para ellos fue inadecuado darles } \\
\text { esta clase a las niñas, que para ellas fue un pecado, me } \\
\text { dijeron a mí: i¿cómo se te ocurre hablarle de esos temas a } \\
\text { las niñas?! Si esos temas, a ellos por ejemplo ayer se } \\
\text { casaron ¡en la misma noche les explicamos cómo es esto! } \\
\text { por que ellas no deben de saber nada" (E03/Pr/M) }\end{array}$ & $\begin{array}{l}\text { "Hicimos un trifoliar verdad, para poder educar a los padres de } \\
\text { familia para que conocieran un poquito sobre el tema, ¿verdad? } \\
\text { Cómo tratar el tema de la coeducación desde el hogar, hicimos } \\
\text { una planificación para poder trabajar con padres de familia, yo } \\
\text { les decía a ellas que cada unidad que ustedes entreguen las } \\
\text { tarjetas den una pequeña plática de lo que es la coeducación, de } \\
\text { la importancia de promover, de erradicar el sexismo" } \\
\text { (E01/PrPr/M) } \\
\text { "Yo veo que sí es un tema que sí se puede trabajar con ellos, } \\
\text { porque yo sé que son personas ya mayores, razonantes, si saben } \\
\text { que es algo interesante, porque ellos mismos son los } \\
\text { perjudicados si ven que los niños, a ellos no se les habla esto } \\
\text { también porque su comunidad va a estar desintegrada y no van } \\
\text { a poder convivir como seres humanos" (E02/PrPr/H) } \\
\text { "Padres de familia, estudiantes, personas de la escuela, los } \\
\text { estudiantes verdad formamos una comunidad, y esa comunidad } \\
\text { es lo que tratamos de hacer, tratamos de tener el desarrollo o un }\end{array}$ \\
\hline
\end{tabular}




\begin{tabular}{|c|c|c|c|}
\hline Categoría & $\begin{array}{l}\text { Sub- } \\
\text { categorías }\end{array}$ & Dimensiones exclusoras & Dimensiones transformadoras \\
\hline & & $\begin{array}{l}\text { "Diversificado el nivel de diferencia que tenemos con las } \\
\text { mujeres verdad, me atrevería a decir que más o menos un } \\
70 \% \text { a un } 75 \% \text { de hombres y el resto de mujeres verdad } \\
{[\ldots] \text { me acabo de topar precisamente con un caso que me }} \\
\text { decía la señora, para qué va a estudiar mi hija? Si se va a } \\
\text { casar" (E07/D/H) }\end{array}$ & $\begin{array}{l}\text { cambio integral en el estudiante, y eso es lo que pretende ahora } \\
\text { lo que es el Curriculum Nacional Base" (E05/B/M) }\end{array}$ \\
\hline & $\begin{array}{l}\text { Actividades } \\
\text { concretas } \\
\text { relacionadas } \\
\text { con } \\
\text { educación } \\
\text { para la } \\
\text { equidad }\end{array}$ & $\begin{array}{l}\text { "Las niñas no quieren participar y los niños no les dan } \\
\text { participación" (E03/Pr/M) }\end{array}$ & $\begin{array}{l}\text { "Los niños se sorprenden cuando yo les he contado cuentos co- } \\
\text { educativos", "el miércoles trabajo los co-educativos y ya tengo } \\
\text { bastantes cuentos co-educativos" (E01/PrPr/M) } \\
\text { "Entonces se dan cuenta que sí, que las mujeres tienen la } \\
\text { misma capacidad de poder hacer lo que un hombre puede y } \\
\text { vamos generando polémica con ellos desde chiquitos" } \\
\text { (E01/PrPr/M) } \\
\text { "[referido a educación sexual] Ya con imágenes, dibujos ya } \\
\text { hasta los niños hacen otras preguntas, entonces ya hay como } \\
\text { que más apertura, pero eso sí se ha trabajado un poquito más" } \\
\text { (E01/PrPr/M) }\end{array}$ \\
\hline & & & "Haciéndolos mixtos [organización de actividades de aula] \\
\hline
\end{tabular}




\begin{tabular}{|c|c|c|c|}
\hline Categoría & $\begin{array}{l}\text { Sub- } \\
\text { categorías }\end{array}$ & Dimensiones exclusoras & Dimensiones transformadoras \\
\hline & & & $\begin{array}{l}\text { porque así como ahorita los tengo yo, los tengo así un varón } \\
\text { una niña, un varón una niña... Entonces ahí yo también les } \\
\text { estoy inculcando que pueden trabajar no importando el género" } \\
\text { (E02/PrPr/H) } \\
\text { "Ahí para todos es lo mismo [actividades de aula diferenciadas } \\
\text { o no por sexo], porque no puedo yo hacerle esto una niña y esto } \\
\text { a otro niño, entonces yo ahí veo que no hay la equidad de } \\
\text { género, para todos es lo mismo, porque yo sé que todos lo } \\
\text { pueden hacer de la misma forma que uno quiere que ellos lo } \\
\text { hacen" (E02/PrPr/H) } \\
\text { "Yo me he sentado con ellos [niños] y les he explicado que } \\
\text { todas las personas somos iguales, y yo le pregunto a los niños, } \\
\text { ¿tu mamá es mujer? Sí, ¿Quién te cocina? Mi mamá, y si tú por } \\
\text { ejemplo vas a crecer ¿te vas a casar con una mujer o con un } \\
\text { hombre? No, con una mujer, entonces a tu esposa no le vas a } \\
\text { hacer eso" (E03/Pr/M) }\end{array}$ \\
\hline
\end{tabular}




\begin{tabular}{|c|c|c|c|}
\hline Categoría & $\begin{array}{l}\text { Sub- } \\
\text { categorías }\end{array}$ & Dimensiones exclusoras & Dimensiones transformadoras \\
\hline & & & $\begin{array}{l}\text { niños tratan muy bien a sus compañeras y empiezan a dibujar, a } \\
\text { pintar y a pensar juntos” (E03/Pr/M) } \\
\text { "Tenemos la escuela de padres con los papás, les explicamos de } \\
\text { que por lo menos ellos [sus hijas e hijos] deben de tener una } \\
\text { mejor oportunidad” (E03/Pr/M) } \\
\text { "Entonces yo les digo a ellos: y ustedes con lavar trastos, ¿se } \\
\text { van a convertir en mujeres? ¡No!, con barrer ¿se van a convertir } \\
\text { en mujeres? ¡No! [...] el martes les enseñé a cocinar, involucré } \\
\text { a los niños, vayan a lavarse las manos, llénenme esto de agua, } \\
\text { háganme esto, esto y usted póngame esto, involucré a los } \\
\text { hombrecitos, ¿pueden cocinar? ¡Sí! ¿Ya vieron que pueden?” } \\
\text { (E03/Pr/M) } \\
\text { "Yo trabajo con los jóvenes utilizando los grupos mixtos y } \\
\text { haciendo trabajos que los hombres pueden hacer y que las } \\
\text { mujeres pueden hacer, entonces no permito que haya grupos así } \\
\text { de hombres o de mujeres que sean mixtos, porque donde } \\
\text { trabajo es una escuela donde hay hombres y mujeres verdad, y } \\
\text { también es una población que también podríamos decir }\end{array}$ \\
\hline
\end{tabular}




\begin{tabular}{|c|c|c|c|}
\hline Categoría & $\begin{array}{l}\text { Sub- } \\
\text { categorías }\end{array}$ & Dimensiones exclusoras & Dimensiones transformadoras \\
\hline & & & $\begin{array}{l}\text { indígena y no hay discriminación también hacia otra cultura o } \\
\text { hacia otra etnia" (E05/B/M) } \\
\text { "Yo llego al aula, todos hacemos una invocación, y esa } \\
\text { invocación la hacemos de manera rotativa; un hombre y una } \\
\text { mujer, un hombre y una mujer...[...] luego cantamos el himno } \\
\text { nacional en k’iche"” (E05/B/M) } \\
\text { "Grupos de trabajo mixtos verdad, para ir promoviendo esa } \\
\text { equidad entonces armamos grupos de trabajo y esos grupos de } \\
\text { trabajo son mixtos y tratan de estar hombres y mujeres juntos } \\
\text { verdad, más que todo para que se vayan adaptando a que la } \\
\text { sociedad necesita eso verdad, que ambas personas se } \\
\text { relacionen" (E06/B/H) } \\
\text { "Dentro de una de las partes que se trabaja en Seminario hay } \\
\text { nueve ámbitos que se trabajan, y uno de los ámbitos } \\
\text { precisamente es equidad verdad, ahí se trabaja equidad laboral, } \\
\text { de género y social, entonces ahí es donde nosotros lo } \\
\text { fomentamos, hay grupos de Seminario que han trabajado este } \\
\text { tema ya específicamente para su proyecto y cuando nosotros lo }\end{array}$ \\
\hline
\end{tabular}




\begin{tabular}{|c|c|c|c|}
\hline Categoría & $\begin{array}{l}\text { Sub- } \\
\text { categorías }\end{array}$ & Dimensiones exclusoras & Dimensiones transformadoras \\
\hline & & & $\begin{array}{l}\text { damos a conocer a padres de familia y al colegio en general ahí } \\
\text { aprovechamos para de alguna manera hacer un hincapié fuerte, } \\
\text { en que los jóvenes puedan retomar eso y se cambia la } \\
\text { mentalidad" (E07/D/H) } \\
\text { "Yo lo que hago es poner en una fila a las niñas y en otra a los } \\
\text { niños y enumerarlos y al momento de hacer grupos tienen que } \\
\text { quedar los niños con las niñas" (E08/P/M) } \\
\text { "Desde el inicio voy tratando de fomentar esa actitud de } \\
\text { equidad. Barren tanto hombres como mujeres, van a ir a traer } \\
\text { refacción tanto hombres como mujeres, entonces si desde el } \\
\text { inicio cimientas eso ya no tienes complicaciones, pero si inicias } \\
\text { y después quieres cambiar algo ya es muy complicado. } \\
\text { Entonces, esa cotidianidad debe trabajarse desde el inicio, al } \\
\text { menos a mí me ha funcionado" (E09/P/H) } \\
\text { "Cuando los niños vienen a la escuela tienen esa costumbre, se } \\
\text { juntan solo los varones o solo las mujeres, y ahí es en donde } \\
\text { nosotros trabajamos esta equidad donde el trabajo en grupo lo } \\
\text { tienen que hacer entre } 3 \text { niñas y } 3 \text { varones, estamos integrando } \\
\text { varones y mujeres. Los juegos, por ejemplo en educación física, }\end{array}$ \\
\hline
\end{tabular}




\begin{tabular}{|l|l|l|l|}
\hline Categoría & $\begin{array}{l}\text { Sub- } \\
\text { categorías }\end{array}$ & Dimensiones exclusoras & Dimensiones transformadoras \\
\hline & & & $\begin{array}{l}\text { también. Basketbol lo juegan los varones y mujeres. El futbol, } \\
\text { también. A las mujeres también les gusta el futbol y el } \\
\text { basketbol. Porque antes el basketbol es solo para mujeres, el } \\
\text { futbol solo para varones, pero ahora gracias a Dios, ahora no, } \\
\text { con este eje, es un cambio que estamos dando" (E10/P/M) }\end{array}$ \\
\hline
\end{tabular}


De entrevistas comunicativas a madres de alumnado

\begin{tabular}{|c|c|c|c|}
\hline Categoría & Sub-categorías & Dimensiones exclusoras & Dimensiones transformadoras \\
\hline $\begin{array}{l}\text { Agentes } \\
\text { socializadores } \\
\text { de género }\end{array}$ & Familia & & $\begin{array}{l}\text { "Pensamos que la educación no solo es aquí, también es en la } \\
\text { casa, si nosotros la educamos bien, aquí viene bien" (E11/M/M) } \\
\text { "Sí, valen igual [mujeres y hombres], porque en otras } \\
\text { comunidades lejanas no les dan educación a las mujeres, en } \\
\text { nuestro caso, tengo } 3 \text { niñas y a ellas les vamos a dar educación } \\
\text { hasta terminar, hasta donde ellas dejen de estudiar" (E11/M/M) } \\
\text { "Cada familia educamos de diferente forma a nuestros hijos y yo } \\
\text { veo que ahora ya es poquito más amplio que ya es casi la } \\
\text { igualdad, no como antes que había más diferencia, verdad, había } \\
\text { un poquito más de machismo, digámoslo así, pero ahora ya es } \\
\text { diferente" (E11/M/M) }\end{array}$ \\
\hline
\end{tabular}




\begin{tabular}{|c|c|c|}
\hline $\begin{array}{l}\text { Educación } \\
\text { para la } \\
\text { equidad de } \\
\text { género, de } \\
\text { etnia y social }\end{array}$ & Familias / comunidad & $\begin{array}{l}\text { "Yo creo que ahora ya no es un tema de ocultarlo [educación } \\
\text { sexual], ya es amplio y platicarlo bien. Yo ya hablo de todo eso } \\
\text { con mi nena y le digo los cambios que va a tener su cuerpo. Ella } \\
\text { tiene } 9 \text { años pero ya pregunta, ella ya dice mama por qué pasa } \\
\text { esto. Yo creo que es mejor hablarles en casa, ser claros a que } \\
\text { después ellos experimenten de otras formas y por eso pasan las } \\
\text { cosas. Sí, que ellos [maestras y maestros] platiquen también con } \\
\text { ellos" (E12/M/M) }\end{array}$ \\
\hline
\end{tabular}




\subsection{De grupos de discusión comunicativos}

\begin{tabular}{|c|c|c|c|}
\hline Categoría & Sub-categorías & Dimensiones exclusoras & Dimensiones transformadoras \\
\hline $\begin{array}{l}\text { Vertebración } \\
\text { social }\end{array}$ & $\begin{array}{l}\text { Construcción } \\
\text { del género }\end{array}$ & $\begin{array}{l}\text { "Un matrimonio se vuelve un campo de batalla, es } \\
\text { porque uno de los dos no está cumpliendo, supongo, que } \\
\text { si el esposo o la esposa están claros de sus derechos y } \\
\text { obligaciones" (GD01) } \\
\text { "Pude estar en un hogar donde la mujer es la encargada } \\
\text { de servir la comida y el hombre aunque se estuviese } \\
\text { muriendo de hambre, no se levantaba a servir la comida, } \\
\text { porque era una obligación de la mujer hacerlo verdad } \\
\text { [...] Tú no puedes subirte a un árbol [creencia } \\
\text { tradicional sobre las mujeres], por ejemplo verdad, } \\
\text { porque el árbol ya no va a dar fruto" (GD01) } \\
\text { "A un hombre ingeniero le pagan mejor que a una mujer, } \\
\text { pero ingeniero y los dos tienen la capacidad, la } \\
\text { inteligencia y tienen el mismo puesto prácticamente } \\
\text { verdad, pero no hay igualdad" (GD02) } \\
\text { "La mayoría de la nueva generación está enterada lo que } \\
\text { es la equidad de género y sí se sabe pero en la realidad }\end{array}$ & $\begin{array}{l}\text { "El género se ha convertido en una división, la religión y la } \\
\text { cultura yo pienso que ya es el momento de empezar a edificar } \\
\text { y no seguir dividiendo más verdad" (GD01) } \\
\text { "El machismo sobresale en muchas comunidades, en otros } \\
\text { lugares no es el machismo si no el feminismo verdad, como } \\
\text { yo ya tengo derechos como mujeres vamos también a } \\
\text { levantarnos, levantemos nuestro movimiento y se ha vuelto } \\
\text { como un campo de batalla hombres contra mujeres, mujeres } \\
\text { contra hombres y yo siento que en lugar de estar en ese } \\
\text { campo de batalla debemos sentarnos a dialogar y a pensar } \\
\text { miren nuestros derechos como hombres son estos y los } \\
\text { derechos de ustedes como mujeres son estos, y nuestras } \\
\text { obligaciones como hombres son estas y nuestras obligaciones } \\
\text { como mujeres son estas, dialogar y tener en mente que todos } \\
\text { tenemos derechos y tenemos obligaciones" (GD01) } \\
\text { "Tenemos un pensamiento completamente distinto [sobre } \\
\text { roles de género] que culturalmente así no lo han enmarcado } \\
\text { como lo decía [el compañero], eso es muy cierto, pero que }\end{array}$ \\
\hline
\end{tabular}




\begin{tabular}{|c|c|c|c|}
\hline Categoría & Sub-categorías & Dimensiones exclusoras & Dimensiones transformadoras \\
\hline & & $\begin{array}{l}\text { no se practica, en su mayoría yo veo que no se practica } \\
\text { porque siempre hay violencia, violencia física, } \\
\text { discriminación si nos referimos a las mujeres hay } \\
\text { discriminación y pienso que aunque se sepa, se ha leído, } \\
\text { se ve en los medios de comunicación pero no se vive en } \\
\text { la realidad" (GD02) } \\
\text { "Porque a veces también a las mujeres se les deja hacer } \\
\text { y exageran y si vemos en las noticias verdad de que } \\
\text { muchas mujeres de que con esa libertad ellas lo tomaron } \\
\text { como libertinaje y no se dan a respetar y hacen las cosas } \\
\text { que quieren" (GD03) } \\
\text { "Yo trabajo con la adolescencia e intentamos darle el } \\
\text { espacio a la mujer pero la mujer es la misma que cede } \\
\text { ese espacio para que sea el hombre quien protagonice. } \\
\text { Muchas veces la misma mujer como dice la seño tiene } \\
\text { un proceso histórico. Se le da la oportunidad y no lo } \\
\text { asume. Son pocas las patojas mujeres que sí se atreven a } \\
\text { ir rompiendo este paradigma. Entonces yo a lo que voy } \\
\text { es que tendrá que venir también muchas veces de las } \\
\text { mujeres hacia las mismas mujeres" (GD03) }\end{array}$ & $\begin{array}{l}\text { también tiene que ir evolucionando" (GD01) } \\
\text { "Hoy gracias a lo que se ha trabajado y al estimulo que la } \\
\text { mujer tiene, ya hay mujeres que están en puestos altos y que } \\
\text { están dirigiendo varones, eso a veces es difícil de manejar } \\
\text { todavía en algunos estratos sociales, pero que ya se está } \\
\text { dando" (GD01) } \\
\text { "Entonces siento yo que el celo como hombres tenemos que } \\
\text { dejarlo a un lado también, verdad, de que una mujer sea } \\
\text { superior a mí en ámbito académico, en ámbito profesional, } \\
\text { eso como dice el compañero no debe hacerme sentirme } \\
\text { inferior, al contrario verdad, debe ser un reto para mí" } \\
\text { (GD01) } \\
\text { "Si hemos avanzado bastante en que ya gracias a Dios, } \\
\text { muchas de nuestras niñas asisten a la escuela, ya conocen y } \\
\text { ya hay un poquito de igualdad, no la que desearíamos verdad, } \\
\text { pero ya se ha logrado bastante" (GD02) } \\
\text { "Ahorita veo yo a mujeres manejando carros, manejando } \\
\text { motos. Cosa que no se daba antes verdad y también yo estoy }\end{array}$ \\
\hline
\end{tabular}




\begin{tabular}{|c|c|c|c|}
\hline Categoría & Sub-categorías & Dimensiones exclusoras & Dimensiones transformadoras \\
\hline & & $\begin{array}{l}\text { "La igualdad entre hombre y mujer es fundamental para } \\
\text { muchos procesos pero cuando la mujer misma no } \\
\text { aprovecha o no se da ese espacio ahí radica el problema. } \\
\text { Pero yo pienso que eso es una herencia de los padres, es } \\
\text { la ideología familiar, que aún lo llevan” (GD03) } \\
\text { "Yo trabajo con los chiquitos y hasta en los colores se ve } \\
\text { la discriminación. Las niñas manejan un color rojo o } \\
\text { rosado. Los niños un color azul, celeste o verde. Pero no } \\
\text { mezclan esos colores del rosado porque según ellos el } \\
\text { rosado es para niñas y los colores verde, azul son para } \\
\text { varones” (GD03) } \\
\text { "En el caso aquí de la escuela pues yo con mis alumnos } \\
\text { trato de concientizar a las mujeres para que sepamos que } \\
\text { todos tenemos los mismos derechos y por supuesto las } \\
\text { mismas obligaciones. Es un proceso lento, eh, por } \\
\text { supuesto que hay que tener siempre el cuidado porque } \\
\text { existe también la cuestión de que las mujeres también } \\
\text { que existen también mujeres que dominan en el hogar y } \\
\text { hasta manejan a los hombres, entonces, como todo }\end{array}$ & $\begin{array}{l}\text { viendo ahora que ya hay profesionales mujeres en cambio } \\
\text { más antes no habían profesionales mujeres habían más } \\
\text { hombres que mujeres y en cuanto también a la política decía } \\
\text { la compañera, si miramos que los que gobiernan son hombres } \\
\text { a como de lugar, no hay mujeres. Pero, siempre ya están } \\
\text { saliendo algunas candidaturas mujeres, pues yo estoy viendo } \\
\text { que se está tratando la manera de tener igualdad. Gracias al } \\
\text { trabajo de los maestros también que están inculcando en los } \\
\text { niños la igualdad de derechos, verdad" (GD03) } \\
\text { "En mi época si yo recuerdo que nunca busqué a un } \\
\text { muchacho, uno espera que lo buscan a uno, pero ahora ya las } \\
\text { muchachas no les da pena, y ya son ellas las que buscan a los } \\
\text { patojos y nos damos cuenta que ahora ya las muchachas } \\
\text { salen. Antes le dan permiso a uno solo si uno va a acarrear } \\
\text { agua, nada más, ahora ya no, entonces todo se está } \\
\text { cambiando" (GD03) }\end{array}$ \\
\hline
\end{tabular}




\begin{tabular}{|c|c|c|c|}
\hline Categoría & Sub-categorías & Dimensiones exclusoras & Dimensiones transformadoras \\
\hline & & $\begin{array}{l}\text { requiere un equilibrio" (GD03) } \\
\text { "Nos dieron la libertad y utilizamos el libertinaje. En mi } \\
\text { casa hay una oficina jurídica, llegan problemas de que } \\
\text { las mujeres pegan a sus maridos y el hombre no se } \\
\text { defiende por vergüenza pero hay mujeres que exageran y } \\
\text { meten a sus maridos en problemas. A mí me extraña, } \\
\text { entonces yo digo no solo el hombre tiene ese problema } \\
\text { sino que ahora las mujeres también damos lugar a que } \\
\text { haya problema en la familia" (GD03) } \\
\text { "Es una cadena de inequidad de género y discriminación } \\
\text { que trasciende fronteras" (GD04) } \\
\text { "Aquí [Almolonga] las mujeres se sientan a parte y los } \\
\text { varones se sientan a parte o sea no pueden estar juntos. } \\
\text { Eso lo hemos trabajado al menos aquí en mi aula poco a } \\
\text { poco, cuando vamos a física o vamos alguna actividad, } \\
\text { nosotros colocamos aquí a los niños, una niña y un niño } \\
\text { agarrados de la mano, para que ellos aprendan a convivir } \\
\text { con el género opuesto verdad, entonces se colocan, al } \\
\text { principio no se toman de la mano [...] pero es algo que }\end{array}$ & \\
\hline
\end{tabular}




\begin{tabular}{|c|c|c|c|}
\hline Categoría & Sub-categorías & Dimensiones exclusoras & Dimensiones transformadoras \\
\hline & & $\begin{array}{l}\text { no podrían hacer afuera tampoco, porque sería marcado } \\
\text { como algo malo, no es correcto, entonces la } \\
\text { discriminación se maneja por cuestiones más de } \\
\text { costumbre [...] costumbres que hacen daño porque } \\
\text { entonces cuando salimos al mundo nos dan pena muchas } \\
\text { cosas que para el mundo es natural, pero para nosotros } \\
\text { no" (GD04) } \\
\text { "Y usted por qué le permitió que le pegara [su hijo, } \\
\text { niño], usted es la mamá... es que como mira lo que hace } \\
\text { el papá, seño" (GD03) } \\
\text { "Es prohibido que digamos que se tiende la ropa del } \\
\text { varón con la ropa de la mujer. Es aparte, hay que lavar la } \\
\text { ropa del hombre y aparte hay que lavar la ropa de la } \\
\text { mujer, hay que asolearlo aparte. Hay que, cuidado, que a } \\
\text { veces juegan las niñas y los niños, verdad y a veces una } \\
\text { niña saltea a un niño y dicen, eso es pecado, no hay que } \\
\text { hacer eso. A veces hablan del corte de la mujer, dicen } \\
\text { ellos que no, que no encuentre la ropa del hombre, la } \\
\text { ropa de la mujer, el corte pues" (GD03) } \\
\text { "Yo a veces he escuchado en familias que la mamá al }\end{array}$ & \\
\hline
\end{tabular}




\begin{tabular}{|c|c|c|c|}
\hline Categoría & Sub-categorías & Dimensiones exclusoras & Dimensiones transformadoras \\
\hline & & $\begin{array}{l}\text { educar a los chiquitos, como los niños pegan, dicen: } \\
\text { todos los hombres son así. Entonces las niñas ya se van } \\
\text { metiendo eso en la cabeza, eso de que los hombres son } \\
\text { así. No es así, todos tienen los mismos derechos, } \\
\text { igualdad" (GD03) } \\
\text { "Yo he participado en la iglesia evangélica y en la } \\
\text { iglesia católica. Se apartan todas las mujeres y todos los } \\
\text { hombres... rara vez cuando van en pareja se sientan } \\
\text { hombres y mujeres. Pero cuando van solos, solo es el } \\
\text { hombre y solo la mujer" (GD03) } \\
\text { "Esto lo trae la cultura occidental porque este tema de } \\
\text { discriminación es bíblico, la cabeza de la familia es el } \\
\text { hombre y eso es bíblico, y la mujer tienen que estar } \\
\text { sumisa al marido, eso es bíblico. Entonces de dónde } \\
\text { viene la religión, retrocedamos un poquito, lo trajeron } \\
\text { los españoles. Porque si usted no hacía el padre nuestro } \\
\text { usted era fusilado, entonces la religión es una cuestión } \\
\text { impuesta" (GD03) }\end{array}$ & \\
\hline & $\begin{array}{l}\text { Pertenencia } \\
\text { étnica }\end{array}$ & $\begin{array}{l}\text { "Sí existe la discriminación. Nuestro país es totalmente } \\
\text { indígena. Españoles así ladinos tal vez hay un } 30 \% \text { y un }\end{array}$ & $\begin{array}{l}\text { "Una persona de Quetzaltenango había peleado una demanda } \\
\text { internacional porque no lo dejaron entrar a un restaurante, por }\end{array}$ \\
\hline
\end{tabular}




\begin{tabular}{|c|c|c|c|}
\hline Categoría & Sub-categorías & Dimensiones exclusoras & Dimensiones transformadoras \\
\hline & & $\begin{array}{l}\text { 70\% indígena. Ya ahí si nos vamos más localmente } \\
\text { nuestra comunidad es netamente indígena, pero ahí sí } \\
\text { que, cómo combatir esto, llevaría mucho tiempo" } \\
\text { (GD04) } \\
\text { "Los de Xela discriminan a tal municipio, el otro } \\
\text { municipio discrimina a otro, a no, que yo soy de Toto, } \\
\text { que se discriminan... total que es como un cáncer que no } \\
\text { se puede curar" (GD04) }\end{array}$ & $\begin{array}{l}\text { llevar el traje típico" (GD04) } \\
\text { "Por ejemplo entre indígenas y ladinos, yo me recuerdo que } \\
\text { años atrás habían muchas situaciones en las que las personas } \\
\text { indígenas no podían entrar a estudiar, vean a ustedes ahora } \\
\text { ellos ya se han superado un montón ya tienen el poderío } \\
\text { también, ya han cambiado" (GD02) } \\
\text { "Qué mundo le vamos a dejar a nuestros hijos si no } \\
\text { aprendemos a convivir en equidad y no discriminar a las } \\
\text { personas, que va a pasar entonces, esa es una situación que } \\
\text { debemos concientizar a las personas como decíamos desde } \\
\text { pequeños, pero también concientizar a las personas grandes } \\
\text { para que ayuden al proceso para que se logre y camine" } \\
\text { (GD04) }\end{array}$ \\
\hline & Clase social & $\begin{array}{l}\text { "Inclusive ya a nivel de países, países con países, nación } \\
\text { con nación, también sigue [la discriminación]" (GD04) } \\
\text { "Yo soy rico y aquí están los ricos y aquí están los } \\
\text { pobres" (GD04) } \\
\text { "Cuando uno va a las instituciones hay fila lo atienden }\end{array}$ & \\
\hline
\end{tabular}




\begin{tabular}{|c|c|c|c|}
\hline Categoría & Sub-categorías & Dimensiones exclusoras & Dimensiones transformadoras \\
\hline & & $\begin{array}{l}\text { más rápido a una persona de clase social alta en } \\
\text { comparación de un indígena que va ahí, como que lo } \\
\text { ignoran, no lo atienden" (GD04) } \\
\text { "Más lo vemos en las instituciones, cuando uno tiene } \\
\text { que hacer tramites, entonces uno ahí se da cuenta de que } \\
\text { aun existe, ya sea por el traje de las personas, ya sea } \\
\text { porque son ladinas o clase social o van presentables, } \\
\text { entonces si siempre existe esa discriminación y falta de } \\
\text { equidad de género al momento que uno va a la ciudad" } \\
\text { (GD04) } \\
\text { "Se marca en que nosotros los mismos indígenas nos } \\
\text { discriminamos, o sea que no es necesario que venga } \\
\text { alguien de afuera para discriminarnos, sino nosotros } \\
\text { mismos marcamos esa situación ya sea por cuestiones de } \\
\text { ideales, cuestiones económicas o académicas también, } \\
\text { hasta incluso de salud" (GD04) } \\
\text { "Incluso hasta en salud porque hay clínicas que son } \\
\text { especiales para personas de alto nivel, clínicas para } \\
\text { personas de nivel medio y el puesto de salud que es a }\end{array}$ & \\
\hline
\end{tabular}




\begin{tabular}{|c|c|c|c|}
\hline Categoría & Sub-categorías & Dimensiones exclusoras & Dimensiones transformadoras \\
\hline & & $\begin{array}{l}\text { donde vamos todos verdad ahí revueltos todos, verdad" } \\
\text { (GD04) } \\
\text { "A nivel de iglesias también hay discriminación, esa es } \\
\text { una situación en la que el niño está acostumbrado a vivir } \\
\text { ya que es parte de su entorno, de que ellos saben de que } \\
\text { la tal iglesia son los de más dinero, la tal iglesia ahí solo } \\
\text { van los pobrecitos, los que no dan diezmo" (GD04) }\end{array}$ & \\
\hline & $\begin{array}{l}\text { Concepción de } \\
\text { equidad en la } \\
\text { cultura maya }\end{array}$ & & $\begin{array}{l}\text { "Vayamos al tema de la cultura maya. Yo sostengo que } \\
\text { existen muchas debilidades de la cultura pero también } \\
\text { muchas cosas que hay que rescatar. Por ejemplo cuando } \\
\text { hablamos de tzacol y bitol, estamos hablando de dios hombre } \\
\text { y dios mujer" (GD03) } \\
\text { "Desde la creación se habla de la creación del hombre con la } \\
\text { abuela Ixmukane, está haciendo un papel fundamental en ese } \\
\text { proceso" (GD03) } \\
\text { "Mi hijo estuvo con esta maestra y les decía lo del awas, lo } \\
\text { que es pecado, y esto venía de los abuelos, y entonces ella les } \\
\text { hablaba del popol vuj, los mandó a leer, y los niños van } \\
\text { cambiando, yo miraba a mi hijo y él me explicaba del awas, }\end{array}$ \\
\hline
\end{tabular}




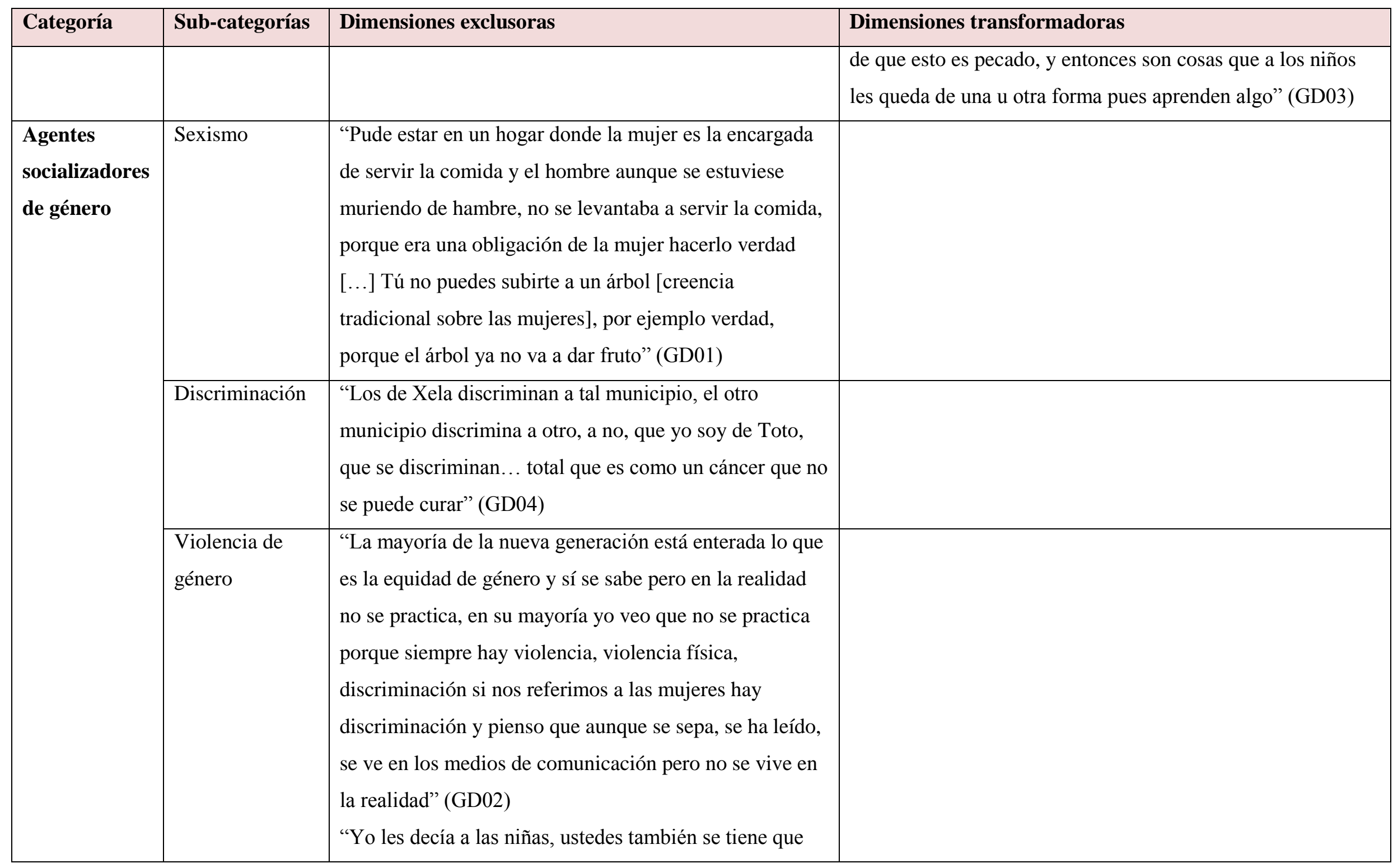




\begin{tabular}{|c|c|c|c|}
\hline Categoría & Sub-categorías & Dimensiones exclusoras & Dimensiones transformadoras \\
\hline & & $\begin{array}{l}\text { valorar, se tienen que dar a respetar, porque un varón } \\
\text { llega hasta donde la mujer le permite. Si en mi casa a mí } \\
\text { me pegan es porque yo así lo he permitido. Porque si } \\
\text { cuando levantó la mano lo detengo, pues el hombre } \\
\text { también se va a acostumbrar a respetar a la esposa } \\
\text { porque hay casos que son así, hay señores que maltratan } \\
\text { a sus esposas hasta dejarlas moradas porque ellas así lo } \\
\text { han querido" (GD03) } \\
\text { "Otro agente socializador, en la tecnología el niño tiene } \\
\text { su facebook y tiene amigos de todo el mundo y participa } \\
\text { con sus amigos de una forma igual, amigo-amiga porque } \\
\text { no hay un contacto directo [...] muchas veces las niñas } \\
\text { caen en errores muy grandes como lo son acosos } \\
\text { sexuales en internet o de maltrato en internet verdad y en } \\
\text { el caso de las mujeres no denuncian porque es una } \\
\text { vergüenza, en el caso de los varones tampoco denuncian } \\
\text { por que también es una vergüenza” (GD04) }\end{array}$ & \\
\hline & Valores & $\begin{array}{l}\text { "Viera que también hay niños que también se } \\
\text { transforman negativamente en la escuela. Cuando traen } \\
\text { principios y valores, entonces como que la escuela } \\
\text { pensándolo bien, de algún modo tiene incidencia. He }\end{array}$ & \\
\hline
\end{tabular}




\begin{tabular}{|c|c|c|c|}
\hline Categoría & Sub-categorías & Dimensiones exclusoras & Dimensiones transformadoras \\
\hline & & $\begin{array}{l}\text { visto casos de gente que viene bien formada, pero como } \\
\text { que lo malo pega más rápido y ya regresan alguna vez en } \\
\text { una mentalidad distinta, que no es necesariamente en el } \\
\text { aula, es precisamente en el espacio de recreo o de otro } \\
\text { lugar” (GD03) }\end{array}$ & \\
\hline & & $\begin{array}{l}\text { "Me he dado cuenta de que el género influye mucho en } \\
\text { la vida de las personas. En el tiempo en que yo estaba } \\
\text { estudiando y era niña a mis papás les decían que las } \\
\text { niñas eran para la casa, que no estudiaran. Mi papá luchó } \\
\text { un poco contra la corriente de esa situación y nos dio }\end{array}$ & \\
\hline
\end{tabular}




\begin{tabular}{|c|c|c|c|}
\hline Categoría & Sub-categorías & Dimensiones exclusoras & Dimensiones transformadoras \\
\hline & & estudio"(GD04) & \\
\hline & Escuela & $\begin{array}{l}\text { "Le digo e insisto de que la base es el hogar, sigue la } \\
\text { escuela, sigue la sociedad" (GD01) } \\
\text { "Yo pienso que la escuela tiene un papel secundario. No } \\
\text { es el espacio principal para este tipo de } \\
\text { transformaciones. Porque se mira bien en la actitud de } \\
\text { los niños, que eso ya lo traen. Por ejemplo, solo un } \\
\text { ejemplo, la refacción. Yo les digo, bueno chicos ahora } \\
\text { les toca. No profe, nosotras" (GD03) } \\
\text { "Es un proceso que yo pienso que la escuela puede } \\
\text { ayudar a un cambio, ayudar, pero de que lo haga, } \\
\text { cambiar de la noche a la mañana, tal vez es un poco } \\
\text { problemático. Se puede trabajar, se puede inculcar, pero } \\
\text { cuesta que se rompan esos paradigmas, porque media } \\
\text { vez es una costumbre, dice que la costumbre se vuelve } \\
\text { ley" (GD03) } \\
\text { compañera o un compañero. Todos somos iguales, pero } \\
\text { ahí tenemos el rollo de que nosotros [maestros] también }\end{array}$ & $\begin{array}{l}\text { "Si yo como hombre creo que no me conviene que las } \\
\text { mujeres manden o que sean iguales a mí, no lo voy a } \\
\text { reproducir, lo puedo ignorar, pero el tema es demasiado } \\
\text { amplio y desde el CNB sí está y en la mayoría de lo que yo } \\
\text { conozco sí se impulsa ese tema" (GD03) } \\
\text { "Si desde chiquitos se empieza a sembrar, cuando salgan de } \\
\text { la Primaria yo sí pienso que no los vamos a cambiar de la } \\
\text { noche a la mañana, pero más o menos hay un cambio. Con } \\
\text { respecto a hacer limpieza yo he visto muchas veces que los } \\
\text { varoncitos como que sí les cuesta: nooo tienen manos, así que } \\
\text { a agarrar la escoba, agarrar la cubeta... todos tenemos que } \\
\text { colaborar" (GD03) } \\
\text { "El agente principal, después de la familia, es la escuela, es el } \\
\text { mayor espacio y tiempo que el niño esta socializado, con un } \\
\text { grupo diferente al que el está acostumbrado" (GD04) }\end{array}$ \\
\hline
\end{tabular}




\begin{tabular}{|c|c|c|c|}
\hline Categoría & Sub-categorías & Dimensiones exclusoras & Dimensiones transformadoras \\
\hline & & $\begin{array}{l}\text { somos partícipes, no culpables, partícipes de esa } \\
\text { situación" (GD03) } \\
\text { "El futuro está en los niños pero lo malo es que unos } \\
\text { somos conscientes y tratamos de cambiar a los niños, } \\
\text { pero ya llegando en la casa ya es... ya no, ya no hay } \\
\text { continuación de lo que nosotros estamos tratando de } \\
\text { hacer" (GD04) } \\
\text { "Vienen los niños y hay niños que le roban al corazón a } \\
\text { uno [maestra] y esa es una discriminación, porque el que } \\
\text { viene más feíto, viene mas shuquito, también tiene } \\
\text { corazón, pero como a mí me robo el corazón el otro, yo } \\
\text { beso y abrazo al que a mí me gusta, pero qué pasa con el } \\
\text { niño pequeño que necesita de cariño y necesita la misma } \\
\text { atención que el niño que viene perfumadito y cambiado" } \\
\text { (GD04) }\end{array}$ & \\
\hline & Familia & $\begin{array}{l}\text { "La familia siento yo que juega el papel, si no el más } \\
\text { importante pero donde pesa aún más la formación de la } \\
\text { persona, como maestros solo venimos a tratar de } \\
\text { modificar algunas cosas que están marchando mal o } \\
\text { querer quizás modificar el modelo. Pero ya los primeros }\end{array}$ & $\begin{array}{l}\text { "La base fundamental son los primeros años de vida con la } \\
\text { que uno crece en la casa, en el hogar, como le enseñan a uno } \\
\text { a tratar a la persona opuesta a su género verdad?" (GD01) } \\
\text { "Nosotros mismos desde ahorita como padres de familia, } \\
\text { para poder ya eliminar en sí y romper el hielo de esta }\end{array}$ \\
\hline
\end{tabular}




\begin{tabular}{|c|c|c|c|}
\hline Categoría & Sub-categorías & Dimensiones exclusoras & Dimensiones transformadoras \\
\hline & & $\begin{array}{l}\text { años de vida están hechos, en los primeros añitos de vida } \\
\text { se grabó todo verdad y es difícil que se borre algo, que } \\
\text { se modifique algo" (GD01) } \\
\text { "Le digo e insisto de que la base es el hogar, sigue la } \\
\text { escuela, sigue la sociedad" (GD01) } \\
\text { "Pude estar en un hogar donde la mujer es la encargada } \\
\text { de servir la comida y el hombre aunque se estuviese } \\
\text { muriendo de hambre, no se levantaba a servir la comida, } \\
\text { porque era una obligación de la mujer hacerlo verdad } \\
\text { [...] Tú no puedes subirte a un árbol [creencia } \\
\text { tradicional sobre las mujeres], por ejemplo verdad, } \\
\text { porque el árbol ya no va a dar fruto" (GD01) } \\
\text { "Cuando una niña es entrada a pedir a corta edad el } \\
\text { orgullo es para los padres, porque híjole se fijaron en mi } \\
\text { hija desde chiquitia... entonces la niña se ve en la } \\
\text { necesidad de decir, bueno yo soy el orgullo de mis papas } \\
\text { y me voy a casar y a qué conlleva esto, a una vida } \\
\text { infeliz, una vida sin sentimientos, una vida con } \\
\text { responsabilidades que no le corresponden, porque lo }\end{array}$ & $\begin{array}{l}\text { situación de que solo el varón puede realizar las cosas, sino } \\
\text { de que también la mujer es capaz de realizarlo" (GD01) } \\
\text { "Hay algunas familias que tratan la manera de ayudar a la } \\
\text { esposa y el esposo a la esposa como trabajo en equipo ayuda } \\
\text { mutua entre ellos pero, solo... son raros, entonces yo me doy } \\
\text { cuenta que sí, la preparación académica les ayuda mucho a } \\
\text { que ellos formen un buen hogar a que ellos traten la manera } \\
\text { de tener igualdad" (GD03) } \\
\text { "La familia, la iglesia, la sociedad, la escuela" (GD03) } \\
\text { "Entonces, si queremos que haya un cambio, nosotras como } \\
\text { mujeres, nosotras como maestras, como madres de familia } \\
\text { tenemos que darnos a respetar porque si no lo hacemos } \\
\text { nosotras quién lo va a hacer... si nosotros queremos cambiar } \\
\text { no para gobernar la casa tampoco. En la familia debe haber } \\
\text { igualdad, hombre y mujer educar a los hijos, cambiar el pañal } \\
\text { a los hijos, tiene que ser equitativo el trabajo, pues" (GD03) } \\
\text { "Mis hermanos ellos hacen de todo, ellos pueden hacer de } \\
\text { todo porque así les enseñaron cuando ellos crecieron, en el }\end{array}$ \\
\hline
\end{tabular}




\begin{tabular}{|c|c|c|c|}
\hline \multirow[t]{5}{*}{ Categoría } & Sub-categorías & Dimensiones exclusoras & Dimensiones transformadoras \\
\hline & & $\begin{array}{l}\text { primero que vienen después del matrimonio, son los } \\
\text { niños y esos niños que tienen papas inmaduros" (GD04) }\end{array}$ & $\begin{array}{l}\text { caso de ellos son mayores, son hombres pero ellos si saben } \\
\text { hacer la labor de una mujer y la labor de un hombre en este } \\
\text { caso" (GD04) }\end{array}$ \\
\hline & Comunidad & & $\begin{array}{l}\text { "Cuando existe [oportunidad de participación para mujeres] } \\
\text { es de aprovechar verdad y de seguir fortaleciendo en ese } \\
\text { sentido, en cualquier ámbito, ya sea en lo educativo o en lo } \\
\text { religioso o en alguna organización donde nosotros podamos } \\
\text { participar o podamos llegara... poder llegar y dar nuestras } \\
\text { opiniones verdad" (GD01) } \\
\text { "En el hogar y la escuela, ah, pero también en la sociedad" } \\
\text { (GD02) }\end{array}$ \\
\hline & $\begin{array}{l}\text { Medios } \\
\text { comunicación }\end{array}$ & $\begin{array}{l}\text { "El área urbana tiene mucho potencial en ese aspecto, } \\
\text { tiene mucho acceso a muchas vías de comunicarse } \\
\text { verdad, radio televisión, Internet, teléfono, celular y por } \\
\text { ese medio entra mucha información y perjudica en algún } \\
\text { momento los programas que ven verdad” (GD01) } \\
\text { "Los medios de comunicación influencian en las áreas } \\
\text { urbanas, pero el área urbana es muchas veces influencia } \\
\text { para el área rural” (GD01) }\end{array}$ & $\begin{array}{l}\text { "La juventud ahora es muy distinta, por supuesto que tiene } \\
\text { sus propios rollos, verdad, que sería otro tema de discusión, } \\
\text { pero la mayoría lo está practicando. Y no es necesariamente } \\
\text { trabajo de la escuela. Quizá ha habido contribución, pero los } \\
\text { medios de comunicación y todo eso también han servido para } \\
\text { cambiar esa mentalidad a la juventud" (GD03) }\end{array}$ \\
\hline & & "Otro agente socializador, en la tecnología el niño tiene & \\
\hline
\end{tabular}




\begin{tabular}{|c|c|c|c|}
\hline Categoría & Sub-categorías & Dimensiones exclusoras & Dimensiones transformadoras \\
\hline & & $\begin{array}{l}\text { su facebook y tiene amigos de todo el mundo y participa } \\
\text { con sus amigos de una forma igual, amigo-amiga porque } \\
\text { no hay un contacto directo [...] muchas veces las niñas } \\
\text { caen en errores muy grandes como lo son acosos } \\
\text { sexuales en internet o de maltrato en internet verdad y en } \\
\text { el caso de las mujeres no denuncian porque es una } \\
\text { vergüenza, en el caso de los varones tampoco denuncian } \\
\text { por que también es una vergüenza" (GD04) }\end{array}$ & \\
\hline & Religión & $\begin{array}{l}\text { "Yo lo observo en la vida religiosa y en la vida social } \\
\text { hay muchos hombres todavía practicando machismo eso } \\
\text { influyo bastante también de que a la mujer no se le deja } \\
\text { hacer lo que quiere hacer y ya sabemos ahora pues de } \\
\text { que si hay igualdad tanto mujer como hombre tiene su } \\
\text { derecho a hablar, opinar o hacer lo que quiere verdad } \\
\text { siempre y cuando equilibrado" (GD03) }\end{array}$ & $\begin{array}{l}\text { "Yo pienso que en las iglesias seria una fuente muy } \\
\text { importante de como socializar géneros y también erradicar la } \\
\text { discriminación que es la más complicada" (GD04) } \\
\text { "En casi todos los niveles y si hay que trabajar muchísimo } \\
\text { verdad, hay que iniciar la inclusión en las escuelas, } \\
\text { instituciones, empresas e iglesias también" (GD04) }\end{array}$ \\
\hline $\begin{array}{l}\text { Educación } \\
\text { para la } \\
\text { equidad de } \\
\text { género, etnia } \\
\text { y social }\end{array}$ & $\begin{array}{l}\text { Eje de equidad } \\
\text { de género, de } \\
\text { etnia y social del } \\
\text { CNB }\end{array}$ & $\begin{array}{l}\text { "Normalmente nos inclinamos dentro de la } \\
\text { planificación, si queremos tocar algún punto, en tocar } \\
\text { conocimientos, en tocar temas que se tienen que } \\
\text { impartir, metodologías muchas veces para impartir a los } \\
\text { jóvenes, tiempos incluso, actividades, recursos, pero en } \\
\text { el tema de equidad muchas veces no vamos a la parte }\end{array}$ & $\begin{array}{l}\text { "Tenemos en nuestras manos, el hacer que nuestras clases } \\
\text { estén involucradas también lo que son las ejes que el } \\
\text { curriculum nos indica, porque ya sabemos verdad que el } \\
\text { curriculum nos da la característica de ser flexibles, por lo } \\
\text { tanto nosotros como docentes debemos de involucrar } \\
\text { contenidos que tengan que ver con lo que... o tenga que }\end{array}$ \\
\hline
\end{tabular}




\begin{tabular}{|c|c|c|c|}
\hline Categoría & Sub-categorías & Dimensiones exclusoras & Dimensiones transformadoras \\
\hline & & $\begin{array}{l}\text { práctica esto verdad y es algo que de alguna manera tal } \\
\text { vez sí se hace, pero no metodológicamente dentro del } \\
\text { plan" (GD01) } \\
\text { "Hay un poquito de desinformación y desbalance en la } \\
\text { situación esa de ponernos de acuerdo, realmente que } \\
\text { objetivos tiene el CNB, o sea si está bien tiene todo } \\
\text { nuestro trabajo, todo lo que tenemos que hacer, el } \\
\text { problema es entenderlo, saberlo llevar y encadenarlo } \\
\text { como realmente debe trabajarlo" (GD04) }\end{array}$ & $\begin{array}{l}\text { fomentar lo que es la equidad de género" (GD01) } \\
\text { "Desde la Pre-Primaria es la base fundamental para } \\
\text { fomentarles ese eje de que todos somos los mismos, todos } \\
\text { valemos por igual y ahí vamos a ver lo que es la realidad, } \\
\text { identidad de género" (GD01) } \\
\text { "No hay necesidad de que esté [eje del CNB], aun cuando no } \\
\text { venía lo hemos aplicado, toda la vida lo hemos aplicarlo. } \\
\text { Incluso que surgió cuando se firmaron los acuerdos de paz } \\
\text { verdad, se reforzó en el CNB pero nosotros ya lo } \\
\text { aplicábamos ahorita ya le están dando más énfasis. Para } \\
\text { nosotros no es nuevo, siempre lo hemos aplicado en } \\
\text { diferentes áreas" (GD02) } \\
\text { "Pues el CNB nos exige y también nosotros tenemos que } \\
\text { poner de nuestra parte para ayudar porque de repente las } \\
\text { personas quieren cambiar pero hay mucho desconocimiento, } \\
\text { entonces ese es el rol de nosotros como maestras, ver qué } \\
\text { hacer" (GD03) }\end{array}$ \\
\hline
\end{tabular}




\begin{tabular}{|c|c|c|c|}
\hline Categoría & Sub-categorías & Dimensiones exclusoras & Dimensiones transformadoras \\
\hline & & & $\begin{array}{l}\text { género, de etnia y social] eso es una ventaja, porque no } \\
\text { estuviera incluido como eje, fuera un curriculum nada más, } \\
\text { un fantasma que pareciera de vez en cuando ahí, en cambio al } \\
\text { estar incluido en el CNB ya es una ventaja porque forci- } \\
\text { voluntariamente todos tenemos que trabajar" (GD04) }\end{array}$ \\
\hline & $\begin{array}{l}\text { Compromiso de } \\
\text { maestras y } \\
\text { maestros }\end{array}$ & & $\begin{array}{l}\text { "En el caso del Básico y Diversificado, como lo manifestaba } \\
\text { lamentablemente no tenemos toda la mañana con ellos verdad } \\
\text { o toda la tarde con ellos, si no que son episodios, momentos } \\
\text { nada más los cuales podemos compartir, pero sin embargo }\end{array}$ \\
\hline
\end{tabular}




\begin{tabular}{|c|c|c|c|}
\hline Categoría & Sub-categorías & Dimensiones exclusoras & Dimensiones transformadoras \\
\hline & & & $\begin{array}{l}\text { esos minutos de nuestra estancia en el salón de clases es un } \\
\text { compromiso nuestro poder involucrar a los dos géneros" } \\
\text { (GD01) }\end{array}$ \\
\hline & $\begin{array}{l}\text { Gerencia del } \\
\text { sistema } \\
\text { educativo }\end{array}$ & $\begin{array}{l}\text { "Nuestro sistema enmarcó verdad, las diferencias, hay } \\
\text { carreras específicamente dirigidas hacia varones y hay } \\
\text { carreras dirigidas específicamente para hombres. Creo } \\
\text { que se tiene que hacer ya un rompimiento en cuanto a } \\
\text { ese sistema” (GD01) } \\
\text { "En el Básico a veces conformamos lo que son juntas } \\
\text { directivas de aula, y así como decían, a veces solo los } \\
\text { hombres valoran, ahora vienen muchas veces que se } \\
\text { propone a la mujer, pero a veces la mujer también no lo } \\
\text { quiere aceptar, yo veo que ese es un error también que la } \\
\text { mujer hace [...](GD01) } \\
\text { “Cuando me tocan los temas de la mujer y todo esto lo } \\
\text { abordo, pero en la práctica no lo hago, no lo quiero ver, } \\
\text { trato, pero es complicado. Yo siento que lo que estamos } \\
\text { haciendo son esfuerzos separados. Y que debería haber } \\
\text { un eje o una política institucional” (GD03) }\end{array}$ & $\begin{array}{l}\text { "El CNB en si es interesante el eje que tiene de equidad de } \\
\text { género, es realmente importante, al menos nos ayuda no a } \\
\text { cumplirlo al cien por cien, es un tanto difícil, pero yo siento } \\
\text { de que nos ayuda al menos a contribuir con un granito de } \\
\text { azúcar, pero al final es un poquito más interesante que los } \\
\text { curriculistas, los que apoyaron a esta situación, den un } \\
\text { poquito más de ampliación a lo que ellos pensaron querer } \\
\text { lograr para que nosotros los docentes entendamos cual es el } \\
\text { objetivo principal” (GD04) } \\
\text { "Yo me recuerdo cuando estudié el Básico, los consejos } \\
\text { estudiantiles debían ser formados por hombres, no por } \\
\text { mujeres y si en caso había una mujer, pero que estuviera de } \\
\text { vocal, verdad, que estuviera de última” [referido a que } \\
\text { actualmente ha cambiado la situación] (GD01) } \\
\text { "La escuela con participación de mujer y hombre, } \\
\text { involucramiento también de mujer y hombre verdad, donde la } \\
\text { mujer opine, donde el hombre opine y donde sean tomados }\end{array}$ \\
\hline
\end{tabular}




\begin{tabular}{|c|c|c|c|}
\hline Categoría & Sub-categorías & Dimensiones exclusoras & Dimensiones transformadoras \\
\hline & & $\begin{array}{l}\text { "El problema ha sido de que el ministerio ha estado } \\
\text { cambiando de capacitadores, viene un capacitador y nos } \\
\text { dice una cosa, viene otro capacitador y nos dice otra } \\
\text { cosa y en fin, o sea han cambiado mucho los términos, } \\
\text { aunque el CNB sea la misma estructura o la misma base. } \\
\text { No se ha tomado de la misma manera, o sea que cada } \\
\text { quien ha jugado un poquito el teléfono descompuesto, } \\
\text { verdad" (GD04) }\end{array}$ & $\begin{array}{l}\text { en cuenta sus opiniones, es soñar con una escuela ideal" } \\
\text { (GD01) } \\
\text { "Cuando realmente se practica la equidad de género ve algo } \\
\text { hermoso, bonito, porque imaginémonos en las aulas de hogar } \\
\text { o de artes industriales actualmente, se ve lindo, se ve } \\
\text { emocionante como ver a un niño o a un jovencito agarrando } \\
\text { una olla, un sartén, lavando alguna fruta [...] y también se ve } \\
\text { bonito ver a una señorita, agarrando el serrucho, el martillo, } \\
\text { para hacer algún material o algún objeto que aunque nos han } \\
\text { dicho que solo el hombre lo podía hacer" (GD01) } \\
\text { "Yo pensaría que un agente principal o que tendría más peso, } \\
\text { seria por ejemplo el ministerio de educación ya que si el } \\
\text { impulsara nuevos proyectos o programas para apoyar tanto a } \\
\text { los maestros como a las comunidades tanto indígenas" } \\
\text { (GD04) }\end{array}$ \\
\hline
\end{tabular}




\begin{tabular}{|c|c|c|c|}
\hline Categoría & Sub-categorías & Dimensiones exclusoras & Dimensiones transformadoras \\
\hline & & & $\begin{array}{l}\text { caminos para fortalecer la educación de los niños" (GD04) } \\
\text { "Tenemos que comenzar nosotros [maestras y maestros] } \\
\text { mismos también verdad porque nadie puede dar lo que no } \\
\text { tiene verdad y si no tenemos una visión amplia de lo que } \\
\text { queremos no podemos exigirle a nadie verdad, pero si es } \\
\text { importante en la educación manejar la situación de equidad" } \\
\text { (GD04) } \\
\text { "Entonces aquí yo siento que la carrera [magisterio Pre- } \\
\text { Primaria] no se trata de mujeres, porque al final hombres y } \\
\text { mujeres hemos sido creados con ese merito con esa facultad } \\
\text { de ayudarnos los seres humanos unos a otros pues" (GD04) } \\
\text { "Pero si aún el ministerio de educación no le ha dado mucho } \\
\text { énfasis a este tema [equidad de género], pues yo considero } \\
\text { que tal vez retomarlo nosotros [maestros], ahí si que darle un } \\
\text { poquito más de espacio a esta situación y de esa manera } \\
\text { nosotros poder contribuir a erradicar lo que es todo este } \\
\text { tema" (GD04). }\end{array}$ \\
\hline & $\begin{array}{l}\text { Familias / } \\
\text { comunidad }\end{array}$ & & $\begin{array}{l}\text { "Si se logra implementar la escuela de padres, yo digo que sí } \\
\text { se puede lograr un cambio mucho más acelerado, tal vez a }\end{array}$ \\
\hline
\end{tabular}




\begin{tabular}{|c|c|c|c|}
\hline Categoría & Sub-categorías & Dimensiones exclusoras & Dimensiones transformadoras \\
\hline & & & $\begin{array}{l}\text { unos } 30 \text { a } 40 \text { años" (GD01) } \\
\text { "Sin ofender a ningún compañero pero considero y pregunto } \\
\text { si ellos en algún momento han incumplido con sus } \\
\text { obligaciones como esposos o padres y si mejor aún conocen, } \\
\text { verdad para ir formando un cambio en esto, también hay que } \\
\text { dialogar y formar a los padres de familia para que este } \\
\text { resultado, como lo vuelvo a repetir no es a corto plazo, puede } \\
\text { ser un resultado de varias poblaciones" (GD01) } \\
\text { "Yo llevo } 6 \text { años trabajando, cuando empecé tenía } 8 \text { alumnos, } \\
\text { de los } 8 \text { solo } 2 \text { mujeres y } 6 \text { varones, se veía eso verdad, } \\
\text { conforme uno de maestro fue inculcándoles a los padres de } \\
\text { familia la importancia de que mandaran a las niñas a la } \\
\text { escuela, la importancia de que era de prepararse a la mujer yo } \\
\text { pienso que ahí también, uno cambia" (GD02) } \\
\text { "Lo que miro es que lo que si necesitamos aquí en nuestra } \\
\text { comunidad de Pachaj es mucha sensibilización, capacitación } \\
\text { a madres y padres de familia porque a madres siempre } \\
\text { hablamos con ellas y todo" (GD03) }\end{array}$ \\
\hline
\end{tabular}




\begin{tabular}{|c|c|c|c|}
\hline Categoría & Sub-categorías & Dimensiones exclusoras & Dimensiones transformadoras \\
\hline & & & $\begin{array}{l}\text { "Lo importante es programar pláticas de orientación a madres } \\
\text { y padres de familia, de repente un día con mamás, otros con } \\
\text { papás, eso es lo malo que los papás casi no llegan" (GD03) }\end{array}$ \\
\hline & $\begin{array}{l}\text { Actividades } \\
\text { concretas } \\
\text { relacionadas con } \\
\text { educación para } \\
\text { la equidad }\end{array}$ & $\begin{array}{l}\text { "Nosotros ya lo hemos implementado, nosotros lo } \\
\text { implementamos [la escuela de padres] hasta hemos } \\
\text { hecho nuestro plan de trabajo, estructuramos los temas y } \\
\text { si es difícil por que estudiamos los temas, los damos a } \\
\text { conocer y muchas veces para que llegaran los papas } \\
\text { tuvimos que gestionar refacciones" (GD01) } \\
\text { "En mi caso yo les digo si pasan primero los hombres, } \\
\text { calzón y chongo les voy a poner y se quedan quietos, } \\
\text { ninguno pasa y todas las mujeres pasan, al principio para } \\
\text { enseñarles que deben darle su espacio a las damas, } \\
\text { porque aparte es la liberación femenina y aparte es la } \\
\text { educación verdad" (GD02) } \\
\text { "Yo muchas veces les digo a los niños: bueno, ahorita sí, } \\
\text { se tiene que sentar una mujer, un hombre, una mujer, un } \\
\text { hombre... va, muy bien, por obediencia lo hacen, pero } \\
\text { ya al rato, otra vez" (GD03) }\end{array}$ & $\begin{array}{l}\text { "Grupos mixtos, saben que tienen que estar hombres y } \\
\text { mujeres, } 4 \text { hombres y } 4 \text { mujeres, entonces de esa manera } \\
\text { vamos a ir inculcándoles que deben relacionarse ambos } \\
\text { géneros" (GD01) } \\
\text { "Una actividad que debemos de implementar, en los centros } \\
\text { educativos, como lo mencioné en la mañana, la escuela de } \\
\text { padres, es una escuela de padres, no reunión con padres, por } \\
\text { que en los centros educativos no se implementa eso, } \\
\text { simplemente es una reunión [...] pienso que tal vez pueda } \\
\text { funcionar la implementación de escuelas de padres a nivel } \\
\text { nacional” (GD01) } \\
\text { "Crear actividades en donde todos participen, tomar en } \\
\text { cuenta a hombres y mujeres por igual, la participación igual, } \\
\text { en todas las actividades comisiones de limpieza de refacción, } \\
\text { gobierno escolar, patrulla de limpieza, que participen tanto } \\
\text { niñas como niñas por igualdad, de una vez decirle a ellos. } \\
\text { Incluso en cómo se sientan, como tienen su escritorio, }\end{array}$ \\
\hline
\end{tabular}




\begin{tabular}{|c|c|c|c|}
\hline Categoría & Sub-categorías & Dimensiones exclusoras & Dimensiones transformadoras \\
\hline & & & $\begin{array}{l}\text { revueltitos verdad" (GD02) } \\
\text { "Nosotros como docentes escuchamos un apodo. Ah! Es que } \\
\text { son niños, es que son niños y es que ellos son así, pero } \\
\text { realmente es un error fatal porque hay que corregirlo desde } \\
\text { esa edad" (GD01) } \\
\text { "En mi caso yo trabajo un valor durante un mes, por ejemplo } \\
\text { la convivencia, tratar de que convivan todos, el respeto, yo } \\
\text { creo que ha sido muy bueno a nivel de escuela trabajar los } \\
\text { valores" (GD03) } \\
\text { "Hay niños que les gusta practicar baloncesto y no mucho les } \\
\text { gusta el futbol, y hay niñas que les gusta más el futbol y no el } \\
\text { basketbol. Entonces se les deja la libertad a ellas para que } \\
\text { elijan de qué les gusta pero sí tratar la manera de practicar no } \\
\text { solo el deporte, también otras actividades sociales" (GD03) } \\
\text { "Ahora si ya lo hacen [servir la refacción lo niños] pero } \\
\text { anteriormente no porque para ellos era malo, era incorrecto } \\
\text { habiendo niñas que podían servirles y no ellos servirse sólitos } \\
\text { verdad, porque recuérdense que yo así les digo a ellos que la } \\
\text { comida no va a llegar a su mesa porque aquí no tienen a una }\end{array}$ \\
\hline
\end{tabular}




\begin{tabular}{|c|c|c|c|}
\hline Categoría & Sub-categorías & Dimensiones exclusoras & Dimensiones transformadoras \\
\hline & & & $\begin{array}{l}\text { niña como sirvienta, si no usted también tiene manitas y } \\
\text { usted se puede servir solito, pero en ocasiones no es así } \\
\text { verdad, porque ellos ya traen costumbres, traen una } \\
\text { educación diferente de su casa, porque ellos mismos } \\
\text { comentan y dicen que sus mamas les sirven y si no están sus } \\
\text { hermanas y si no cualquier otra persona pero del sexo } \\
\text { femenino verdad" (GD04) } \\
\text { "Yo pensaría que tal vez no solo es un proyecto de } \\
\text { educación, salud de todos los ministerios, si no de todas las } \\
\text { empresas, trabajarlo como una ética, trabajarlo como un plan } \\
\text { a llevar diario, de que todas las empresas, todas las oficinas, } \\
\text { tiendas supermercados, mercados tratar a las personas con un } \\
\text { mismo respeto, verdad" (GD04) } \\
\text { "Eso de los cuentos no sexistas yo he estado leyéndolos un } \\
\text { poquito y cuesta un poquito porque hasta uno mismo termina } \\
\text { diciendo: no, hombre! Pero si no termina así el cuento el } \\
\text { cuento, pero igual hay que aprender a que los niños manejen } \\
\text { sus propios criterios y que tengan sus propios finales a como } \\
\text { ellos crean, o sea que no es como diga yo, si no como ellos } \\
\text { piensan y lleguen a consolidar su propio criterio" (GD04) }\end{array}$ \\
\hline
\end{tabular}




\begin{tabular}{|c|c|c|c|}
\hline Categoría & Sub-categorías & Dimensiones exclusoras & Dimensiones transformadoras \\
\hline & & & $\begin{array}{l}\text { "Son actividades que nosotros hacemos [haciendo que } \\
\text { participen niñas y niños en tareas como servir refacción] pero } \\
\text { nunca nos ponemos a pensar, pero también estamos } \\
\text { contribuyendo a que los dos sean iguales al mismo tiempo" } \\
\text { (GD04) } \\
\text { "En las actividades de educación física por ejemplo ponemos } \\
\text { a brincar caballito a los niños, antes pasarse las niñas encima } \\
\text { de niños eso es un pecado grandísimo, eso no se hace, es } \\
\text { pecado grande o sea que como pasarse una niña encima de un } \\
\text { niño, pero ahora ellas ya lo hacen verdad, hacen el caballito y } \\
\text { se pasan encima de los varones verdad, en el caso de } \\
\text { comunicación y lenguaje, antes hablar con varones... } \\
\text { hablábamos mas entre mujeres, no podemos platicar tanto } \\
\text { con hombres, ahora la inclusión como dice el compañero ya } \\
\text { se ven los niños jugando con las niñas, las niñas juegan } \\
\text { fútbol, los varones incluso juegan rodas con las niñas" } \\
\text { (GD04) }\end{array}$ \\
\hline
\end{tabular}




\section{Anexo 5: Recolección de información previa y complementaria}

Se realizaron las siguientes actividades para la toma de contacto y para completar aspectos relevantes de la investigación con maestras y maestros y madres y padres.

\begin{tabular}{|c|c|c|c|}
\hline & \multicolumn{3}{|c|}{ Participantes } \\
\hline & $\mathbf{M}$ & $\mathbf{H}$ & Total \\
\hline $\begin{array}{l}1 \text { Encuesta previa a maestras en activo } \\
\text { profesionalizándose en la universidad }\end{array}$ & 48 & 0 & 48 \\
\hline $\begin{array}{l}1 \text { Conversa grupal con maestras en activo } \\
\text { profesionalizándose en la universidad }\end{array}$ & 5 & 0 & 5 \\
\hline $\begin{array}{l}5 \text { entrevistas a expertas-os en educación y } \\
\text { género: ex rectora de Universidad Rafael } \\
\text { Landívar, ex ministro de educación, consultora } \\
\text { especializada en género del Ministerio de } \\
\text { Educación, investigadoras del área de género } \\
\text { de la Facultad Latinoamericana de Ciencias } \\
\text { Sociales -FLACSO. }\end{array}$ & 4 & 1 & 5 \\
\hline $\begin{array}{l}2 \text { Talleres de discusión con maestras y } \\
\text { maestros de las escuelas Pacajá Alto y Pacajá } \\
\text { Centro, Quetzaltenango }\end{array}$ & 13 & 4 & 17 \\
\hline $\begin{array}{l}2 \text { Talleres de discusión con madres y padres de } \\
\text { la escuela de la aldea Pachaj, Cantel, } \\
\text { Quetzaltenango }\end{array}$ & 15 & 5 & 20 \\
\hline
\end{tabular}

A continuación se incorporan los instrumentos utilizados y el análisis de la información recolectada. Se incluyen algunos de los dibujos y escritos realizados por madres y padres. 


\subsection{Formato de encuesta previa a maestras y maestros}

Encuesta sobre "Escuela y educación para la equidad de género"

Dirigida a docentes

Esta encuesta es anónima y forma parte de un estudio sobre la educación para la equidad de género en escuelas y colegios de Guatemala, cuyos resultados serán difundidos en espacios académicos a nivel nacional e internacional.

Conteste con toda sinceridad, según sus conocimientos y experiencia. ¡Muchas gracias!

\section{INFORMACIÓN GENERAL}

Sexo: $\square$ M $\square$ H $\quad$ Edad:___ Años de experiencia docente:

Nombre del establecimiento en el que labora:

$\square$ Público $\square$ Privado

$\square$ Área urbana $\square$ Área rural

Imparte clases en:

$\square$ Pre - Primaria $\square$ Primaria $\quad \square$ Básico $\square$ Bachillerato

Grado/s: Materia/s:

¿Su aula es intercultural? $\square$ No $\square$ Sí ¿Qué culturas conviven?

\section{ÍTEMS}

1. Equidad en la escuela/colegio se refiere a que... (marque solo 1 casilla)

$\square$ Se respeten todas las culturas

$\square$ Se promuevan relaciones justas entre niñas y niños de todas las culturas y procedencias sociales

$\square$ Se promueva la superación de niñas y niños por igual

2. Las niñas y niños aprenden a ser mujeres y hombres en diferentes espacios socializadores. Numere estos espacios del 4 al 1 según tengan más influencia o menos en el proceso de socialización (4 el más importante, 1 el menos)

Medios de comunicación (televisión, radio, internet, etc.)

$\square$ Estructuras de la comunidad (grupos comunitarios, asociaciones, iglesias, etc.)

$\square$ Familia

$\square$ Escuela/colegio 
3. ¿Las niñas y los niños nacen con caracteres, gustos, habilidades y capacidades diferentes?

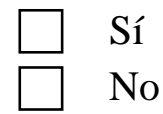

4. Anote 3 adjetivos que describan a:

Sus alumnas

1.

2 .

3 .

5. ¿Cree que existe relación entre la violencia de género y la forma de educar a niñas y niños en las escuelas/colegios?

Sí ¿Por qué?

$\square$ No ¿Por qué?

6. En su establecimiento, ¿ha podido observar alguna situación que considere como violencia de género?

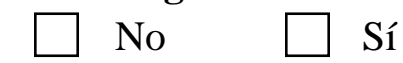

¿Cuál?

7. Usted aplica de alguna forma el eje del Curriculum Nacional Base llamado "equidad de género, de etnia y social"?

$\square$ No $\square$ Sí

¿Cómo? (actividades concretas, formas de planificar, materiales, forma de trato al alumnado, etc.) 


\subsection{Extracto de tabulación de encuestas a docentes}

Participantes: 67 estudiantes de Magisterio a nivel universitario, de las cuales 48 son maestras de Pre-primeria o Primaria en activo.

Respuestas de la pregunta 1. :

1 Se respeten todas las culturas

2 Se promuevan relaciones justas entre niñas y niños de todas las

culturas y procedencias sociales

3 Se promueva la superación de niñas y niños por igual

\begin{tabular}{|c|c|c|c|c|c|c|c|c|c|c|}
\hline$\#$ & $\begin{array}{c}\text { Sexo } \\
\text { (mujer, } \\
\text { hombre) }\end{array}$ & Edad & $\begin{array}{l}\text { Docente } \\
\text { activo/a? }\end{array}$ & $\begin{array}{c}\text { Área } \\
\text { urbana } \\
\text { ó rural } \\
\end{array}$ & $\begin{array}{l}\text { Grado: párvulos } \\
\text { incluye pre- } \\
\text { kinder y kinder) }\end{array}$ & $\begin{array}{c}1 . \\
\text { Equidad } \\
\text { se refiere } \\
\text { a... }\end{array}$ & $\begin{array}{l}\text { 2. Espacio } \\
\text { socializ }+ \\
\text { imp }\end{array}$ & $\begin{array}{l}\text { 2.1 Segundo } \\
\text { espacio sociliaz + } \\
\text { imp }\end{array}$ & $\begin{array}{l}2.2 \text { Espacio } \\
\text { socializ - imp }\end{array}$ & $\begin{array}{l}\text { 3. Niñas y } \\
\text { niños nacen } \\
\text { dif? }\end{array}$ \\
\hline 1 & $\mathrm{~m}$ & 25 & si & $\mathrm{u}$ & parvulos & 2 & $\begin{array}{l}\text { medios } \\
\text { comunicación }\end{array}$ & familia & comunidad & no \\
\hline 2 & $\mathrm{~m}$ & 22 & si & $\mathrm{u}$ & parvulos & 2 & no válida & no válida & comunidad & si \\
\hline 3 & $\mathrm{~m}$ & 22 & si & $\mathrm{u}$ & parvulos & 1 & familia & escuela & $\begin{array}{l}\text { medios } \\
\text { comunicación }\end{array}$ & si \\
\hline 4 & $\mathrm{~m}$ & 19 & si & $\mathrm{u}$ & parvulos & 1 & familia & escuela & $\begin{array}{l}\text { medios } \\
\text { comunicación }\end{array}$ & si \\
\hline 5 & $\mathrm{~m}$ & 20 & no & & & 1 & familia & escuela & $\begin{array}{l}\text { medios } \\
\text { comunicación }\end{array}$ & si \\
\hline 6 & $\mathrm{~m}$ & 20 & no & & & 3 & no válida & no válida & $\begin{array}{l}\text { medios } \\
\text { comunicación }\end{array}$ & si \\
\hline 7 & $\mathrm{~m}$ & 19 & no & & & 2 & comunidad & familia & $\begin{array}{l}\text { medios } \\
\text { comunicación }\end{array}$ & si \\
\hline 8 & $\mathrm{~m}$ & 20 & si & $\mathrm{u}$ & prepa & 2 & no válida & & $\begin{array}{l}\text { medios } \\
\text { comunicación }\end{array}$ & si \\
\hline
\end{tabular}




\begin{tabular}{|c|c|c|c|c|c|c|c|c|c|c|}
\hline 9 & $\mathrm{~m}$ & 20 & no & & & 2 & familia & $\begin{array}{l}\text { medios } \\
\text { comunicación }\end{array}$ & escuela & si \\
\hline 10 & $\mathrm{~m}$ & 26 & si & $\mathrm{r}$ & prepa & 2 & escuela & no válida & no válida & si \\
\hline 11 & $\mathrm{~m}$ & 25 & no & & & 3 & $\begin{array}{l}\text { medios } \\
\text { comunicación }\end{array}$ & comunidad & familia & si \\
\hline 12 & $\mathrm{~m}$ & 21 & si & $\mathrm{r}$ & parvulos & 3 & $\begin{array}{l}\text { medios } \\
\text { comunicación }\end{array}$ & comunidad & familia & si \\
\hline 13 & $\mathrm{~m}$ & 22 & si & $\mathrm{u}$ & parvulos & 2 & familia & comunidad & escuela & si \\
\hline 14 & $\mathrm{~m}$ & 45 & no & & & 2 & comunidad & familia & $\begin{array}{l}\text { medios } \\
\text { comunicación }\end{array}$ & no \\
\hline 15 & $\mathrm{~m}$ & & si & $\mathrm{u}$ & parvulos & 2 & familia & comunidad & $\begin{array}{l}\text { medios } \\
\text { comunicación }\end{array}$ & si \\
\hline 16 & $\mathrm{~m}$ & 22 & no & & & 2 & familia & comunidad & $\begin{array}{l}\text { medios } \\
\text { comunicación }\end{array}$ & si \\
\hline 17 & $\mathrm{~m}$ & 24 & si & $\mathrm{r}$ & parvulos & 3 & escuela & familia & $\begin{array}{l}\text { medios } \\
\text { comunicación }\end{array}$ & si \\
\hline 18 & $\mathrm{~m}$ & 34 & no & & & 2 & familia & comunidad & escuela & $\mathrm{si}$ \\
\hline 19 & $\mathrm{~m}$ & 22 & no & & & 2 & familia & escuela & $\begin{array}{l}\text { medios } \\
\text { comunicación }\end{array}$ & si \\
\hline 20 & $\mathrm{~m}$ & & si & $\mathrm{r}$ & prepa & 1 & comunidad & no válida & no válida & si \\
\hline 21 & $\mathrm{~m}$ & 21 & si & $\mathrm{u}$ & 1 primaria & 2 & familia & comunidad & $\begin{array}{l}\text { medios } \\
\text { comunicación }\end{array}$ & si \\
\hline 22 & $\mathrm{~m}$ & 24 & no & & & 2 & comunidad & escuela & familia & si \\
\hline 23 & $\mathrm{~m}$ & 38 & si & $\mathrm{u}$ & \begin{tabular}{|l} 
magisterio \\
parvulos
\end{tabular} & 3 & comunidad & escuela & familia & si \\
\hline 24 & $\mathrm{~m}$ & 26 & si & $\mathrm{r}$ & prepa & 3 & comunidad & escuela & familia & $\mathrm{si}$ \\
\hline 25 & $\mathrm{~m}$ & 28 & si & $\mathrm{r}$ & parvulos & 3 & comunidad & escuela & familia & si \\
\hline 26 & $\mathrm{~m}$ & 27 & no & & & 2 & familia & comunidad & $\begin{array}{l}\text { medios } \\
\text { comunicación }\end{array}$ & si \\
\hline 27 & $\mathrm{~m}$ & 21 & si & $\mathrm{u}$ & prepa & 2 & familia & escuela & $\begin{array}{l}\text { medios } \\
\text { comunicación }\end{array}$ & si \\
\hline
\end{tabular}




\begin{tabular}{|c|c|c|c|c|c|c|c|c|c|c|}
\hline 28 & $\mathrm{~m}$ & 23 & si & $\mathrm{r}$ & multigrado & 2 & familia & comunidad & $\begin{array}{l}\text { medios } \\
\text { comunicación }\end{array}$ & si \\
\hline 29 & $\mathrm{~m}$ & 22 & si & $\mathrm{u}$ & parvulos & 2 & familia & comunidad & $\begin{array}{l}\text { medios } \\
\text { comunicación }\end{array}$ & si \\
\hline 30 & $\mathrm{~m}$ & 26 & si & $\mathrm{r}$ & prepa & 2 & $\begin{array}{l}\text { medios } \\
\text { comunicación }\end{array}$ & comunidad & familia & si \\
\hline 31 & $\mathrm{~m}$ & 48 & si & $\mathrm{u}$ & parvulos & 2 & familia & escuela & comunidad & no \\
\hline 32 & $\mathrm{~m}$ & 25 & no & & & 2 & & & & si \\
\hline 33 & $\mathrm{~m}$ & 21 & si & $\mathrm{u}$ & prepa & 2 & no válida & no válida & comunidad & no \\
\hline 34 & $\mathrm{~m}$ & 24 & no & & & 2 & familia & escuela & $\begin{array}{l}\text { medios } \\
\text { comunicación }\end{array}$ & si \\
\hline 35 & $\mathrm{~m}$ & 23 & no & & & 2 & familia & escuela & $\begin{array}{l}\text { medios } \\
\text { comunicación }\end{array}$ & si \\
\hline 36 & $\mathrm{~m}$ & 20 & no & & & 2 & $\begin{array}{l}\text { medios } \\
\text { comunicación }\end{array}$ & comunidad & familia & si \\
\hline 37 & $\mathrm{~m}$ & 21 & si & $\mathrm{r}$ & multigrado & 2 & familia & escuela & $\begin{array}{l}\text { medios } \\
\text { comunicación }\end{array}$ & si \\
\hline 38 & $\mathrm{~m}$ & 23 & no & & & 2 & familia & escuela & $\begin{array}{l}\text { medios } \\
\text { comunicación }\end{array}$ & no \\
\hline 39 & $\mathrm{~m}$ & 23 & si & $\mathrm{r}$ & prepa & 2 & familia & escuela & $\begin{array}{l}\text { medios } \\
\text { comunicación }\end{array}$ & si \\
\hline 40 & $\mathrm{~m}$ & 21 & no & & & 2 & familia & escuela & $\begin{array}{l}\text { medios } \\
\text { comunicación }\end{array}$ & si \\
\hline 41 & $\mathrm{~m}$ & 28 & no & & & 2 & comunidad & no válida & no válida & no \\
\hline 42 & $\mathrm{~m}$ & 20 & si & $\mathrm{r}$ & prepa & 2 & $\begin{array}{l}\text { medios } \\
\text { comunicación }\end{array}$ & comunidad & familia & si \\
\hline 43 & $\mathrm{~m}$ & 21 & no & & & 3 & familia & escuela & $\begin{array}{l}\text { medios } \\
\text { comunicación }\end{array}$ & si \\
\hline 44 & $\mathrm{~m}$ & 25 & si & $\mathrm{u}$ & parvulos & 2 & $\begin{array}{l}\text { medios } \\
\text { comunicación }\end{array}$ & familia & comunidad & no \\
\hline 45 & $\mathrm{~m}$ & 22 & $\mathrm{si}$ & $\mathrm{u}$ & parvulos & 2 & no válida & no válida & comunidad & si \\
\hline
\end{tabular}




\begin{tabular}{|c|c|c|c|c|c|c|c|c|c|c|}
\hline 46 & $\mathrm{~m}$ & 22 & $\mathrm{si}$ & $\mathrm{u}$ & parvulos & 1 & familia & escuela & $\begin{array}{l}\text { medios } \\
\text { comunicación }\end{array}$ & si \\
\hline 47 & $\mathrm{~m}$ & 19 & $\mathrm{si}$ & $\mathrm{u}$ & parvulos & 1 & familia & escuela & $\begin{array}{l}\text { medios } \\
\text { comunicación }\end{array}$ & si \\
\hline 48 & $\mathrm{~m}$ & 20 & si & $\mathrm{u}$ & prepa & 2 & no válida & & $\begin{array}{l}\text { medios } \\
\text { comunicación }\end{array}$ & si \\
\hline 49 & $\mathrm{~m}$ & 26 & $\mathrm{si}$ & $\mathrm{r}$ & prepa & 2 & escuela & no válida & no válida & si \\
\hline 50 & $\mathrm{~m}$ & 21 & si & $\mathrm{r}$ & parvulos & 3 & $\begin{array}{l}\text { medios } \\
\text { comunicación }\end{array}$ & comunidad & familia & si \\
\hline 51 & $\mathrm{~m}$ & 22 & si & $\mathrm{u}$ & parvulos & 2 & familia & comunidad & escuela & si \\
\hline 52 & $\mathrm{~m}$ & & $\mathrm{si}$ & $\mathrm{u}$ & parvulos & 2 & familia & comunidad & $\begin{array}{l}\text { medios } \\
\text { comunicación }\end{array}$ & si \\
\hline 53 & $\mathrm{~m}$ & 24 & si & $\mathrm{r}$ & parvulos & 3 & escuela & familia & $\begin{array}{l}\text { medios } \\
\text { comunicación }\end{array}$ & si \\
\hline 54 & $\mathrm{~m}$ & & $\mathrm{si}$ & $\mathrm{r}$ & prepa & 1 & comunidad & no válida & no válida & si \\
\hline 55 & $\mathrm{~m}$ & 21 & si & $\mathrm{u}$ & 1 primaria & 2 & familia & comunidad & $\begin{array}{l}\text { medios } \\
\text { comunicación }\end{array}$ & si \\
\hline 56 & $\mathrm{~m}$ & 38 & $\mathrm{si}$ & $\mathrm{u}$ & $\begin{array}{l}\text { magisterio } \\
\text { parvulos }\end{array}$ & 3 & comunidad & escuela & familia & si \\
\hline 57 & $\mathrm{~m}$ & 26 & si & $\mathrm{r}$ & prepa & 3 & comunidad & escuela & familia & si \\
\hline 58 & $\mathrm{~m}$ & 28 & $\mathrm{si}$ & $\mathrm{r}$ & parvulos & 3 & comunidad & escuela & familia & si \\
\hline 59 & $\mathrm{~m}$ & 21 & si & $\mathrm{u}$ & prepa & 2 & familia & escuela & $\begin{array}{l}\text { medios } \\
\text { comunicación }\end{array}$ & si \\
\hline 60 & $\mathrm{~m}$ & 23 & si & $\mathrm{r}$ & multigrado & 2 & familia & comunidad & $\begin{array}{l}\text { medios } \\
\text { comunicación }\end{array}$ & si \\
\hline 61 & $\mathrm{~m}$ & 22 & si & $\mathrm{u}$ & parvulos & 2 & familia & comunidad & $\begin{array}{l}\text { medios } \\
\text { comunicación }\end{array}$ & si \\
\hline 62 & $\mathrm{~m}$ & 26 & si & $\mathrm{r}$ & prepa & 2 & $\begin{array}{l}\text { medios } \\
\text { comunicación }\end{array}$ & comunidad & familia & si \\
\hline 63 & $\mathrm{~m}$ & 48 & si & $\mathrm{u}$ & parvulos & 2 & familia & escuela & comunidad & no \\
\hline 64 & $\mathrm{~m}$ & 21 & si & $\mathrm{u}$ & prepa & 2 & no válida & no válida & comunidad & no \\
\hline
\end{tabular}




\begin{tabular}{|l|l|l|l|l|l|l|l|l|l|l|}
65 & $\mathrm{~m}$ & 21 & $\mathrm{si}$ & $\mathrm{r}$ & multigrado & 2 & familia & escuela & $\begin{array}{l}\text { medios } \\
\text { comunicación }\end{array}$ & \multicolumn{2}{c|}{ si } \\
\hline 66 & $\mathrm{~m}$ & 23 & $\mathrm{si}$ & $\mathrm{r}$ & $\mathrm{prepa}$ & 2 & familia & escuela & comunicación & si \\
\hline 67 & $\mathrm{~m}$ & 20 & $\mathrm{si}$ & $\mathrm{r}$ & $\mathrm{prepa}$ & 2 & $\begin{array}{l}\text { medios } \\
\text { comunicación }\end{array}$ & comunidad & familia & si \\
\hline
\end{tabular}

\begin{tabular}{l}
\cline { 2 - 3 } \multicolumn{1}{l|}{ Resumen } \\
\begin{tabular}{|l|c|c|}
\hline Docentes en activo & 48 & 100 \\
\hline Género es biológico & 42 & 87.5 \\
\hline Género no es biológico & 6 & 12.5 \\
\hline
\end{tabular}
\end{tabular}




\subsection{Preguntas generadoras conversa grupal con maestras y maestros}

Conversa grupal "Escuela y educación para la equidad de género"

Dirigida a docentes de Pre-Primaria y Primaria

\section{INFORMACIÓN GENERAL}

Lugar: Fecha:

Hora inicio: Hora fin:

Número de participantes: $\mathrm{N}^{\mathrm{o}}$ mujeres: $\mathrm{N}^{\mathrm{o}}$ hombres:

$\mathrm{N}^{\circ}$ mujeres docentes de Pre - Primaria: $\mathrm{N}^{\circ}$ mujeres docentes Primaria: Ídem hombres: Ídem hombres:

\section{PREGUNTAS GENERADORAS}

1. Las niñas y los niños en la escuela o colegio, ¿qué cosas tienen en común? ¿y qué diferencias tienen?

2. Alcanzar la equidad de género, ¿es importante para Guatemala? ¿Por qué?

3. En su escuela o colegio, ¿ha podido observar alguna situación que considere como violencia de género? ¿Cuál?

4. ¿Cuál es el origen de la violencia de género? ¿de alguna manera una raíz puede estar en la escuela? Si es así, ¿qué situaciones o formas de trabajar de las escuelas o colegios promueven esta violencia?

5. ¿Cuál es el propósito del eje de "equidad de género, de etnia y social” del Curriculum Nacional base?

6. ¿Se está implementando en las escuelas o colegios de Pre-Primaria y Primaria el eje de “equidad de género, de etnia y social” del Curriculum Nacional Base? Si se está implementando, ¿cómo? ¿a través de qué herramientas, tipos de planificación, reflexiones, etc.? 


\section{NO ES UNA TRANSCRIPCIÓN LITERAL. SÍNTESIS DE LAS NOTAS TOMADAS DURANTE CONVERSACIÓN GRUPAL.}

\section{INFORMACIÓN GENERAL}

Lugar: Universidad Rafael Landívar, Quetzaltenango

Fecha: 15 marzo 2014

Hora inicio: 3 pm aprox. Hora fin: 40 minutos

Número de participantes: ___ 5__ $\mathrm{N}^{\mathrm{o}}$ mujeres: ___ 5_ $\mathrm{N}^{\mathrm{o}}$ hombres: ___

$\mathrm{N}^{\mathrm{o}}$ mujeres docentes de Pre - Primaria:

4 __ Ídem hombres:

0

$\mathrm{N}^{\mathrm{o}}$ mujeres docentes Primaria: Ídem hombres: 0

Docentes en activo que estudian Magisterio Pre-Primaria, etapa licenciatura.

Algunas de ellas han cursado una materia llamada Coeducación (ubicada en el $8^{\circ}$ o $9^{\circ}$ semestre de carrera, pertenecientes a la licenciatura)

\section{PREGUNTAS GENERADORAS}

1. Las niñas y los niños en la escuela o colegio, ¿qué cosas tienen en común? ¿y qué diferencias tienen?

- Diferencias en trato, niños más violentos por cómo han sido educados.

- Están cambiando roles en la sociedad. Tienen los mismos juegos porque la sociedad se está auto educando. $50 \%$ de madres tienen algún grado académico. La equidad de género es un eje de la reforma (educativa).

- Mucha diferencia. Los padres les han educado así. Los niños son más importantes, las niñas no pueden hacer cosas. Hace 3 años había más diferencias. Ahora las niñas dicen yo también puedo manejar un avión. Todos tenemos las mismas capacidades, depende de la educación.

- Docentes somos responsables e no hacer diferencias entre niños y niñas. Mucho viene de casa. En primer lugar es responsabilidad de docentes que se sienten juntos, hagan juegos juntos, etc. Pero sí hay diferencias más en el área rural. Hasta al momento de escribir, los niños tienen la mano más dura. 
- Área urbana juegan futbol mixto. Niños cuida a las niñas, son responsables de ellas.

- Docentes pelean que se pone en peligro a las niñas si juegan futbol. Los docentes no respetamos equidad.

- Más es en el área rural los padres tiene el paradigma de niños-estudio, niñas-casa-

- Ahora hay más niñas que niños en escuelas de párvulos.

\section{Alcanzar la equidad de género, ¿es importante para Guatemala? ¿Por qué?}

- Tenemos que preparar líderes. Las mujeres tienen mucha capacidad.

- Dejar a tras el machismo, que solo el hombre tiene que trabajar. Inculcar que somos iguales en derecho.

- En el establecimiento educativo no tenemos que hacer diferencias cuando los derechos son para todos.

- Formamos a niñas y niños en el gobierno escolar. Debemos empezar nosotros como docentes.

- En las áreas rurales no se dan oportunidades a las mujeres. De mujer hay que tener fuerza para salir adelante.

3. En su escuela o colegio, ¿ha podido observar alguna situación que considere como violencia de género? ¿Cuál?

- El bullyng: los hombres lo hacen hacia las mujeres. No quieren hacer grupos con las niñas.

- Caso: niño de prepa pide dinero a niña de $2^{\circ}$ primaria. Su maestra no hizo nada. Si empezamos así, después va a más.

- Caso: los niños grandes le dicen a las niñas que ellas tiene que trapear en clase. La maestra les llamó la atención.

- Caso: niño que habla con lenguaje de grande y no se junta con niñas porque su mamá dice que las mujeres no sirven. Llegó la mamá y dijo que su hijo no estuviera con niñas porque ellas no pueden, "dice mi marido que mi hijo solo tiene que aprender con hombres".

4. ¿Cuál es el origen de la violencia de género? ¿de alguna manera una raíz puede estar en la escuela? Si es así, ¿qué situaciones o formas de trabajar de las escuelas o colegios promueven esta violencia?

- Todo viene de casa, familia. Papás que toman, pelean, etc. 
- En la pobreza, falta de empleo, las personas roban, matan.

- Somos parte de una cultura machista donde era normal maltratar a las mujeres. Ahora tenemos que cambiar eso. En la historia, todo el tiempo había esos casos.

- La historia no se dedicaba a estudiar a las mujeres. Religiosos que dicen que en la biblia dice que la mujer debe ser sumisa. Se creen los dueños de las mujeres. La ignorancia es otro factor. Ignorar derechos y obligaciones.

- Ahora hay instituciones para mujeres pero las mujeres van y luego regresan con sus esposos. La ley no actúa.

- Los docentes a veces tenemos culpa. Hacemos diferencias de dibujos, colores, juegos, etc. tenemos un poquito de responsabilidad.

- Tenemos responsabilidad muy grande para cambio, no solo con niños sino con padres de familia porque los patrones se repiten. Los modelos violentos de familia hacen a niños violentos.

- Platicar con ellos (niños pequeños) para que todos seamos iguales. Con los jóvenes que son los papás ahora, tienen mentalidad de que todos son iguales. Las generaciones antiguas piensan retrógrado.

- Contacto con los padres es esencial para que los padres entiendan que en la escuela se tiene que dar (igualdad).

- Hacemos diferencias en las mesas de trabajo separadas. Filas: adelante niños, atrás niñas. Ciertos cuentos marcan diferencias demasiado.

- Hacer actividades donde todos se relacionan. Marcarlo desde el primer día de clases.

- Cambiar de lugar cada semana para relacionarse todos.

- Física: niños-futbol, niñas-basket. En los juegos, hay que integrar.

- Patio: propósito de que todos interactúen.

- Que no se pierda lo que se trabaja de un curso a otro.

5. ¿Cuál es el propósito del eje de “equidad de género, de etnia y social” del Curriculum Nacional base?

- Trabajar el eje en contenido actitudinales.

- Falta conocer bien el eje y también el CNB.

- Diferencia a nivel nacional de conocimiento del CNB. Como docentes no nos preocupamos de estudiar lo que conlleva la equidad de género.

- No discrimina a los que tienen discapacidad (niño con deficiencia del lenguaje, caso)

- De nosotros depende que haya 0 discriminación. 
6. ¿Se está implementando en las escuelas o colegios de Pre-Primaria y Primaria el eje de "equidad de género, de etnia y social" del Curriculum Nacional Base? Si se está implementando, ¿cómo? ¿a través de qué herramientas, tipos de planificación, reflexiones, etc.?

- Rompecuentos.

- Trabajando coeducación.

- Integración a niñas en los juegos

- Dinámicas de rompimiento

- Participación por igual

- Juegos

- No hacer filas separadas

\section{Comentarios posteriores relevantes:}

- Grupo no ha conocido centro educativo con un plan de equidad de centro "no hemos tenido la iniciativa (de crearlo nosotras...)".

- Todavía hay escuelas separadas, solo de varones.

- Cuando hay un maestro de prepa decimos "será gay"?

- Un maestro de prepa ganó premio a maestro 100 puntos y las maestras no estaban de acuerdo.

- Cuando asignan un maestro a prepa las maestras no están de acuerdo porque dicen que niños necesitan rol maternal. 


\subsection{Protocolo entrevista a expertas /os en educación}

- ¿Qué importancia tiene la educación para la equidad en Guatemala?

- ¿De qué forma se encuentran unidas la equidad de género, de etnia y social en la realidad del país?

- ¿Cómo ha evolucionado la educación en Guatemala desde la implantación de la educación mixta?

- ¿Qué protagonismo ha tenido y tiene la educación para la equidad de género, de etnia y social en la agenda educativa?

- ¿Cuáles son las principales fortalezas con las que cuenta Guatemala en el ámbito de la educación para la equidad de género?

- ¿Y las principales carencias o debilidades?

- ¿Existen actualmente debates teóricos en el país en torno a la educación para la equidad?

- ¿Qué se necesita para que la implementación del eje curricular de equidad de género, de etnia y social sea una realidad en las aulas? (profesorado, direcciones de establecimientos, MINEDUC, transversalidad curricular...)

- ¿Conoce alguna experiencia concreta de implementación de este eje?

- ¿Cuáles son los principales retos que enfrenta la educación para la equidad en Guatemala durante los próximos años? 


\subsection{Transcripciones de entrevistas a expertas /os}

\section{Entrevista 1 a expertos-as}

Lingüista y experta en equidad.

Miembro de la Academia Guatemalteca de la Lengua.

Ex rectora de la Universidad Rafael Landívar.

P: ¿Qué significa para usted la equidad y cómo se relacionan los elementos de equidad de género, equidad de etnia, equidad social (que dice el currículum nacional base) u otras equidades?

R: Para mí el tema de equidad no es un tema aislado sino que forma parte de una concepción del ser humano desde el valor del respeto a la diferencia. Por eso está íntimamente ligado al respeto a la diversidad, a las diferencias étnicas, religiosas, etc.

\section{P: En su experiencia, ¿por qué es fundamental que Guatemala pueda avanzar en equidad?}

R: Avanzar en equidad es fundamental en cuanto a que si hombres y mujeres en la realidad gozan de las mismas libertades y derechos y tienen que cumplir las mismas obligaciones y deberes, la sociedad va a avanzar en humanidad.

P: ¿Cómo la coeducación puede aportar precisamente a este avance que está mencionando?

R: La coeducación, partiendo como la educación desde el respeto por la diferencia, no nace como resultado de generación espontánea. Por tanto, en una sociedad en la que tradicionalmente ha habido machismo y misoginia, la escuela puede abrir la brecha para hacer de los niños y de las niñas personas tolerantes, y más que eso, personas solidarias hacia las personas que son diferentes. Desde luego, es toda una cadena porque los maestros y las maestras tienen que estar comprometidos y llevarlo al aula.

\section{P: ¿Qué estrategias utilizar para hacer realidad la coeducación en el aula?}

R: Yo creo que el Currículum Nacional Base, que obliga desde el Ministerio de Educación, tiene que asumir esta coeducación y luego de ahí la formación del maestro, los materiales, el trato igualitario, las vivencias... 
Tenemos en Guatemala una mayoría de maestras. Ahora, esto no es garantía de nada, ya que muchas de estas maestras no han sido formadas en este tipo de materias y ellas mismas estarán convencidas de que el trato no es igualitario. Son un grupo social muy receptivo al tema de coeducación por las vivencias que han tenido en su entorno laboral y social. El maestro lo es todo, podemos tener todas las facilidades materiales que si el maestro no está formado de nada va a servir.

\section{P: ¿Y qué rol cree que tienen los diversos actores?}

R: Obviamente, el Estado por medio de otras instituciones a parte del Ministerio. Hay una ley contra la discriminación étnica y de género pero es una ley muy general y no se aplica. Yo creo que un medio rápido a partir del cual aprende la sociedad es una acción legal.

Corresponde a la sociedad civil hacer cumplir esas leyes, educarse, enterarse y formarse. Aquí la sociedad civil en Guatemala es compleja; tenemos dos culturas, una cultura de raíz occidental y una cultura maya, y cada una de ella va por sus caminos hacia el reconocimiento de las materias de género. Y no debiera de haber nada cultural que impida que la mujer sea respetada, eso está por encima de cualquier base cultural.

Y también otros actores como la familia y la escuela. 


\section{Entrevista 2 a expertos-as}

Educador popular y profesor en la Universidad de San Carlos de Guatemala.

Doctor en Pedagogía.

Ex viceministro de Educación de Guatemala.

\section{P: ¿Qué significa para ti la equidad y cómo se relacionan la equidad de género, equidad de etnia y equidad social, que dice el Currículum Nacional Base, y otras equidades?}

R: Cuando hablamos de equidad, hay dos vías para entender esto: desde la experiencia o desde la teoría. Desde la experiencia lo que pasa en Guatemala, es que somos un país con la mayor carencia en la equidad. Este país es uno de los mayores ejemplos para demostrar la inequidad, varias inequidades: en la cultura, lo material-económico-, de género, de edades y la inequidad respecto a las discapacidades.

Yo creo que cuando hablamos de equidad estamos hablando de un tipo de esfuerzo o de lucha que garantice no solo acceso a oportunidades, no solo la igualdad de oportunidades que se plantea tanto en Guatemala, sino que garantice que la oportunidad se da a partir de procesos previos. No es lo mismo decir "en Guatemala todos tienen la misma oportunidad y depende de sus condiciones para ver si gana (aprueba un curso en la escuela)" sino garantizar desde los inicios que todo el mundo tiene las mismas oportunidades económicas-culturalespsicológicas-educativas y también asegurar condiciones en visiones culturales para que el acceso a las oportunidades posibles se dé en condiciones de verdadera igualdad.

No es lo mismo un niño o una niña pobre desnutrida que ingresa a un centro educativo, sin condiciones nutritivas de proteínas desde su nacimiento, a un niño o niña que entra con todo eso garantizado. Decir "tiene igualdad de oportunidades" es una falacia porque en realidad no las tiene desde el principio de su vida.

Entonces, garantizar prácticas, políticas, visiones que hagan que cualquier niño o niña tenga acceso a las condiciones mínimas para su desempeño educativo. Equidad, en Guatemala, debiera ser hablar de la creación de condiciones (de políticas, de estructuras, de procesos...) en los que todas las necesidades y todas las potencialidades humanas estén garantizadas desde el Estado y no desde la iniciativa privada. Asegurar el acceso a derechos humanos no es satisfacer necesidades humanas, es el goce de derechos humanos. La equidad va a ser 
entonces, la garantía del acceso, del goce, de la práctica, del ejercicio de todo tipo de derechos humanos.

Mientras no hablemos de derechos y hablemos solo de necesidades estaremos hablando de ciertas condiciones que no garantizan esa equidad.

\section{P: ¿Y en tu experiencia en el campo educativo (que es amplia), cómo ves la contribución específica de la educación al logro de esta equidad?}

La educación en Guatemala no ha contribuido a la equidad, la educación en Guatemala ha contribuido en la inequidad. En primer lugar, de manera más tradicional, el acceso y la cobertura siempre ha sido más fácil para los niños que para las niñas (hablando del sistema educativo formal). Pero también en el aspecto cualitativo, el sistema curricular y la práctica curricular en Guatemala también ha favorecido la inequidad porque favorece los resultados más adecuados de los niños versus niñas, ya que el lenguaje curricular está plagado, aún cuando digan "no, eso ya está superado, eso no es cierto", el lenguaje y la actitud cotidiana están plagadas de sexismo, de diferenciaciones innecesarias, de valores que son más masculinos que femeninos... Y, de hecho, el éxito escolar está fundado en la capacidad de un escolar de responder a los parámetros o criterios de valores más masculinos (la competencia, la capacidad matemática, por ejemplo).

Entonces, ahí tenemos unos elementos: el acceso, la calidad y luego, si vamos a pensar en la pirámide mayor de la universidad, vemos que las mujeres tienen mayor facilidad de tener acceso a carreras femeninas y los hombres a carreras masculinas. Entonces, al ver en el cuadro político del país dónde se toman decisiones, dónde se deciden los rumbos del país, vemos que los profesionales masculinos son los que más participan en la toma de decisiones. La inequidad de género está desde el acceso hasta la constitución de la toma de decisiones que dirigen el país.

A pesar de eso, el discurso está cambiando; ahora se habla más de las niñas, de la educación intercultural... uno ve que hay un discurso muy políticamente correcto para estar en sintonía con lo que el mundo pide pero en la práctica (toma de decisiones, organización escolar, las conductas cotidianas...) ahí todavía vemos sexismo, un patriarcado muy claro, desprecio a las culturas originarias del país.

Tampoco ha habido relevo de los antiguos maestros, por tanto los nuevos maestros no han sido formados y lo curricular sigue siendo producto de la inequidad. 


\section{P: ¿Qué estrategias educativas puedes identificar donde de verdad sí se está trabajando esta equidad?}

El primer paso hacia ello fue lo que hoy llamamos la educación mixta, que no es el paso hacia el ámbito coeducativo. Entonces ese paso fue un avance porque ya exigió otras condiciones; fue una estrategia que permitió hacer cambios curriculares. Pero el problema en Guatemala es que el paso de una educación diferenciada a una educación mixta se dio sin un proceso de verdadera formación coeducativa donde se requerían valores para esa convivencia, ese aprendizaje entre géneros.

Y la idea es que no se dio ese aprendizaje inicial, se volvió mixto el sistema educativo y después vino el concepto de "coeducación", aunque la gente pensaba que con tener niños y niñas en un aula ya estaban haciendo coeducación. Y entonces lo que ocurre es que esa educación más mixta fue más dañina que la otra porque aquí se empezaron a privilegiar convivencias, prácticas, valores... donde las niñas frente a los niños quedaban abajo y entonces se reprodujo de una manera nueva, de manera más moderna, el sexismo del anterior. Pero eso es solo una estrategia, la otra que he visto es que, en algunos establecimientos (más privados que públicos) de corrientes incluso católicas (no es una generalización del país), se empezaron a crear procesos de equidad de género gracias a los maestros $\mathrm{y}$, por supuesto, las maestras. Lo que he visto es que muchos maestros no fueron tan sensibles a ello y se resistieron. Poco a poco han sido como unos años de transición, ya que o entraban en el asunto o se salían del establecimiento. Y he visto a muchas señoritas formadas en estos niveles con un discurso, con una práctica, con una lucha en los derechos de las mujeres que lo han llevado a su vida personal. También he visto que algunas mujeres empezaron a proyectar una imagen feminista del asunto y eso empezó a generar contradicciones en los establecimientos públicos, contradicciones contradichas por el profesorado más tradicional. Y tristemente en algunas han prevalecido porque el profesorado alternativo coeducativo era una minoría.

Luego en Guatemala hay que tener en cuenta que la Reforma Educativa tiene como base los Acuerdos de Paz (1996). En esos acuerdos se referencia a la mujer y la lucha de las mujeres. El Gobierno de ahora no representa el espíritu de los Acuerdos de Paz, entonces la ejecución, implementación y el diseño curricular en el inicio fue de otro tipo, entonces hay una contradicción terrible intercurricular y la ausencia de procesos, de formación... 
Otra estrategia que he visto mucho en educadores y educadoras indígenas es formar fuera del sistema en equidad de género, a través de la educación no formal; ese intento ha tendido muchas veces la pretensión de impactar hacia adentro. Se ha visto que a partir de la formación no formal del profesorado se impacta más en la educación formal, y eso es muy interesante ya que hay muchas ONGs en Guatemala que hacen procesos de formación con impacto hacia dentro.

\section{P: ¿Cuál es tu opinión de este aporte de diferentes actores (ONGs, sociedad civil...)?}

R: El tema de la equidad de género va a pasar siempre y debe pasar por el tema de la educación integral y sexualidad, porque el tema de la sexualidad es como tan nuclear... quizá el tema más nuclear de todos. Con una sana sexualidad en este país podemos tirarnos a equidad porque el tema de la sexualidad tiene que ver con género, tiene que ver con relaciones sociales, tiene que ver con toma de decisiones, tiene que ver con relaciones de poder.

Es muy probable que muchos de los cambios actitudinales profundos de gente dentro del sistema escolar sea más por procesos educativos fuera del sistema escolar que dentro del sistema escolar (de los profesores que trabajan dentro de sistema educativo formal).

\section{P: ¿Qué retos está afrontando el sistema educativo guatemalteco con el fin de avanzar en coeducación?}

El primer reto se basa en no creer en lo obvio, si creemos en la obviedad vamos a asumir cosas que no son y el primer reto es que la gente entienda qué es coeducación, que supere la educación mixta para llegar a la coeducación.

La coeducación es una visión educativa donde la existencia de roles sexistas está dañando el profundo derecho a una educación integral. La coeducación es una visión educativa donde se privilegia la equidad y la igualdad. Y eso es partir de las diferencias para encontrar la igualdad. Yo creo firmemente que en cuanto se entienda el verdadero significado se darán cambios conductuales en todos los ámbitos educativos, mientras no se comprenda, seguiremos con el discurso.

El segundo reto es entender que para llegar a la igualdad hay que partir de las diferencias, incluso de sexos, las diferencias científicas que hay entre hombres y mujeres. Entonces sería 
la comprensión de las diferencia a favor de las igualdades; entender las diferencias para asegurar igualdades.

El otro reto es la integración de la sexualidad. En un país tan conservador, tan atrasado, tan cercano a los impactos de la guerra, ver que la educación integral en sexualidad es fundamental, es algo importante, una deuda.

Y el cuarto reto, es comprender cómo la coeducación implica otras variables que no se han integrado en coeducación: sexualidad, interculturalidad, educación política y ciudadana... La coeducación va por ahí, en cuanto los niños aprendan a interactuar de manera digna y equitativa eso va a impactar en la ruptura de patrones de poder que hay en Guatemala. $\underline{\text { La }}$ coeducación es educación política, plenamente política. 


\section{Entrevista 3 a expertos-as}

Consultora del Ministerio de Educación en materia de género.

Fundadora de la primera Unidad de Género dentro del Ministerio de Educación.

Productora de materiales educativos de educación sexual integral.

\section{P: ¿Cómo definirás tú la equidad y cómo la relacionarías con las demás equidades?}

R: Yo creo que es importante contextualizarla dentro de toda la parte de la Ilustración, del Humanismo... y cómo la sociedad representada no era la humanidad que se deseaba en ese momento. Este movimiento tan interesante abre cabida a los derechos de las personas. Lo plateo porque no siempre es así, y, afectivamente, tienes un marco regulatorio y normativo social que nos dice que todas las personas somos iguales y tenemos derechos, como nuestra dignidad, y que deberíamos entonces tener acceso a condiciones básicas que nos permitan desarrollarnos con plenitud. Y en ese sentido Simone de Beauvoir, nos hizo una contribución muy importante planteando el tema de la equidad de género. Ella, y antes de ella un montón de mujeres dentro de la época, se dan cuenta de que a pesar de que tanto los hombres como mujeres somos seres humanos, encontramos diferencias a nivel social y tampoco se cumplen los derechos de la misma manera. $\mathrm{Y}$ en ese sentido entonces, entender que hay una concepción social patriarcal que efectivamente nos ubica a las personas en una sociedad jerárquica, tanto en contextos simbólicos como en cuestiones materiales.

Entonces, aunque formalmente se reconoce la igualdad, ya en términos de la realidad, a partir del análisis de género, identificar cómo se vive finalmente esa desigualdad sustentada en lo que llamamos el "sistema patriarcal".

Afortunadamente, a partir de esta construcción teórica empezamos a hacernos preguntas referidas a la relación existente entre la equidad de género y otras equidades.

Pero una cosa es la teoría, que te ayuda a entender que eso existe, y otra cosa es cómo aplicas el análisis de género para que sobre esa base, podamos ir haciendo los cambios necesarios.

\section{P: ¿Cómo analizas el contexto de Guatemala en referente a la equidad?}

R: Yo creo que no es sencillo porque estamos en un momento en el cual tenemos diferentes marcos organizativos a partir de los cuales está organizada la sociedad. Están los sistemas democráticos, que no están cumpliendo con su tarea. Entonces creo que se combina toda una 
realidad desigual que tiene este país, seguimos teniendo muy poca gente con un poder adquisitivo que les dota de poder para esclavizar a otra gente. Y, por otro lado, la gran mayoría, con una calidad de vida muy en el nivel de supervivencia.

Esas condiciones conformadas históricamente, están sustentadas bajo un sistema racista y patriarcal. Lo que yo veo es una institucionalidad no solo devastada sino que varía dependiendo del partido electoral, del partido político. Hay muy poca transparencia, es superficial.

Yo diría que todos esos componentes se mezclan, entonces no es una cuestión tan sencilla; en un país con cada vez más exclusión.

\section{P: Y según tu experiencia en el ámbito educativo, ¿cuál es el aporte a la equidad desde la educación?}

R: Pensando en el Ministerio de Educación de Guatemala, para mí ha sido muy fuerte la experiencia por que pasamos de un contexto donde asumimos la igualdad de género por primera vez en la existencia del Ministerio en 2010, y ya hace rato que la tenía que reconocer. Esta institución en particular ha estado siempre coartada por el Opus Dei, desde la creación del Ministerio. Y creo que no es gratuito que haya sucedido así.

Yo a veces pienso que el sistema está diseñado para que no haya un proceso de aprendizaje, porque es imposible que el alumno aprenda teniendo tal cantidad de temas y áreas que abordar, con un nivel de rebuscamiento y de abstracción, tan lejos de la realidad de las personas que es imposible. La educación no está pensada para la población, la educación no está pensada para que la persona aprenda y eso para mí es la mayor tragedia. Pero es posible que un Ministerio de Educación marque la diferencia. Estamos hablando de cerca de 300.000 personas que trabajan en la planta de Ministerio; con 300.000 personas formadas en ese marco pues algún cambio se podría dar en el país.

En la historia guatemalteca, podemos destacar que se le ha dado mucho más poder y atención a instituciones que fomentaban la represión y el control de la sociedad. No se nota el potencial educativo porque el Ministerio no ha respondido. La opción de Guatemala fue el ejército no el sistema educativo. Se empezó e intervenir en el tema de género desde la caridad “pobrecitas las niñas”, no desde el marco de los Derechos Humanos. 
Desde el feminismo sabemos que es en la sexualidad donde efectivamente se explota a la persona, es ese el punto medular, la educación en sexualidad es un derecho.

Entonces, ¿se pueden llevar cambios desde las instituciones? Sí, pero para eso se necesita gente que tenga la decisión y la formación para hacerlo. Hay una necesidad y lo importante de un proceso educativo es que la persona sienta la necesidad de, y en este caso se da totalmente. 


\section{Entrevista 4 a expertos-as}

Programa de Género de la Facultad Latinoamericana de Ciencias Sociales -FLACSO.

\section{P: ¿Cuál es la importancia de educar en la equidad de género, etnia y social, como dice el Curriculum Nacional Base aquí en Guatemala, en la realidad del país?}

R (A): Yo diría que algo clave es poder entender la educación como institución social, es decir, un espacio requerido incluso por los grandes grupos de poder para ir generando esa reproducción de hegemonías. Algo que es clave es que la educación da sentido, y al dar sentido, y apoyándose con los medios de comunicación y con la familia, la comunidad, la iglesia... pues va generando toda una idea de roles asignados y de destinos, pero también tiene una fuerte capacidad de transformación. Y en un país donde se ha dado tanta exclusión de grupos históricamente vulnerables o marginados, es clave volver la mirada y centrarla en qué está pasando dentro de un sistema escolarizado: se está reproduciendo, hay espacios para otras cosas, qué es lo que se está dando, cómo se está viviendo la escuela, para cada una de las niñas y de los niños también. Para mí eso es clave.

$\mathrm{R}(\mathrm{W})$ : Yo diría que también hay como un parte aguas, así como un antes y un después, porque a partir de los acuerdos de paz es que se reconoce a Guatemala como un país pluriétnico, plurilingüe y pluricultural, entonces se le empieza a dar importancia a una educación bilingüe. No es algo que se haya conseguido del todo en la práctica pero, igual que lo de la equidad de género, es relativamente reciente aunque ya vamos casi para 18 años desde la firma de uno de los procesos de paz y que quiso ser un proceso transformador.

$\mathrm{R}$ (A): También es un tema interesante el que sale cuando se entrevista a las mujeres que formaron parte de las organizaciones para impulsar la Reforma Educativa, por ejemplo, y el Acuerdo sobre el Derecho de los Pueblos Indígenas que te dicen sí querían ver el acceso de las niñas a la educación pero también saber qué estaba pasando dentro de las clases. Las mujeres indígenas te dicen "queríamos el acceso de nuestras niñas a la educación pero respetando, por ejemplo, su traje". Entonces peleamos por el uso del traje dentro de la escuela, entonces es interesante, porque varias cosas que están en los Acuerdos fueron puestas por las organizaciones de mujeres, esa diversidad de mujeres que pusieron puntos clave en los Acuerdos de Paz y que impactan en el sistema educativo. 


\section{P: Precisamente esto viene al hilo de que es particular de Guatemala el hecho de que se una la equidad de género, de etnia y social. Yo quisiera saber cómo ven ustedes esa trilogía (o ese trío) porque esto en otros contextos, como podría ser el del País Vasco, no se da.}

$\mathrm{R}(\mathrm{W})$ : A mí me gusta mucho algo que decía Santiago Bastos y es que, dicho más o menos en mis propias palabras, decía que transitamos por distintas identidades y en esa transición por diversas identidades, pues nos vinculamos; y el hecho de identificarnos con algunas personas, como los mayas o con el área rural o urbana o con cierta clase social, eso hace una situación mucho más compleja a nivel educativo porque se pretende poder entender esa interseccionalidad, que no se trata solo de acumular identidades sino que es ver cómo están "envueltas" en mi persona y como el contexto también puede partir de comprender esa complejidad interseccional. En algún momento, el enfoque interseccional ha sido criticado porque dicen que deja a un lado género o porque se prioriza solo tal cosa, pero creo que necesitamos vincular de alguna manera la clase con la etnia para comprender lo que las niñas viven dentro de la escuela.

R (A): Por ser la población indígena mayoritaria o, por lo menos, el sesenta por ciento creo que son, en Guatemala no puede dejarse fuera lo étnico; que esa es una de las cuestiones que en el pasado se había dejado fuera casi siempre porque los indígenas se veían como un sector para ser oprimido y explotado y no como actores sociales. Entonces, a partir de los Acuerdos empiezan a ser más protagonistas de la historia. Por eso es que la discriminación persiste, bueno igual es muy poco tiempo el que ha pasado desde el reconocimiento.

$\mathrm{R}$ (W): Incluso es más fácil que se acerque la cuestión de género que la cuestión étnica porque aquí el racismo y el machismo están en la misma balanza.

$\mathrm{R}$ (A): Y quizá es por eso que hablamos de un patriarcado neoliberal, racista... con un montón de "apellidos" y cuando ves por ejemplo el CNB, que es el Currículum Nacional Base que se está implementando pues sí, un eje fundamental es el eje de equidad de género que se está implementando a nivel social, pero cuando se hace un análisis mucho más profundo para poderlo entender desde diferentes categorías o indicadores, encontramos que la idea de neutralidad se sigue no produciendo o el igualitarismo etnocéntrico sigue invisibilizado en las mujeres, hay un lenguaje excluyente, se sigue manejando la familia 
como reproductora de la división sexual del trabajo... Hay una lógica empresarial que les motiva a las niñas a ser empresarias pero ¿cuáles son las condiciones de vida en las que están? Se sigue negando el cuerpo como territorio, y a mí me parece esta parte muy interesante; el multiculturalismo estético salta a la vista en el CNB, a pesar de que saben que hay un reconocimiento firmado entre cuatro pueblos en Guatemala, en un mismo grado, en $5^{\circ}$ o $6^{\circ}$ de primaria si no recuerdo mal, en una misma asignatura te dicen que son cuatro culturas, que son dos culturas, que fue el choque de dos culturas, que hay veinticuatro pueblos. También la idea de la naturaleza como mercancía o el privilegio del pensamiento racional y lineal, la violencia contra las mujeres... y todo eso.

\section{P: ¿Cómo se ha dado la evolución de la educación en Guatemala desde que se implantó la educación mixta hasta el día de hoy?}

R (W): Yo estudié siempre en una escuela mixta porque mi mamá era partidaria de la educación mixta, sin embargo se seguían manteniendo los roles separados y más aún en mi época. Deportes, juegos y cosas que eran exclusivos para niños y lo que era exclusivo para niñas, entonces era como estar juntos en el espacio físico pero siempre diferenciar las tareas, las actividades y hasta las prioridades y, pues me atrevería a decir que eso sigue así aunque ya no tengo relación con escolares.

R (A): Y yo creo que aquí la iglesia católica ha jugado un papel fundamental en la historia de nuestro país, en esta parte se hace como una historia de la escuela primaria que podría ayudar. Pero antes de entrar dentro de la escuela católica, solo algunos ejemplos por acá. Por ejemplo, en la época de los liberales y los conservadores a los niños se les enseñaba: ejercicio de lectura, escritura, reglas elementales de la aritmética, estoy hablando del 1870 y pico, elementos de religión y moral, catecismo político, reducido a una breve explicación sobre los derechos y obligaciones civiles; para las niñas lectura y escritura para contar las labores propias de su sexo más los elementos de religión y moral como a los varones y más forzosamente el catecismo. O sea, la historia de división fuerte y de asignación de un tipo de educación diferente a niños y niñas de nuestro país ha sido histórica.

$\mathrm{R}(\mathrm{W})$ : En mi época ni siquiera daban esa asignatura, a nosotras nos daban educación para el hogar. 
R (A): Y digamos en esta misma época y aquí es también cuando se vincula la situación, fíjense, educación primaria era ocho años de duración y de seis a catorce años, y se enseñaba, lectura, escritura, aritmética, castellano, composición, recitación, higiene. Las niñas recibían además aguja, economía doméstica y otros oficios propios de las mujeres de la época.

Educación rural campesina para los niños, cuatro años de duración, lectura, escritura, castellano, aritmética, moral, lectura de manuscritos, dictado, moral y humanidad, nociones de contabilidad rural y ortografía. Y no se permitía que estudiaran más porque tenían que ayudar a los padres en las tierras, en el campo. Entonces, va pasando el tiempo y digamos que esta división se sigue manteniendo entre niños y niñas, área urbana - área rural, y la iglesia católica desde la Colonia hace esa división. Más adelante, sobre los 80, hay un levante fuerte de instituciones laicas, de colegios laicos donde ya entonces se mira lo mixto, pero no necesariamente coeducación. Yo creo que hay colegios mixtos, pero pocas instituciones te reconocen una perspectiva de equidad de género, te hablan más de que son colegios laicos.

Yo ahora que estoy viendo esto del colegio para mi chiquito me parece interesante la fuerza que tienen aquí los colegios, que no es la de antes pero en muchos de ellos se sigue manejando el prestigio, de que solo van a estar mujeres y solo van a estar hombres. Pero creo que hay también un despertar más fuerte en lo mixto, siento que todavía hace falta un paso para entender lo coeducativo y garantizar que estén juntos.

\section{P: Hablando de coeducación, ¿se utiliza ese término a nivel académico?}

R (W): Sí, se utiliza pero está vacío de contenido porque es más mixto que coeducativo; sigue siendo tan separado como era en aquellos tiempos, a nivel de Ministerio de Educación en sí. Es que hay otra situación interesante a estudiar, la división entre lo privado y lo público, porque no se da con tanta fuerza como en otros países. En Europa por ejemplo, lo público es general.

En lo privado sí que se sigue dando esa división de hombres y mujeres, en lo público no. Ahora el término coeducación, en el Ministerio de Educación yo no lo oigo tanto.

$\mathrm{R}(\mathrm{A})$ : Incluso si ves las escuelas se llaman mixtas y como Walda decía, el contenido no es el adecuado. 


\section{P: Desde la perspectiva de ustedes, desde la agenda del Ministerio, de la preocupación educativa del país, ¿qué peso creen que ha tenido y tiene esto de la educación para la equidad?}

R (A): Yo creo que hay un peso desde la presión que ejercen los organismos internacionales para empezar a utilizar el término, pero sí siento, y haciendo este análisis curricular, que le hace falta contenido de fondo porque, incluso aunque se tiene el término, al menos en la parte que yo vi, no había un análisis sobre qué es género.

Haciendo una revisión sobre el contenido de $\mathrm{CNB}$ de $4^{\circ}, 5^{\circ}$ y $6^{\circ}$ grado, no se habla mucho sobre lo que se entiende por sexismo, aparece una sola vez en $6^{\circ}$ grado; el tema de la discriminación aparece dentro del tema de la multiculturalidad que ya habíamos visto, pero el tema de género, por ejemplo, aparece como la formulación de oraciones y párrafos en las que los adjetivos, sustantivos, pronombres y verbos tienen una concordancia de género y número. O la formación de palabras al añadirle elementos del lenguaje que señalan el género y número.

La recolección y clasificación de información aparece una vez, ó, la utilización del sistema binario en ciencias naturales para la clasificación de los reinos animales en género, subgénero, clase y reino, pero la idea de género, la idea de desigualdad, la idea de equidad, aparece de alguna manera pero hace falta el sustento.

$\mathrm{R}(\mathrm{W})$ : Y los procesos de formación para los profesores, porque no hay. Género es un nuevo concepto, un nuevo contenido y no como se consideraba en el pasado. ¿Quién les enseña a los maestros estas nuevas categorías y la forma de enseñarlas? Género, interculturalidad, equidad... Hay un esfuerzo que se está dando desde el Ministerio de Educación, que creo que rompió el molde digamos y es la representante llamada Cecilia.

Sería interesante hablar con Cecilia aunque no esté ahora, ya que ella estuvo a cargo de toda la creación de la unidad, con una visión muy buena alrededor de cómo permear en esto si hay un marco legal, que te habla sobre la equidad de género, donde todo funcionario o funcionaria estará pegado. Pero ella manejó procesos de formación y doce como líneas de formación clave la Asesora del Ministerio de Educación para temas de género entre 2010 y 2014, que fueron los derechos sexuales y reproductivos y la situación de la violencia. Es una información buenísima porque tiene toda esa visión desde lo interno del Ministerio.

Y Cecilia si no recuerdo mal hizo todo un proyecto piloto con las escuelas pero uniendo también las personas de salud, entonces se hacía como algo mucho más integral y viendo toda 
esta carta de prevenir con educación desde el Ministerio de Educación y Salud con el fin de tratar el tema de equidad de género con más amplitud.

\section{P: ¿Cuáles son las fortalezas que ustedes ven en el país, a nivel educativo, para hacer real esta educación para la equidad?}

$\mathrm{R}$ (W): Que habría que aprovechar muchísimo porque haciendo las entrevistas con quienes estuvieron en la época, hacían memoria sobre todo lo que costó posicionar el eje ahí e incluso todo lo que les costó dentro de la misma comisión de Reforma Educativa. Pero el hecho de que a esté ahí creo que es como una ventana que podría irse trabajando más, y pienso que las organizaciones de mujeres del movimiento necesitamos estar más pendientes de lo que está ocurriendo dentro de las clases. Y también hay maestros y maestras con mucho interés en basar su vocación en transformar. Y se necesita buscar a esos maestros para ver de qué manera pueden ser multiplicadores, en contraposición al discurso que siempre dan, diciendo que los maestros tienen solo que recibir la formación que ya estudió. Si solo se plantea una Reforma Educativa y le dices al maestro que como no está formado se le va a formar, pero, ¿y el resto? Las escuelas, si no hay agua, no hay materiales... entonces cómo tener una visión más ampliada de la situación. Entonces, pienso yo que hay muchas organizaciones que están apoyando desde afuera pero para incidir de alguna manera en el ámbito educativo escolarizado.

R (A): Se está haciendo un trabajo histórico a favor de los pueblos indígenas.

\section{P: ¿Y sobre las debilidades?}

R (W): El Ministerio de Educación tiene mal la asignación presupuestaria y luego todo este nuevo modelo educativo que, en lugar de fortalecer el magisterio, no sé yo si va a funcionar o no, pero no parece lo correcto para la situación del país. Me refiero a todo esto de la profesionalización.

$\mathrm{R}$ (A): Y también la visión que se tiene porque esto ya viene desde los 80 con toda la reestructuración de las reformas educativas pero, se está favoreciendo la idea de una educación que responde al mercado. Entonces, claro, acá se necesita un medio de vida y es entendible frente a todas las condiciones pero en el por qué y el para qué educar se está 
perdiendo de alguna manera la dimensión humanista, de fortalecimiento ciudadano que de alguna manera se necesitaría hoy por hoy en el país. Es más, ¿para qué educar? y esta idea de que la educación te genera empleo y el empleo te genera ingresos y los ingresos generan desarrollo. Entonces, las autoridades educativas lo que hacen es manejar esta fórmula lineal en lugar de comprender bajo qué contextos se está dando que la educación no siempre te va a garantizar trabajo y tal vez es al revés la fórmula, como decía Carlos Aldana a la hora de entrevistarlo acá, que se necesita ir viendo de qué manera el desarrollo social fortalece una educación para la creación de la ciudadanía y dar vuelta a esa fórmula tan economicista que se ha venido manejando.

Estamos luchando por los derechos de las mujeres sí, pero también por una educación de calidad, y no desde la educación económica o empresarial sino de la calidad que implica mi desarrollo humano pleno. Desde quién soy, desde mi identidad... y eso es un reto para las organizaciones de empresa.

P: Y a nivel teórico ¿hay debates abiertos ahora mismo sobre esta conceptualización de género, de equidad... o está bastante claro?

R (W): Tenemos unas jornadas que se llaman María Chinchilla y están dedicadas a revitalizar todos los debates alrededor de la educación. Hemos tenido varias en relación a la educación no sexista. Entonces, de alguna manera pienso que hay organizaciones interesadas en plantear los debates. Y más que para los teóricos, las jornadas están dedicadas a los maestros. Aunque algunos temas no se enfocan desde la perspectiva de género pero sí que giran alrededor.

R(A): Sí, sí hay debate teórico y los maestros sí están interesados; esa es la gran fortaleza y la gente está trabajando en ello en las peores condiciones.

P: Se cree que hay una diferencia biológica en las inquietudes y vocacionales entre niños y niñas. Y creen que la escuela no es protagonista, sino que todo viene de la casa, la familia. En parte puede ser cierto, teniendo en cuenta la escolarización tardía y demás, pero tenemos que recuperar ese nivel protagonista de la escuela y los maestros. Yo recuerdo un ejemplo de un niño de dos años y medio sin escolarizar que decía que él pegaba porque era "hombre", y uno se pregunta qué tipo de mensajes habrá recibido en su entorno familiar. 
R (A): Pero es lo que tú comentabas justo al inicio, los mayores espacios educativos no son cuando el maestro está al frente como en los recreos, la dinámica entre la relación con los maestros... ¿a quién le asignan las tareas? Porque la limpieza a las niñas o, por ejemplo, a la hora de formar consejos estudiantiles las niñas no presiden en ningún momento, las encargan de secretarias, mientras que los niños son los presidentes. Es como todo el sistema educativo la verdad, que se necesita transformar de alguna manera.

\section{P: ¿Qué necesitaríamos transformar?}

R (W): Pues la verdad que las estructuras porque el patriarcado está muy internalizado y son siglos de educación sexista.

$R(A)$ : La publicidad tiene que cambiar y también las redes institucionales porque no solo te enfocas en la labor del maestro, también es lo local, la escuela. Habrá que ver las instituciones de los líderes comunitarios, los Consejos de Desarrollo cómo se están manejando, las familias asociaciones de padres y madres también son clave, los contenidos, el presupuesto... son como varias situaciones en conjunto. Y también la idea de que las niñas no pueden ser educadas porque siempre van a ser las madres de desarrollo que pasan a las nuevas generaciones, pero no se le entiende a la niña como sujeto de derechos que puede ser educada. Había otro programa dentro del Ministerio de Educación que me llamó la atención, porque se llamaba La cocina en mi aula pero se hizo una alianza con empresas de ciertos empresarios de Guatemala donde daban el producto. Entonces hacían la demostración cocinando en el aula haciendo publicidad a sus productos y asumiendo los roles de que las niñas estaban en la cocina pero también muy vinculados a esa parte de un patriarcado capitalista.

\section{P: ¿Cómo miran ustedes la operatividad del eje de equidad de género, de etnia y social del Curriculum Nacional Base? ¿Teniéndolo como trasversal podemos llegar a que se haga realidad?}

$R(A)$ : Tiene que ser trasversal pero también tiene que ver algo específico porque la gente no transversaliza. En teoría es más importante porque aquello que se transversaliza en todo debe estar. Eso lo hemos visto en la Universidad San Carlos; la Universidad San Carlos tiene tres ejes: interculturalidad, medio ambiente y equidad de género. $\mathrm{Y}$ se supone que es toda la 
universidad en donde debe lograrse esa incidencia y supone sale un presupuesto terrible. Pero al menos hace incidencia política, hace ruido y busca alianzas. Entonces sí, tiene que ser transversal para que puedas exigirle a la gente.

$\mathrm{R}$ (W): Y yo también creo que hace falta transmitir el sustento, qué es eso de la transversalización porque hay unos contenidos que no corresponden a los ejes. No hay operatividad, entonces hay que buscar cómo operativizar esos ejes y hacer que lleguen a las aulas. Hay que pensar de abajo para arriba, o un movimiento más dialéctico.

P: Estos maestros a los que he entrevistado dicen que saben que existen unos ejes porque los han estudiado pero que no saben cómo hacer porque nadie se los ha explicado. Es eso, que les faltan esas herramientas para saber cómo esa transversalidad llevarla a la práctica.

R (W): Nosotras formamos parte de un proyecto con el objetivo de aplicar el enfoque en un caso de género y en uno de etnicidad, pero en educación superior. Aquí ni las aplican ni las conocen; los dos institutos de la Universidad San Carlos de género y etnicidad son microscópicos y no tienen dinero para hacerlo. Tendría que ser algo de docencia o de investigación, desde arriba, esas direcciones que tienen más poder y más recursos.

$\mathrm{R}$ (A): Además, hay que saber cuáles son los indicadores que te van a mostrar que los ejes están, cómo vas a monitorear, cómo vas a formar, a identificar dónde están los vacíos... y todo eso implica también la formación, la sensibilización.

R (W): Y es una política institucional. En el caso del Ministerio de Educación, es una política pública; en el caso de la San Carlos debería de ser una política institucional, que no existe. Y si en lugares chiquititos como este no funciona bien, imagínense en otros. Así que necesitamos combinar. Solo trasversal no, porque tiende a la invisibilización ya que te dicen que está y no es cierto. 
P: ¿Se trabaja el tema del machismo con las mujeres adultas con un nivel de cultura bajo?

R(A): No, no se trabaja. Desde el Ministerio al menos no hay nada que vaya dirigido a los adultos, que debería. 


\subsection{Análisis de talleres de discusión con docentes de Pacajá Alto y Centro, Quetzaltenango}

NO ES UNA TRANSCRIPCIÓN LITERAL. SÍNTESIS DE LAS NOTAS TOMADAS DURANTE LOS TALLERES

2 Talleres de discusión con maestras y maestros de las escuelas Pacajá Alto y Pacajá Centro, Quetzaltenango.

Participantes: 13 maestras y 4 maestros. 17 participantes en total.

\section{Temas abordados}

1. Igualdad en de género, etnia y social en Guatemala.

2. Agentes socializadores de género y papel de la escuela.

3. Curriculum oculto.

4. Eje de equidad de género, de etnia y social del CNB.

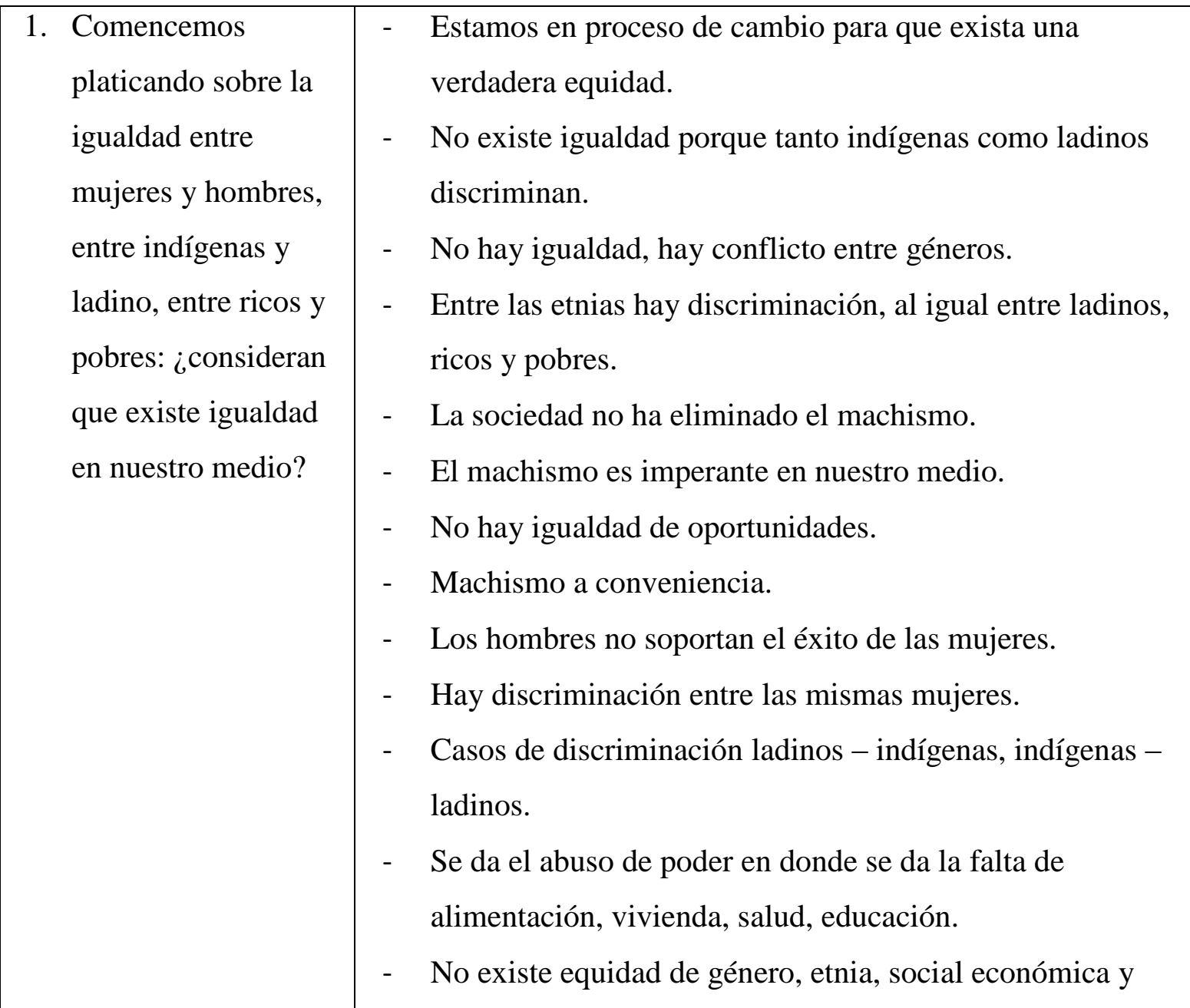




\begin{tabular}{|c|c|}
\hline & $\begin{array}{l}\text { política. } \\
\text { - El hombre en nuestro contexto tiene más oportunidades. }\end{array}$ \\
\hline $\begin{array}{l}\text { 2. ¿Podríamos poner } \\
\text { algunos ejemplos } \\
\text { que refuercen su } \\
\text { respuesta? }\end{array}$ & $\begin{array}{l}\text { - Que las niñas ya asistan a centros educativos es indicador } \\
\text { de cambio. } \\
\text { - Si alguien llega muy arreglado a un almacén lo súper } \\
\text { atienden y si llega alguien humilde solo por su forma de } \\
\text { vestir y aspecto ya lo tratan de manera desigual. } \\
\text { - Cuando en una familia se da educación solo a los varones. } \\
\text { - Las clases en algunas comunidades no se realizan en el } \\
\text { idioma del niño. }\end{array}$ \\
\hline $\begin{array}{l}\text { 3. Desde su } \\
\text { experiencia, ¿cuáles } \\
\text { son los agentes } \\
\text { socializadores } \\
\text { principales donde } \\
\text { las niñas y niños } \\
\text { aprenden lo que } \\
\text { serán de adultos? }\end{array}$ & $\begin{array}{ll}\text { - } & \text { Hogar, escuela, sociedad en general. } \\
\text { - } & \text { La casa, la escuela. } \\
\text { - } & \text { Inicia en el hogar y se refuerza en la escuela. } \\
\text { - } & \text { En el hogar y la convivencia con el entorno. } \\
\text { - } & \text { En el hogar, en su ambiente cultural y en la educación. } \\
\text { - } & \text { Casa, escuela, iglesia, sociedad. } \\
\text { - } & \text { En la familia, fuente integral de transmisión de valores. } \\
\text { - } & \text { La escuela como ente formador de niñas y niños. } \\
\text { - } & \text { La familia, escuela, iglesia. }\end{array}$ \\
\hline $\begin{array}{l}\text { 4. ¿Creen que la } \\
\text { escuela puede hacer } \\
\text { algo para educar en } \\
\text { la igualdad? }\end{array}$ & $\begin{array}{l}\text { - } \text { Que en todas las actividades como las comisiones de } \\
\text { limpieza, de refacción, en el gobierno escolar, participen } \\
\text { tanto niños como niñas. } \\
\text { - } \quad \text { Promoviendo la no discriminación con charlas, } \\
\text { exposiciones y técnicas educativas. } \\
\text { - } \quad \text { Enseñando y reforzando valores y practicándolos. } \\
\text { - } \quad \text { Brindar charlas a padres de familia de los derechos y } \\
\text { nuevas leyes que apoyan la igualdad. } \\
\text { - Realización de actividades que refuerzan la equidad como } \\
\text { la limpieza y orden del día y pláticas a los niños de cómo } \\
\text { ayudar en el hogar. } \\
\text { - Tareas que se realizan en el aula sin división de género. }\end{array}$ \\
\hline
\end{tabular}




\begin{tabular}{|c|c|}
\hline & $\begin{array}{l}\text { - Educando con imparcialidad, tratando a niñas y niños por } \\
\text { igual en las diferentes actividades dentro y fuera del aula. } \\
\text { - El docente debe ser el primer agente de cambio y el } \\
\text { primer convencido de la igualdad. }\end{array}$ \\
\hline $\begin{array}{l}\text { 5. ¿Qué experiencias } \\
\text { tienen ustedes } \\
\text { respecto al } \\
\text { curriculum oculto? }\end{array}$ & $\begin{array}{l}\text { - Que los niños aprenden muy bien con el ejemplo y no con } \\
\text { lo teórico. } \\
\text { - } \quad \text { Curriculum oculto es lo que no se planifica. } \\
\text { - } \quad \text { Nos toca la resolución de conflictos niño - niña, padres de } \\
\text { familia, maestros y maestras. } \\
\text { - } \quad \text { En la actualidad todavía hay docentes que refuerzan la } \\
\text { desigualdad de género y etnia en actividades dentro y } \\
\text { fuera de su salón de clases. } \\
\text { El docente en su mayoría pone en práctica el curriculum } \\
\text { oculto cuando pone en su clase un material que no } \\
\text { planifica. } \\
\text { Experiencias negativas cuando los padres se entrometen a } \\
\text { querer dirigir la enseñanza y la forma de disciplinar en el } \\
\text { aula. } \\
\text { Experiencias positivas orden, consejos, valores que los } \\
\text { maestros deben escuchar a sus alumnos. }\end{array}$ \\
\hline $\begin{array}{l}\text { 6. ¿Qué experiencias } \\
\text { tienen respecto al } \\
\text { eje de equidad de } \\
\text { género, de etnia y } \\
\text { social que tiene el } \\
\text { CNB? }\end{array}$ & 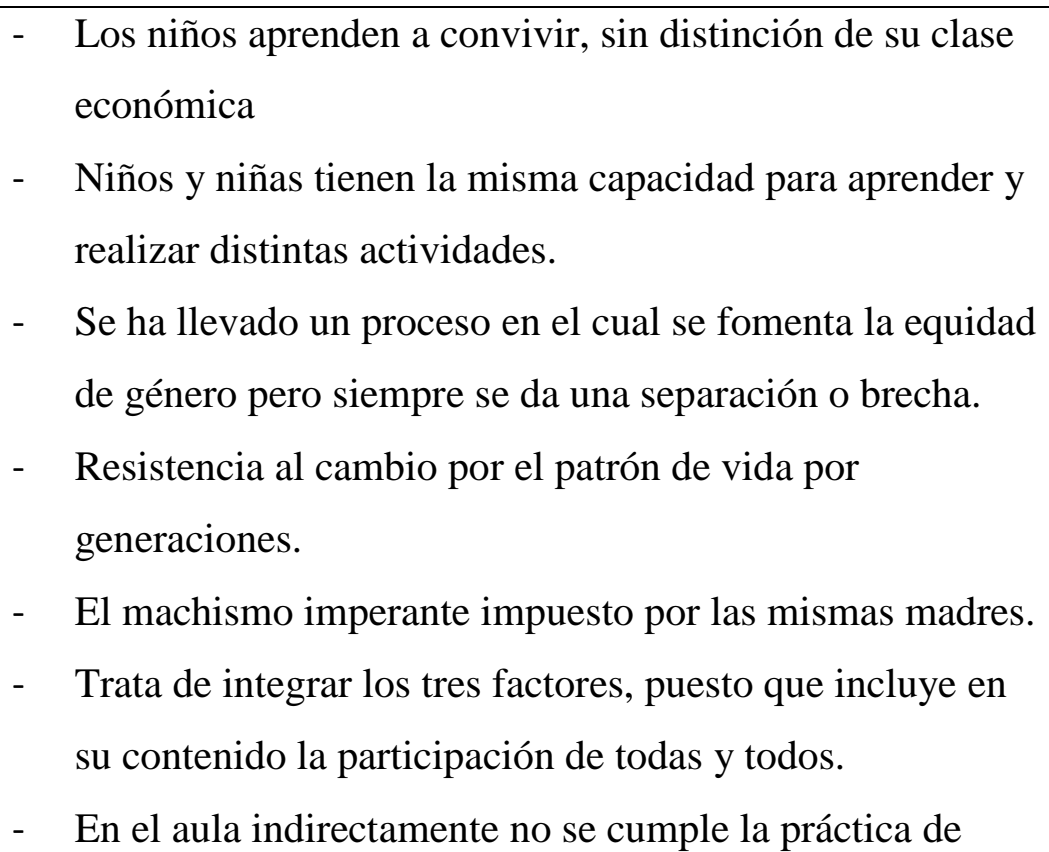 \\
\hline
\end{tabular}




\begin{tabular}{|l|l|}
\hline & \multicolumn{1}{|c|}{$\begin{array}{c}\text { equidad al separar niños de niñas en actividades } \\
\text { culturales. }\end{array}$} \\
\hline $\begin{array}{l}\text { 7. } \\
\text { En esta escuela, ¿de } \\
\text { trabajan la forma } \\
\text { educación para la } \\
\text { igualdad en las } \\
\text { aulas? }\end{array}$ & \\
\hline $\begin{array}{l}\text { ¿Con qué apoyos } \\
\text { cuentan para esta } \\
\text { tarea? }\end{array}$ & No hubo respuestas. \\
\hline $\begin{array}{l}\text { 9. } \\
\text { Y ¿qué limitantes } \\
\text { encuentran para esta } \\
\text { tarea? }\end{array}$ & No hubo respuestas. \\
& \\
\hline $\begin{array}{l}\text { implementar el eje } \\
\text { género, de etnia y } \\
\text { social? }\end{array}$ & \\
\hline
\end{tabular}


5.6. Análisis de talleres de discusión con madres y padres de la escuela Pachaj, Cantel, Quetzaltenango

NO ES UNA TRANSCRIPCIÓN LITERAL. SÍNTESIS DE LAS NOTAS TOMADAS DURANTE LOS TALLERES

2 Talleres de discusión con madres y padres de la escuela de la aldea Pachaj, Cantel, Quetzaltenango

Participantes: 15 madres y 5 padres. Total 20 participantes.

\section{Temas abordados}

1. ¿Qué es la igualdad?

2. Identificación de roles diferenciados de género.

3. Dibujar y/o escribir: ¿Cómo me imagino el futuro de mis hijas? ¿Y de mis hijos? ¿Qué deseo para ellas y ellos?

4. Papel de la escuela en la educación para la igualdad: ¿en qué queremos que nos ayude la escuela?

a) Roles de género diferenciados expresados por madres y padres:

\begin{tabular}{|l|l|}
\hline \multicolumn{1}{|c|}{ Mujer } & \multicolumn{1}{c|}{ Hombre } \\
\hline Rosado. & Azul. \\
No se da prioridad al estudio. & Carros y juegos de armas. \\
Juegos con muñecas, trastes. & Herencia mayor o mejor. \\
No descansa. & Menos trabajo, más salario. \\
Menos dinero. & \\
No herencia o poco. & \\
\hline
\end{tabular}


b) El futuro de hijas e hijos, expresado por madres y padres:

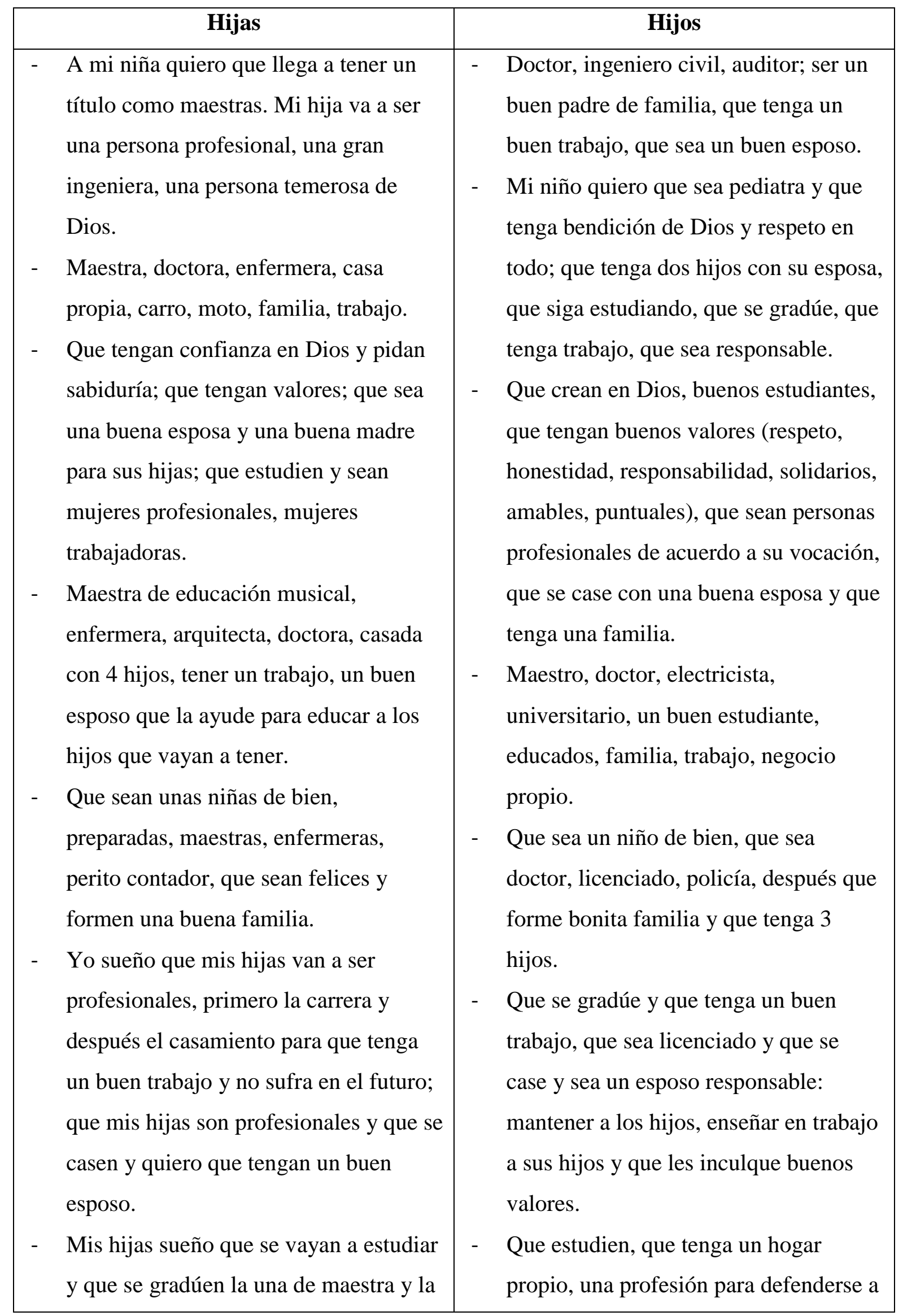


otra de doctora, espero en Dios que sea así, las niñas y los niños tienen los mismos derechos.

- Que sea una persona obediente y que termine sus estudios; que mi hija sea una gran doctora, que cuando esté graduada se case y que tenga 2 hijos, que tenga casa propia.

- Graduarse de doctora, de perito contador, que se gradúe en la universidad, que se case y que tenga 2 hijos y que sea feliz en su matrimonio, también que tenga casa propia.

- Que tenga una profesionalidad, cuando tenga 20 años que estén graduadas. Que busquen a Dios y que encuentren un buen esposo y que tengan una buena familia.

- Que nuestras hijas tengan su nivel medio y trabajando y estudiando en la universidad y que tengan oportunidad para participar en un deporte.

- Que estudie, que se gradúe para que no sufra y que tenga su propio trabajo, quiero que sea maestra y que sea muy inteligente y respetuosa.

- Oportunidad de salir adelante, familia feliz también con oportunidades, que estudien y que tengan carrera, que puedan viajar, que tenga una casa propia y vehículo.

- Que las niñas tengan oportunidad de estudiar, también tienen el derecho de sí mismo para tener un trabajo

excelente.

- Que sean hijos estudiosos para que cuando sean grandes puedan sostener a sus familias, que no san machistas y que den oportunidad a que sus esposas trabajen, que tengan 2 hijos, casa propia y que sean muy felices.

- Que sea policía, doctor, piloto, que tenga su hospital, que tenga su empresa, que tenga casa propia, que tenga luz, agua, electricidad, que tenga una familia feliz.

- Estudiar, graduarse, trabajar, compartir con la familia, tener buenos valores.

- Que sean profesionales para que el día de mañana tengan un buen futuro y que tengan un buen trabajo para mantener a su familia el día de mañana.

- Que se gradúen para tener oportunidad en un trabajo y que tenga un espacio para tener una casa antes de casarse y que tenga las mismas oportunidades para sus hijos.

- Que mi varón esté graduado como maestro para párvulos, joven responsable, para poder defender a su familia más adelantes, que sea un joven universitario y a la vez empresario.

- Se graduarán de la carrera que a ellos les guste, serán profesionales respetuosos, trabajarán en empresas grandes, se casarán algún día y 
casar, pero que antes tenga una buena profesión para que le día de mañana no sufran.

- Que mi hija esté graduada como maestra para el hogar, graduada y trabajando, como enfermera profesional, una mujer con sus propios negocios.

- Serán señoritas graduadas y trabajadoras y dependerán de ellas mismas, serán mujeres respetuosas, educadas y también formarán algún día una familia, y ellos estudiarán de la misma manera.

- Seguir estudiando el Básico y Diversificado, estudiar en la universidad la carrera de medicina para ser una gran profesional y así poder ser útil en la sociedad y en la vida personal.

- Que nuestras hijas sean profesionales para que el día de mañana no sean dependientes de nadie. Mi hija quiero que sea una mujer profesional doctora.

- Mi hija quiere ser maestra. MI hija quiere ser enfermera profesional para ayudar a las personas necesitadas y de escasos recursos.

- Buscar a Dios, debe ser responsable, cuidar de ellas misma, continuar sus estudios, graduarse en la universidad, trabajar. formarán un hogar e inculcarán valores a sus hijos y la misma educación.

- Imagino ver a mi hijo sacando el Básico y luego graduarse de licenciatura con buena conducta y buen aspecto y tener su propio bufet. Graduado de secretario y ser alguien importante e ir por buen camino, apartarlos de la delincuencia.

- Mi hijo quiero que sea médico, que tenga esposa y tenga casa propia. $\mathrm{Mi}$ hijo quiere ser mecánico, cuando sea grande y tenga casa propia y vehículo propio.

- Buscar a Dios, lograr sus metas, practicar los valores, graduarse de perito contador, casarse a sus 30 años.

- Estudiar en el nivel Básico, continuar Diversificado, estudiar en la universidad para ser un gran profesional y así poder colaborar en nuestra comunidad. 
c) Papel de la escuela, expresado por madres y padres:

- Que la escuela controle la seguridad de los hijos.

- Que niñas y niños no caigan en otros roles.

- A la escuela vienen a aprender, a estudiar, pero el corregimiento se lleva en casa.

- Que les enseñen a respetarse unos a otros, niñas y niños y respetar a los diferentes.

- Hacer limpieza parejo.

- Que las niñas barran, trapeen, y los niños hagan otros trabajos en la escuela.

- No permitir teléfonos en la escuela. 
Dibujos y reflexiones de madres y padres sobre el futuro de sus hijas e hijos

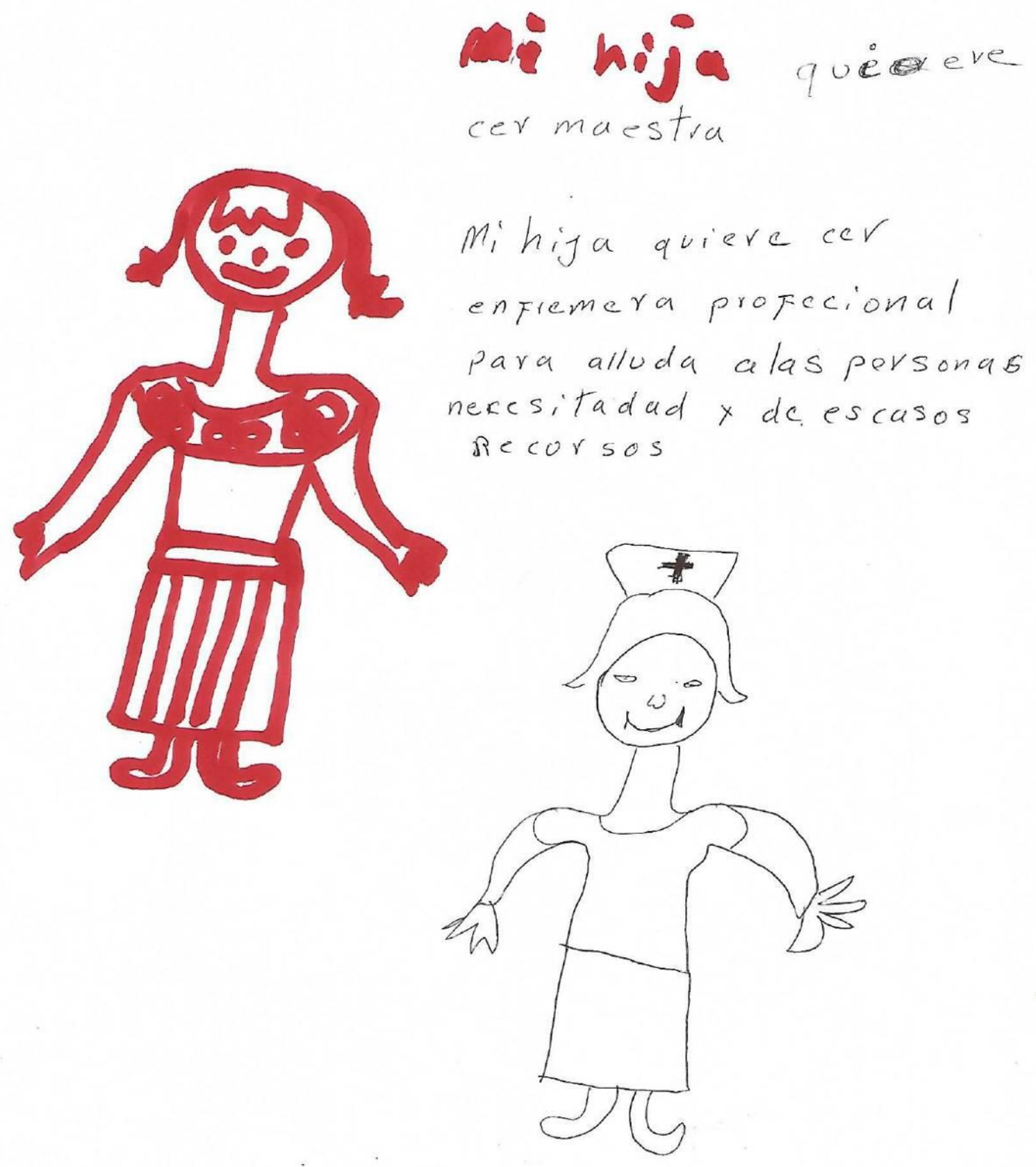


mi hijo que sea medico que tenga esposa que tenga casa propia

Mihigoquiere ser mecan!co ese esel anelo de el cuan sea grande y tega casa propia y bciculo propio

559 
Nuestras hijas en el futuro.

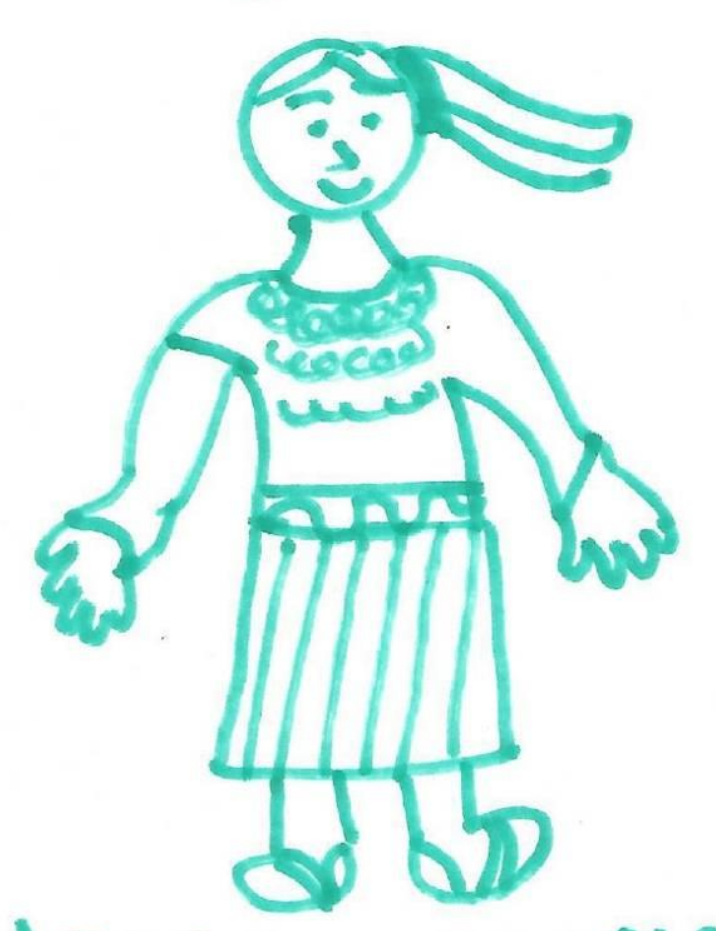

$\rightarrow$ Que tengan comfianza en Dios y pidan sabiduria.

$\rightarrow$ Que tengan valores.

- Que sea un buena esposa

$\rightarrow$ una buena madre para sus hijas.

$\rightarrow$ Que estudien y stan mujeres profesionales.

$\rightarrow$ Mujeres trabajadoras.

560 
Nuestros hijos en el futur

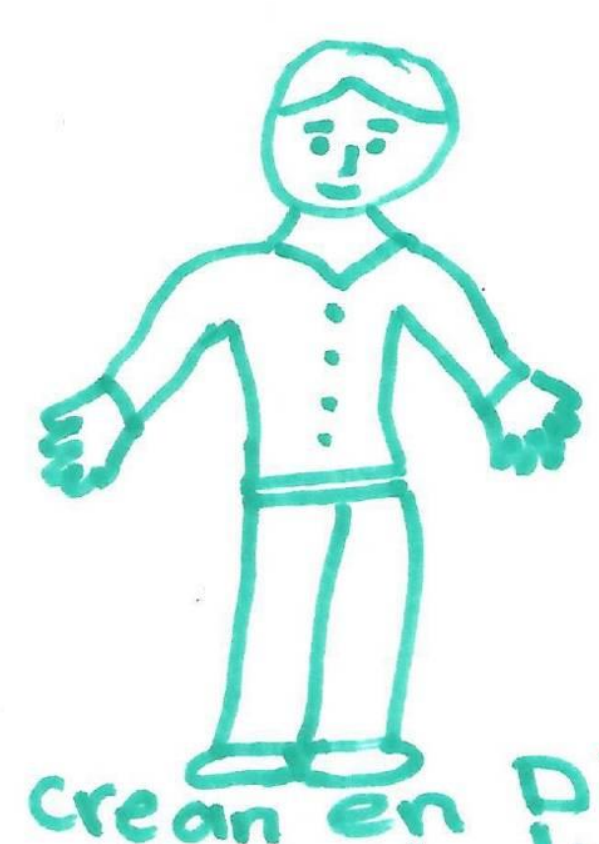

$\rightarrow$ Que crean en pios.

$\rightarrow$ Buenos Estudiantes.

$\rightarrow$ Que tengan buenos valore - Respeto, honestidad - Responsabilidad. Solida. rios. Amables, puntuale.

$\rightarrow$ Gue sean personas profe cionales de acuerdo a si vocnción. Poue se case con una buti

561 
Que se gradue Th y que tenga un 10 buen trabajo, qu yo sea lieenciado y que sea un esposo responsable. Es manter a tos hyos ensenar al trabajo a sus hyos y que le inculque buencs valores.

562 


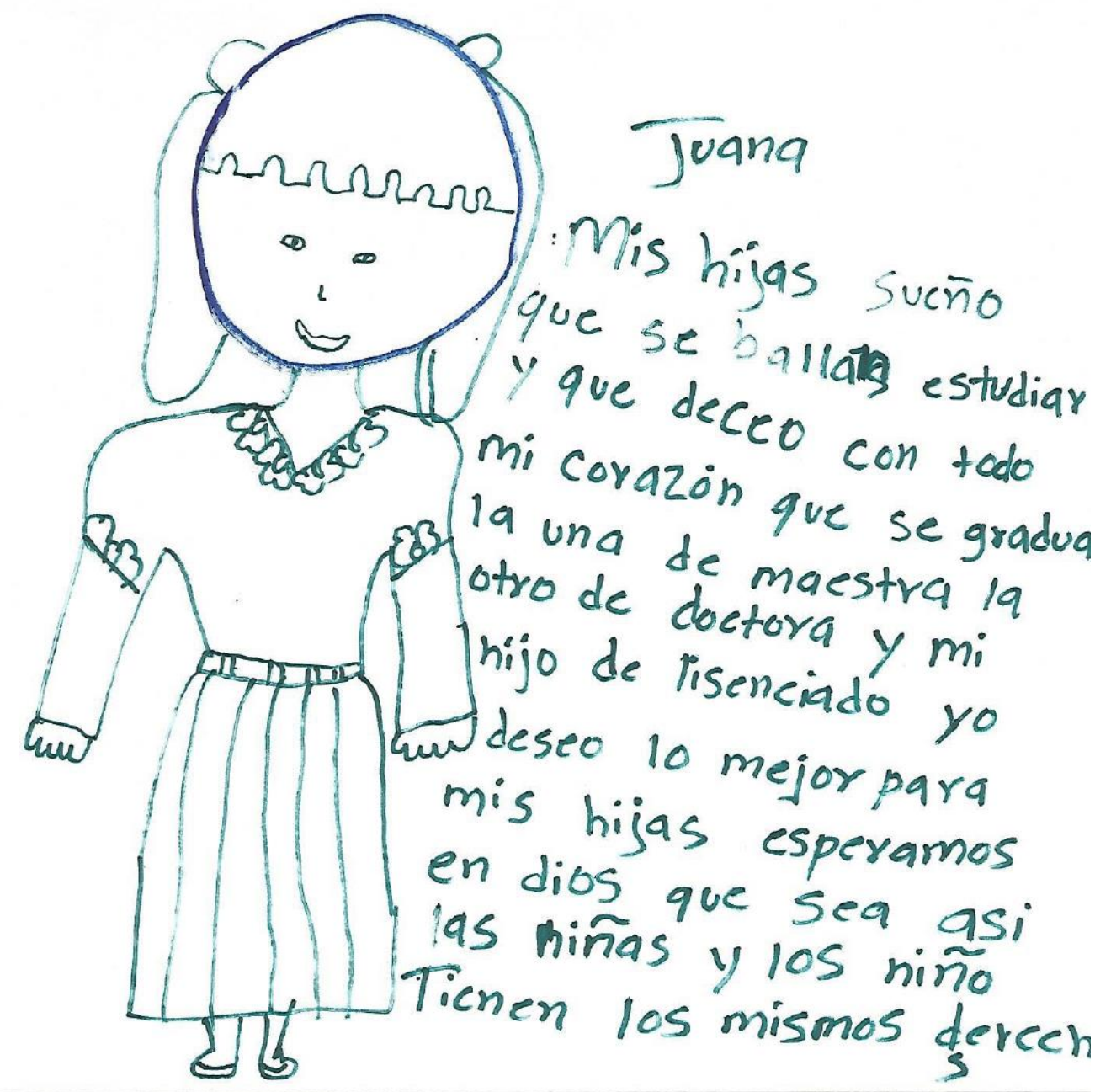

563 


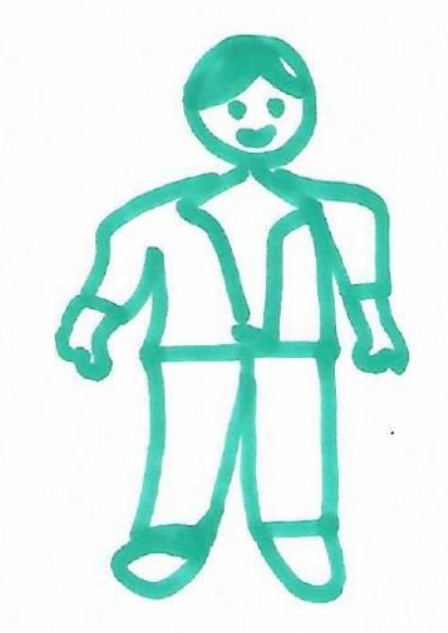

Que mi varon:

$\rightarrow$ Este graduado como maestro para parvulos joven responsable.

$\rightarrow$ Que este graduado Para poder defender a su familia mas adelante.

$\rightarrow$ Que sea Un joven Universitario y a la vez un empresario.

564 


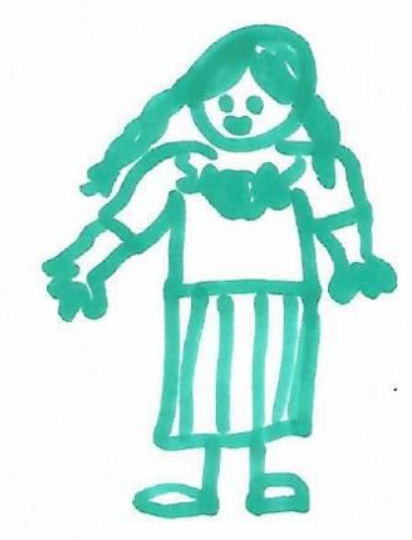

$\rightarrow$ Que mi hija este graduada como maestra para el hogar

$\rightarrow$ Graduada y trabajando

$\rightarrow$ Graduada como enfermen Profesional. $\rightarrow$ una miujer con sus propios

565 


\section{REPUBLICA DE GUATEMALA \\ POR DEPARTAMENTOS}
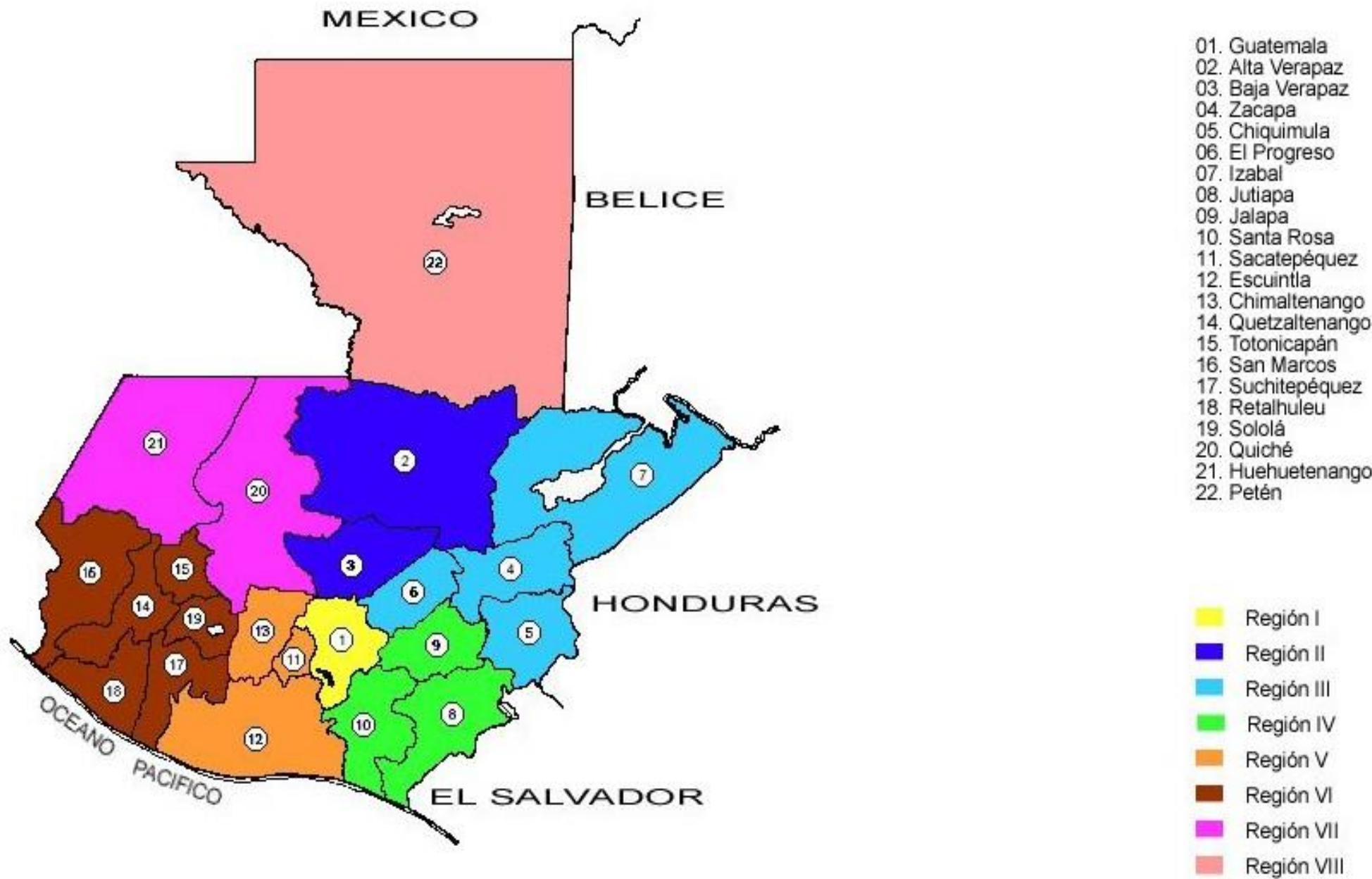


\section{Notas}

${ }^{\mathrm{i}}$ El pueblo ladino surgió a partir de la mezcla entre indígenas y criollos descendientes de los colonizadores españoles. Históricamente estas mujeres han tenido más acceso a educación y a todo tipo de oportunidades que las mujeres indígenas.

${ }^{\text {ii }}$ Palabra en el idioma del pueblo Kuna panameño utilizada por los movimientos de pueblos indígenas americanos para nombrar la territorialidad del continente de América.

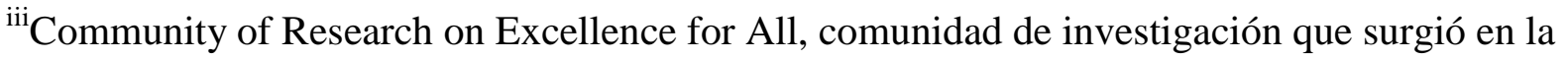
Universidad de Barcelona en 1991. Actualmente, es una comunidad de investigación en el marco de la comunidad científica internacional.

${ }^{\mathrm{iv}}$ https://www.prensalibre.com/revista-d/formacion-superior/

vhttps://datosmacro.expansion.com/estado/gasto/educacion/guatemala

${ }^{\mathrm{vi}}$ https://elperiodico.com.gt/inversion/2018/08/15/identifican-departamentos-con-alta-brechadigital/

${ }^{\mathrm{vii}}$ https://www.prensalibre.com/guatemala/comunitario/catolicos-evangelicos-cifras-encuesta/ viiihttps://www.prensalibre.com/guatemala/justicia/violencia-baja-pero-el-temor-continua/

${ }^{\mathrm{ix}} \mathrm{Se}$ utiliza el término femicidio en lugar de feminicidio por ser el término utilizado en Guatemala tanto en las leyes específicas que protegen a las mujeres como en el ámbito de las organizaciones de mujeres.

xhttps://www.prensalibre.com/guatemala/comunitario/guatemala-registra-hasta-22violaciones-sexuales-al-dia/

${ }^{\mathrm{xi}}$ https://osarguatemala.org/embarazo/datos/

xii https://lahora.gt/impunidad-en-casos-de-violencia-sexual-es-del-99-52/

xiii https://www.publinews.gt/gt/noticias/2018/12/06/mas-cuatro-millones-guatemaltecostrabajan-sector-informal.html

${ }^{\mathrm{xiv}}$ https://republica.gt/2019/03/09/mujeres-mayoria-en-padron-elecciones-tse/ 
${ }^{x v}$ El Consejo Nacional de Educación tiene como misión orientar las políticas educativas del país y está conformado por: el MINEDUC, la Universidad de San Carlos de Guatemala, universidades privadas, Academia de las Lenguas mayas, Comisión Nacional Permanente de Reforma Educativa, Consejo Nacional de Educación Maya, Consejo Nacional para la Atención de Personas con Discapacidad, Alianza Evangélica de Guatemala, Conferencia Episcopal de Guatemala, Asamblea Nacional del Magisterio, Comité Coordinadora de Asociaciones Agrícolas, Comerciales, Industriales y Financieras, Sector de Mujeres Organizadas, Organizaciones del Pueblo Xinca, Organizaciones del Pueblo Garífuna, Asociación de Colegios Privados.

${ }^{\mathrm{xvi}}$ https://www.mineduc.gob.gt/UNEGEPE/

${ }^{\text {xvii }}$ http://iumusac.usac.edu.gt/

xviii http://www.ibe.unesco.org/es/documento/datos-mundiales-de-educaci\%C3\%B3ns\%C3\%A9ptima-edici\%C3\%B3n-2010-11

${ }^{\mathrm{xix}} \underline{\mathrm{https} / / / \text { www.mineduc.gob.gt/digeduca/documents/resultados/Resultados_Graduandos_2018 }}$ .pdf

${ }^{\mathrm{xx}}$ http://www.mineduc.gob.gt/digeduca/documents/pisa/InformePISADGuatemala.pdf

${ }^{x x i}$ Disponible en http://www.mineduc.gob.gt/DIGECUR/

xxii https://www.usac.edu.gt/catalogo/humanidades.pdf

xxiii http://www.mineduc.gob.gt/digeduca/documents/evaluacionDiagnostica/guias/Guia_Estrat egias.pdf

${ }^{\text {xxiv }}$ https://www.prodessa.net/

${ }^{\mathrm{xxv}}$ http://www.feyalegria.org.gt/

${ }^{\mathrm{xxvi}}$ https://www.iger.edu.gt/

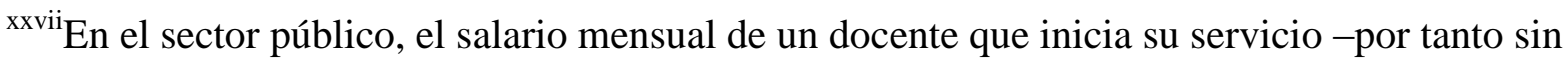
antigüedad o escalafón- se sitúa en Q4.011, alrededor de $470 €$

(http://infopublica.mineduc.gob.gt/mineduc/images/5/5c/DIREH_Puestos_y_salarios_docent 
es_incluye_Escalafon-2019.pdf). En el sector privado, los salarios mensuales para maestras y maestros de Pre-Primaria y Primaria en la práctica quedan a criterio de las y los dueños de dichos centros educativos, siendo imposible establecer un rango certero, que muy en general puede oscilar entre los Q600 y los Q1,500 al mes (de 70 a $175 €$ aprox.) en centros privados de bajo nivel y alcanzar el salario mínimo legalmente establecido de Q2.992,37 (352€ aprox.) solo en centros privados de prestigio. Las maestras y maestros de Básico y Diversificado del área estudiada generalmente son contratados por horas de docencia en su materia de especialidad, con pagos también muy variables, que pueden rondar los Q15 o Q20 la hora (entre 1.75 y $2.35 €$ la hora). Hay que resaltar que estos pagos, incluso el salario mínimo de ley, no se corresponden en absoluto con los costos de la canasta básica alimentaria, que según el Instituto Nacional de Estadística -INE- en 2019 alcanza los Q3.572,38 mensuales para una familia promedio de 4.7 miembros (alrededor de $420 €$ ). Esta canasta no incluye los costos de los servicios Básicos como luz y agua y otros que frecuentemente deben ser pagados como educación, salud, transporte, etc.

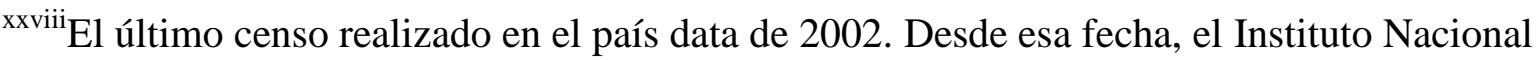
de Estadística INE realiza proyecciones anuales de población y otros indicadores. En 2018, se realizó el levantamiento de información de campo para un nuevo censo pero en agosto de 2019 no se tiene información sobre los resultados.

${ }^{\text {xxix }}$ https://www.populationpyramid.net/es/guatemala/2019/

${ }^{\mathrm{xxx}}$ http://estadistica.mineduc.gob.gt/Anuario/home.html\#

${ }^{x x x i}$ Porcentaje de estudiantes matriculados en cada nivel educativo, independientemente de que ese grado corresponda a su edad o no.

${ }^{\text {xxxii }}$ http://www.mineduc.gob.gt/digeduca/documents/resultados/Resultados_Graduandos_201 $\underline{\text { 8.pdf }}$

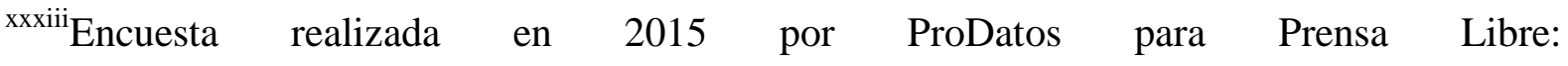
https://www.prensalibre.com/guatemala/comunitario/catolicos-evangelicos-cifras-encuesta/

${ }^{\text {xxxiv }}$ http://cdn.agilitycms.com/who-makes-thenews/Imported/reports_2015/regional/America_latina.pdf 
${ }^{\mathrm{xxxv}}$ https://dca.gob.gt/noticias-guatemala-diario-centro-america/controles-para-evitar-abusos-

en-las-escuelas/ 